



\section{COMITÉ EDITORIAL}

\author{
Director: Agustín Santana Talavera \\ Instituto de Investigación Social y Turismo \\ Universidad de La Laguna (España) \\ E-mail: asantana@ull.es
}

Adjunto a dirección: Eduardo C. Cordeiro Gonçalves Universidade da Maia (Maia, Portugal)

E-mail: egoncalves@docentes.ismai.pt

Adjunto a dirección: Francisco Calero

Instituto de Investigación Social y Turismo

Universidad de La Laguna (España)

E-mail: fcalero@ull.edu.es

Secretaría: António Valério Maduro

Universidade da Maia (Maia, Portugal)

E-mail: avmaduro@docentes.ismai.pt

Secretaría Ejecutiva: Raquel Jacinto Fariña

E-mail: secretaria@pasosonline.org

\section{EDITORES TEMÁTICOS}

Luisa Andreu Simó Univ. de Valencia, España Juan Aguirre Univ. Latina-Heredia, Costa Rica Ma Esther Chávez Álvarez Univ. de La Laguna, España

Margarita Barretto Univ. Federal de Santa Catalina, Brasil

Enrique Bigne Univ. de Valencia, España

Heredina Fernández Betancort Univ. de Las Palmas de Gran Canaria, España

Alberto Jonay Rodríguez Darias Univ. de La Laguna, España

Pablo Díaz Rodríguez Ostelea, España

Nuria Gali Univ. de Girona, España

Antonio Guevara Plaza Univ. de Málaga, España

Margaret Hart Robertson Univ. de Las Palmas de Gran Canaria, España

Raúl Hernández Martín Univ. de La Laguna, España

Edgar Bernardo Universidade de Trás-os-Montes e Alto Douro, Portugal

Sergio Moreno Gil Univ. de Las Palmas de Gran Canaria, España

Maribel Osorio García Univ. Autónoma del Estado de México, México

José J. Pascual Fernández Univ. de La Laguna, España

Xerardo Pereiro Pérez Universidade de Trás-os-Montes e Alto Douro, Portugal

Roque Pinto Univ. Estadual de Santa Cruz, Brasil

María Velasco González Univ. Complutense de Madrid, España

Emilio Romero Macías Univ. de Huelva, España

José María Valcuende del Río Univ. Pablo de Olavide, España

José Antonio Fraiz Univ. de Vigo, España

Cristiana Pereira Teixeira de Oliveira Univ. Europea de Canarias, España

Desiderio Gutiérrez Taño Univ. de La Laguna, España

Gustavo Marín Guardado CIESAS, México

Diego Medina Muñoz Univ. de las Palmas de Gran Canaria, España

Pitu Espeso-Molinero Univ. de Alicante, España

Raffaele Scuderi Univ. de Bolzano, Italia

Laurentina Maria da Cruz Vareiro Inst. Politécnico do Cavado e do Ave, Portugal
José Cadmina Ribeiro Univ. of Minho, Portugal

Javier Hernández Ramírez Univ. de Sevilla, España

Rogelio Martínez Cárdenas Univ. de Guadalajara, México

Carlos Fernandes Inst. Politécnico do Viana do Castelo, Portugal

Jordi Gascón Univ. de Lleida, España

Elena $M^{a}$ Pérez González Univ. Europea de Canarias, España

Ana Priscila Sosa Ferreira Univ. del Caribe, México

Aurora Arjones Fernández Univ. de Málaga, España

Eduardo Parra-López Universidad de La Laguna, España

Rosa Maria Chávez Dagostino Universidad de Guadalajara, México

Carlos Gauna Ruíz de León Universidad de Guadalajara, México

Raquel de la Cruz Modino Universidad de La Laguna, España

\section{CONSEJO CIENTÍFICO ASESOR}

Alessandro Simonicca Univ. La Sapienza di Roma, Italia

Álvaro López Gallero Univ. de la República, Uruguay

Anya Diekmann Univ. Libre de Bruxelles, Bélgica

Artur Cristovao UTAD, Portugal

Arurora Pedro Bueno UV, España

Juan Gabriel Brida Univ. de Bolzano, Italia

Cebaldo de León Smith UTAD, Portugal

Christou Evangelos Aegen Univ., Grecia

Dallen J. Timothy Brigham Young Univ., USA

Daniel Hiernaux UAM, México

Davis Gruber Sansolo Univ., Brasil

Dimitros Buhalis Univ. of Bournemouth, Reino Unido

Fernando Vera Rebollo Univ. de Alicante, España

Elisabeth Kastenholz Univ. de Averio, Portugal

Elizabette Tamanini Uniplac/SC, Brasil

Gemma McGrath Univ. of the Arts London, Reino Unido

Jafar Jafari Univ. of Wisconsin at Stout, Menomonie, USA

Juan Agudo Torrico US, USA

Juan Ramón Oreja Rodríguez ULL, España

Julia Fraga CINVESTAV, México

Julia Sanmartín Sáez UV, España

Julio Grande Sepinum, España

Marcelino Sánchez UCLM, España

María D. Álvarez Bogazici University, Turquía

Marianna Sigalas Aegen Univ., Grecia

Michael Riley Univ. of Surrey, Reino Unido

Noemí Rabassa URV España, España

Raoul Bianchi Univ. of East London, Reino Unido

Ratana Chuenpagdee Memorial University of Newfoundland, Canadá

Regina Schlüter CIET, Argentica

René Baretje-Keller CIRET, Francia

Ricardo Díaz Armas ULL, España

Richard W. Butler Univ. of Strathclyde, Escocia

Rosana Guevara Ramos UAM, México

Svein Jentoft Univerity of Tromsø, Noruega

Thomas George Baum Univ. of Strathclyde, Escocia

Vicente Montfort Mir UJI, España

Carlos Alberto Steil Univ. Federal do Rio Grande do Sul, Brasil

Edición digital: Varadero Informática

(C) PASOS. Revista de Turismo y Patrimonio Cultural. D.L. TF-2059/2002 ISSN 1695-7121

Revista trimestral gratuita de distribución en web

http://www.pasosonline.org E-mail: info@pasosonline.org 
PASOS. Revista de Turismo y Patrimonio Cultural PASOS. Journal of Tourism and Cultural Heritage (An external peer review and open acess journal)

\section{Bases de datos / Databases:}

La revista se encuentra indexada en In-Recs y MIAR, e incluída, entre otras, en las bases de datos: Redalyc (repositório completo y descarga directa. Impacto 2005-2009 0,170); DOAJ (repositório completo y descarga directa); Latindex; CAB Abstracts; E-Revistas; Dialnet; COPAC; SUDOC; ISOC; DICE; CIRET; Altis Intute: social sciences; EBSCO Publishing. Para su inclusión ha sido necesario cumplir con los requisitos de evaluación de cada uno de ellas. Incluida en Web of Science (WOS) en Emerging Sources Citation Index (ESCI); Incluída en JCR - Journal Citation Reports /Clarivate Analytics (JCR year 2020; JCI Rank 109/128; JCI Quartile Q4; JCI Percentile 15.23).

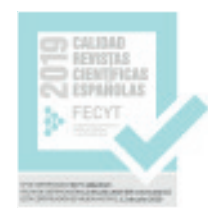

\section{Edita / Publisher:}

Instituto de Investigación Social y Turismo

Universidade de La Laguna (Tenerife, España)

Centro de Estudos de Desenvolvimento Turístico

Universidade da Maia (Maia, Portugal)

\section{Periodicidad / Publication:}

Trimestral / Four times annualy

\section{Número de ejemplares / Copies: 100}

\section{ISSN 1695-7121}

D. L. TF 2059-2002

Octubre-Diciembre 2021. Volumen 19 - Número 4

October-December 2021. Volume 19 - Number 4

Correo electrónico / E-mail:

info@pasosonline.org

Postal Address:

P.O. Box 33

38360 El Sauzal (Tenerife)

España 


\section{PASOS. REVISTA DE TURISMO Y PATRIMONIO CULTURAL \\ GUÍA DE ESTILO PARA AUTORES \\ Revista indexada en: DOAJ; Latindex; ISOC; Redalyc; DICE; E-Revistas; CAB-Abstract; Incluida en Web of Science (WOS)}

\begin{abstract}
PASOS. Revista de Turismo y Patrimonio Cultural es una publicación en web que se especializa en el análisis académico y empresarial de los distintos procesos que se desarrollan en el sistema turístico, con especial interés a los usos de la cultura, la naturaleza y el territorio, la gente, los pueblos y sus espacios, el patrimonio integral. Desde una perspectiva inter y transdisciplinar solicita y alienta escritos venidos desde las ciencias y la práctica administrativo-empresarial. Su objetivo es cumplir con el papel de foro de exposición y discusión de metodologías y teorías, además de la divulgación de estudios y experiencias. Pretende contribuir a otros esfuerzos encaminados a entender el turismo y progresar en las diversas formas de prevención de efectos no deseados, pero también perfeccionar la manera en que el turismo sirva de complemento a la mejora y desarrollo de la calidad de vida de los residentes en las áreas de destino.
\end{abstract}

PERIODICIDAD (números de carácter ordinario): ENERO; ABRIL; JUNIO; OCTUBRE

Para simplificar el proceso de revisión y publicación se pide a los colaboradores que se ajusten estrictamente a las normas editoriales que a continuación se indican.

Entrega de originales: Los trabajos deberán ser incorporados a la plataforma de gestión de la revista, previo registro del autor principal, en www.pasosonline.org/ojs

Metadatos: Deben incorporarse todos los metadatos solicitados en el registro del trabajo incorporado, incluyendo los datos referentes a los autores y en el apartado Resumen el realizado en el idioma original y, seguido, en inglés.

\section{TEXTO A INCORPORAR}

Formato de archivo: El archivo a incorporar deberá estar en formato MSWord (*.doc; *.docx) o OpenOffice Writer (*.odt) Idioma: Los trabajos serán publicados en el idioma en el que sean entregados (español, portugués, inglés o francés).

Márgenes: Tres centímetros en todos los lados de la página.

Tipografia: Se utilizará en el texto la letra Times New Roman o Arial, tamaño 10, o similar. En las notas se utilizará el mismo tipo de letra a tamaño 9. No utilizar diversidad de fuentes ni de tamaños. Si se desea destacar alguna palabra o párrafo dentro del texto utilizar la misma fuente en cursiva.

Notas: Siempre serán situadas al final, utilizando el mismo tipo de letra que en el texto (Times New Roman o Arial) a tamaño 9

Título: El trabajo debe ir encabezado por su título en minúsculas y negrita. Bajo él se insertará el título en inglés. Es aconsejable que el título no supere en ningún caso los 100 caracteres (incluyendo espacios).

Resumen: Se debe insertar un resumen del artículo (120 150 palabras) en el idioma en que está escrito y su traducción al inglés. Para los artículos escritos en inglés se aportará su traducción al español.

Palabras clave: Se indicarán 5 - 7 palabras clave sobre el tema principal y su correspondiente traducción a inglés.

Texto: El texto debe ser escrito a 1,5 de espaciado y con una extensión de 5.000 a 9.000 palabras para artículos y de 3.000 a 5.000 tanto para opiniones y ensayos como para notas de investigación, incluyendo Título (y su traducción a inglés), Resumen (y su traducción a inglés), Palabras clave (y su traducción a inglés), Introducción, los apartados que se estimen oportunos, Conclusión, Agradecimientos (si fuera pertinente) y Bibliografía.

Cuadros, Gráficos e Imágenes: Los artículos pueden incluir cualquier grafismo que se estime necesario. Deberán estar referidos en el textos y/o situados convenientemente y acompañados por un pie que los identifique. Pueden utilizarse colores, pero ha de tenerse en consideración la posibilidad de una publicación en soporte papel en blanco y negro.

Abreviaturas y acrónimos: Deberán ser bien deletreados y claramente definidos en su primer uso en el texto.

Citas y Bibliografía: En el texto las referencias bibliográficas harán referencia al autor y el año de publicación de la obra citada. Por ejemplo: (Smith, 2001) o (Nash, 1990; Smith, 2001). Cuando se considere necesaria una cita más precisa se indicará el número de página (Smith, 2001: 34). La lista bibliográfica al final del texto seguirá el orden alfabético de autores, siguiendo el formato:

Smith, Valene L. y Brent, Maryann 2001. "Introduction to Hosts and guests revisited: Tourism issues of the 21st century". En Smith, Valene L. y Brent, Maryann (Eds.), Hosts and guests revisited: Tourism issues of the 21st century (pp. 1-14). New York: Cognizant Communication.

Smith, Valene L. 1998. "War and tourism. An American Ethnography". Annals of Tourism Research, 25(1): 202-227.

Urry, J. 1990. The tourist gaze. Leisure and travel in contemporary societies. London: Sage.

Para otro tipo de publicaciones se hará constar siempre autor, año, título y lugar de celebración o publicación y un estándar para documentos electrónicos, indicando dirección y fecha de acceso.

Originalidad: Se requiere el compromiso de los autores tanto de la originalidad de su trabajo como de no remitir su texto simultáneamente a otros medios para su publicación.

Derechos de autor y Responsabilidad: Es importante leer la sección "Declaración Ética" en el sitio web de la revista. Los autores serán los únicos responsables de las afirmaciones y declaraciones realizadas en su texto. El equipo editorial de PASOS se reserva el derecho de utilizar en ediciones compilatorias sucesivas los artículos editados. Los textos son publciados bajo licencia Creative Commons, por lo que podrán ser reproducidos como archivo pdf sin alteraciones, íntegramente y citando la fuente PASOS Revista de Turismo y Patrimonio Cultural (www.pasosonline.org). La integración en publicaciones que impliquen la alteración del archivo original requerirán de permiso expreso del autor o autores y del Comité Editorial de PASOS.

Una vez comunicada la ACEPTACIÓN del texto para su publicación, los autores deben cumplimentar el formulario disponible en la sección "Declaración de derechos" y remitirlo al correo electrónico de la revista.

Proceso de revisión: Es importante leer la sección "Proceso de revisión" en el sitio web de la revista. Todos los trabajos serán sometidos a evaluación por pares anónimos externos a la revista. Se notificará a los autores el resultado de la revisión realizada mediante correo electrónico con una ficha resumen del arbitrio.

(C) PASOS. Revista de Turismo y Patrimonio Cultural. D.L. TF-2059/2002 ISSN 1695-7121

Revista trimestral gratuita de distribución en web

http://www.pasosonline.org E-mail: info@pasosonline.org 


\section{PASOS. REVISTA DE TURISMO Y PATRIMONIO CULTURAL GUÍA DE ESTILO PARA AUTORES \\ Revista indexada en: DOAJ; Latindex; ISOC; Redalyc; DICE; E-Revistas; CAB-Abstract; Incluida na Web of Science (WOS)}

\begin{abstract}
PASOS. Revista de Turismo e Património Cultural é uma publicação web especializada na análise académica e empresarial dos destintos processos que se desenvolvem no sistema turístico, com especial incidência nos usos da cultura, da natureza e do território, nas gentes, nos povos e nos seus espaços, no património integral. A partir de uma perspectiva inter e transdisciplinar solicita e encoraja escritos provenientes desde as ciências sociais à prática administrativa empresarial. Tem como escopo cumprir o papel de foro de exposição e discussão de metodologias e teorias, além da divulgação de estudos e experiências. Pretende ainda contribuir para a compreensão do turismo e o progresso das diversas formas de prevenção de impactes não desejados, mas também contribuir para que o turismo sirva de complemento à melhoria e desenvolvimento da qualidade de vida dos residentes nas áreas de destino.
\end{abstract}

Periodicidade de números ordinários: Janeiro; Abril; Junho; Outubro

Para simplificar o processo e revisão de publicação pede-se aos colaboradores que se ajustem estritamente ás normas editoriais que a seguir se indicam.

Metadados: Devem ser indicados todos os metadados solicitados no registo do trabalho incorporado, incluindo os dados referentes aos autores e, em separado, o resumo no idioma original seguido de uma versão em inglês.

TEXTO A INCORPORAR Formato do arquivo: O arquivo a incorporar deverá estar em formato MSWord (*.doc; *.docx) ou OpenOffice Writer (*.odt) Idioma: Os trabalhos serão publicados no idioma em que sejam entregues (espanhol, português, inglês ou francês). Margens: Três centímetros em todos os lados da página. Grafia: Deverá utilizar no texto a letra Times New Roman ou Arial, tamanho 10, ou similar. Nas notas utiliza-se o mesmo tipo de letra em tamanho 9. Não utilizar diversidade de fontes nem de tamanhos. Se desejar destacar alguma palavra ou parágrafo dentro do texto deve utilizar a mesma fonte em cursiva.

Notas: Serão sempre colocadas no final, utilizando o mesmo tipo de letra do texto (Time New Roman ou Arial) tamanho 9.

Título: O trabalho deve ser encabeçado pelo seu título em minúsculas e bold.

Não devem incluir-se no documento dados do autor. Por baixo deve ser inscrito o título em inglês. É aconselhável que o título não ultrapasse os 100 caracteres (incluindo espaços)

Resumo: Deve constar um resumo do artigo (120 a 150 palavras) no idioma em que está escrito e a sua tradução em inglês. Para os artigos escritos em inglês deve incluir-se a sua tradução em espanhol.

Palavras-chave: Incluem-se 5-7 palavras-chave sobre o tema principal e a sua correspondente tradução para inglês.

Texto: Este deve apresentar o espaçamento de 1,5 ter uma extensão de cerca de 5000 a 9000 palavras paraartigos e 3 000 a 5000 , tanto para opiniões e ensaios como para notas de investigação, incluindo título (e a sua correspondente tradução para inglês), Palavras-chave (e a sua correspondente tradução para inglês), Introdução, as notas que se entendam oportunas, Conclusão, Agradecimentos (se se justificarem) e Bibliografia.

Quadros, gráficos e imagens: Os artigos podem incluir qualquer grafismo que se ache necessário. Deverão estar referenciados com o número correspondente no texto e acompanhados por um título que os identifique. Podem utilizar-se cores; porém, a considerar-se a possibilidade de uma publicação em suporte de papel serão usadas apenas a preto e branco.

Abreviaturas e acrónimos: Deverão ser bem definidos na primeira vez que forem usados no texto.

Citações e bibliografia: No texto as referencias bibliográficas terão que reportar o autor e o ano da publicação da obra citada. Por exemplo: (Smith, 2001) ou (Nash, 1990; Smith, 2001). Quando se considere necessário uma referencia mais precisa deve incluir-se o número da página (Smith, 2001: 34). O aparato bibliográfico do final do texto surge consoante a ordem alfabetizada dos autores, respeitando o seguinte formato:

Smith, Valene L. y Brent, Maryann 2001. "Introduction to Host and guest revisited: Tourism issues of the 21st century". En Smith, Valene L. y Brent, Maryann (Eds.), Host and guest revisited: Tourism issues of the 21st century (pp.-14). New York: Cognizant Communication.

Smith, Valene L. 1998. "War and tourism. An American Ethnography". Annals of Tourism Research, 25(1): 2002-227.

Urry, J. 1990. The tourist gaze. Leisure and travel in contemporary societies. London: Sage.

Para outro tipo de publicação terá que ser sempre referenciado o autor, ano, título e lugar do evento ou publicação e um standard para documentos electrónicos, indicando endereço e data de acesso.

Originalidade: Requere-se o compromisso. tanto da originalidade do trabalho, como o de o texto não ter sido remetido simultaneamente para outros suportes para publicação.

Direitos e Responsabilidade: É importante ler a secção "Declaração Ética" no sítio da web da revista. Os autores serão os únicos responsáveis pelas afirmações e declarações proferidas no seu texto. À equipa editorial da PASOS reserva- -se o direito de utilizar em edições compilatórias sucessivas os artigos editados. Os textos são publicado ao abrigo da licença Creative Commons, pelo que poderão ser reproduzidos como arquivo pdf sem alterações, integralmente e citando a fonte PASOS Revista de Turismo e Património Cultural (www. pasosonline. org). A integração em publicações que implique a alteração do arquivo original requererão a autorização expressa do autor e da Comissão Editorial PASOS. Uma vez comunicada a ACEITAÇÃO do texto para publicação, os autores devem completar o formulário disponível na secção "Declaração de direitos" e remetê-lo pelo correio electrónico da revista.

Processo de revisão: É importante ler a seç̧ão "Processo de revisão" no sítio web da revista. Todos os trabalhos serão submetidos e avaliados por pares anónimos externos à revista. Os autores serão notificados dos resultados da revisão realizada mediante uma ficha- resumo da arbitragem. 
PAS SS

Revista de Turismo y Patrimonio Cultural

wwwpasosonline.org

\section{Índice}

Héctor Moreno Mendoza

Juan Manuel Parreño Castellano

César Ubierna Expósito

Diogo José Goes

Luís Filipe Sardinha

Eva Parga Dans

Pablo Alonso González

Raimundo Otero Enríquez

David Barreiro

Felipe Criado Boado

Juan Ángel Martín

Marta Domínguez Pérez

Alicia Castillo Mena

Fernando Pellicer

Raquel Camprubí

Daniel Dorta-Afonso

Hugo Padrón-Ávila

Silvia María González

Hugo Martins

Carlos Silva

António Pinheiro

Eduardo Gonçalves

María del Mar Martín García

María Pilar Palomar Anguas

Daya Morales Jaime

Jacilene Barbosa de Arruda

André Falcão Durão

Alexandre César Batista da Silva

Carla Borba da Mota Silveira

Rosario Lucía Angaramo Corvalán

Vanesa Pérez-Torres

Andre Fontan Kohler

Luciano Antonio Digiampietri
The ecomuseum as a space for the activation of governance processes. Co-management of heritage in responsible tourism management.

Turismo e museus: uma reflexão empírica sobre a Região Autónoma da Madeira

El valor social como factor estratégico en la gestión patrimonial y turística: el caso del sitio patrimonio de la humanidad Cueva de Altamira (España)

La activación de la ciudadanía como estrategia para la sostenibilidad turística en lugares patrimoniales cercanos a la gran ciudad.

El caso de la región madrileña

La autopercepción del turista cultural en su rol de turista

Gestión de turismo gastronómico: identificación del mercado potencial en Canarias

Una aproximación conceptual y literaria a la gastrodiplomacia como conductora de marca de un destino

A importância da marca no turismo: o caso da entidade regional do Turismo do Porto e Norte de Portugal

El turismo de golf en Almería y su carácter desestacionalizador

El parque del Buen Retiro de Madrid: valor patrimonial y uso ciudadano y turístico

O engajamento on-line do consumidor em mídias sociais de serviços turísticos: uma análise comparativa entre as companhias aéreas brasileiras a partir de suas fanpages

Instagram: inspiración, reconocimiento social y motivación en la elección del destino turístico

Turismo cultural: análise bibliométrica e de redes sociais do campo de turismo no Brasil, 1990-2018

(C) PASOS. Revista de Turismo y Patrimonio Cultural. D.L. TF-2059/2002 ISSN 1695-7121

Revista trimestral gratuita de distribución en web http://www.pasosonline.org E-mail: info@pasosonline.org 


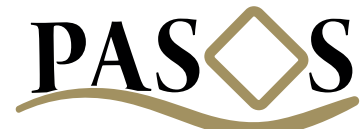

Revista de Turismo y Patrimonio Cultural www.pasosonline.org

Florencia Viviana Moscoso

Paula Vera

\section{Opiniones y Ensayos}

Nuevas relaciones entre cultura, turismo y

845 territorio en el contexto de la posmodernidad

\section{Reseña de Publicaciones}

Los imaginarios sociales y el turismo. Conceptos

853 


\title{
The ecomuseum as a space for the activation of governance processes. Co-management of heritage in responsible tourism management.
}

\section{Héctor Moreno Mendoza* Juan Manuel Parreño Castellano**}

Universidad de Las Palmas de Gran Canaria (España)

\author{
César Ubierna Expósito*** \\ Cabildo de Gran Canaria (España)
}

\begin{abstract}
An ecomuseum orients its conservation, formation and reproduction of identity and patrimonial tasks based on the proximity to the territory and the population area it serves. This entails a flexible management system that adapts to contextual specificities of this socio-cultural and geographical area, empowering local populations to govern themselves in relation to a common project. This study explores the activation of governance processes in ecomuseums, The Cultural Project of Community Development of La Aldea on the island of Gran Canaria (Canary Islands, Spain) is taken as a case study, related to manners and traditional work. Methodologically, interviews, informal conversations and direct observation have been conducted to determine the presence of governance in the management. To assess the opinion of the visitor, questionnaires were made. From the analysis it is possible to confirm that co-management, in accordance with governance provides better decision-making in the formation of the cultural tourism product.
\end{abstract}

Keywords: Ecomuseum; Responsible tourism management; Governance; Case study; Identity; Community development.

El ecomuseo como espacio para la activación de procesos de gobernanza. Co-gestión del patrimonio en la gestión responsable del turismo

Resumen: Un ecomuseo orienta su conservación, formación y reproducción de tareas identitarias y patrimoniales en función de la proximidad al territorio y sus poblaciones. Esto implica un sistema de gestión flexible que se adapte a las especificidades contextuales del área sociocultural y geográfica, empoderando a las poblaciones locales para gobernarse a sí mismas en relación a un proyecto común. Este estudio explora la activación de los procesos de gobernanza en los ecomuseos, se toma como caso de estudio el Proyecto Cultural de Desarrollo Comunitario de La Aldea en la isla de Gran Canaria (Canarias, España), relacionado con las costumbres y tradiciones. Metodológicamente, se han realizado entrevistas, conversaciones informales y observación directa para determinar la presencia de gobernanza en la gestión. Para valorar la opinión del visitante se realizaron cuestionarios. A partir del análisis se puede constatar que la cogestión, acorde con la gobernanza, proporciona una mejor toma de decisiones en la formación del producto turístico cultural.

Palabras Clave: Ecomuseo; Gestión responsable del turismo; Gobernanza; Caso de estudio; Identidad; Desarollo comunitario.

\section{Introduction}

The high cultural content on offer in museums and other cultural assets, has made these institutions develop their capabilities to manage environmental challenges better (Lebek et al., 2006), but also in

\footnotetext{
* Universidad de Las Palmas de Gran Canaria (España); E-mail: hectormormen@gmail.com; https://orcid.org/0000-0001-8405-8776

** Universidad de Las Palmas de Gran Canaria (España); E-mail: juan.parreno@ulpgc.es; https://orcid.org/0000-0002-1082-456X

**** Cabildo de Gran Canaria (España); E-mail: subierna092@gmail.com; https://orcid.org/0000-0001-5870-3348
} 
terms of social challenges. Due to the constant innovation in management, recently ecomuseums challenge a single accepted definition (Davis and Corsane, 2014: 119). It is understood here that ecomuseums are characterized by identifying, in a given region, the traditional living environment through cultural and natural heritage valued to be protected and preserved (Elliot, 2006). In this sense, and based on the Declaration of Intentions of the Long Net Workshop, Trento (Italy, 2004), the ecomuseum is taken as a form of dynamic community agreement by which heritage is preserved, interpreted and managed for sustainable development.

These agreements are the basis for the implementation of governance mechanisms, with the common objective of the social, environmental and economic development of the local population. This common process of management in heritage (Davis, 1997: 199; Haveri et al., 2009) involves the responsibility among the actors of the cultural resource, promoting multiple uses of heritage.

Responsible tourism is based on sustainability, but without becoming a specific or thematic tourism typology (Idelhadj, Rivera and Rodríguez, 2012). More than a product, it is a series of commitments, sensitivities, and responsibilities on the actions that affect both the tourist and the tour operators and intermediaries and the public administrations involved. All must, following these principles, recognize the central role of the local population and the control that it can practice in the tourism development processes of their territory (Santana-Talavera, 2008). This way of conceiving tourism has a social aspect that implies respecting, promoting and developing local cultures and protecting them from cultural homogenization, over-marketing and overexploitation.

Responsible tourism (RT), as a tourist action linked to the movement of ecomuseums, constitutes in itself a social movement that involves a niche market (Reverté and Guix, 2013). The application of such actions on a territory, in addition to contributing positively to the conservation of the natural and cultural heritage, promotes memorable experiences and better perception of the places both for the hosts and for the visitors. The RT, as an attitude, tends to minimize unwanted socio-cultural, socio-economic and environmental impacts, to improve the welfare of host populations, to involve these populations in decisions that affect their lives and future opportunities, and to improve understanding of the local culture by tourists. This responsible vision must be articulated on some notions of management, with governance being the tool to involve the local population in decisions about cultural heritage.

The purpose of this paper is to explore the activation of governance processes in ecomuseums, starting from the involvement of different agents in their development, establishing the level of participation and co-management of the local population in the administration of the resources of the ecomuseum. For this purpose, the Cultural Project of Community Development of La Aldea (PDCLA) on the island of Gran Canaria (Canary Islands, Spain) has been chosen as a case study. Based on interviews, informal conversations, questionnaires and direct observation, the application of co-management of heritage is determined as an aspect of responsible management.

For this research, co-management in the administration of the museum is conceived as the set of decisions and activities in terms of conservation and sustainable development of the environment; assumes the principle of community management. In this way, it constitutes a management paradigm with respect to the traditional museum administration (depending on its management model).

Otherwise, it is hypothesized that co-management, as a form of application of governance, is shown as an effective tool for the sharing of responsibilities and competencies in the management of resources, being sustainable over time and contributing to overcoming crisis intermediate (economic and social).

\section{Co-management as a strategy for governance in the ecomuseum}

Governance, as a negotiation and cooperation mechanism between different actors (at the private or public level, and from the individual, business or institutional point of view), has gained prominence in recent years in various sectors of society. Unesco (2005, p.78) proposes governance in the heritage sector as maintaining the balance between social and economic objectives and between individual and communal goals. The purpose of the governance framework is to promote the efficient use of resources and to demand responsibility for the administration of those resources. What is sought is to align as much as possible the interests of individuals, cultural heritage and society. For the context of museums, the adaptation that Legget (2006) makes for this area has been taken: "The Stakeholders of a museum 
are individuals or organizations that have an interest or influence in the capacity of a museum to achieve its objectives".

This mechanism has been studied in other areas, such as in the context of global intellectual property policies, understood as a set of agreements and legal systems, which largely regulate the flow of information on the Internet (Souza et al., 2014), or in environmental policies (Durant, 2017; Newin et al., 2018; Videira et al., 2018). It is in the case of museums where there is special interest to link the diversity of actors in the formation of strategies for a common social, economic and cultural development (Cosmin, 2018, Elsorady, 2018, Loach et al., 2017, Zuned, 2018).

A fundamental challenge in achieving governance is to involve a diversity of partners and gain legitimacy (Huxham and Vangen, 2005, Vangen and Huxham, 2012). The very attraction to collaborate is to take advantage of this diversity of capabilities and disparate resources, generate new solutions and synergies between partners in response to this spectrum of diversity of challenges. Governance is discussed in the literature from different dimensions.

First, by the degree of collaboration in the short or long term (Keast et al., 2007). Secondly, the degree of formality and rank of centralization, from a loose network to a strong association with its own legal entity, administration, organization and staff (Bryson et al., 2006; Provan and Kenis, 2008). Third, there are systems of accountability that clarify who in the association is responsible and for what (Geddes and Shand, 2013). Finally, there is the value of openness in the degree of participation of the members and clarity of assigned roles (Huxham and Vangen, 2000), through people who represent partners without pre-established role assignments.

The term "co-management" (also referred to as participatory management, co-administration, or shared management) constitutes an "institutional arrangement between the local users of a territory or set of natural resources and / or groups interested in their conservation, and the public agencies in charge of the administration of these resources. It implies both a distribution of responsibilities and competencies, and a clear definition between the exercise of public authority and the patterns of use, access, control and subsequent management of resources" (Girot, 1998). The same author mentions that co-management is essentially a "partnership" between parties that share an interest, a responsibility and a vision about the sustainable use of a resource. These alliances must include various sectors. In the field of museums, co-management involves the participatory use of communities in areas related to eco-cultural spaces or in the process of musealization (Adán Alfaro, 2010; Janes 2016). This eco-management has the challenge of reaching agreements between the various economic sectors that make up the productive framework in a given area.

\section{Challenges of intersectoral alliances}

An intersectoral partnership (a museum) involves the public and private sectors and third parties that work together to manage resources and capacities and share decision-making in the medium and long term, or to address a complex social problem (Selsky and Parker, 2005; Bryson et al., 2006). The existing literature on intersectoral alliances is very diverse, and depends specifically on the specific sector (Huxham and Vangen, 2005, Bryson et al., 2006).

In a cross-sectional sector, such as culture, partnerships take time to come to fruition and delivery is often slow, and often many intersectoral partnerships do not achieve their objectives. The literature on the cross-sector on partnerships can be summarized in relation to three particular challenges: governance, strategy and leadership.

Previous studies characterize the nature of the strategy as multilevel, interconnected, dynamic, and as a result, with unintended consequences (2006, Seitanidi, 2008, Clarke and Fuller, 2010, Vangen and Huxham, 2012). That is why many authors emphasize the need to negotiate an agreement on a purpose, but there is a division in the literature on the best way to overcome this problem (a fast and slower way).

The initial challenge of leadership is to create partnership (Crosby, 2010; Klijn et al., 2010), which is helped by an organization or coordinator, who is powerful, credible, committed in the long term, capable of rethinking and raising the profile of the problem, and has a large capital (Waddock and Post, 1991; Bryson et al., 2006). Once the intersectoral partnership has been initiated, leaders need to balance the number and diversity of people involved, between a more democratic one (Bryson et al., 2006) or selective approach (Klijn et al., 2010). When conflicts arise, leaders must have an essential role of mediation (Crosby and Bryson, 2010; Klijn et al., 2010). 
In the literary review, the need to have a strong individual leader is highlighted, either from the public (or private) sector based on authority is emphasized (Ansell and Gash, 2008, Crosby, 2010, Geddes and Shand, 2013) or a private social entrepreneur (Waddock and Post, 1991).

\section{Case study: The Community Project of La Aldea}

The PDCLA emerges in a very specific context in which many of the reasons that led to its creation are determined by the special geographical conditions in which it is located. La Aldea de San Nicolás is located in the west of the island of Gran Canaria (Map 1) and is surrounded by a rugged orography. Previously, communications with the outside were made by sea. Its relief, eroded and very abrupt, is divided by numerous ravines. The weather is dry with a semiarid landscape, has determined the proliferation of small core scattered throughout the municipality looking for the wettest areas, flat ravines and their heights crowned by extensive pine forests. (López García, 2003, Sánchez González, Suárez Espino and Moya Otero, 2002). The municipality of La Aldea de San Nicolás is about 50 kilometers from the tourist area and 63 or 111 kilometers according to the chosen route, from the capital of the island, Las Palmas de Gran Canaria. The population is of 7,613 inhabitants (2017). The cultivation of tomatoes is the main activity of the municipality (Cabildo de Gran Canaria, 2018).

\section{Map 1: Location of the Community Project of La Aldea}

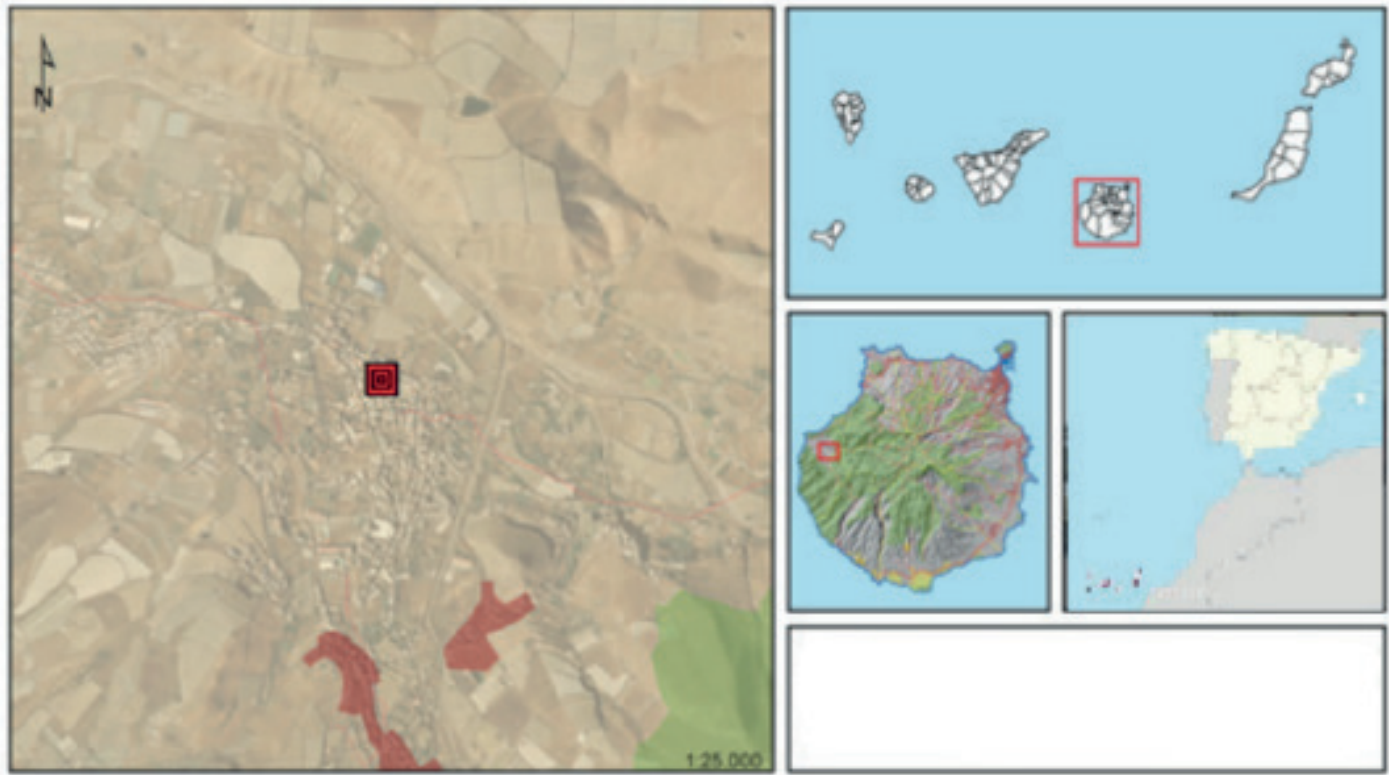

The authors.

The Cultural Project of Community Development La Aldea (PDCLA), in Gran Canaria, begins when two teachers from the Public School Cuermeja, José Pedro Suárez and Lidia Sánchez, decide to incorporate popular culture into the activities of the educational center where they worked. This happened in 1980 in the School Residence of La Aldea de San Nicolás de Tolentino. The teachers' concern for achieving coexistence was accompanied by the idea of reducing the negative effects that the prolonged separation of their family environment could have on the residents. In this way, a commendable didactic and ethnographic experience emerges (Sánchez González, Suárez Espino and Moya Otero, 2002). 


\section{Image 1: Visitors entering the Pottery Center}

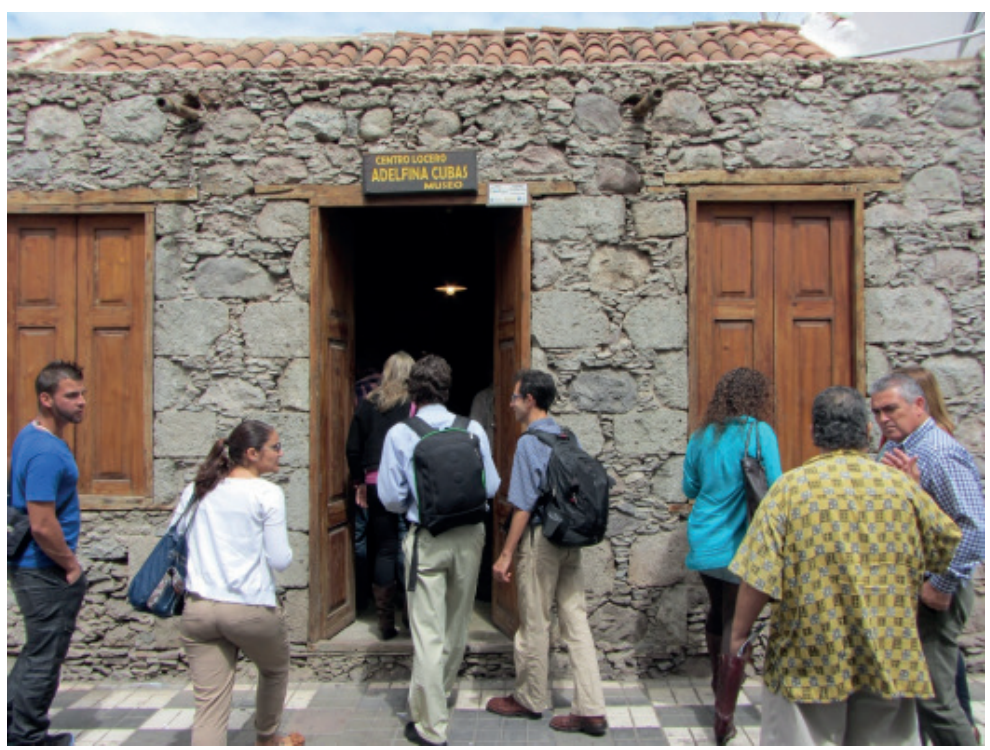

Photo: the authors

Image 2: Visitors at the Gofio's Grinder

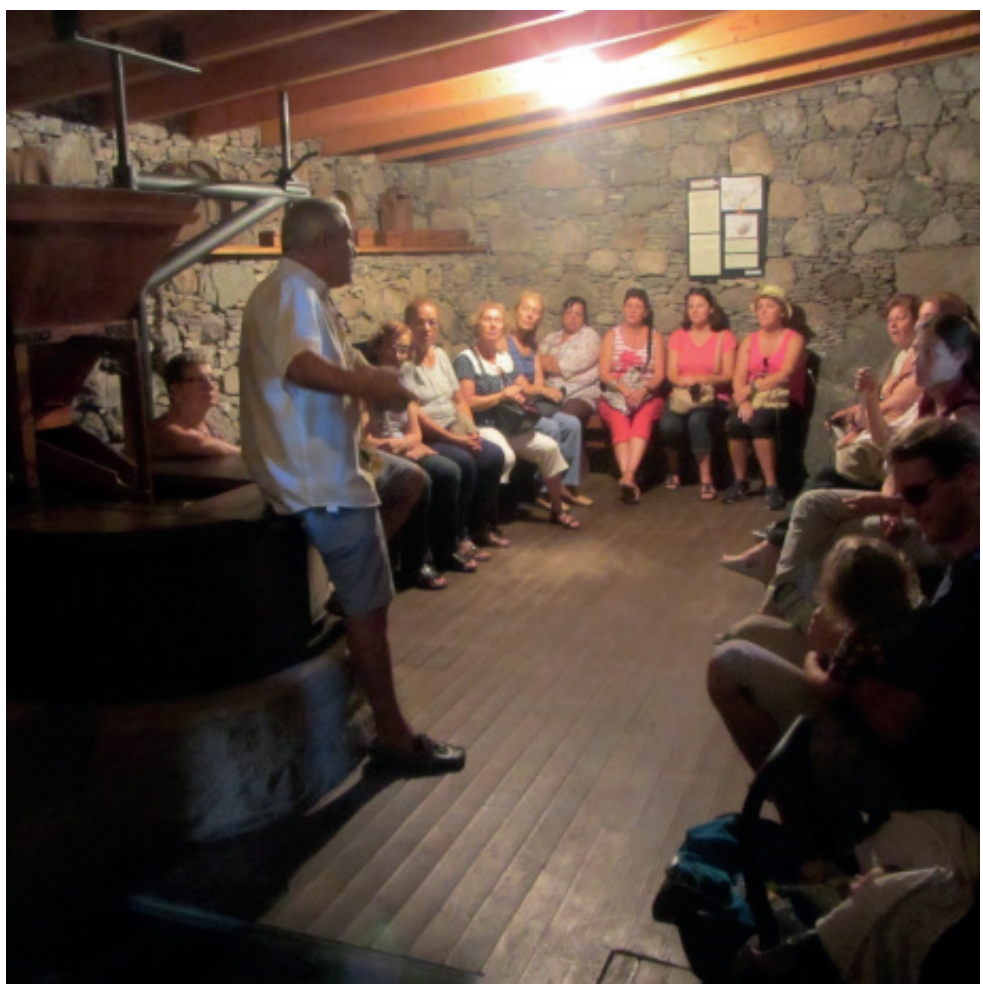

Photo: the authors 
This experience of ethnographic participation has been recognized nationally and internationally for its cultural and educational values, but mainly for its concern for the recovery and transmission of intangible heritage. UNESCO considers intangible heritage traditions that are transmitted orally or through gestures and are modified over time through a process of collective recreation, with each individual being the patron of their own community. In short, PDCLA has been considered by the International Scientific Committee of Museums, as "the most important living museum in Europe" (Sánchez González and Suárez Espino, 2006).

\section{Description}

There are various activities that make up the PDCLA: the Living Museums, the handicraft workshops, the native sports, the Regional Annual Folklore Days, the participation in popular events (Auto de los Reyes Magos, Rancho de Ánimas), etc. Since its creation, the Community Development Project has created numerous living museums where you can enjoy traditions (Sánchez González, Suárez Espino and Moya Otero, 2002).

\section{Image 3: Sketch of the distribution of museums in the PDCLA}

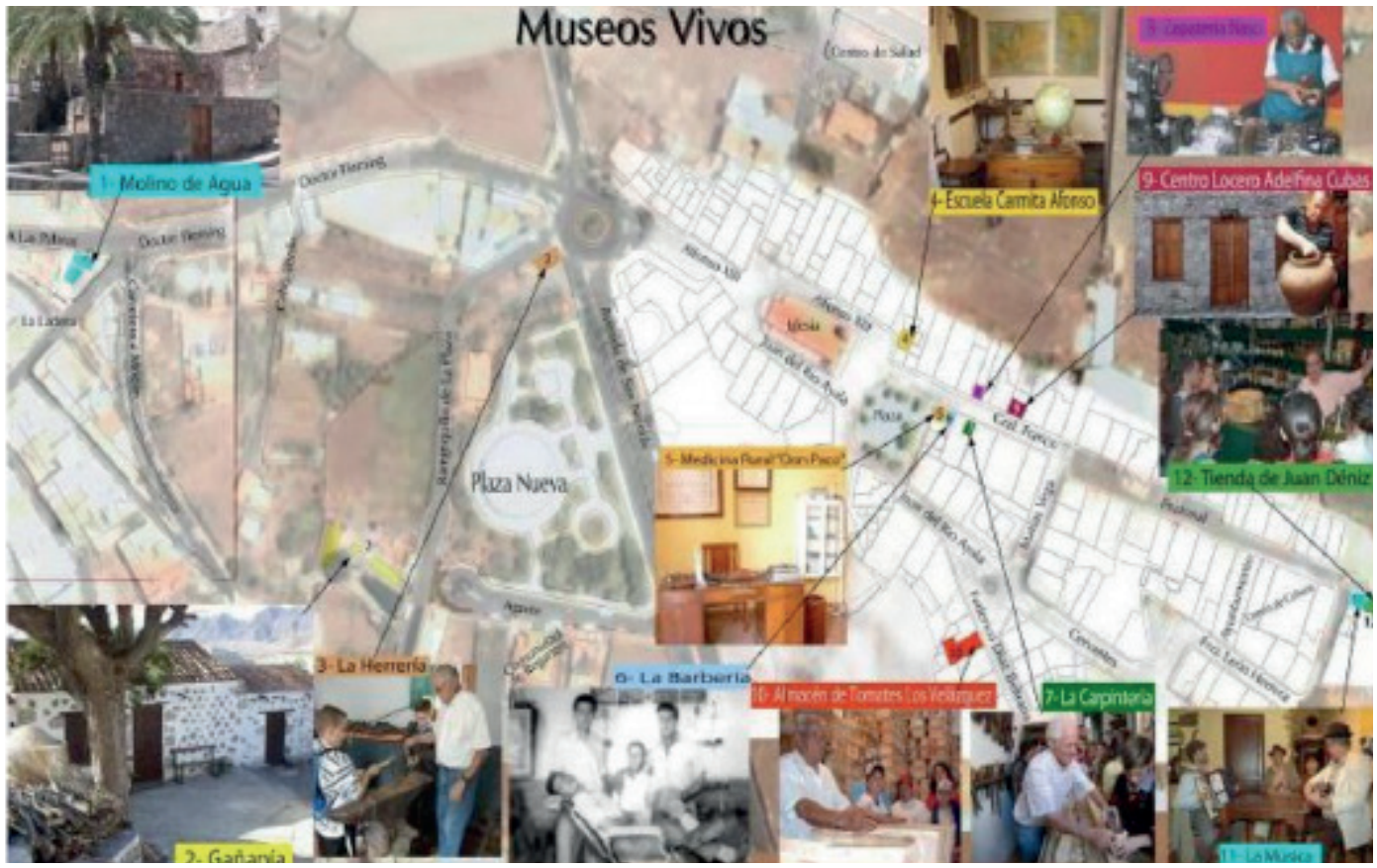

Source: http://www.proyectolaaldea.com/

They started with La Gañanía, a traditional farm from the early twentieth century with original rooms that show the ways of life of rural culture, and the Water Mill to grind the Gofio ${ }^{1}$, a building of the late nineteenth century that has been rebuilt (Sánchez González, Suárez Espino and Moya Otero, 2002). Then, other museums were added with the trades and activities of the town in the 20th century: the Shop, the Music Museum, the Pottery Center, the Barber Shop, the School, the Tomato Store, the Shoe Store, the Rural Medicine, the Smithy, and the Butcher Shop (Suarez Moreno and others, 2005). The last two spaces incorporated into the Project are the Museum of the Shepherd (2014) and the Museum of Traditional Clothing (2016). 


\section{Image 4: Museum of Rural Medicine}

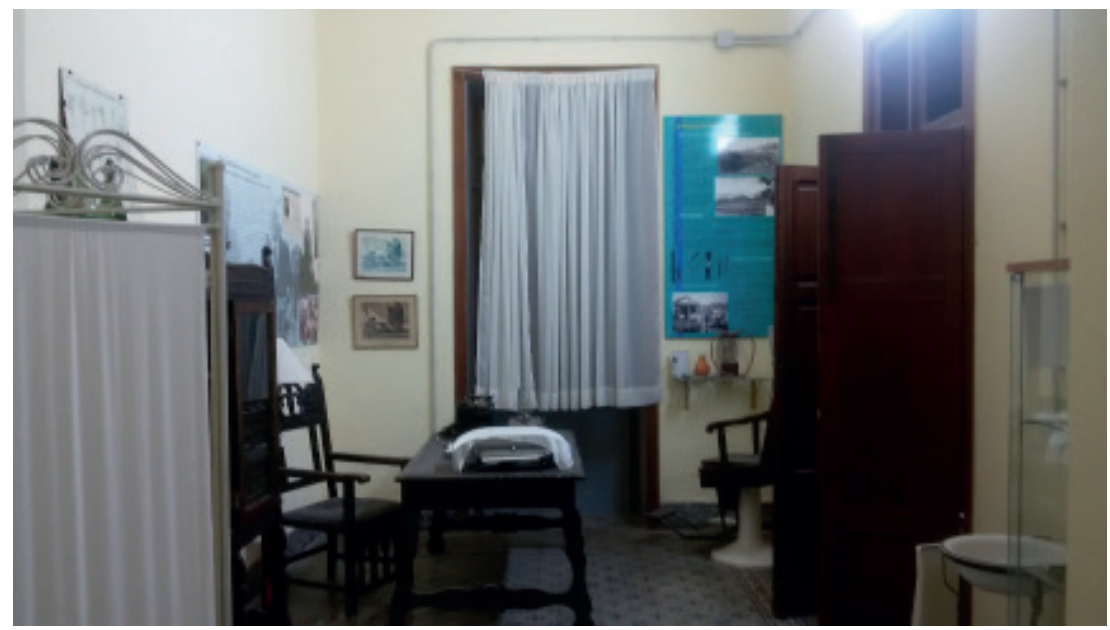

Photo: the authors

\section{Permanent and temporary offer}

You can make three visits or different routes: a first "short", a second "medium" and a third "long. This route is also configurable in terms of spaces.

\section{Image 5: Music Museum}

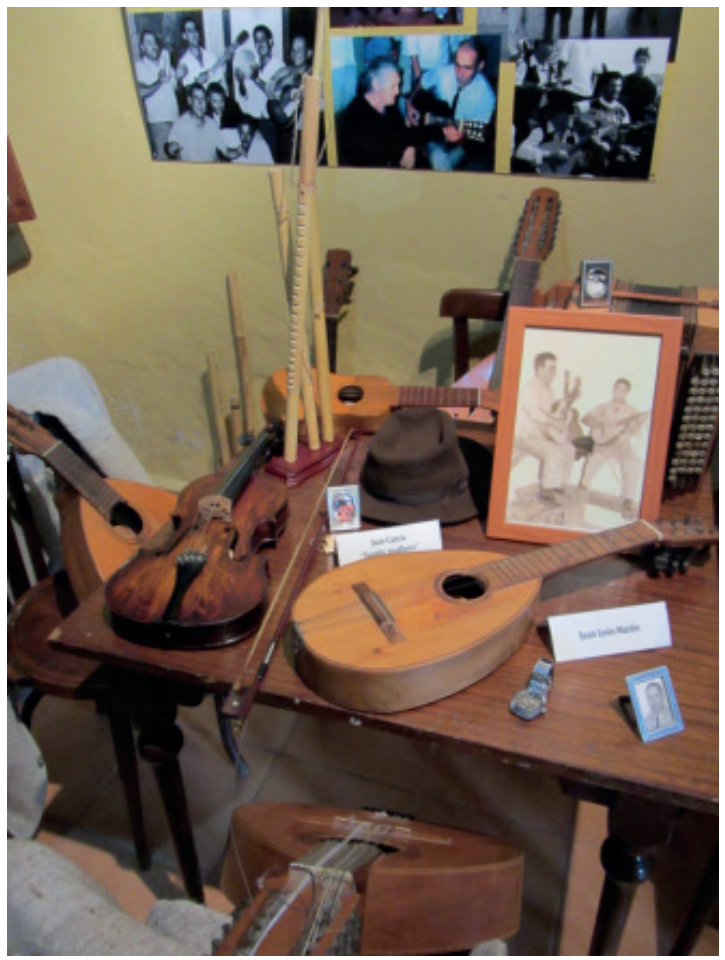

Photo: the authors 
As management aspects, schedules can be arranged with the organization, usually adapted to the needs of the group (it is requested that they are at least 10 - 12 people, there is no maximum, although groups larger than 25 are not recommended). The entry price is free. The museum has brochures (only in Spanish and digital), panels and posters (Spanish), guided tours (Spanish) and does not have videos or projections.

The Project is formed as a non-profit association, led by an assembly that is coordinated by a president, a vice president, a treasurer, a secretary and a vocal. The assembly is the form of government in the Project. They meet twice every week (Tuesday and Thursday). Normally fifty people meet, the managerial positions are assigned by means of proposals. Votes are taken to make decisions. There is a statute and a memory of association. Decisions are made in the assembly, people reach an agreement easily. People delegate to other people.

The annual income $€ 15,000$ (2017) comes from a grant from the FEDAC: Foundation for the Ethnography and Development of the Canarian Crafts (Autonomous Foundation belonging to the Cabildo de Gran Canaria). For a long time they were not assigned or registered. Now they make up an association. As for the staff, the number of those directly involved is 45 volunteers. For some events, over 200 participants are exceeded.

The Project does not have a cafe or restaurant, nor a souvenir shop, there are no staff hired for cleaning, security or guided tours. As a Project policy, they never talk about bad relationships with governments. There is a collaboration agreement with the education council of the Government of the Canary Islands. There is another agreement with Fedac, to be able to pay rents and food for the animals. There is no agreement with the local council. There is no relationship (for decision making or financing) with private companies. For example, if you have to go to a congress, the project or sometimes members have to pay all expenses.

\section{Governance (principles and criteria) and actors in the ecomuseum}

The Project complies with the 35 criteria of the 5 principles of Governance: Legitimacy and voice, Management (strategic vision), Efficiency and efficiency (performance), Responsibility and transparency (accountability) and Justice (compliance with the law). Some aspects to be highlighted in relation to Governance are: People want to take off problems. They delegate decisions to other people. There is discussion; the decisions to be made are shared. There is an annual report where the objectives of the following year are established. Those responsible believe that there is diversity and effectiveness in this project, as well as a great work of learning, what is done and what is to be done. There has never been distrust with this management model. The only problems could be political and money. There have never been legal problems. The human group (volunteers) is the main stakeholder in this project. All are real characters and each one has a specific role in the group.

Therefore the strategy is to give prominence to those who really have it, that each one is a protagonist within its scope, for example the carpenter will always be the person best seen within the carpentry. It is not possible to supplant protagonisms of anyone. The people who make up the project are those who possess the attributes of power, legitimacy and urgency, all without exception, since without them the project could not be continued. Each of these people represents an important part of a collective project that is the total of knowledge and individual contributions, both material and immaterial.

\section{Methodology}

The purpose of this research is to explore the activation of governance processes in the Cultural Project of Community Development of La Aldea, starting from the involvement of different agents in its development, establishing the level of participation and co-management of the local population in the administration of the resources of the Project. For this, a qualitative research strategy focused on the case study has been chosen (Eisenhardt 2002, Hamel et al., 1993, Simons, 2011, Yacuzzi, 2005, Yin 2003). The selection of the case was made, after a review of the island museums (Gran Canaria, Spain) and determination of their areas of competence, taking into account the best existing ecomuseum reference on the island of Gran Canaria, which receives more than four thousand visits annual (Table $\mathrm{n}^{\circ} 1$ ). Subsequent applications, at least partially, follow the work of Adie and Hall (2017), which perform a comparative analysis of three case studies. 


\section{Image 6: Making the cheese in the "Gañanía"}

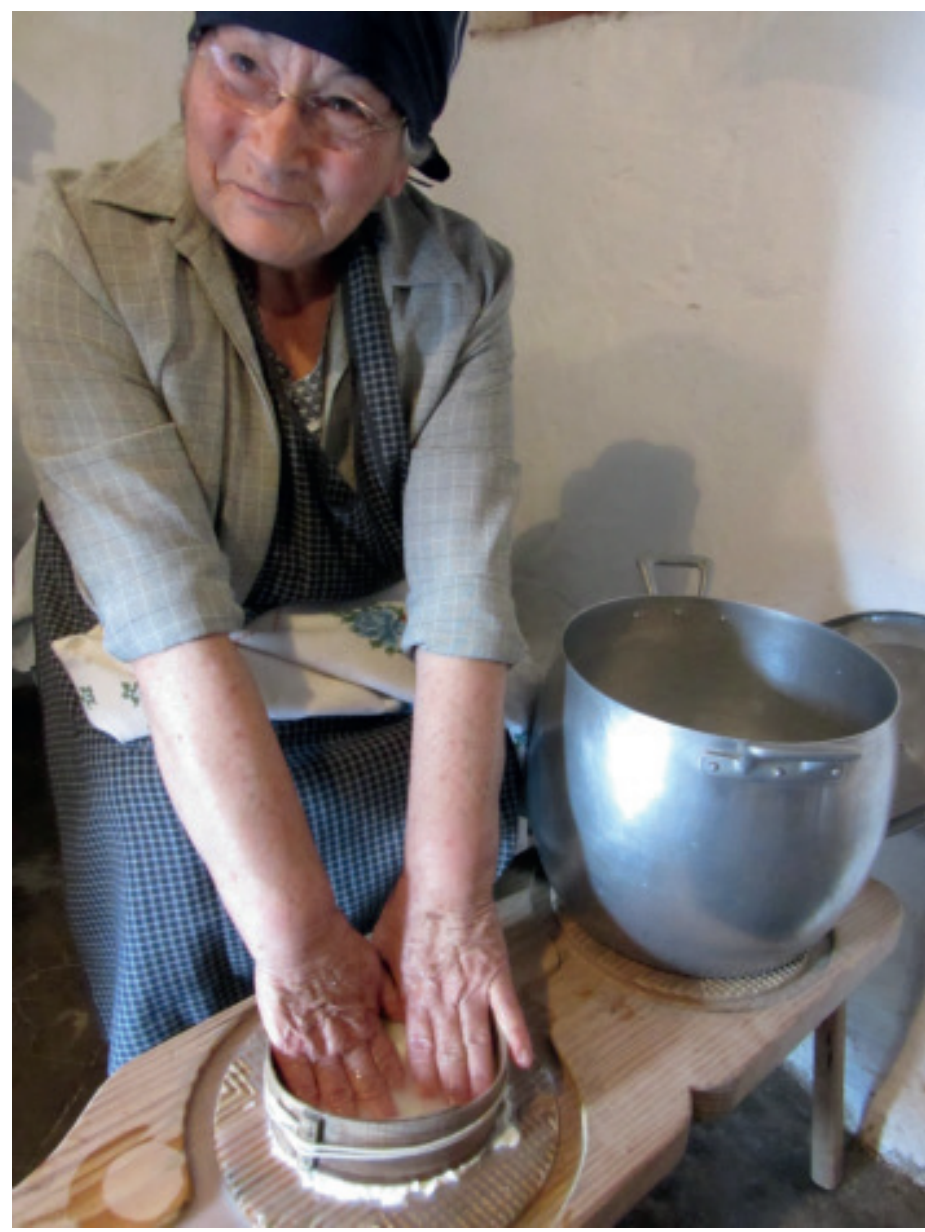

Photo: the authors

For this study, a qualitative approach is taken (Shaw \& Ivens, 2002). The application of this perspective is applied by analyzing the responses of the questionnaires, determining the sample according to the degree of saturation detected in open responses (Thomas and James, 2006), and contrasting this information with that obtained through other techniques such as the semi-structured in-depth interview, the conversational interview and the direct observation.

Table $n^{\circ}$ 1: Distribution of visitors in the case study.

\begin{tabular}{|c|c|c|c|c|c|c|}
\hline Visits (2019) & TOTAL & $\begin{array}{c}\text { Students and } \\
\text { Groups\% }\end{array}$ & Local \% & National \% & International\% & Activities \% \\
\hline P.C. Aldea & 4.600 & 55 & 15 & 10 & 15 & 5 \\
\hline
\end{tabular}

The authors.

Starting from the problems highlighted in the theoretical framework of the research, and the objectives that focus it, a guide questionnaire was prepared for the interviews (in-depth and conver- 
sational) deciding that the informants would be allowed to introduce topics of interest, conducted by the interviewer at the right moments. This strategy allows, beyond the information previously considered relevant, the informants provide nuances that were revealed in each case as inflection points in the configuration of the network, its interpretation and the consequent application in the management of the museum.

For the interviews, it was considered to take those responsible for management as key informants. Establishing a semi-structured guide that raised 14 topics or issues of interest. The digital audio recording of each one was carried out, favoring a more exact interpretation (Yin, 2003) and allowing to take clarifying and complementary notes, useful at the time of the transcription. With the informed consent and the confidentiality due to the interviewees, the protection of the audios obtained was guaranteed.

The conversational interviews conducted with the volunteers, complemented by direct observation, served to determine the objectives and hypotheses of the present study. These techniques contribute especially to the qualitative determination of the degrees of relative importance of each of them in the management of the museum, guiding the interpretation of results in the analysis of indicators made with the Caqdas.

In a pre-interview phase, a questionnaire was carried out on a random sample, determined by saturation, of 100 visitors (table 2).

Table $\mathrm{n}^{\circ}$ 2: Period, areas and sociodemographic characteristics of the survey

\begin{tabular}{|l|l|l|l|}
\hline Period & \multicolumn{2}{|l|}{ 29/7/2016 $-21 / 12 / 2016$} & Data collection system \\
Sample & $\begin{array}{l}\text { 100 (intentional } \\
\text { sampling) }\end{array}$ & Paper \\
\hline & $\begin{array}{l}<18 \text { years: } 7 \% \\
18-30 \text { years: } 16 \%\end{array}$ & \\
Age & $31-50$ years: $37 \%$ & & Woman $55 \%$ \\
& $51-70$ years: $32 \%$ & Gender & Man $44 \%$ \\
& $>70$ years: $6 \%$ & & NA: $1 \%$ \\
& NA: $2 \%$ & & \\
\hline
\end{tabular}

The authors

The questionnaire was designed to assess the opinion of visitors, distributed in 14 questions: 1) country of residence, 2) type of accommodation, 3) how it has arrived at the museum, 4) with whom visits the museum, 5) age, 6 ) gender, 7) reasons for the visit, 8) how knew the museum, 9) guided visit (quality and time), 10) assessing characteristics (treatment, environment, presentation, quality and usefulness, learning, interest, accessibility, signage, price of tickets, services, and waiting time, 11) quality - price, 12) aspects that "they liked", 13) aspects that "they did not like" and 14) suggestions.

To analyze the content and proceed to the coding of the last three, due to the wide possibility of answers, since the questions were open, eight categories have been established in terms of their content, taking as reference the aspects of the museum that establishes the Permanent Laboratory of Public of Museums of Spain (Ministry of Education, Culture and Sport, 2013, pp. 95-98): 1) exhibition, 2) communication and information, 3) operation, 4) conservation, 5) facilities, 6 ) staff, 7) promotion and 8) others.

To perform the qualitative analysis and make it effective (Gibbs, 2012), data management has been efficient, coherent and systematic. A computer-aided Qualitative Data Analysis Software (CAQDAS) was used, specifically Nvivo 10.

The first step taken in Nvivo has been to import the information for each one of the case studies: internal elements (questionnaires, interviews and observational notes) and external elements (taken from the social networks and web pages), the latter with the Ncapture tool.

The second step with Nvivo has been coding (gathering material by subject, topic or case) and creating nodes (sections that allow information to be collected and searched by patterns). For the codification of contents, nodes have been created, codified, with the "automatic codification based on patterns", then all the nodes and documents that make up the same are actively linked in each project. 
The third step has been to perform queries to search and analyze words or phrases in the resources or nodes, for example, those words that appear most frequently. You can also ask questions and find patterns based on the classification, check the congruence of project classifications and review progress. A project was carried out in the analysis of the data entitled "PC La Aldea".

The fourth step is to explore data with graphs, models or other visualization techniques. This serves to help explore trends, test theories and make sense of what happens in the resource material. You can create models and charts to make connections between the data, not just to plan the project. The graphs show how the elements of the project are connected, for example, to see which elements are connected to a selected resource or node.

\section{Results}

The need to correlate the intention of the participation process, and by extension the principles of governance, with the specific characteristics of the museums, is shown as a relevant aspect due to the socio-economic and identity implications that these cultural implications have on the linked populations. The identification of the main actors (volunteers) and secondary actors (linked to the Project), both real and potential that have the capacity to influence the network and, to take part in the agreements reached on the cultural offer, has been decisive. The traditional approach in the management of museums is, generally and with exceptions, incapable of evaluating the effects that the incorporation of new agents and new forms of management would have on the strategy concerning the agents involved or with the capacity to be. With the tools used (direct observation, interviews with the staff of the museums and questionnaires to the public, which triangulate the information (Patton, 2002), the results obtained with Nvivo will be interpreted, from the case study treated.

\section{Management model and its limitations}

It should be noted that in the case of the Community Project of La Aldea, the projection of image and the consequent capture of the public is tremendously intuitive and not professional, (Table 3). In this case, based on local volunteering and the assembly regime, it meets twice a week (usually about forty people, with delegation of votes among its members), taking decisions on the functioning and even new projects (each project with a coordinator) in a participatory manner in the majority system. Achieved leadership, individually proposed but accepted by a majority, faces the structural challenge of obtaining financing. 
Image 7: Visitors in "the Store"

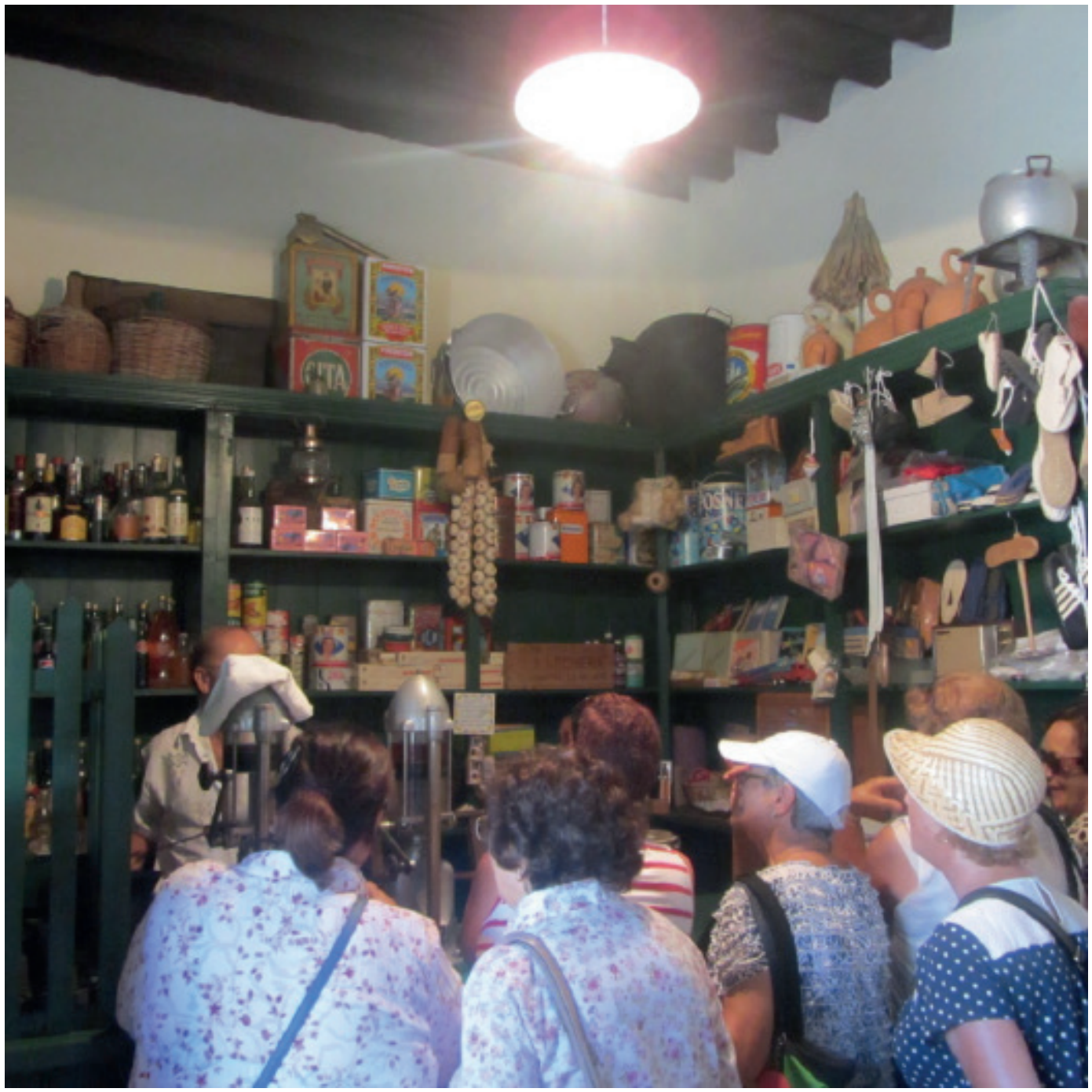

Photo: the authors

It could be observed that the final execution of its commitments of conservation, diffusion and improvement of the uses of the cultural heritage, will be largely framed in the distribution of economic resources. However, the structure that delimits both the internal agreements and the relations with their environment, in a broad sense, contribute in large part to the degree of agility in the execution of projects. The Community Project of La Aldea, is capable of executing small (in duration and target audience) samples and museum activities almost self-managed and self-financed by their promoters. 
Table 3: Characteristics of the management model of the Community Project of La Aldea.

\begin{tabular}{|c|c|}
\hline Characteristics & Community Project of La Aldea \\
\hline Ownership & Private \\
\hline Financing & Dependent on grants, agreements and donations \\
\hline Board of directors & $\begin{array}{l}\text { Self-government Only submitted to the endorsement given by } \\
\text { the assembly }\end{array}$ \\
\hline Staff & $\begin{array}{l}\text { Volunteers. Everyone is involved in what they know and can } \\
\text { without compensation }\end{array}$ \\
\hline Staff number & $\begin{array}{l}45 \text { fixed volunteers } \\
\text { Approx. } 200 \text { eventual volunteers }\end{array}$ \\
\hline Financing (2017) & $15.000 €$ \\
\hline Funding source & $\begin{array}{l}\text { Grant from the Foundation for Ethnography and } \\
\text { Development of the Canarian Crafts (FEDAC, Cabildo de } \\
\text { Gran Canaria) }\end{array}$ \\
\hline Decision making model & Assemblyman. Selected executive positions. \\
\hline Donations & Habitual \\
\hline Public-private relationship & With companies it is practically non-existent. \\
\hline Compliance with 35 governance criteria & Perform all criteria \\
\hline
\end{tabular}

The authors.

The representation of the organizational structure and financing makes a gradient that ranges from the professionalization of the activity to emotional voluntarism perceptible. It is worth noting the commitment of each member of a community with a project that is taken for granted through its proposal and demonstration, each one contributing their time and concrete experience.

The analysis of the ecomuseum shows a lack of relations with the insular business framework. This need of relationships is largely due to the lack of strategic vision (and commercial responsibilities) of the Project, but also due to the voluntary nature of its members. Canarias focuses its economy on the provision of services, receiving about 16 million tourists in 2017, of which the island of Gran Canaria has more than 4 million. These visitors are accommodated in 164 hotels and 425 non-hotel establishments, but there should also be a multiplicity of transport companies (buses and rental vehicles), gastronomy and catering, leisure services (especially travel agencies and tour guides), etc. The direct involvement of companies in the activity of heritage, where the culture is considered as a complement to the trip (only $2.6 \%$ declare it as a reason to choose the Canary Islands election), shows the lack of interest shown by the promoters of the heritage.

It is true that the performance of a museum / heritage site is due, initially and legislatively, in the first place, to local populations, although the definition of the local in a globalized world is quite uncertain (Borja and Castells, 2006; Catrina, 2015). Governance, as a mechanism of democratic participation (Mercer, 2005), is a non-parity commitment to the complex areas of economic, human and sociocultural power relations, where citizens are partners, stakeholders and actors. In principle, any museum, when making museum decisions and social extension, must take into account that the visitor plays an important role. This without forgetting its economic responsibility for the territory and, therefore, its commitment to visibility, in this case, to residents and tourists. 


\section{Image 8: Visitors in the "Gañanía"}

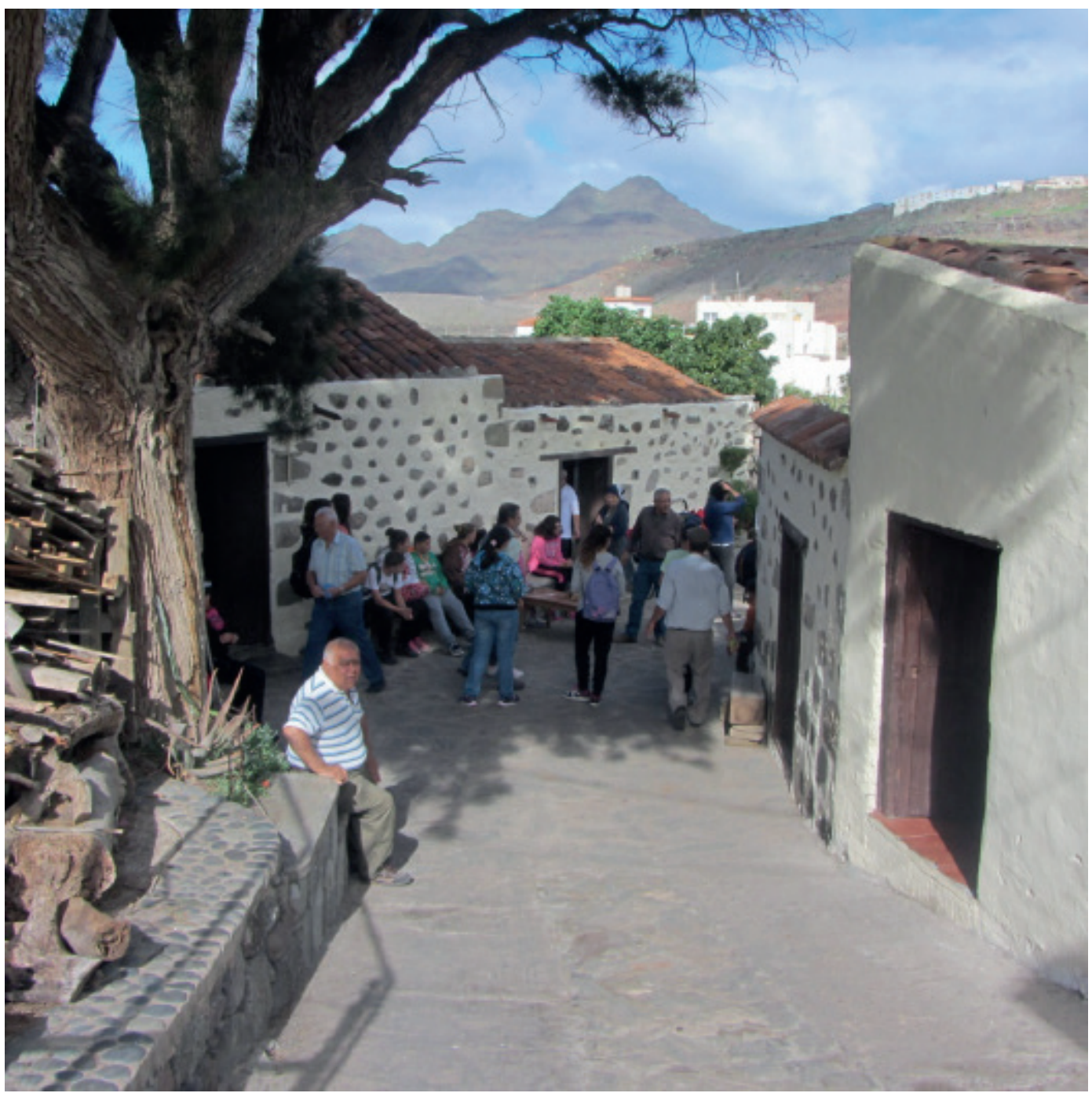

Photo: the authors

In this analysis, the Project's difficulty of belonging to tourist circuits (9\% tourists) is notorious, but it is necessary to clarify the territorial context. But, in addition, the Community Project is practically invisible both in tourism promotion and for the island population. To the oblivion and difficulty of structural and historical communications of this municipality, the patrimonial is also added. 


\section{Image 9: Museum of the "School"}

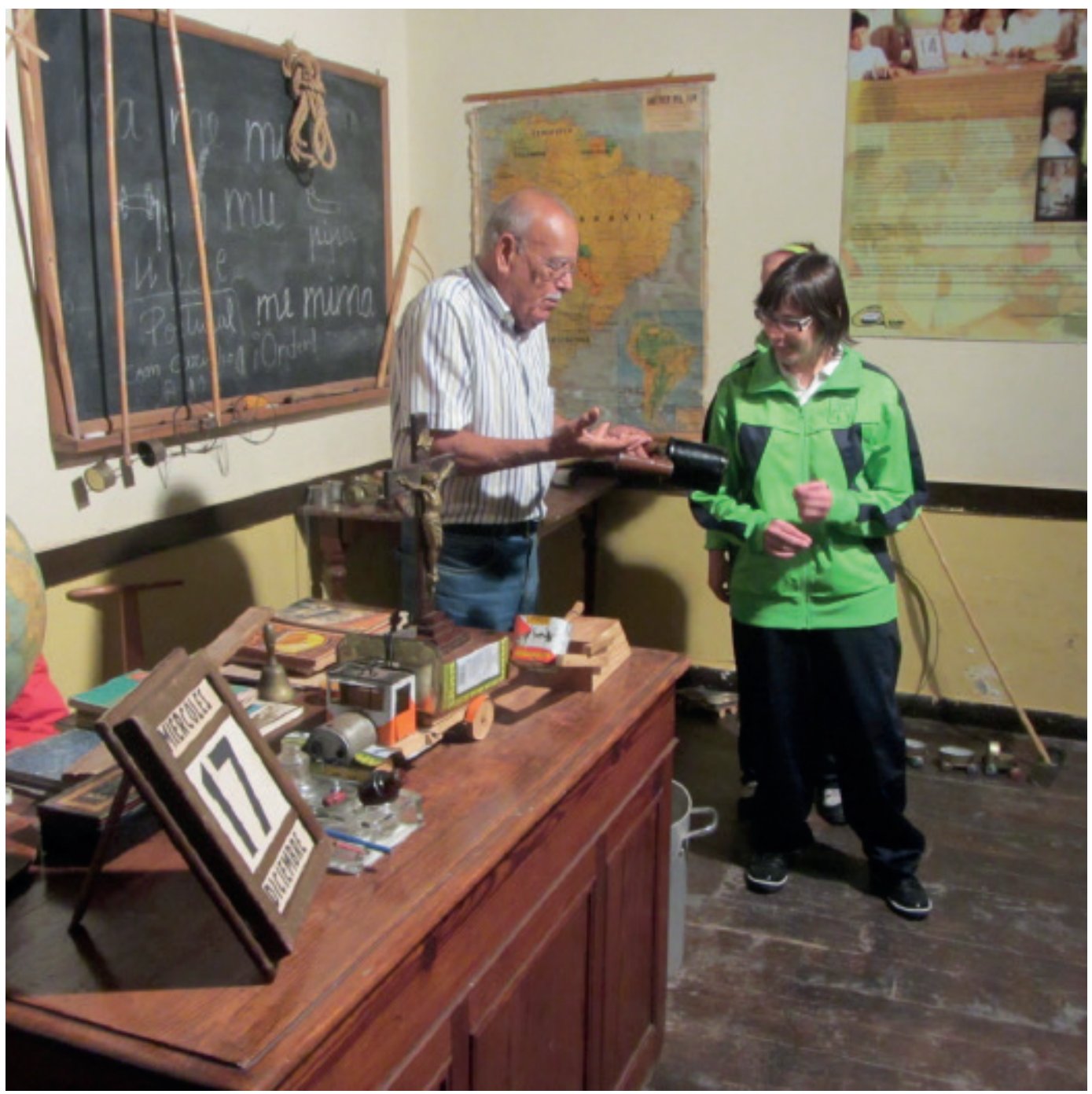

Photo: the authors

Trying to measure the satisfaction of the visit, respondents were asked to rate a number of aspects on a likert scale 10 (treatment, environment, presentation, clarity and usefulness of content, learning, interest, accessibility, signaling, entries, services, time waiting), obtaining an average of 8.88. The aspects most valued were learning (9.5) and treatment (9.4), while the worst rated were accessibility (8.7) and services (6.5). These data can, taken systematically, help to improve the project's commitments, giving voice to visitors. However, the most notable is the number and quality of the comments or free responses, which show the interest of the visitors for intervening in the process of patrimonial representation. 

Table 4: Characterization and opinion of the visitors
of the Community Project of La Aldea.

\begin{tabular}{|c|c|}
\hline Characterization of the visitor & Cultural Community Project of La Aldea $(n=100)$ \\
\hline \multirow{2}{*}{ Visitors } & $\begin{array}{l}\text { Students and groups: } 60 \% \text {, Local: } 15 \% \text {, National: } \\
10 \% \text {, International: } 15 \%\end{array}$ \\
\hline & $\begin{array}{l}9 \% \text { tourists } \\
80 \% \text { residents }\end{array}$ \\
\hline How do they get there? & $75 \%$ excursion \\
\hline Knowledge of the museum & $\begin{array}{l}\text { Association or group } \\
\text { Friends and family }\end{array}$ \\
\hline Outstanding motivation & $\begin{array}{l}\text { "improve knowledge" } 27 \% \\
\text { "it is one of the main attractions" } 17 \%\end{array}$ \\
\hline Satisfaction $(0-10)$ & 8.88 \\
\hline Free comments & $\begin{array}{l}162 \text { comments, of which } 48 \text { are suggestions } \\
\text { Positive } 101 \\
\text { Negative } 13\end{array}$ \\
\hline
\end{tabular}

The authors.

Beyond requesting improvements in services, such as restaurants or souvenir shops (which are still important in these heritage and leisure contexts), visitors indicate that they want other issues, for example, that the communication of contents needs to be adapted (videos and brochures). The problem lies in the lack of professionalism and resources to have a team responsible for communication. In fact, the brochure available for non-school audiences does not meet the appropriate characteristics for the communication of patrimonial content.

\section{Image 10: A group of students learning to plant in the "Gañanía"}

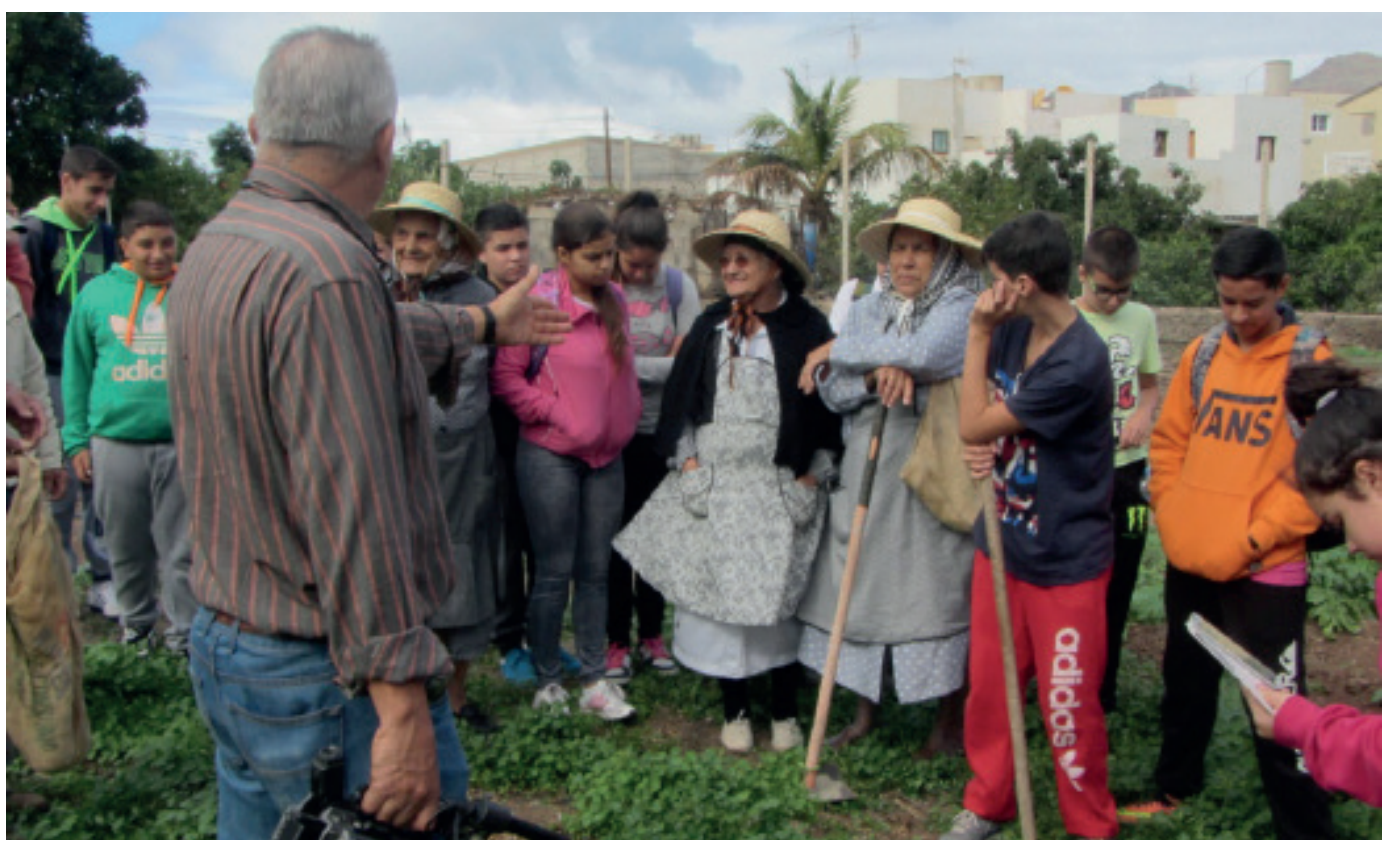

Photo: the authors 


\section{Governance in the Community Development Project}

Governance as a mechanism to exercise power can be established through 5 principles and 35 criteria (Aggarwal et al 2016, Graham et al., 2003). In the case of the Community Project of La Aldea, it has been determined that all the principles and criteria are met.

In the Project, the volunteer, conformed in assembly, is the main stakeholder of the patrimonial action. It is a group of people who, since 1980, have tried to transmit ethnographic values that are considered part of the tradition, forming a living ensemble of museum representations. From a stable nucleus, between 200 and 300 people meet in a flexible manner, to which specific roles and functions are granted. In a long time and with a diversity of opinions, the responsibility of managing personal relationships has relapsed on the elected leaders. The people who make up the Project are those who possess the attributes of power, legitimacy and urgency, all without exception, without them the project could not be continued.

\section{Image 11: Volunteer explaining the gofio grind}

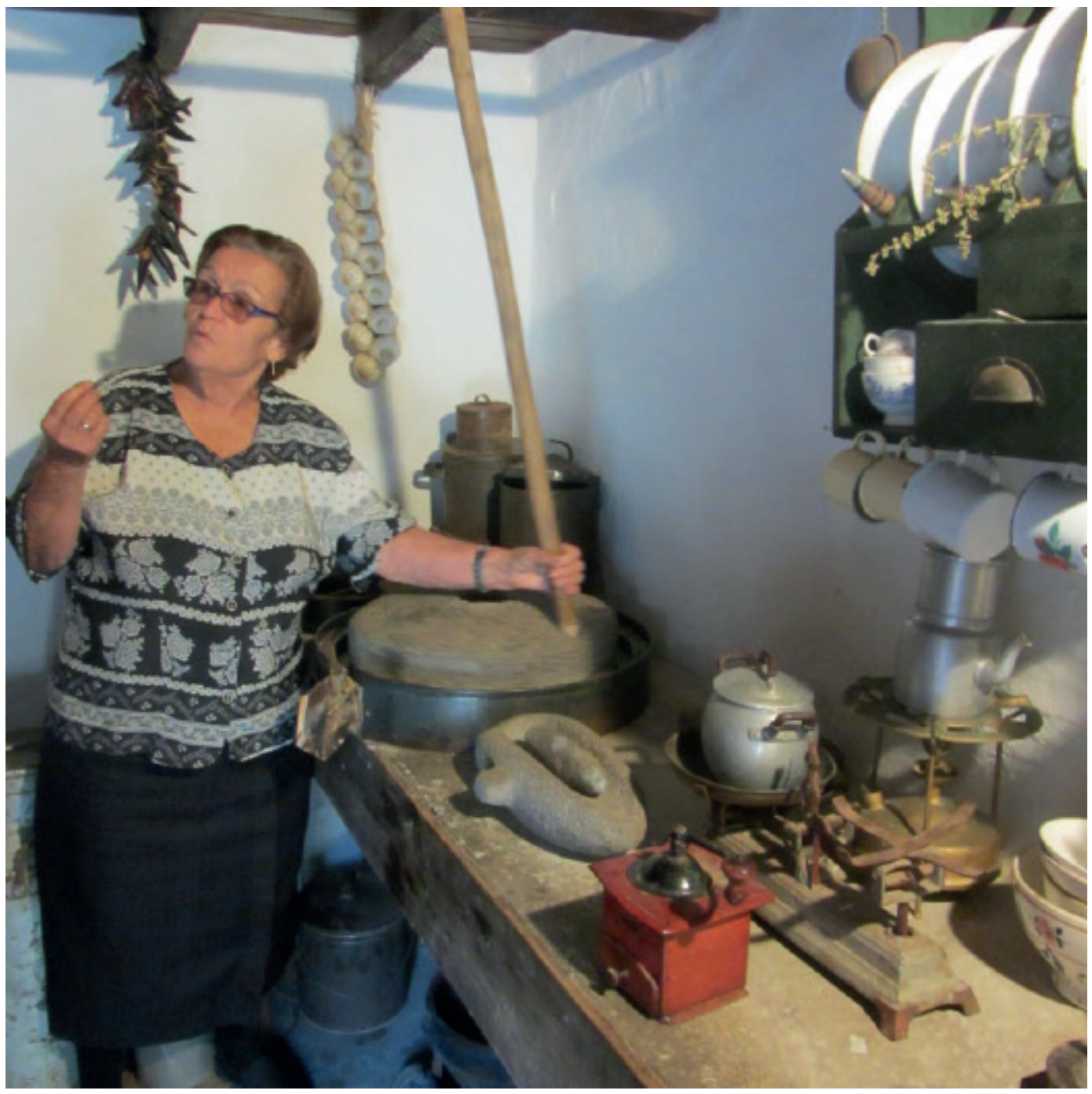

Photo: the authors 


\section{The project from the point of view of the volunteers}

The interviews were conducted with 10 volunteers from the most active of the Project, aged between 66 and 86 years, four women and six men. With the interviews, it is corroborated that the Project has been beneficial for the community, since it has provided economic and social benefits. On a personal level, the volunteers have brought joy, will and entertainment. It follows that the main contributions have been the recovery of lost or near-lost traditions and the learning experiences of the volunteers themselves. Some of these traditions are folklore (the Rancho de Animas) and dances, as well as the pursuit of activities after the retirement of their respective jobs. Many volunteers declare to feel happiness, pride, affection or devotion for their work in the Project, as well as not feel obligations when participating. There is variety in the motivation to participate in the Project, although the highlight is to dance or to sing. Some volunteers highlight their role as part of the exhibition in museums: grinding, sowing, explaining the carpentry or packaging tomatoes. All volunteers show the sensation of feeling useful in their participation. There are various contributions that highlight personal level, such as gain health or maintain friendships.

The interviewees emphasize that everything is important in the Project, although more specifically the relationships established with the volunteers and the conservation of the tangible and intangible assets of the same. The totality of the participants in the interview expressed that they would not change anything of the Project, as well as that when they have a proposal they propose it in the assembly.

Although all volunteers understand that the Project can grow with more visitors and visibility, they consider that they can not be overwhelmed to attend large masses of visitors. They believe that it can be given more promotion from the public administration. All the interviewees think that it would not be necessary to professionalize all or part of the Project, and that if this happened, they would stop participating in it.

The problems, although they do not stand out, are mainly the lack of economic aid to carry out the maintenance of the museums, as well as the loss of volunteers. The volunteers understand that the Project must be maintained with the people who are joining. The public institutions have the possibility of helping to maintain the current model, buying the private spaces and transferring the management to the assembly, the property would be municipal.

\section{The perception of the local traders about The Project}

It follows from the informal conversations held with the heads of ten commercial establishments near the center of of La Aldea de San Nicolás (where the PDCLA is located), that the realization of the various activities carried out by the Project has a significant impact on positive in their businesses. The totality of the people with whom these conversations took place, shows their support to it, and declares that since its inception, it has been fruitful both from a social point of view, but above all economic.

In terms of sustainability over time of the Project, there is a diversity of opinions. Approximately half of the traders surveyed, question the viability and long-term maintenance (10 years as a reference) of the Project. The main reason they show is the high age of the majority of volunteers who currently participate in living museums, and they fear that it can not be sustainable for several years. However, the other half does not question the social sustainability, which would imply economic sustainability of the Project (including museums and other representations), and consider that other people will assume responsibilities, and that therefore they will continue with the activities that so far, obviously, those who have doubts develop, if they hope to keep the visits to the environment, since they benefit economically from the visitor.

\section{Conclusiones}

The PDCLA volunteers think that this model is the most appropriate for the management, involving more people, especially concerning young people. The mission (short term) of the Project is to continue growing, since those involved understand that it is not all over. While the vision (the future projection) is to perpetuate in time the culture generated by the different forms of life.

As conclusions to the case study that has been selected, three aspects have been determined, which are generalizable in other ecomuseums: a) the high emotional load, so the word predominates over the texts. While in other museums you have to keep quiet and obviously nothing can be touched, in 


\section{Image 12: Visitor at the Tomato Packaging Store}

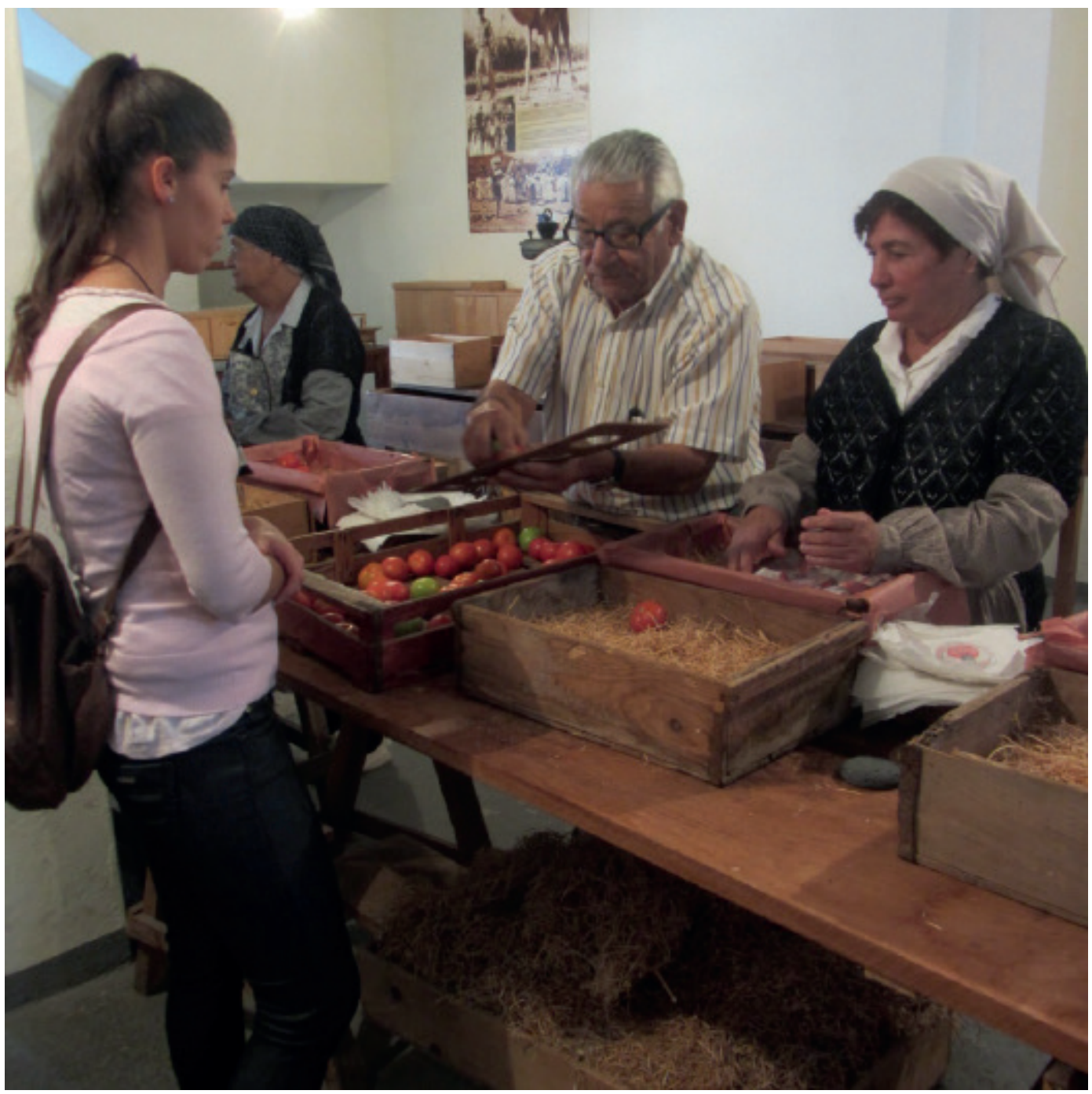

Photo: the authors

this model, they want people to talk and touch the artifacts as much as possible, b) people who are in the museum spaces, sometimes, are who have lived in some way in each of those places, that makes it different from others, c) the altruistic side of the people that make up this museum.

The success of a museum should not be measured as that of a company, in terms of economic profit for itself or the institution that sponsors it (Barbieri et al., 2017, Evemuseografía, 2017), but is based on social utility that can contribute to the community of which it is depositary. It is not efficient to make a direct inference between success and number of visitors, while that figure would have to be weighted with respect to the capacity to call (connected with the projected image) and the influence on the institutions, as well as the level of satisfaction of its employees. Other indicators would be the impact it generates on the quality of the community's scientific education and the economic flows directly or deferred promoted, including the capacity to generate jobs and business skills (Beel, 2017). Due to 
this, the commitment of all the parties involved in the development of the museum and its activation and patrimonial dissemination actions is required. The set of stakeholders, from the managers, to the local community, the companies and the visitor, as the main actor to which the efforts of maintenance and updating of the museum offer are destined, forms the nucleus of the possible strategies aimed at good practices (Soren, 2005) in the governance of the institution.

This work is part of a larger analysis, which seeks to verify not so much the success of museums, but the common benefits that can be obtained by their success for the populations involved. Enhance patrimonial sensibility (both cultural and environmental), generate funds for non-profit causes and establish community awareness, in some cases identity, more than justify the institution's effort to create broad networks of social impact. For this reason, it is important to establish methodological instruments to infer degrees of governance and governability, determine the range and depth of their networks, and the quality of relationships among stakeholders. Such information, generated in a systematic way, can contribute to establish a bidirectional and symbiotic relationship between the museum and local actors, also detecting possible conflicts of interest or gaps in the structure of the network.

The governance of museums goes through the value of what is shown, the rigor of what is communicated, the approach to the user, the involvement in local environments and an acceptable degree of political and financial independence. In tourist destinations, or when the museum itself is an attractor or motivating complement to the visit, the case literature seems to advise the development of strategies that, through knowledge, estimate the profile of its potential users-tourists and their needs, above the mere interest of communication of speeches. It is about complying with the directive to transmit to conserve, and not to trivialize the heritage.

It is recognized as a limitation of the research presented and of these conclusions the impossibility of having carried out a diachronic analysis that included the follow-up of concrete actions in the network of relationships. Even with this, it is considered that the exposed perspective can contribute to the generation and promotion of new forms of public-private-community relationship, establishing measurable roles and responsibilities that support the road to sustainability. It does not seem rational that the museum is a value only for itself and its proponents, nor that the museum is a kind of theme park. The analysis of the operation of governance applied to heritage shows different possible scenarios.

\section{Bibliography}

Adán Alfaro, J. (2010). Cuestiones para la gobernabilidad y planeación de espacios ecoculturales y restricciones para su musealización en Chile. Her\&Mus, Heritage \& Museography, $\mathrm{N}^{\circ} 04$ (mayo-junio 2010), 56-66

Adie, B. A. \& Hall, C. M. (2017). Who visits World Heritage? A comparative analysis of three cultural sites. Journal of Heritage Tourism, 12 (1), 67-80.

Álvarez, V. y Gallegos, N. (2005). Manual introductorio al Análisis de Redes Sociales. http://revista-redes. rediris.es/webredes/talleres/Manual_ARS.pdf Acceso 21 de diciembre de 2017

Barbieri, L., Bruno, F. \& Muzzupappa, M. (2017). Virtual museum system evaluation through user studies. Journal of Cultural Heritage, 26: 101-108. http://dx.doi.org/10.1016/j.culher.2017.02.005

Beel, D. E. (2017). 'The will to empower': reworking governmentality in the museum. Area. doi:10.1111/ area. 12330

Borja, J. y Castells, M. (2006). Local y global. La gestión de las ciudades en la era de la información. México: Taurus.

Cabildo de Gran Canaria (2018). http://cabildo.grancanaria.com/la-aldea-de-san-nicolas Consultado el 2 de octubre de 2018.

Catrina, S. (2015). Local Heritage Interpretation by Private "Cultural Agents" from Maramures. Procedia - Social and Behavioral Sciences, 188: 174 - 180. http://dx.doi.org/10.1016/j.sbspro.2015.03.361

Cosmin, I. (2018). Untaping the potential of strategic partnerships with the stakeholders in museums-a managerial approach. In Proceedings of the International Conference on Business Excellence (Vol. 12, No. 1, pp. 446-456). Sciendo.

Davis, P. (1999). Ecomuseums: a sense of place. Leicester University Press.

Davis, P. \& Corsane, G. (2014) "Communities, Heritage and new cultural landscapes", in New Cultural Landscapes, Roe, M. \& Taylor, K. (editors), 2014, Routledge, Abingdon, UK.

Durant, R. F. (2017). Environmental governance reconsidered: challenges, choices, and opportunities. MIT Press. 
Eisenhardt, K. M., (2002). « Building theories from case study research ». En: Huberman, A. M. Y Miles, M. B. (ed). The qualitative researcher's companion. London: Sage Publications.

Elsorady, D. A. (2018). The role of stakeholders as a competitive advantage in the formulation of antiquity museum strategies in Egypt. Museum Management and Curatorship, 1-17.

Elliot, S. (2006). Targets for the arrows of fate: ecomuseology as a rescue mechanism in response to the threatened cultural landscapes of Southeast Turkey.

Evemuseografía (2017). Museos y medición de éxito. Museos + innovación. https://evemuseografia. com/2016/03/29/museos-y-la-medicion-del-exito/ Acceso 28 de Octubre de 2017

Gibbs, G. (2012). El análisis de datos cualitativos en Investigación Cualitativa. Madrid: Ediciones Morata

Girot, P. O. (1998). Co-Manejo de Recursos Naturales y Áreas Protegidas: Teoría y Práctica, CEESP / UICN. Documento impreso. 38p.

Hamel, J., Dufour, S., Fortin, D. (1993). Case study methods. Sage Publications. California.

Haveri, A., Nyholm, I., Roiseland, A. R. \& Vabo, I. (2009). Governing collaboration: Practices of meta-governance in Finnish and Norwegian local governments. Local Government Studies, 35(5), 539-556.

Idelhadj, I., Rivera Mateos, M. y Rodríguez García, L. (2012). Turismo responsable, espacios rurales y naturales y cooperación para el desarrollo: a propósito de la " Delaración de Tetuán» (Marruecos). PASOS : Revista de Turismo y Patrimonio Cultural. Vol. 10 N 5, págs 651-664 http://www.pasosonline. org/Publicados/10512/PS0512_19.pdf

Janes, R. R. (2016). Museums without borders. Routledge. New York.

Legget, J. (2006). Mapping what matters in New Zealand museums. Stakeholders perspectives on museum performance and accountability. Thesis in management and museums studies. New Zealand: Massey University.

Mercer, C. (2005). From indicators to Governance to Mainstream: Tools for Cultural Policy and Citizenship. In Accounting for Culture: Thinking Through Cultural Citizenship, Publisher: University of Ottawa Press, Editors: Andrew, C., Gattinger, M., Jeannotte, M. S., Straw, W.

Ministerio de Educación, Cultura y Deporte (2013). La experiencia de la visita al museo. Colección Conociendo a nuestros visitantes. Madrid: Secretaría General Técnica. Centro de Publicaciones. Ministerio de Educación, Cultura y Deporte.

Newig, J., Challies, E., Jager, N. W., Kochskaemper, E. \& Adzersen, A. (2018). The environmental performance of participatory and collaborative governance: a framework of causal mechanisms. Policy Studies Journal, 46(2), 269-297.

Prat Forga, J. y Cánoves Valiente, G. (2013). La centralidad de las administraciones públicas en las redes sociales de turismo industrial. Una comparación entre el Bages - Berguedá y el Haut - Rhin. PASOS. Revista de Turismo y Patrimonio Cultural. 11 (4).

Reverté, F. G. \& Gui, A. S. (2013). El turismo responsable en España a debate. Consideraciones desde el punto de vista de la producción y del consumo turístico. Investigaciones Turísticas, (5), 60-85.

Rocha, G. \& Tosta, S. P. (2017). O campo, o museu e a escola: antropologia e pedagogia em Franz Boas. Horizontes Antropológicos, (49), 61-88.

Rodríguez, J. A. y Mérida, F. (2006). Guía práctica de redes sociales. Universitat de Barcelona. Departamento de Sociología y Análisis de las Organizaciones.

Lebel, L., Anderies, J., Campbell, B., Folke, C., Hatfield-Dodds, S., Hughes, T. \& Wilson, J. (2006). Governance and the capacity to manage resilience in regional social-ecological systems. Ecology and Society, 11(1).

Loach, K., Rowley, J. \& Griffiths, J. (2017). Cultural sustainability as a strategy for the survival of museums and libraries. International journal of cultural policy, 23(2), 186-198.

López García, J. S. (Dir.) (2003). Norte de Gran Canaria. Guía de Patrimonio Cultural y Turismo Sostenible. Mancomunidad de Ayuntamientos del Norte de Gran Canaria. Las Palmas de Gran Canaria.

Sánchez González, L. Suárez Espino J. P. y Moya Otero, J. (2002). Proyecto comunitario de La Aldea: un compromiso con la cultura popular. Santa Cruz de Tenerife: Gobierno de Canarias. Versión digital disponible en: http://www.proyectolaaldea.com/wp-content/uploads/2011/10/LIBRO-HISTORIA2.pdf

Sánchez González, L. y Suárez Espino J.P. (2006). Rescatar el Patrimonio intangible: el proyecto comunitario de La Aldea de San Nicolás. Boletín no 3-4 año 2006. Patrimonio Histórico. Cabildo de Gran Canaria.

Santana-Talavera, A. (2008). El turismo cultural: ¿un negocio responsable? Estudios y Perspectivas en Turismo. 17 - 3, pp. 279 - 294. 2008. ISSN 1851-1732

Shaw, C. \& Ivens, J. (2002). Building great customer experiences. Palgrave Mcmillan UK

Simons, H. (2011). El estudio de caso: Teoría y práctica. Madrid: Ediciones Morata. 
Soren, B. J. (2005). Best practices in creating quality online experiences for museum users. Museum Management and Curatorship, 20(2): 131-148. https://doi.org/10.1016/j.musmancur.2005.03.001

Souza, R. H. V. D., Solagna, F. \& Leal, O. F. (2014). As políticas globais de governança e regulamentação da privacidade na internet. Horizontes Antropológicos, 20(41), 141-172.

Suárez Moreno F. y otros (2005). Guía del patrimonio etnográfico de Gran Canaria. Las Palmas de Gan Canaria: Cabildo de Gran Canaria.

Thomas, G. \& James, D. (2006) Reinventing grounded theory: some questions about theory, ground and discovery. British Educational Research Journal. Volume 32, Issue 6 December 2006. 767-795

Unesco (2014). Gestión del patrimonio cultural. Paris: Centro del Patrimonio Mundial de la Unesco.

Videira, N., Antunes, P. \& Santos, R. (2017). Engaging stakeholders in environmental and sustainability decisions with participatory system dynamics modeling. In Environmental modeling with stakeholders (pp. 241-265). Springer, Cham.

Yacuzzi, E. (2005). El estudio de caso como metodología de investigación: teoría, mecanismos causales, validación. Universidad del CEMA, CEMA Working Papers: Serie Documentos de Trabajo.

Yin, R. K. (2003). Case study research: design and methods. $3^{\text {a }}$ ed. London: Sage Publications.

Zuned, A. (2018). Museum Tourism: A Comparative Study on the Royal Museum of Greenwich and the Ironbridge Gorge Museum. In Innovative Approaches to Tourism and Leisure (pp. 67-87). Springer, Cham.

\section{Notas}

1 Thick flour of toasted corn, wheat or barley and occasionally mixed with sugar 


\title{
Turismo e museus: uma reflexão empírica sobre a Região Autónoma da Madeira
}

\author{
Diogo José Goes* Luís Filipe Sardinha** \\ Instituto Superior de Administração e Línguas (Portugal)
}

\begin{abstract}
Resumo: O objetivo deste estudo é analisar a evolução dos hóspedes e visitantes dos museus da Região Autónoma da Madeira (RAM), no período 2012 - 2018. Um museu por definição, é uma entidade sem fins lucrativos, ao serviço do desenvolvimento de uma sociedade. Os museus surgem na sociedade com várias finalidades das quais salientam-se: serviço à sociedade, difundir conhecimento, preservar a memória, conservar os objetos de estudo museológico, investigar, divulgar e valorizar cada uma das diferentes tipologias de património cultural e artístico tangível e intangível. A estratégia deste estudo baseou-se na obtenção de informação através da consulta de dados disponíveis nas diversas bases de dados estatísticos existentes. Assim procurou-se fazer a recolha de dados consultando o Instituto Nacional de Estatística e a Direção Regional de Estatística da Madeira. Verificou-se que o número global de visitantes aumentou no período considerado, que sendo provável a relação com o turismo, não foi possível demonstrar uma relação direta entre os fluxos turísticos e a afluência de visitantes nos museus, face aos dados disponíveis. Apurou-se que a realidade museológica da RAM, a par do contexto nacional, está fortemente exposta ao setor do Turismo, colocando em causa a subversão da instituição museológica.
\end{abstract}

Palavras-chave: Cultura; Ilha da Madeira; Museus; Turismo Cultural; Visitantes.

\section{Tourism and museums: an empirical reflection on the Autonomous Region of Madeira}

Abstract: The aim of this study is to analyze the evolution of guests and visitors to the museums of the Autonomous Region of Madeira (RAM), in the period between 2012 - 2018. By definition, a museum is a non-profit entity, serving the development of a society. Museums carry out many services such as spreading knowledge, preserving memory, conserving objects for museum research, and by so doing adding value to both tangible and intangible cultural and artistic heritage. Theresearch was based on existing statistics from the National Statistics Institute and the Regional Statistics Office in Madeira. It was found that the global number of visitors increased over the period considered, probably because of tourism though it was not possible to demonstrate a direct relationship between tourist flows and the influx of visitors to museums, on the basis of the data available. It was found that the museological reality of RAM,is highly exposed to tourism as occurs in the rest of the national context and so may be subverting the institutional characteristics of a museum.

Keywords: Culture; Cultural Tourism; Madeira Island; Museums; Visitors.

\section{Introdução}

A atenção dedicada ao sector da Cultura e à especificidade do universo da museologia está relacionada com os resultados almejados para o Turismo e com a necessidade crescente satisfação da procura, em busca de novas experiências, e sensações, claramente diferenciadoras da oferta turística. Esta procura de sensações, por parte do turismo cultural, leva à consideração de quais as melhores "experiências identitárias" dos lugares visitados.

Instituto Superior de Administração e Línguas (Portugal); E-mail: diogo.costa.goes@gmail.com; https://orcid.org/0000-0003-1996-9789

** Instituto Superior deAdministração e Línguas (Portugal); E-mail: sar_dinha@hotmail.com; https://orcid.org/0000-0002-0920-7599 
O sector museológico português, ao longo dos últimos anos, tem vindo a afirmar-se como um sector dinâmico, mas igualmente heterogéneo, em muitos casos revelando grandes fragilidades (Neves, Santos \& Nunes, 2008).

Neves, Santos \& Nunes (2008), apontando os problemas de operacionalização do sector, consideram que a dificuldade da captação e da qualificação de novos públicos são constrangimentos para a sua afirmação. Disto decorre a dificuldade em implementar uma estratégia de comunicação, e promoção internacional integrada de uma "marca" dos museus, ou do seu património museológico, assistindo à apócope da valorização das coleções e a acervos (Raposo, 2016).

A necessidade de aproximação à realidade identitária e atualização do discurso e das práticas museológicas, museográficas e curatoriais, muitas vezes distam da crescente mutação dos públicos, nomeadamente nas questões das acessibilidades e do uso das novas tecnologias. Torna-se necessário os museus adequarem o discurso museográfico personalizando-o em função das especificidades de cada sujeito-espectador de modo a que cada instituição possa potenciar a melhor experiência ao visitante. Provavelmente, a experiência e a expectativa do turista serão diferentes do residente.

Assim o "público visitante" não pode ser analisado como um sujeito coletivo uniforme, nem como um corpo pluridisciplinar provido de uma pele plurilinguística ou de acesso à informação única, mas sim tendo em conta cada sujeito-espectador, tendo em especificidade cultural e geográfica de cada pessoa, valorizando o carácter humano da mesma, nas suas diferentes motivações, interesses e expectativas (Davis \& Verlag, 2018).

Potenciar o aumento de públicos para os museus somente será possível com uma oferta que coloque a fruição participada, ao nível da experiência sensorial, fazendo corresponder uma progressiva autonomização dos visitantes, que lhes permita leituras inteligíveis dos discursos museográficos, das obras ou objetos expostos.

Com base nestas premissas, procura-se responder à seguinte pergunta de investigação: "Qual a evolução dos hóspedes na Região Autónoma da Madeira (RAM) e dos visitantes nos seus museus?". Definiu-se como objetivo principal refletir sobre os visitantes dos museus situados na RAM, no período entre 2012 e 2018. Como objetivos específicos definiu-se identificar o tipo de visitante dos museus e inferir sobre os resultados.

O presente trabalho, após a introdução, encontra-se estruturado em quatro seç̧ões. No segundo ponto, através de uma revisão bibliográfica pretende-se fazer um enquadramento do tema. No terceiro, apresentamos a metodologia usada e no quarto ponto os resultados e discussão. Em último, apresentamos as conclusões desta investigação.

\section{Revisão da Literatura}

\subsection{Conceito de museu}

Anterior ao próprio conceito de museu estão subjacentes a prática e a conceção de colecionismo. Contudo, a consolidação da lógica do colecionismo e da preocupação pela documentação, inventariação, catalogação e organização das coleções - subjacente ao conceito de museu moderno - tem a sua génese só a partir do final do século XVI e ao longo dos séculos XVII e XVIII, disseminando por toda a Europa a instalação de "Cabinets de Curiosités", Schlosser \& Falguières (2012) na designação francesa ou as "Wunderkammer" na designação germânica, ao gosto humanista, patrocinado, comum à burguesia "de toga”, letrada, em progressiva ascensão e emancipação social, como às cortes europeias iluminadas.

Desde o "gabinete" naturalista de Francesco Calceolari à instalação no Colégio Romano, de objetos da coleção de Alfonso Donnini, à edição de tratado por Frambotto (1656), ou mesmo a obra de Brandolese (1791), demonstra-se a preocupação tratadística sobre o colecionado - depois, sobre o musealizado - ao longo dos séculos seguintes, talvez, tenha vindo a permitir o encontro de uma definição de museu, também enquanto instância de estudo e investigação e não apenas como depósito ou repositório expositivo.

A instituição museológica moderna pública é uma construção ideológica dos liberalismos e republicanismos do século XIX e XX, traduzindo as ideologias estéticas dos novos regimes triunfantes tornando públicas as coleções da aristocracia do Ancien Régime.

Em Portugal, o setor museológico é caracterizado por uma dinâmica própria e heterógena. A definição International Council Of Museums (ICOM) é a referência base para as diferentes definições que se observam. Desde 1946, esta definição tem evoluído, dotando-se de uma maior precisão e abrangência (Neves et al., 2008). 
Etimologicamente, museu (do gr. Mouseion, lat. Museum) significa o templo das Musas que, na mitologia grega, eram divindades femininas, filhas de Zeus e Mnemósine, a personificação da memória. A definição da International Council of Museums Portugal (2015), informa que

"O museu é uma instituição permanente sem fins lucrativos, ao serviço da sociedade e do seu desenvolvimento, aberta ao público, que adquire, conserva, investiga, comunica e expõe o património material e imaterial da humanidade e do seu meio envolvente com fins de educação...”.

Mais recentemente, a ICOM apresenta uma nova proposta de definição contemporizada e adequada às novas especificidades e problemáticas que os museus enfrentam na sociedade em que se inserem, uma sociedade hipermediatizada ou uma "sociedade da sedução" na definição de Gilles Lipovetsky (2019).

Não havendo ainda uma tradução oficial, à presente data deste artigo, o ICOM Portugal (2019) apresenta uma tradução do texto original:

"Os Museus são espaços democratizantes, inclusivos e polifónicos, orientados para o diálogo crítico sobre os passados e os futuros (...) Os museus não têm fins lucrativos. São participativos e transparentes; trabalham em parceria ativa com e para comunidades (...) com o objetivo de contribuir para a dignidade humana e para a justiça social, a igualdade global e o bem-estar planetário.”

Para Carvalho (2003) a conceção moderna de museu e sua prática exige às instituições uma maior componente dinâmica, centrando a projeção do museu no espaço exterior e no envolvimento das comunidades onde se insere.

Se nas décadas de 80 e 90 do século XX a arquitetura de museus de arte, em Portugal, foi marcada por projetos com um sentido completo e durável, no início dos anos 2000 evidencia-se uma nova tendência, baseada no entendimento do museu como uma obra aberta ou "work in progress" (Silva \& Barranha, 2013).

Contudo, entre o museu que se almeja e a realidade da sua inserção no contexto de uma sociedade contemporânea ou "hipermoderna" na definição de Lipovetsky (2019), pode-se empiricamente colocar a hipótese destes museus, presentemente e para futuro, cederem "participar numa estratégia de branding da cidade" conforme Thörn (2011). Os museus confrontam-se com os seguintes desafios: a democratização do acesso à Cultura; a adequação às novas realidades das tecnologias da informação e comunicação com vista à captação de novos públicos. Quanto às necessidades de financiamento, a atratividade turística e a dinamização de atividades de entretenimento e lazer poderão ser uma resposta. Contudo, as atividades de entretenimento nos museus, desfasadas da programação ou da prática museológica, vêm subverter a lógica de preservação de memória e consciência de civilização. Em alguns casos, entronizando ideologias, estéticas, políticas e económicas em vez de possibilitarem a formação integral de novos públicos, promovem o seu contrário. Sobre este aspeto, Lipovetsky $(2019)$ refere que "o mundo dos museus é estruturado pelo princípio da sedução-lazer. Em toda a parte, as cidades em busca de atratividade dotam-se de museus com arquiteturas inovadoras nos antípodas dos antigos museus neoclássicos", traduzindo-se numa dicotomia do fascínio pelo edificado por antítese à fruição dos acervos e coleções. O mesmo autor refere ainda que "O museu era um local de recolhimento (...) agora é um destino turístico de massas, um espaço cultural virado para o consumo visual e hedonista das multidões itinerantes. Já não são museus com objetivos educativos, mas museus atrativos e recreativos".

$\mathrm{O}$ fascínio pelo objeto arquitetónico tem vindo a responder à procura da atratividade turística. Assim, a monumentalidade ou espetacularidade do edificado tem vindo a ganhar relevância em várias geografias. A disseminação transnacional de museus de marca e instituições culturais passam a integrar as estratégias de regeneração urbana orientadas para o lazer e o turismo (Ponzini, Ruoppila \& Jones, 2019). "Ao museu-templo sucedeu o museu-sedução, cuja arquitetura atrai mais o olhar do que as obras e cujas cenografias permitem visitas interativas, distrativas e lúdicas.” Lipovetsky (2019). Vejam-se a título de exemplo os casos de Guggenheim Museum, em Bilbau, e em New York, ou aquele projetado para Abu Dhabi.

Em Portugal continental assiste-se a novos museus, cuja arquitetura é tornada ícone de atração, marcando o território e a paisagem, contribuindo para a mediatização do edificado urbano, a autoria por Mestres da Arquitetura Contemporânea.

O Museu de Arte Contemporânea de Serralves, no Porto, foi da autoria do Arquiteto Álvaro Siza Vieira, prémio Pritzker em 1992 (“Álvaro Siza Vieira | The Pritzker Architecture Prize,” 2020). 
O Museu Nacional dos Coches, em Lisboa, foi instalado em novo edifício, da autoria do arquiteto Paulo Mendes da Rocha, prémio Pritzker em 2006, que, em parceria com o arquiteto Ricardo Bak Gordon, realizou o projeto do novo museu (Coches, 2020; "Paulo Mendes da Rocha | The Pritzker Architecture Prize," 2020).

Note-se que a Resolução do Conselho de Ministros 78/2008 (Diário da República n. ${ }^{\circ}$ 94/2008) considerou a construção de novo Museu Nacional dos Coches enquanto "projeto âncora da reabilitação da zona de Belém-Ajuda" assegurando o seu financiamento, demonstrando uma visão definidora da estratégia cultural de atração turística e do desenvolvimento urbano para cidade de Lisboa. O Museu de Arte, Arquitetura e Tecnologia, desenhado pelo ateliê de arquitetura Amanda Levete Architects, acentua a resposta a essa estratégia, marcando claramente e redefinindo a paisagem, à beira do Tejo (Museu de Arte, 2020).

Estes equipamentos museológicos, tendo sido projetados especificamente para o efeito, absorvem algumas das premissas requeridas para um museu contemporâneo, conseguindo, no entanto, desempenhar um forte papel de atração turística.

No caso da Madeira, merece destaque o premiado Centro das Artes Casa das Mudas, projetado pelo Arquiteto Paulo David, que atualmente acolhe o Museu de Arte Contemporânea da Madeira (Mudas). Este museu foi instalado em 2015, na sequência da trasladação da coleção de arte contemporânea, em depósito na Fortaleza de São Tiago, no Funchal (Madeira, 2020).

As intervenções arquitetónicas dos "novos" museus, a reabilitação de espaços transformando-os e conferindo-lhes um novo uso - o museológico - talvez uso primeiro da "monumentalidade" inscrita num discurso da arquitetura contemporânea, como a melhor estratégia de branding, sobrepondo-se à valorização das próprias coleções e acervos.

Esta dicotomia, quase "neomaneirista", permite ao museu revestir-se de uma pele, que esconde a sua real substância - as coleções, os acervos, a programação. E, provavelmente, basta esta pele para colher os reais impactos, imediatos, no turismo.

"Simultaneamente, estas intervenções tendem a afastar-se do conceito tradicional de reabilitação, transpondo do quotidiano para o campo da arquitetura e da curadoria as noções contemporâneas de reutilização e reciclagem, que pressupõem uma contínua renovação de espaços e de conteúdo" (Silva \& Barranha, 2013).

Os museus hedonistas deixariam de contribuir para consciência e progresso da civilização, passando a ter como principal objetivo a atratividade turística, subvertendo os objetivos do museu contemporâneo, determinando o espaço público e mediático e contribuindo para uma alienação cultural (Goes, 2019).

Armando Coelho, no prefácio do livro "O pincel é uma arma - para a construção de um Museu de Causas" (Santos, 2015) considera que um museu contemporâneo deve aspirar à construção de "um espaço polissémico, de celebração, de criação e expressão pessoal e/ou coletiva em permanente denúncia das patologias do mundo contemporâneo em prol da justiça social: uma heterotopia, outro lugar, como o definiria Michel Foucault."

Por antítese, Muxi (2004) citado por Cruz (2012) constata que, apesar de uma conceção fortemente determinada do ponto de vista da rentabilidade, um museu poderá ser um fator de dinamização económica e atração do potencial turístico. Edifícios históricos, reabilitados e transformados em museus poderão ser catalisadores de regeneração urbana.

Daqui resulta o equívoco, no discurso político e mediático, de que a Cultura tem de satisfazer o interesse das massas e só assim se torna sustentável. Constata-se a aparente impossibilidade de coexistência de uma lógica não lucrativa e filantrópica, definida como princípio cultural orientador, com a interferência das dinâmicas de mercado, como fator de sustentabilidade para as instituições museológicas.

Trata-se, pois, de questões de princípio: a preservação da memória e o acesso ao conhecimento não se coadunam com as lógicas de uma economia de mercado, correndo o risco de substituir a aquisição de um conhecimento aprofundado, por uma lógica de entretenimento fugaz e imediato.

Segundo Goes (2019), "A Cultura do entretenimento tornou-se no melhor e mais hábil instrumento do marketing político e do controlo das massas. E os museus tornaram-se nas hipérboles demagógicas do discurso político e na melhor metáfora do assédio do fruidor/eleitor".

Para Serra \& Carvalho (2010) a atribuição valorativa dos espaços museológicos como lugares hedonistas propícios a práticas de lazer, veio possibilitar que, as instituições museológicas, fossem vistas de um outro modo, ou pelo menos desempenhando um outro papel. Os espaços contíguos aos museus passaram a agregar novas valências: jardins, lojas, cafetarias, contribuindo para a habituação de novos 
públicos. Do ponto de vista da programação e a atualização dos discursos museográficos levaram a que, através de consecutivas exposições temporárias de curta duração, ao invés de permanentes, os visitantes mantenham um constante interesse nas atividades dos museus. Os autores referem que a necessidade de implementação de mecanismos de gestão leva a que o museu assuma uma quota de mercado.

O museu contemporâneo nasce da dicotomia entre as políticas de responsabilidade social de intervir na comunidade onde se insere e na necessidade de justificar a afluência de público para a sua existência ou para seu financiamento, ficando por isso fortemente comprometidos com uma lógica de mercado.

Sobre o conceito de museu, para futuro, pode-se considerar como corpo da sua missão e objetivos, a promoção da inclusão social. Sobre este propósito fará sentido afirmar que todos os museus são de facto museus de causas, ou como na proposta de Santos (2015) para a criação de uma instituição museológica "Paleta Contemporânea - Museus de Causas" que possa não ser apenas repositório, mas se afirme também como verdadeiro Centro Cultural (...) e seja protagonista no próprio desenvolvimento dos mais diversos canais de divulgação de todo o processo criativo (Santos, 2015). O mesmo autor aponta que será desejável "estabelecer um estreito diálogo entre o público e neste caso especial, com o mais jovem, tentando assim contribuir para uma maior sensibilização da comunidade juvenil, para o gosto e para a prática das artes plásticas."

De acordo com Goes (2019), os museus do futuro, deverão ser "mais inclusivos e politicamente comprometidos, não sistematizando hierarquias historiográficas" e criando novas narrativas em diálogo com as comunidades, despoletando nelas o interesse no património museológico.

A Lei Quadro dos Museus Portugueses, Lei n. ${ }^{\circ}$ 47/2004, de 19 de agosto, embora assuma basear-se no conhecimento da realidade portuguesa, está conforme as orientações internacionais e apresenta uma definição de museu muito próxima da veiculada pelo ICOM.

Segundo Monge (2018), "a opinião consensual é a de que a Lei-Quadro, necessitando embora de adaptação a novas realidades, designadamente com a criação da Direção-Geral do Património Cultural (DGPC), configura o enquadramento desejável para os museus portugueses.”. A mesma autora ainda refere que o ICOM Portugal "(...) assume a preocupação com o desinvestimento na qualificação dos museus (...).” Promover a implementação da totalidade das disposições previstas na Lei-Quadro parece ser a melhor forma de garantir que qualquer projeto de descentralização de competências na área dos museus significará uma opção propiciadora de um tecido museológico qualificado e empenhado na construção de uma sociedade melhor e mais justa.

Considere-se ainda legislação aplicável sobre a matéria em estudo, demonstrando a vocação das instituições museológicas, nomeadamente na criação de novos públicos locais, jovens, através da gratuitidade do acesso aos bens culturais. Como exemplo, veja-se a iniciativa "Cultura para todos!", conforme o despacho n. ${ }^{\circ}$ 2880/2020 (Diário da República n. ${ }^{\circ}$ 45/2020, Série II de 2020-03-04, 2020).

A Constituição da República Portuguesa (2005) consagra no seu artigo 9. ${ }^{\circ}$, alíneas d) e e), como tarefa fundamental do Estado: promover a efetivação "dos direitos culturais" e "proteger e valorizar o património cultural”, respetivamente, também nos artigos $42 .^{\circ}$ e $43 .^{\circ}$, o princípio da liberdade de criação cultural e de ensinar e aprender.

\subsection{Tipologias de Museu}

Os museus apresentam uma tipologia heterogénea e podem ser classificados de acordo com diferentes critérios. O Instituto Nacional de Estatística (2009) identifica diferentes tipos de museus, os quais estão resumidamente apresentados na tabela 1.

\section{Tabela 1: Tipologia de Museus}

Segundo o Instituto Nacional de Estatística (2009) existem 7 tipologias principais de museus, a saber:

Museu de Arte (consagrado às belas-artes, às aplicadas e às performativas); Museu de História (ilustra um determinado tema, personalidade ou momento histórico); Museu de Ciências Naturais e História Natural (consagrado a uma ou mais disciplinas das ciências naturais); Museu de Ciência e Técnica (consagrado às ciências exatas ou técnicas); Museu de Etnografia e de Antropologia (relacionados com a cultura, estruturas sociais, crenças, costumes e tradições); Museus de Territórios (representativas de um território específico) e Museus Mistos e Pluridisciplinares (com coleções heterogéneas, não identificadas por um tema em particular) e outros. 
As tipologias apresentadas fazem uma triagem de acordo com a natureza das coleções dominantes. Outra categorização distingue os museus por dimensão (museus nacionais, museus regionais, museus locais, etc.); tutela (museus privados, museus municipais, museus mistos, etc.); unidades (polinucleados e núcleos, etc.), e relação com as comunidades (ecomuseus, museus de região, museus de comunidade, etc.), entre outras (Marques, 2014; Raposo, 2010).

\subsection{Museus na Região Autónoma da Madeira}

Os dados disponibilizados pelo Instituto Nacional de Estatística (2020) indicam que no período de 2012 a 2018, o número de museus tem crescido. Em 2018 o número de museus em Portugal ascendeu a 431.

Relativamente à Região Autónoma da Madeira, verifica-se que o seu crescimento apesar de positivo não foi uniforme (Tabela 2).

Tabela 2: Evolução do Número de museus na RAM por ano

\begin{tabular}{|c|c|c|c|c|c|c|c|}
\hline Localização & 2012 & 2013 & 2014 & 2015 & 2016 & 2017 & 2018 \\
\hline $\begin{array}{l}\text { Região } \\
\text { Autónoma da } \\
\text { Madeira }\end{array}$ & 15 & 17 & 19 & 16 & 16 & 19 & 18 \\
\hline Calheta & 0 & 0 & 0 & 0 & 0 & 1 & 1 \\
\hline Câmara de lobos & 0 & 0 & 0 & 0 & 0 & 0 & 0 \\
\hline Funchal & 10 & 12 & 13 & 10 & 11 & 12 & 12 \\
\hline Machico & 2 & 2 & 2 & 2 & 2 & 2 & 2 \\
\hline Ponta do Sol & 0 & 0 & 0 & 0 & 0 & 0 & 0 \\
\hline Porto Moniz & 1 & 1 & 1 & 1 & 1 & 1 & 0 \\
\hline Porto Santo & 0 & 0 & 1 & 1 & 1 & 1 & 1 \\
\hline Ribeira Brava & 1 & 1 & 1 & 1 & 1 & 1 & 1 \\
\hline Santa Cruz & 0 & 0 & 0 & 0 & 0 & 0 & 0 \\
\hline Santana & 1 & 1 & 1 & 1 & 0 & 1 & 1 \\
\hline São Vicente & 0 & 0 & 0 & 0 & 0 & 0 & 0 \\
\hline
\end{tabular}

Fonte: Adaptado de Instituto Nacional de Estatística (2020)

Em 2018, a Região Autónoma da Madeira apresentava 18 museus, sendo que um está localizado no Porto Santo. O concelho que apresenta maior número de museus é o do Funchal. Já os concelhos de São Vicente, Santa Cruz, Ponta do Sol, Porto Moniz e Câmara de Lobos não apresentam nenhum museu.

\subsection{Turismo}

O turismo em Portugal tem sido um impulsionador da economia. Portugal tem um plano definido até 2027. Neste documento, "Estratégia Turismo 2027 - Liderar o Turismo do futuro", é feita uma análise da evolução do turismo em Portugal da qual se destaca: em 2002, o número de hóspedes em estabelecimentos hoteleiros portugueses era praticamente metade do que se registou em 2017 . À exceção de 2009, a tendência é de crescimento; desde 2010, o número de dormidas em Portugal tem crescido, em 2017 apresentou um aumento de quase quatro milhões de dormidas. Os estrangeiros representaram sete em cada dez dormidas; em 2017 a receita por quarto disponível é de 50,2 €; Reino Unido, Alemanha, Espanha e França são os países que mais visitam Portugal.

Em 2018, os portugueses efetuaram 22,1 milhões de deslocações turísticas, das quais 19,6 milhões dentro do território nacional. As dormidas em Portugal totalizaram 69,6 milhões e no estrangeiro ascenderam a 18,3 milhões, ascendendo no global a 87,8 milhões. Os portugueses gastaram, em média, $121,5 €$ em cada viagem em Portugal e 525,7€ no estrangeiro Mello (2019).

Ao nível da Região Autónoma da Madeira "o Sector do Turismo desempenha um papel fundamental na economia da RAM, envolvendo diversos setores da atividade económica, incluindo hotelaria, 
operadores turísticos, agências de viagem, restauração, (...)" (Associação Comercial e Industrial do Funchal \& KPMG, 2014).

Em 2015, o Turismo era responsável por 15\% do emprego regional e com um contributo para o PIB da RAM que ronda os 25\%. Cerca de $84 \%$ dos passageiros do Aeroporto da Madeira residem fora do Arquipélago. Destes destacam-se os Portugueses, Alemães, Ingleses e Franceses (Secretaria Regional da Economia Turismo e Cultura, 2016). Verifica-se assim que o setor do turismo é o principal motor e alavanca da economia regional.

Em 2017 é aprovado o Plano para o Ordenamento do Território na Região Autónoma da Madeira (POTRAM) (Decreto Legislativo Regional n ${ }^{\circ}$ 15/2017/M, 2017). Neste documento estão patentes as principais linhas orientadoras e metas para o futuro em relação ao desenvolvimento sustentável do setor, no qual se salientam os seguintes objetivos: "3) Reforçar a formatação dos produtos de nicho, tendo em vista aumentar a atração dos públicos turísticos (...) 5) Otimizar a oferta secundária numa lógica de articulação em rede, aproveitando o facto de a Madeira apresentar hoje uma oferta secundária mais rica e diversificada, seja em termos culturais (...) 6) Aumentar o peso da Cultura no ordenamento estratégico do Turismo pelo facto de a oferta cultural da RAM ser rica e diversificada ao nível das atividades, dos equipamentos e dos agentes.”. A visão defendida para o futuro assenta num novo paradigma que assume a qualificação e consolidação da oferta, o reforço da notoriedade e atratividade do destino e a melhoria dos seus indicadores de desempenho, como prioridades.

Em 2018, a RAM, ao nível da oferta turística disponível no conjunto dos meios de alojamento, abrangendo a hotelaria, turismo no espaço rural e alojamento local (excluindo o alojamento local abaixo das 10 camas), apresentava 34399 camas, cuja a oferta se encontra concentrada em 16284 quarto. O número de dormidas no alojamento turístico aproximou-se dos 8,4 milhões, sendo 938,3 mil provenientes de residentes em Portugal. Os principais mercados emissores no alojamento turístico coletivo em 2018 foram Alemanha (28,2\%) e Reino Unido (26,6\%). A receita por quarto disponível (RevPAR), em 2018, na RAM, foi de 47,47 € (Direção Regional de Estatística da Madeira, 2019).

Num contexto em que o Turismo mundial cresce acima dos 3\% e vários indicadores no território continental português, registam sucessivos aumentos da procura turística, 7,7\%, face a 2017 e um valor acrescentado bruto (VAB) gerado pelo setor, que cresceu 8\% em 2018. O turismo cresceu em Portugal mais $4,1 \%$ do que o resto da economia em 2018. Na Região Autónoma da Madeira tem se vindo a verificar sucessivos e acentuados decréscimos contrariando a tendência nacional em períodos homólogos, exceto em 2017. Em 2019, foram mais de 214 mil as dormidas perdidas em 11 meses, segundo os dados disponibilizados, que quando comparadas com o período homólogo de 2018, demonstram uma acentuada diminuição dos proveitos totais, rondando $5 \%$ de perdas (Goes, 2020).

\subsection{Turismo Cultural e os Museus}

Segundo Gonçalves (2009b) no atual contexto da sociedade global os conceitos de museus e turismo são relacionáveis ou até interdependentes na medida em que podem potenciar a atração do público turista, contribuindo para o debate do papel dos equipamentos culturais numa sociedade da informação e do lazer.

A mesma autora, considera a possibilidade dos museus se constituírem como fator diferenciador da oferta e da atração turística e também dinamizadores do tecido económico e cultural. Sobre este aspeto, se os museus constituem ou não, atratividade para o turismo, ou se deles beneficiam, com o aumento de número de visitantes, pode-se constatar que no caso Português, desde 2012, existe uma dissonância entre um tendencial crescimento do turismo a nível internacional e o baixo número de visitantes a nível nacional, replicando-se o mesmo "sintoma" às regiões autónomas.

Para a captação de novos públicos aos museus e maximização do seu potencial, importa que hajam "abordagens próximas do território e dos seus recursos" que ao possibilitarem a inclusão das comunidades locais, nas quais os museus estão inseridos, colaborando desde a sua conceção e participando na programação, permitem que o espaço se constitua "como um estímulo à diversidade cultural, assim como, a proximidade espacial entre vários recursos turísticos, culturais e patrimoniais podem potenciar a constituição de clusters nas áreas do turismo e do lazer, afirmando-se como ofertas diferenciadoras dos destinos turísticos. Estas aglomerações de recursos também são boas oportunidades para a construção de economias nas operações destes espaços e equipamentos, que, por sua vez, trazem ganhos de atratividade para o turismo." (Gonçalves, 2009b).

De acordo com Luís Raposo (2016), constatava que, segundo resultados de um inquérito de 2012 que lamentava "a ausência de Portugal da lista dos 100 museus de arte mais visitados do Mundo. 
Situação mais agravada ainda porque Lisboa nem sequer figurava também na lista das exposições com mais 1000 visitantes/dia (contrariamente ao Porto, através de cinco exposições realizadas em Serralves).”. Verificou-se que a retoma económica e o crescimento do turismo, poderão ter contribuído para uma evolução: "Em 2015, Portugal já surge representado na lista dos 100 museus, com um museu lisboeta (Museu Berardo). E, com onze exposições, todas no Porto e em Serralves" (Raposo, 2016). $\mathrm{O}$ mesmo autor ainda refere que, contudo, "num contexto em que o turismo estrangeiro conhece uma verdadeira explosão, com taxas anuais superiores a dois dígitos, refletidas em alguns museus (...)" continuam as dificuldades sistémicas das estruturas de decisão. "Ninguém ousa atuar audaciosamente (...) criando no imediato uma task force para pensar pacote de museus e exposições a incluir na oferta turística de uma capital". Acrescenta ainda a sua crítica, quer ao plano da promoção, quer no plano dos dados disponíveis.

"As vistas curtas não são apenas estreitas no plano da promoção dos nossos museus junto dos circuitos internacionais. São também, e antes de tudo, junto dos cidadãos nacionais. No caso português escasseiam os dados e o inquérito referido abrange um universo de museus muito restrito".

Uma plausível razão para este efeito poderá ser a falta de divulgação internacional dos mesmos, e o facto de alguns museus manterem ainda, exposições permanentes sem rotatividade do exposto e/ou exposições de longa duração, com pouco estímulo para o retorno do visitante - o que subverte a lógico da conceção de "museu contemporâneo".

Refere-se que, em 2012, a influência do público nacional, no considerado baixo número de visitantes, poderá refletir o estado de crise financeira e económica em Portugal, estando intervencionado externamente. Poderemos extrapolar os impactos na Região Autónoma da Madeira. A crise poderá ter originado uma quebra de confiança dos consumidores, nomeadamente os consumidores culturais, contudo tal não vem justificar o baixo número de visitantes à data e o exponencial de crescimento subvalorizado (Instituto Nacional de Estatística, 2015).

Gonçalves (2009a) considera a partir de Aalst and Boogaarts (2002) que os clusters baseados nos museus se constituem como estratégias de sucesso e que, quase todas as grandes cidades, apostaram nos museus como forma de regeneração dos seus centros urbanos e de revitalização das suas economias. Demonstrou-se que a concentração dos museus traz vantagens, nomeadamente no estabelecimento de sinergias, partilha de meios e infraestruturas e na melhoria das acessibilidades possibilitando a abrangência de diferentes públicos, especificamente os turistas.

A cultura tem ganho uma dimensão estratégica e os museus, não raramente, promovem atividades com potencial de atração turística que estão na base de economias locais e regionais. Atualmente, os turistas representam uma parte importante das visitas aos museus, tornando-se, em alguns casos, uma percentagem expressiva do seu público (Gonçalves, 2009a).

A possibilidade de estabelecer relações/diálogos entre os museus e o mercado turístico, visa fundamentalmente a sua inserção e viabilização "como atrativos turísticos, através da sua transformação em produtos turísticos-culturais" dando perceção de que "para a concretização dos museus como roteiros de destinos culturais é necessário identificar qual o tipo/perfil de turista que os visitam; turista este identificado pela literatura como "turista cultural" (Morais, 2013). Por essa razão, os museus deverão investir na identificação dos públicos e investigação das especificidades dos seus interesses, origens e caraterísticas, para melhor direcionar a sua promoção e estratégias de comunicação. Acrescenta que, o turismo constitui uma oportunidade para garantir a sustentabilidade dos museus, pela importância de estes serem os garantes da transmissão de conhecimento e desenvolvimento de valores universais e tolerância, pela identidade do representado. Gonçalves (2009b) aponta também como principais pressupostos os factos decorrentes da mudança de paradigma do turismo, onde se substituiu o produto de destino comercial pela oferta de uma experiência que não se dissocia da identidade cultural do território visitado e experienciado. Por essa razão, tornar-se-á cada vez mais difícil não relacionar as práticas turísticas com as práticas culturais e com estas surgir novos fenómenos de sincretismo cultural. Daqui emerge a necessidade de preservação do património edificado e artístico, material e imaterial confirmando autenticidade da experiência tida pelo turista visitante.

"O reconhecimento da importância da sustentabilidade cultural já foi apreendido pelo turismo cultural e os agentes do turismo estão hoje conscientes que o futuro da indústria turística depende da proteção e preservação dos recursos ambientais, patrimoniais e culturais de cada região" (Gonçalves, 2009b). 
Se por um lado é possível deduzir impactos económicos positivos nas estratégias adotadas, de transformação dos centros históricos, em "clusters museológicos" também é possível notar que os habitantes desses mesmos centros, poderão ter de coexistir com um novo antagonismo originado pelo fenómeno turístico: em vez (da arte, dos clusters culturais e das instituições museológicas) promoverem a inclusão social, submetem a um novo julgo económico aqueles que habitam aqueles lugares, instituindo novos "não-lugares" nas cidades. Os Museus como o espaço público que os envolve, e no qual estão edificados, poderão potenciar a não habitabilidade das cidades e com isso torná-las "não-lugares", na definição de Marc Augé, lugares transitórios, de passagem. Daqui decorre também o perigo das cidades ao se tornarem museus ao ar livre, perderem a sua essência de lugar habitado e de não cumprirem a sua missão e se tornarem num lugar contemplativo apenas do sublime (Goes, 2019).

Como refere Queiró (2017), "O que faz Portugal permanecer é a história da população que sente como sua, uma cultura antiga e enraizada, mesmo que também modificada e adaptada. E, sobretudo um sentido de pertença, uma vontade assumida de existência como comunidade.”. É válido extrapolar que este sentimento de pertença e identificação cultural, esteja intimamente ligado aos papéis das instituições museológicas, como pelas instituições de ensino. É de destacar a possibilidade do estabelecimento de sinergias entre ambas instituições, principalmente no foro da investigação científica, na conservação e preservação e numa vertente educativa.

Russo e Van de Borg (2002), citados por Serra \& Carvalho (2010), afirmam que sob o vetor de análise do turismo, o património deve ser explorado para a obtenção de lucro, nas mais diversas atividades e situações. A relação entre turismo e património deve ser bem ponderada, na medida em que nem sempre o desenvolvimento turístico é compatível com a conservação patrimonial. Porém, acontece que em muitos locais são os recursos financeiros obtidos da exploração turística do património que viabilizam orçamentos de preservação e salvaguarda deste.

A tentativa de atrair novos públicos, com diferentes especificidades geográficas e culturais, na perspetiva de divulgação e partilha de conhecimento poderá ser uma mais valia. $\mathrm{Na}$ ótica de mercado poderá responder às suas necessidades, invertendo a função de museu. Assim, museus e turismo olham o património de diferentes ângulos: os primeiros procuram a sua preservação e conservação por meio de processos e estudos interpretativos, numa vertente educativa; o segundo tem uma visão mais exploradora do património, visando a criação de valor económico, sendo que sua sustentabilidade varia consoante estejam orientadas as práticas turísticas e com as políticas de salvaguarda patrimonial em vigor no local (Serra \& Carvalho, 2010).

Clara Camacho (ICOM Portugal), a propósito da palestra «O Método como Mensagem: Participação e Valor das Coleções» ministrada por Peter Van Mensch, destaca a importância de "um envolvimento ativo da comunidade nas decisões dos museus, designadamente quanto à relevância das coleções, conectando-as com o mundo exterior" (Portugal, 2018). A melhor forma dos museus comunicarem a sua mensagem é através da participação das comunidades, conseguindo que estas reconheçam a importância da preservação, conservação e divulgação do acervo neles existentes.

\subsection{Museus em rede e fluxos turísticos}

Lira (2002) citado por Serra \& Carvalho (2010), defende que integração de museus em redes e roteiros turísticos traz benefícios quer para o turismo, quer para o museu, pois a articulação entre ambos fará com que os turistas visitem mais espaços uma vez interligados. Será de notar a inexistência de um roteiro entre museus na Região Autónoma da Madeira (RAM) - existentes são alguns roteiros ou percursos sobre património, nomeadamente a arquitetónico e religioso, ou de arte contemporânea, de iniciativa privada - sendo a tarefa complexa pela dificuldade de trabalho em redes intermunicipais ou entre os próprios museus de mesmas tutelas, salvo exceções, de alguns projetos pontuais.

Considere-se o exemplo no território continental, o projeto «Rede de Museus e Equipamentos Culturais de Évora», apresentado por Filipe Barata (Universidade de Évora) com o objetivo de envolver "a gestão dos fluxos turísticos e a maximização do retorno económico.". Contudo a rede proposta "não tem preocupações nas áreas dos conteúdos e da programação, da educação patrimonial e ligação à comunidade e, sobretudo, dos recursos humanos" (Monge, 2018) e poderá levar a colocar como hipótese, a subversão da lógica do próprio museu.

A conceção de redes ou roteiros que não tenham, em conta a envolvência das comunidades poderá constituir razão para um maior afastamento das populações locais, porque o papel do museu, dista da vocação de um centro cultural, temático, interpretativo ou de uma galeria, desfasado de uma lógica mais "comercial". 
O visitante do museu é também um turista cultural, uma vez que procura contactar com outras culturas, conhecer outros povos e tradições, para enriquecer a sua própria cultura (Serra \& Carvalho, 2010). Os mesmos autores afirmam que no contexto internacional dos mercados emissores, o turista, com recurso às tecnologias de informação digital, "planeia autonomamente as suas deslocações, tendo um total controlo sobre a administração do seu tempo livre" tentando fugir à massificação nos destinos turísticos, excetuando os locais icónicos da História e Património mundial.

No caso do destino Madeira, empiricamente, sugere-se que, na atualidade, o fator museus, as suas coleções e acervos, só por si não constituem fator preferencial para atração turística, quer porque não existem dados que o possam verificar, quer porque não existe um real dimensionamento dos Museus na Madeira para essa própria promoção.

Outro aspeto que importa realçar é o facto de um museu "para turistas" provavelmente exclui aqueles que habitam em seu redor. Os museus que não potenciem a inclusão social, poderão originar a exclusão, das pessoas que com eles não se identificam (Moreno-Mendoza, Santana-Talavera, \& Boza-Chirino, 2020).

A relação com o turismo e museologia, nos demais contextos, "trouxe mutações em ambas as partes, sendo que são mais notórias as mudanças nos museus, que se adaptaram para receber a atividade turística”. Pesa o facto de o turismo deixar uma pegada ecológica, acentuada, sem que os proveitos reais se traduzam numa real preservação do património edificado e da conservação dos acervos e coleções, justificando-se para isso um relacionamento que potencie a sustentabilidade não só económica de ambos sectores, como a cultural e patrimonial (Serra \& Carvalho, 2010).

\section{Metodologia}

\subsection{Dados e Métodos}

De acordo com Gil (2017), a pesquisa descritiva tem como principal objetivo descrever características de determinada população ou fenómeno ou o estabelecimento entre relações entre variáveis. Tem o objetivo de "descrever as características de determinada população ou fenómeno ou o estabelecimento de relações entre variáveis" (Prodanov \& Freitas, 2013).

Segundo Barañano (2008), dados secundários

“... são dados previamente recolhidos por outros investigadores ou instituições e com objetivos diferentes dos posteriores utilizados. A utilização de dados secundários é uma ferramenta metodológica comum em Gestão e apresenta algumas vantagens, tais como: análise de amostras grandes e são mais baratos que a criação de dados primários (Barañano, 2008; Lakatos \& Marconi, 2017; Prodanov \& Freitas, 2013).

A estratégia deste estudo baseou-se na obtenção de informação através da consulta de dados disponíveis nas diversas bases de dados estatísticos existentes. Assim procurou-se fazer a recolha de dados consultando o Instituto Nacional de Estatística (INE) e a Direção Regional de Estatística da Madeira (DREM). Os dados foram levantados em janeiro de 2020. O tratamento estatístico foi realizado recorrendo do Microsoft Office Excel.

\section{Resultados}

Tendo em conta a natureza do estudo, optou-se por apresentar e analisar os dados e depois fazer a discussão e conclusão em simultâneo. Para o cálculo das estatísticas descritivas e para os tratamentos estatísticos recorreu-se ao Microsoft Office Excel. 
Figura 1: Hóspedes entrados nos estabelecimentos de alojamento turístico por país de residência habitual

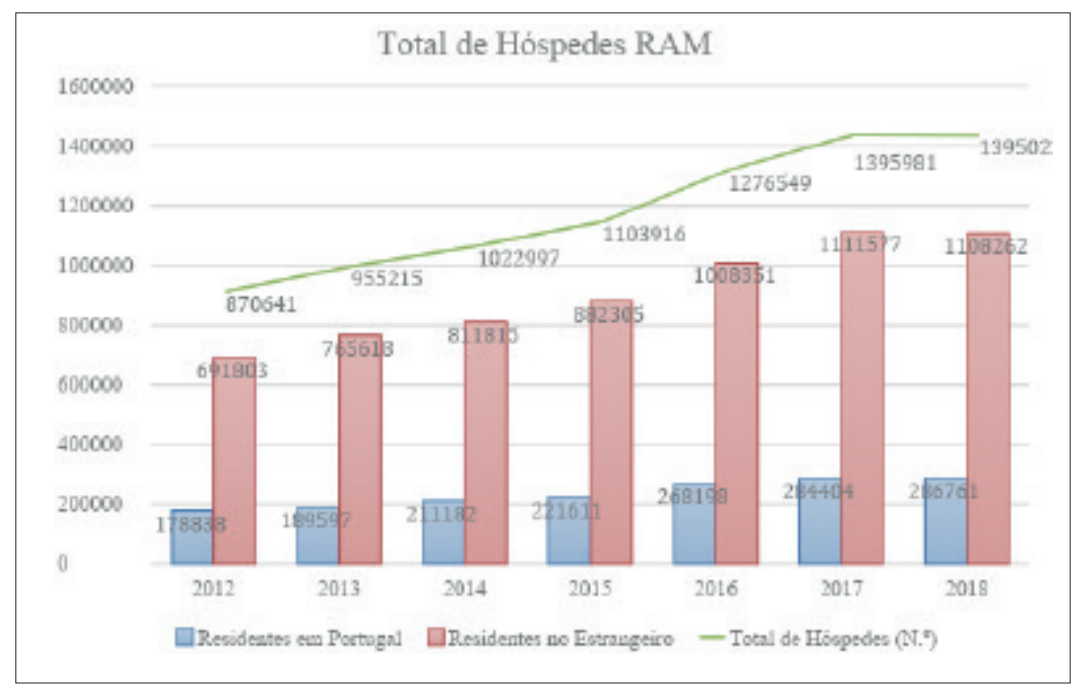

Fonte: Direção Regional de Estatística da Madeira (2019b)

No período considerado, 2012 a 2018, verifica-se um aumento constante do número de hóspedes, com ligeira atenuação entre 2017 e 2018 passando de 1395981 para 1395023 . De 2015 para 2016 existiu um aumento do número de hóspedes maior que nos outros anos passando de 1103916 para 1273 549 traduzindo-se num aumento de 15\%. Relativamente à sua nacionalidade, os hóspedes residentes em Portugal têm aumentado de uma forma constante. Já os hóspedes estrangeiros têm aumentado, no período considerado e com maior expressão em comparação aos hóspedes residentes em Portugal.

\subsection{Visitantes de Museus}

Figura 2: Evolução do número de visitantes museus da RAM

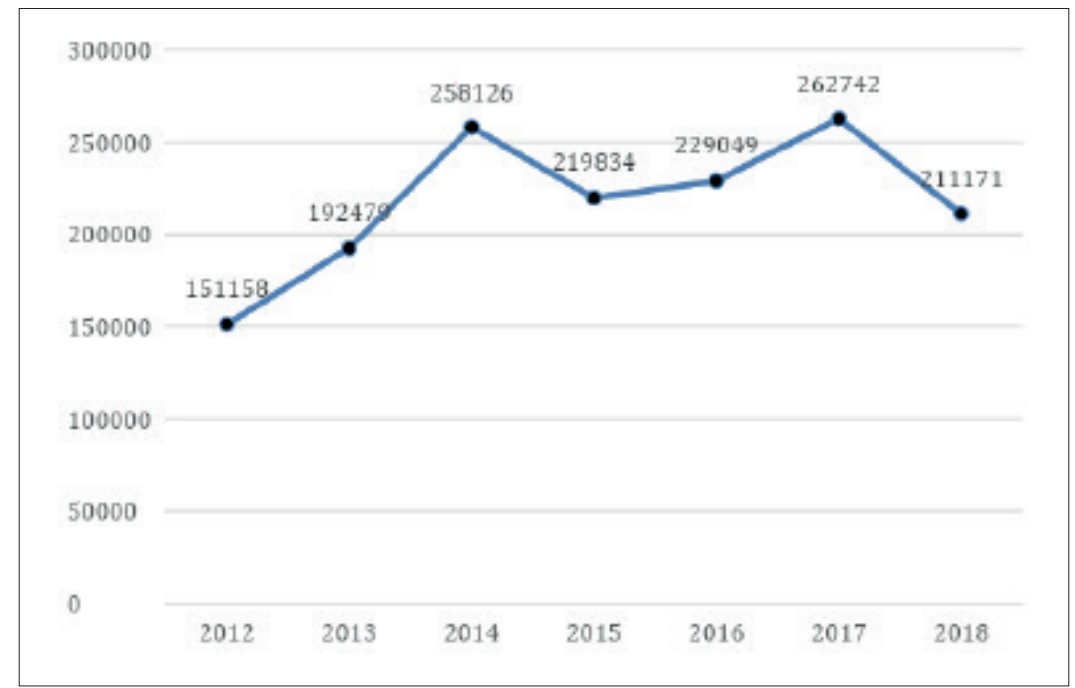

Fonte: Instituto Nacional de Estatística (2019) 
Tabela 3: Visitantes de museus por localização na RAM por ano

\begin{tabular}{|l|c|c|c|c|c|c|c|}
\hline \multicolumn{1}{|c|}{$\begin{array}{c}\text { Visitantes } \\
\text { (N. }{ }^{\mathbf{9}}\end{array}$} & $\mathbf{2 0 1 2}$ & $\mathbf{2 0 1 3}$ & $\mathbf{2 0 1 4}$ & $\mathbf{2 0 1 5}$ & $\mathbf{2 0 1 6}$ & $\mathbf{2 0 1 7}$ & $\mathbf{2 0 1 8}$ \\
\hline $\begin{array}{l}\text { Regiáa } \\
\text { Autónoma da } \\
\text { Madeira }\end{array}$ & 151158 & 192479 & 258126 & 219834 & 229049 & 262742 & 211171 \\
\hline Calheta & 0 & 0 & 0 & 0 & 0 & 16352 & 20206 \\
\hline $\begin{array}{l}\text { Câmara de } \\
\text { Lobos }\end{array}$ & 0 & 0 & 0 & 0 & 0 & 0 & 0 \\
\hline Funchal & Confidencial & 144906 & 204741 & 162191 & 161392 & 176398 & 128522 \\
\hline Machico & 17825 & 21699 & Confidencial & 24285 & 29871 & 32158 & 33788 \\
\hline Ponta do Sol & 0 & 0 & 0 & 0 & 0 & 0 & 0 \\
\hline Porto Moniz & Confidencial & 3947 & Confidencial & 9782 & 10017 & 8320 & 0 \\
\hline Porto Santo & 0 & 0 & Confidencial & 15001 & 17360 & 16754 & 17499 \\
\hline $\begin{array}{l}\text { Ribeira } \\
\text { Brava }\end{array}$ & 12617 & Confidencial & Confidencial & Confidencial & 10409 & 9960 & Confidencial \\
\hline Santa Cruz & 0 & 0 & 0 & 0 & 0 & 0 & 0 \\
\hline Santana & Confidencial & Confidencial & Confidencial & Confidencial & 0 & 2800 & Confidencial \\
\hline São Vicente & 0 & 0 & 0 & 0 & 0 & 0 & 0 \\
\hline
\end{tabular}

Fonte: Instituto Nacional de Estatística (2020)

Com base nos dados apresentados pelo INE foi possível verificar um aumento, não constante, do número de visitantes nos museus situados na Região Autónoma da Madeira (RAM), no período de 2012 a 2018 (figura 2). Foi possível analisar que o ano de 2014 apresentou quase tantos visitantes (258 126) como o ano de 2017 (262 742).

No ano de 2018, os 18 museus na RAM que cumpriram os 5 critérios de elegibilidade de apuramento do Inquérito aos Museus, registaram cerca de 211 171, -19,63\% que em 2017 (262 742).

Numa perspetiva de análise por concelhos, no Funchal verifica-se que 2014 foi o ano que apresentou maior número de visitantes de museus. Os concelhos de Câmara de Lobos, Ponta do Sol, Santa Cruz e São Vicente não apresentaram registos de visitantes. Os concelhos de Machico, Porto Moniz, Porto Santo, Ribeira Brava e Santana em alguns períodos apresentaram os dados como confidenciais (tabela 3).

\subsection{Visitantes Estrangeiros (VE) de Museus}

Ao nível dos visitantes estrangeiros é possível constatar que o seu crescimento, apesar de positivo não foi constante (figura 3). O período que apresentou um maior crescimento do número de visitantes foi de 2015 para 2016, passando de 108569 para 138 046, o que representa um aumento de 27\%.

Do total de visitantes registados em 2018, 63,2\% eram estrangeiros (133 448) (figura 4) e 13,6\% eram visitantes inseridos em grupos escolares (figura 5). 
Figura 3: Número de visitantes estrangeiros dos museus

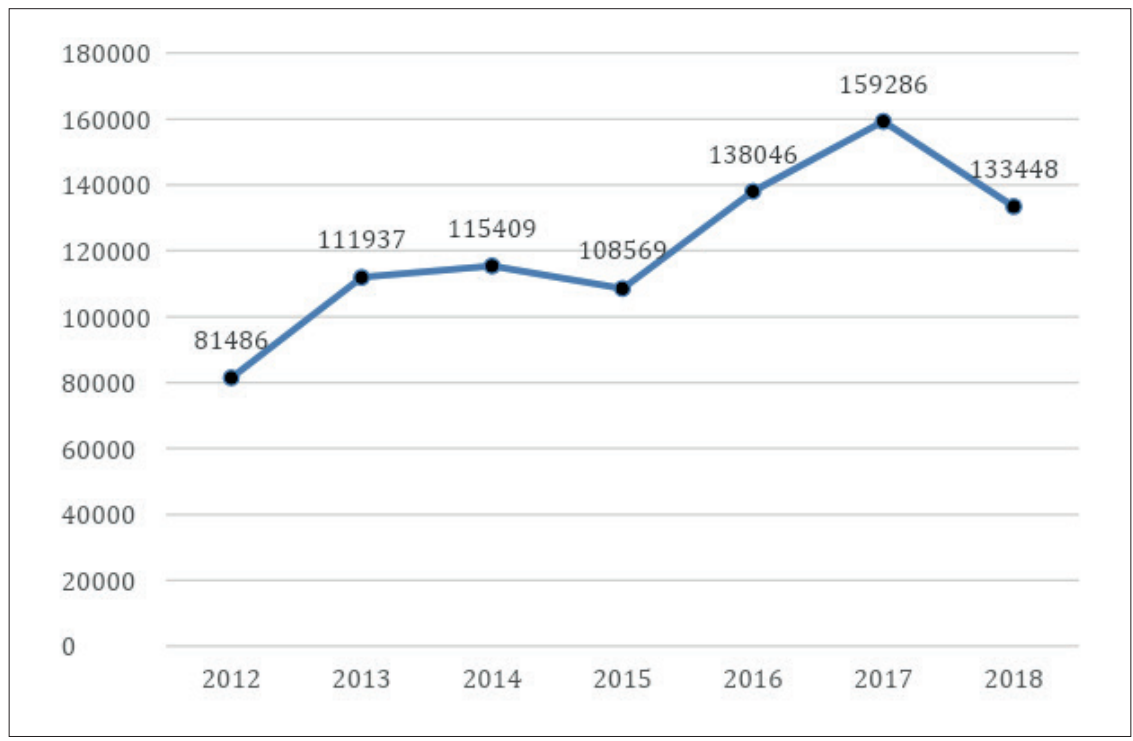

Fonte: Instituto Nacional de Estatística (2019)

Numa análise comparativa entre VE e o número total de visitantes dos museus, verifica-se que durante o ano de 2012 e 2013 o número de visitantes totais aumentou bem como o número de visitantes estrangeiros. Durante o período de 2013 a 2015, apesar do número de visitantes totais ter aumentando o número de VE não acompanhou essa tendência. A partir do ano de 2015 até ao de 2017 ambos aumentaram de forma gradual, invertendo o padrão em 2018 (figura 4).

Figura 4: Total de visitantes dos museus vs Visitantes Estrangeiros na RAM

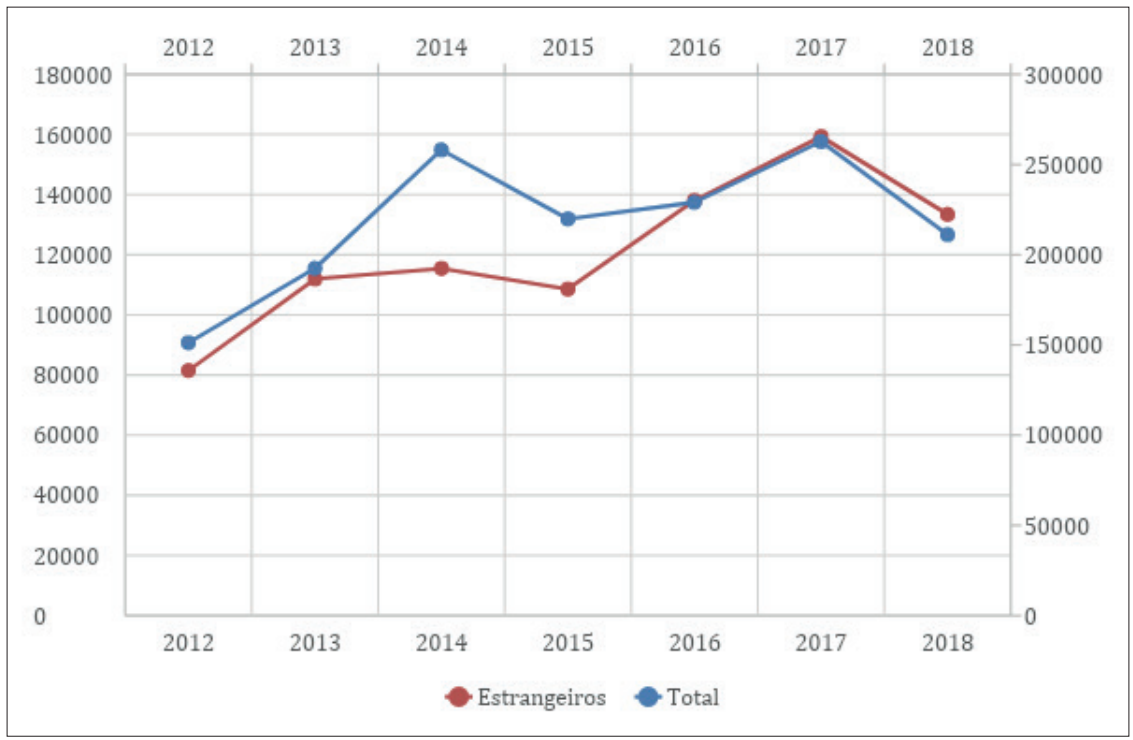

Fonte: Instituto Nacional de Estatística (2019) 


\subsection{Visitantes de Grupos Escolares}

Quando se analisa os visitantes de museus que são oriundos de grupos escolares, verifica-se que, no período considerado, a sua evolução foi positiva do ano de 2012 ao ano de 2014. Entre 2014 e 2015 existiu uma quebra acentuada do número de visitantes de grupos escolares, passando de 29304 para 23 609. Desde 2015 até 2017 existiu um aumento progressivo, sendo que o ano de 2017 apresenta o maior número deste tipo de visitantes com 33 796. Em 2018 verifica-se uma inversão do comportamento com diminuição do número de visitantes de museus de grupos escolares (figura 5).

Figura 5: Visitantes de Grupos Escolares dos museus

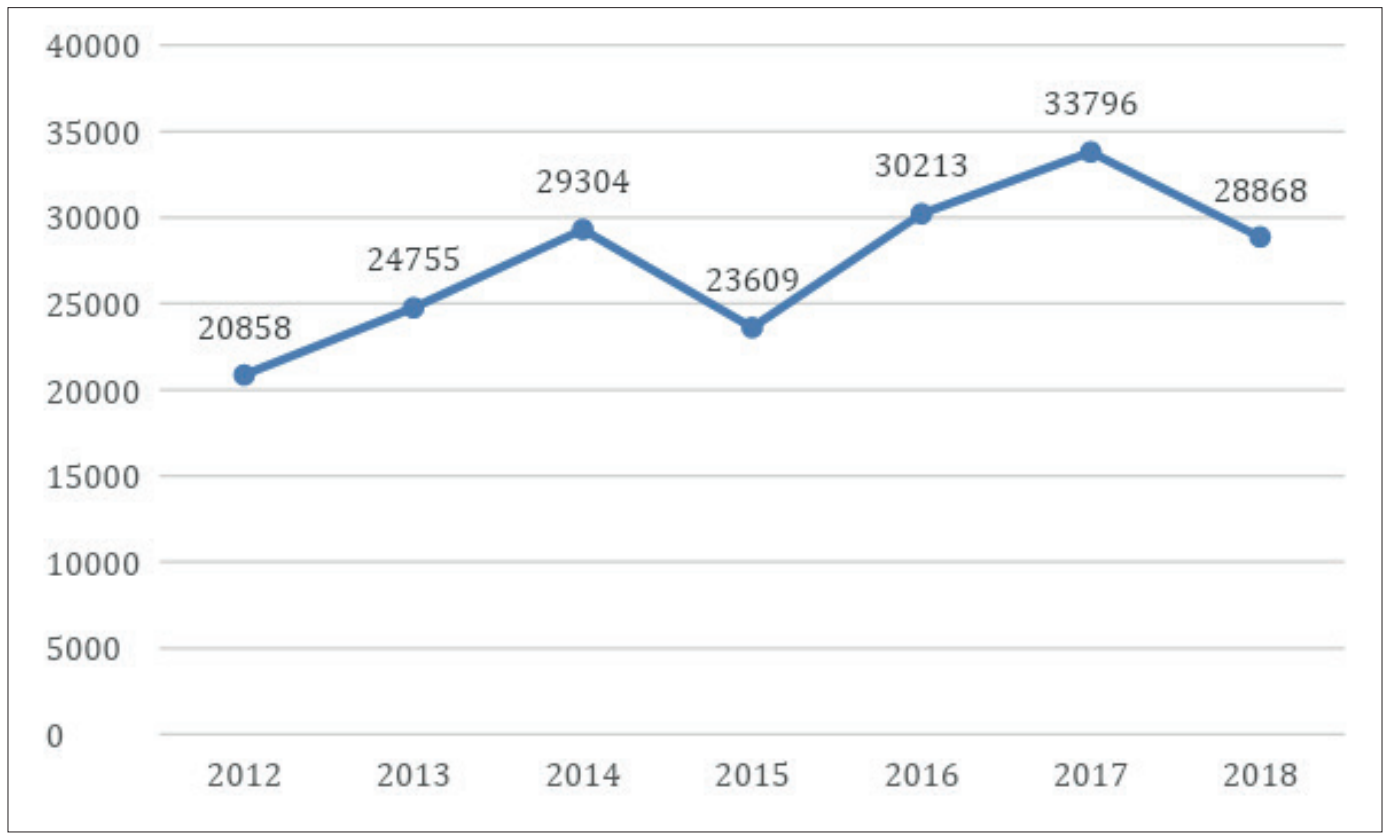

Fonte: Instituto Nacional de Estatística (2019)

\section{Limitações ao estudo}

Este estudo não esgota o tema. O aprofundamento do tema e estudo das diferentes variáveis são necessários. Não podendo concluir que o número de visitantes estrangeiros esteja diretamente relacionado com aumento de turistas, contudo podemos constatar que existe um aumento de ambos indicadores, o que sugere que um possa estar a influenciar positivamente o outro. Sugere-se por isso, que para futuro, se possa aprofundar este estudo, a fim de verificar se existe alguma relação direta entre o número de turistas e o número de visitantes estrangeiros nos museus situados na Região Autónoma da Madeira, e qual o impacto do Turismo nos mesmos, nomeadamente no número de visitantes e na respetiva receita. Outra limitação é existência de alguns dados que são confidenciais, conforme se pode verificar na tabela 3, limitando a análise.

Será igualmente interessante indagar sobre as motivações dos visitantes dos museus e compreender os aspetos que são mais valorizados por estes, para clarificar e melhor direcionar a comunicação com o público visitante.

Pelo de facto de provavelmente alguns espaços contabilizados estatisticamente, corresponderem por hipótese a centros culturais ou interpretativos ou a sítios de interesse patrimonial, mas não musealizado, importará considerar e verificar se os critérios de elegibilidade da amostra se correspondem ou não à definição e tipologia de museus, inscrita na Lei-quadro ou pelo ICOM e se os mesmos integram a rede portuguesa de museus. 
Do mesmo modo, é de suma importância a disponibilização e organização de dados por subsecções tutelares (públicas regionais, municipais e privados) e diferenciando as diferentes tipologias de museus, de outros espaços culturais, monumentos e sítios, a fim de melhor esclarecer a investigação científica.

\section{Discussão/Conclusão}

Na generalidade, o setor museológico tem evoluído a nível nacional, tendo a RAM vindo acompanhar esta evolução. Contudo, notamos que a realidade museológica, da RAM, está condicionada ou fortemente exposta ao setor do Turismo, determinada pela acentuada proporção de número de visitantes estrangeiros. Entre 2017 e 2018, as estatísticas oficiais, constatam um decréscimo do número de visitantes em museus nos quais uma grande maioria são estrangeiros. Importa continuar a ativar mecanismos de captação de novos públicos locais, envolvendo-os desde a génese das coleções ou da produção artística (Goes, 2020).

Apesar da nota que acompanha a estatística justificar "a quebra acentuada no número de visitantes" dever-se "fundamentalmente ao encerramento temporário do Museu da Quinta das Cruzes", importa realçar o porquê de os números globais de visitantes não terem sido compensados pela transferência, ou distribuição dos visitantes pela restante oferta museológica no tecido regional. Interessa ainda destacar o facto de o decréscimo do número de visitantes poder apenas se sustentar no facto do encerramento temporário de um museu, quando provavelmente não se apostou no reforço da oferta dos serviços educativos, com grupos escolares e outros públicos regionais. Destaca-se a forte dependência do número de visitantes estrangeiros, que com o devido cuidado poderemos considerá-los como turistas, provavelmente provenientes dos principais mercados emissores e nacionais.

O principal fundamento dos museus, preservação da memória e consciência da civilização, poderá estar subvertido pela distrofia do público visitante. Se o público alvo dos museus, deve ser as comunidades no qual está inserido e tendo como tarefa a sensibilização das futuras gerações - educação não formal - para a história, a arte e a preservação do património, ao subverter uma lógica memorialista, em prol da atratividade turística, estaremos não só a limitar o campo de ação, como a determinar provavelmente a qualidade da oferta e subordinando-a a mecanismos de atração turística.

Ainda mais que num contexto do aumento do investimento público regional e municipal - 2017 para 2018 - nas áreas da Cultura, será de refletir sobre a estranheza dos resultados, manifestamente inferiores, quer no número de visitantes de museus, como já vimos, quer em outros indicadores, nomeadamente na diminuição do número de exposições, podendo servir para outro estudo.

Se a partir de 2017, data dos melhores resultado no turismo na Região Autónoma da Madeira, temos vindo a registar um decrescimento dos fluxos turísticos, até à data, importará refletir para futuro sobre a necessidade de uma estratégia para o sector, na especificidade dos museus, que clarifique, quais os reais propósitos do decisor público, para a existência de um museu, e seja consequente com a necessidade de criar mecanismos de atração e promoção junto do seu público alvo: residentes, públicos escolares e turistas.

Este artigo propôs-se a levantar hipóteses e apresentar uma análise dos dados estatísticos disponíveis correlacionando-os. Existiu uma impossibilidade de estabelecer uma relação direta e objetiva com base nos dados disponíveis e pela amostra estatística e pelo facto de não ter sido realizado outro estudo específico sobre o efeito.

Se é certo que importa trabalhar conjuntamente, diversificando os públicos e contribuir para um conhecimento universal, e para a sua partilha no contexto global, importa que, sem pretender uma sedução do espetador, se determine a oferta museológica à promoção turística e por conseguinte ao modo como esta oferta é "vendida" ou apresentada no exterior. De acordo com Goes (2020), "Tenhamos a capacidade de acrescentar à memória e assim atualizarmos o discurso estético, conferindo-lhe uma dimensão global e só assim deste modo, talvez consigamos preservá-lo”. Urge aprofundar as relações com as populações locais, que habitam o território onde estão inseridos os museus e abri-los à comunidade e verdadeiramente democratizar o acesso à Cultura".

Observa-se que o "público visitante" não pode ser analisado como um sujeito coletivo uniforme, nem como um corpo pluridisciplinar provido de uma pele plurilinguística ou de acesso a informação única, mas sim, tendo em conta cada que sujeito-espectador tem uma especificidade cultural e geográfica própria, valorizando o carácter humano da mesma, nas suas diferentes motivações, interesses e expectativas (Davis \& Verlag, 2018).

A recolha e disponibilização dos dados, enquanto segmentados em grandes grupos heterogéneos, poderá não ser suficiente para estudos mais aprofundados. 
Os Museus na Região Autónoma da Madeira, à semelhança dos situados em território continental, em espaço nacional, são:

“(...) fortemente condicionados (...) um tardio e incipiente desenvolvimento da ciência e indústria nacionais, que entravou a constituição de instituições museológicas durante um longo período de tempo, e a permeabilidade à influência das tendências europeias e internacionais (...).” (Delicado, 2006).

Apesar do aumento do número de museus desde há várias épocas e ao progressivo crescimento do número de visitantes, a frequência destes espaços fica aquém das expectativas e do potencial económico gerado, distando dos seus congéneres a nível nacional e internacional. Na Madeira, como no caso nacional, "... face às baixas taxas de frequência pelo público destes equipamentos, ficam por aferir os reais impactos sociais que este forte investimento na promoção da cultura científica tem provocado" (Delicado, 2006).

Em anteriores estudos, apontava-se que "a população madeirense continuava pouco sensibilizada para a arte e para a cultura, sendo que os museus continuavam a ser visitados, preferencialmente, por turistas, que constituíam cerca de $98 \%$ de visitantes" (Silva, 2003). Volvida mais de uma década, através dos dados disponibilizados pelo presente estudo, foi possível constatar um crescimento da atividade na RAM, sendo que em 2018, apresentou um número global de 211171 visitantes (figura 2). Já em relação aos visitantes estrangeiros - que podem não representar o universo dos turistas nos museus - segundo o Instituto Nacional de Estatística - representavam em 2018, 63\% do universo de visitantes (figura 4).

Verifica-se que o aumento de visitantes nos museus da RAM, está influenciado pelo aumento dos visitantes estrangeiros na Madeira, mas não só, pois a sua proporção diminui de $98 \%$ no ano 2000 (Silva, 2003) para 63\% no ano 2018.

Não obstante o notório aumento de visitantes, é necessário equacionar o aumento da oferta museológica disponível. No entanto, permanecem as mesmas dificuldades na captação de novos públicos, ficando aquém do potencial social, cultural e económico gerado em torno dos museus.

Potenciar o aumento de públicos para os museus somente será possível com uma operação contínua de experiências pessoais diferenciadas e de uma programação que acompanhe as necessidades de transformação constante e de adequação dos públicos. O trabalho de mediação cultural relacionado com os serviços educativos dos museus, a atualização de informação e digitalização da mesma, a formação contínua de agentes turísticos e guias-intérpretes desempenham um papel fundamental na dotação e transmissão de conhecimento aos espectadores.

A atratividade dos museus, depende da programação, da atualização discursos museográficos e da capacidade de comunicabilidade. No caso da RAM, à semelhança do caso Português, são fatores decisivos para a afluência de mais públicos.

Independentemente da sua execução, está definido no Documento de Orientação Estratégica Regional, (2018), uma estratégia articulada assente em cinco premissas, que propõe minimizar os aspetos negativos supracitados, tendo como horizonte o ano de 2020. Salienta-se os seguintes aspetos: promover a utilização das tecnologias de informação e de comunicação (TIC) como instrumento de um marketing; estimular as parcerias com diversos agentes culturais; incrementar políticas de conservação, investigação, restauro e divulgação; apostar na rentabilização dos conteúdos culturais; fomentar a investigação científica.

A análise dos dados disponíveis permitiu verificar um aumento ainda que pouco acentuado dos visitantes dos grupos escolares, sendo que no ano de 2017 foram 33796 visitantes, o que corresponde à percentagem de $13 \%$ dos visitantes globais, com ligeira inversão no número de visitantes dos grupos escolares em 2018, com um total de 28868 visitantes. A par desta evolução, é possível verificar uma evolução no trabalho, dos serviços educativos e de divulgação que tem sido expressa numa progressiva ligação das instituições à comunidade em que se insere, deduzindo-se uma relação entre estes.

A falta de sensibilização dos madeirenses pela cultura, à imagem dos restantes portugueses, é uma realidade que tenta ser contrariada pelos responsáveis dos museus que começam a tentar encontrar novas formas de persuasão da população procurando desmistificar a ideia de um "Museu fechado" exclusivo de uma elite intelectual e turistas (Silva, 2003).

O museu tem na sua missão, como objeto e desígnio, o papel da responsabilidade social, e deste modo deve atuar junto da comunidade em que se insere, possibilitando que esta a reconheça como sua pertença e dele usufrua. É neste contexto que se apresenta como hipótese, o turismo como fator de diálogo, e o estabelecimento de novas relações entre públicos e sinergias entre instituições, entre agentes culturais e económicos, mas sempre envolvendo a comunidade local e os turistas. 
Herreman (2000) citado por (Silva, 2003) "O Turismo é precisamente um dos movimentos mundiais que sacudiu os fundamentos do museu e outras instituições culturais. (...) desenvolveu-se paralelamente ao modelo de consumo da atual sociedade moderna para tornar-se (...) um maior fator económico cultural e social, específico do final do II milénio".

Apesar de o turismo e museus contemplarem diferentes objetivos e metodologias, ambos "são hoje conceitos interdependentes em diversas áreas, existindo, no entanto, diferenças substanciais entre estas práticas, assim como alguns riscos, nomeadamente ao nível da sustentabilidade" (Serra e Carvalho, 2010). Recomenda-se um acompanhamento através de investigação científica, nomeadamente no estudo dos públicos, como acontece nos Museus Nacionais. Pretende-se limitar os impactos negativos do turismo nas opções museológicas e nas práticas de gestão em museus.

Constatou-se, no período em estudo, um aumento do fluxo turístico tendencial até 2017, verificando-se uma quebra em 2018, ficando por demonstrar a relação direta na afluência de visitantes aos museus. Por antítese, os dados disponíveis permitem-nos aferir que a frequência de público escolar [(13,6\% em 2018 do total de visitantes (figura 5)] não interfere com relevância no aumento dos resultados globais de visitantes nos museus no espaço regional, considerando-se por isso que falta potenciar o papel dos serviços educativos e da mediação cultural, nomeadamente junto do público infantojuvenil.

Os museus poderão ser um "instrumento privilegiado de regeneração urbana em cidades históricas", (Silva \& Barranha, 2013). Contudo não se esgotam na pura reabilitação do edificado, mas na necessidade de implementação de práticas discursivas museológicas atualizadas e de uma programação envolvente com a comunidade, que com ela se identifique e por essa razão preserve a identidade do lugar (Moreno-Mendoza et al., 2020). Assim, a preservação da identidade do lugar habitado - museu - poderá permitir a inculturação de hábitos de lazer e desenvolvimento intelectual.

O sucesso de uma relação entre Turismo e Museus, envolvendo as comunidades nos projetos de conceção e programação, trará os ganhos pretendidos para uma sociedade, nomeadamente na Região Autónoma da Madeira, redimensionando-a num contexto Atlântico e global, onde a Cultura muito contribui para o desenvolvimento económico sustentável, o desenvolvimento social e humano, a coesão territorial e para a construção de uma sociedade mais justa, tolerante, inclusiva e solidária.

\section{Bibliografia}

Álvaro Siza Vieira | The Pritzker Architecture Prize. (2020). Retrieved February 17, 2020, from https:// www.pritzkerprize.com/laureates/1992

Associação Comercial e Industrial do Funchal, \& KPMG. (2014). Documento Estratégico para o Turismo na RAM (2015-2020). Retrieved from https://estrategia.turismodeportugal.pt/sites/default/files/ Doc_Estrategico_Turismo_RAM_0.pdf

Barañano. (2008). Métodos e Técnicas de Investigação em Gestão. (Edições Sílabo, Ed.) (1ª Edição). Lisboa: Europress, Lda.

Brandolese, P. (1791). Le cose più notabili di Padova : principalmènte riguardo alle belle arti. Padoa.

Carvalho, P. (2003). Património Cultural e Iniciativas de Desenvolvimento Local no Espaço Rural, (January 2003).

Museu Nacional dos Coches (2020). Retrieved February 17, 2020, from http://museudoscoches.gov.pt/ $\mathrm{pt} / \mathrm{museu} /$

Cruz, F. (2012). Encontro de Estudos Multidisciplinares em Cultura. In A esteticização e a espetacularização da cidade pós-moderna (Vol. 27). Salvador da Bahia.

Davis, C. \& Verlag, T. (2018). Davis, A . and Smeds , K . (Eds .) ( 2016 ). Visiting the Visitor : An Enquiry into the Visitor Business in Museums.

Decreto Legislativo Regional no 15/2017/M da Região Autónoma da Madeira - Assembleia Legislativa. Diário da República n. ${ }^{\circ}$ 109/2017, Série I de 2017-06-06 (2017). Retrieved August 23, 2019, from https://dre.pt/home/-/dre/107477153/details/maximized

Delicado, A. (2006). Os museus e a promoção da cultura científica em Portugal. Sociologia, Problemas e Práticas, 53-72. Retrieved from http://www.scielo.mec.pt/pdf/spp/n51/n51a04.pdf

Direção Regional de Estatística da Madeira (2019). Estatísticas do Turismo da Região Autónoma da Madeira Resultados Definitivos 2018. Direção Regional de Estatística da Madeira, Ed. Retrieved from https://estatistica.madeira.gov.pt/

Frambotto, P. (1656). Note, overo, Memorie del museo di Lodovico Moscardo. Padoa.

Gil, A. (2017). Como Elaborar Projetos de pesquisa. $6^{a}$ edição. São Paulo: E. Atlas, Ed. 
Goes, D. (2019). Cultura em tempos de engate. Retrieved August 26, 2019, from https://jornaleconomico. sapo.pt/noticias/cultura-em-tempos-de-engate- 476177

Goes, D. (2020). Barraca no presépio - O Jornal Económico. Retrieved February 17, 2020, from https:// jornaleconomico.sapo.pt/noticias/barraca-no-presepio-539730

Gonçalves, A. (2009a). As Comunidades Criativas, O Turismo E a Cultura, 11-18.

Gonçalves, A. (2009b). Museus e Turismo: que experiências? - breve reflexão. ICOM Portugal. Retrieved from www.icom-portugal.org

ICOM PORTUGAL (2014). Boletim ICOM Portugal. Série II, n. ${ }^{\circ}$ 1, out. Retrieved from http://icom-portugal.org/multimedia/documentos/201410_BoletimICOMPortugal.pdf

ICOM PORTUGAL (2019). Nova definição de Museu. Retrieved August 22, 2019, from http://icom-portugal.org/2019/08/16/nova-definicao-de-museu/

Instituto de Desenvolvimento Regional, I.-R. (2018). Documento de Orientação Estratégica Regional. Funchal. Retrieved from www.idr.madeira.gov.pt

Instituto Nacional de Estatística (2015). Conta Satélite da Cultura.

Instituto Nacional de Estatística, I. P. (2009). Inquérito aos museus - Documento Metodológico.

International Council of Museums Portugal (2015). Definição: Museu | ICOM Portugal. Retrieved August 12, 2019, from http://icom-portugal.org/2015/03/19/definicao-museu/

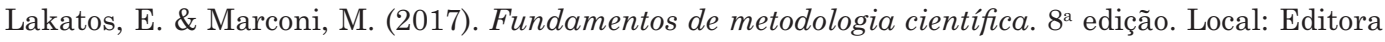
Atlas S. A.

Lei no 47/2004 da Assembleia da República. Diário da República n 195/2004 - Série I-A de 2004-08-19. (2004). Retrieved from https://dre.pt/pesquisa/-/search/480516/details/maximized

Lipovetsky, G. (2019). Ensaio sobre a sociedade da sedução. E. 70, Ed. Lisboa: Pentaedro, Lda.

Madeira, M. da (2020). Plataforma Online - Museus da Madeira. Retrieved February 17, 2020, from https://museus.madeira.gov.pt/Apresentacao

Marques, S. (2014). Museu de Comunidade e Experiência Turística Cultural e Criativa: o caso do Museu Agrícola de Riachos. Instituto Politécnico de Tomar.

Mello, A. (2019). Mercados em Números - Portugal. Mercados em Números. Lisboa. Retrieved from https://travelbi.turismodeportugal.pt/pt-pt/Documents/Mercados/Portugal/portugal-mercado-em-numeros-agosto-2019.pdf

Monge, M. (2018). Lei Quadros dos Museus e Descentralização. Que caminhos? Boletim ICOM Portugal, Série III, n. ${ }^{\circ}$ 11. Retrieved from https://issuu.com/icomportugal/docs/boletim_icom_portugal_11_fev_2018

Morais, I. A. de L. (2013). Quem são os turistas culturais dos museus? PASOS Revista de Turismo y Patrimonio Cultural, 11(1), 29-43. https://doi.org/10.25145/j.pasos.2013.11.001

Moreno-Mendoza, H., Santana-Talavera, A. \& Boza-Chirino, J. (2020). Perception of governance, value and satisfaction in museums from the point of view of visitors. Preservation-use and management model. Journal of Cultural Heritage, 41, 178-187. https://doi.org/10.1016/j.culher.2019.06.007

Museu de Arte, A. e T. (2020). Sobre | MAAT. Retrieved February 17, 2020, from https://www.maat.pt/ pt/art and architecture museum in lisbon

Neves, J. S., Santos, J. A. dos \& Nunes, J. S. (2008). Os museus em Portugal: políticas públicas e dinâmicas do sector em Portugal nos anos mais recentes. VI Congresso Português de Sociologia. Retrieved from http://historico.aps.pt/vicongresso/pdfs/768.pdf

Paulo Mendes da Rocha I The Pritzker Architecture Prize. (2020). Retrieved February 17, 2020, from https://www.pritzkerprize.com/laureates/2006

Ponzini, D., Ruoppila, S. \& Jones, Z. M. (2019). What difference does democratic local governance make? Guggenheim museum initiatives in Abu Dhabi and Helsinki. Environment and Planning C: Politics and Space, O(0), 1-19. https://doi.org/10.1177/2399654419857096

Portugal, I. (2018). Boletim ICOM Portugal. Série III Fevereiro $2018 N^{\circ}$ 11, 72. Retrieved from http:// icom-portugal.org/wp-content/uploads/2018/02/Boletim_ICOMPT_11_Fev_2018_site.pdf

Prodanov, C. C. \& Freitas, E. C. de. (2013). Metodologia do Trabalho Científico: Métodos e Técnicas de Pesquisa e do Trabalho Acadêmico. Universidade FEEVALE. https://doi.org/10.1017/ CBO9781107415324.004

Queiró, J. (2017). O Ensino Superior em Portugal. (F. F. M. dos Santos, Ed.) (1ª Edição). Lisboa.

Raposo, L. (2010). Uma viagem aos museus com paragem prolongada no Museu Nacional de Arqueologia. Retrieved August 28, 2019, from http://home.fa.utl.pt/ jaguiar/MIARQ/Luis RaposoAula3MIARQ.pdf Raposo, L. (2016). Boom turístico, estatísticas e museus. Ípsilon. 
Resolução do Conselho de Ministros da Presidência do Conselho de Ministros. Diário da República n. ${ }^{\circ}$ 94/2008, Série I de 2008-05-15. Retrieved February 13, 2020, from https://dre.pt/web/guest/pesquisa/-I search/249206/details/maximized

Santos, A. (2015). O Pincel é uma Arma. (Âncora, Ed.) (1ª edição). Porto.

Schlosser, J. \& Falguières, P. (2012). Les Cabinets d'Art et de Merveilles de la Renaissance Tardive: Une Contribuition à l'Histoire du Collectionnisme. (1st ed.). Paris: Éditions Macula.

Secretaria Regional da Economia Turismo e Cultura. (2016). Estratégia para o Turismo da Madeira 2017-2021. Secretaria Regional da Economia Turismo e Cultura.

Serra, P. \& Carvalho, P. (2010). Museus e Turismo. Dois casos de estudo (Caldas da Rainha e Óbidos) na Região Oeste de Portugal. In Investigação e Desenvolvimento Sócio-Cultural (actas).

Silva, R. \& Barranha, H. (2013). Museus na cidade: lisboa como exemplo. In Encontro Internacional Arquimemória.

Silva, S. (2003). Realidade Museológica no Arquipélago da Madeira - da génese à actualidade. Lusófona.

Thörn, C. (2011). Spotcity: a arte e a política do espaço público. Forum Sociológico, (21), 43-53. https:// doi.org/10.4000/sociologico.435

Turismo de Portugal. (2019). Estratégia Turismo 2027 Liderar o Turismo do futuro. Retrieved from https://www.turismodeportugal.pt/SiteCollectionDocuments/estrategia/estrategia-turismo-2027.pdf 


\section{ENOMEMÓRIAS \& ENOTURISMO O Património Secular do Vinho}

HISTÓRIA, TRADIÇÃO, IDENTIDADES

Eds.

Alberto Guerreiro António Maduro Eduardo Gonçalves Jorge Custódio

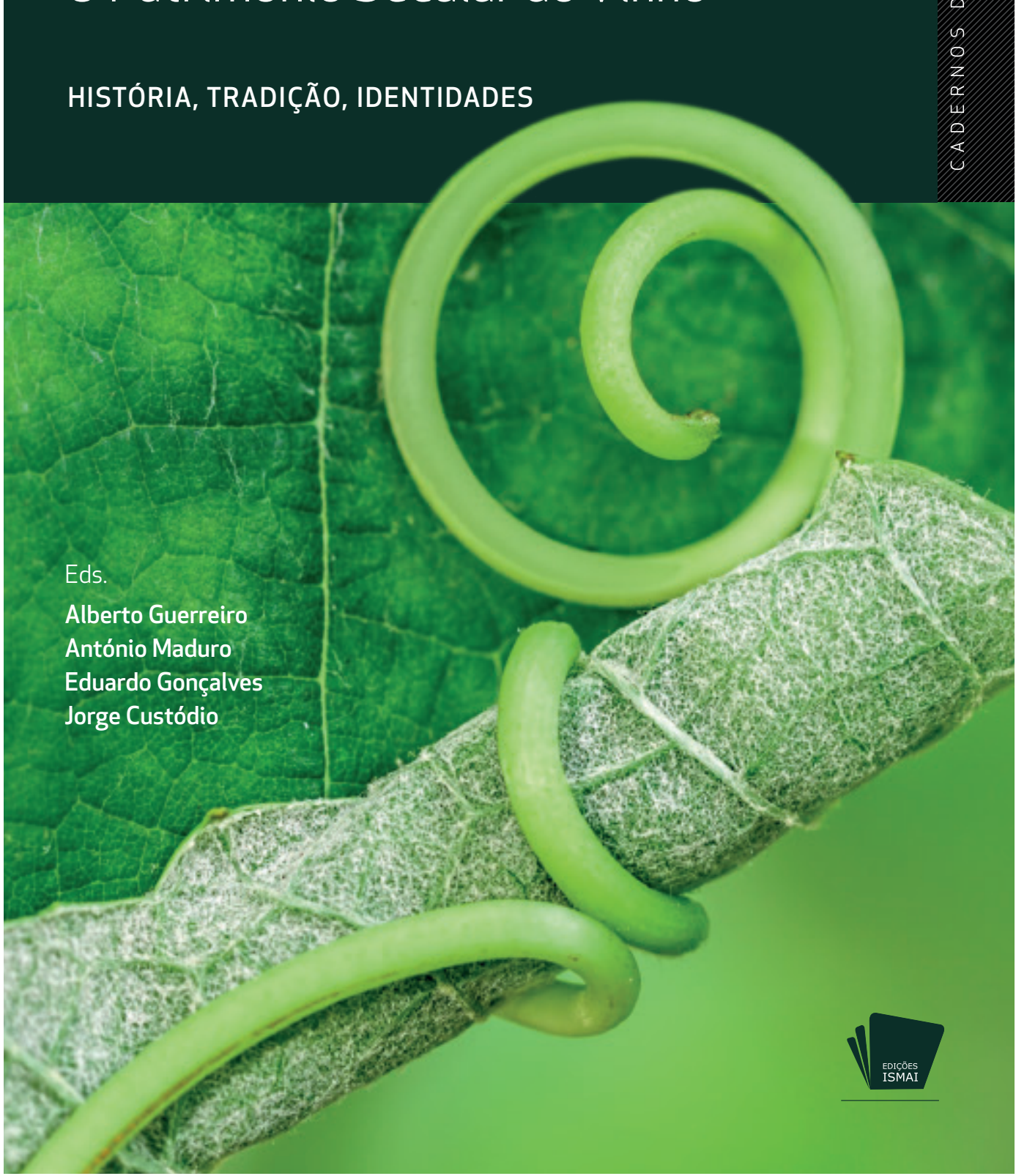




\title{
El valor social como factor estratégico en la gestión patrimonial y turística: el caso del sitio patrimonio de la humanidad Cueva de Altamira (España)
}

\author{
Eva Parga Dans* Pablo Alonso González** \\ Instituto de Productos Naturales y Agrobiología (IPNA-CSIC) (España) \\ Raimundo Otero Enríquez**** \\ Universidade da Coruña (España) \\ David Barreiro**** Felipe Criado Boado***** \\ Instituto de Ciencias del Patrimonio - Incipit-CSIC (España)
}

\begin{abstract}
Resumen: La dimensión social del valor se ha convertido en una piedra angular del debate sobre conservación, gestión y sostenibilidad turísticas en relación al patrimonio cultural. El presente artículo examina el papel del valor social en la gestión patrimonial y promoción turística a través del caso de la Cueva de Altamira como lugar Patrimonio de la Humanidad UNESCO mediante el análisis de las perspectivas de colectivos no expertos en la gestión del patrimonio. Para ello, se realizaron dos encuestas, una dirigida a visitantes (1047 cuestionarios válidos), y otra a la población española como comunidad anfitriona (1000 cuestionarios válidos). Los resultados muestran cómo estos agentes interpretan el valor de existencia, estético, económico y de legado de formas divergentes a la de los expertos, profundizando en la compleja relación entre la promoción y preservación patrimonial, y ampliando el debate sobre cómo el valor social puede contribuir a fortalecer la imagen internacional y nacional de los destinos patrimoniales ante el futuro incierto del mercado turístico global.
\end{abstract}

Palabras Clave: Valor social; Sitio Patrimonio de la Humanidad de Altamira; Turismo cultural; Preservación patrimonial; Perspectiva comunitaria; Destino turístico.

Social value as a strategic factor in heritage and tourist management: The case of the Altamira Cave World Heritage Site (Spain)

Abstract: The social dimension of value has become a cornerstone of the debate about tourism conservation, management and sustainability in relation to cultural heritage. This article examines the role of social value in heritage management and tourism promotion through the case of the Altamira Cave as a UNESCO World Heritage site by analysing the perspectives of non-expert actors in heritage management. To do this, two surveys were conducted, one aimed at visitors (1047 valid questionnaires) and the other at the Spanish population at large as the host community (1000 valid questionnaires). The results show how these agents interpret the existence, aesthetic, economic and legacy value in ways that differ from those of the experts, deepening the complex relationship between heritage promotion and preservation, and broadening the

Instituto de Productos Naturales y Agrobiología (IPNA-CSIC); E-mail: eva.parga.dans@ipna.csic.es; https://orcid.org/0000$-0002-0095-2963$

* Instituto de Productos Naturales y Agrobiología (IPNA-CSIC) (España); E-mail: pablo.alonso.gonzalez@ipna.csic.es; https://orcid.org/0000-0002-5964-0489

*** Universidade da Coruña (España); E-mail: raimundo.otero@udc.es; https://orcid.org/0000-0002-8074-3765

**** Instituto de Ciencias del Patrimonio - Incipit-CSIC (España); E-mail: david.barreiro@incipit.csic.es; http://orcid.org/0000$-0001-9963-1555$

***** Instituto de Ciencias del Patrimonio - Incipit-CSIC (España); E-mail: felipe.criado-boado@incipit.csic.es; https://orcid. org/0000-0003-4235-706X 
debate on how social value can contribute to strengthen the international and national image of heritage destinations in the face of the uncertain future of the global tourism market.

Keywords: Social value; Altamira World Heritage Site; Heritage tourism; Heritage preservation; Stakeholder perspective; Tourism destination.

\section{Introducción}

Con anterioridad a que la crisis del Covid-19 paralizase la actividad turística a nivel global, la literatura científica identificó el turismo cultural, y más específicamente el turismo patrimonial, como el segmento de más rápido crecimiento en el mercado turístico del siglo XXI (Prats, 2011). Las estadísticas de la Organización Mundial del Turismo así lo corroboran, estableciendo que cuatro de cada diez turistas eligen su destino de acuerdo a factores culturales, y estimando un aumento del turismo cultural en un 15\% a finales de siglo (OMT, 2018). El patrimonio cultural es un activo estratégico para el desarrollo económico, social y territorial, y la Comisión Europea llegó a declarar el Año Europeo del Patrimonio Cultural en 2018, haciendo hincapié en la necesidad de una agenda política para la gestión del patrimonio.

Desde las ciencias humanas y sociales se ha explorado ampliamente la controversia asociada a la gestión del patrimonio, es decir, a la necesidad de su preservación, conservación y/o protección a la vez que la de favorecer su difusión, promoción y disfrute (Parga Dans, 2019). Tradicionalmente, disciplinas como la historia, arqueología, derecho, economía, sociología y, más recientemente, los estudios de mercadotecnia, organizativos y de gestión, así como los estudios del patrimonio, se han centrado en este debate (Timothy, 2018, Alonso González, 2017, Parga Dans y Alonso González, 2020), adquiriendo mayor complejidad en elementos declarados Sitios Patrimonio de la Humanidad (en adelante SPH) por la UNESCO (Tucker y Carnegie, 2014). Los SPH se designan siguiendo una serie de directrices establecidas por la Convención del Patrimonio Mundial de la UNESCO, que atienden a diversos factores determinantes de la declaración de su valor universal excepcional mediante la evaluación de especialistas (Bertacchini, Liuzza, y Meskell, 2017). Tal reconocimiento funciona de manera similar a una marca de destino turístico, suponiendo un reclamo o atractivo turístico a nivel internacional (Ryan y Silvanto, 2010) y transformando el valor simbólico de estos espacios (Michelson y Paadam, 2016).

Sin embargo, el reconocimiento de un SPH en función de los antedichos criterios técnicos, puede no ser interpretada de la misma forma por otros grupos de interés que conviven en estos espacios, por ejemplo, la comunidad local y visitantes, ocasionando controversias en cuanto a su gestión (Parkinson, Scott, y Redmond, 2016). En este ámbito, la dimensión de valor social del patrimonio (en adelante VSP) adquiere especial relevancia. Recientemente, Jones ha definido el VSP como "el apego colectivo a un lugar, incorporando significados y valores que son importantes para una comunidad" (2017, p. 22). Desde esta perspectiva, el VSP se entiende como una dimensión dinámica en relación al apego colectivo, significado o valor que diferentes grupos de personas otorgan al patrimonio (Prats, 2003). El VSP no puede comprenderse como una categoría fija o estable, sino como un proceso que requiere el reconocimiento de las "ontologías múltiples del patrimonio", de las diferentes perspectivas que van más allá de las de los especialistas (Alonso González, 2016). Por tanto, la consideración del VSP como categoría analítica implica un desafío académico, pues requiere, además de su teorización, una puesta en práctica y una implementación (Díaz-Andreu, 2017).

Hasta la fecha, la investigación no ha dado cuenta de la controversia entre la conservación y la promoción turística desde la perspectiva del VSP en SPH. Por ello, el objetivo de este trabajo es caracterizar el VSP en Altamira, localizada en el municipio cántabro de Santillana del Mar (España) y declarada SPH en 1985, posteriormente ampliado a Cueva de Altamira y Arte Rupestre Paleolítico de la Cornisa Cantábrica en 2008. Este caso de estudio es paradigmático debido a la histórica controversia entre quienes defienden el cierre de la cueva a visitantes para asegurar su preservación futura, y los que apoyan su reapertura para su disfrute y explotación turística presente. Precisamente por ello, la Subdirección de Museos Estatales del Ministerio de Cultura de España, encargó al Instituto de Ciencias del Patrimonio (Incipit) del CSIC el Proyecto "Valor Social de Altamira". Este proyecto se realizó entre 2012 y 2014 como parte del "Programa de Investigación para la Conservación Preventiva y Régimen de Acceso de la Cueva de Altamira" coordinado por el IPCE, y sus resultados informaron la postura final del Ministerio sobre ese problema ${ }^{1}$. Esta polémica nos permite explorar la dimensión del VSP con respecto a la lógica de los SPH como destinos turísticos, realizando una contribución teórica y práctica 
para su gestión y avanzando en el conocimiento en este ámbito teórico en los estudios del turismo y el patrimonio. Para ello, realizamos dos encuestas, una dirigida a visitantes ( $\mathrm{n}=1047$ cuestionarios válidos) y otra a la población española como comunidad anfitriona de este SPH ( $\mathrm{n}=1000$ cuestionarios válidos). Ambos colectivos son considerados como no expertos en la toma de decisiones sobre patrimonio cultural. Los resultados muestran cómo estos agentes interpretan el VSP, profundizando en la compleja relación entre la promoción y preservación patrimonial, y ampliando el debate sobre cómo el valor social puede contribuir a fortalecer la imagen internacional y nacional de los destinos patrimoniales ante el futuro incierto del mercado turístico global.

\section{Marco teórico}

El rápido crecimiento del turismo en SPH a principios del siglo XXI es resultado de una compleja relación entre la oferta turística patrimonial y la interpretación de estos destinos por parte de la demanda (Poria, Reichel, y Cohen, 2013). Múltiples investigaciones han conectado esta relación con la cuestión de la gestión patrimonial (Bourdeau, Gravari-Barbas, y Robinson, 2018; Martín Ríos y Parga Dans, 2016a). La declaración de qué es patrimonio y qué no lo es representa la visión de ciertas élites y profesionales que poco tiene que ver con la visión de la mayoría de la población (González-Ruibal, Alonso González, y Criado-Boado, 2018; Parga Dans et al., 2016), esto es, una serie de criterios científicos, históricos o culturales establecidos por un grupo de especialistas dominantes en la toma de decisiones patrimoniales. Diversas investigaciones han mostrado, sin embargo, que la exclusión de otras partes interesadas en el proceso de patrimonialización puede generar un cuestionamiento del valor, autenticidad o apego colectivo a estos espacios (Benito Del Pozo y Alonso González, 2012), amenazando, incluso, su sostenibilidad a medio y largo plazo (Alonso González, Macías Vázquez, y Fernández Fernández, 2017; Martín Ríos y Parga Dans, 2016b).

El VSP adquiere, por tanto, relevancia analítica en el debate sobre la conservación y promoción patrimonial. El VSP no deriva de los atributos asignados a un sitio patrimonial, sino de la percepción de las diferentes partes interesadas (Jones, 2017). Carta de Burra (Icomos Australia, 1999 [1979]) reconocía la importancia de la dimensión social para la gestión patrimonial, entendida como la suma de los valores de varios grupos sociales, enfatizando que son las comunidades contemporáneas las que atribuyen significados y valores al patrimonio. Desde entonces, emerge una discusión en el área de los Estudios del Patrimonio sobre la necesidad de profundizar en el VSP (Araoz, 2011). Y aunque existe cierto consenso sobre la necesidad de implicar a diferentes colectivos en la gestión patrimonial, su implementación continúa siendo un desafío (Díaz-Andreu, 2017)

En el ámbito de los Estudios Turísticos la noción de valor asociado a SPH y marca de destino adquieren relevancia estratégica. Michelson y Paadam (2016) exploran cómo a través del valor simbólico del patrimonio se construyen marcas de destino turístico reforzadas por la actividad socioeconómica que se genera en los espacios urbanos en torno a este valor simbólico. Paralelamente, Chen y Chen (2010) evalúan la marca de destino patrimonial en relación a la calidad de la experiencia y los servicios turísticos ofrecidos a visitantes. Recientemente, Ramires et al. (2018) analizan el valor patrimonial en relación al gasto turístico, mientras Parga Dans y Alonso González (2017) evalúan el efecto multiplicador del gasto turístico en el PIB autonómico. Sin embargo, todas estas investigaciones divergen en sus conclusiones: algunos estudios refuerzan la relevancia estratégica de SPH como atractivo turístico (Carter, Jolliffe, y Baum, 2001); otros consideran dicho atractivo turístico exagerado (Hall y Piggin, 2002). Tal controversia ha conducido a una crítica estructural de la noción de valor universal como principio fundamental de los SPH, analizando las tensiones sociales que despierta la declaración de la UNESCO (Alonso González, 2017; Tucker y Carnegie, 2014).

De todo este debate teórico se desprende la necesidad de incorporar diversas aproximaciones disciplinares a casos de estudio específicos que aborden la percepción de diferentes colectivos para el establecimiento de una serie de pautas útiles respecto a la conservación, gestión y promoción de SPH (Jansen-Verbeke, 2016). La noción de VSP resulta fundamental para comprender el atractivo y la problemática inherente a SPH como marca de destino turístico. Para la construcción de una categoría analítica sobre VSP nos basamos en el enfoque iniciado por Goulding (2000), quien sustentó la autenticidad del patrimonio como construcción social mediante tres perfiles de visitantes: los buscadores de experiencia existencial, los que asocian autenticidad a estética, y los que persiguen una experiencia social. También retomamos el reciente estudio de Parga Dans y Alonso González (2019), quienes conceptualizan el apego colectivo a SPH a través de cuatro dimensiones del valor patrimonial: existencia, estética, economía y legado. Todas estas dimensiones configuran el VSP. 


\subsection{Valor de existencia}

El patrimonio cultural no es algo que posea un valor intrínseco o inherente (Poulios, 2010). Como enfatiza la Carta de Burra (Icomos Australia, 1999 [1979]), una gestión patrimonial sostenible debe comenzar por comprender su existencia. El reconocimiento de un lugar patrimonial por parte de diferentes agentes o colectivos, más allá de su declaración institucional, puede legitimar un interés social y un valor de existencia (Darvill, 1994) o un valor histórico (Mason y Avrami, 2002). El reconocimiento de la existencia de un lugar patrimonial implica una capacidad colectiva de atribuir significado o un valor a éste, justificando la necesidad de su gestión. El trabajo de Goulding (2000) caracteriza a un perfil de visitantes que buscan experiencias turísticas basadas en el valor de existencia, es decir, en el reconocimiento contemporáneo de la cultura material, el patrimonio y los objetos del pasado. De la misma forma, el trabajo de Parga Dans y Alonso González (2019) propone que el valor de existencia es el conjunto de percepciones, expectativas y conocimientos sobre un sitio específico a través de un colectivo no experto, incluidos visitantes y comunidades locales.

\subsection{Valor estético}

Una vez reconocido el valor de existencia del patrimonio es posible avanzar hacia su valor estético. La dimensión estética del patrimonio se asocia con la función simbólica del pasado en el presente (Parga Dans y Alonso González, 2019). En este sentido, Goulding (2000) explica el colectivo que valora el patrimonio cultural a través de la dimensión estética, busca experiencias turísticas contemporáneas basadas en la comprensión del pasado a través de las artes, la arquitectura o la artesanía. En este sentido, la dimensión estética del patrimonio se asocia con la autenticidad percibida (Viu, Fernández, y Caralt, 2008), buscando entender el presente mediante la cultura material, lugares y objetos de épocas anteriores.

\subsection{Valor económico}

La dimensión económica del patrimonio es controvertida, pues a la vez que es reconocida como factor estratégico para el desarrollo territorial presenta desafíos con respecto a su conservación y sostenibilidad (Mason y Avrami, 2002). Específicamente, el valor económico de SPH ha sido abordado desde diferentes puntos de vista, atendiendo a su impacto directo e indirecto en el PIB regional (Parga Dans y Alonso González, 2017), o mediante el nivel de satisfacción de los servicios turísticos en relación con el gasto turístico (Chen y Chen, 2010). En términos generales, los estudios que abordan el valor económico del patrimonio muestran el potencial de su promoción, pero también cuestionan la dimensión cuantitativa, pues es necesaria ponerla en relación con la sostenibilidad turística del espacio patrimonial (Parga Dans y Alonso González, 2019).

\subsection{Valor de legado}

Dado que el patrimonio cultural tiene un valor de existencia (se reconoce como tal) y un valor estético o artístico (suscita percepciones sensoriales o simbólicas sobre el pasado en el presente), y se considera un recurso (genera gastos e ingresos), es probable que se planteen modelos de gestión para su preservación futura o de legado (Graham, Ashworth, y Tunbridge, 2016). Por tanto, la necesidad de equilibrar la relación entre conservación y promoción patrimonial en el presente para el futuro hace referencia al valor de legado. Aunque la capacidad de preservar la herencia patrimonial ha sido abordada en múltiples sociedades, períodos y culturas, la cuestión de quién o qué colectivos deberían tener la potestad en la toma de decisiones sobre SPH y para quién, continúa siendo fuente de controversia (ICOMOS, 2019).

\section{Metodología}

\subsection{Contexto de investigación}

La Cueva de Altamira se descubrió fortuitamente en 1868. Desde entonces comenzó un debate científico y social acerca de su autenticidad, cuestionada en el ámbito académico durante décadas. En 1902, un estudio francés confirmó la autenticidad de las pinturas y su origen prehistórico (Cartailhac, 1902). Los resultados de esta investigación posicionaron a Altamira como lugar único y emblemático del patrimonio cultural, arqueológico, e histórico del Paleolítico Superior; un icono mundial para comprender el origen de la humanidad y el arte con pinturas y grabados de más de 15.000 años. Durante los 70, Altamira se convirtió en un importante destino turístico que atraía más de 150.000 visitantes al año. La excelente calidad y estado de las pinturas hace que esta cueva sea considerada una obra maestra de la humanidad, también conocida como la "Capilla Sixtina del arte rupestre europeo" (Schabereiter-Gurtner, Saiz-Jimenez, Piñar, Lubitz, y Rölleke, 2002). Sin embargo, la elevada afluencia de visitantes abrió un debate sobre la necesidad de implementar un programa de conservación. 
La cueva se cerró temporalmente en 1977, tras una alerta de elevados niveles de $\mathrm{CO}^{2}$ por parte de la comunidad científica que amenazaba el paulatino deterioro de las pinturas a causa de las más de 4.000 visitas diarias. En 1979 el Ministerio de Cultura asumió la gestión de la cueva, reabriéndola en 1982 con un cupo de 11.300 visitas al año. Este límite de acceso derivó en una larga lista de espera que alcanzó los tres años. En el año 2001, los Reyes de España inauguraron el Museo y la "Neo-cueva" (una réplica a escala real de la cueva), permitiendo una forma alternativa de acceso a este SPH. En 2002 la cueva se cerró nuevamente al público tras la aparición de una serie de microorganismos en las pinturas similares a los encontrados en la cueva de Lascaux, Francia. Pese al cierre de la cueva, el Museo y la "Neo-cueva" lograron atraer un promedio de 250.000 visitas anuales durante el período 2002-2019, siendo el segundo museo público más visitado en España y un impulsor estratégico para el desarrollo regional cántabro.

A pesar del estado aparente de equilibrio entre la conservación patrimonial y la promoción turística de Altamira, el debate sobre la reapertura de la cueva no está resuelto (Barreiro et al., 2018). Diferentes posturas continúan enfrentadas, entre las que se encuentran el discurso científico y técnico que alerta sobre el impacto de la presencia humana en la conservación de las pinturas, frente al discurso empresarial, político y social de la localidad de Santillana del Mar, quienes reclaman un rol activo en la toma de decisiones sobre la gestión de este SPH, así como su promoción (Barreiro y Criado-Boado, 2015). Esta controversia llevó al gobierno español a sentar las bases científicas de un programa que garantizase la conservación adecuada de la cueva y un régimen de acceso a visitantes.

En 2012 se puso en marcha el Programa de Investigación para la Conservación Preventiva y Régimen de Acceso a la Cueva de Altamira impulsado desde la Secretaría de Estado de Cultura del Ministerio de Educación, Cultura y Deporte, previo acuerdo del Patronato del Museo de Altamira. Dicho Programa se emprende con el objetivo de determinar el impacto que la presencia humana tiene sobre la conservación de las pinturas de la cueva, y decidir si es compatible un régimen de visitas con una adecuada conservación. La originalidad de esta iniciativa es que contempla, por primera vez, un estudio sobre el VSP, incorporando a un equipo de especialistas en el ámbito de la sociología y la antropología. En él, las ciencias sociales desempeñan un papel estratégico en la valorización y gestión patrimonial mediante la incorporación de otros colectivos en el proceso de toma de decisiones. El presente manuscrito presenta los resultados de la investigación sobre VSP en SPH, con el objeto de facilitar el desarrollo de directrices políticas y recomendaciones para resolver la histórica controversia de la gestión de Altamira.

\subsection{Recopilación de datos}

La recopilación de datos implicó la realización de dos encuestas dirigidas a diferentes colectivos no expertos (a los visitantes de Altamira, y otra al conjunto de la población española), lo cual resulta especialmente útil para abordar la multidimensionalidad del VSP en Altamira como SPH. La encuesta a visitantes incluye un total de 35 preguntas/variables distribuidas en cuatro bloques temáticos que identifican el VSP: (1) el valor de existencia (expectativas y motivaciones previas al viaje); (2) el valor estético (impacto sensorial-artístico del destino, su evaluación y satisfacción derivada); (3) el valor económico (información del viaje y gasto de los visitantes); (4) y el valor de legado (opiniones, actitudes y comportamientos de los visitantes respecto a la promoción-preservación de Altamira). Por último, el cuestionario incorpora una serie de variables destinadas a identificar el perfil sociodemográfico de visitantes. La encuesta fue realizada in situ en la salida del museo de Altamira y dirigida a una muestra aleatoria simple, teniendo en cuenta el número total de visitantes del año 2013 (239.829), estratificada por género y edad (con un nivel de confianza del 95\% y error del 3\%, cumpliéndose la condición de partida de que p=q=0,5). Dicha muestra alcanza un total de 1.047 encuestas válidas, que se realizan durante tres temporadas turísticas diferentes (alta, media y baja), entre junio de 2013 y febrero de 2014, de viernes a domingo.

Por otro lado, la encuesta dirigida a la población española incluye 28 preguntas/variables que aportan información sobre los cuatro sub-valores que configuran el valor social de Altamira: (1) de existencia (conocimiento y visibilidad de Altamira); (2) estético (impacto sensorial-artístico de Altamira); (3) económico y (4) de legado (opiniones acerca de la dicotomía apertura-cierre de la cueva, preferencias sobre la financiación y toma de decisiones sobre la gestión). Esta encuesta, de formato telefónico, se sustenta en una muestra no probabilística dirigida a la población española mayor de 18 años, formada por 1000 cuestionarios válidos realizados durante el período mayo-septiembre de 2014, de viernes a domingo. Dicha muestra se desglosa, a su vez, en cuotas proporcionales atendiendo al volumen de población tanto de la Comunidad Autónoma de Cantabria (donde se encuentra Altamira), como de las siete Nomenclaturas de las Unidades Territoriales Estadísticas (en adelante NUTS) que abarcan el conjunto del territorio español, y diseñadas por la Unión Europea con fines estadísticos (Figura 1). 
Estas divisiones geográficas son fundamentales a la hora de evaluar si la proximidad residencial a un $\mathrm{SPH}$ altera las desviaciones respecto de los resultados generales de la encuesta.

\section{Figura 1: NUTS españolas y Comunidad Autónoma de Cantabria.}

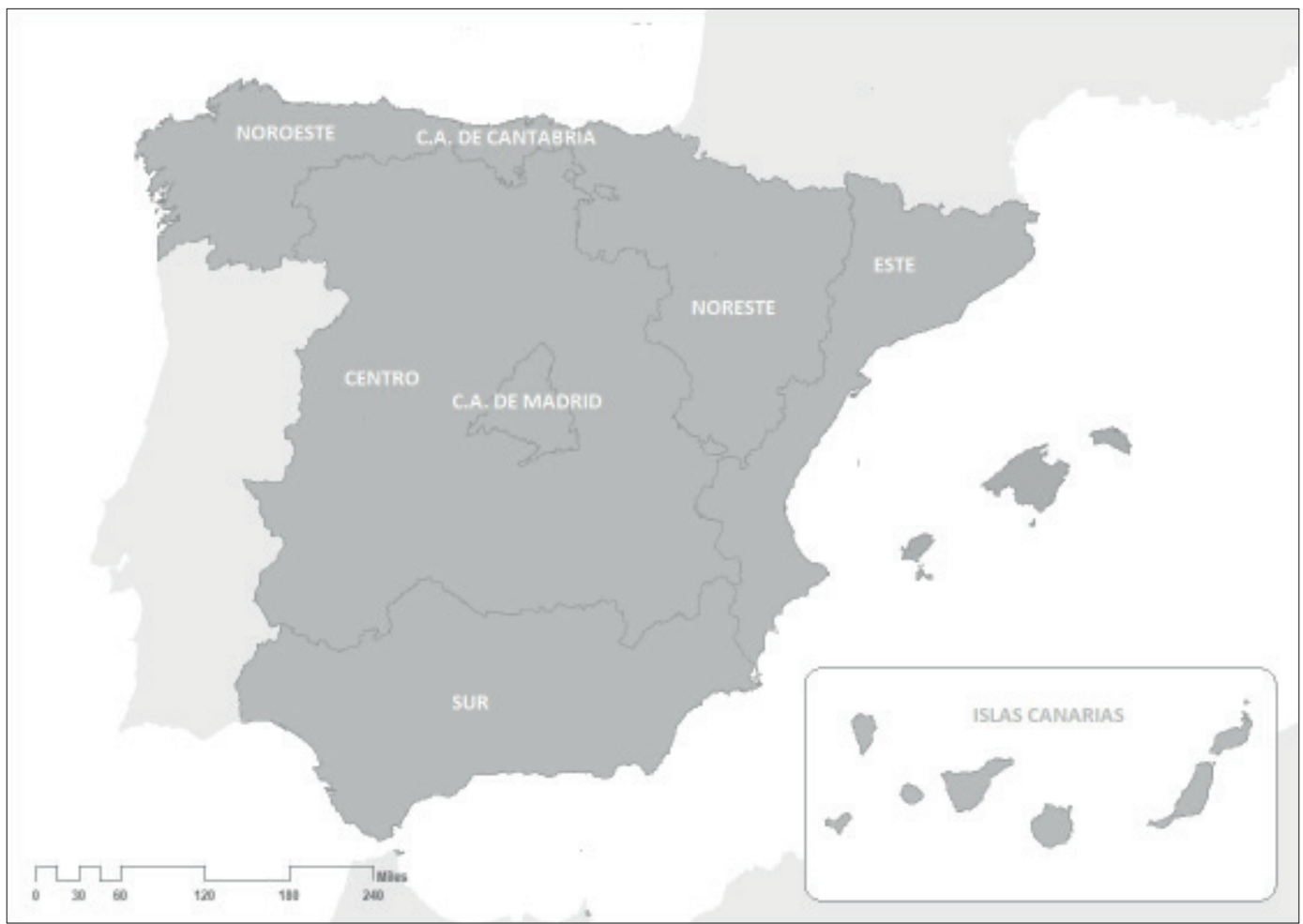

Fuente: Elaboración propia.

\subsection{Análisis de los datos}

El VSP se categoriza en la presente investigación a través del sub-valor de existencia, estético, económico y de legado, los cuales a su vez se categorizan mediante una variable específica o demostrativa de cada uno de los bloques temáticos diseñados con esta finalidad. Posteriormente, cada una de las dimensiones del VSP ha sido cruzada con variables sociodemográficas (género, edad, nivel educativo, situación laboral y tipo de ocupación) y geográficas (NUTS). Específicamente, aplicamos un análisis simple de correspondencias (en adelante ACS), o un análisis de componentes principales categórico (en adelante CATPCA) para el sub-valor de existencia, estético y de legado, teniendo en cuenta que la mayor parte de las variables de referencia son categóricas. Ambas técnicas, además de identificar correspondencias entre diversas variables, permiten desarrollar una interpretación visual de dicha correlación. Para ello, realizamos un mapa perceptual o gráfico de dispersión de dos dimensiones, siempre partiendo de variables sociodemográficas y geográficas que mostrasen una correspondencia significativa con respecto a la variable de contraste seleccionada para representar cada uno de los sub-valores (atendiendo al valor de $\chi^{2}$ y nivel de significación asociado al valor de la prueba p. $<0,01$, o p.< 0,05). De esta forma, aumentamos el porcentaje de varianza explicada o el valor de la inercia, concentrándose éstos fundamentalmente en la primera dimensión del mapa perceptual y estableciendo relaciones explicativas entre categorías de variables (Joaristi y Lizasoain Hernández, 2000; Santa-Cruz y López-Guzmán, 2017).

Finalmente, realizamos un análisis de varianza de un factor (en adelante ANOVA) aplicado al sub-valor de legado, con el objetivo de profundizar en la capacidad explicativa del discurso museístico de 
Altamira a la hora de transmitir la problemática en torno a la gestión de este SPH. La técnica ANOVA ha sido frecuentemente aplicada en contextos patrimoniales (e.g., Ramires et al., 2018), para identificar diferencias significativas entre las medias de una variable dependiente cuantitativa y variables independientes cualitativas o categorías de un factor (Hair, Black, Babin, y Anderson, 2010). Específicamente, contrastamos de qué manera los niveles de satisfacción de la vista a Altamira (variable de escala) son significativamente diferentes, en función de dos variables independientes que representan el sub-valor de legado: por un lado, el grado de aceptación de cerrar la cueva para mantener su conservación futura; y, por otro, la capacidad educativa del museo para explicar por qué la cueva está cerrada.

Además, para cada ANOVA realizado, los supuestos estadísticos de homocedasticidad y normalidad se evaluaron mediante la prueba post-hoc de Games-Howell y de Kolmogorov-Smirnov, descartando la igualdad de las varianzas, e ilustrando la significatividad de la relación entre las diferencias de las medias (Hair et al., 2010). En cuanto al sub-valor económico, desarrollamos un estudio específico para evaluar el impacto económico de Altamira sobre el PIB cántabro a partir del gasto de los visitantes, obtenido mediante la síntesis de dos variables descriptivas numéricas: la duración promedio de la estancia en la región cántabra y el gasto medio de la visita a Altamira.

\section{Resultados y discusión}

\subsection{Valor de existencia}

La importancia contemporánea de Altamira tanto para el público visitante como para la población española, muestra el valor de existencia de este SPH. Primero, el complejo museístico de Altamira consigue atraer a un número significativo de visitantes en el presente, a pesar del cierre de la cueva. De hecho, tras la apertura de la "Neo-Cueva" y el Museo en el año 2001, Altamira alcanzó un promedio de 250.000 visitas anuales, superando la cifra histórica de 174.000 visitas a la cueva original registrada en 1973 (Figura 2). Desde entonces, Altamira se posiciona como el segundo museo público más visitado de España, suponiendo un factor estratégico de atracción turística para Cantabria y España (LPPM, 2010).

Figura 2: Datos de visitantes de Altamira (1952-2019).

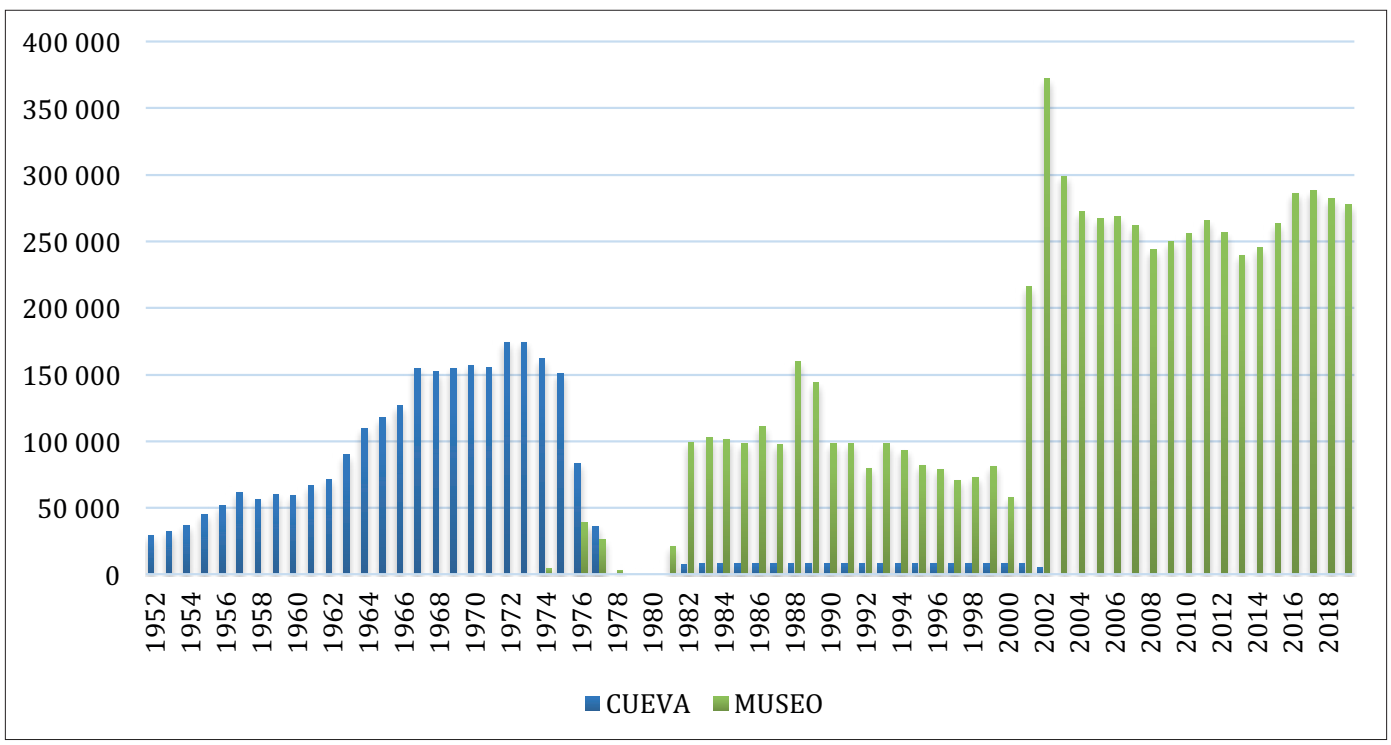

Fuente: Elaboración propia a partir del registro de visitantes del complejo museístico de Altamira.

Segundo, los resultados de la encuesta dirigida a visitantes corroboran el valor de existencia de Altamira en el presente. Así, Altamira es el principal determinante de la organización del viaje para el $60 \%$ del público visitante. Además, el $84 \%$ de los visitantes organizan su desplazamiento sin ninguna 
expectativa de poder acceder a la cueva original y, de éstos, el 71\% espera encontrar una buena réplica de la cueva mediante la visita a la "Neo-Cueva", mostrando un conocimiento sobre la situación actual de este SPH.

Tercero, los resultados de la encuesta a la población española muestran que el 83\% de las personas encuestadas conoce Altamira. Así, existe un amplio reconocimiento social de este SPH, atribuyéndole un valor de existencia y un poder para atraer turistas (Poulios, 2010). El alcance del valor de existencia se caracteriza de manera más precisa considerando las variables sociodemográficas de la población encuestada. El análisis de las variables de segmentación muestra que son las personas de entre 40 y 64 años (87.9\%), con estudios universitarios (94.6\%) y ocupaciones relacionadas con educación, artes, cultura o investigación (95.0\%) las que mayoritariamente afirman conocer la existencia de Altamira (Tabla 1).

Este análisis muestra que el nivel educativo discrimina significativamente los niveles más altos y más bajos de conocimiento sobre la existencia de Altamira $\left(\chi^{2}=123,087, p<.001\right)$. Específicamente, en comparación con el $94.6 \%$ de reconocimiento alcanzado por personas con educación universitaria, las de un nivel formativo inferior son las que en menor medida habían oído hablar de la cueva (un $62,1 \%$ manifestaron conocer la existencia de la cueva). Así, un nivel de educación superior implica un mayor valor de existencia, cuestionando el argumento de Petr (2009) sobre la importancia per se de la marca SPH como atractivo turístico. En Altamira podemos concluir que, a mayor nivel de formación y trabajo vinculado con la cultura, mayor conocimiento sobre la existencia del patrimonio.

Tabla 1: Tabla de contingencia (valor de existencia * variables de segmentación).

\begin{tabular}{|c|c|c|c|c|c|c|c|c|c|}
\hline \multicolumn{10}{|c|}{ ¿Ha oído hablar de la cueva de Altamira? } \\
\hline \multirow{2}{*}{\multicolumn{2}{|c|}{$\begin{array}{c}\text { Variables de segmentación } \\
\text { Recuento }\end{array}$}} & \multicolumn{2}{|c|}{ Sí } & \multicolumn{2}{|c|}{ No } & \multicolumn{2}{|c|}{ Total } & \multirow{2}{*}{\multicolumn{2}{|c|}{$\begin{array}{c}\text { Valor de } \\
\text { chi-cuadrado } \\
\text { y nivel } \\
\text { asociado de } \\
\text { significación }\end{array}$}} \\
\hline & & Recuento & $\begin{array}{l}\% \text { de } \\
\text { la fila }\end{array}$ & Recuento & $\begin{array}{l}\% \text { de } \\
\text { la fila }\end{array}$ & Recuento & $\begin{array}{l}\% \text { de } \\
\text { la fila }\end{array}$ & & \\
\hline \multirow{2}{*}{ Sexo } & Hombre & 406 & $84,2 \%$ & 76 & $15,8 \%$ & 482 & $100 \%$ & \multirow{2}{*}{1,165} & \multirow{2}{*}{,280 } \\
\hline & Mujer & 423 & $81,7 \%$ & 95 & $18,3 \%$ & 518 & $100 \%$ & & \\
\hline \multirow{3}{*}{$\begin{array}{l}\text { Edad en } \\
\text { grandes grupos }\end{array}$} & $18-39$ & 278 & $81,0 \%$ & 65 & $19,0 \%$ & 343 & $100 \%$ & \multirow{3}{*}{17,142} & \multirow{3}{*}{, 000} \\
\hline & $40-64$ & 392 & $87,9 \%$ & 54 & $12,1 \%$ & 446 & $100 \%$ & & \\
\hline & 65 o más & 159 & $75,4 \%$ & 52 & $24,6 \%$ & 211 & $100 \%$ & & \\
\hline \multirow{2}{*}{$\begin{array}{l}\text { ¿Su ocupación } \\
\text { actual tiene } \\
\text { alguna } \\
\text { relación con } \\
\text { la educación, } \\
\text { el arte, la } \\
\text { cultura o la } \\
\text { investigación? }\end{array}$} & Sí & 113 & $95,0 \%$ & 6 & $5,0 \%$ & 119 & $100 \%$ & \multirow{2}{*}{13,854} & \multirow{2}{*}{, 000} \\
\hline & No & 716 & $81,3 \%$ & 165 & $18,7 \%$ & 881 & $100 \%$ & & \\
\hline \multirow{4}{*}{$\begin{array}{l}\text { Nivel de } \\
\text { estudios } \\
\text { recodificado }\end{array}$} & $\begin{array}{l}\text { Sin estudios / } \\
\text { Primarios }\end{array}$ & 110 & $62,1 \%$ & 67 & $37,9 \%$ & 177 & $100 \%$ & \multirow{4}{*}{123,087} & \multirow{4}{*}{, 000} \\
\hline & ESO & 36 & $64,3 \%$ & 20 & $35,7 \%$ & 56 & $100 \%$ & & \\
\hline & Bachillerato / FP & 292 & $89,0 \%$ & 36 & $11,0 \%$ & 328 & $100 \%$ & & \\
\hline & $\begin{array}{l}\text { Universitario / } \\
\text { Superiores }\end{array}$ & 370 & $94,6 \%$ & 21 & $5,4 \%$ & 391 & $100 \%$ & & \\
\hline \multirow{4}{*}{$\begin{array}{l}\text { Situación } \\
\text { laboral } \\
\text { recodificada }\end{array}$} & Estudiantes & 33 & $84,6 \%$ & 6 & $15,4 \%$ & 39 & $100 \%$ & \multirow{4}{*}{6,211} & \multirow{4}{*}{,102 } \\
\hline & Ocupados/as & 428 & $87,3 \%$ & 62 & $12,7 \%$ & 490 & $100 \%$ & & \\
\hline & $\begin{array}{l}\text { Jubilados/as } \\
\text { - Pensionistas }\end{array}$ & 201 & $81,0 \%$ & 47 & $19,0 \%$ & 248 & $100 \%$ & & \\
\hline & Desempleados/as & 145 & $81,9 \%$ & 32 & $18,1 \%$ & 177 & $100 \%$ & & \\
\hline
\end{tabular}

Fuente: Elaboración propia. 
Delimitando la región Cántabra y las NUTS españolas, el valor de existencia de Altamira se ilustra desde una perspectiva territorial. Con la excepción de la NUT Islas Canarias (con un 53\% de respuestas afirmativas), más del 75\% de la población de las restantes NUTS afirma conocer la existencia de Altamira. Sobresalen Cantabria y las NUTS del centro peninsular y de Madrid, territorios que muestran porcentajes superiores al 90\%. La proximidad geográfica al complejo museístico de Altamira juega un papel importante en su reconocimiento, factor que explica que la correspondencia entre ambas variables sea significativa $\left(\chi^{2}=36,174 ; \mathrm{p}<.001\right)$.

El CATPCA proporciona una representación visual del comportamiento conjunto de las variables de segmentación y el reconocimiento de la existencia de Altamira. La figura 3 representa, por un lado, los segmentos de población cuyos centroides se aproximan a la categoría "nunca oí hablar de Altamira", los cuales se corresponden con la población mayor de 65 años, principalmente sin estudios o con formación primaria o secundaria, y residente en las Islas Canarias. Por otro lado, una gran cantidad de categorías sociodemográficas y áreas geográficas de España se agrupan en torno al "sí ha oído hablar de la Cueva", lo que demuestra, en síntesis, la fortaleza del valor de existencia de Altamira.

Figura 3: Gráfico de categorías conjuntas (valor de existencia - ¿Ha oído hablar de la cueva de Altamira? * variables de segmentación * unidades territoriales). Autovalor $($ Total $)=3,463 /$ Alfa de Cronbach $($ Total $)=0,871$. Autovalor $($ Dimensión 1) = 2,360 / Alfa de Cronbach $($ Dimensión 1) = 0,692.

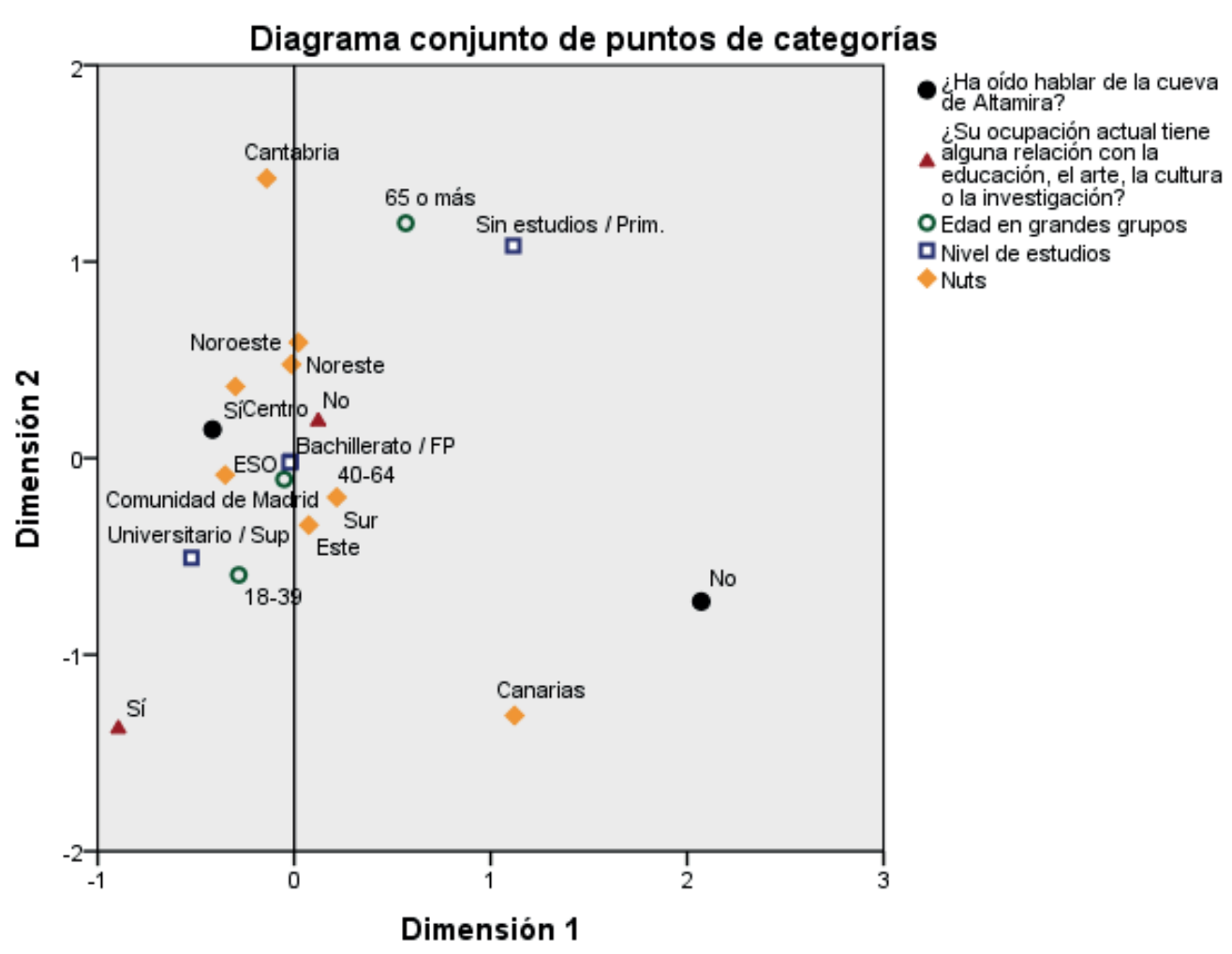

Normalización principal por variable.

Fuente: Elaboración propia.

Profundizando en el conocimiento de la población visitante sobre Altamira, los resultados de la encuesta permiten matizar algunas cuestiones sobre el valor de existencia. El 83,3\% de los visitantes 
afirman que Altamira es un lugar fundamental para comprender o aprender nociones sobre la prehistoria de la humanidad, a pesar de no poder acceder a la cueva y pinturas originales. La visita a Altamira, independientemente del perfil demográfico y procedencia territorial, también contribuye a apuntalar esta dimensión del valor. Más allá de esta generalidad, factores como la proximidad geográfica al complejo museístico y el nivel educativo de la persona juegan un papel decisivo en el reconocimiento de Altamira. Así, el reconocimiento del valor de existencia por parte de visitantes, población española y colectivo experto, quienes en 1985 declararon Altamira SPH, evidencia la importancia del debate social contemporáneo sobre la gestión de este lugar.

Específicamente, varios estudios han demostrado que la actividad turística generada por los SPH supone una oportunidad para aumentar la visibilidad y la demanda de un determinado destino en el mercado global del turismo patrimonial (Adie, Hall, y Prayag, 2017; Ramires et al., 2018). Nuestro estudio demuestra lo contrario: Altamira atrae en mayor medida el interés turístico nacional, puesto que el 86\% de los visitantes son población residente en España. Así, el valor de existencia por parte de la comunidad anfitriona puede ser un factor determinante para reforzar la imagen de los SPH, quienes, a su vez, pueden convertirse en comunidad visitante. Esta cuestión no ha sido investigada en profundidad, motivo por el cual nos parece esencial identificar vínculos de múltiples colectivos no expertos con los SPH.

\subsection{Valor estético}

En cuanto a la dimensión estética del valor, analizamos las percepciones contemporáneas sobre Altamira en relación con la función simbólica del pasado. En este sentido, los resultados de la encuesta muestran que más del 70\% de la población española considera que el elemento más importante de Altamira son las pinturas rupestres, en detrimento de otros factores como la declaración SPH (4,7\%), ser un destino de interés turístico (1,5\%), o una marca nacional o identitaria (1,5\%). Por tanto, además del reconocimiento contemporáneo de la existencia de Altamira por parte de sus visitantes y de la población española, observamos un proceso de atribución de significados vinculados a este lugar patrimonial en conexión con sus pinturas, lo cual configura su valor estético.

Como observamos con el valor de existencia, el reconocimiento del valor estético para la población española conocedora de la existencia de Altamira es muy elevado en todas las NUTS (superior al 68\% en todos los casos). Con la excepción de Cantabria (donde el 44,8\% de su población asume que Altamira tiene múltiples reclamos), el reconocimiento de las pinturas como único factor determinante de la importancia de Altamira no presenta disparidades geográficas, razón por la cual la correspondencia entre la variable geográfica y el valor estético no es significativa $(\chi 2=14,012, \mathrm{p}>0.05)$.

Atendiendo al cruce con las variables de segmentación sociodemográfica, el consenso sobre la importancia de las pinturas es determinante, superando valores por encima del $50 \%$ en todos los casos (Tabla 2). Por el contrario, la categoría de respuesta "ser SPH" como factor asociado a la importancia de Altamira obtiene un volumen de respuesta claramente inferior en todos los ítems contemplados (que, salvo en el caso de los estudiantes, no supera el $10 \%$ ). 
Tabla 2: Tabla de contingencia (valor de existencia * variables de segmentación).

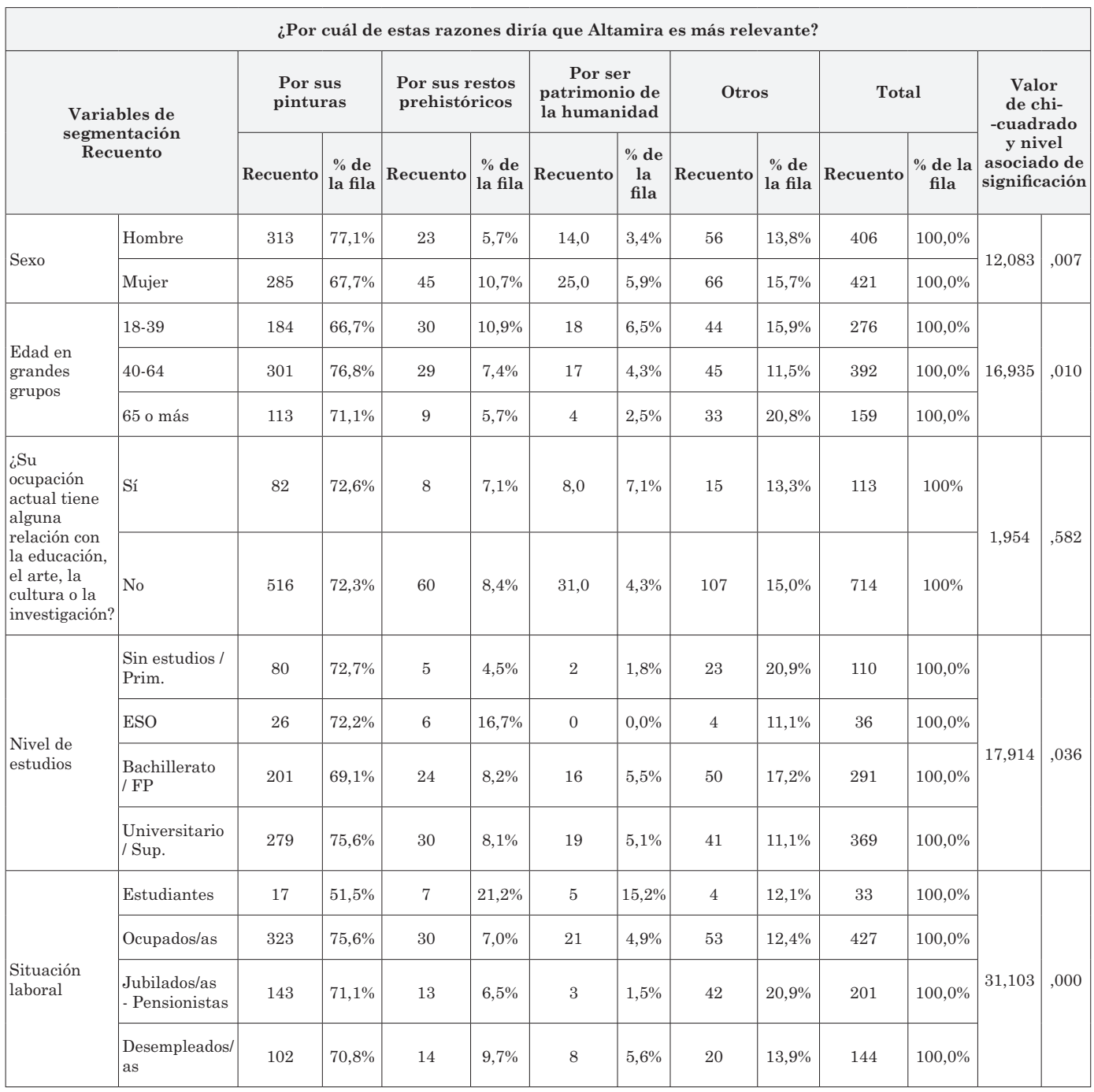

Fuente: Elaboración propia.

El CATPCA entre las variables de segmentación y de contraste (es decir, por qué Altamira es importante) discrimina en una primera dimensión un perfil sociodemográfico que asume claramente y aprecia la relevancia estética de las pinturas de Altamira. Dicho perfil se refiere a personas ocupadas con estudios universitarios o de bachillerato-FP, frente a otro que lo hace con menos intensidad, formado por personas jubiladas o pensionistas, de edad avanzada, sin estudios o con formación primaria (Figura 4). 
Figura 4: Gráfico de categorías conjuntas ("valor estético"- ¿Por cuál de estas razones diría que Altamira es más relevante? * variables de segmentación.

Autovalor $($ Total $)=3,701 /$ Alfa de Cronbach $($ Total $)=0,876$. Autovalor $($ Dimensión 1$)=2,392 /$ Alfa de Cronbach $($ Dimensión 1) $=0,698$.

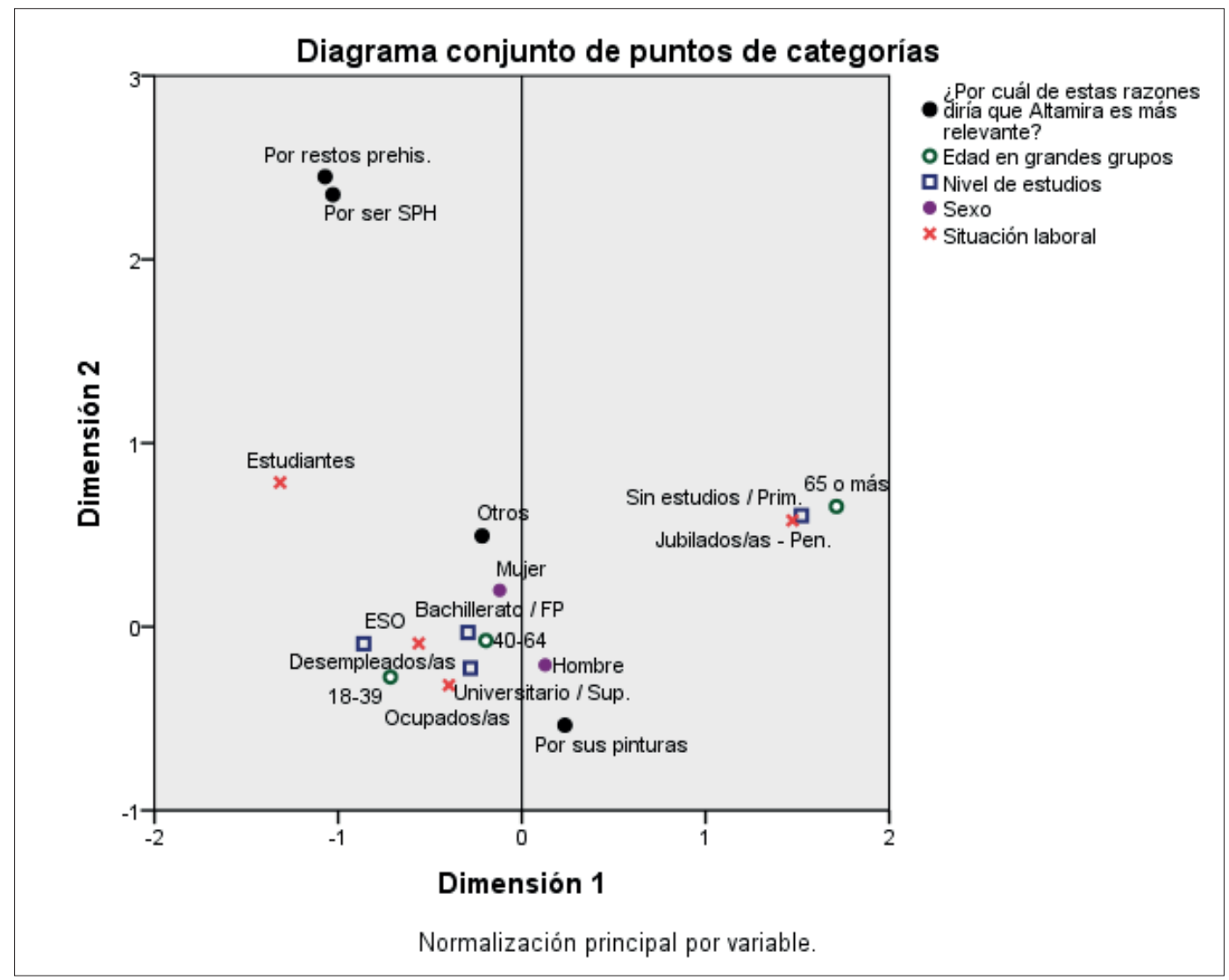

Fuente: Elaboración propia.

En definitiva, las percepciones estéticas de los visitantes resaltan la conexión entre el reconocimiento público de Altamira y sus pinturas prehistóricas. Al igual que ocurría con su valor de existencia, es el nivel educativo el que determina preferentemente el valor estético de Altamira: a mayores niveles de conocimiento y formación, más fácil resulta conectar el valor estético de las pinturas de Altamira con su importancia patrimonial, conexión que va más allá de la marca SPH. De hecho, los resultados de este estudio muestran que la declaración de Altamira como SPH no supone un factor determinante para visitantes o población local a la hora de construir la percepción contemporánea de este lugar, o al menos dicho factor está muy lejos de la capacidad atribuida a las pinturas. Esta asociación ocurre independientemente del perfil sociodemográfico de los visitantes y de la proximidad geográfica a Altamira para la población española.

Además, los resultados muestran un elevado nivel de satisfacción tras la visita a Altamira con 5,9 puntos de media en una escala del 1 al 7. Por lo tanto, la visita a la "Neo-Cueva" no merma el valor estético de Altamira, sobre todo entre el público visitante, quien tiene una comprensión consolidada de la importancia artística de las pinturas de Altamira, a pesar de no poder acceder a la versión original. Estos resultados relativizan el valor universal excepcional establecido por colectivos expertos a través de la declaración de SPH, coincidiendo en esta cuestión con el estudio de Tucker y Carnegie (2014). De hecho, a través de la comprensión de los factores que discriminan el valor estético o los sesgos perceptivos 
de actores no expertos, es posible evaluar la valoración social de este SPH, y los factores subyacentes que explican su capacidad de atracción como destino turístico y marca cultural.

\subsection{Valor económico}

El valor social de Altamira también está asociado con su valor económico. El complejo de Altamira atrae a un número significativo de visitantes y, por tanto, es un factor determinante a la hora de elegir Cantabria como destino turístico. En concreto, la duración media de la estancia de los visitantes de Altamira en esta región es de 4,6 noches, representando el 26\% de las pernoctaciones anuales en establecimientos turísticos cántabros (INE, 2013). Los costes relacionados con el alojamiento y la manutención representan la mayor parte del gasto total (63\%) de este colectivo. Igualmente, los gastos relacionados con el ocio, la cultura y el entretenimiento representan un $11 \%$ del total. En total, el gasto medio per cápita y por día es de 104,5 €. Estos datos han sido utilizados para estimar el impacto económico directo de Altamira en Cantabria, que asciende a $113 €$ millones en el año 2014. Esta cifra representó el 8,5\% del PIB turístico cántabro, y un 0,9\% del PIB total.

En definitiva, el gasto de la población visitante tiene un importante impacto en la economía regional $\mathrm{y}$, por tanto, el impacto generado por Altamira se traduce en una importante fuente de ingresos para la región cántabra y sus habitantes. A su vez, el valor económico está asociado claramente con la trascendencia sociocultural de este espacio patrimonial, lo que denota la necesidad de garantizar la conservación a largo plazo de la cueva, a la vez que promocionar de manera continua las visitas a este lugar. En este sentido, Altamira conforma un "imaginario cultural" y un "recurso operativo" para la dinamización de este espacio arqueológico, con implicaciones socioeconómicas para la comunidad local, siguiendo la terminología del estudio de Ross, Saxena, Correia y Deutz (2017).

\subsection{Valor de legado}

Las percepciones de los visitantes y la población española sobre la dimensión de legado, muestran que la cueva de Altamira es un activo patrimonial que debe preservarse para las generaciones futuras, cuestión ésta más importante que cualquier otra que incluya un posible escenario de reapertura. Primero, de la población española que conocía la existencia de la cueva (83\%), el 81,2\% también sabía que estaba cerrada al público. Igualmente, una amplia mayoría de las personas encuestadas (92,2\%) aceptan que la cueva permanezca cerrada para garantizar su conservación futura. Tercero, una mayoría de la población (55,3\%) también se muestra de acuerdo con el hecho de que su conservación futura sea costeada, impositivamente, por todos los españoles.

Asimismo, precisar que el conocimiento del cierre de la cueva al público es general en todas las NUTS españolas y en Cantabria, con porcentajes de respuestas afirmativas superiores al $87 \%$. Respecto al valor de legado, las disparidades territoriales no fueron lo suficientemente significativas como para alterar este alto grado de consenso $\left(\chi^{2}=6,031, \mathrm{p}>0.05\right)$. Así, la importancia del valor de legado es independiente de la región geográfica de residencia.

Además, se manifiesta un claro consenso entre la población encuestada sobre la necesidad de implementar medidas concretas de conservación para favorecer la sostenibilidad y gestión futura de la cueva de Altamira. Una mayoría significativa entiende que la cueva debería abrirse a "un número limitado de personas" (68,9\%), o acepta que debiera estar "cerrada al público" (17,4\%). Contrastando este valor de legado con los ítems de segmentación, aflora un amplio consenso alrededor de las actitudes/ categorías "proteccionistas" sobre el futuro de la cueva ("cerrada"/"abierta con límites"). Una variable destaca, nuevamente, sobre esta cuestión: el nivel educativo muestra una correspondencia claramente significativa con respecto al valor de legado. Así, la diferencia entre la formación de las personas encuestadas es la que determina la polaridad de opiniones sobre cómo preservar el «valor de legado" $\left(\chi^{2}=28,692 ; \mathrm{p}<.01\right)($ Tabla 3$)$. 
Tabla 3: Tabla de contingencia (valor de legado * variables
de segmentación). Fuente: elaboración propia.

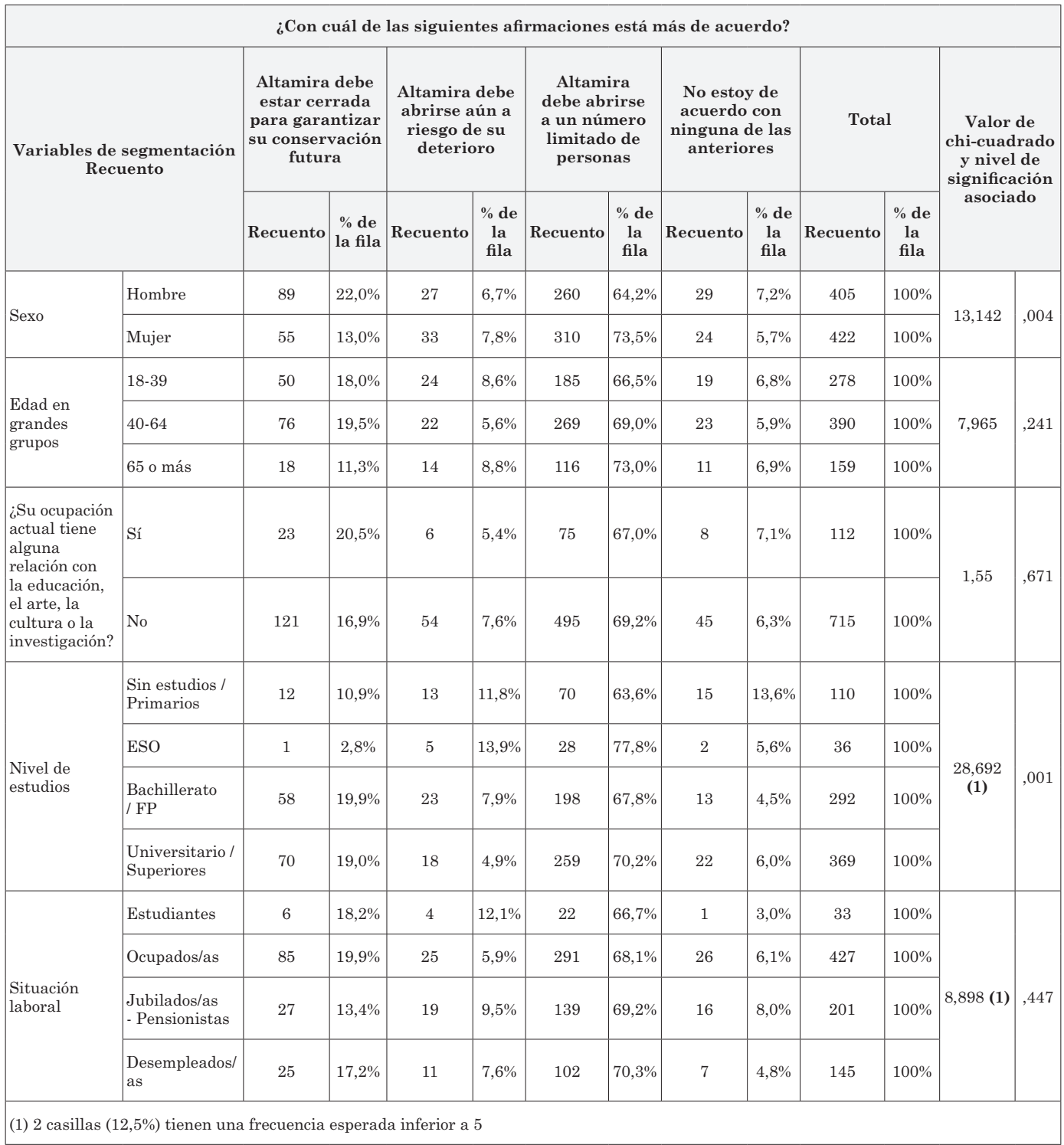

Examinando esta última evidencia mediante un ACS, se vuelve a constatar la importancia del nivel educativo de las personas encuestadas al evaluar la fortaleza del valor de legado. Por ejemplo, la mayor "intensidad proteccionista" se corresponde con un mayor nivel de educación, algo evidente a través del gráfico de dispersión (Figura 5). En éste se observa la proximidad espacial de los centroides de las categorías "Altamira tiene que estar cerrada" y la población con estudios "universitarios o superiores". 
Figura 5: Gráfico de categorías conjuntas ("valor de legado" * nivel de estudios). Inercia $($ Total $)=0,036$. Dimensión 1: inercia $=0,026$; proporción de inercia explicada $=0,741$.

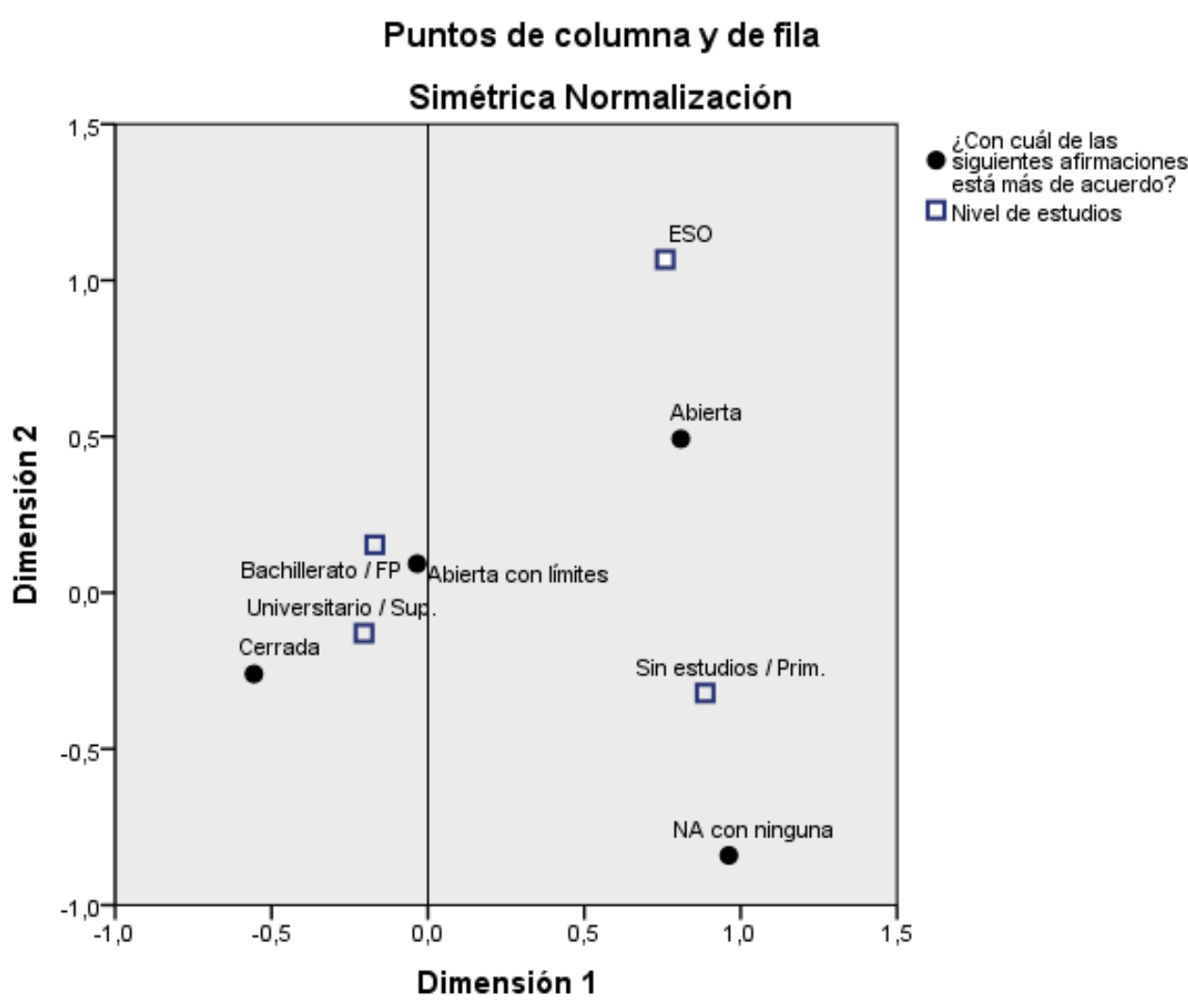

Fuente: Elaboración propia.

También podemos concluir que la aceptación del cierre de la cueva para garantizar su conservación futura fue muy elevada entre la población visitante. De hecho, el 63,8\% califica esta opción como "muy buena" y el 31,8\% como "buena". Es importante enfatizar que la mayoría de las personas visitantes que apoyan el cierre son también las más satisfechas con la "Neo-Cueva" y la visita al Museo. Tras la realización de un ANOVA, se observa la importancia del valor de legado entre el público visitante. Para una amplia mayoría, el cierre de la cueva no merma los grados de satisfacción con el conjunto museístico de Altamira; todo lo contrario, los incrementa y diferencia de modo significativo (Tabla 4). 
Tabla 4: Tabla de contingencia (valor de legado * variables de segmentación).

\begin{tabular}{|c|c|c|c|c|c|c|c|c|c|c|c|}
\hline \multirow[b]{2}{*}{$\begin{array}{l}\text { Variables } \\
\text { de } \\
\text { contraste }\end{array}$} & \multicolumn{6}{|c|}{$\begin{array}{c}\text { Motivos. Impresión que le produce: } \\
\text { Porque así se garantiza su conservación } \\
\text { futura }\end{array}$} & \multicolumn{2}{|c|}{ ANOVA } & \multicolumn{3}{|c|}{ Games-howell } \\
\hline & $\begin{array}{c}\text { Muy } \\
\text { mal } \\
(1)\end{array}$ & $\begin{array}{c}\text { Mal } \\
\text { (2) }\end{array}$ & $\begin{array}{c}\mathrm{Ni} \\
\text { bien } \\
\text { ni } \\
\text { mal } \\
(3) \\
\end{array}$ & Bien (4) & $\begin{array}{l}\text { Muy } \\
\text { bien } \\
(5)\end{array}$ & Total & $\mathbf{F}$ & Sig. & $\begin{array}{l}\text { Ejemplos de } \\
\text { relaciones } \\
\text { significativas }\end{array}$ & $\begin{array}{l}\text { Diferencia } \\
\text { de medias } \\
\text { (I-J) }\end{array}$ & Sig. $<0,01$ \\
\hline $\begin{array}{l}\text { Grado de } \\
\text { satisfacción } \\
\text { con la Neo- } \\
\text {-Cueva }\end{array}$ & 5,29 & 4,80 & 5,22 & 5,76 & 6,04 & 5,91 & 8,139 &, 000 & 4 у 5 &,- 283 & ,004 \\
\hline $\begin{array}{l}\text { Grado de } \\
\text { satisfacción } \\
\text { general con } \\
\text { respecto a } \\
\text { la visita al } \\
\text { Museo }\end{array}$ & 5,25 & 5,10 & 5,44 & 5,65 & 6,03 & 5,88 & 10,308 &, 000 & 4 y 5 &,- 384 & ,000 \\
\hline
\end{tabular}

Fuente: Elaboración propia.

Respecto a esta última evidencia, cabe señalar que la visita a Altamira es muy efectiva a la hora de reforzar el valor de legado mediante una experiencia de enseñanza-aprendizaje. De hecho, después de recorrer el museo, el $56,0 \%$ y el $24,5 \%$ de sus visitantes, respectivamente, entendieron "mucho" o "bastante" el porqué del cierre de la cueva. Además, tras la realización de un segundo ANOVA, se corrobora esta función didáctica del Museo en cuanto al valor de legado. Así, la mayoría de las personas que entendieron las razones por las cuales la cueva se encuentra cerrada, mostraron un grado de satisfacción con la visita al Museo y con la "Neo-Cueva" significativamente más alto que el de la minoría que no comprendió tales motivos (Tabla 5).

Tabla 5: Tabla de contingencia (valor de legado * variables de segmentación).

\begin{tabular}{|c|c|c|c|c|c|c|c|c|c|c|c|}
\hline \multirow{2}{*}{$\begin{array}{l}\text { Variables } \\
\text { de } \\
\text { contraste }\end{array}$} & \multicolumn{6}{|c|}{$\begin{array}{c}\text { Aumento de conocimientos: He aprendido } \\
\text { sobre la evolución humana }\end{array}$} & \multicolumn{2}{|c|}{ ANOVA } & \multicolumn{3}{|c|}{ Games-howell } \\
\hline & $\begin{array}{c}\text { Nada } \\
\text { (1) }\end{array}$ & $\begin{array}{l}\text { Poco } \\
(2)\end{array}$ & $\begin{array}{c}\text { Algo } \\
(3)\end{array}$ & $\begin{array}{l}\text { Bastante } \\
\quad(4)\end{array}$ & $\begin{array}{l}\text { Mucho } \\
(5)\end{array}$ & Total & $\mathbf{F}$ & Sig. & $\begin{array}{l}\text { Ejemplos de } \\
\text { relaciones } \\
\text { significativas }\end{array}$ & $\begin{array}{c}\text { Diferencia } \\
\text { de medias } \\
\text { (I-J) }\end{array}$ & $\begin{array}{c}\text { Sig. } \\
<0,01\end{array}$ \\
\hline \multirow{2}{*}{$\begin{array}{l}\text { Grado de } \\
\text { satisfacción } \\
\text { con la Neo- } \\
\text {-Cueva }\end{array}$} & \multirow{2}{*}{5,06} & \multirow{2}{*}{5,66} & \multirow{2}{*}{5,72} & \multirow{2}{*}{6,18} & \multirow{2}{*}{6,49} & \multirow{2}{*}{5,91} & \multirow{2}{*}{21,701} & \multirow{2}{*}{,000 } & $1 \mathrm{y} 4$ & $-1,122$ &, 001 \\
\hline & & & & & & & & & 1 y 5 & $-1,430$ & ,000 \\
\hline \multirow{2}{*}{$\begin{array}{l}\text { Grado de } \\
\text { satisfacción } \\
\text { general } \\
\text { con } \\
\text { respecto a } \\
\text { la visita al } \\
\text { Museo }\end{array}$} & \multirow[b]{2}{*}{4,86} & \multirow[b]{2}{*}{5,41} & \multirow[b]{2}{*}{5,77} & \multirow[b]{2}{*}{6,16} & \multirow[b]{2}{*}{6,45} & \multirow[b]{2}{*}{5,88} & \multirow[b]{2}{*}{34,981} & \multirow[b]{2}{*}{, 000} & $1 \mathrm{y} 4$ & $-1,292$ & ,000 \\
\hline & & & & & & & & & 1 y 5 & $-1,583$ & ,000 \\
\hline
\end{tabular}

Fuente: Elaboración propia.

El estudio del valor de legado nos permite plantear diferentes interpretaciones acerca del dilema sobre la promoción-protección de Altamira desde perspectivas no expertas, aportando nuevas ideas al debate sobre su futura reapertura o cierre. La principal conclusión de este análisis es que el nivel educativo es la variable sociodemográfica que más capacidad tiene de polarizar las opiniones sobre cómo mantener el valor de legado. De hecho, los niveles educativos más altos están vinculados a una mayor 
satisfacción con el complejo museístico, lo que nuevamente resalta la relevancia de este ítem para la comprensión del patrimonio cultural, su preservación y su interacción con las medidas de promoción turística. El valor de legado, asociado con un espacio patrimonial específico, juega un papel decisivo en la implementación de políticas de conservación y la gestión como marca de destino turístico, a la vez que promueve la integración del turismo con actividades económicas locales y un vínculo con sus residentes. Finalmente, según lo establecido por Craik (1997), el nivel educativo es un factor clave para abordar el turismo cultural y no sólo como una estrategia de marketing. La creación de una cultura del turismo que entienda los espacios patrimoniales y su apego a los mismos resulta fundamental para fomentar el VSP.

\section{Conclusiones}

La presente investigación abre una nueva vía de investigación teórica y metodológica al abordar la relación entre el VSP y la imagen de marca de SPH mediante el estudio de la dicotomía entre promoción y preservación entre diversos actores sociales. Para dilucidar esta cuestión se examinó el caso de la Cueva de Altamira (España), cuyos resultados de investigación muestran cómo aspectos sociales tales como los niveles de conocimiento y educación por parte de la población anfitriona pueden legitimar su interés social más allá de su declaración institucional, así como un valor de existencia, estético, económico y de legado. Así, cuanto mayores son los niveles de conocimiento y educación de una población o comunidad anfitriona de $\mathrm{SPH}$, mayor es la posibilidad de construcción de una imagen de marca en torno a estos espacios, superando estrategias de marketing a corto plazo. Paralelamente, cuanto mayor es el nivel educativo y el conocimiento de los visitantes sobre SPH, mayores son los niveles de satisfacción alcanzados durante la vista. Estas conclusiones resultan novedosas en el ámbito de los estudios del patrimonio y de turismo, destacando la importancia de analizar el VSP como constructo social y dinámico en la gestión patrimonial y turística de SPH.

Las consecuencias normativas y aplicadas contribuyen a una mejor toma de decisiones políticas respecto a SPH, donde interactúan diferentes dimensiones valorativas y confluyen problemas de escala y población (de qué comunidades estamos hablando, qué agentes las constituyen y cuán diversos son sus capitales e intereses), así como de proceso (cómo evolucionan estos elementos en función del propio desarrollo de los enclaves patrimoniales). Esto significa que la forma de analizar, modelizar y comprender los fenómenos valorativos asociados a los procesos patrimoniales tiene que atender a una diversidad empírica y metodológica importante. Para poder diseñar y ejecutar planes patrimoniales sostenibles e integrados con las políticas turísticas y de desarrollo comunitario debemos reconocer la existencia de los procesos sociales valorativos en torno al patrimonio, es decir, el valor social del patrimonio en toda su complejidad, algo más que una cuestión de ingresos monetarios y expectativas de visita. Y para que esto sea efectivo es preciso posibilitar una investigación transdisciplinar que dé sentido al análisis de dichos procesos. Sólo esta investigación puede proporcionar los datos necesarios para respaldar y orientar políticas de gestión y fomento turístico hacia un horizonte de sostenibilidad y de racionalidad en el acceso y uso de los recursos patrimoniales en base a su genérico valor social. Futuras investigaciones deberían profundizar en otros aspectos del valor social del patrimonio desde perspectivas diversas, dejando atrás concepciones del patrimonio ancladas en su dimensión material y construida que limitan la amplitud del debate alrededor del complejo y conflictiva entente entre turismo, patrimonio, economía y comunidad.

\section{Bibliografía}

Adie, B. A., Hall, C. M. y Prayag, G. (2017). World Heritage as a placebo brand: a comparative analysis of three sites and marketing implications. Journal of Sustainable Tourism, 26(3), 399-415.

Alonso González, P. (2016). Patrimonio y ontologías múltiples: hacia la co-producción del patrimonio cultural. En C. Gianotti (Ed.), Patrimonio y multivocalidad. Teoría, práctica y experiencias en torno a la construcción del conocimiento en Patrimonio (pp. 179-198). Montevideo: CSIC - UdelaR.

Alonso González, P. (2017). El Antipatrimonio: Fetichismo y dominación en Maragatería (España). Madrid: CSIC.

Alonso González, P., Macías Vázquez, A. y Fernández Fernández, J. (2017). Governance Structures for the Heritage Commons: La Ponte-Ecomuséu-Ecomuseum of Santo Adriano, Spain. En P. Gould y A. 
Pyburn (Eds.), Collision or Collaboration: archaeology encounters economic development (pp. 153-170). Cham: Springer.

Araoz, G. F. (2011). Preserving heritage places under a new paradigm. Journal of cultural heritage management and sustainable development, 1(1), 55-60.

Barreiro, D. y Criado-Boado, F. (2015). Analizando el Valor Social de Altamira. Revista PH, 87, 108-127.

Barreiro, D., Criado-Boado, F., Téllez Delgado, V., Sánchez Carretero, C., Parga Dans, E. y Sánchez Martín, R. (2018). Las tres vidas de Altamira y el futuro. Sémata, 30, 479-502.

Benito Del Pozo, P. y Alonso González, P. (2012). Industrial Heritage and Place Identity in Spain: From Monuments to Landscapes. Geographical Review, 102(4), 446-464.

Bertacchini, E., Liuzza, C. y Meskell, L. (2017). Shifting the balance of power in the UNESCO World Heritage Committee: an empirical assessment. International journal of cultural policy, 23(3), 331-351.

Bourdeau, L., Gravari-Barbas, M. y Robinson, M. (2018). World heritage, tourism and identity: inscription and co-production. London: Routledge.

Cartailhac, É. (1902). Les cavernes ornées de dessins. La grotte d'Altamira, Espagne. Mea culpa d'un sceptique. L'anthropologie, 13(1), 41-68.

Carter, L. S., Jolliffe, L. y Baum, T. (2001). Heritage tourism and world heritage sites the case of Newfoundland. Tourism Recreation Research, 26(1), 113-116.

Craik, J. (1997). The culture of tourism. En C. Rojek y J. Urry (Eds.), Touring cultures (pp. 113-136). London: Routledge.

Chen, C.-F. y Chen, F.-S. (2010). Experience quality, perceived value, satisfaction and behavioral intentions for heritage tourists. Tourism management., 29-35(1), 29.

Darvill, T. (1994). Value systems and the archaeological resource. International Journal of Heritage Studies, 1(1), 52-64.

Díaz-Andreu, M. (2017). Heritage Values and the Public. Journal of Community Archaeology \& Heritage, 4(1), 2-6.

González-Ruibal, A., Alonso González, P. y Criado-Boado, F. (2018). Against reactionary populism: towards a new public archaeology. Antiquity, 92(362), 507-515.

Goulding, C. (2000). The commodification of the past, postmodern pastiche, and the search for authentic experiences at contemporary heritage attractions. European Journal of Marketing, 34(7), 835-853.

Graham, B., Ashworth, G. y Tunbridge, J. (2016). A geography of heritage. London; New York: Routledge.

Hair, J., Black, W. C., Babin, B. J. y Anderson, R. (2010). Multivariate data analysis: International version. New Jersey: Pearson.

Hall, C. M. y Piggin, R. (2002). Tourism business knowledge of World Heritage sites: A New Zealand case study. International Journal of Tourism Research, 4(5), 401-411.

ICOMOS. (2019). European quality principles for EU-funded interventions with potential impact upon cultural heritage. Paris.

Icomos Australia. (1999 [1979]). The Burra Charter and guidelines to the Burra Charter. Canberra: Icomos. INE. (2013). Hotel Occupancy Survey (HOS). Madrid: Spanish National Statistic Institute.

Jansen-Verbeke, M. (2016). Foreword. En M. D. Alvarez, F. M. Go, y A. Yuksel (Eds.), Heritage tourism destinations: preservation, communication and development (pp. xii-xiv). Wallingford: CABI.

Joaristi, L. y Lizasoain Hernández, L. (2000). Análisis de correspondencias. Madrid; Salamanca: La Muralla; Hespérides.

Jones, S. (2017). Wrestling with the social value of heritage: problems, dilemmas and opportunities. Journal of Community Archaeology \& Heritage, 4(1), 21-37.

Martin-Rios, C. y Parga-Dans, E. (2016a). The early bird gets the worm, but the second mouse gets the cheese: Non-technological innovation in creative industries. Creativity and innovation management, $25(1), 6-17$

Martin-Rios, C. \& Parga-Dans, E. (2016b). Service response to economic decline: Innovation actions for achieving strategic renewal. Journal of business research, 69(8), 2890-2900.

Mason, R. y Avrami, E. (2002). Heritage values and challenges of conservation planning. En J. Teutonico y G. Palumbo (Eds.), Management planning for archaeological sites (pp. 13-26). Los Angeles: Getty Institute Loyola University.

Michelson, A. y Paadam, K. (2016). Destination branding and reconstructing symbolic capital of urban heritage: A spatially informed observational analysis in medieval towns. Journal of destination marketing \& management, 5(2), 141-153.

Parga Dans, E. (2019). Heritage in danger. The collapse of commercial archaeology in Spain. Archaeological Dialogues, 26(2), 111-122. doi:10.1017/S1380203819000217 
Parga Dans, E. y Alonso González, P. (2017). The Altamira controversy: Assessing the economic impact of a world heritage site for planning and tourism management. Journal of cultural heritage, 30, 180-189.

Parga Dans, E. y Alonso González, P. (2019). Sustainable tourism and social value at World Heritage Sites: Towards a conservation plan for Altamira, Spain. Annals of Tourism Research, 74, 68-80.

Parga Dans, E. y Alonso González, P. (2020). The Unethical Enterprise of the Past: Lessons from the Collapse of Archaeological Heritage Management in Spain. Journal of Business Ethics. https://doi. org/10.1007/s10551-020-04504-6

Parga-Dans, E., Barreiro, D. y Varela-Pousa, R. (2016). Isomorphism and legitimacy in Spanish contract archaeology: the free-fall of an institutional model and the caveat of change. International journal of heritage studies, 22(4), 291-301.

Parkinson, A., Scott, M. y Redmond, D. (2016). Defining “Official” Built Heritage Discourses within the Irish Planning Framework: Insights from Conservation Planning as Social Practice. European Planning Studies, 24(2), 277-296.

Petr, C. (2009). Fame is not always a positive asset for heritage equity! Some clues from buying intentions of national tourists. Journal of Travel and Tourism Marketing, 26(1), 1-18.

Poria, Y., Reichel, A. y Cohen, R. (2013). Tourists perceptions of World Heritage Site and its designation. Tourism management, 35, 272-274.

Poulios, I. (2010). Moving Beyond a Values-Based Approach to Heritage Conservation. Conservation and Management of Archaeological Sites, 12(2), 170-185. doi:10.1179/175355210X12792909186539

Prats, L. (2003). Patrimonio+ Turismo=i Desarrollo? PASOS, 1(2), 127-136.

Prats, L. (2011). La viabilidad turística del patrimonio. PASOS, 9(2), 249-264.

Ramires, A., Brandao, F. y Sousa, A. C. (2018). Motivation-based cluster analysis of international tourists visiting a World Heritage City: The case of Porto, Portugal. Journal of Destination Marketing and Management, 8, 49-60.

Ross, D., Saxena, G., Correia, F. y Deutz, P. (2017). Archaeological tourism: A creative approach. Annals of Tourism Research, 67, 37-47.

Ryan, J. y Silvanto, S. (2010). World Heritage Sites: The Purposes and Politics of Destination Branding. Journal of Travel \& Tourism Marketing, 27(5), 533-545.

Santa-Cruz, F. G. y López-Guzmán, T. (2017). Culture, tourism and World Heritage Sites. Tourism Management Perspectives, 24, 111-116.

Schabereiter-Gurtner, C., Saiz-Jimenez, C., Piñar, G., Lubitz, W. y Rölleke, S. (2002). Altamira cave Paleolithic paintings harbor partly unknown bacterial communities. FEMS Microbiology Letters, 211(1), 7-11. doi:10.1111/j.1574-6968.2002.tb11195.x

Tucker, H. y Carnegie, E. (2014). World heritage and the contradictions of 'universal value'. Annals of Tourism Research, 47, 63-76.

Viu, J. M., Fernández, J. R. y Caralt, J. S. (2008). The impact of heritage tourism on an urban economy: the case of Granada and the Alhambra. Tourism Economics, 14(2), 361-376.

\section{Notas}

Todos los informes y datos brutos generados por este proyecto están disponibles en http://digital.csic.es/handle/10261/112860

Recibido:

$21 / 06 / 2020$

Reenviado:

$27 / 09 / 2020$

Aceptado:

$29 / 09 / 2020$

Sometido a evaluación por pares anónimos 


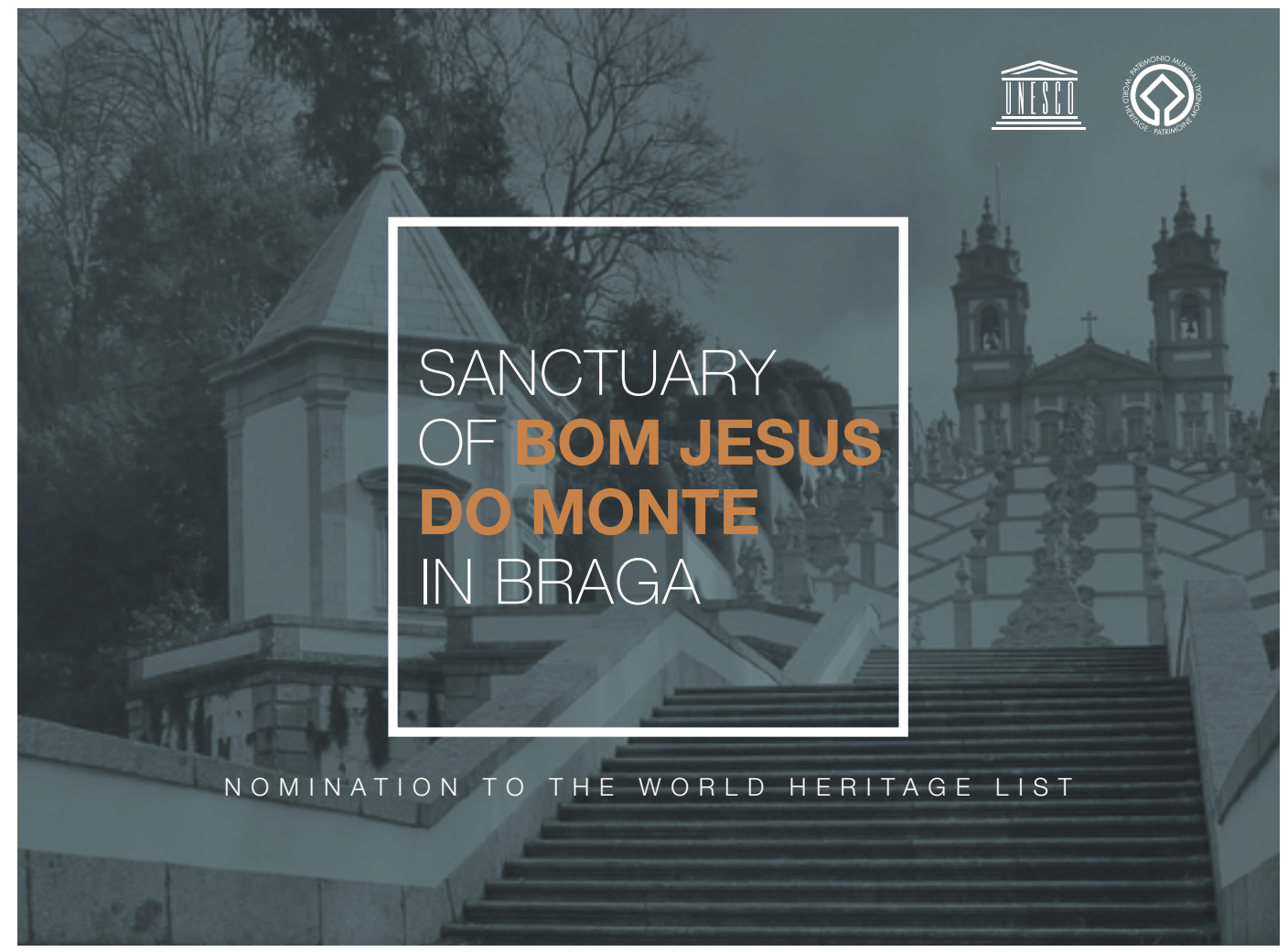




\title{
La activación de la ciudadanía como estrategia para la sostenibilidad turística en lugares patrimoniales cercanos a la gran ciudad. El caso de la región madrileña
}

\author{
Juan Ángel Martín* Marta Domínguez Pérez** \\ Alicia Castillo Mena***: \\ Universidad Complutense de Madrid (España)
}

\begin{abstract}
Resumen: Aunque el Patrimonio Cultural es fuente reconocida de bienestar, su sobreexplotación turística genera fuertes impactos negativos, agravados en las grandes ciudades por la concentración de efectos en el espacio. Este trabajo aborda el caso de Madrid, ciudad que cuenta en su periferia metropolitana con activos patrimoniales de primer nivel, cuyo mejor aprovechamiento turístico ayudaría a mitigar el impacto negativo en la capital, a la vez que contribuiría al desarrollo económico y social de la periferia. En la investigación se aplicó un planteamiento metodológico dinámico con cuatro planos de análisis complementarios: documental y de redes, cualitativo, cuantitativo y procesos participativos. Los resultados evidencian la necesidad de adoptar estrategias de gestión cultural y de planificación turística orientadas al reequilibrio de los flujos de visitantes. La activación de los propios vecinos se revela como un recurso especialmente valioso para fortalecer un turismo de proximidad, experiencial y más sostenible. El impacto de la Covid-19, por una parte, y la declaración del Paseo del Prado y el Retiro como Patrimonio de la Humanidad, por otra, han puesto aún más de actualidad esta situación.
\end{abstract}

Palabras Clave: Turismo cultural; Patrimonio Cultural; Ciudadanía; Turistificación; Sostenibilidad.

The activation of citizenship as a strategy for tourism sustainability in heritage sites near the big city. The case of Madrid region.

Abstract: Although Cultural Heritage is a recognized source of well-being, its touristic overexploitation generates strong negative impacts, aggravated in large cities due to the concentration of effects in space. This work addresses the case of Madrid, a city that has first-rate heritage assets in its metropolitan periphery, whose better touristic use would help to mitigate the negative impact on the capital, while contributing to the economic and social development of the periphery. In the research, a dynamic methodological approach was applied with four complementary analysis planes: documentary and networks, qualitative, quantitative and participatory processes. The results show the need to adopt cultural management and tourism planning strategies aimed at rebalancing visitor flows. The activation of the neighbors themselves is revealed as an especially valuable resource to strengthen proximity, experiential and more sustainable tourism. The The impact of Covid-19, on the one hand, and the declaration of Paseo del Prado and El Retiro as World Heritage Sites, on the other, have made this situation even more topical.

Keywords: Cultural tourism; Cultural Heritage Management; Citizenship; Touristification; Sustainability.

\section{Introducción ${ }^{1}$}

En la actualidad, la turistificación en las grandes ciudades es uno de los temas estrella en el panorama urbano, sobre todo por sus efectos negativos sobre la población local, la pérdida de identidad, la saturación

\footnotetext{
* Universidad Complutense de Madrid (España); E-mail: umartin@ucm.es; https://orcid.org/0000-0003-4766-4552

** Universidad Complutense de Madrid (España); E-mail: madoming@ucm.es; https://orcid.org/0000-0002-3145-6671

**** Universidad Complutense de Madrid (España); E-mail: alicia.castillo@ghis.ucm.es; https://orcid.org/0000-0002-9168-1803
} 
turística, el encarecimiento de la vivienda, etc. (UNWTO, 2013). Siguiendo las directrices de ONU, la sostenibilidad del turismo urbano es uno de los retos que se proponen a las ciudades a través del marco de la Agenda Urbana 2030. Algunas de las principales recomendaciones apuntan a una corrección de la saturación turística (Perkumiene et al, 2019) y, por tanto, a una más equilibrada distribución del turismo en el territorio. Esto es, potenciar la difusión y el esponjamiento que permitan la minimización de los impactos negativos del turismo más intensivo, en aras de la sostenibilidad urbana y la mejora de la calidad de vida. De este modo, tras décadas de énfasis en los aspectos positivos del turismo, a partir de los años noventa del pasado siglo, se plantean discursos críticos centrados en los problemas de tipo social, cultural, etc. (Barrado e Hidalgo, 2019).

También el Patrimonio Cultural tiene una presencia significativa en la Agenda Urbana 2030, que señala su relevancia para el desarrollo local, la cohesión social y el sentimiento de pertenencia, por más que, como se ha señalado por algunos (Gómez, Crespi y Domínguez, 2020), no lo hace de manera explícita ni ampliamente desarrollada. La potencialidad del Patrimonio Cultural más allá de su atractivo turístico se viene demostrando en la ya amplia tradición académica española (Herrero et al, 2006; López Guzmán y Sánchez, 2009; Manero, 2011; Martos, 2012; Rengifo et al, 2015; Andrés, 2015; entre otros), aunque también se ha constatado que los recursos patrimoniales podrán tener un mayor aprovechamiento (VanBlarcom \& Kayahan, 2011; Snowball, 2013; Castillo, 2015; Pérez, 2015; Cavailles et al, 2016; Cortijo \& Pulido, 2016; OMT, 2017; Pérez \& Lois, 2018). Puede afirmarse, por tanto, que si bien el Patrimonio Cultural es un elemento clave de desarrollo local, su sobreexplotación de la mano de un turismo excesivo tiene en algunos casos importantes repercusiones sobre el espacio.

En este trabajo nos acercamos a un escenario que supone un ejemplo ilustrativo de ese complejo entramado y de las dificultades de su articulación. Una gran ciudad, Madrid, que ha visto cómo el incremento de la presión turística produce la saturación de su centro urbano, al tiempo que cuenta con algunos núcleos en su área regional de influencia de gran atractivo por su valor patrimonial y cuyo mayor aprovechamiento turístico podría favorecer, por una parte, el reequilibrio de la actividad turística regional y, por otra, la sostenibilidad urbana de la capital. En tal sentido, la puesta en valor de la ciudadanía ofrece nuevos activos de gran utilidad para potenciar ese reequilibrio regional, al tiempo que se fomenta la identidad local.

La ciudad de Madrid posee un amplio atractivo turístico. Es un destino destacado en los rankings internacionales ${ }^{2}$ que recibe un gran número de turistas ${ }^{3}$, situándose en el primer puesto de entre las ciudades españolas ${ }^{4}$ ya desde hace varias décadas. Sin embargo, también sus impactos negativos son conocidos (Liu, 2003; Saarinen, 2006; Weaver, 2009; García, De la Calle y Mínguez, 2015; Barrado e Hidalgo, 2019). Más allá de sus recursos patrimoniales, Madrid atrae por muchos otros aspectos: cultura, ocio, imagen, compras, negocios, multiculturalidad, etc., lo cual promueve una gran oferta turística, pero que también conlleva la saturación de sus espacios centrales (Barrado e Hidalgo, 2019; Calle, Ferreiro y Mendoza, 2018; Crespi y Domínguez Pérez, 2016).

Sin embargo, en el radio de acción de la ciudad de Madrid, en su región metropolitana, existen otros enclaves de amplio atractivo que podrían jugar un relevante papel como espacios de esponjamiento del turismo. La potenciación de las visitas a dichos espacios, más allá de desplazamientos cortos que además incrementan la movilidad regional (Calle, García y Mínguez, 2015), serviría como mecanismo de redistribución del turismo que gravita sobre Madrid. La reciente incorporación del eje Prado-Retiro al listado de lugares Patrimonio Mundial, lejos de seguir incidiendo en la centralidad de la capital como atractor cultural, podría contribuir, gracias a las sinergias existentes, a esa redistribución de flujos e impactos hacia los tres lugares que han sido objeto de estudio en nuestro trabajo: "Universidad y Barrio Histórico de Alcalá de Henares" (1998), "Paisaje Cultural de Aranjuez" (2001) y "Monasterio y sitio de El Escorial, Madrid" (1984). Declarados Patrimonio Mundial por UNESCO, son exponentes de un gran atractivo turístico y cultural en un entorno regional cuyo centro neurálgico es Madrid capital (Figura 1).

Desafortunadamente, la capacidad de atracción de esos lugares se ve limitada también por la falta de conocimiento específico, afectando en última instancia de manera negativa a la gestión del sector y al reajuste de las estrategias de desarrollo locales y regionales. Existen, no obstante, precedentes destacados que se han ocupado de la transformación de las ciudades patrimoniales y los reales sitios de la Comunidad de Madrid, atendiendo sobre todo a la convivencia entre el Patrimonio, los visitantes y sus habitantes (Troitiño, 2002; Mínguez, 2007; Troitiño, 2012). Nuestro trabajo quiere contribuir a la generación de conocimiento, con un enfoque centrado en el interés por un turismo sostenible (Stabler, 1997) en áreas de influencia amplias, como la región metropolitana, en aras de una descentralización 
Figura 1: Localización en el territorio y áreas respectivas de influencia
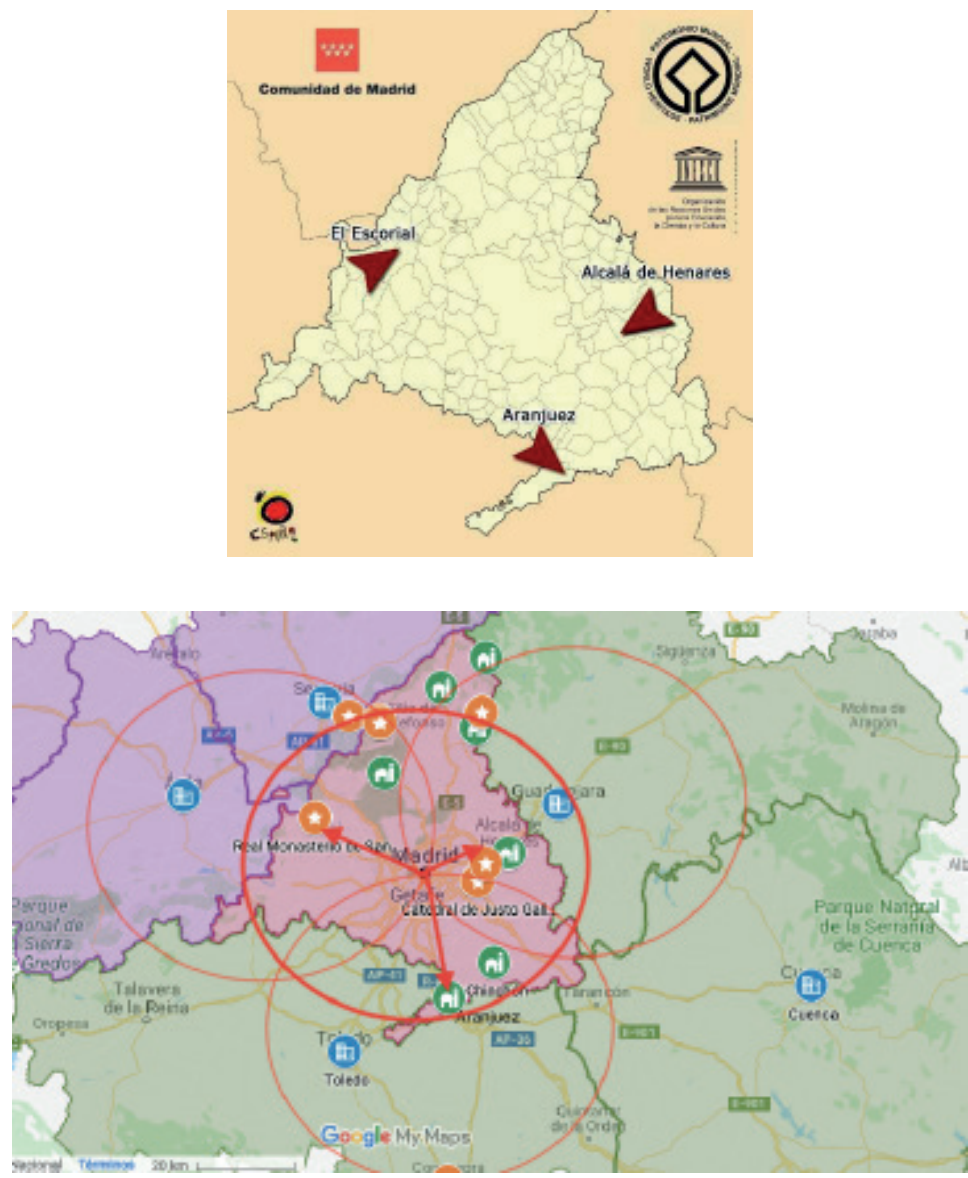

Fuente: Ciudades patrimonio. https://susanaclavero.wordpress.com/2016/05/09/ciudades-patrimonio-mundial-de-la-humanidad-en-la-comunidad-de-madrid/ consultado 8 de julio de 2020.

y diversificación del mismo que, sin dejar de ser un instrumento de desarrollo local, alivie los impactos negativos sobre el centro de las ciudades (Frey y Steiner, 2011; Bonet, 2013; García, De la Calle y Yubero, 2017; Barrado e Hidalgo, 2019). Este tipo de planteamientos se han vuelto incluso más importantes en contextos como el actual, marcado a nivel global por la COVID-19, que está obligando al replanteamiento de algunas estrategias turísticas tradicionales (Arold, 2021) para, en su lugar, potenciar un turismo de proximidad y al margen de los espacios más habituales, desde los centros masificados hacia las periferias en un planteamiento más sostenible.

Consiguientemente, tres áreas constituyen el foco de interés sobre el que se centra el artículo: la estrategia regional de sostenibilidad, la potencialidad multidimensional del Patrimonio Cultural a diferentes escalas -regional y local- y la participación de las poblaciones locales en la gestión del turismo y el patrimonio en las ciudades.

Los resultados obtenidos entendemos que son de utilidad para la articulación de estrategias regionales patrimoniales y turísticas tendentes a reequilibrar los impactos positivos (desarrollo local) y negativos (saturación de los centros urbanos) asociados a estos fenómenos. Las conclusiones alcanzadas no sólo son válidas para el caso concreto aquí analizado, sino también para muchos otros con un escenario similar al que describimos: la presencia de lugares con riqueza patrimonial cercanos a grandes ciudades, las cuales funcionan como nodos de alta atracción turística o que son en sí mismas potentes mercados, lo que da lugar a interesantes sinergias y puede ser utilizado para mejorar la sostenibilidad de los flujos, 
desde entornos saturados hacia otros con potencialidad de acogida. Estas apreciaciones se vuelven aún más significativas tras la incorporación del cuarto espacio madrileño al listado de UNESCO, de cara a articular los flujos de este complejo escenario de forma equilibrada y sostenible. El recurso a la participación de la ciudadanía es una herramienta de incomparable valor para potenciarlos y, en tal sentido, ha resultado muy alentador comprobar cómo los propios vecinos de los municipios estudiados constituyen un recurso de primer orden para articular una mejor relación turista-residente, enriquecer la experiencia de la visita y, al mismo tiempo, fomentar la activación de la ciudadanía.

\section{Fundamentacion teórica}

El Patrimonio Cultural presenta una vertiente de rendimiento multidimensional. Por un lado, una dimensión económica de desarrollo local basada fundamentalmente en el aprovechamiento turístico (Lara de Vicente y López Guzmán, 2004; ICOMOS, 2011) y, por otro, una dimensión más sociológica, cultural y política, ligada a la participación ciudadana y la identificación con un pasado histórico e identitario que revierte en la cohesión social y la gobernanza urbana (Agenda Urbana Española, 2019; Domínguez Pérez, 2019; Gómez, Crespi y Domínguez, 2020).

De este modo, el Patrimonio Cultural juega un papel fundamental en el atractivo turístico y urbano de las ciudades (Zukin, 1995), dando lugar a una demanda "cultural" fundamentada en unos bienes que han de ser considerados como un stock de activos (Throsby, 1998). Estos activos culturales, materiales e inmateriales (intrínsecamente relacionados, sobre todo por el poder sensible y simbólico de lo físico), dan lugar a un flujo de servicios de mayor valor que suponen su fuente de retorno económico fundamental y entre los cuales el turismo juega un papel preponderante (Alonso y Martín, 2013). Soslayar la dimensión económica del Patrimonio Cultural desde posiciones estrictamente conservacionistas, contribuye a debilitar su imprescindible preservación. Mientras que aprovecharlo de manera sostenible y responsable supone una oportunidad de contribuir a mejorar las condiciones de vida de las personas, tanto en lo material (riqueza, empleo, innovación, emprendimiento), como en lo inmaterial (identidad, participación, formación, satisfacción, disfrute, calidad de vida, etc.) (Carta de Bruselas 2009).

También respecto de la actividad turística la importancia de la sostenibilidad ha quedado plasmada en la literatura científica. Son de sobra conocidos los impactos ambivalentes del turismo (Jurowski y Gursoy, 2004; Mason, 2008; UNWTO, 2013), entre los que la turistificación es actualmente uno de los más destacados, negativamente. La turistificación, entendida como el "impacto que tiene para el residente de un barrio o ciudad el hecho de que los servicios, instalaciones y comercios pasen a orientarse y concebirse pensando más en el turista que en el ciudadano que vive en ellos permanentemente" (Fundéu, 2018), hace énfasis en los agentes externos más que en los internos. Cuando lo que se viene definiendo como turismo sostenible es el hecho de que "Una ciudad, (que) pueda vivir con el turismo y no solamente de turismo" (Milano, Cheer y Novelli, 2019), respetando y conservando las distintas dimensiones urbanas.

La necesaria sostenibilidad del turismo fue puesta de relevancia con la celebración de la Comisión Mundial sobre Medio Ambiente y Desarrollo en 1987 (Informe Brundtland) y desde entonces se ha ido consolidando la postura de que no sólo importa el desarrollo económico, sino que hay que compatibilizarlo con el respeto medioambiental y social (Elkington, 2002). Es lo que posteriormente ha ido derivando hacia el turismo responsable (Declaración de Ciudad del Cabo, 2002), el turismo verde o la utopía del turismo sostenible (Pulido y Pulido, 2015; Aronsson, 2000).

Pese a esa orientación, a menudo la sostenibilidad turística parece ser un compromiso más retórico que real (Aronsson, 2000; Liu, 2003; Saarinen, 2006; Weaver, 2009; Rull, 2010), debido a la dificultad de su garantía en las distintas intervenciones (Becker, 2013; McCool et al, 2013). Ya en la Conferencia de Naciones Unidas sobre el Desarrollo Sostenible (Río de Janeiro 2012), se reconocía la dificultad de avanzar por ese camino y se planteaban soluciones por la vía de la Economía Verde (Pulido y Pulido, 2015; Stone, 2013). Se planteaba como uno de los principales objetivos el asegurar un compromiso político renovado para el desarrollo humano sostenible (Ehrlich, 2009). Bramwell (2015: 204) recuerda que el turismo sostenible se ha vinculado tradicionalmente con "la preservación de los ecosistemas, la promoción del bienestar humano, la equidad inter e intergeneracional, y la participación pública en la toma de decisiones". Se trata de que los agentes excluidos de la gestión del turismo y el patrimonio cobren un papel relevante, contribuyendo al enriquecimiento de las visiones y al ejercicio del derecho a la ciudad de las personas que la viven, sustanciados en el derecho a la participación y apropiación de la ciudad (Lefebvre, 1969; Fenster, 2010; Buckingham, 2011). 
Si es cierto que el desarrollo económico es uno de los resultados de la puesta en valor del Patrimonio Cultural $^{5}$, en ocasiones la saturación turística genera la turismofobia de los residentes (Navarro, 2015) y otros efectos negativos sobre la comunidad local (Calle, 2019). En lo sociocultural, la conflictividad entre residentes y turistas, la pérdida de idiosincrasia de la cultura receptora, de identidad local y del valor patrimonial de lo local (Sánchez, 2012; Crespi y Domínguez, 2016). De ahí la importancia para el futuro del turismo de tomar en consideración a la población local, adaptarse a los cambios y comprometerse con la sostenibilidad (Prats, 2009; Huete, 2010; García, 2019; Domínguez, 2019).

Mientras tanto, el aprovechamiento social de los bienes culturales para dotar de mayor calidad de vida a las personas se hace cada vez más presente (Florida, 2009; Hania et al, 2012; Alonso y Martín, 2013; Pérez y Lois, 2018). Aspectos como la imagen externa que proyectan los territorios son considerados también como un activo económico, social y político (Zukin, 1995; Beck, Giddens y Lash, 1997; Nyseth y Sognnaes, 2013) para la identidad urbana. Mediante estrategias de promoción, se potencia la consolidación del sentimiento de pertenencia, asociado al orgullo y la calidad de vida percibida, lo cual permite una mayor satisfacción de los ciudadanos e implicación en la vida colectiva (Radoslav, Branea y Gaman, 2013). En este marco, la preservación y promoción del Patrimonio Cultural como condensación de la historia también incrementa la mejora de la imagen de los agentes públicos y privados responsables, que experimentan una mayor legitimación social de sus actuaciones (Marcos, 2004; Dormaels, 2011; Preece, 2020). Lejos de la gestión excluyente del Patrimonio y lo urbano -desde arriba- se han ido proponiendo nuevas líneas que dan cabida a la participación ciudadana que favorece el empoderamiento de aquella y la legitimidad de las políticas públicas.

Esta línea es la que se viene poniendo de manifiesto en las actuales tendencias de los estudios sobre patrimonio (Castillo, 2015; ICOMOS, 2017) y donde se inscribe este estudio. Los resultados obtenidos han sido útiles para hacer una primera aproximación a los cambios necesarios en el tratamiento del Patrimonio Cultural de estas tres localidades cercanas a la ciudad de Madrid, a fin de armonizar, su necesaria preservación con un mejor aprovechamiento social y político y su sostenibilidad como destino turístico responsable. Supone una contribución de base práctica y empírica, a los estudios sobre Patrimonio Cultural y sostenibilidad, que puede revertir en una mejor gestión y que, de manera evidente, pueden ser de utilidad en otros escenarios con realidades parecidas.

\section{Objetivos y metodología}

Como ya se ha planteado, el problema de partida es el de los impactos negativos del turismo en la gran ciudad (densidad turística, ruido, airbnbización urbana, saturación, pérdida de identidad, etc.), como el caso del municipio de Madrid, que lo hacen insostenible en varias dimensiones. El objetivo es analizar la posibilidad y potencialidad de difundir el turismo más allá de los confines de Madrid municipio, para redistribuir sus impactos en aras de una mayor sostenibilidad regional. Prestamos especial atención a un activo hasta hace poco no considerado, como es la ciudadanía de dichos espacios, capaz de proporcionar una información de gran relevancia para la estrategia a desarrollar. El objeto de análisis elegido está conformado por tres lugares de gran riqueza patrimonial: Alcalá de Henares, Aranjuez y San Lorenzo de El Escorial, que sirven como arena de investigación. A ellos habría que añadir, a partir de ahora (julio de 2021), el eje Prado-Retiro, que viene a reforzar el papel central de la capital en el escenario patrimonial regional.

Una vez problematizado el estudio, se hace un diagnóstico de la actividad turística de dichas localidades, que son visitadas principalmente por su patrimonio cultural, pero desde una visión clásica y conservadora del atractivo turístico, pese a contar con atractivos adicionales.

En segundo lugar y debido a la ausencia de estudios locales, se desplegó una metodología ad hoc: documental y de redes, cualitativa (grupos de discusión y entrevistas), cuantitativa (encuestas y sondeos) y con procesos participativos, para indagar acerca de las preferencias y actitudes de agentes implicados y dar voz a la base social para la gestión urbana. En síntesis, la metodología de estudio se conformó por cuatro herramientas complementarias:

a) Análisis documental: científico-técnico, de guías de turismo, turoperadores y redes sociales.

b) Metodología cualitativa: entrevistas en profundidad a responsables de la gestión patrimonial y turística regional. Posteriormente se celebraron tres grupos de discusión, uno en cada municipio, con representantes locales de las administraciones a nivel político y técnico, del empresariado vinculado a la actividad turística y de las asociaciones culturales. 
c) Metodología cuantitativa: aplicación de encuestas a residentes y visitantes. Residentes: 585 cuestionarios en las tres localidades ${ }^{6}$, Alcalá de Henares (196), Aranjuez (196) y San Lorenzo de El Escorial (193). Turistas: 297 cuestionarios estructurados ${ }^{7}, 99$ en cada municipio.

d) Metodología participativa: procesos participativos en las tres ciudades que fomentó las relaciones entre agentes (habitantes y visitantes) y proporcionó información sobre atractivos potenciales.

Tabla 1: Ficha técnica de entrevistas en profundidad, grupos de discusión y procesos participativos

\begin{tabular}{|c|c|c|}
\hline \multicolumn{3}{|c|}{ Entrevistas en profundidad } \\
\hline Organismo responsable & Fecha de celebracion & Responsable \\
\hline E1 Comunidad de Madrid & 3 marzo 2015 & $\begin{array}{l}\text { Dirección General de Patrimonio } \\
\text { Histórico }\end{array}$ \\
\hline E2 Comunidad de Madrid & 4 marzo 2015 & $\begin{array}{l}\text { Subdireccion General de Desarrollo y } \\
\text { Sostenibilidad Turística }\end{array}$ \\
\hline $\begin{array}{l}\text { E3 Admon. General del } \\
\text { Estado - Patrimonio Nacional }\end{array}$ & 10 abril 2015 & $\begin{array}{l}\text { Dirección de Inmuebles y Medio } \\
\text { Natural }\end{array}$ \\
\hline \multicolumn{3}{|c|}{ Grupos de Discusión } \\
\hline Ciudad Patrimonio & Fecha de celebracion & Participantes \\
\hline G1 Alcala de Henares & 26 mayo 2015 & \multirow{3}{*}{$\begin{array}{l}\text { Técnicos de la Administración Local y } \\
\text { agentes públicos y privados relacionados } \\
\text { con la gestión patrimonial y turística }\end{array}$} \\
\hline G2 San Lorenzo de el Escorial & 27 mayo 2015 & \\
\hline G3 Aranjuez & 28 mayo 2015 & \\
\hline \multicolumn{3}{|c|}{ Acciones Participativas } \\
\hline Ciudad Patrimonio & Fecha de celebracion & Participantes \\
\hline A1 San Lorenzo de el Escorial & 1 y 10 octubre 2015 & $\begin{array}{l}\text { Encuentro-taller con asociaciones y } \\
\text { acción en polideportivo municipal }\end{array}$ \\
\hline A2 Aranjuez & 10 octubre 2015 & Acción en Plaza de la Constitución \\
\hline A3 Alcala de Henares & 28 noviembre 2015 & Acción en Plaza Cervantes \\
\hline
\end{tabular}

Fuente: elaboración propia.

Figura 2: Fotografías de los procesos participativos (Alcalá de Henares y San Lorenzo de El Escorial)
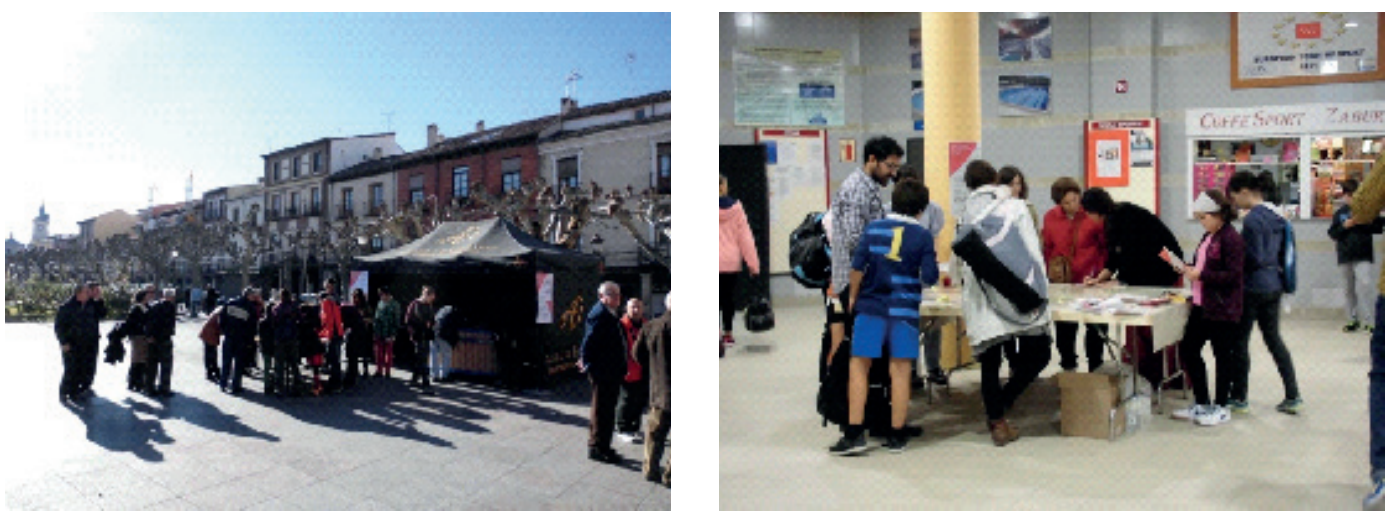

Fuente: Autoría de la empresa Paisaje Transversal (colaborador en el estudio referenciado) 
Gracias al planteamiento metodológico dinámico y triangulado, las distintas fases del desarrollo de la investigación (estudio documental, de redes, entrevistas a responsables, grupos de discusión, etc.) fueron aportando resultados que sirvieron a su vez para perfilar el diseño del análisis de demanda turística (determinación del momento y los lugares de ejecución de las encuestas; selección de dimensiones y variables; redacción de cuestionarios).

\section{Resultados: el turismo en lugares patrimoniales de la periferia madrileña}

En nuestra investigación, obtuvimos información de primera mano sobre la actitud de la población hacia el turismo y su incremento, el perfil del turista, la identificación de potenciales recursos de atracción más allá del Patrimonio tradicional y la puesta en valor de otras áreas que fortalecen la identidad urbana.

\subsection{La visión de los residentes como valor}

En la consulta a residentes se ponía de relieve el valor del Patrimonio entre la población y la potencialidad del atractivo local. Los ciudadanos, a la hora de valorar los elementos clave para la marcha de la economía local, coincidían en señalar al turismo y al Patrimonio Cultural (8,2 puntos sobre 10) como motores activos de sus municipios (Gráfico 1). Una imagen de clara de vinculación del desarrollo económico de estos municipios con el turismo cultural, con la puesta en valor del Patrimonio y con Madrid ciudad como nodo, mercado turístico prioritario y fuente de sinergias para la atracción de visitantes.

\section{Gráfico 1: Valoración de elementos clave para la economía local, promedios}

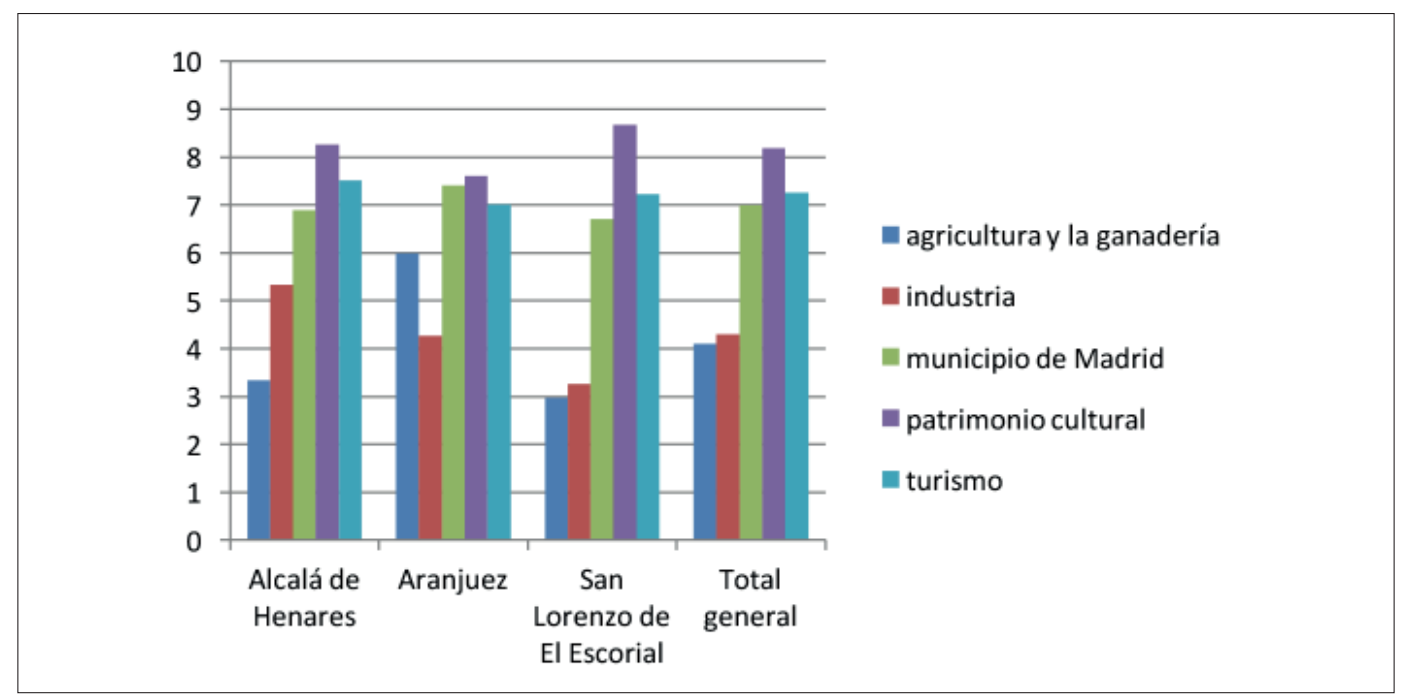

Fuente: Elaboración propia a partir de las encuestas a residentes.

Además, este posicionamiento hacia el turismo cultural como motor de la economía local tiene recorrido en las tres ciudades y no denota excesivo problema en cuanto al impacto de saturación turística en ellas. Esta cuestión importante y complicada, no parece ser un problema en estas tres localidades. De hecho, la mayoría de encuestados califica el número de visitantes como aceptable $(47,6 \%$ del total) y otros muchos desearían recibir aún más (el 34\% los considera insuficientes), siendo marginales los casos que los consideran excesivos. Así pues, el turismo cultural es considerado un sector relevante para el desarrollo local, ante el que la población muestra una actitud positiva y con cierta capacidad para acoger a un mayor número de turistas.

\subsection{Cómo son los turistas: realidad y potencialidades}

A continuación, se abordaba el estudio de las actitudes de los turistas en dichos municipios para poder abrir el campo de interés del turismo sobre estos espacios en aras de desarrollo local más allá del 
Patrimonio. En un primer lugar se define el perfil de los turistas a partir de la información primaria que aporta este estudio para entender quién y cómo es este público target de las campañas de atracción.

En el caso del turismo cultural, se habla de la atracción de turistas, la experiencia de las visitas, la atención coordinada y con perspectiva global, la oferta, en suma, de un producto integral y adaptado a la demanda. Y es que, pese a ser una cuestión vital siempre que se hable de la demanda de cualquier mercado, demasiado a menudo en la gestión turística y cultural, predomina una aproximación basada en la experiencia de los agentes implicados, mientras que sólo se dispone, en el mejor de los casos, de información parcial sobre los demandantes. A menudo dicha información proviene de las oficinas de turismo o de los inmuebles visitados, pero se carece de cifras detalladas a nivel municipal sobre el perfil de los turistas, la satisfacción con su experiencia, sus demandas o su relación con las poblaciones locales. Como se verá, esta situación también afecta de manera significativa a los tres destinos estudiados.

La muestra de turistas de las tres localidades presenta perfiles similares, componiéndose principalmente de un público de edades intermedias (la mitad de entre 40 y 64 años), equilibrado en cuanto a hombres o mujeres, con nivel de estudios medio y medio alto, y que mayoritariamente trabajaba ( $70 \%$ de ocupados). Un elemento a tener muy en cuenta es la importancia del turismo nacional para las tres ciudades, pero sobre todo en Aranjuez, donde casi el 90\% de los encuestados residía en España. Que se trate en gran medida de destinos turísticos fundamentalmente nacionales, tiene importantes implicaciones, tanto positivas como negativas. Más aún si tenemos en cuenta que el $85 \%$ de los visitantes españoles de Aranjuez, el $75 \%$ de los de El Escorial y el 68\% de Alcalá de Henares, son de la región madrileña, y de entre éstos, fundamentalmente con origen en la ciudad de Madrid, confirmando su importancia como atractivo turístico de referencia, pero también algunos condicionantes importantes derivados de la cercanía de sus domicilios (los tres destinos se sitúan a 35-55 kilómetros de la ciudad de Madrid). Consiguientemente se cuenta con un turista de origen regional, madrileño en gran medida, y que se corresponde con un perfil de edad mediana, con titulación media y que trabaja principalmente.

\subsection{El atractivo turístico del Patrimonio Cultural}

Se comprueba a continuación cómo es la estancia media del turista tipo de estos tres lugares, evidenciándose que la mayoría de los visitantes no pernocta en estas localidades. Esta situación es especialmente acusada en Aranjuez, donde sólo el 15\% de los encuestados no era excursionistas ${ }^{8}$. Otra cuestión destacada es que la mayor parte de esa minoría de turistas que sí pernocta, no lo hace en estas tres localidades (como media, sólo uno de cada tres de ellos), sino sobre todo en la ciudad de Madrid.

Esa situación condiciona de manera necesaria otro aspecto clave: la duración de las visitas, aspecto fundamental para la demanda de servicios y el volumen final de gasto turístico. El 90\% de encuestados sólo pasa medio día en esas ciudades y apenas un 6\% permanece más de un día en ellas. También se extrae información interesante al atender al tamaño del grupo turístico, observándose que Aranjuez destaca como destino de viajes en pareja y también El Escorial, aunque en menor medida, mientras que Alcalá presenta un mayor volumen de viajes grupales (familias, organizados, etc.).

Tabla 2: Características del viaje (porcentajes y escala Likert)

\begin{tabular}{|l|c|c|c|c|}
\hline & $\begin{array}{c}\text { Alcalá de } \\
\text { Henares }\end{array}$ & Aranjuez & $\begin{array}{c}\text { San Lorenzo } \\
\text { del Escorial }\end{array}$ & Total \\
\hline Duración en número de días \\
\hline 1 & $55,56 \%$ & $84,85 \%$ & $65,66 \%$ & $68,69 \%$ \\
\hline 2 & $22,22 \%$ & $9,09 \%$ & $14,14 \%$ & $15,15 \%$ \\
\hline 3 & $6,06 \%$ & $3,03 \%$ & & $3,03 \%$ \\
\hline Más de 3 & $16,16 \%$ & $2,02 \%$ & $20,20 \%$ & $12,80 \%$ \\
\hline No contesta & $1,01 \%$ & & $0,34 \%$ \\
\hline Lugar de pernoctación & & & \\
\hline Esta ciudad & $36,36 \%$ & $53,33 \%$ & $23,53 \%$ & $34,41 \%$ \\
\hline Madrid & $52,27 \%$ & $40,00 \%$ & $52,94 \%$ & $50,54 \%$ \\
\hline
\end{tabular}




\begin{tabular}{|c|c|c|c|c|}
\hline & $\begin{array}{l}\text { Alcalá de } \\
\text { Henares }\end{array}$ & Aranjuez & $\begin{array}{l}\text { San Lorenzo } \\
\text { del Escorial }\end{array}$ & Total \\
\hline $\begin{array}{l}\text { Otra ciudad en la Comunidad de } \\
\text { Madrid }\end{array}$ & $11,36 \%$ & $6,67 \%$ & $20,59 \%$ & $13,98 \%$ \\
\hline Otros & & & $2,94 \%$ & $1,08 \%$ \\
\hline \multicolumn{5}{|l|}{$\begin{array}{l}\text { Duración de la visita a la } \\
\text { ciudad }\end{array}$} \\
\hline Medio día & $80,81 \%$ & $90,82 \%$ & $91,92 \%$ & $87,84 \%$ \\
\hline 1 día & $7,07 \%$ & $6,12 \%$ & $4,04 \%$ & $5,74 \%$ \\
\hline 2 días & $3,03 \%$ & $2,04 \%$ & $3,03 \%$ & $2,70 \%$ \\
\hline 3 días & $6,06 \%$ & & & $2,03 \%$ \\
\hline Más de 3 días & $3,03 \%$ & $1,02 \%$ & $1,01 \%$ & $1,69 \%$ \\
\hline \multicolumn{5}{|l|}{$\begin{array}{l}\text { Número de personas con las } \\
\text { que viaja }\end{array}$} \\
\hline Solo & $19,19 \%$ & $22,45 \%$ & $16,33 \%$ & $19,32 \%$ \\
\hline 2 personas & $24,24 \%$ & $51,02 \%$ & $43,88 \%$ & $39,66 \%$ \\
\hline 3 a 9 personas & $48,48 \%$ & $22,45 \%$ & $31,63 \%$ & $34,24 \%$ \\
\hline 10 o más personas & $8,08 \%$ & $4,08 \%$ & $8,16 \%$ & $6,78 \%$ \\
\hline \multicolumn{5}{|l|}{ Como conoció el sitio } \\
\hline Agencia de viajes & $1,01 \%$ & & $3,03 \%$ & $1,35 \%$ \\
\hline Amigos/conocidos/familia & $63,64 \%$ & $24,24 \%$ & $42,42 \%$ & $43,43 \%$ \\
\hline Internet & $6,06 \%$ & $5,05 \%$ & $6,06 \%$ & $5,72 \%$ \\
\hline Prensa/radio/TV & $1,01 \%$ & & $4,04 \%$ & $1,68 \%$ \\
\hline Publicidad & $2,02 \%$ & & & $0,67 \%$ \\
\hline Otros & $26,26 \%$ & $67,68 \%$ & $42,42 \%$ & $45,45 \%$ \\
\hline No sabe / No contesta & & $2,03 \%$ & $2,02 \%$ & $1,68 \%$ \\
\hline \multicolumn{5}{|l|}{$\begin{array}{l}\text { Motivos de elección del destino } \\
\text { (promedio escala Likert 1-5) }\end{array}$} \\
\hline Patrimonio cultural & 4,64 & 4,51 & 4,70 & 4,62 \\
\hline Actividades culturales & 3,09 & 2,31 & 2,36 & 2,63 \\
\hline Ocio (gastronomía, compras, etc.) & 3,84 & 3,59 & 3,39 & 3,61 \\
\hline Entorno natural & 3,09 & 4,35 & 4,56 & 4,00 \\
\hline Cercanía al domicilio & 3,18 & 3,68 & 3,52 & 3,46 \\
\hline Paquete turístico & 1,28 & 1,42 & 1,21 & 1,30 \\
\hline
\end{tabular}

Fuente: Elaboración propia a partir de resultados de las encuestas a turistas.

En cuanto a la vía de conocimiento de estos destinos que motivó la decisión de su visita, se puso de manifiesto el bajo impacto de la difusión turística vía Internet, medios de comunicación o publicidad (sólo alrededor de un 8\% del total conocieron la existencia de esos destinos gracias a estas vías) o de las agencias de viajes (indicativo de un mayor grado de auto-organización y pérdida de peso de los turoperadores); y sin embargo, el alto impacto del boca a boca (amigos, conocidos, familiares, etc.), junto a otros factores muy diversos (por cercanía, por ser conocidas desde siempre, por trabajo, etc.). Esta situación llama la atención, pues en el análisis cualitativo de los discursos de agentes locales se ponía énfasis en la promoción en los medios de comunicación tradicionales, lo cual demuestra la disonancia entre la difusión que los agentes creían más eficaz (y por eso se utiliza: web, publicidad, etc.) y lo que en realidad lo era (el boca a boca). Precisamente esto último abre la puerta a incorporar la visión que 
los vecinos destacaban como atractiva, más cerca del turismo experiencial y diferenciado, que del estandarizado y patrimonial. Así las aportaciones hechas desde la base social servirían de atractivos para otros sectores supralocales, tanto de la región como de otras escalas.

Por su parte, los turistas de las tres ciudades tienen claro que llegan a ellas atraídos primeramente por su Patrimonio Cultural y, en el caso de San Lorenzo de El Escorial y Aranjuez, también por su entorno natural (segundo lugar). El tercer factor de atracción es la oferta de ocio y de actividades recreativas y el cuarto la proximidad al domicilio. Por lo tanto, es evidente que el activo patrimonial es el principal atractor y que, sin embargo, la oferta cultural, de ocio, gastronómica, etc. valorizada por la población local, podría potenciarse más, puesto que aparece insuficientemente desarrollada. Es en esta área donde el estudio señalaba una de las potencialidades de desarrollo social y político al tiempo que económico. En el corto plazo, además, el escenario pandémico y -en su momento- pospandémico, refuerzan la ventaja que otorga a estos lugares su cercanía al mercado emisor madrileño sobre todo cuando las distancias se acortan.

\subsection{Cómo revierte el gasto turístico en el destino}

Puesto que supondría un indicador de éxito de las estrategias promotoras, así como fuente para el desarrollo local, también se ha incluido un apartado de estudio acerca del impacto del turismo sobre la economía local. Un primer determinante del gasto turístico es el número de personas que viajan (cuya consideración lleva al concepto de gasto per cápita) y la lejanía de su domicilio. Se comprobó que los encuestados que residían más lejos hicieron un gasto general mayor que los más cercanos, pareciendo así que la atracción de más turistas más allá del ámbito regional, podría tener un mayor impacto económico. Sin embargo, el estudio indicó que la mayoría de los visitantes provenían, como ya se ha señalado, del área española y madrileña, con un gasto total promedio de 100 euros por persona y viaje. Otro factor clave es el número de días del viaje, siendo generalmente mayor el gasto a medida que aumenta su duración global. Este elemento afecta a la cantidad diaria gastada: el 44\% de los encuestados gastaba menos de 20 euros por persona por día; un tercio, de 20 a 49 euros y el $22 \%, 50$ euros o más. Sin embargo, no toda esa cantidad se desembolsa en las ciudades estudiadas. De hecho, más del 8\% de los encuestados no incurría en ningún gasto en Aranjuez y San Lorenzo del Escorial y más de un tercio en general gastaba menos de 10 euros por persona por día. Solo el 15\% gastaba más de 50 euros por día por persona. Se hace así evidente que sólo una limitada fracción del gasto turístico acaba siendo recibido a nivel local. Pese a que se necesitan estudios de mayor alcance y representatividad, vemos que en el impacto económico del turismo sobre estas localidades el factor determinante es la duración de la visita, dado que el gasto potencial está determinado por factores que se escapan a la gestión de los agentes locales (renta de los turistas, lugar de procedencia, hábitos y preferencias individuales, etc.). En consecuencia, resulta esencial para conseguir un mayor retorno efectivo, no sólo potenciar la atracción de visitantes, sino también proponer una oferta cultural capaz de fijar al visitante en el municipio por más tiempo o más a menudo.

\subsection{Qué elementos se pueden potenciar según la ciudadanía}

Continuando con esa idea de conveniencia de enriquecer la oferta de este tipo de destinos, analizamos la experiencia de la visita con la vista puesta en la detección de recursos que muestran el atractivo real y con potencial para dinamizar el turismo. Para ello, se pidió a participantes -a través de las distintas metodologías implementadas- que propusieran una serie de lugares a visitar y de actividades a realizar en cada una de las tres ciudades. De este modo, los atractores locales para los residentes se ponían en el punto de mira de los turistas para conseguir una mayor efectividad. El propósito era hacer de los vecinos embajadores turísticos, difundiendo el atractivo de sus municipios, lo que potencia su implicación y sus sentimientos de orgullo, pertenencia e identidad, revirtiendo todo ello en beneficio del conjunto del municipio. Ya que nos movemos en marcos de turismo como experiencia, la experiencia de los locales puede ser un buen atractivo para los visitantes, y de hecho los vecinos aportaron mucha información sobre lugares y actividades atractivas que podrían ponerse en valor. La ya antigua definición del turismo cultural como conocimiento de lo físico, el monumento, etc. (Yale, 1991), queda denostada ante el turismo cultural experiencial. Este sería el punto clave para potenciar eslóganes como To live like a local:

"Pero si la gente que pernocta no le damos facilidades para tomar algo hasta tal hora no es una cosa que atraiga a la pernoctación, si no puedes salir y tener unos alicientes (...) Cuando están los cursos de verano 
viene gente y eso se nota, salen por la noche a tomar algo y se sientan en las terrazas de la peatonal, se nota se ven grupos" (G2 grupo de discusión de El Escorial)

"Lo importante es arraigar a la generación siguiente. El hospital nos hizo mucho bien porque la gente empezó a poner en el DNI Alcalá de Henares y ya empezó a haber mucha gente que se sentía de Alcalá pero cuando éramos pequeños la gente no se sentía de Alcalá y si no te sientes de Alcalá no puedes amar algo que no sientes como tuyo, para amar algo tienes que sentirlo como tuyo y entonces uno de los desafíos que tenemos es conseguir que la gente ame a la ciudad y para que ame a la ciudad debe conocerla y para conocerla debe sentirla como suya” (G1 grupo de discusión Alcalá de Henares)

El análisis de la información publicitada en redes y webs reveló un discurso promotor oficial, tradicional, estandarizado y repetitivo en contenidos, sin apenas innovación. Incluso la "marca" Patrimonio Mundial, aparecía vacía de contenido y, aunque resultaba conocida por visitantes y habitantes, era poco utilizada en estos destinos. Frente a ello, los locales proponían experiencias que iban más allá de la visión clásica, para incluir experiencias que aludían a significados diferentes de los lugares. En los procesos participativos se registraron amplios listados de sugerencias y se plantearon rutas de ocio sobre los mapas, para componer una agenda experiencial y de actividades más atractiva:

"En el momento de la salida del sol en septiembre, me encanta el reflejo del sol en las ventanas del Monasterio. Refleja una bola de fuego"; "La silla de Felipe II es un lugar de culto y mágico de la antigüedad. Es el sitio donde da el último rayo de sol del día». (A1 Proceso participativo de vecinos de San Lorenzo del Escorial). "Jugaba al fútbol enfrente del Palacio; "la plaza elíptica era un campo de fútbol, las porterías eran los plátanos. Encajaban el balón en el palacio Real” (A2 Proceso participativo de vecinos de Aranjuez).

"La plaza Cervantes era de barro, por un lado paseaban las mujeres y por otro los hombres" (A3 Proceso participativo de vecinos de Alcalá de Henares).

Así, por ejemplo, sugerían incluir en las visitas zonas ubicadas fuera de los casos históricos, como los yacimientos arqueológicos de Alcalá de Henares; o la difusión de otros valores, como la sostenibilidad con aparcamientos disuasorios o la recomendación del transporte público para la visita; o la propuesta de un turismo de naturaleza (disfrute de entornos naturales, paseos en bicicleta, etc.) o experiencial (barco en el río en Aranjuez, experiencia enológica, etc.); o la elaboración de mapas de atractivo para los visitantes (rutas gastronómicas, guías de los mejores bares y restaurantes, qué hacer un viernes o en familia, turismo con niños, etc.). También se recogieron propuestas que iban más allá del ámbito municipal, como la coordinación con otros enclaves turísticos cercanos para promocionar áreas de desconcentración en lugar de incidir en la atracción sobre un solo punto. Este tipo de medidas requeriría la coordinación de los agentes institucionales en sus diferentes escalas territoriales (nacional, regional, local), aspecto que en la actualidad se evidencia relativamente descoordinado. Un buen ejemplo en tal sentido es una estrategia comunicacional coordinada entre la ciudad de Madrid y los tres sitios, propuesta que emergió en distintos momentos de la investigación. Entendemos que la declaración del Paseo del Prado y el Parque del Retiro como nuevo sitio Patrimonio Mundial en julio de 2021, es una oportunidad añadida en esa misma línea.

\section{Discusión}

Comenzábamos este trabajo partiendo del problema actual de los impactos negativos del turismo, en particular para las ciudades: sobreexplotación de recursos, pérdida de calidad de vida de los residentes, merma de la experiencia turística, etc. (Barrado e Hidalgo, 2019). Los destinos basados en el Patrimonio Cultural, como son los analizados en este trabajo, no escapan a esa situación (Troitiño, 2012), siendo en su caso menos soportable aún, ya que afecta a la naturaleza misma de esos bienes, que lleva implícita la necesidad de su sostenibilidad y la gestión responsable (UNWTO, 2013; ICOMOS, 2017).

En este estudio ha quedado demostrada la conveniencia de poner en marcha estrategias orientadas a la sostenibilidad de los destinos, mediante el esponjamiento en áreas supralocales del turismo que gravita sobre dichos espacios centrales. Para ello, es clave potenciar el atractivo de otros lugares cercanos, incrementar el tiempo de estancia de los visitantes en ellos -con el consiguiente aumento del gasto turístico- y atraer a otros sectores no interesados hasta el momento. No memos importante es la realización de estudios de público, la mejora de los sistemas de información turística y, sobre 
todo, hacer partícipe de la gestión del Patrimonio y el turismo a la población local, de manera que su conocimiento se ponga al servicio del proceso. En esa captación de mercados nuevos, destacaría como apuesta el turismo de proximidad, de gran potencial y clave en contextos como el actual, marcado en el corto y medio plazo por la pandemia de Covid-19 (Arold, 2021), en el que se restringen los movimientos de larga distancia. Ello permitiría, además, constituirse en alternativa a la ciudad de Madrid en los movimientos turísticos, aliviando la saturación de ese destino de referencia. Como venimos proponiendo, la reciente incorporación de la arteria capitalina al listado UNESCO, supone una oportunidad que se suma al puzzle actual y abre nuevas posibilidades para reforzar la capacidad de atracción del conjunto de lugares patrimoniales de una región que se consolida como referencia internacional.

De igual modo y desarrollando esa idea, en áreas supralocales donde predomina una gestión fundamentada en criterios de competencia administrativa, parcial y localista, el estudio pone en valor la necesidad de coordinar las distintas administraciones y agentes en entornos relacionales sobre áreas más amplias. Se trataría de considerar los flujos y movimientos espaciales sobre la base de áreas funcionales y no estrictamente administrativas o sectoriales. Para ello, insistimos, es imprescindible orientar en tal sentido la gestión patrimonial y turística (UNWTO, 2013), mediante la coordinación de los múltiples agentes implicados en ambas dimensiones: administraciones de distintos niveles, agentes económicos y los propios vecinos de las localidades. Los primeros tienen en su mano diseñar políticas públicas reequilibradoras del desarrollo regional, utilizando como palancas el Patrimonio y el turismo cultural. Los segundos, tienen la necesidad evidente de continuar adaptando su oferta comercial a los cambios de la demanda turística. Y la base social es un actor de primer orden con mucho que aportar para enriquecer las experiencias de los visitantes (turismo experiencial, emocional, etc.), al tiempo que su participación en esos procesos fortalece su identidad, mejora la cohesión social y contribuye a una mejor gobernanza urbana, proporcionando nuevas rentabilidades al Patrimonio y al turismo más allá de la contabilidad económica. Se consigue de ese modo alcanzar sinergias entre distintos ámbitos, sectores, colectivos, etc., de cara a una planificación integral y holística, de acuerdo a una perspectiva relacional.

Las estrategias tradicionales, de amplia tradición en la planificación turística y del patrimonio, se ponen así en cuestión por su tendencia a generar intensas inercias en el funcionamiento de las instituciones, difíciles de abandonar y que son una barrera para la implementación de planteamientos nuevos más participativos, a pesar de sus buenas intenciones (Santana, 1997; Lara de Vicente y López-Guzmán, 2004; ICOMOS, 2011; Díez et al, 2013). Dichas estrategias clásicas normalizan una planificación que va de arriba-abajo, esto es, desde las instituciones implicadas (arriba) hacia la ciudadanía y la demanda turística (abajo). En ellas el agente es la institución en sentido amplio y el objeto de las políticas es la ciudadanía y el turismo. En contraposición a esas políticas públicas e institucionales de sujeto versus objeto, planteamientos alternativos abogan por la consideración de líneas más relacionales, inclusivas, integrales y participativas, en un planteamiento de abajo-arriba y de ida y vuelta. En ellas se propone de manera efectiva perspectivas no tan jerarquizadas, que ponen énfasis en lo relacional e integral. En esta línea se destacan, por ejemplo, los trabajos de Prats, 2009; Huete, 2010; Rivera y Rodríguez, 2012; Castillo, 2015; ICOMOS, 2017; Agenda Urbana Española, 2019; Domínguez Pérez, 2019; García, 2019 y Gómez, Crespi y Domínguez, 2020.

Más aún, en este trabajo hemos constatado -en la línea de la Agenda Urbana Española (2019) y Gómez, Crespi y Domínguez (2020)- que un elemento fundamental que subyace a toda esta dinámica, es la conveniencia de potenciar la participación ciudadana en la elaboración de estrategias de turismo que pudieran revertir, tanto en el reequilibrio turístico regional, como en la mejora de la vida interna de los municipios, su identidad y gobernanza.

Por último, aparece la necesidad de mejorar los sistemas de información, promoviendo la realización de detallados estudios especializados que cuenten también con los agentes implicados, incluyendo la ciudadanía, los turistas, etc. Como ha sido reiteradamente señalado en tantos ámbitos y en particular en el del Patrimonio Cultural y el turismo (Pedersen, 2005; Comisión Europea, 2013; UNESCO, 2014; Adie y Hall, 2016; Kempiak et al, 2017; OMT, 2017), disponer de información fiable es la base que permite desarrollar estrategias de gestión adecuadas. Y es que resulta imprescindible conocer de manera efectiva dónde radican los respectivos mercados turísticos con mayor potencial, cuáles son las demandas actuales de los visitantes y su grado de satisfacción con las visitas, así como su potencialidad para abrir nuevas vías de interés. 


\section{Conclusiones}

Los casos que se han analizado en este trabajo, localizados en la periferia de la ciudad de Madrid, son un buen ejemplo del delicado escenario que aparece por el uso turístico del Patrimonio Cultural. En particular, de la necesidad de encontrar equilibrios entre las oportunidades de desarrollo económico y social y los riesgos de sobreexplotación de recursos y generación de impactos negativos sustantivos.

En nuestro acercamiento hemos encontrado, en primer lugar, tres lugares con una gran riqueza patrimonial y en los que el turismo tiene un papel preponderante en su economía, que hacen del Patrimonio Cultural y el turismo, motores de la actividad y el desarrollo locales. También con un gran potencial para contribuir, más allá de lo local, a la redistribución del impacto turístico regional, a su esponjamiento desde la concentración en la ciudad de Madrid.

Para lograr ambos objetivos, tres elementos son particularmente necesarios: 1) el establecimiento de actuaciones coordinadas de los múltiples agentes presentes en el escenario, orientadas a ese propósito concreto; 2) la incorporación activa de los residentes locales, generadora de sinergias hacia afuera (atracción turística) y hacia adentro (vertebración social) de las localidades; 3) la generación de conocimiento especializado sobre la materia.

Así lo revelan algunos de los resultados más significativos de la investigación, como la conveniencia no sólo de atraer e intentar prolongar la estancia de turistas lejanos, sino también de fomentar la reiteración de la visita de visitantes procedentes del rico mercado madrileño (estrategias de fidelización, aún más importantes en momentos como los actuales); la importancia del boca a boca en la promoción del destino, por encima de otros medios de difusión más establecidos (y caros); la conveniencia de modernizar y diversificar una imagen turística clásica-patrimonial para incorporar más elementos de cultura, ocio, gastronomía, etc. o una mayor integración con la población local, lo que ampliaría el horizonte de la oferta y renovarían el atractivo de estas ciudades, tanto para turistas como para unos ciudadanos que actúan como embajadores turísticos.

Aunque las conclusiones alcanzadas también resultan de aplicación en otros territorios que presenten una configuración semejante, los tres casos analizados resultan idóneos para poner en práctica este tipo de indicaciones, pues suscitan un gran interés turístico, sus vecinos se muestran receptivos a la recepción de visitantes y se detecta un recorrido significativo en los contenidos que se pueden ofertar. La clave parece estar, una vez más, en una gestión patrimonial y una programación cultural más abiertas y flexibles, adaptadas a la nueva realidad social y cultural. Todo ello redundará, en última instancia, en el desarrollo económico y social de los lugares con activos patrimoniales y la sostenibilidad territorial de la actividad turística a nivel regional.

\section{Bibliografía}

Adie, B. A. y Hall, C. M. (2017). "Who visits World Heritage? A comparative analysis of three cultural sites". Journal of Heritage Tourism,12(1): 67-80.

Agenda Urbana Española (2019). https://apps.fomento.gob.es/CVP/detallepublicacion.aspx?idpub=BAW061 Visitado 29 de septiembre de 2020.

Aguado, L. F., Palma, L. y Pulido, N. (2017). "50 años de economía de la cultura. Explorando sus raíces en la historia del pensamiento económico", Cuadernos de Economía, 36 (70): 197-225.

Alonso, J. y Martín, J. (2008). Conservación del Patrimonio Histórico de España. Análisis económico. Madrid: Fundación Caja Madrid.

Alonso, J. y Martín, J. (2013). “Activos culturales y desarrollo sostenible: la importancia económica del Patrimonio Cultural”, Política y Sociedad, 50 (3): 1133-1147.

Andres, J. L. (2015). "Mito y estrategias para un destino romántico: la ciudad de Teruel". Cuadernos de Turismo, 36: 39-54

Arold, P. (2021). Apuntes para la gestión del turismo en España tras la crisis sanitaria de la Covid-19. PASOS Revista De Turismo Y Patrimonio Cultural, 19(1), 189-194.

Aronsson, L. (2000). The Development of sustainable tourism. Nueva York: Continuum.

Barrado, D. e Hidalgo, C. (2019). "Golden hordes or mere barbarians? Discourses on tourism, touristification, and tourismophobia in Madrid's Lavapiés neighborhood”. Boletín de la Asociación de Geógrafos Españoles, (83). 
Barrio, M. J. y Herrero, L.C. (2014). "Evaluating the efficiency of museums using multiple outputs: evidence from a regional system of museums in Spain", International Journal of Cultural Policy, 20(2): 221-238.

Beck, U., Giddens, A. y Lash, S. (1997). Modernización reflexiva. Política, tradición y estética en el orden social moderno. Madrid: Alianza Editorial.

Becker, E. (2013). Overbooked. The exploding business of travel and tourism. New York.

Bedate, A. et al. (2004). "Economics Valuation of the Cultural Heritage. Application to four case studies in Spain", Journal of Cultural Heritage, 5(1): 101-111.

Bonet, L. (2013). "Heritage Tourism", en Rizzo, I. y Mingosa, A. (Eds.) Handbook on the Economics of Cultural Heritage (pp. 386-401). Cheltenham (UK): Edward Elgar.

Bramwell, B. (2015). "Theoretical activity in sustainable tourism research". Annals of Tourism Research, 54: $204-218$.

Buckingham, S. (2011). "Análisis del derecho a la ciudad desde una perspectiva de género". En Sugranyes, A. y Mathivet, C. Ciudades para tod@s. Por el derecho a la ciudad, propuestas y experiencias (pp. 59-64). Santiago: Hábitat International Coalition,

Calle, M. de la (2019). "Turistificación de centros urbanos: clarificando el debate". Boletín de la Asociación de Geógrafos Españoles, 83, 2829, 1-40.

Calle, M. de la; Ferreiro, E. y Mendoza, S. (2018). "Concentración y desconcentración de la actividad turística sobre el espacio urbano. Reflexiones en torno a Madrid”. Polígonos. Revista de Geografía, 30, 143-170.

Calle, M. de la, García, M. y Mínguez, M.C. (2015). "El despliegue del ocio turístico en el territorio de la Comunidad de Madrid”. Ciudad y Territorio. Estudios territoriales. Vol. XLVII, nº 184, pp. 293-308.

Carta de Bruselas (2009). Carta de Bruselas sobre el papel del Patrimonio Cultural en la Economía. Junta de Castilla y León.

Castillo, A. (Ed.) (2015). Actas del II Congreso de Buenas Prácticas en Patrimonio Mundial: Personas y Comunidades. Madrid: Universidad Complutense de Madrid.

Cavailles, C., Laurent, M., Maurin, S. y Sánchez, J. L. (2016). "Los turistas en el centro histórico de Salamanca: tránsito, percepción y (des)conocimiento", Cuadernos de Turismo, 37: 37-67.

Comisión Europea (2013). Herramienta del Sistema Europeo de Indicadores Turísticos para Destinos Sostenibles. Bruselas: D. G. Empresa e Industria.

Cortijo, E. y Pulido, M. (2016). "Percepción de la población residente en Cañamero acerca del geoparque Villuercas-Ibores-Jara (Extremadura, España)", Cuadernos de Turismo, 37: 93-112.

Crespi Vallbona, M. y Domínguez Pérez, M. (2016). "Food markets and tourist cities". PASOS: Revista de Turismo y Patrimonio Cultural, 14(2), 401-416.

Devesa, M. et al. (2012). "Repercusiones económicas y sociales de los festivales culturales. El caso el Festival Internacional de Cine de Valdivia”, EURE - Revista Latinoamericana de Estudios Urbano-Regionales, 38: 95-115.

Díez, J. I. M., Gutiérrez, R. R. \& Pazzi, A. (2013). “De arriba hacia abajo o de abajo hacia arriba?: un análisis crítico de la planificación del desarrollo en América Latina”, Geopolítica(s), vol. 4, núm. 2, 199-235.

Domínguez Pérez, M. (2019). "Del patrimonio como la cristalización de la historia de la comunidad urbana y su identidad”, PH Revista Patrimonio Histórico, 97. Instituto de estudios andaluces.

Dormaels, M. (2011). "Patrimonio, patrimonialización e identidad. Hacia una hermenéutica del patrimonio". Revista Herencia, 24 (1-2), 7-14.

Ehrlich, P. E. (2009). "Cultural evolution and the human predicament". Trends in Ecology \& Evolution, 24: 409-412.

Elkington, J. (2002). Cannibals with forks: the triple bottom line of 21st century business (Reprint). Capstone.

Encuesta de Ocupación Hotelera (2020). INE https://www.ine.es/dyngs/INEbase/es/operacion.htm?c=E stadistica_C\&cid $=1254736177015 \&$ menu $=$ resultados\&secc $=1254736195376 \& i d p=1254735576863 \#$ !tabs-1254736195376 visitado 29 de septiembre de 2020

European Commission (2012). Promoting cultural and creative sectors for growth and jobs in the EU. Brussels.

Fenster, T. (2010). "El derecho a la ciudad y la vida cotidiana basada en el género", en Sugrañes, A. y Mathivet, C. Ciudades para tod@s: por el derecho a la ciudad, propuestas y experiencias (pp. 65-80). Santiago de Chile: HIC.

Florida, R. (2009). Ciudades creativas. Barcelona, Paidós. 
Frey, B. y Steiner L. (2011). "Correcting the imbalance of the Word heritage list: did the UNESCO strategy work?", Journal of International Organizations Studies, 3(1): 25-40.

FUNDEU (2018). Diccionario. (Fundación patrocinada por la Agencia Efe y el BBVA, asesorada por la RAE). https://www.fundeu.es/recomendacion/turistificacion-neologismo-valido/ visitado 8 de octubre 2020

García, M., De la Calle, M. y Yubero, C. (2017). "Cultural Heritage and Urban Tourism: Historic City Centres under Pressure”. Sustainability 9: 1346.

García, M., de la Calle, M. y Mínguez, M. (2015). "Cultura y Patrimonio en las prácticas turísticas de la población madrileña”, International Journal of Scientific Management and Tourism, 4: 97-124.

García, R. (2019). La Sostenibilidad, clave para el futuro de la industria turística. Fecha de consulta: 5 de septiembre de 2019. https://bit.ly/2ZKwyod

Gómez, M., Crespi, M. y Domínguez, M. (2020). "El patrimonio urbano como intersección de espacio y sociedad. Una oportunidad para el replanteamiento del rol del patrimonio en las agendas urbanas", en Alonso, M. R., De Gregorio, S. y González, M. Las agendas urbanas y el gobierno de las ciudades: transformaciones, desafíos e instrumentos. Barcelona: Reus.

Hania, U., Azzadinaa, I., Sianipara, C., Setyagunga, E. e Ishii, T. (2012). "Preserving cultural heritage through creative industry: A lesson from Saung Angklung Udjo”, Procedia Economics and Finance, 4: 193-200.

Herrero, L. C. y Gómez, M. (2017). "Cultural resources as a factor in cultural tourism attraction: Technical efficiency estimation of regional destinations in Spain", Tourism Economics, 23 (2): 260-280.

Herrero, L.C. et al. (2006). "The economic impact of cultural events: a case-study of Salamanca 2002, European Capital of Culture", European Urban and Regional Studies, 13 (1): 41-57.

Huete, R. (2010). Opiniones y actitudes ante el turismo residencial en el sur de la Comunidad Valenciana http://www.theeconomyjournal.com/texto- diario/mostrar/591498/saturacion-destinos-turisticos-barcelona-exporta-modelo-sur.

ICOMOS (2011). Declaración de París sobre el Patrimonio como motor de desarrollo. Paris, UNESCO.

ICOMOS (2017). Delhi Declaration on Heritage and Democracy. Paris, UNESCO.

Informe Brundtland (1987). Nueva York: ONU.

Jurowski, C. y Gursoy, D. (2004). "Distance effects on residents; attitudes toward tourism". Annals of Tourism Research, 31(2): 296-312.

Kempiak J., Hollywood, L., Bolan, P. y McMahon-Beattie, U. (2017). "The heritage tourist: an understanding of the visitor experience at heritage attractions", International Journal of Heritage Studies, 23(4): 375-392.

Landriani, L. y Pozzoli, M. (2014). Management and Valuation of Heritage Assets. A Comparative Analysis Between Italy and USA. Springer International Publishing.

Lara de Vicente, F. y López-Guzmán, T. (2004). "El turismo como motor de desarrollo económico en ciudades Patrimonio de la Humanidad". Pasos 2(2): 243-256.

Lefebvre, H. (2017). El derecho a la ciudad, Madrid: Capitán Swing.

Liu, Z. (2003). "Sustainable tourism development: A critique". Journal of Sustainable Tourism, 11(6), 459-475.

López-Guzmán, T. y Sánchez, S. M. (2009). “Turismo comunitario y generación de riqueza en países en vías de desarrollo. Un estudio de caso en El Salvador". REVESCO. Revista De Estudios Cooperativos, 99: 85 - 103.

Manero, F. (2011). "Patrimonio cultural y transformación urbana: ordenación espacial y proyección turística de los yacimientos arqueopaleontológicos de Atapuerca (Burgos)". Cuadernos de Turismo, 27: 617-640.

Marcos, J. (2004). "La tradición, el patrimonio y la identidad”. Revista de estudios extremeños, 60 (3): 925-956.

Martos Molina, M. (2012). "Las ciudades patrimoniales en el mercado turístico cultural. Úbeda y Baeza". Gran Tour: Revista de Investigaciones Turísticas, 6: 32-82.

Mason, P. (2008). Tourism impacts Planning and management. Londres: Butterworth-Heinemann.

McCool, S., Butler, R., Buckley, R., Weaver, D. y Wheller, B. (2013). "Is Concept of Sustainability Utopian: Ideally Perfect but Impracticable?” Tourism Recreation Research, 38(2): 213-242.

Milano, C., Novelli, M. y Cheer, J. M. (2019). "Overtourism and Tourismphobia: A Journey Through Four Decades of Tourism Development, Planning and Local Concerns", Tourism Planning \& Development, $16: 4,353-357$ 
Mínguez, M.C. (2007). "Planificación y Gestión Turística en destinos patrimoniales: el caso de San Lorenzo de El Escorial (Comunidad de Madrid)". Anales de la Geografía de la Universidad Complutense de Madrid, n ${ }^{\circ}$ 27. Pp. 83-102.

Navarro, E. (2015). "La saturación de los destinos turísticos; Barcelona exporta su modelo al sur". The Economy Journal.

Nyseth, T. y Sognnaes, J. (2013). "Preservation of old towns in Norway: Heritage discourses, community processes”, Cities, 31: 69-75.

Organización Mundial del Turismo (OMT) (2017). Compendium of Tourism Statistics. Data 2011- 2015. OMT.

Palma, L. A. y Aguado, L. F. (2010). "Economía de la Cultura. Una nueva área de especialización de la Economía", Revista de Economía Institucional, 12 (22): 129-165.

Pedersen, A. (2005). Gestión del turismo en sitios del Patrimonio Mundial: Manual práctico para administradores de sitios del Patrimonio Mundial. Centro del Patrimonio Mundial, UNESCO.

Pérez, Y. (2015). "Diseño de un Sistema Integral de Análisis del Turismo (SIAT) en destinos patrimoniales", Investigaciones Turísticas, 10: 57-75.

Pérez, Y. y Lois, R. C. (2018). "Sustainability and visitor management in tourist historic cities: the case of Santiago de Compostela, Spain”. Journal of Heritage Tourism 13 (6): 489-505.

Perkumiene, D. y Pransküniené, R. (2019). “Overtourism: Between the Right to Travel and Residents' Rights". Sustainability, 11(7), 21-38.

Prats, F. (2009). "La evaluación integrada de la sostenibilidad en destinos turísticos". Conferencia Internacional de Turismo. El conocimiento como valor diferencial de los destinos turísticos. Málaga.

Preece, J. (2020). "Belonging in working-class neighbourhoods: dis-identification, territorialisation and biographies of people and place". Urban Studies Vol. 57 (4), 827-843.

Pulido, J. I. y Pulido, M. C. (2015). “Sigue vigente el paradigma del turismo sostenible? Reflexiones a la luz de la literatura reciente". Pasos. Revista de Turismo y Patrimonio Cultural, 13(6), 1315-1335.

Radoslav, R., Branea, A. M. y Gaman, M. S. (2013). "Rehabilitation through a holistic revitalization strategy of historical city centres - Timisoara, Romania", Journal of Cultural Heritage, 14 (3): e1-e6.

Rengifo, J. L., Campesino, A. J. y Sánchez, J. M. (2015). "El turismo en la ciudad de Cáceres (1986-2010): un cuarto de siglo emblemático". Boletín de la Asociación de Geógrafos Españoles, 67: 375-401.

Rivera, M. y Rodríguez, L. (2012). "Turismo responsable, sostenibilidad y desarrollo local comunitario". Córdoba (España): Cátedra Intercultural, Universidad de Córdoba.

Rizzo, I. y Mignosa, A. (Eds.) (2013). Handbook on the Economics of Cultural Heritage. Cheltenham (UK): Edward Elgar.

Rull, V. (2010). "El mito del desarrollo sostenible". Collectanea Botanica, 29: 103-109.

Saarinen, J. (2006). "Traditions of sustainability in tourism studies". Annals of Tourism Research, 33(4): 1121-1140.

Sánchez Carretero, C. (2012). "Hacia una antropología del conflicto aplicada al patrimonio". En Santamarina, B. (Ed.) Geopolíticas patrimoniales: De culturas, naturalezas e inmaterialidades. Una mirada etnográfica (pp. 195-210). Valencia: Editorial Germania, Colección Antropológicas, Valencia.

Santana, A. (1997). Antropología y Turismo, ¿Nuevas hordas, viejas culturas? Barcelona, Ariel.

Snowball, J. D. (2013). "The economic, social and cultural impact of cultural heritage: methods and examples", en Rizzo, I. y Mingosa, A. Handbook on the Economics of Cultural Heritage (pp. 438-455). Cheltenham (UK): Edward Elgar.

Stabler, M. (1997). Tourism and sustainability: Principles and Practice. Oxon: CABI.

Stone, S. (2013). "Los beneficios de la transición hacia una economía verde". En Uría, A. (coord.): De la economía verde a las sociedades verdes (pp. 9-24). Madrid: Los libros de La Catarata.

Throsby, D. (1998). "Cultural capital", conference on International Association for Cultural Economics. Barcelona.

Trotiño, L. (2012). "Las Ciudades Patrimonio de la Humanidad de la Región Turística de Madrid: Niveles de medios de funcionalidad y adecuación turística del Patrimonio Cultural". Papers de Turisme, $\mathrm{n}^{\circ}$ 51. Pp. 109-132.

Troitiño, M. A. (2002). "Aranjuez: Patrimonio cultural, recuperación urbana y turismo". Anales de Geografía de la Universidad Complutense. Extraordinario/2002. Pp. 495-518.

UNESCO (2014). Indicadores UNESCO de Cultura para el desarrollo. Manual Metodológico. París, UNESCO.

United Nations world tourism organization UNWTO (2013). Sustainable Tourism for Development Guidebook. Madrid. 
Vanblarcom, B. L. y Kayahan, C. (2011). "Assessing the economic impact of a UNESCO World Heritage designation". Journal of Heritage Tourism, 6(2): 143-164.

Weaver, D. (2009). "Reflections on sustainable tourism and paradigm change". En Gössling, S., Hall, M. y Weaver, D. (eds.) Sustainable tourism futures. Perspectives on systems, restructuring and innovations (pp. 33.40). New York: Routledge.

Yale, P. (1991). From tourist attractions to heritage tourism. Huntingdon: ELM publications

Zukin, S. (1995). The cultures of cities (Vol. 150). Oxford: Blackwell.

\section{Notas}

1 Investigación enmarcada en el proyecto “Guía Ciudades Legado Patrimonio Mundial en Madrid” (Ref. 346/2014), (2014-15) por encargo de la Subdirección General de Desarrollo y Sostenibilidad de la Dirección General de Turismo de la Comunidad de Madrid, subvencionado por la Asociación Plataforma Turística de Madrid. IP del Proyecto: Alicia Castillo Mena

2 https://www.turismomadrid.es/es/profesionales/estadisticas.html

3 https://www.madrid-destino.com/turismo/estadisticas

4 Encuesta de ocupación hotelera 2020, INE.

5 Desde el último cuarto del pasado siglo se ha desarrollado un sólido cuerpo científico que ha evidenciado las capacidades socioeconómicas del Patrimonio Cultural (Palma y Aguado 2010, Aguado et al 2017). Casos concretos: Bedate et al, 2004; Alonso \& Martín, 2008; Devesa et al, 2012; European Commission, 2012; Rizzo \& Mingosa, 2013; Barrio \& Herrero, 2014; Landriani \& Pozzoli, 2014; Herrero y Gómez, 2017.

6 Encuesta representativa según cuotas de sexo, grupo de edad y barrio de residencia. Intervalo de confianza: 95\%; margen de error: $7 \%$. Campo: junio y julio de 2015 .

7 Se seleccionaron al azar no residentes en una muestra equilibrada por género. Dado que no hay bases de datos que definan los grupos turísticos de estas ciudades, la muestra no pudo ser afijada por cuotas, por lo que las características de la población encuestada deben entenderse como indicativas del perfil y actitudes de la muestra.

8 Visitante sin pernoctación. Todo visitante que no pernocta en un medio de alojamiento colectivo o privado en el lugar visitado. Definición: Glosario Instituto de Estudios Turísticos. 


\section{Patrimónios Durienses}

UMA HERANÇA CULTURAL DA HUMANIDADE

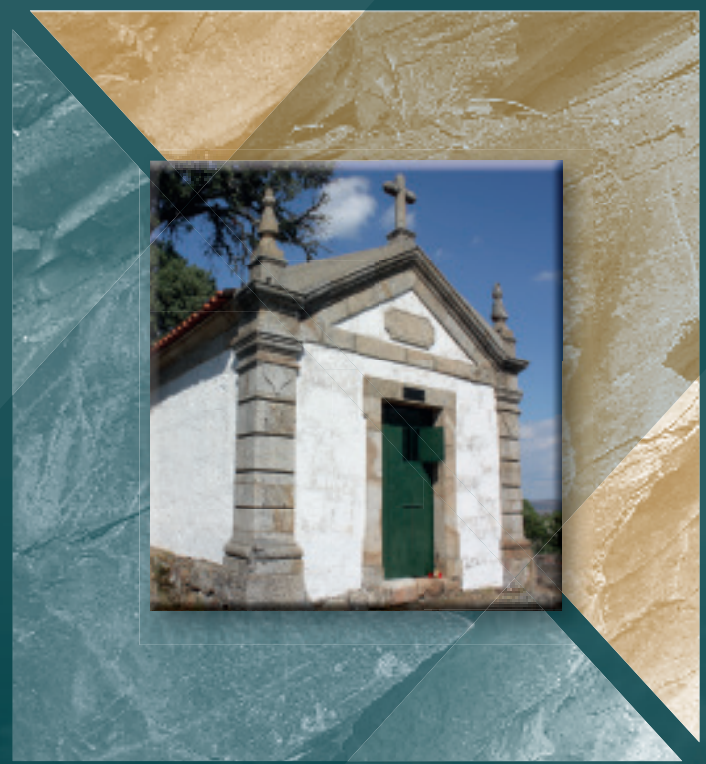

Turismo

Património

Desenvolvimento

Aurélio de Oliveira Brochado de Almeida Eduardo Gonçalves 


\title{
La autopercepción del turista cultural en su rol de turista
}

\author{
Fernando Pellicer* Raquel Camprubí** \\ Universidad de Girona (España)
}

\begin{abstract}
Resumen: La autopercepción del individuo ha sido explorada desde distintas aproximaciones de las ciencias sociales, aunque muy pocos estudios se han centrado en la autopercepción del individuo como turista. A partir del uso de entrevistas semiestructuradas, este trabajo pretende servir de aproximación a la percepción que el turista tiene de sí mismo en un contexto turístico de tipología cultural. Si bien los turistas culturales suelen autopercibirse de manera distinta al resto de visitantes, las actividades que realizan son bastante similares. Los resultados del estudio muestran que la autopercepción del turista cultural está sujeta a múltiples factores, que el hecho de considerarse un turista típico no necesariamente supone un atributo negativo en la percepción individual propia y que el turista cultural se identifica como tal, aunque no de manera inmediata.

Palabras Clave: Turismo cultural; Autopercepción; Autoconcepto; Turista cultural; Girona.

\section{Tourist self-perception in its tourist role}

Abstract: Self-perception of individuals has been explored from various perspectives in the social sciences; although, very few studies have focused on self-perception of individuals as tourists. By using semi-structured interviews, this research aimed at approximating a vision of a tourist's self-perception indestinations defined as cultural. The activities of tourists who visit cultural destinations are in every way similar to other tourists although they perceive themselves differently. Hence, the results of the study show that the cultural tourist' self-perception depends on multiple factors, that it is not necessarily negative for them to perceive themselves as typical tourists but that it is not an immediate self-perception.
\end{abstract}

Keywords: Cultural tourism; Self-perception; Self-concept; Cultural tourist; Gerona.

\section{Introducción}

Según datos de la Organización Mundial del Turismo (OMT), en 2017 se estimó que el turismo cultural se vinculaba con algo más del 39\% de las llegadas internacionales (UNWTO, 2018:21). No obstante, solo un pequeño porcentaje que oscila entre el $5 \%$ y el $10 \%$ de los turistas se llega a identificar como turista cultural (Richards, 2018). Cabe señalar entonces que, en ocasiones, hay discrepancias entre lo que las personas piensan que son y lo que realmente son, especialmente cuando se trata de atributos negativos (Prebensen et al., 2003). Según Culler (2007), ser turista constituye un aspecto negativo en la percepción individual propia, de modo que los turistas no quieren ser vistos como turistas sino como viajeros.

Son muchas las definiciones existentes sobre la autopercepción que se pueden encontrar en la literatura académica de las ciencias sociales, siendo mayoritariamente las tradicionales aquellas que presentan un enfoque individualista mientras que las más recientes hablan de la existencia de múltiples personalidades (Sirgy y Su, 2000). De hecho, numerosos estudios confirman que el consumo es un vehículo de autoexpresión que lleva al cliente a elegir los productos y marcas que percibe como similares al concepto que tiene de sí mismo (Hosany, 2016). En materia turística se ha demostrado que la congruencia de la autoimagen tiene una gran influencia en la toma de decisiones del destino a visitar (Phucharoen et al., 2016).

Por otra parte, las diferencias entre los distintos tipos de turistas ha sido un tema central de los estudios turísticos (McCabe, 2005). De hecho, las investigaciones relacionadas con el turismo cultural

\footnotetext{
* Universidad de Girona (España); E-mail: fernandopellicer95@gmail.com

** Universidad de Girona (España); E-mail: raquel.camprubi@udg.edu; https://orcid.org/0000-0001-7084-7889
} 
han prestado gran atención a la identificación de distintos tipos de perfiles a través de enfoques y perspectivas muy diversas, siendo las motivaciones de los visitantes una forma comúnmente utilizada para clasificar a los turistas culturales (Richards, 2018). Similarmente, la tipificación de segmentos turísticos en función de los estilos de vida de los usuarios ha sido una práctica usada para aproximarse de mejor manera a la comprensión del comportamiento de los turistas (Swarbrooke y Horner, 2007). Sin embargo, según Todd (2001), esta forma de segmentar no tiene en consideración el cómo se siente la persona en el momento en el que se está llevando a cabo la actividad, habiendo muy pocos estudios acerca de cómo se perciben los individuos en su rol de turista. Eso resulta especialmente interesante si se tiene en cuenta que la gente viaja para escapar de las rutinas establecidas de su espacio habitual, desplazándose a nuevos lugares y entornos que conllevan que el individuo cambie su modo normal de comportamiento (Boissevain, 2005).

Con todo ello, el objetivo principal de este trabajo es aproximarse a la autopercepción del turista cultural. Esto no solamente implica el cómo se percibe éste a sí mismo y si se considera un turista cultural o no, sino también tratar de identificar qué factores son los que configuran su propia imagen, entender cuáles son las diferencias que estos turistas encuentran entre ellos y el resto de visitantes, y verificar si el hecho de ser un turista se percibe realmente de manera negativa. Debido a que son varios los estudios que tratan el tema de la autopercepción en el ámbito turístico de manera cuantitativa (Todd, 2001; Prebensen et al., 2003; Doran et al., 2015; Hosany, 2016; Yu et al., 2012), esta investigación pretende responder a estas cuestiones a partir de un enfoque cualitativo aplicado a un contexto de destino turístico cultural, tomando la ciudad de Girona como caso de estudio.

\section{Marco teórico}

\subsection{El turismo y el turista cultural}

Se entiende por turismo cultural la actividad turística en la cual el motivo principal del viaje es el afán por aprender, descubrir y experimentar los distintos productos y atractivos culturales tangibles e intangibles de un destino (Richards, 2018). Ésto incluye el acercamiento a una serie de manifestaciones materiales, intelectuales, espirituales y emocionales que presenta una sociedad a través de múltiples aspectos como puede ser su patrimonio histórico y cultural, su arquitectura, arte, gastronomía, tradiciones y estilos de vida, entre otros (UNWTO, 2017:18). De este modo se deja de vincular el turismo cultural al mero disfrute de monumentos y museos, para relacionarlo con la tendencia creciente de que el turista busca la experiencia original y vivir la realidad del destino (Yeoman et al., 2007). Sin embargo, no todos los turistas culturales presentan las mismas motivaciones ni intereses por el mismo tipo de vivencias (McKercher, 2002), habiendo múltiples formas de catalogar a éstos.

Una de las clasificaciones más aceptadas es la elaborada por Richards (1996) que diferencia entre el turista cultural "general" y el "específico" en función de si el consumo de cultura forma sólo una parte de las vacaciones o si, en cambio, ésta es el motivo principal del viaje. Silberberg (1995), por su parte, identifica cuatro tipos de turistas culturales. Así pues, los clasifica en "altamente motivados" o "motivados en parte" por la cultura según el nivel de importancia que los turistas dan al aspecto cultural de la visita a un destino. A su vez también identifica a los turistas "adjuntos" que perciben en la cultura una motivación secundaria; mientras que el último grupo es el conformado por los turistas culturales "accidentales" que son aquellos que asisten a atracciones culturales sin realmente haberlo planeado. De forma similar, Hughes (2002) determina dos grandes grupos también en función de la importancia que los turistas dan a los elementos culturales. Por un lado, identifica a los turistas "culture-core" que son aquellos para los cuales la cultura es el núcleo de la visita y dentro de esta categoría diferencia a los "primarios" de los "multiprimarios". Por otro lado, reconoce a los "culture-peripheral" que son aquellos turistas que no dan tanto peso al aspecto cultural en su desplazamiento al destino y en cuyo grupo identifica a los "incidentales" de los "accidentales". Basándose en la centralidad y la profundidad de la experiencia, McKercher (2002) distingue cinco tipos de turistas culturales: los decididos, los observadores, los casuales, los incidentales y los fortuitos. Según McKercher y du Cros (2003), dicha clasificación guarda cierta relación con la manera en la que Plog clasifica a los turistas a partir de sus características psicográficas. Así pues, Plog (1976) identifica dos grandes grupos de turistas. En un extremo sitúa al turista "psicocéntrico" el cual es algo reacio a viajar, hace estancias breves y se limita a visitar destinos maduros para conocer solamente sus principales atractivos, mientras que en el otro extremo se encuentra el turista "alocéntrico" que se caracteriza por hacer largos viajes en destinos descono- 
cidos donde intenta mezclarse con los locales. Entre estos dos perfiles, Plog (1976) identifica varios escenarios intermedios entre los cuales destaca la figura del turista "mediocéntrico" por ser la más común entre los visitantes según el racionamiento de este autor. Este tipo de turista se caracteriza por no ser excesivamente arriesgado en sus viajes, aunque sí muestra cierta disposición a vivir nuevas experiencias. Por consiguiente, la clasificación del turista de McKercher (2002) se vincula con esta agrupación psicográfica realizada por Plog en cuanto que los turistas culturales decididos se asemejan en motivaciones a los turistas alocéntricos, los observadores a los mediocéntricos, en tanto que los tres restantes se corresponden con los psicocéntricos (McKercher y du Cros, 2003). Otra clasificación del turista es la planteada por Galí y Donaire (2006) en un estudio que tuvo como campo de investigación la ciudad de Girona. Éstos identificaron cuatro tipos de turistas en función de la relación que los visitantes presentaban con el patrimonio de la localidad, siendo los turistas rituales, los no culturales, los interesados y los eruditos los grupos establecidos en dicho estudio.

Con todo, identificar quién es un turista cultural es algo complejo, no solamente porque se aplica a las visitas de una amplia y diversa gama de atracciones y el hecho que los motivos de visita a los destinos suelen ser difusos e interrelacionados (Hughes, 2002; Niemczyk, 2013), tal y como se ha argumentado; sino también debido a la actual inmersión en una sociedad basada en el concepto de liquidez de Bauman (2000). El movimiento constante y la falta de permanencia son a vistas de este autor la principal característica de la sociedad moderna actual, en la que las fronteras que definen al individuo se difuminan, y en la que todos podemos ser o no ser turistas en función del tiempo y el espacio (Bauman, 1996; 2000).

\subsection{El antiturismo como contraposición al turista típico}

Pese a las múltiples clasificaciones existentes acerca de la figura del turista cultural, McKercher (2004) llega a la conclusión de que éstos tienden a participar en el mismo tipo de actividades y atracciones culturales independientemente del país o lugar de destino. Esto puede resultar paradójico si se tiene en cuenta que en los años noventa ya múltiples autores afirmaban la existencia de una tendencia creciente por la búsqueda de viajes individualizados en contraposición a los tradicionales paquetes turísticos, siendo ésta una característica del turismo contemporáneo (Osti et al., 2009). Así pues, el impacto de las nuevas tecnologías y la contribución de las mismas en el proceso de globalización del conocimiento, han permitido que las personas puedan dibujar su identidad a través del acceso a productos y servicios que satisfagan sus necesidades individuales (Yeoman et al., 2007). Esto deriva del significado que las personas otorgan a los distintos tipos de bienes, servicios o marcas, siendo el consumo un medio de expresión que sirve al consumidor para diferenciarse del resto (Sirgy, 1982). En turismo, la recreada necesidad que tienen algunos turistas de distanciarse de sus iguales se denomina antiturismo (Jacobsen, 2000), motivo por el cual en muchas ocasiones el turista intente aproximarse al local y trate de ser "uno de ellos" puesto que eso implica una mayor autenticidad. No obstante, para Bauman (Franklin, 2003) esto no es nada más que una paradoja, ya que según su razonamiento la posibilidad de tener un encuentro genuino es más probable cuando el individuo se queda en casa (en grandes ciudades) que cuando viaja a miles de kilómetros de distancia de su residencia.

Según MacCannell (1973) el término "turista" se vincula cada vez más con experiencias de contenidos poco auténticos. Festinger (1954) sostiene que las personas presentan una clara tendencia en comparar sus propias habilidades y opiniones con la del resto porque existe una necesidad inherente de la autoevaluación. Es en esta comparativa en la cual los turistas acaban afirmando que su perfil no se corresponde con el del turista típico incluso cuando las actividades realizadas son las mismas (Prebensen et al., 2003). Doran et al. (2015) confirma que los turistas dicen diferenciarse del turista típico en términos de motivaciones. Con todo, se considera por típico el rol del turista que participa en tours guiados y viajes organizados (Jacobsen, 2000). De hecho, Pizam y Sussmann (1995) elaboran una lista enumerando veinte características comúnmente asociadas a la figura del turista típico y entre las cuales están el hacer fotos, comprar suvenires o querer ver "la parte real" del destino. En contraposición, los turistas son más propensos a identificar sus propias experiencias y actividades en categorías que consideran menos ofensivas a la vinculada al concepto "turista" (McCabe, 2005), evitando afirmar que visitan algunos espacios porque son populares o atraen mucho turismo (McCabe y Stokoe, 2004). Todo ello conforma un paradigma en el cual los turistas tratan de huir de lo turístico (Richards y Russo, 2016), siendo la denigración feroz de los turistas un intento de convencerse de que uno no forma parte de ese grupo (Culler, 2007). 


\subsection{El autoconcepto en materia turística}

El autoconcepto es la totalidad de pensamientos y sentimientos que un individuo referencia sobre sí mismo (Rosenberg, 1979:7). Sin embargo, la percepción de la propia persona no es constante sino que varía en función de la situación en la que ésta se encuentre (Todd, 2001). El turista en el viaje se enfrenta a un cambio de rutina puesto que realiza un desplazamiento hacia un espacio y contexto distinto al de su vida cotidiana, cambiando así su forma habitual de comportarse (Cohen, 1974; Boissevain, 2005). De este modo, el autoconcepto debe entenderse desde un punto de vista multidimensional que depende de variables personales y situacionales (Malhotra, 1988), teniendo la persona tantos seres sociales como individuos que la reconocen y crean una imagen de la misma en su mente (James, 1950:254). Es por ello que Sirgy (1980) considera la existencia de cuatro perspectivas del autoconcepto. Por un lado, identifica la "autoimagen actual" como el grado en el cual un sujeto cree que tiene una imagen específica, diferenciándose de la "autoimagen social" en cuanto que ésta se relaciona con el hecho de que el individuo percibe que los otros tienen una imagen de él. Por otro lado, este autor define a la "autoimagen ideal" como el grado en el cual un sujeto quisiera tener una imagen concreta, siendo finalmente la "autoimagen social ideal" aquella que a la persona le gustaría que los otros percibieran de sí misma. Esto revela el papel que tiene la opinión de terceros en la determinación del autoconcepto de un individuo.

Además de todo esto, Yu et al. (2012) señala que en materia turística la lejanía condiciona la autopercepción del sujeto, habiendo una correlación positiva entre la distancia recorrida y la probabilidad de que un visitante se considere turista. Similarmente, la repetición también es un factor influyente en el autoconcepto del turista, observándose una mayor tendencia a identificarse como tal entre las personas que visitan un destino por primera vez y no tanto entre aquellas que han estado con anterioridad (Woosnam et al., 2018). Esto generalmente se atribuye al hecho de que los que viajan por primera vez suelen hacerlo más interesados en conocer un lugar, mientras que los repetidores se desplazan por motivos de recreación, enfocados en una actividad muy concreta o a visitar amigos y familiares (Yu et al., 2012). Asimismo, Hosany (2016) afirma que, en cierto tipo de experiencias turísticas, el nivel de congruencia existente entre la imagen propia de un turista con la que éste tiene sobre los otros turistas, afecta en el grado de satisfacción global. De hecho, en turismo el autoconcepto ha sido utilizado frecuentemente en el estudio de la congruencia de la imagen (Beerli et al., 2007), demostrándose a través de la investigación empírica que cuanto mayor es el acuerdo entre la imagen de un destino y el autoconcepto, mayor es la tendencia del turista a visitar dicho lugar (Sirgy y Su, 2000). A pesar de ello, son muy pocos los trabajos llevados a cabo para entender cómo se perciben los sujetos en su rol de turista (Doran et al. 2015), siendo el objetivo principal de este estudio el realizar una aproximación a la percepción y los sentimientos que el turista cultural tiene sobre sí mismo en el momento en el que está realizando el viaje.

\section{Metodología}

\section{1. Área de estudio}

Girona es una ciudad española situada en el noreste de la Península Ibérica, a escasos sesenta kilómetros de la frontera francesa. Su casco antiguo presenta una gran cantidad de elementos patrimoniales que configuran un marco de alto valor histórico y artístico. En los últimos años, la ciudad ha consolidado su estrategia turística convirtiéndose así en un importante centro de turismo cultural (Galí et al., 2015). Según Galí y Donaire (2006), Girona es considerada un arquetipo de los lugares que representan la cultura europea en España, por lo que este trabajo se enmarca en un contexto y espacio caracterizado por su valor histórico y monumental.

\subsection{Población y muestra de estudio}

La población a investigar en este estudio está constituida por todos los turistas que visitan la ciudad de Girona. Esto, según la definición de la OMT, implica que solamente formaron parte de la población aquellos visitantes que pernoctaron en dicha ciudad al menos una noche (UNWTO, 2008).

La técnica de muestreo empleada fue la del muestreo por conveniencia que, según Mejía (2000), es un procedimiento de muestreo comúnmente utilizado en las investigaciones de carácter cualitativo en el que los informantes son seleccionados en función de su fácil disponibilidad y acceso. Los únicos criterios que se tuvieron en cuenta a la hora de elegir a los entrevistados fue que el informante pernoctase al menos una noche en la ciudad de Girona durante su estancia, y que no estuviese realizando una actividad organizada contractualmente en el momento en el que se hizo la entrevista. La muestra seleccionada para 
el desarrollo de este trabajo estuvo formada por 30 turistas de diferentes edades y procedencias (tabla 1 y 2). Según Bertaux (1993) el nivel de saturación se consigue a partir de los 30 casos, es decir, el punto en el cual introducir más participantes en la investigación no aporta nada nuevo (Bowen, 2008). En este caso se empezó a apreciar la reiteración de ideas a partir de la entrevista número veinticinco, aunque se hicieron cinco más para asegurar dicho nivel de saturación. La interceptación de los participantes fue llevada a cabo en seis de los puntos gerundenses más frecuentados por la actividad turística: las escaleras de la Catedral de Girona, la Plaza de los Apóstoles, el Paseo Arqueológico, los Jardines de los Alemanes, la Rambla de la Libertad y las escaleras de la Basílica de San Félix, entre los días 30 de abril y 09 de mayo de 2019 .

Tabla 1: Perfil sociodemográfico de la muestra

\begin{tabular}{|c|c|c|}
\hline \multicolumn{1}{|c|}{ Variables } & Frecuencia & \\
\hline Sexo & 18 & 60 \\
\hline Hombre & 12 & 40 \\
\hline Mujer & 15 & 50 \\
\hline Edad & 9 & 30 \\
\hline$<30$ & 6 & 20 \\
\hline $30-50$ & & \\
\hline$>50$ & 7 & 23,3 \\
\hline Origen & 3 & 10 \\
\hline Nacional & 4 & 13,3 \\
\hline Cataluña & 23 & 76,7 \\
\hline España & 15 & 50 \\
\hline Extranjero & 4 & 13,3 \\
\hline Luropa & 4 & 13,3 \\
\hline Otros & & \\
\hline
\end{tabular}

Tabla 2: Caracterización y perfil sociodemográfico de los entrevistados

\begin{tabular}{|c|c|c|c|c|}
\hline $\begin{array}{c}\text { Código } \\
\text { entrevista }\end{array}$ & Sexo & Procedencia & Edad & Repetición \\
\hline E1 & F & Bélgica & $30-50$ & Sí \\
\hline E2 & M & Israel & $<30$ & No \\
\hline E3 & F & Cataluña & $<30$ & Sí \\
\hline E4 & M & España & $<30$ & No \\
\hline E5 & M & Holanda & $30-50$ & No \\
\hline E6 & F & Argentina & $30-50$ & Sí \\
\hline E7 & M & Cataluña & $<30$ & No \\
\hline E8 & M & Italia & $<30$ & No \\
\hline E9 & F & Chile & $30-50$ & $30-50$ \\
\hline E10 & F & Francia & & \\
\hline
\end{tabular}




\begin{tabular}{|c|c|c|c|c|}
\hline $\begin{array}{c}\text { Código } \\
\text { entrevista }\end{array}$ & Sexo & Procedencia & Edad & Repetición \\
\hline E11 & M & Hawái & $>50$ & No \\
\hline E12 & M & Rusia & $<30$ & No \\
\hline E13 & M & China & $<30$ & No \\
\hline E14 & M & Cataluña & $30-50$ & Sí \\
\hline E15 & M & Estonia & $<30$ & No \\
\hline E16 & $\mathrm{F}$ & Francia & $<30$ & Sí \\
\hline E17 & M & Reino Unido & $<30$ & No \\
\hline E18 & M & Francia & $30-50$ & Sí \\
\hline E19 & $\mathrm{F}$ & Argentina & $>50$ & No \\
\hline E20 & $\mathrm{F}$ & Holanda & $>50$ & No \\
\hline E21 & M & Portugal & $>50$ & No \\
\hline $\mathrm{E} 22$ & $\mathrm{~F}$ & Polonia & $<30$ & No \\
\hline E23 & $\mathrm{F}$ & España & $<30$ & No \\
\hline E24 & M & Alemania & $>50$ & No \\
\hline E25 & M & Letonia & $<30$ & No \\
\hline E26 & $\mathrm{F}$ & Reino Unido & $30-50$ & No \\
\hline E27 & M & Cataluña & $<30$ & No \\
\hline E28 & $\mathrm{M}$ & España & $>50$ & No \\
\hline E29 & $\mathrm{F}$ & Argentina & $30-50$ & No \\
\hline E30 & M & Italia & $<30$ & No \\
\hline
\end{tabular}

\subsection{Recogida y análisis de datos}

Con el objetivo de obtener respuestas abiertas, se empleó el uso de entrevistas semiestructuradas previamente testadas. Éstas, según Barriball y While (1994), resultan especialmente adecuadas para explorar las percepciones y opiniones de los participantes, sobre todo cuando la muestra presenta características personales muy dispares. De esta forma, todas las entrevistas realizadas partieron de un guión preestablecido el cual se configuró a partir de la teoría de la autopercepción planteada por Sirgy (1980). Con todo, la función principal de dicho guión fue la de dirigir la conversación entre el investigador y el informante, ejerciendo así de material de apoyo para asegurar el tratamiento de todos los temas de interés en cada una de las entrevistas. La estructura marcada, por tanto, no se cumplió de manera estricta en todas ellas, sino que se las dotó de cierta flexibilidad. Sin embargo, el proceso general de recopilación de datos comenzaba preguntando al informante por las motivaciones de su visita en Girona, los medios y canales de información utilizados, la planificación, expectativas y actividades realizadas. Una vez comentados estos aspectos, se le pedía al entrevistado que tratase de concretar qué tipo de turista se consideraba para luego preguntarle si realmente era ese el turista que le gustaba ser. Tras profundizar un poco más en el tema, se le planteaba al informante el hecho de poder considerarse a sí mismo el típico turista, pues a partir de su respuesta se le pedía que intentase explicar cuáles eran las características y actividades que él vinculaba al turista típico que visitaba Girona e hiciese una breve comparativa con lo que había hecho hasta el momento. Seguidamente, se le preguntaba al entrevistado cómo creía que era percibido por el resto en su rol de turista y si prefería que éstos le viesen de un modo distinto. Por último, cabe señalar que al final de las entrevistas se le solicitaba al informante que justificase si le molestaba poder ser visto como el típico turista y también si se llegaba a considerar un turista cultural en la ciudad gerundense. 
Para el análisis de los datos obtenidos y la correspondiente extracción de conclusiones se ha empleado la metodología de análisis de contenido de carácter cualitativo. Se trata de una técnica cada vez más utilizada en investigaciones turísticas desarrolladas a partir de entrevistas (Camprubí y Coromina, 2016). Esta técnica supone una aproximación empírica a través del análisis metodológico y detallado de textos producidos en un contexto de comunicación concreto (Mayring, 2000). Es por ese motivo que las entrevistas fueron grabadas y cuidadosamente transcritas, identificando posteriormente patrones comunes entre los informantes, pero también prestando atención a las particularidades de sus respuestas como bien señala Elo y Kyngäs (2008). Según Cáceres (2008), uno de los usos de esta metodología es la de integrar los datos obtenidos a interpretaciones de nivel superior que permitan establecer relaciones entre los puntos de estudio con la teoría existente, tal y como queda recogido en los resultados que se presentan en el siguiente apartado.

\section{Resultados}

\subsection{La autoimagen actual y la autoimagen ideal del turista}

Son muchas las motivaciones que llevan a los turistas a emprender un viaje (Richards, 2018). Tras el análisis del contenido de las entrevistas realizadas, se afirma que éstas tienen una gran influencia a la hora de constituir la autopercepción del turista. "Conocer una ciudad nueva, relajarse, pasar unos días agradables, cambiar de ambiente..." Estos fueron algunos de los ejes fundamentales de las respuestas a la pregunta ¿qué tipo de turista te consideras? Sin embargo, cuando se les pidió a los informantes que se definiesen como turistas, sus respuestas resultaron asociarse a rasgos del perfil psicográfico identificados por Plog (2001). Así pues, resaltaron no sólo características personales como lo son la curiosidad o la organización, sino también aspectos vinculados con la forma de viajar tales como lo son los conceptos de turista mochilero, turista independiente, turista de paso o turista que intenta ser un local.

Asimismo, se encontraron otros tres factores determinantes a la hora de definir la autopercepción del turista. Dos de ellos son la distancia y la repetición, elementos ya identificados por Yu et al. (2012) y Woosman et al. (2018). Con ello, cabe destacar la expresión "no me considero tan turista ya que vivo a escasos 80 kilómetros" (E18) por parte de un visitante francés que no solamente había cambiado de país, sino que pernoctaba dos noches en la ciudad catalana. Similarmente, entre los repetidores era bastante común escuchar aquello de "este fin de semana no venimos tanto a visitar sino a pasear"(E14) o "hemos estado varias veces en Girona y ya nos sentimos como en casa. La primera vez fue distinto, mucho más de hacer turismo" (E1). El tercer elemento es el acompañante, pues aquellos entrevistados que se encontraban haciendo la visita acompañados de algún residente afirmaron sentirse menos turistas al considerarse en mayor contacto con la gente local. En consecuencia, y pese a considerarse turista, una participante manifestaba lo siguiente: "creo que me alejo un poco del concepto turista en cuanto que me dejo llevar por ella [su amiga]. He estado en calles y bares por los que los turistas no pasan. Voy a quedar con gente de aqui” (E3).

Todo lo hasta ahora mencionado trata de configurar la autoimagen actual descrita por Sirgy (1980) en la figura del turista. Independientemente de cuál fuese ésta, se encontró pleno consenso en cuanto que todos los entrevistados afirmaron estar contentos siendo el tipo de turista que ellos creían ser, con la única excepción de una participante que expresaba su deseo por ser una turista algo más organizada. Este hallazgo indica que suele existir un gran ajuste entre la autoimagen actual e ideal del turista cultural. Ahora bien, ¿puede estar esto relacionado con que los turistas culturales realmente se perciben a sí mismos como turistas no típicos?

\subsection{Turista típico vs Turista no típico}

Algunas personas son reacias a ser vistas como turistas cuando están viajando (Jacobsen, 2000). Esto coincide con los resultados de Prebensen et al. (2003) en el que un 89'5\% de los encuestados afirmaba no ser el típico turista alemán que visitaba Noruega. Según Culler (2007), este hecho se debe a que el concepto turista comporta connotaciones negativas en la percepción del individuo. En este caso de estudio el fenómeno volvió a repetirse, encontrándose a una gran mayoría de los entrevistados que afirmaron no considerarse el típico turista. Los participantes justificaron ese sentimiento no tanto en las actividades y nodos de visita, sino en la forma de viajar, algo ya señalado por Prebensen et al. (2003). Con todo, se atribuyó al turista típico que visita Girona características como una notable preparación y organización del viaje, preferencia por la realización de tours guiados y estancias de corta duración que normalmente no implican dormir en la ciudad. Así lo manifestaba un entrevistado al decir que "el 
turista típico que visita Girona, en mi opinión, se aloja en Barcelona y simplemente pasa unas horas en esta ciudad. Tienen que venir con todo organizado para poder visitarlo todo" (E11). Por otra parte, el hecho de que los participantes utilizasen el término turista para referirse a visitantes que no pernoctan en el destino, confirma lo apuntado por Yu et al. (2012) en cuanto que la distinción entre turista y excursionista es principalmente técnica y que, por tanto, no acaba de ser asimilada entre la población general. De este modo, los entrevistados se distanciaron del concepto del turista típico alegando que ellos viajaban sin prácticamente haber planificado nada, siendo un tipo de turista individual e independiente cuya libertad le permitía visitar todos los atractivos que verdaderamente llamasen su atención, sin las limitaciones de ningún recorrido impuesto. "Ellos reservan tours, excursiones, actividades... Todo preparado. Y nosotros hemos venido a la aventura" (E2). Igualmente, de manera similar a lo afirmado por MacCannell (1973), fueron muchos los participantes que emplearon su interés de vivir experiencias locales como elemento de diferenciación entre ellos y el resto de turistas. En esto hicieron mayor énfasis los más jóvenes, los que hicieron estancias más largas, los repetidores y los acompañados por residentes.

No obstante, y pese a que en su autoimagen actual los participantes no se concibieron como turistas típicos, éstos no manifestaron sentirse molestos en caso de ser vistos como tal por el resto. "¿Cómo me va a molestar que me identifiquen con una turista si el turismo me parece algo maravilloso, que disfruto y que conlleva un aprendizaje?" (E29). De hecho, algunas de las respuestas fueron llamativas en cuanto que expresaban que ser un típico turista no significaba nada malo en la percepción propia sino más bien que dicha negatividad se vinculaba con el concepto que el resto pudiese tener acerca de lo que es un turista típico. Un ejemplo de ello fue la respuesta de un participante italiano que textualmente dijo: "en un principio no me molesta, aunque depende de lo que la gente considere por típico turista. Si implica que no voy a respetar a la gente ni a la ciudad, pues obviamente me molesta que me vean asi" (E8). Visto de esta forma, resulta bastante evidente que en la formación de la autopercepción del turista interviene la percepción que los otros tienen del mismo (Sirgy y Su, 2000), especialmente en un contexto en el que el turista se encuentra de manera temporal y en el cual no percibe la necesidad de seguir las normas y pautas establecidas, tal y como determina Bauman (Franklin, 2003).

\subsection{La autoimagen social y la autoimagen social ideal del turista}

En la mayoría de los estudios de consumo se ha prestado atención solamente a la autoimagen actual e ideal del individuo (Hosany, 2016). Sin embargo, Sirgy (1980) defiende que toda autopercepción está en cierto modo condicionada a la opinión de terceros. En este caso de estudio, resultó interesante observar cómo los informantes confirmaban tener la sensación de ser percibidos como el típico turista pese a ellos no identificarse con este término. Según los participantes, esta imagen se transmitía a partir de aspectos visibles como el simple hecho de llevar un mapa, una mochila o una cámara de fotos; coincidiendo así con algunas de las características atribuidas al típico turista por Pizam y Sussmann (1995). Los entrevistados extranjeros añadieron, además, que existía una alta probabilidad de que se les considerase un turista típico simplemente por su forma de vestir, su color de piel o el idioma hablado. Sin embargo, esta autoimagen social quedó dividida en dos partes. Por un lado, la imagen percibida por el resto de turistas y, por otro, la interpretada por los locales. La primera de ellas fue algo más generalista en cuanto que, según los entrevistados, entre turistas todos acaban percibiéndose de igual a igual. La segunda, en cambio, sí acarreaba connotaciones negativas ante la posibilidad de ser percibidos por los locales como un estorbo. "Yo creo que algunos de los que viven aquí me ven mal, como que les molesto e interrumpo su paso... Incluso creo que pueden llegar a pensar que por mi culpa todo es más caro" (E6) fueron las palabras de una entrevistada argentina. Esto se relaciona con el hecho de que a medida que una ciudad depende cada vez más del sector turístico, los efectos negativos son más reconocibles que los positivos entre la población local (McGehee y Andereck, 2004). Con todo, esta sensación de ser percibido como un turista típico por el resto no fue expresada por los visitantes de proximidad, los repetidores o los acompañados por residentes en Girona.

Siguiendo las aportaciones de Sirgy (2000), el último de los componentes que conforman la autopercepción del turista es la autoimagen social ideal. Para ello se le preguntó a los entrevistados si preferían ser vistos de otra forma una vez planteada la cuestión de cómo creían ser percibidos por el resto en su rol de turista. Ante esta pregunta los informantes mostraron dar poca importancia al hecho de ser vistos de una forma u otra, asumiendo muchos de ellos que les parecía normal que se les percibiese como turistas porque esa imagen se correspondía con lo que en ese momento eran. "Para nada me importa que me vean como el típico turista. Yo sé que lo parezco" (E17) por parte de un entrevistado inglés, al igual que la respuesta de una visitante chilena al decir "estoy haciendo turismo y soy otra turista más. 
Es normal que me vean así y no me molesta en absoluto" (E9) son solamente algunos ejemplos de ello. Sin embargo, se expresó el deseo de no querer ser visto como algo molesto entre los residentes por parte de aquellos turistas que contemplaron la posibilidad de que el turismo pudiese incomodar a la población local, como bien señalan algunos autores (McGehee \& Andereck, 2004; Woosnam et al., 2018).

\subsection{La autopercepción del turista cultural}

El turismo cultural representa una parte considerable de las llegadas internacionales (UNWTO, 2018), y aunque son muchas las definiciones y clasificaciones que se hacen del turista cultural (Richards, 1996; Silberberg, 1995; Hughes, 2002; McKercher, 2002; Galí y Donaire, 2006), solamente se identifican como tal entre el 5\% y el 10\% (Richards, 2018). Teniendo en cuenta que Girona es un importante centro de turismo cultural (Galí et al., 2015), cabría esperar que una gran proporción de los entrevistados fuesen, en alguna de todas sus acepciones, turistas culturales. Si bien es cierto que muchos de ellos afirmaron encontrar entre sus motivaciones principales para viajar el hecho de conocer la cultura e historia de la ciudad de Girona, ninguno de ellos se identificó directamente como un turista cultural cuando se le preguntó por el tipo de turista que era. A pesar de ello, al final de la entrevista se planteaba a los participantes si llegaban a considerarse un turista cultural en la ciudad catalana, obteniendo un sí como respuesta en la gran mayoría de las ocasiones. No lo hicieron tanto aquellos que ya habían estado con anterioridad en Girona. Igualmente, hubo algunos casos aislados que respondieron que todavía no se consideraban turistas culturales porque no habían llegado a visitar apenas nada en el momento en el que se estaba realizando la entrevista, apuntando que esta sensación cambiaría una vez visto todo aquello que tenían en mente. Esto implica que, en cierta medida, el autoconcepto de ser un turista cultural o no está sujeta tanto a un factor temporal, como a los elementos y espacios visitados.

Además de ello, cabe destacar que no todos los que dijeron considerarse un turista cultural lo hicieron por los mismos motivos, otorgando diversos niveles de importancia a los elementos culturales, tal y como señalan las clasificaciones de Silberberg (1995) o la de Hughes (2002) anteriormente citadas. En consecuencia, se encontraron posturas del tipo "me considero turista cultural porque disfruto viendo los monumentos, aunque tampoco voy a buscar información [sobre los monumentos]" (E2), "lo sería a medias ya que mi objetivo principal es despejarme, aunque está claro que estoy viendo cosas culturales y me están gustando" (E6), "yo creo que sería semicultural porque no voy a poder abarcar todo lo que la ciudad ofrece" (E28) o "he venido sobre todo por la cultura, de ahi que haya estado dentro de la Catedral, de la Basílica de San Félix, de los Baños Árabes y en el Museo de Historia”(E10).

En términos generales, también se le preguntó a los entrevistados si a la hora de elegir un destino al que visitar tenían en consideración que éste ofreciese atracciones y elementos culturales. De manera prácticamente unánime los participantes contestaron que sí, mostrando nuevamente matices muy distintos en sus respuestas. Con ello, algunos manifestaron que la presencia de estos elementos era imprescindible porque cuando viajan les gusta ver "cosas y monumentos", apuntando que éstos consiguen que un viaje sea mucho más sencillo de estructurar en el sentido de que saben qué es lo que tienen que ir a visitar. Para otros la importancia residía en que a partir de estos atractivos podían llegar a entender la cultura y la historia de la ciudad que estaban visitando y la forma de pensar y actuar de sus habitantes.

Así pues, pese que de primeras los turistas no lleguen a identificarse de manera inmediata como turistas culturales (Richards, 2018), este estudio llega a la conclusión de que éstos sí se consideran como tal, pues el autoconcepto del turista cultural reside en la reflexión que lleva al sujeto a darse cuenta de que los elementos culturales constituyen, de una manera u otra, a formar parte de manera más o menos destacada en su viaje.

\section{Conclusiones}

El turismo implica un cambio en el espacio habitual del individuo que rompe su rutina diaria y modifica su forma normal de comportamiento (Cohen, 1974; Boissevain, 2005). A pesar de ello, la literatura académica ha prestado poca atención a cómo se percibe la gente en su rol de turista (Todd, 2001; Doran et al., 2015). Teniendo en cuenta que la autopercepción de un individuo no es constante y que depende de variables personales y situacionales (Malhorta, 1988), el presente estudio ha tratado de aproximarse a la concepción que el turista cultural tiene de sí mismo atendiendo a los cuatro componentes que según Sirgy (1980) configuran la autopercepción: la autoimagen actual, la autoimagen ideal, la autoimagen social y la autoimagen social ideal. 
De este modo, constituyen la autoimagen actual del turista cultural no tanto las actividades realizadas por éste sino más bien las motivaciones que le llevan a emprender el viaje, sus características psicográficas, la distancia entre el destino y el lugar de origen, el haber estado con anterioridad o no en el sitio visitado y el posible hecho de ir acompañado por un residente. Independientemente de cuál sea esta autoimagen actual, los turistas culturales no suelen manifestar deseo por cambiarla, existiendo así un ajuste entre ésta y su autoimagen ideal. Este acuerdo entre ambas dimensiones de la autopercepción no necesariamente se debe a que los turistas culturales acaben viéndose a sí mismos como turistas no típicos puesto que, en contra de lo afirmado por Culler (2007), ser turista no constituye un aspecto negativo en la percepción individual propia, sino que dicha negatividad se relaciona con la creencia de que el resto pueda considerar que ser un turista típico es algo peyorativo. Por consiguiente, la opinión de terceros influye en el proceso de formación de la autopercepción. Con ello, y de manera opuesta a lo determinado por la autoimagen actual, el visitante es consciente de que tanto locales como turistas le perciben como un turista típico. Esta autoimagen social solamente pretende ser cambiada cuando el sujeto considera que el turismo puede molestar a los residentes del lugar visitado, pues de lo contrario parece existir otro ajuste entre la autoimagen social y la autoimagen social ideal en cuanto que el turista cultural no manifiesta ningún interés por ser visto de otra forma que no sea la de ser un turista más.

Con el objetivo de verificar lo señalado por Richards (2018) respecto a que solo un pequeño porcentaje de turistas llega a identificarse como turista cultural en un momento en el que el turismo cultural se relaciona con aproximadamente el 40\% de las llegadas internacionales (UNWTO, 2018), este estudio enmarca su área de investigación en la ciudad de Girona, un destino de tipología cultural (Galí et al., 2015). Con todo, este trabajo llega a la conclusión de que el turista cultural sí llega a percibirse como tal aunque no de manera inmediata, pues el visitante es conocedor de que los elementos culturales, de algún modo, forman parte de su viaje. Este hecho conlleva a que el individuo pase a considerarse un turista cultural en mayor o menor grado, pudiéndose clasificar así en alguna de las múltiples catalogaciones existentes en torno a la figura del turista cultural (Richards, 1996; Silberberg, 1995; Hughes, 2002; McKercher, 2002; Galí y Donaire, 2006).

Por todo ello, este estudio contribuye a la literatura aportando mayores datos y conocimientos sobre la autopercepción del turista cultural. Además, esta investigación ha sido llevada a cabo a partir de técnicas cualitativas y teniendo en cuenta la influencia de la llamada dimensión social en la creación del autoconcepto, un punto escasamente analizado en los estudios turísticos. Sin embargo, es el propio contexto del caso examinado una limitación en sí mismo en cuanto que no permite confirmar que los hallazgos identificados sean aplicables a la autopercepción de turistas que visitan otros tipos de destinos tales como espacios naturales, parques temáticos, entre otros. Es por este motivo que futuras investigaciones deberían tratar de aproximarse a la autopercepción de otras tipologías de turistas y también de los excursionistas al ser éstos un tipo de visitante con características muy particulares.

\section{Bibliografía}

Ahn, T. H. \& Hosany, S. (2017). The Effects of Self-image Congruence, Tourists' Experiences and Satisfaction on Behavioral Intentions. Asia-Pacific Journal of Business, 8(1), 1-13.

Barriball, L. K. y While, A. (1994. Collecting data using a semi-structured interview: A discussion paper. Journal of Advanced Nursing, 19, 328-335.

Bauman, Z. (1996). Tourists and vagabonds: heroes and victims of postmodernity. (Reihe Politikwissenschaft / Institut für Höhere Studien, Abt. Politikwissenschaft, 30). Wien: Institut für Höhere Studien (IHS), Wien. https://nbn- resolving.org/urn:nbn:de:0168-ssoar-266870.

Bauman, Z. (2000). Liquid Modernity. Cambridge: Polity.

Beerli, A., Díaz, G. \& Moreno, S. (2007). Self-congruity and destination choice. Annals of Tourism Research, 34(3), 571-587.

Bertaux, D. (1993). De la perspectiva de la historia de vida a la transformación de la práctica sociológica. Marinas, J. y Santamarina, C. La historia oral. Métodos y experiencias. Madrid: Ed. Debate.

Boissevain, J. (2005). Rituales ocultos. Protegiendo la cultura de la mirada turística. Pasos. Revista de turismo y patrimonio cultural, 3(2), 217-228.

Bowen, G. A. (2008). Naturalistic inquiry and the saturation concept: a research note. Qualitative research, 8(1), 137-152. 
Cáceres, P. (2008). Análisis cualitativo de contenido: una alternativa metodológica alcanzable. Psicoperspectivas. Individuo y sociedad, 2(1), 53-82.

Camprubí, R. \& Coromina, L. (2016). Content analysis in tourism research. Tourism Management Perspectives, 18, 134-140.

Cohen, E. (1974). Who is a tourist? A conceptual clarification. The sociological review, 22(4), 527-555.

Culler, J. (2007). Semiotics of tourism. The American Journal of Semiotics, 1(1/2), 127-140.

Doran, R., Larsen, S. \& Wolff, K. (2015). Different but similar: Social comparison of travel motives among tourists. International Journal of Tourism Research, 17(6), 555-563.

Elo, S. \& Kyngäs, H. (2008). The qualitative content analysis process. Journal of advanced nursing, 62(1), 107-115.

Festinger, L. (1954). A theory of social comparison processes. Human relations, 7(2), 117-140.

Franklin, A. (2003). The tourist syndrome: An interview with Zygmunt Bauman. Tourist studies, 3(2), 205-217.

Galí, N., Donaire, J. A., Martínez, E. \& Mundet, L. (2016). Turistas entre monumentos. El comportamiento de los visitantes en el centro histórico de Girona (2003 y 2013). RITUR-Revista Iberoamericana de Turismo, 5(2), 70-84.

Galí, N. \& Donaire, J. A. (2006). Visitors' Behavior in Heritage Cities: the case of Girona. Journal of Travel Research, 44(4), 442-448.

Hughes, H. L. (2002). Culture and tourism: a framework for further analysis. Managing Leisure, 7(3), 164-175.

Jacobsen, J. K. S. (2000). Anti-tourist attitudes: Mediterranean charter tourism. Annals of Tourism Research, 27(2), 284-300.

James, W. (1950). The Principles of Psychology, $3^{\text {rd }}$ edition, Dover Publications Inc., USA.

MacCannell, D. (1973). Staged authenticity: Arrangements of social space in tourist settings. American journal of Sociology, 79(3), 589-603.

Malhotra, N. K. (1988). Self concept and product choice: An integrated perspective. Journal of Economic Psychology, 9(1), 1-28.

Mayring, P. (2000). Qualitative content analysis. In Forum: Qualitative Social Research (Vol. 1, No. 2, p. 10).

McCabe, S. (2005). 'Who is a tourist?' A critical review. Tourist studies, 5(1), 85-106.

McCabe, S. \& Stokoe, E. H. (2004). Place and identity In tourist's accounts. Annals of Tourism Research, 31(3), 601-622.

McGehee, N. G. \& Andereck, K. L. (2004). Factors predicting rural residents' support of tourism. Journal of travel research, 43(2), 131-140.

McKercher, B. (2002). Towards a classification of cultural tourists. International journal of tourism research, 4(1), 29-38.

McKercher, B. (2004). A comparative study of international cultural tourists. Journal of Hospitality and Tourism Management, 11, 95-107.

McKercher, B. \& du Cros, H. (2003). Testing a cultural tourism typology. International Journal of Tourism Research, 5(1), 45-58.

Mejía, J. (2000). El muestreo en la investigación cualitativa. Investigaciones sociales, 4(5), 165-180.

Niemczyk, A. (2013). Cultural tourists:"An attempt to classify them". Tourism Management Perspectives, 5, 24-30.

Osti, L., Turner, L. W. \& King, B. (2009). Cultural differences in travel guidebooks information search. Journal of Vacation Marketing, 15(1), 63-78.

Phucharoen, P., Sriboonlue, U. \& Assarut, N. (2016). The effects of destination image, destination personality and self- congruity on tourists' intention. 14. 8991-9007.

Pizam, A. \& Sussmann, S. (1995). Does nationality affect tourist behavior? Annals of Tourism Research, 22(4), 901-917.

Plog, S. (1976). Why destination areas rise and fall in popularity. The Cornell hotel and restaurant administration quarterly, 55-58.

Prebensen, N. K., Larsen, S. \& Abelsen, B. (2003). I'm not a typical tourist: German tourists' self-perception, activities, and motivations. Journal of Travel research, 41(4), 416-420.

Richards, G. (1996). Production and consumption of European cultural tourism. Annals of tourism research, 23(2), 261-283. 
Richards, G. (2018). Cultural tourism: A review of recent research and trends. Journal of Hospitality and Tourism Management, 36, 12-21.

Richards, G. \& Russo, A. P. (2016). Synthesis and Conclusions: Towards a new geography of tourism?. En Antonio Paolo Russo y Greg Richards (Eds.) Reinventing the Local in Tourism: Producing, Consuming and Negotiating Place. Bristol: Channel View, pp. 251-266.

Rosenberg, M. (1979). Conceiving the Self. New York: Basic Books.

Silberberg, T. (1995). Cultural tourism and business opportunities for museums and heritage sites. Tourism management, 16(5), 361-365.

Sirgy, M. J. (1980). Self -concept in relation to product preference and purchase intention. In Developments in Marketing Science, Vol. 3, ed. V. V. Bellur, Marquette, MI: Academy of Marketing Science, 350-354.

Sirgy, M. J. (1982). Self-concept in consumer behavior: A critical review. Journal of consumer research, 9(3), 287-300.

Sirgy, M. J. \& Su, C. (2000). Destination image, self-congruity, and travel behavior: Toward an integrative model. Journal of Travel Research, 38(4), 340-352.

Swarbrooke, J. \& Horner, S. (2007). Consumer behaviour in tourism. Routledge.

Todd, S. (2001). Self-concept: A tourism application. Journal of Consumer Behaviour, 1(2), 184-196.

UNWTO (2008). International recommendations for tourism statistics.

UNWTO (2017). Definitions Committee on Tourism and Competitiveness (CTC).

UNWTO (2018). Report on Tourism and Culture Synergies. Madrid: UNWTO.

Woosnam, K. M., Draper, J., Jiang, J. K., Aleshinloye, K. D. \& Erul, E. (2018). Applying self-perception theory to explain residents' attitudes about tourism development through travel histories. Tourism Management, 64, 357-368.

Yeoman, I., Brass, D. \& McMahon-Beattie, U. (2007). Current issue in tourism: The authentic tourist. Tourism management, 28(4), 1128-1138.

Yu, X., Kim, N., Chen, C. C. \& Schwartz, Z. (2012). Are you a tourist? Tourism definition from the tourist perspective. Tourism Analysis, 17, 445-457. 


\title{
Gestión de turismo gastronómico: identificación del mercado potencial en Canarias
}

\author{
Daniel Dorta-Afonso* \\ Universidad de Las Palmas de Gran Canaria (Spain) \\ Hugo Padrón-Ávila** \\ Universidad de La Laguna (España)
}

\begin{abstract}
Resumen: La coyuntura turística actual ha derivado en que los turistas demandan experiencias únicas y auténticas. Sin embargo, la provisión de dichas experiencias no es una tarea fácil para los destinos y las empresas turísticas. La literatura sugiere que la gastronomía, como parte de la cultura de las comunidades que visitan los turistas tiene el potencial de ofrecer a los turistas esa autenticidad y singularidad demandada. Así, nos basamos en la literatura sobre turismo gastronómico para identificar su potencial como factor motivador en la organización del viaje y como potenciador de la satisfacción de los turistas. El objetivo de este estudio es analizar cuáles son las características de los visitantes más propensos a mostrarse más interesados por la gastronomía de Canarias. Por lo tanto, en el presente estudio identificamos el perfil del turista para los cuales la gastronomía juega un papel esencial motivador a la hora de viajar. Para ello hemos utilizado las respuestas de los turistas a la Encuesta sobre Gasto Turístico y llevado a cabo análisis de regresión. Los resultados sugieren que existen diferencias en el perfil sociodemográfico, motivacional y en las características del viaje de este segmento particular de turistas motivados por la gastronomía. Las conclusiones del estudio señalan que el segmento de turistas motivado por la gastronomía tiene un tamaño considerable en Canarias y es necesario mejorar la satisfacción de estos turistas ya que son más propensos a gastar más en el destino que el visitante medio.
\end{abstract}

Palabras Clave: Gastronomía; Turismo gastronómico; Segmentación de turistas; Turista gastronómico; Motivación de turistas.

\section{Gastronomic tourism management: identifying the potential market in the Canaries}

Abstract: The current situation of tourism has derived towards tourists demanding authentic and unique tourism experiences. However, providing tourists with such experiences is not a simple task for tourism firms and destinations. The literature suggests that gastronomy, as part of the culture of the communities tourists visit, has the potential to offer the uniqueness and authenticity demanded. We therefore build on food tourism literature to identify its potential as a motivational factor as well as an enhancer of tourists' satisfaction. The aim of this study is to analyzs the characteristics of those visitors most likely to be interested in the consumption of typical local gastronomical products when visiting the Canary Islands. Consequently, in the present study we identify the profile of tourists for whom gastronomy plays an essential motivational role when travelling. To do so, we have used the answers given by tourists on the Tourism Expenditure Survey and conducted regression analysis. The results suggest that there are differences in the socio-demographic profile of gastronomic tourists to Canary Islands, their motivations and also the characteristics of their trips. The conclusions of the study indicate that the segment of tourists motivated by gastronomy is considerable in the Canary Islands and it is necessary to improve the satisfaction of these tourists since they are more likely to spend more in the destination than the average visitor.

Keywords: Gastronomy; Food tourism; Tourist segmentation; Food tourists; Tourist motivations.

\footnotetext{
* Universidad de Las Palmas de Gran Canaria (Spain); E-mail: daniel.dorta@ulpgc.es; https://orcid.org/0000-0002-9955-1202

**Universidad de La Laguna (España); E-mail: hpadrona@ull.edu.es; https://orcid.org/0000-0001-6181-4698
} 


\section{Introducción}

El turismo es la principal actividad económica de muchas regiones y está ampliamente aceptado que su fin último es mejorar la calidad de vida de los habitantes de una región determinada (e.g., Dwyer \& Kim, 2003; Ritchie \& Crouch, 2003). De hecho, las últimas cifras económicas corroboran que efectivamente el turismo contribuye a un 10,4\% del PIB mundial, con una tasa de crecimiento mayor al del total de la economía, y que además supone el 3,8\% de los empleados a nivel global (WTTC, 2019). Sin embargo, mantener niveles altos de competitividad no es una tarea fácil para los destinos y empresas del sector.

En esta línea, existe un determinado consenso en que los destinos turísticos pueden mantener y mejorar sus niveles de competitividad mediante la provisión a los turistas de experiencias satisfactorias y memorables (Dorta-Afonso \& Hernández-Martín, 2015; Ritchie \& Crouch, 2003). Sin embargo, la búsqueda de autenticidad y de experiencias cada vez más únicas por parte de los turistas se ha ido convirtiendo de manera progresiva en uno de los principales retos para empresas y destinos turísticos de cara a la provisión de experiencias satisfactorias mencionada (Wang, 1999). En este sentido, la gastronomía ha sido señalada en numerosos estudios como una parte esencial de la cultura local de los destinos turísticos y por lo tanto tiene la capacidad, por sí misma, de ofrecer a los turistas experiencias nuevas, agradables y auténticas (Berbel-Pineda, Palacios-Florencio, Ramírez-Hurtado, \& Santos-Roldán, 2019; S. Kim, Park, \& Lamb, 2019; Lin \& Mao, 2015; Tikkanen, 2007). Así, no es de extrañar que en los últimos años haya incrementado el interés por parte de la comunidad científica en el turismo gastronómico, o en la gastronomía como parte esencial de las experiencias en destino (e.g., Chavarria \& Phakdee-auksorn, 2017; Cohen \& Avieli, 2004; López-Guzmán, Uribe Lotero, Perez Galvez, \& Rios Rivera, 2017).

El presente artículo está organizado de la siguiente forma: tras la introducción presentamos la revisión de la literatura y los objetivos del estudio. Posteriormente, pasamos a presentar la metodología del estudio incluyendo la descripción de la base de datos utilizada y la estrategia de análisis estadísticos que se ha seguido. Por último, se presentan los resultados del estudio antes de proceder a la discusión de los resultados y las principales conclusiones que se derivan de esta investigación.

\section{Revisión de la literatura sobre gastronomía y turismo}

El turismo gastronómico se define como la visita de los turistas a productores de comida, festivales orientados a la gastronomía, restaurantes o localizaciones para los cuales la degustación de productos gastronómicos es un factor motivacional a la hora de elegir el destino turístico y las características del viaje (Chen \& Huang, 2016; Hall, Sharples, Mitchell, Macionis, \& Cambourne, 2004). Con vistas a delimitar el concepto de turismo gastronómico, es importante destacar que el consumo de gastronomía es una actividad llevada a cabo por la totalidad de los turistas que visitan un destino y que, por lo tanto, cualquier visita a un restaurante no debería de ser considerado como turismo gastronómico. Además, y en aras de pulir la definición, también hay que destacar que los ofertantes de gastronomía no tienen por qué cumplir ninguna característica específica, como la posesión de una estrella Michelin, sino que el consumo de platos típicos en cualquier restaurante local puede ser considerado como turismo gastronómico, siempre que haya sido uno de los motivadores esenciales del viaje (Berbel-Pineda et al., 2019).

El debate con respecto al tamaño del segmento de mercado que tiene un interés especial por la gastronomía, así como su importancia como factor motivador y su impacto económico está actualmente abierto (e.g., Berbel-Pineda et al., 2019; López-Guzmán et al., 2017; McKercher, Okumus, \& Okumus, 2008). Por una parte, existen investigadores que claman activamente que la importancia del turismo gastronómico está en auge bajo la premisa de que cada vez más personas viajan exclusivamente motivados por los atributos gastronómicos de un determinado destino (Quan \& Wang, 2004). En este sentido, se entiende que la gastronomía es un elemento motivador por sí mismo y por lo tanto tiene la capacidad de atraer a turistas que viajan en busca de la autenticidad que deriva de la degustación de este tipo de productos (Sánchez-Cañizares \& López-Guzmán, 2012; Wijaya, King, Nguyen, \& Morrison, 2013). Por otro lado, otros estudios llaman la atención sobre la posible sobreestimación que puede haber en los estudios que abogan por la importancia del turismo gastronómico y, de hecho, sugieren que la realidad del mercado puede ser muy diferente y que en términos prácticos el segmento de mercado motivado exclusivamente por la gastronomía a la hora de viajar no sea tan importante en términos relativos (McKercher et al., 2008).

Sea como fuere, sí que existe un amplio acuerdo en que la gastronomía de un destino, como parte esencial de su cultura e identidad puede mejorar la competitividad de empresas y destinos independientemente de la demanda que genera por sí misma (Berbel-Pineda et al., 2019). Esto es debido a que ya sea un factor motivador principal o accesorio puede influir en los patrones de consumo de los turistas (S. Kim et al., 2019). De hecho, los estudios previos indican que la gastronomía constituye una 
de las principales fuentes de gasto independientemente del rol motivacional de la misma en la elección del destino (Chen \& Huang, 2016). Así, la gastronomía tiene, definitivamente, el potencial de añadir valor a la experiencia de los viajeros, y por lo tanto, es un factor determinante de la satisfacción de los turistas con sus vacaciones (Chen \& Huang, 2016; Kim, Goh, \& Yuan, 2010). Sin embargo, la mayoría de los estudios se han centrado en situar los atributos gastronómicos del destino como herramienta estratégica en el marketing de los destinos (Du Rand \& Heath, 2006), mientras que pocos estudios se han llevado a cabo desde el punto de vista de la demanda. Así, es necesario profundizar en la literatura sobre turismo gastronómico sobre la importancia de conocer el perfil del turista gastronómico (Chen \& Huang, 2016; Ryu \& Jang, 2006).

\section{Objetivo, propuesta e innovación del estudio realizado}

En el presente estudio pretendemos dar respuesta a varias preguntas que están actualmente sin respuesta en la literatura académica. En primer lugar queremos cuantificar la importancia del segmento de turistas que consideran la gastronomía como elemento motivador a la hora de planificar sus vacaciones, dando respuesta así a la controversia planteada con respecto a la importancia del mercado de turismo gastronómico (McKercher et al., 2008; Sánchez-Cañizares \& López-Guzmán, 2012). Además, y debido a que la mayoría de los estudios se plantean desde la perspectiva de la oferta, con un enfoque mayoritario en el potencial de la gastronomía como elemento de marketing de destinos, la literatura no se ha centrado en caracterizar el perfil del turista que viaja en base a esta motivación determinada (Du Rand \& Heath, 2006; Mason \& Paggiaro, 2012). Así, con un enfoque desde el punto de vista de la demanda, damos respuesta a la caracterización necesaria del perfil del turista cuya motivación de viaje es la gastronomía (Chen \& Huang, 2016). Para ello, hemos acudido a la Encuesta sobre Gasto Turístico (EGT) realizada por el Instituto Canario de Estadística (ISTAC) que recoge el perfil sociodemográfico de los turistas que visitan el destino Islas Canarias, así como los elementos motivacionales que inspiraron el viaje, las características de los viajes realizados, el gasto que han llevado tanto en origen como en destino, así como su satisfacción y lealtad con el destino.

La realización de esta investigación tiene importantes contribuciones teóricos y prácticas. En primer lugar damos respuesta a la problemática planteada con respecto a la cuantificación real del segmento de mercado que viaja motivado por la gastronomía (McKercher et al., 2008). Además, con la caracterización del perfil del turista gastronómico, complementamos los estudios previos que se han centrado en el estudio de la oferta (Du Rand \& Heath, 2006). Así, nuestros resultados pueden ser utilizados por las empresas de restauración, así como por las asociaciones gestoras de los destinos de cara a mejorar sus propuestas de valor gastronómicas y para mejorar el enfoque de sus campañas de marketing.

\section{Metodología}

En este estudio se emplean dos herramientas de análisis diferentes para conocer cuáles son las características de los turistas que visitan Canarias con el objetivo de realizar un viaje de turismo gastronómico. En primer lugar, se ha realizado un análisis mediante tablas de contingencia para conocer cuáles son las características del turista que da mayor importancia a la gastronomía a la hora de elegir el destino de su viaje. Tras ello, se ha aplicado una regresión lineal para conocer cuáles son las variables significativas que explican por qué los turistas con estas características eligen Canarias como destino. La investigación previa apunta a otras técnicas de análisis que podrían haberse aplicado para estudiar las elecciones de los turistas, como modelos de elección discreta (Padrón-Ávila \& Hernández Martín, 2019a, 2019b) o ecuaciones estructurales (Quan \& Wang, 2004). Sin embargo, en el caso de los datos empleados para el análisis, la variable dependiente presenta una escala Likert que no permite que sea utilizada como variable dependiente en modelos de elección discreta y, al existir múltiples formatos de variables independientes (no solo Likert), tampoco pueden aplicarse ecuaciones estructurales. Por ello, se ha decidido realizar una regresión lineal, que permite combinar estos tipos de variables (Rasoolimanesh, Ali, \& Jaafar, 2018).

Para la realización de este estudio se ha utilizado la base de datos de la EGT del ISTAC. En concreto, se han utilizado los datos recopilados durante 2018. En la encuesta, se pregunta a los turistas por sus características demográficas, motivaciones, medio usado para conocer el destino, características del viaje, acompañantes, etc. La base de datos empleada contiene las respuestas de 37.904 turistas que fueron encuestados en los aeropuertos canarios que cuentan con vuelos interregionales o internacionales, antes de regresar a sus lugares de origen (ISTAC, 2018).

Para procesar los datos, la función para crear tablas dinámicas de Excel fue utilizada para realizar tablas de contingencia, mientras que el software SPSS fue empleado para realizar una regresión lineal y 
conocer cuáles son las variables relacionadas con que los turistas gastronómicos visiten el archipiélago. $\mathrm{Al}$ realizar el estudio mediante tablas de contingencias, solo se han considerado variables demográficas de los turistas que permitan establecer las diferencias generales entre los turistas gastronómicos y aquellos que no lo son, tal como se realizó en el estudio de Padrón-Ávila \& Hernández-Martín (2017). Sin embargo, hemos considerado una variedad mayor de variables al realizar la regresión lineal. Se han tenido en cuenta diferentes variables relativas a las características demográficas de los turistas, sus motivaciones, canales para conocer la existencia de Canarias, características del viaje, número y tipo de acompañantes, gasto durante el viaje, actividades realizadas, y satisfacción y fidelización con el destino.

Para realizar ambos análisis, la variable motivacional relacionada con elegir el destino por su gastronomía ha sido utilizada como variable dependiente. Se trata de una variable con formato de escala Likert de 4 ítems, donde el valor 1 significa que la gastronomía no influyó en la elección del viaje y el 4 que fue un aspecto fundamental para elegir el mismo. En la Tabla 1 puede observarse el peso relativo de cada una de las variables motivacionales incluidas en la encuesta del ISTAC. Así, cuando el coeficiente es positivo en la regresión, un mayor valor de la variable dependiente estará vinculado a un mayor valor de la variable independiente. Por ejemplo, si la variable "Edad" muestra un coeficiente positivo, cuanto mayor sea la edad, mayor tenderá a ser la probabilidad de elegir el destino por su gastronomía. En el caso de variables binarias como los canales para conocer el destino o los acompañantes durante el viaje; se les ha otorgado el valor 1 cuando el visitante ha marcado en la encuesta la casilla correspondiente a cada ítem (como viajar solo o conocer el destino por amigos) y el valor 0 se ha dado cuando la variable no ha sido marcada. En el caso de la variable "Sexo", el valor 0 ha sido dado a los turistas que indicaron ser hombres y el 1 a las mujeres.

\section{Tabla 1: Importancia relativa de los factores motivacionales de elección de Canarias como destino}

\begin{tabular}{|l|c|c|c|c|}
\hline Motivación & Nada relevante & Poco relevante & Relevante & Muy relevante \\
\hline Clima & $1,08 \%$ & $2,75 \%$ & $19,02 \%$ & $77,15 \%$ \\
\hline Playa & $8,87 \%$ & $22,02 \%$ & $32,11 \%$ & $37,00 \%$ \\
\hline Mar & $5,86 \%$ & $17,17 \%$ & $33,50 \%$ & $43,46 \%$ \\
\hline Paisajes & $7,42 \%$ & $21,91 \%$ & $36,60 \%$ & $34,07 \%$ \\
\hline Medioambiente & $5,88 \%$ & $19,10 \%$ & $43,15 \%$ & $31,87 \%$ \\
\hline Senderos & $49,94 \%$ & $25,22 \%$ & $14,65 \%$ & $10,19 \%$ \\
\hline Alojamiento turístico & $9,31 \%$ & $13,47 \%$ & $37,21 \%$ & $40,01 \%$ \\
\hline Patrimonio histórico & $30,81 \%$ & $37,32 \%$ & $24,42 \%$ & $7,45 \%$ \\
\hline Oferta cultural & $26,84 \%$ & $39,04 \%$ & $26,60 \%$ & $7,52 \%$ \\
\hline Diversión & $14,30 \%$ & $27,61 \%$ & $36,66 \%$ & $21,43 \%$ \\
\hline Ocio nocturno & $49,12 \%$ & $28,71 \%$ & $14,42 \%$ & $7,75 \%$ \\
\hline Oferta comercial & $32,69 \%$ & $33,99 \%$ & $23,79 \%$ & $9,53 \%$ \\
\hline Gastronomía & $14,64 \%$ & $23,89 \%$ & $39,14 \%$ & $22,32 \%$ \\
\hline Viaje sencillo & $9,89 \%$ & $16,66 \%$ & $40,26 \%$ & $33,18 \%$ \\
\hline Seguridad & $4,82 \%$ & $9,79 \%$ & $35,28 \%$ & $50,11 \%$ \\
\hline Tranquilidad & $3,16 \%$ & $10,66 \%$ & $39,80 \%$ & $46,38 \%$ \\
\hline Pertenencia a Europa & $19,09 \%$ & $16,76 \%$ & $29,37 \%$ & $34,78 \%$ \\
\hline Precio & $4,86 \%$ & $17,28 \%$ & $41,68 \%$ & $36,18 \%$ \\
\hline Exotismo & $27,55 \%$ & $34,40 \%$ & $26,75 \%$ & $11,30 \%$ \\
\hline Autenticidad & $13,97 \%$ & $28,25 \%$ & $37,66 \%$ & $20,12 \%$ \\
\hline & & & & \\
\hline
\end{tabular}

Fuente: Elaboración propia en base a los datos de la EGT 


\section{Resultados}

En primer lugar, se pretendía conocer si el sexo era una variable relevante para explicar por qué los turistas elegían Canarias como destino para su viaje. Estudios previos han mostrado que el sexo no es una variable relevante que determine la elección de actividades por parte de los turistas que visitan el archipiélago (Padrón-Ávila \& Hernández-Martín, 2019b). Sin embargo, esto no había sido probado al estudiar la relación entre esta variable y la elección del destino para disfrutar de su gastronomía. Los resultados aparecen en la Tabla 2 y no muestran grandes diferencias entre hombres y mujeres. Los hombres parecen ser algo más propensas a emitir valoraciones intermedias (algo o bastante), mientras que las mujeres parecen presentar una tendencia un poco mayor a marcar nada o mucho (los extremos). Además, los hombres señalan, de media, que son un poco más propensos a elegir el destino por su gastronomía.

Tabla 2: Turistas gastronómicos en función de su sexo

\begin{tabular}{|l|c|c|c|c|c|}
\hline \multirow{2}{*}{ Edad } & \multicolumn{4}{|c|}{ Elegir Canarias por la gastronomía } & \multirow{2}{*}{$\begin{array}{c}\text { Valoración } \\
\text { media }\end{array}$} \\
\cline { 2 - 5 } & Nada & Algo & Bastante & Mucho & 2,70 \\
\hline Hombre & $14 \%$ & $24 \%$ & $41 \%$ & $22 \%$ & 2,68 \\
\hline Mujer & $15 \%$ & $24 \%$ & $38 \%$ & $23 \%$ & \\
\hline
\end{tabular}

Fuente: Elaboración propia en base a los datos de la EGT

Tras realizar este análisis, se creó una segunda tabla de contingencia para analizar el impacto de la edad en la elección de Canarias como destino de turismo gastronómico. Los resultados del análisis se presentan en la Tabla 3 y parecen indicar que, en general, los turistas de mayor edad tienen una tendencia mayor a elegir el destino para practicar turismo gastronómico que los turistas más jóvenes. Esta tendencia es más elevada en el segmento de turistas que tiene entre 56 y 65 años. De hecho, a pesar de que, en general, los turistas gastronómicos están más motivados a elegir Canarias como destino conforme incrementa su edad, a partir del rango 56-65, parece que esta tendencia comienza a reducirse. De hecho, los turistas de 76 o más años parecen ser menos propensos a elegir Canarias por su gastronomía que los turistas entre 46 y 55 años.

Tabla 3: Turistas gastronómicos en función de su edad

\begin{tabular}{|c|c|c|c|c|c|}
\hline \multirow{2}{*}{ Edad } & \multicolumn{4}{|c|}{ Elegir Canarias por la gastronomía } & \multirow{2}{*}{$\begin{array}{c}\text { Valoración } \\
\text { media }\end{array}$} \\
\cline { 2 - 5 } & Nada & Algo & Bastante & Mucho & 2,49 \\
\hline $16-25$ & $24 \%$ & $25 \%$ & $30 \%$ & $21 \%$ & 2,66 \\
\hline $26-35$ & $16 \%$ & $24 \%$ & $36 \%$ & $24 \%$ & 2,67 \\
\hline $36-45$ & $15 \%$ & $25 \%$ & $39 \%$ & $21 \%$ & 2,75 \\
\hline $46-55$ & $12 \%$ & $23 \%$ & $42 \%$ & $22 \%$ & 2,78 \\
\hline $56-65$ & $11 \%$ & $23 \%$ & $43 \%$ & $23 \%$ & 2,77 \\
\hline $66-75$ & $12 \%$ & $22 \%$ & $43 \%$ & $23 \%$ & 2,73 \\
\hline 76 o más & $13 \%$ & $24 \%$ & $41 \%$ & $22 \%$ & \\
\hline
\end{tabular}

Fuente: Elaboración propia en base a los datos de la EGT

El último análisis mediante una tabla de contingencia realizado ha consistido en comparar la elección de Canarias como destino de turismo gastronómico en función del país de procedencia de los turistas. Los resultados alcanzados se presentan en la Tabla 4. Los resultados apuntan a grandes diferencias en función de la nacionalidad del visitante. Los turistas residentes en Islandia son los menos propensos a elegir Canarias como destino por su gastronomía, mientras que los senegaleses son los más propensos a hacerlo, existiendo 
una diferencia de más de un punto de media (sobre 4) entre ellos. Sin contar a los turistas residentes en Senegal, los residentes en Rumania son los turistas para los que la gastronomía canaria tiene un mayor peso en su elección del destino. Los datos indican que los turistas residentes en países africanos son, en general, los más propensos a viajar a Canarias por su gastronomía. Sin embargo, los países del norte europeo tienden a mostrar la propensión más baja a haber elegido el destino debido a su gastronomía.

Tabla 4: Turistas gastronómicos en función de su país de residencia

\begin{tabular}{|c|c|c|c|c|c|}
\hline \multirow{2}{*}{ País } & \multicolumn{4}{|c|}{ Elegir Canarias por la gastronomía } & \multirow{2}{*}{$\begin{array}{c}\text { Valoración } \\
\text { media }\end{array}$} \\
\hline & Nada & Algo & Bastante & Mucho & \\
\hline Alemania & $11 \%$ & $26 \%$ & $41 \%$ & $21 \%$ & 2,73 \\
\hline Austria & $12 \%$ & $17 \%$ & $45 \%$ & $27 \%$ & 2,86 \\
\hline Bélgica & $8 \%$ & $22 \%$ & $44 \%$ & $26 \%$ & 2,88 \\
\hline Chequia & $9 \%$ & $18 \%$ & $44 \%$ & $29 \%$ & 2,93 \\
\hline Dinamarca & $23 \%$ & $28 \%$ & $33 \%$ & $17 \%$ & 2,44 \\
\hline España & $11 \%$ & $26 \%$ & $40 \%$ & $23 \%$ & 2,75 \\
\hline Estonia & $3 \%$ & $36 \%$ & $40 \%$ & $21 \%$ & 2,78 \\
\hline Finlandia & $14 \%$ & $29 \%$ & $44 \%$ & $14 \%$ & 2,57 \\
\hline Francia & $8 \%$ & $28 \%$ & $45 \%$ & $18 \%$ & 2,74 \\
\hline Hungría & $10 \%$ & $19 \%$ & $48 \%$ & $24 \%$ & 2,86 \\
\hline Irlanda & $19 \%$ & $18 \%$ & $33 \%$ & $30 \%$ & 2,75 \\
\hline Islandia & $25 \%$ & $34 \%$ & $28 \%$ & $13 \%$ & 2,29 \\
\hline Italia & $10 \%$ & $28 \%$ & $43 \%$ & $20 \%$ & 2,73 \\
\hline Letonia & $27 \%$ & $9 \%$ & $32 \%$ & $32 \%$ & 2,68 \\
\hline Lituania & $17 \%$ & $0 \%$ & $50 \%$ & $33 \%$ & 3,00 \\
\hline Luxemburgo & $8 \%$ & $14 \%$ & $44 \%$ & $34 \%$ & 3,04 \\
\hline Marruecos & $6 \%$ & $22 \%$ & $36 \%$ & $36 \%$ & 3,02 \\
\hline Mauritania & $12 \%$ & $16 \%$ & $32 \%$ & $40 \%$ & 3,00 \\
\hline Noruega & $18 \%$ & $25 \%$ & $39 \%$ & $18 \%$ & 2,58 \\
\hline Países Bajos & $22 \%$ & $29 \%$ & $36 \%$ & $13 \%$ & 2,40 \\
\hline Polonia & $8 \%$ & $18 \%$ & $43 \%$ & $31 \%$ & 2,97 \\
\hline Portugal & $11 \%$ & $32 \%$ & $39 \%$ & $18 \%$ & 2,65 \\
\hline Reino Unido & $20 \%$ & $21 \%$ & $36 \%$ & $23 \%$ & 2,62 \\
\hline Rumania & $3 \%$ & $16 \%$ & $46 \%$ & $35 \%$ & 3,14 \\
\hline Rusia & $9 \%$ & $19 \%$ & $36 \%$ & $36 \%$ & 2,99 \\
\hline Senegal & $0 \%$ & $0 \%$ & $50 \%$ & $50 \%$ & 3,50 \\
\hline Suecia & $14 \%$ & $21 \%$ & $43 \%$ & $22 \%$ & 2,72 \\
\hline Suiza & $12 \%$ & $25 \%$ & $30 \%$ & $32 \%$ & 2,82 \\
\hline Venezuela & $11 \%$ & $33 \%$ & $22 \%$ & $33 \%$ & 2,78 \\
\hline
\end{tabular}

Fuente: Elaboración propia en base a los datos de la EGT

Por último, se presenta la Tabla 5 en la que pueden observarse los resultados obtenidos mediante la regresión lineal para las variables empleadas. Se utilizaron 86 variables independientes para conocer 
cómo se vinculan las mismas con la elección de Canarias como destino gastronómico. De entre las mismas, 37 mostraron no ser significativas para el estudio realizado, 5 mostraron una ligera tendencia a influir en la elección de Canarias con el objetivo de disfrutar de su gastronomía, 11 fueron significativas y el resto mostraron tener un nivel de significatividad muy elevado. No pudo incluirse la nacionalidad como variable demográfica en el análisis porque se trataba de una variable categórica en lugar de ser numérica. En la tabla, se han dividido las variables por categorías para facilitar su análisis.

Tabla 5: Resultados de la regresión lineal estableciendo cuáles son las variables que explican por qué los turistas eligen Canarias como destino gastronómico.

\begin{tabular}{|c|c|c|}
\hline Variable & Coeficiente & p value \\
\hline \multicolumn{3}{|l|}{ Demográficas } \\
\hline Sexo & $-0,009$ & $0,000 * * *$ \\
\hline Edad & 0,006 & $0,000 * * *$ \\
\hline Nivel educativo & 0,055 & $0,000 * * *$ \\
\hline Ingresos & 0,026 & $0,000 * * *$ \\
\hline Personas en el hogar & $-0,018$ & $0,000 * * *$ \\
\hline \multicolumn{3}{|c|}{ Motivos de elección del Canarias } \\
\hline Clima & $-0,003$ & 0,779 \\
\hline Playa & 0,011 & 0,169 \\
\hline Mar & 0,036 & $0,000 * * *$ \\
\hline Paisajes & 0,030 & $0,000^{* * *}$ \\
\hline Entorno ambiental & 0,033 & $0,000 * * *$ \\
\hline Senderismo & 0,023 & $0,000 * * *$ \\
\hline Oferta alojativa & 0,037 & $0,000 * * *$ \\
\hline Patrimonio histórico & 0,059 & $0,000 * * *$ \\
\hline Oferta cultural & 0,068 & $0,000 * * *$ \\
\hline Diversión & 0,025 & $0,000 * * *$ \\
\hline Ocio nocturno & 0,040 & $0,000 * * *$ \\
\hline Oferta comercial & 0,155 & $0,000 * * *$ \\
\hline Facilidad del viaje & 0,164 & $0,000 * * *$ \\
\hline Seguridad & 0,076 & $0,000 * * *$ \\
\hline Tranquilidad & 0,075 & $0,000 * * *$ \\
\hline Estar en Europa & $-0,012$ & $0,016^{* *}$ \\
\hline Precio & $-0,025$ & $0,001^{* * *}$ \\
\hline Exotismo & 0,022 & $0,001^{* * *}$ \\
\hline Autenticidad & 0,109 & $0,000 * * *$ \\
\hline \multicolumn{3}{|c|}{ Canales para conocer el destino } \\
\hline Visitas previas & $-0,001$ & 0,780 \\
\hline Amigos & 0,002 & 0,417 \\
\hline Redes sociales & 0,003 & 0,188 \\
\hline Medios de comunicación & $-0,001$ & 0,942 \\
\hline Revistas turismo & $-0,010$ & $0,003^{* * *}$ \\
\hline
\end{tabular}




\begin{tabular}{|c|c|c|}
\hline Variable & Coeficiente & p value \\
\hline Blogs & 0,015 & $0,001^{* * *}$ \\
\hline Televisión & $-0,021$ & $0,084^{*}$ \\
\hline Intermediario & $-0,000$ & 0,989 \\
\hline Asociaciones & 0,013 & 0,385 \\
\hline Otros & 0,015 & $0,043^{* *}$ \\
\hline \multicolumn{3}{|c|}{ Características del viaje } \\
\hline Paquete turístico & 0,006 & 0,320 \\
\hline Pernoctaciones & $-0,002$ & $0,006^{* * *}$ \\
\hline Categoría alojamiento & 0,008 & $0,039 * *$ \\
\hline Coste paquete & $-0,006$ & 0,290 \\
\hline \multicolumn{3}{|l|}{ Acompañantes } \\
\hline Solo & $-0,002$ & 0,654 \\
\hline Pareja & 0,006 & $0,059^{*}$ \\
\hline Hijos & $-0,003$ & 0,386 \\
\hline Otros familiares & $-0,003$ & 0,484 \\
\hline Amigos & $-0,002$ & 0,551 \\
\hline Compañeros de trabajo & 0,003 & 0,874 \\
\hline Viaje organizado & $-0,004$ & 0,746 \\
\hline Número personas & 0,006 & 0,224 \\
\hline \multicolumn{3}{|l|}{ Gasto durante el viaje } \\
\hline Total & 0,000 & $0,000 * * *$ \\
\hline Alojamiento & 0,001 & 0,266 \\
\hline Vuelo & 0,002 & $0,058^{*}$ \\
\hline Taxi & 0,001 & 0,185 \\
\hline Alquiler coche & 0,000 & 0,930 \\
\hline Transporte público & 0,001 & 0,534 \\
\hline Supermercados & 0,000 & 0,508 \\
\hline Restaurantes & 0,002 & $0,000^{* * *}$ \\
\hline Excursiones & 0,000 & 0,924 \\
\hline Deportes & $-0,001$ & $0,096^{*}$ \\
\hline Actividades culturales & 0,001 & 0,758 \\
\hline Museos & $-0,001$ & 0,422 \\
\hline Parques de ocio & $-0,001$ & 0,209 \\
\hline Discotecas & 0,000 & 0,660 \\
\hline Salud & 0,001 & 0,499 \\
\hline Suvenires & 0,000 & 0,833 \\
\hline Bienes inmuebles & $-0,007$ & $0,018^{* *}$ \\
\hline Otras compras & 0,002 & 0,263 \\
\hline Farmacia & 0,000 & 0,950 \\
\hline
\end{tabular}




\begin{tabular}{|c|c|c|}
\hline Variable & Coeficiente & p value \\
\hline Otros & 0,001 & $0,042^{* *}$ \\
\hline \multicolumn{3}{|l|}{ Actividades realizadas } \\
\hline Playa & $-0,009$ & $0,001^{* * *}$ \\
\hline Piscina & $-0,005$ & $0,042^{* *}$ \\
\hline Pasear & 0,002 & 0,424 \\
\hline Visitar otra isla & $-0,005$ & $0,043^{* *}$ \\
\hline Excursiones organizadas & $-0,009$ & $0,002^{* * *}$ \\
\hline Excursiones marítimas & $-0,001$ & 0,751 \\
\hline Astronomía & 0,012 & $0,021^{* *}$ \\
\hline Museos & $-0,011$ & $0,003^{* * *}$ \\
\hline Cultura popular & 0,011 & $0,000^{* * *}$ \\
\hline Gastronomía & 0,054 & $0,000 * * *$ \\
\hline Parques de ocio & $-0,009$ & $0,005^{* * *}$ \\
\hline Ocio & $-0,014$ & $0,000 * * *$ \\
\hline Belleza & 0,006 & 0,224 \\
\hline Deportiva & 0,008 & $0,011^{* *}$ \\
\hline Naturaleza & $-0,007$ & $0,054^{*}$ \\
\hline Mar & $-0,002$ & 0,647 \\
\hline \multicolumn{3}{|l|}{ Lealtad al destino } \\
\hline Satisfacción & $-0,003$ & 0,547 \\
\hline Calificar experiencia & $-0,019$ & $0,011^{* *}$ \\
\hline Repetir viaje & 0,010 & $0,027^{* *}$ \\
\hline Recomendar destino & 0,005 & 0,374 \\
\hline (Constante) & $-0,127$ & 0,544 \\
\hline
\end{tabular}

Fuente: Elaboración propia en base a los resultados de los análisis de regresión realizados

Los resultados indican que las variables demográficas son las más importantes para establecer por qué los turistas eligen Canarias como destino gastronómico. A mayor edad, nivel educativo e ingresos, mayor es la probabilidad de que el turista elija el destino por este motivo. Sin embargo, cuantas más personas vivan en el hogar del turista, menor es la probabilidad de que viaje para disfrutar la gastronomía canaria. Además, a pesar de que en las tablas de contingencia mostró no tener una gran relevancia, la regresión lineal indica que los hombres (la variable "Sexo" toma el valor 0 ) son más propensos a elegir Canarias como destino gastronómico que las mujeres.

El análisis muestra también la gran relevancia de los motivos de elección del destino. Esto implica que lo turistas que eligen Canarias por su gastronomía no lo hacen únicamente por este motivo, sino que combinan su deseo de probar la gastronomía de las islas con otros atributos del destino que también desean disfrutar. Curiosamente, elegir el destino para practicar turismo de sol y playa no muestra ser significativo para el análisis. Probablemente porque, al ser el producto principal del archipiélago, la mayor parte de los turistas lo elijan por ello, tanto los que ven la gastronomía como un incentivo para visitar Canarias, como los que no. Llama la atención, que aquellos turistas que eligen el archipiélago por estar en Europa y por el precio del viaje son menos propensos a elegirlo por su gastronomía. Seguramente, estos turistas hayan elegido Canarias como destino por conveniencia en el momento de reservar sus vacaciones (cercanía, facilidad de acceso, precio...) y no por los atributos del mismo. 
Los turistas que eligen Canarias como destino de turismo gastronómico suelen conocer el destino a través de blogs o canales no especificados en la encuesta. Sin embargo, los que lo conocen a través de revistas de turismo o por anuncios publicitario televisivos, son menos propensos a visitar Canarias con este objetivo. Además, los turistas gastronómicos suelen permanecer en el destino por periodos más cortos y alojarse en establecimientos de mayor categoría. En lo relativo a los acompañantes con los que se realiza el viaje, esta variable no parece ser relevante para explicar por qué se elige Canarias como destino gastronómico. Tan solo los que viajan en pareja muestran una ligera tendencia a ser algo más propensos a elegir el destino por este motivo.

En cuanto al gasto incurrido para realizar el viaje, los turistas gastronómicos tienden a gastar más, en general, al viajar a Canarias que los turistas que no muestran estar motivados por la gastronomía del destino. En concreto, son más propensos a pagar más en el vuelo y, obviamente, en restaurantes. Sin embargo, gastan menos que otros turistas en practicar deportes y en comprar bienes inmuebles. Los turistas gastronómicos muestran ser más propensos a realizar actividades realizadas con la observación de estrellas (en Canarias, usualmente es combinado con la degustación de vino), el disfrute de la cultura tradicional, el consumo de productos gastronómicos y la realización de deporte (a pesar de ser menos propensos a gastar más dinero en practicar deportes). A pesar de ello, son menos propensos a visitar playas, piscinas, otras islas distintas a su destino principal, realizar excursiones organizadas, visitar museos, parques de ocio, practicar actividades de ocio y visitar espacios naturales.

Por último, resulta llamativo el hecho de que los turistas gastronómicos, a pesar de ser más propensos a valorar peor el viaje realizado a Canarias que otros turistas, tengan una tendencia mayor que otros segmentos a repetir su viaje a las islas.

\section{Discusión de Resultados y Conclusión}

El objetivo del presente estudio era llevar a cabo una caracterización del perfil del turista que elegía Islas Canarias para disfrutar de su gastronomía. Para ello, se acudió a la EGT elaborada por el ISTAC y se llevaron a cabo análisis mediante tablas de contingencia y regresión lineal. En base a los resultados, podemos afirmar que más de un 50\% de los turistas que visitan Islas Canarias consideraron la gastronomía como un factor que influyó "bastante" o "mucho" en su elección del destino. Además, se encontraron diferencias significativas en aspectos tales como la nacionalidad y otras variables sociodemográficas, así como las características del viaje en este segmento concreto de turistas gastronómicos.

El presente estudio presenta importantes contribuciones a la literatura sobre turismo gastronómico. En primer lugar, hemos resuelto la controversia planteada en cuanto a la importancia del segmento del turismo gastronómico, pues diversos estudios han dudado de la magnitud de dicho segmento (McKercher et al., 2008). Así, derivado de los resultados obtenidos, concluimos que el segmento de turistas motivados por la gastronomía sí tiene una importancia considerable con respecto al total de segmentos. En este sentido, podemos afirmar que nos posicionamos del lado de los investigadores que abogan por una clara importancia creciente de dicho segmento de mercado (Quan \& Wang, 2004). Además, hemos dado respuesta a la urgente necesidad planteada en la literatura previa en turismo gastronómico sobre la caracterización del perfil del turista que tiene la gastronomía como elemento motivacional del viaje (Chen \& Huang, 2016; Ryu \& Jang, 2006).

Sin embargo, nuestros resultados contradicen las investigaciones previas que mantenían que la gastronomía podía contribuir positivamente a la satisfacción del viaje (e.g., Berbel-Pineda et al., 2019; Du Rand \& Heath, 2006), pues la regresión lineal realizada indica que cuanto mayor sea la motivación por disfrutar de la gastronomía por parte de los turistas, menor tenderá a ser su valoración del viaje realizado. A pesar de ello, los turistas gastronómicos son más propensos a repetir sus viajes a Canarias que otros turistas. Esto podría explicar los resultados contradictorios a la literatura previa hallados, pues los turistas repetidores tienden a valorar peor los viajes realizados (Padrón-Ávila \& Hernández-Martín, 2019b).

Nuestro estudio también presenta importantes implicaciones prácticas que pueden ser utilizadas por los profesionales del turismo gastronómico, así como por los agentes encargados de llevar a cabo la promoción de destinos turísticos. La literatura académica sobre turismo gastronómico está de acuerdo en presentar los atributos gastronómicos del destino como un factor esencial en la promoción de destinos turísticos (e.g., Du Rand \& Heath, 2006). Y de hecho, una buena caracterización de la demanda a través del estudio del perfil del turista parece un buen punto de partida para empresas y destinos de cara a enfocar sus acciones de comunicación así como sus propuestas de valor a los clientes (Dorta-Afonso \& 
Cantero-García, 2018). Los resultados obtenidos en el presente estudio sugieren que la mejor forma de llevar a cabo acciones de comunicación por parte de organizaciones gestoras de destinos así como empresas de restauración serían los blogs y no tanto los canales tradicionales como la televisión o las revistas de turismo. Además, debido a que son turistas más interesados en los aspectos culturales, las acciones de comunicación de los destinos y empresas de restauración podrían ser llevadas a cabo conjuntamente con otro tipo de organizaciones culturales que pongan en valor la autenticidad del destino a través de la cultura en general y de la gastronomía en particular.

A pesar de las importantes contribuciones teóricas y prácticas que derivan de la presente investigación, nuestro estudio también presenta algunas limitaciones que merecen la atención y que abren interesantes líneas de investigación futuras. A pesar de que el tamaño de la muestra utilizado en los análisis es mucho mayor a la mayoría de estudios sobre turismo gastronómico (e.g., Berbel-Pineda et al., 2019), es cierto que el ámbito geográfico está limitado al de los turistas que han visitado las Islas Canarias. Por lo tanto, sería interesante que futuros estudios comprobasen si el perfil del turista gastronómico identificado aquí se corresponde con el de otros destinos diferentes. También, se podrían considerar diferencias dentro del propio destino Islas Canarias, como las diferentes islas o regiones, para comprobar si el perfil del turista motivado por la gastronomía difiere en función de la zona visitada. Además, aunque se ha señalado en la literatura la poca estacionalidad del turismo gastronómico desde el punto de vista de la oferta (Hjalager \& Corigliano, 2000), en este estudio se ha seguido la premisa y no se ha tenido en cuenta el momento del año en el que los turistas visitaban el destino. En este sentido, sería interesante comprobar si existen diferencias en los turistas motivados por gastronomía en los diferentes trimestres del año para concluir si la demanda tiene algún tipo de característica diferenciadora en función de la estacionalidad. Por último, hay que resaltar la índole transversal del análisis que se ha llevado a cabo, que si bien arroja luz sobre la situación actual del perfil del turista que visita Islas Canarias motivado por la gastronomía, no ofrece información sobre la evolución de las características diferenciales. Así, se propone que en un futuro se planteen diseños longitudinales con el fin de identificar las tendencias en la evolución de las características diferenciales del perfil del turista motivado por la gastronomía.

Como conclusión, planteamos que el segmento de mercado de los turistas motivados por la gastronomía tiene un tamaño considerable en Canarias, así como unas características particulares que lo diferencian del resto. Empresas y destinos que quieran centrarse en este segmento deberían tener en cuenta el perfil del turista gastronómico de cara a adaptar tanto sus propuestas de valor como sus acciones de comunicación al mismo. Además, el estudio realizado es relevante para dar a conocer a los gestores turísticos de Canarias la necesidad de mejorar la satisfacción de los turistas gastronómicos con el viaje al archipiélago, pues los resultados indican que son más propensos a gastar más en el destino que otros turistas. Esto podría ayudar, a su vez, a incrementar las probabilidades de que recomienden el destino a otros turistas gastronómicos. Para las empresas gastronómicas, este estudio les ayuda a conocer el perfil del turista más propenso a consumir en ellas, ayudándoles a diseñar campañas de promoción y a adecuar su producto al segmento de mercado al que se orientan.

\section{Bibliografía}

Berbel-Pineda, J. M., Palacios-Florencio, B., Ramírez-Hurtado, J. M. \& Santos-Roldán, L. (2019). Gastronomic experience as a factor of motivation in the tourist movements. International Journal of Gastronomy and Food Science, 18, 100171.

Chavarria, L. C. T. \& Phakdee-auksorn, P. (2017). Understanding international tourists' attitudes towards street food in Phuket, Thailand. Tourism Management Perspectives, 21, 66-73.

Chen, Q. \& Huang, R. (2016). Understanding the importance of food tourism to Chongqing, China. Journal of Vacation Marketing, 22, 42-54.

Cohen, E. \& Avieli, N. (2004). Food in tourism: Attraction and impediment. Annals of tourism Research, 31, 755-778.

Dorta-Afonso, D. \& Cantero-García, M. (2018). Adaptación al español de la escala NES: segmentación de turistas en base a motivaciones ambientales.

Dorta-Afonso, D. \& Hernández-Martín, R. (2015). Subnational tourism competitiveness performance. The Canary Islands vs. The German Länder. European Journal of Tourism Research, 10, 51-63.

Du Rand, G. E. \& Heath, E. (2006). Towards a framework for food tourism as an element of destination marketing. Current issues in tourism, 9, 206-234. 
Dwyer, L. \& Kim, C. (2003). Destination competitiveness: Determinants and indicators. Current issues in tourism, 6(5), 369-414.

Hall, C. M., Sharples, L., Mitchell, R., Macionis, N. \& Cambourne, B. (2004). Food tourism around the world. Routledge.

Hjalager, A. \& Corigliano, M. A. (2000). Food for tourists-Determinants of an image. International journal of tourism research, 2, 281-293.

ISTAC. (2018). Encuesta sobre el Gasto Turístico. Metodología 2018. Recuperado de http://www.gobiernodecanarias.org/istac/galerias/documentos/C00028A/2018/EGT-2018-metodologia.pdf

Kim, S., Park, E. \& Lamb, D. (2019). Extraordinary or ordinary? Food tourism motivations of Japanese domestic noodle tourists. Tourism Management Perspectives, 29, 176-186.

Kim, Y. H., Goh, B. K. \& Yuan, J. (2010). Development of a multi-dimensional scale for measuring food tourist motivations. Journal of Quality Assurance in Hospitality \& Tourism, 11, 56-71.

Lin, L. \& Mao, P.-C. (2015). Food for memories and culture-A content analysis study of food specialties and souvenirs. Journal of Hospitality and Tourism Management, 22, 19-29.

López-Guzmán, T., Uribe Lotero, C. P., Perez Galvez, J. C. \& Rios Rivera, I. (2017). Gastronomic festivals: Attitude, motivation and satisfaction of the tourist. British Food Journal, 119, 267-283.

Mason, M. C. \& Paggiaro, A. (2012). Investigating the role of festivalscape in culinary tourism: The case of food and wine events. Tourism management, 33, 1329-1336.

McKercher, B., Okumus, F. \& Okumus, B. (2008). Food tourism as a viable market segment: It's all how you cook the numbers! Journal of Travel \& Tourism Marketing, 25, 137-148.

Padrón-Ávila, H. \& Hernández-Martín, R. (2017). Tourist points of interest: Analytical relevance, methodological proposal and study case. PASOS: Revista de Turismo y Patrimonio Cultural, 15(4), 979-1000.

Padrón-Ávila, H. \& Hernández-Martín, R. (2019a). Preventing Overtourism by Identifying the Determinants of Tourists' Choice of Attractions. Sustainability, 11, 5177.

Padrón-Ávila, H. \& Hernández-Martín, R. (2019b). Why do tourists differ in their likelihood to visit attractions? The case of Lanzarote. International Journal of Tourism Research.

Quan, S. \& Wang, N. (2004). Towards a structural model of the tourist experience: An illustration from food experiences in tourism. Tourism management, 25, 297-305.

Rasoolimanesh, S. M., Ali, F. \& Jaafar, M. (2018). Modeling residents' perceptions of tourism development: Linear versus non-linear models. Journal of Destination Marketing \& Management, 10, 1-9.

Ritchie, J. B. \& Crouch, G. I. (2003). The competitive destination: A sustainable tourism perspective. Cabi.

Ryu, K. \& Jang, S. (2006). Intention to experience local cuisine in a travel destination: The modified theory of reasoned action. Journal of Hospitality \& Tourism Research, 30, 507-516.

Sánchez-Cañizares, S. M. \& López-Guzmán, T. (2012). Gastronomy as a tourism resource: Profile of the culinary tourist. Current issues in tourism, 15, 229-245.

Tikkanen, I. (2007). Maslow's hierarchy and food tourism in Finland: Five cases. British food journal, 109, 721-734.

Wang, N. (1999). Rethinking authenticity in tourism experience. Annals of tourism research, 26, 349-370.

Wijaya, S., King, B., Nguyen, T.-H. \& Morrison, A. (2013). International visitor dining experiences: A conceptual framework. Journal of Hospitality and Tourism Management, 20, 34-42. 


\title{
Una aproximación conceptual y literaria a la gastrodiplomacia como conductora de marca de un destino Silvia María González* \\ Universidad de Deusto (España)
}

\begin{abstract}
Resumen: Este artículo analiza y describe los diferentes términos conceptuales que se utilizan en la gastronomía con el fin de comprenderla como un arte para la promoción de una región o un destino en el exterior y como una herramienta de la diplomacia cultural, la llamada gastrodiplomacia. El eje central del artículo investiga y analiza los actores principales encargados de promocionar y gestionar este sector y las diferentes estrategias y acciones que se pueden llevar a cabo para revalorizar este campo. Por último y en la tercera parte del artículo se extraen unas reflexiones sobre el futuro y las tendencias en la gastronomía en el turismo, la cultura y la sociedad.
\end{abstract}

Palabras Clave: Gastrodiplomacia; Gastronomía; Cultura; Imagen; Estrategia.

\section{A conceptual and literary approach to gastrodiplomacy as a destination branding driver}

Abstract: This article analyses and describes the different conceptual terms used in gastronomy to understand it as an art and way of promoting a region or a destination, as a tool for cultural diplomacy, now known as gastro-diplomacy. The central axis of the article studies and researches the main agents in the sector and the different strategies that can be carried out to improve this field. In the conclusions, we offer some reflections on trends in gastronomy, tourism, culture, and society.

Keywords: Gastro-Diplomacy; Gastronomy; Culture; Image; Strategy.

\section{Introducción}

La alimentación es tan antigua como la humanidad, por ser un elemento necesario para la supervivencia del individuo. A medida que evolucionamos, la forma de alimentarse se ha visto modificada, desarrollándose como un placer y una experiencia vivencial única, es decir, dando lugar a la gastronomía. Esta se ha convertido en un componente inequívoco de nuestra sociedad. La "gastrodiplomacia" que se analiza en este artículo es un concepto multidisciplinar que abarca diferentes campos (sector agroalimentario, cultura, turismo, exportaciones y comercio, etc.). La gastronomía es parte del patrimonio cultural de la humanidad declarado por la Organización de las Naciones Unidas para la Educación, la Ciencia y la Cultura (UNESCO, 2014). Es una parte esencial de la cultura, y es un elemento intrínseco de la identidad de los ciudadanos.

La gastronomía es vista actualmente como una parte esencial de las relaciones internacionales y una guía para alcanzar objetivos institucionales y gubernamentales (Nirwandy y Awang, 2014). A parte de ser un componente de la diplomacia cultural (Nye, 2008), la gastronomía también puede ser un activo del poder blando "soft power" y duro "hard power". El poder blando utiliza mecanismos para crear prestigio e incrementar la influencia en el exterior a través de la cultura, los valores y las políticas exteriores, mientras que el poder duro incide directamente en las exportaciones y en el comercio a través del uso de recursos militares o económicos ${ }^{1}$ (Reynolds, 2010).

Ello es importante no solo por su aportación económica al producto interior bruto de una región o país, sino también para la creación de la marca de un destino (Anholt, 2010) con el consecuente posicionamiento de un lugar en el exterior y la atracción del turismo y de las inversiones empresariales. El éxito depende de la coordinación y el consenso de las estrategias y decisiones tomadas por los diferentes actores involucrados en la gestión de la marca y de la cooperación entre ellos. Como se puede verificar

Universidad de Deusto (España); E-mail: silviamaria.gonzalez@gmail.com; https://orcid.org/0000-0002-4822-2847 
en este artículo, los países orientales son los precursores en la utilización de la gastronomía como una herramienta para la mejora de las relaciones internacionales y para posicionar la imagen de marca de un destino. Por ello, se toman como referencia los estudios y acciones utilizadas por países como Japón, Tailandia o China en esta materia y que aportan valor añadido a la gastronomía.

\section{La gastronomía, patrimonio cultural inmaterial de la humanidad y una herramienta de gestión en la diplomacia cultural}

Los investigadores Karagiannis y Metaxas (2015) señalan que la palabra gastronomía apareció por primera vez en Francia en el siglo diecinueve, gracias a un poema redactado por Berchoux (1804). En este sentido, la primera obra sobre gastronomía fue de Jean Anthelem Brillat-Savarin (1862) cuya obra "The physiology of Taste" cautivó al mundo por promover la resiliencia a través de la gastronomía.

Actualmente, la Enciclopedia Británica define la gastronomía como el arte de seleccionar, preparar, servir y disfrutar de la comida. Esta acepción difiere en España, ya que la gastronomía es definida por la Real Academia Española, RAE (s.f) como "el conjunto de platos y usos culinarios propios de un determinado lugar", mientras que la cocina es un término definido por la RAE, como el arte, estilo o manera de guisar de un país. La gastronomía estudiada desde una vertiente científica cultural es vista como un arte y una ciencia, y es un concepto que se extiende a las nociones de tradición, cultura, sociedad y civilización (Gillespie y Cousins, 2001).

La definición de gastronomía tradicional es recogida por Vanhonacker y et al., (2010:453) como "un producto frecuentemente consumido o asociado a celebraciones y/o temporadas específicas, transmitido de una generación a otra, hecho de una manera especifica de acuerdo con el patrimonio gastronómico, procesado naturalmente, $y$ distinguido y conocido por sus propiedades sensoriales y asociadas, a una determinada área local, región o país". En esta misma línea, Kesimoglu (2015) está de acuerdo en que la gastronomía se puede convertir es un producto, mayormente turístico, pero es algo más, es patrimonio, identidad y por tanto, tiene un potencial cultural muy amplio.

Matviyiv (2014) indica que el patrimonio gastronómico comprende los platos nacionales cocinados utilizando ingredientes locales de un país, aunque otros autores como Barrére, Bonnard y Chossat (2012) incluyen la manera de beber y comer propia de un determinado lugar. La gastronomía es la combinación de elementos intangibles diferentes como la sociabilidad, la transmisión, identidad, tradición, evolución y la comida local. En el 2005, la gastronomía se incluye como parte del patrimonio inmaterial en la lista representativa del patrimonio cultural inmaterial de la humanidad de la UNESCO gracias a que se demostró su valor simbólico, social y cultural en la identidad y herencia de un lugar. En España, "la ley para la salvaguardia del Patrimonio Cultural Inmaterial fue aprobada definitivamente por el Congreso de los Diputados el 25 de mayo de 2015, publicada en el BOE 126, entrando en vigor el día 28 de mayo de 2015. Una de las enmiendas aceptadas fue la inclusión en el texto de la gastronomía, a iniciativa de la Real Academia de Gastronomía, con el objetivo de salvaguardar, difundir y promover nuestro patrimonio cultural gastronómico, como afirmó su presidente Rafael Ansón, siguiendo así la estela de la Resolución del Parlamento Europeo Patrimonio Gastronómico Europeo: aspectos culturales y educativos, aprobada por la Comisión de Consultas el 11 de marzo de 2015" (Gabardón de la Banda, 2016: 285)

La UNESCO en el 2004 desarrolló globalmente la red de las ciudades creativas (UCCN) para apoyar los esfuerzos realizados por algunas ciudades en los campos enmarcados dentro de las industrias culturales y creativas. La UNESCO (2008) ha designado "ciudades del diseño", "ciudades del cine", "ciudades gastronómicas", "ciudades de la música", "ciudades de la literatura" o "ciudades de la artesanía y el folklore", siempre en línea con su filosofía y animando la diversidad cultural y siguiendo la línea de los objetivos sostenibles 2030 de las Naciones Unidas (NU). ${ }^{2}$

La creación de la red de ciudades creativas promueve la creatividad y participación en la cultura y el desarrollo sostenible. En el caso de la gastronomía, la UNESCO creó una lista para ayudar a todas esas ciudades que estén dispuestas a seguir los criterios para ser una ciudad gastronómica (Pearson y Pearson, 2017):

- Una gastronomía muy bien desarrollada en la región.

- Una comunidad gastronómica con numerosos restaurantes tradicionales o chefs.

- El uso claro de ingredientes locales utilizados en la cocina tradicional.

- El conocimiento y saber hacer de las prácticas culinarias y métodos de cocina que han sobrevivido al avance tecnológico. 
- El mercado tradicional gastronómico y festivales, premios, y otro tipo de eventos en los que se reconozca el patrimonio gastronómico.

- Respeto por el medio ambiente y la promoción de productos locales.

En España existen actualmente dos ciudades designadas como ciudades gastronómicas por la UNESCO; Denia (https://deniacreative.city) y Burgos (https://burgosgastronomycity.com). La red de ciudades creativas de la UNESCO promueve la cooperación entre ciudades y desarrollar planes en el ámbito local y que cooperan en el escenario internacional. La gastronomía es un elemento vital de los recursos urbanos que merece la misma atención que otros sectores como la artesanía, las artes tradicionales o el folklore, la música o la literatura. La red de ciudades creativas de la UNESCO se encarga de representar todos los sectores que forman parte de la economía creativa a través de criterios tanto cuantitativos como cualitativos. Para designar a las "ciudades gastronómicas", la UNESCO elabora una guía con veintidós dimensiones y sesenta y seis indicadores cualitativos que son extraídos de ocho criterios (Xiaomin, 2017; Pearson y Pearson, 2017; UNESCO, 2014). A modo de ejemplo vamos a desarrollar uno de los criterios:

"Nurturing of public appreciation, promotion of nutrition in educational institutions and inclusion of biodiversity conservation programs in cooking schools curricula". [Fomentar la apreciación pública (de la alimentación gastronómica), promocionar la nutrición en instituciones educativas y la inclusión de programas de conservación de la biodiversidad en los planes de estudio de las escuelas de cocina (Xiaomin, 2017:62)].

La primera dimensión de este criterio mide la educación y la formación. Los indicadores que se utilizan para medir las dimensiones son los siguientes:

- Número de instituciones culinarias que se dedican a este sector;

- Número de talentos culinarios de todos los niveles;

- Clases sobre artes culinarias en todos los niveles educativos, instituciones y centros de investigación que se dedican a la transferencia de resultados I+D+I y número de libros de comida tradicional y de cultura culinaria, tanto profesional como de lectura general.

La siguiente dimensión en esta materia es la de la gastronomía tradicional y la de una carrera reconocida (todavía continúa realizando festivales y ferias de cocina tradicional), especialistas en enseñar al público los diferentes procesos, turismo gastronómico (interno e internacional) y la influencia internacional en la cocina local. La siguiente dimensión versa sobre la difusión y comunicación de la cocina tradicional. Se mide mediante el número de canales de difusión digital como internet o la televisión, el número de canales de comunicación convencionales como las publicaciones, el número de canales de material que no son de difusión como la literatura, la poesía, los personajes públicos, etc., y el último indicador es el número de canales de diseminación tangible como los negocios, museos gastronómicos, galerías o eventos de demostraciones culinarias. La última dimensión se refiere a los esfuerzos realizados en promociones, con indicadores como la participación gastronómica gubernamental, el apoyo financiero, los programas de intercambio culinario, las organizaciones e instituciones de investigación...

Francia aprovechó la Declaración de la UNESCO en el 2010 de nombrar a la cocina francesa como patrimonio cultural de la humanidad para elaborar estrategias de gastrodiplomacia centradas en el turismo y en la alimentación. En el 2013 el gobierno francés lanzó el programa de "red de ciudades de la gastronomía" para crear espacios dedicados a la gastronomía. Con este programa se declararon cuatro ciudades de gastronomía en todo Francia con el fin de crear un espacio para la innovación y la educación de la gastronomía francesa. Cada una de las ciudades se enfocaba en un tema diferente: Dijón para los vinos; Lyon para la salud y la nutrición y, por último, París y Rungis para el comercio y suministro de alimentos en áreas urbanas y creación de Tours gastronómicos (DeSoucey, 2010). En España, destaca el Basque Culinary Center con estudios en esta materia. La gastronomía es una herramienta para unir a diferentes públicos que pueden ser de diferentes culturas y disfrutar de la hospitalidad, sabor y relaciones que esta ofrece. Es una forma sutil de agradar a la persona con el fin de persuadir y tener cierta influencia en las decisiones o negociaciones pertinentes. En este sentido, la gastronomía forma parte de la diplomacia, cultural, conceptualizando esta como "una herramienta para crear diálogo entre los pueblos, fomentar la cohesión social y el desarrollo económico" Montiel (2007:20). Desde esta visión, 
Bounds and Briggs et al., (2007) definen la diplomacia cultural como uno de los aspectos de las relaciones internacionales. Es por eso, que el concepto de cultura y diplomacia se basa en el concepto de poder.

En muchos estudios, la alimentación es un indicador de poder. Nye (2008) argumenta que el éxito depende del poder político y se suele estudiar después de ser aplicado a través de la observación en la consecución de las acciones. Reynols (2010) menciona que el poder gastronómico no es muy diferente de otros tipos de poder, incluso puede llegar a ser un mecanismo de poder duro debido a los embargos y las tasas en comercio. Sin embargo, también es un mecanismo de poder suave debido a que puede cambiar decisiones tanto a través de su contenido simbólico como a su contenido económico y político (Morgan, 2008).

Henderson (2014) subraya la importancia de los feriantes y comerciantes en festivales o en países en desarrollo que contribuyen a la creación de la identidad local y al patrimonio. En países europeos se puede observar la venta ambulante diaria reglamentada. La seguridad alimentaria se encuentra regulada y es uno de los puntos fuertes en comunidades españolas y/o europeas. Sin embargo, esto se ha modificado en los últimos años con la aparición de los food trucks. Según la página oficial de Food Truck ya. com, el reglamento 2004/852/CE es el que regula la higiene alimentaria en la Unión Europea, siendo competencia de cada país y en España, de las comunidades autónomas en cuanto a las autorizaciones sanitarias. Los mecanismos y regulaciones en materia sanitaria de un país cobran vital importancia no solo para prevenir riesgos en la salud de los consumidores, sino también porque intervienen activamente en las relaciones culturales, en el proteccionismo económico, o en la imagen que emite una región dentro o fuera de su país.

Maffei (2012) señala que la globalización puede ser compatible con las tradiciones y que no significa necesariamente homogenización. La gastronomía tradicional conecta con el pasado y representa sabores y experiencias inolvidables. La diversidad y la identidad pueden convivir, todo depende de la eficiencia en la gestión.

Desde una perspectiva neoliberalista en la economía global, la gestión de la marca ha ganado mucha importancia como una estrategia de regeneración urbana. Este es el caso de George Town's, cuya inscripción en la lista de patrimonio Mundial de la UNESCO en el 2008 ha ayudado a posicionar la ciudad en el mapa (Khoo and Badarulzaman, 2014).

Las ciudades están haciendo esfuerzos para posicionarse en el mercado internacional para darse a conocer internacionalmente en diferentes campos. La economía creativa es un activo que incentiva el desarrollo en el sector servicios. Se trata de un output ilimitado de recursos cuyo esquilmado es prácticamente imperecedero. La gastronomía ofrece la posibilidad de crecer y atraer al turismo, esta puede dar vida a la identidad de la comunidad a través de productos locales.

\section{Gastrodiplomacia: sinónimos y homónimos}

Desde la época de los Griegos y los Romanos, la gastronomía, la hospitalidad y el protocolo han sido protagonistas de grandes decisiones estratégicas de orden mundial. Ya en estos tiempos, los Romanos utilizaban delegaciones especiales para negociar y muchos diplomáticos acarreaban regalos y productos de esas regiones, no para sobornar, sino como símbolo de hospitalidad y agradecimiento para los anfitriones. En otras épocas, como el renacimiento, las Ciencias y las Artes cobran una especial relevancia, haciendo hincapié en el protocolo del menaje y la cubertería como una muestra de buenas dotes hospitalarias y negociadoras. En el siglo XIX, la gastronomía cobra interés en asuntos internacionales, pero es durante la guerra fría cuando las artes culinarias han influido de manera positiva o negativa en las decisiones y negociaciones informales. La gastronomía ha tenido un papel vital en la comunicación de las sociedades y en las personas. Esta ha influenciado a la ciencia, la filosofía, la política, las matemáticas y las relaciones internacionales en la forma de relacionarse y producir sinergias (Bahls, et al., 2019). Además, la gastronomía actualmente es estudiada desde diversos ámbitos y disciplinas (como un arte, una ciencia, un recurso...) Desde esta perspectiva, existen actualmente estudios sobre técnicas de resolución de conflictos en los que se incluye la gastronomía como la cocina del conflicto ${ }^{3}$. Actualmente, no se puede negar la importancia de la Diplomacia gastronómica, aun cuando muchos no la consideran relevante en la Diplomacia Pública (Trejo, 2013). Es por ello, que la gastrodiplomacia es un activo importante de las relaciones internacionales y merece ser estudiada:

La gastrodiplomacia se refiere a las prácticas y estrategias llevadas a cabo y el presupuesto que un país realiza para conseguir un objetivo en promocionar su cultura alimentaria y su influencia en el exterior (Rockower, 2012; Nirwandy y Awang, 2014).

Aunque la gastrodiplomacia es un concepto más desarrollado en los estudios diplomáticos, Onaran (2016) subraya que en el campo del turismo conlleva un potencial ilimitado. 
La gastrodiplomacia es un término que difiere de la diplomacia gastronómica. Este último concepto se refiere a la importancia de la comida en los actos diplomáticos y en las relaciones entre países. La diplomacia gastronómica es el arte de organizar eventos diplomáticos a través de la gastronomía, utilizando símbolos y/o protocolos para mejorar las negociaciones (Morgan, 2008). Las comunicaciones y las negociaciones se realizan a través de las comidas o de las cenas. Rockower (2014) la menciona como un medio para alcanzar la diplomacia formal en actos oficiales y que utiliza la alimentación y las experiencias gastronómicas como medio para mejorar las relaciones bilaterales. Rockower (2012) reitera que la gastrodiplomacia es muy diferente ya que se trata de aunar esfuerzos hospitalarios para usar los alimentos con fines diplomáticos y para transmitir mensajes a funcionarios de otros países con la intención de que este quede satisfecho y genere una imagen positiva del país. La gastrodiplomacia utiliza a la gastronomía como una dimensión y como un acercamiento a la diplomacia pública y al uso de comunicar la cultura culinaria en asuntos públicos. La gastrodiplomacia es más que promocionar la cocina de una región en el extranjero, pues la utiliza como una herramienta de poder suave (González, 2017), con el fin de obtener prestigio, alcanzar objetivos económicos como la exportación de productos o incrementar el turismo.

Los programas de gastrodiplomacia actuales tratan de alcanzar un público más amplio a través de diversas audiencias en festivales, programas de televisión, campañas, redes sociales, etc...

Zhang (2015) estudia las diferentes estrategias en gastrodiplomacia realizada fundamentalmente por los países asiáticos (Tailandia, Japón, Taiwán) pioneros en esta tendencia a través de estrategias en las diferentes categorías: salud, diversidad, misticismo y exotismo, cultura, naturalidad, ambientalismo y estética.

Tailandia fue el primer país que se esforzó en gastrodiplomacia. Tettner and Kalyoncu (2016) subrayan que China, Japón e India han realizado promoción cultural de su gastronomía abriendo restaurantes en todo el mundo. Estos ejemplos han tenido repercusión diplomática directa ya que el propio gobierno en muchos casos no apoyó la iniciativa, pero otros gobiernos donde se establecieron los restaurantes sí que tomaron acciones directas en este campo. Tailandia lanzo la iniciativa "Global Thai" en el 2002 a través de abrir restaurantes de comida tailandesa alrededor del mundo. La gastronomía fue definida en un primer momento por Rockower como una idea romántica de ser un método para llegar a las personas y conquistar su mente y corazón a través del estómago (Wallin, 2013). Chapple-Sokol (2013) define la gastronomía como el uso de la alimentación y de la cocina para crear entendimiento intercultural y mejorar las interacciones y la cooperación. Strugart (2015) incide en que este término se ha comenzado a utilizar en la última década como un utensilio de poder suave y mejorar la imagen pública. Otros claros ejemplos de éxito en la imagen de un país a través de su gastronomía es Japón. Assmann (2017) definió el poder suave como un elemento clave en la política culinaria. Japón ha sabido popularizar su gastronomía con el Sushi (Allen, 2011) y la creación de una cultura e identidad única a través de su alimentación. Farrer (2015) desarrolla el concepto de poder suave culinario como aquél que genera atractivo en la cultura gastronómica y que es inherente a una nación, región o localidad. Cabe resaltar de nuevo que no se debe tampoco confundir con "food power" o poder alimentario, ya que este es conceptualizado como la habilidad de un estado para usar la alimentación como un arma con el fin de alterar la economía en mercados internacionales (Nau, 1978; Wallensteen, 1976).

La gastrodiplomacia es una forma de diplomacia pública que combina diplomacia cultural, diplomacia gastronómica y la marca nación/región para constituir una cultura en el exterior tangible para probarla y tocarla. Es un espacio que combina la cultura culinaria y la política exterior (Wilson, 2011; Suntikul, 2019).

La gastrodiplomacia es algo más que promover las relaciones a través de la comida, se trata de difundir la imagen de un destino. El término gastrodiplomacia es complejo, además de comunicar y construir relaciones, consigue propósitos en las relaciones internacionales. No es simplemente realizar campañas para promover un determinado producto en el exterior. Es más que eso, es representar la identidad nacional y el patrimonio cultural a través de un producto. Quizás se trata de un término holístico y difuso, pero trata de influenciar y llegar a todo tipo de audiencias, más allá de las elites. Por ejemplo, en Corea los viajeros "mochileros" han representado su cultura visitando 23 ciudades de 15 países través de sus platos más típicos. Taiwán, ha programado festivales internacionales en el propio país y ha enviado a sus mejores chefs a las competiciones extranjeras. También ha abierto restaurantes fuera del país. El embajador de Indonesia también realizó un programa en Holanda para promover la cultura culinaria del país (The Yakarta Post, 2011). El turismo es una forma muy eficaz en la promoción de la cultura de un país en el exterior. En esta línea, la Organización Mundial del Turismo promueve una distribución equitativa de los beneficios que brinda el turismo gastronómico entre los sectores involucrados. No solo es crucial que los agricultores, cocineros y chefs sean vistos como una parte integral de la cadena de valor del turismo, sino también que las propuestas les ofrezcan un papel central con la intención de preservar la biodiversidad y la cultura gastronómica (WTO, 2017). 
Otro ejemplo de buenas prácticas en gastrodiplomacia es la de una Organización sin ánimo de lucro fundada en Jerusalén "chefs for peace", en la que varios chefs de diferentes religiones (cristianos, judíos y musulmanes) realizan eventos en las cocinas de todo el mundo. Se trata de un ejemplo de gastrodiplomacia o eventos $\mathrm{P} 2 \mathrm{P}$ en los que predomina la democratización, el acceso a las tecnologías y los contactos virtuales con las personas.

Otros ejemplos de gastrodiplomacia son las campañas realizadas por las escuelas de elite que intentan atraer a los turistas y profesionales de alto nivel (Suntikul, 2019).

\section{El papel de la gastrodiplomacia en la imagen de marca de un destino}

Las marcas a menudo proveen de valor a una audiencia potencial de comprar un producto o servicio (Aaker, 2009). Si la marca tiene éxito, hace que la audiencia no busque otras marcas. Las características que conforman la marca de una comunidad son la cultura, el tiempo, la lengua o el idioma, y el gusto de lo que ofrece. Las fotos o imágenes subidas en los medios y redes sociales siempre y cuando sea positivo, tiene un valor publicitario importante en la imagen. Hankinson (2007) indica que muchas ciudades crean imagen de marca para competir nacional e internacionalmente con el objetivo de tener una imagen positiva y atraer diversas audiencias, con el consecuente crecimiento económico, crear una imagen de destino interesante o seguro y atraer turismo.

Suntikul (2019) profundiza en los estudios de gastronomía, turismo y gobierno, vinculando la gastrodiplomacia y la marca nación. La gastronomía en turismo es estudiada como una herramienta tractora que promueve y atrae al turista al destino visitado. Esta vinculación es positiva ya que el turista entra en contacto con la identidad y cultura local a través de su cocina. Muchos países aspiran a desarrollar una identidad cultural a través de la de desarrollar una cocina atractiva que pueda fomentar un sentimiento de orgullo ciudadano (Henderson, 2014).

Algunos investigadores como Appadurai, (1988) o Cook y Crang (1996) señalan que muchas veces la cocina nacional es a menudo más imaginada o inventada que real pero que los platos que tienen una conexión con la comida local podrían ayudar a definir más la identidad local entre sus ciudadanos (Guerrero et al., 2009).

El liberalismo económico y la globalización han presionado a que los destinos compitan en los mercados internacionales. Actualmente, esto ha empujado a que los gobernantes de las ciudades tengan que adoptar estrategias de planificación y mercadotecnia que solamente se utilizaban en el ámbito empresarial (De los Reyes Cruz, Ruiz, y Zamarreño, 2017). En este contexto, la marca territorio se ha vuelto un fenómeno viral estudiado por diversos autores en el ámbito internacional (Landry 2000; Kavaratzis 2004, Papadopoulos, 2004; Anholt 2010). Existen diversas etiquetas y estudios utilizados en la marca de un destino, como "place branding, destination image" (Ku y Mak, 2017), "destination brand, location brand" (Kerr, 2006) and "place marketing, place branding" (Gertner, 2011). De hecho, el concepto de marca ciudad está intrínsecamente ligada al desarrollo económico en un contexto global.

Uno de los más conocidos estudiosos de la marca ciudad es Anholt (2004, 2008). El hexágono analiza la marca ciudad o región desde diversas dimensiones que son: la gente, los lugares, la presencia, el potencial, el pulso y los prerrequesitos.

Figura 1: Dimensiones de la marca ciudad de Anholt

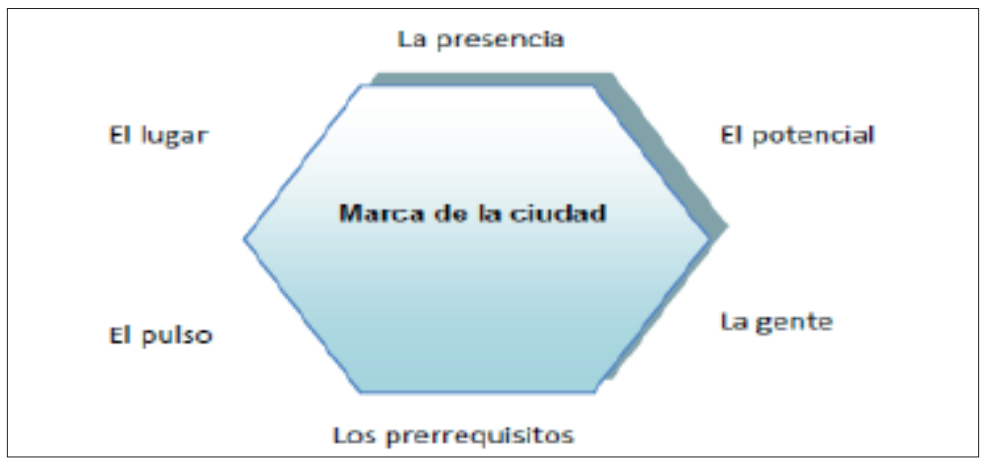

Fuente: Anholt (2008) 
Vamos a ir analizando que afecta a la gastronomía en la marca ciudad/región.

\subsection{La dimensión ciudadana}

La dimensión ciudadana es el alma de la ciudad. En esta dimensión se analizan conductas de la ciudadanía. ¿Cómo son los habitantes de las ciudades? ¿Cómo son ante los turistas? Los locales pueden ser amables, abiertos, respetuosos, o por el contrario pueden ser prejuiciosos, evasivos, agresivos o fríos con los turistas. La seguridad en la ciudad y como los ciudadanos difunden su cultura son indicadores para medir esta dimensión. La hospitalidad es un elemento esencial para la gastrodiplomacia, ya que el buen trato, la persuasión y la amabilidad juegan un papel esencial en las relaciones internacionales. La gastronomía juega un papel fundamental en esta dimensión y los eventos p2p son bastante fructíferos en la comunicación de la identidad de un destino.

\subsection{El lugar}

En esta dimensión se exploran las percepciones de la gente sobre el aspecto estético de la ciudad. El atractivo, el clima, la seguridad, la limpieza, la arquitectura. La gastronomía proporciona satisfacción si se observa limpieza, seguridad en las calles, una temperatura agradable y un lugar atractivo estéticamente.

\subsection{El Pulso}

El atractivo de la ciudad y el estilo de vida es muy importante para la imagen de una ciudad. En general, la oferta de los servicios, los eventos y el dinamismo que ofrece la ciudad son la esencia de la ciudad.

\subsection{Los prerequisitos}

La relación calidad y precio de la oferta de la ciudad forman parte de esta dimensión. Los servicios de primera necesidad como las escuelas, los hospitales, los restaurantes, el transporte público o las instalaciones deportivas. Estos, son muy importantes para el turismo, ya que este busca satisfacer unas necesidades básicas específicas como disponer de un buen sistema sanitario en caso de que tener algún percance o una red de transportes eficiente.

\subsection{El Potencial}

El hexágono de Anholt (2008) considera que las oportunidades económicas y laborales de la ciudad se encuentran dentro de esta dimensión. Las oportunidades de inversión, o el acceso a la educación son partes esenciales. La gastrodiplomacia es un activo fundamental a considerar en esta dimensión, ya que mediante ella se consiguen muchos acuerdos, negociaciones y oportunidades.

\subsection{La presencia}

Por último, esta dimensión mide la contribución de la ciudad en la ciencia, la cultura y la gobernanza. También mide la familiaridad de la ciudad.

Otro instrumento conocido para medir la marca ciudad, es el barómetro de la Unión Europea "the European city Brand Barometer" elaborado por Saffron Brand Consultants (Hildreth, 2008; Papp-Váry, 2011) con 10 dimensiones que se encargan de medir la imagen de marca de un lugar.

DeSoucey (2010) creo el término gastronacionalismo para referirse al consumo interno, distribución y producción que construye un sentimiento de pertenencia. Las imágenes de los alimentos constituyen una especie de "marca de alimentación" que alude a la identidad regional/local y nacional de un destino (Çalışkan, 2013; Fox, 2007; Frochot, 2003; Lin, Pearson y Cai, 2011; Mahachi-Chatibura, 2016). De hecho, en lugares muy turísticos, o restaurantes preparados para la recepción del turismo internacional, los platos de la carta o del menú vienen acompañados de imágenes y fotografías para los turistas. También suelen traer una lista con productos con denominación de origen y productos locales certificados.

El turismo tiene una relación muy cercana con la gastronomía ya que la mayoría de las veces, los viajeros tienen un especial interés en la cocina local desde el punto de vista antropólogico (Tettner y Kalyoncu, 2016). El turismo tiene un papel muy relevante en difundir, atraer y comunicar a los viajeros la gastronomía y la cultura de una comunidad Williams, Williams y Omar (2014).

El turismo es un elemento indispensable en la gastrodiplomacia. Además de ser utilizado para promover y publicitar la identidad de un lugar, es una herramienta que posibilita el conocimiento de la misma a través de ferias, concursos, campañas donde se exportan alimentos al exterior a través de ferias y eventos $\mathrm{B} 2 \mathrm{~B}$, chefs conocidos en ese destino que son enviados para promocionar la región y/o restaurantes lugareños que quieren crecer y abrirse en el exterior. La visión tiene que ser muy bien 
comunicada y definida (Anholt, 2004). Las diferentes disciplinas que incluyen la marca ciudad son las comparaciones entre un producto y un servicio en los destinos (Cai, Gartner y Munar, 2009; Gnoth, 2002; Kavaratzis y Ashworth, 2005; Parkerson and Saunders, 2005); las comparaciones entre las estrategias corporativas y de marca (Kavaratzis, 2004; Olins, 2003; Trueman, Klemm y Giroud, 2004); Los parecidos con la marca corporativa Gnoth, 2002; Papadopoulos y Heslop, 2002); y las impresiones entre posicionamiento de marca y (re) posicionamiento (Gilmore, 2002).

\subsection{Actores que intervienen en la gastronomía}

En general, y los países vecinos con una historia en común tienen el potencial de promocionar la paz y estrechar lazos entre las regiones, por tanto, las comunidades locales y los ciudadanos son actores esenciales en el sector gastronómico. Estos son los primeros actores a tener en cuenta en el sector gastronómico ya que influyen directamente en la cultura y en la identidad gastronómica. En segundo lugar, desde las organizaciones sin ánimo de lucro, la gastrodiplomacia es una oportunidad para crear diálogo y puede ser utilizada para conseguir objetivos comunes. Un ejemplo son las iniciativas "Slow food" ${ }^{4}$

Los actores o agentes que intervienen en el sector gastronómico son: las empresas y profesionales, la ciudadanía, las organizadoras y gestoras de destinos (DMOs), el Gobierno, las organizaciones gubernamentales y los turistas.

1) Empresas y profesionales: Los negocios y empresas que tienen alto potencial con las aerolíneas pueden formar parte de campañas gastro alimentarias con un alto impacto en la publicidad local. También las compañías de transporte y logística, las cadenas hoteleras, bancos, y otro tipo de compañías proveedoras y suministradoras de alimentación pueden crear iniciativas con una alta repercusión en la economía gastronómica local.

2) Ciudadanía: Como se ha mencionado anteriormente en el hexágono de Anholt (2008), la gente es el motor de la ciudad. Actualmente, con los procesos de participación ciudadana y la coparticipación, las personas son las que tienen el poder de decidir en la toma de decisiones en la ciudad.

3) Gobierno. Los gobiernos que intervienen en esta materia en España son el Ministerio de Agricultura Pesca y Alimentación; Ministerio de Sanidad y Consumo; Ministerio de Educación y Cultura; Ministerio de Industria, Comercio y Turismo, Ministerio para la Transición Ecológica y Ministerio de asuntos exteriores. En este sentido, la cultura japonesa es un ejemplo de "saber hacer". Japón ha sabido mantener su tradición y cultura y expandirla internacionalmente. El Ministerio de Economía, Comercio e Industria de Japón y el Ministerio de Asuntos Exteriores han jugado un papel muy activo promocionando la cultura japonesa en el exterior (Farrer, 2014). Farina (2018) menciona que el Ministerio de Asuntos Exteriores ha creado un Departamento de Diplomacia Pública en el año 2004, creando dos divisiones: la División del Departamento de Planificación en Diplomacia Pública y Asuntos Culturales. Japón enmarco la estrategia de relaciones públicas e intercambio cultural (Diplomatic Bluebook 2005, 2009) y publicó que la marca Japón era uno de los principales pilares de la diplomacia económica en el 2011 y el Washoku era un vehículo para promocionarlo. Estos documentos también aluden a los eventos gastronómicos como propulsores de la diplomacia cultural, en su caso con Francia a través de eventos de gran escala, como por ejemplo Japonismes llevado a cabo en Francia en el 2018.

4) Organizaciones no gubernamentales (cámaras de comercio, universidades, las organizadoras y gestoras de destino y las organizaciones sin ánimo de lucro). Las colaboraciones a largo plazo con organismos no gubernamentales y agencias de desarrollo local pueden ser un punto de conexión importante sobre todo en programas de cooperación interregional con terceros países. Las organizaciones de gestión de destinos (OGDs) y las administraciones nacionales de destinos (ANTs) siguen los mismos objetivos del turismo gastronómico y del turismo sostenible. Tienen un papel indispensable en la promoción, gestión y planificación del turismo.

5) Turistas. Los turistas son un elemento esencial en promocionar la gastronomía de un lugar. Los turistas disponen de unas expectativas previas a su viaje sobre el destino y la comunidad que van a visitar. De sus expectativas, sus motivaciones y sus experiencias depende que su vivencia sea satisfactoria y, por tanto, memorable.

El posicionamiento de un destino gastronómico y cultural y el éxito en la gastrodiplomacia depende de la unión de todas las estrategias y acciones llevadas a cabo de manera conjunta y planificada de todos los actores involucrados en el sector mencionados previamente. 
De cara a fortalecer la eficiente toma de decisiones en el sector, algunos autores recomiendan una serie de estrategias y acciones claves para posicionarse gastronómicamente en el exterior (Sakamoto y Allen, 2011; Rockower, 2014; Zhang, 2015; Xiaomin, 2017):

Tabla 1: Estrategias en materia de promoción, comunicación y educación alimentaria a llevar a cabo por los diferentes actores involucrados en el posicionamiento de marca sectorial

\begin{tabular}{|c|c|c|c|c|c|}
\hline Estrategia & Ciudadanos & Empresas & Gobierno & $\begin{array}{l}\text { Organizaciones } \\
\text { no } \\
\text { gubernamentales }\end{array}$ & Turistas \\
\hline $\begin{array}{l}\text { Utilizar la certificación } \\
\text { sanitaria como garantía de } \\
\text { creación de productos con } \\
\text { calidad. }\end{array}$ & & $\mathrm{X}$ & $\mathrm{X}$ & & \\
\hline $\begin{array}{l}\text { Crear plataformas de } \\
\text { consultoría y publicidad. }\end{array}$ & & $\mathrm{X}$ & & $\mathrm{X}$ & \\
\hline $\begin{array}{l}\text { Abrir cadenas locales en el } \\
\text { exterior. }\end{array}$ & & $\mathrm{X}$ & $\mathrm{X}$ & & \\
\hline $\begin{array}{l}\text { Creación de puestos de } \\
\text { trabajo, tiendas y marcas de } \\
\text { alimentación. }\end{array}$ & & $\mathrm{X}$ & $\mathrm{X}$ & $\mathrm{X}$ & \\
\hline $\begin{array}{l}\text { Realizar un certificado } \\
\text { especial internacional para } \\
\text { la apertura de restaurantes } \\
\text { extranjeros que genere } \\
\text { beneficios locales. }\end{array}$ & & & $\mathrm{X}$ & & \\
\hline $\begin{array}{l}\text { Llevar a cabo investigaciones } \\
\text { en los restaurantes y realizar } \\
\text { propuestas al gobierno. }\end{array}$ & & $\mathrm{X}$ & & $\mathrm{X}$ & \\
\hline $\begin{array}{l}\text { Ayudar a las franquicias a } \\
\text { desarrollar e implementar } \\
\text { gastronomía regional en sus } \\
\text { menús. }\end{array}$ & & & $\mathrm{X}$ & & \\
\hline $\begin{array}{l}\text { Crear acuerdos de } \\
\text { implementación de comida } \\
\text { procesada en el exterior } \\
\text { que se hayan exhibido en } \\
\text { ferias agroalimentarias } \\
\text { internacionales. }\end{array}$ & & & $\mathrm{X}$ & & \\
\hline $\begin{array}{l}\text { Exportación en los mercados } \\
\text { internacionales (Tailandia } \\
\text { exportó marisco y produjo } 191 \\
\text { billones de dólares en el 2010). }\end{array}$ & & $\mathrm{X}$ & $\mathrm{X}$ & & \\
\hline $\begin{array}{l}\text { Buscar sponsors } \\
\text { internacionales para eventos } \\
\text { puntuales, incluyendo } \\
\text { campañas específicas como } \\
\text { festivales, viajes de chefs, } \\
\text { máster clases. }\end{array}$ & & $\mathrm{X}$ & $\mathrm{X}$ & $\mathrm{X}$ & \\
\hline $\begin{array}{l}\text { Ser espónsores y embajadores } \\
\text { de algún evento extranjero } \\
\text { celebrado en la región }\end{array}$ & $\mathrm{X}$ & $\mathrm{X}$ & $\mathrm{X}$ & $\mathrm{X}$ & $\mathrm{X}$ \\
\hline
\end{tabular}




\begin{tabular}{|c|c|c|c|c|c|}
\hline Estrategia & Ciudadanos & Empresas & Gobierno & $\begin{array}{c}\text { Organizaciones } \\
\text { no } \\
\text { gubernamentales }\end{array}$ & Turistas \\
\hline $\begin{array}{l}\text { Organizar y buscar premios } \\
\text { internacionales (Gourmand } \\
\text { World Cookbook awards). }\end{array}$ & & $\mathrm{X}$ & $\mathrm{X}$ & $\mathrm{X}$ & \\
\hline Participar en Madrid fusión. & & $\mathrm{X}$ & $\mathrm{X}$ & $\mathrm{X}$ & \\
\hline $\begin{array}{l}\text { Reconocer y publicitar los } \\
\text { destinos turísticos mejores del } \\
\text { mundo. }\end{array}$ & $\mathrm{X}$ & & $\mathrm{X}$ & $\mathrm{X}$ & $\mathrm{X}$ \\
\hline $\begin{array}{l}\text { Celebrar y crear el día } \\
\text { internacional de la } \\
\text { alimentación. }\end{array}$ & $\mathrm{X}$ & $\mathrm{X}$ & $\mathrm{X}$ & $\mathrm{X}$ & $\mathrm{X}$ \\
\hline $\begin{array}{l}\text { Realizar guías profesionales } \\
\text { de buenas prácticas en la } \\
\text { cocina. }\end{array}$ & & $\mathrm{X}$ & $\mathrm{X}$ & $\mathrm{X}$ & \\
\hline $\begin{array}{l}\text { Presentar un premio exclusivo } \\
\text { a mujeres chefs. }\end{array}$ & & $\mathrm{X}$ & $\mathrm{X}$ & $\mathrm{X}$ & \\
\hline Llevar a cabo Cook offs. & & $\mathrm{X}$ & & & \\
\hline $\begin{array}{l}\text { Promover guías de productos } \\
\text { locales. }\end{array}$ & & $\mathrm{X}$ & $\mathrm{X}$ & $\mathrm{X}$ & \\
\hline $\begin{array}{l}\text { Organizar foros de recursos } \\
\text { naturales. }\end{array}$ & & $\mathrm{X}$ & $\mathrm{X}$ & $\mathrm{X}$ & \\
\hline $\begin{array}{l}\text { Organizar en las redes sociales } \\
\text { una competición. }\end{array}$ & & $\mathrm{X}$ & & $\mathrm{X}$ & \\
\hline $\begin{array}{l}\text { Incentivar a los clientes que se } \\
\text { unan a programas específicos } \\
\text { que ganen una experiencia } \\
\text { culinaria. }\end{array}$ & & $\mathrm{X}$ & & & \\
\hline $\begin{array}{l}\text { Promocionar a los } \\
\text { Masterchefs. }\end{array}$ & $\mathrm{X}$ & $\mathrm{X}$ & $\mathrm{X}$ & $\mathrm{X}$ & $\mathrm{X}$ \\
\hline $\begin{array}{l}\text { Publicar recetas clave a nivel } \\
\text { internacional. }\end{array}$ & $\mathrm{X}$ & $\mathrm{X}$ & $\mathrm{X}$ & $\mathrm{X}$ & $\mathrm{X}$ \\
\hline $\begin{array}{l}\text { Crear sinergias con } \\
\text { organizaciones internacionales } \\
\text { de comida. }\end{array}$ & & $\mathrm{X}$ & $\mathrm{X}$ & $\mathrm{X}$ & \\
\hline $\begin{array}{l}\text { Dar la posibilidad siempre de } \\
\text { pagar con visa o MasterCard. }\end{array}$ & & $\mathrm{X}$ & & & \\
\hline $\begin{array}{l}\text { Crear una red de } \\
\text { investigadores, } \\
\text { organizaciones, nutricionistas, } \\
\text { actores agroalimentarios... }\end{array}$ & & & $\mathrm{X}$ & & \\
\hline $\begin{array}{l}\text { Invitar a chefs internacionales } \\
\text { y nacionales reconocidos para } \\
\text { intercambiar experiencias, } \\
\text { recetas... }\end{array}$ & & $\mathrm{X}$ & & & \\
\hline $\begin{array}{l}\text { Servir los caterings de premios } \\
\text { y actos de gran prestigio } \\
\text { (pueblo ejemplar, Premios } \\
\text { Príncesa de Asturias...). }\end{array}$ & & $\mathrm{X}$ & & & \\
\hline $\begin{array}{l}\text { Tratar de unir más la cultura, } \\
\text { arte y gastronomía. }\end{array}$ & & & $\mathrm{X}$ & $\mathrm{X}$ & \\
\hline
\end{tabular}




\begin{tabular}{|c|c|c|c|c|c|}
\hline Estrategia & Ciudadanos & Empresas & Gobierno & $\begin{array}{c}\text { Organizaciones } \\
\text { no } \\
\text { gubernamentales }\end{array}$ & Turistas \\
\hline $\begin{array}{l}\text { Publicar revistas científicas } \\
\text { sobre gastronomía. }\end{array}$ & & & $\mathrm{X}$ & $\mathrm{X}$ & \\
\hline $\begin{array}{l}\text { Hacer documentales de la } \\
\text { gastronomía regional. }\end{array}$ & $\mathrm{X}$ & $\mathrm{X}$ & $\mathrm{X}$ & $\mathrm{X}$ & \\
\hline $\begin{array}{l}\text { Llevar a cabo un show cooking } \\
\text { para diplomáticos. }\end{array}$ & & & $\mathrm{X}$ & $\mathrm{X}$ & \\
\hline $\begin{array}{l}\text { Llevar a cabo acciones } \\
\text { específicas de probar comida } \\
\text { en universidades. }\end{array}$ & & $\mathrm{X}$ & $\mathrm{X}$ & $\mathrm{X}$ & \\
\hline $\begin{array}{l}\text { Llevar a cabo seminarios } \\
\text { de comida, workshops e } \\
\text { investigaciones. }\end{array}$ & & $\mathrm{X}$ & $\mathrm{X}$ & $\mathrm{X}$ & \\
\hline $\begin{array}{l}\text { Desarrollar un observatorio } \\
\text { gastronómico y un laboratorio } \\
\text { de innovación gastronómica. }\end{array}$ & & & $\mathrm{X}$ & $\mathrm{X}$ & \\
\hline $\begin{array}{l}\text { Diseñar y llevar a cabo } \\
\text { sinergias con otros sectores de } \\
\text { la economía creativa. }\end{array}$ & & $\mathrm{X}$ & $\mathrm{X}$ & $\mathrm{X}$ & \\
\hline $\begin{array}{l}\text { Promocionar y valorar } \\
\text { la importancia de los } \\
\text { agricultores, chefs y gourmets, } \\
\text { así como a los creadores y los } \\
\text { artesanos. }\end{array}$ & $\mathrm{X}$ & $\mathrm{X}$ & $\mathrm{X}$ & $\mathrm{X}$ & $\mathrm{X}$ \\
\hline $\begin{array}{l}\text { Promover la gastronomía } \\
\text { como un elemento esencial de } \\
\text { desarrollo urbano. }\end{array}$ & $\mathrm{X}$ & $\mathrm{X}$ & $\mathrm{X}$ & $\mathrm{X}$ & $\mathrm{X}$ \\
\hline $\begin{array}{l}\text { Llevar a cabo acciones de } \\
\text { educación alimentaria desde } \\
\text { la educación primaria. }\end{array}$ & & & $\mathrm{X}$ & $\mathrm{X}$ & \\
\hline
\end{tabular}

Fuente: Elaboración propia (2019) a partir de estudios de (Sakamoto y Allen, 2011; Rockower, 2014; Zhang, 2015; Xiaomin, 2017)

Estas estrategias han sido elaboradas previamente y llevadas a cabo por diversas regiones y países cuyo objetivo era posicionar la gastronomía internacionalmente, con el consecuente impacto en el turismo y la economía del destino. Los países orientales son los países pioneros en la utilización de la gastronomía como una herramienta para la mejora de las relaciones internacionales.

\section{Conclusiones}

La gastrodiplomacia es una parte esencial de las relaciones internacionales. A través de ella se desarrollan y fortalecen relaciones entre lugares, regiones y países. Cada región o país tiene una fortaleza en una o varias disciplinas pertenecientes o no a la economía creativa. En el caso de la gastronomía, este tiene una aportación al producto interior de un país muy importante, ya que los productos agroalimentarios son una pujante fuente de ingresos y de desarrollo económico a través de diversos sectores, siendo los más pujantes el turismo y la restauración. No se debe olvidar que, aunque la sociedad del conocimiento abarque otros tipos de actividades del sector terciario, las actividades del sector primario son necesarias para el desarrollo de la economía y para mejorar la calidad de vida de los ciudadanos. La gastronomía es parte de la identidad de una comunidad o de una nación. Es patrimonio cultural y una parte intrínseca de la cultura de un lugar. Esta ayuda a posicionar la imagen de marca en el exterior y es un elemento tractor del turismo. Sin embargo, este artículo trata de revalorizarla y de no 
utilizarla como un recurso neoliberal infinito, sino que la gestión debe ser sostenible y duradera en el tiempo. De ello depende su misión. Esta debe ayudar a promocionar los productos locales, la economía local y los productos con certificación sanitaria que son cada vez más demandados. No hay que olvidar que se necesita una fuerte coordinación e implicación de todos los actores involucrados en este sector (ciudadanos, empresas y profesionales, turistas, organizaciones no gubernamentales y Gobierno), de ello depende el éxito en las acciones y decisiones estratégicas para desarrollar este ámbito.

\section{Referencias}

Aaker, D. A. (2009). Managing brand equity. Simon and Schuster.

Allen, A. (2011). The role of history in place marketing: Can branding create a sense of place? Journal of Town \& City Management, 2(1).

Anholt, S. (2004). Editor's foreword to the first issue. Place Branding, 1(1), 4-11.

Anholt, S. (2008). Place Branding: Is it marketing, or isn't it? Place branding and Public Diplomacy.4(1), 1-6. DOI: 10.1057/palgrave.pb.6000088.

Anholt, S. (2010). Place Branding and Public Diplomacy (2010) 6, 1 - 10. DOI: 10.1057/pb.2010.3.

Appadurai, A. (1988). Putting hierarchy in its place. Cultural anthropology, 3(1), 36-49.

Assmann, S. (2017). Global Recognition and Domestic Containment: Culinary Soft Power in Japan. En Farina, F. (2018). "Japan's gastrodiplomacy as soft power: global washoku and national food security”. Journal of Contemporary Eastern Asia, 17 (1), 153. DOI: 10.17477/jcea.2018.17.1.153.

Bahls, Álvaro \& Krause, Rodolfo \& Añaña, Edar. (2019). Comprensión de los conceptos de culinaria y gastronomía. Estudios y perspectivas en turismo, 28(2). 312-330.

Barrère, C., Bonnard, Q. \& Chossat, V. (2012). Food, gastronomy and cultural commons. En Bertacchini, E., Bravo, G., Marrelli, M. and Santagata, W. (Eds.). Cultural commons: A new perspective on the production and evolution of cultures (pp. 129-150). Cheltenham, UK. Edward Elgar.

Berchoux, J. (1804). La gastronomie, ou l'homme des champs à table: Poème didactique en quatre hants. Paris: Giguet et Michaud. En: Metaxas, T. y Karagiannis, D. (2016). Culinary tourism in Greece: Can the past define the future? Dimensions of innovation, entrepreneurship and regional development. Journal of Developmental Entrepreneurship, 21(03), 1650018.

Brillat-Savarin, J. A. (1826). Physiologie du goût, ou Me'ditations de gastronomie transcendante; ouvrage the'orique, historique et à l'ordre du jour, De'die' au Gastronomes parisiens, par un professeur...(2 Vols.). Paris: Chez A. Sautelet et Cie Libraires.

Bound, K. y Briggs, R. (2007). Cultural Diplomacy. London: Lemos.

Cai, L. A., Gartner, W. C. y María Munar, A. (Eds.). (2009). Tourism branding: Communities in action. Emerald Group Publishing Limited.

Çalışkan, O. (2013). Destinasyon rekabetçiliği ve seyahat motivasyonu bakımından gastronomik kimlik. Journal of Tourism and Gastronomy Studies, 1(2), 39-51.

Chapple-Sokol, S. (2013). Culinary diplomacy: Breaking bread to win hearts and minds. The Hague Journal of Diplomacy, 8(2), 161-183. DOI:10.1163/1871191X-12341244

Cook, I. y Crang, P. (1996). The world on a plate: culinary culture, displacement and geographical knowledges. Journal of material culture, 1(2), 131-153.

De La Banda, J. F. G. (2016). La tutela del patrimonio cultural inmaterial en España: la ley para la salvaguardia del patrimonio cultural inmaterial. Anuario jurídico y económico escurialense, (49), 275-292.

De los reyes Cruz Ruiz, E., Romero de la Cruz, E. y Zamarreño, G. (2017). "Marca Territorio y mrca ciudad, utilidad en el ámbito del turismo. El caso de Málaga". International journal of scientific management and tourism, 3(2), 155-174

De-Miguel-Molina, María \& De-Miguel-Molina, Blanca \& Santamarina, Virginia \& Segarra-Oña, Marival. (2016). Intangible Heritage and Gastronomy: The Impact of UNESCO Gastronomy Elements. Journal of Culinary Science \& Technology. 14. 293-310.

De Soucey, M. (2010). Gastronationalism: Food Traditions and Authenticity Politics in the European Union. American Sociological Review 75(3):432-455. DOI: 10.1177/0003122410372226

Diplomatic BlueBook. (2005). Ministry of Foreigns Affairs of Japan. Recuperado de https://www.mofa. go.jp/policy/other/bluebook/index.html

Diplomatic BlueBook. (2019). Japanese Diplomacy and International Situation in 2019. Recuperado de https://www.mofa.go.jp/files/000515910.pdf 
Farina, F. (2018). "Japan's gastrodiplomacy as soft power: global washoku and national food security". Journal of Contemporary Eastern Asia, 17 (1), 153-DOI: 10.17477/jcea.2018.17.1.153

Farrer, J. (2015). "Introduction: Traveling Cuisines in and out of Asia: Toward a Framework for Studying Culinary Globalization”, En Farrer, J. (ed.). The Globalization Of Asian Cuisines: Transnational Networks And Culinary Contact Zones.NY : Palgrave Macmillan.

Food Truck Ya. (S.f). Resúmen Normativas Food Trucks. Recuperado de http://www.foodtruckya.com/ blog/resumen-normativas-food-trucks/

Fox, R. (2007). Reinventing the gastronomic identity of Croatian tourist destinations. International Journal of Hospitality Management, 26(3), 546-559.

Frochot, I. (2003). An analysis of regional positioning and its associated food images in French tourism regional brochures. Journal of Travel \& Tourism Marketing, 14(3-4), 77-96.

Gertner, D. (2011). Unfolding and configuring two decades of research and publications on place marketing and place branding. Place Branding and Public Diplomacy, 7(2), 91-106.

Gilmore, F. (2002). A country-Can it be repositioned? Spain-The success story of country branding. Journal of Brand management, 9(4), 281-293.

Gillespie, C. y Cousins, J.A. (2001) "European gastronomy into the 21st century". Oxford, Butterworth Heinemann.

Gnoth, J. (2002). Leveraging export brands through a tourism destination brand. Journal of brand management, 9(4), 262-280.

Guerrero, L., Guàrdia, M. D., Xicola, J., Verbeke, W., Vanhonacker, F., Zakowska-Biemans, S. y Scalvedi, M. L. (2009). Consumer-driven definition of traditional food products and innovation in traditional foods. A qualitative cross-cultural study. Appetite, 52(2), 345-354.

González, S.M. (2017). Ocio y movilidad creativa: una herramienta clave para la comunicación entre China y España. Tesis Doctoral. Universidad de Deusto, Bilbao.

Hankinson, G. (2007). The management of destination brands: Five guiding principles based on recent developments in corporate branding theory. Journal of Brand Management, Vol. 14(3), 240-254

Henderson, J. (2014). "Food and Culture: in search of a Singapore cuisine". British Food Journal. 116(6), pp. 904-917. DOI: 10.1108/BFJ-12-2012-0291

Hildreth, J. (2008). The European City Brand Barometer- Revealing which cities get the brands they deserve. Safron Brand Consultants.

Karagiannis, D. y Metaxas, T. (2015). Culinary Tourism in Greece: Can the past define the future? A comparative analysis by using 10 case studies. Munich Personal RePEc Archive. Recuperado de https://mpra.ub.uni-muenchen.de/66846/

Kavaratzis, M. y Ashworth, G. (2005) 'City Branding: an affective assertion of identity or a marketing trick', Tijdschrift voor Economische en Sociale Geografie, Vol. 96(5), pp.506-614

Kavaratzis, M. (2004). From city marketing to city branding: Towards a theoretical framework for developing city brands. Place branding, 1(1), 58-73

Kerr, G. (2006). From destination brand to location brand. Journal of Brand Management, 13(4-5), 276-283

Kesimoglu, A. (2015) "A reconceptualization of gastronomy as relational and reflexive". Hospitality \& Society 5(1): 71-91

Khoo, S. L. y Badarulzaman, N. (2014). Factors Determining George Town as a City of Gastronomy, Tourism Planning \& Development, 11(4), 371-386, DOI:10.1080/21568316.2013.874365

$\mathrm{Ku}$, G. C. y Mak, A. H. (2017). Exploring the discrepancies in perceived destination images from residents' and tourists' perspectives: A revised importance-performance analysis approach. Asia Pacific Journal of Tourism Research, 22(11), 1124-1138

Landry, C. (2000) 'The Creative City: A Toolkit for Urban Innovators'. London, RU: Earthscan

Lin, Y. C., Pearson, T. E. y Cai, L. A. (2011). Food as a form of destination identity: A tourism destination brand perspective. Tourism and Hospitality Research, 11(1), 30-48.

Maffei, M. C. (2012). Culinary traditions as cultural intangible heritage and expressions of cultural diversity. In S. Borelli \& F. Lenzerini (Eds.), Cultural heritage, cultural rights, cultural diversity: New developments in international law (pp. 223-252). Boston, MA: Martinus Nijhoff.

Mahachi-Chatibura, D. (2016). Local cuisine as a potential tourism attractor and marker of national identity in Botswana. Journal of Gastronomy and Tourism, 2(2), 117-134.

Matviyiv, M. (2014). Forming the concept of hospitality in innovative marketing services of restaurant enterprise. Journal of European Economy. 13(3), 299-317. En: De-Miguel-Molina, María \& De-Miguel-Molina, Blanca \& Santamarina, Virginia \& Segarra-Oña, Marival. (2016). Intangible Heritage 
and Gastronomy: The Impact of UNESCO Gastronomy Elements. Journal of Culinary Science \& Technology. 14. 293-310.

Metaxas, T. y Karagiannis, D. (2016). Culinary tourism in Greece: Can the past define the future? Dimensions of innovation, entrepreneurship, and regional development. Journal of Developmental Entrepreneurship, 21(03), 1650018

Montiel, G. (2007). Estudios sobre la cultura y las identidades sociales. Cultura y representaciones sociales, 2(4), 202.

Morgan, L. (2008). Diplomatic Gastronomy: Style and Power at the Table. School of History and Politics. Adelaide, The University of Adelaide and Le Cordon Bleu. Master of Arts (Gastronomy).

Nau, H. R. (1978). "The Diplomacy of World Food: Goals, Capabilities, Issues and Arenas." International Organization 32(3): 775-809. En Reynolds, C. (2009). Tipping the Scales: Examining the power of food in international politics. University of Adelaide, School of History and Politics, Discipline of Politics, International Studies.

NU, Naciones Unidas. (2014). The United Nations at a glance. Recuperado de http://www.un.org/en/ aboutun/index.shtml

Nirwandy, N. y Awang, A. (2014). Conceptualizing Public Diplomacy Social Convention Culinary: Engaging Gastro Diplomacy Warfare for Economic Branding. Procedia - Social and Behavioral Sciences, 130, 325-332.

Nye Jr, J. S. (2008). Public diplomacy and soft power. The annals of the American academy of political and social science, 616(1), 94-109.

Olins, W. (2003) 'Hull: Pioneering city', Case Study. En Hanna, S. \& Rowley, J. (2008). Place Brand Public Diplomacy, 4 (1), 61-75. DOI: 10.1057/palgrave.pb.6000084

Onaran, B. (2016, June 16). Interview about gastronationalism [In person]. (interview date: 17/06/2016) En Tettner, S. \& Kalyoncu, B. (2016). Gastrodiplomacy 2.0: culinary tourism beyond nationalism. Ara: journal of tourism research= revista de investigación en turismo, 6(2), 47-55.

Papadopoulos, N. (2004). Place branding: Evolution, meaning and implications. Place branding, 1(1), 36-49.

Papadopoulos, N. y Heslop, L. (2002). Country equity and country branding: Problems and prospects. Journal of brand management, 9(4), 294-314.

Papp-Váry, Árpád. (2011). The Anholt-GMI City Brand Hexagon and the saffron European City Brand Barometer: a comparative study. Regional and Business Studies, 3(1), 555-562. Recuperado de http:// journal.ke.hu/index.php/rbs/article/view/510

Parkerson, B. y Saunders, J. (2005). City branding: can goods and services branding models be used to brand cities?. Place branding, 1(3), 242-264.

Pearson, D. y Pearson, T. (2017). Branding Food Culture: UNESCO Creative Cities of Gastronomy, Journal of Food Products Marketing, 23(3), 342-355, DOI:10.1080/10454446.2014.1000441

Real Academia Española (RAE). Acepciones "gastronomía" y "cocina". Recuperado de https://dle.rae. es/gastronom $\% \mathrm{C} 3 \% \mathrm{ADa}$

Reynolds, C. (2010). Tipping the Scales: A New Understanding of Food's Power in the Political Sphere. The International Journal of Interdisciplinary Social Sciences, 7(5), 295-304.

Rockower, P. (2012). Recipes for gastrodiplomacy. Place Branding and Public Diplomacy, 8(3), 235-246.

Rockower, P. S. (2014). The State of Gastrodiplomacy/Public Diplomacy. University of Southern California. Winter, 71 .

Sakamoto, R. y Allen, M. (2011). There's something fishy about that sushi: How Japan interprets the global sushi boom. Japan Forum, 23(1), 99-121. En Zhang, J. (2015). The food of the worlds: Mapping and comparing contemporary gastrodiplomacy campaigns. International Journal of Communication, 9, 24. Recuperado de https://ijoc.org/index.php/ijoc/article/view/2847

Strugar, T. (2015). Eastern Gastrodiplomatic Efforts: Asian Nations as Pioneers in the Use of Cuisine in Cultural Diplomacy. The Art of Food Reader, 29. Recuperado de http://igcat.org/wp-content/ uploads/2014/10/Art_of_Food_2015_Reader_IGCAT.pdf\#page=29

Suntikul. (2019). Gastrodiplomacy in tourism, Current Issues in Tourism, 22(9), 1076-1094. DOI: 10.1080/13683500.2017.1363723

Tettner, S. y Kalyoncu, B. (2016). Gastrodiplomacy 2.0: culinary tourism beyond nationalism. Ara: journal of tourism research = revista de investigación en turismo, 6(2), 47-55.

Trejo, J. (2013). Gastronomía y Diplomacia; La relación internacional perfecta. Recuperado de http:// repositorio.usfq.edu.ec/bitstream/23000/2291/1/106969.pdf 
Trueman, M., Klemm, M. y Giroud, A. (2004). Can a city communicate? Bradford as a corporate brand. Corporate Communications: An International Journal, 9(4), 317-330. DOI: 10.1108/13563280410564057

The Yakarta Post. (2011). RI envoy to Netherlands to promote culinary. Recuperado de http://www. thejakartapost.com/news/2011/12/28/ri-envoy-netherlands-promote-culinary-diplomacy.html. En Rockower, P. (2012). Recipes for gastrodiplomacy. Place Branding and Public Diplomacy, 8(3), 235-246

UNESCO. (S.f.). ¿Qué es la Red de Ciudades Creativas? Recuperado de https://es.unesco.org/creative-cities/content/acerca-de

UNESCO. (2008). Medium Term Strategy. Recuperado de http:// unesdoc.unesco.org/images/0014/ 001499/149999e.pdf

UNESCO. (2010). Gastronomic meal of the French. Recuperado de https://ich.unesco.org/en/RL/ gastronomic-meal-of-the-french-00437

UNESCO. (2014). Creative Cities Network: Gastronomy, UNESCO. Recuperado de http://www.unesco. org/new/en/culture/themes/creativity/creative-cities-network/gastronomy/

Vanhonacker, F., Verbeke, W., Guerrero, L., Claret, M., Scaveldi, L. and Herlesth, M. (2010). How European define the concept of traditional food: Evidence from a survey in six countries. Agribusiness, 26, 453-476. DOI: 10.1002/agr.20241 . En: De-Miguel-Molina, María, De-Miguel-Molina, Blanca., Santamarina, Virginia y Segarra-Oña, Marival. (2016). Intangible Heritage and Gastronomy: The Impact of UNESCO Gastronomy Elements. Journal of Culinary Science \& Technology. 14. 293-310.

Wallensteen, P. (1976). Scarce goods as political weapons: The case of food. Journal of Peace Research, 13(4), 277-298.

Wallin, Matthew. (2013). "Gastro-diplomacy- "Reaching Hearts and Minds through Stomachs"'. American Security Project. Recuperado de http://www.americansecurityproject.org/gastro-diplomacy-reaching-hearts-andminds-through-stomachs/.

Williams, H.A., Williams, R.L y Omar, M. (2014). Gastro-tourism as destination branding in emerging Markets. Int. J. Leisure and Tourism Marketing, 4(1), 1-18.

Wilson, R. (2011) Cocina Peruana Para El Mundo: Gastrodiplomacy, the culinary nation brand, and the context of national cuisine in Peru. Exchange: The Journal of Public Diplomacy, 2(2), 13 - 20

Xiaomin, C. (2017). "City of Gastronomy" of UNESCO Creative Cities Network: From International Criteria to Local Practice. 社会システム研究, 55.

WTO, 2017. Second Global Report on Gastronomy Tourism. Madrid: WTO

Zhang, J. (2015). The food of the worlds: Mapping and comparing contemporary gastrodiplomacy campaigns. International Journal of Communication, 9, 24. Recuperado de https://ijoc.org/index. php/ijoc/article/view/2847

\section{Notes}

1 Para saber más acerca del poder duro ver: Nye, J. (2009). Get Smart: Combining Hard and Soft Power. Foreign Affairs, 88(4), 160-163. Recuperado de http://www.jstor.org/stable/20699631

2 Las Naciones Unidas es un órgano mundial promotor de la paz formado por 193 estados independientes (NU, 2014). Este contribuye a la erradicación de la pobreza, el desarrollo sostenible y el diálogo intercultural a través de la educación, de las ciencias, la cultura, la comunicación y la información (UNESCO, 2008).

3 La cocina del conflicto (2011). Diario de la gastronomía. Recuperado de: https://diariodegastronomia.com/la-cocina-del-conflicto/ Última consulta el 02/07/2020.

4 Slow food hace referencia a aquella forma de cocinar atendiendo a la calidad y origen de las materias primas, los ingredientes y la forma de cocinarlas. Más información en: Andrews, Geoff. (2008). The Slow Food Story: Politics and Pleasure. London: Pluto Press. 


\section{¿El turismo es cosa de pobres?}

Patrimonio cultural, pueblos indígenas

y nuevas formas de turismo en

\section{América Latina}

\section{Raúl H. Asensio Beatriz Pérez Galán (Eds.)}

\section{PASOS}

IEP Instituto de Estudios Peruanos

Colección PASOS edita, $\mathrm{n} \div 8$

Serie TURISMO, nำ 


\title{
A importância da marca no turismo: o caso da entidade regional do Turismo do Porto e Norte de Portugal

\author{
Hugo Martins* Carlos Silva** António Pinheiro*** \\ Eduardo Gonçalves**** \\ Universidade da Maia (Portugal)
}

\begin{abstract}
Resumo: Nas últimas décadas o conceito de marca tem sido associado ao turismo, funcionando como uma ferramenta de marketing. Os destinos turísticos passaram a ser vistos como empresas e começam a utilizar a marca como forma de atrair e fidelizar o visitante. A marca assenta numa perspetiva de criação de valor funcionando como estratégia de diferenciação num mercado cada vez mais competitivo.

Neste enquadramento, o estudo aqui apresentado procurou perceber como a entidade regional do Turismo do Porto e Norte de Portugal tem desenvolvido o seu marketing através do conceito de marca. Em termos metodológicos, numa primeira parte foi feita uma análise da literatura sobre o conceito de marca, associada ao turismo, e numa segunda parte analisaram-se as estratégias adotadas pela entidade alvo do nosso estudo. Como principais conclusões, constatou-se que esta entidade procurou criar uma marca própria, agregadora de todos os produtos estratégicos âncora e produtos complementares, das suas sub-regiões com vista a promover os seus recursos naturais e patrimoniais, transmitindo a ideia de um destino cosmopolita e glamoroso, com história e tradição.
\end{abstract}

Palavras-chave: Marca; Turismo; Personalidade da Marca; Branding do Destino; Porto e Norte de Portugal; Entidade Regional.

The importance of branding in tourism: the case of the regional entity of Tourism in Porto and Northern of Portugal

Abstract: In the last few decades, branding is an important part of marketing tourism destinations. Tourist destinations started to be seen as companies and started to use the brand as a way to attract and retain visitors. The brand is based on a perspective of value creation acting as a differentiation strategy in an increasingly competitive market.

In this context, this study presented here sought to understand how the regional entity of Tourism in Porto and Northern Portugal has developed its marketing through branding. In methodological terms, in a first part, there is an analysis of the literature on the concept of brands, and in a second part, the strategies adopted by the target entity of our study were analysed. As main conclusions, it was found that this entity sought to create its own brand, aggregating all anchor strategic products and complementary products, from its sub-regions with a view to promoting its natural and heritage resources, and to convey the idea of a glamorousa cosmopolitan destination with history and tradition.

Keywords: Brand; Tourism; Brand Personality; Destination Branding; Porto and Northern Portugal; Regional Entity.

\section{Introdução}

A marca (brand em inglês) tem sido um conceito amplamente estudado sendo, atualmente, considerada uma ferramenta de marketing muito utilizada por empresas de variadíssimos setores. O recurso à marca é, assim, uma das estratégias mais importantes na venda de produtos ou serviços. No entanto,

\footnotetext{
* Universidade da Maia (Portugal); Email: E-mail: hugomartins@ismai.pt; https://orcid.org/0000-0002-1651-8715

* Universidade da Maia (Portugal); E-mail: cavsilva@yahoo.com; https://orcid.org/0000-0002-2841-7356

*** Universidade da Maia (Portugal); E-mail: ajpinheiro@ismai.pt; https://orcid.org/0000-0002-8846-295X

***** Universidade da Maia (Portugal); E-mail: egoncalves@ismai.pt; https://orcid.org/0000-0003-0908-2623
} 
não é um conceito muito consensual, tendo havido várias conceções acerca da sua definição. Do ponto de vista económico, a marca representa um ativo intangível para as empresas. Por isso, os gestores dão prioridade às atividades que estão ligadas com a construção da marca (Fischer, Völckner e Sattler, 2010).

Face ao número crescente de destinos turísticos, tem havido uma necessidade em estudar e compreender a importância da marca associada ao turismo, isto porque as entidades promotoras dos territórios passaram a perceber o quão importante é haver essa associação, indo de encontro aos desafios do mundo globalizado. A marca assume um papel preponderante em termos económicos e sociais tendo "a capacidade de simplificar o processo de tomada de decisão e reduzir os riscos, num contexto no qual a vida se torna cada vez mais complexa" (Keller, 2003, p.30).

Neste estudo procuramos perceber, relativamente ao conceito de marca, que estratégias a entidade do Turismo do Porto e Norte de Portugal adotou que permitiram diferenciar a região na mente dos consumidores, diferenciar os seus produtos dos produtos da concorrência. Esta entidade abarca a região denominada de NUT II do Norte.

Assim, através da literatura científica procuramos perceber a importância que o conceito de marca tem atualmente. Seguidamente, contextualizamos o aparecimento da entidade do Turismo do Porto e Norte de Portugal, procurando compreender a importância que esta deu à marca, analisando detalhadamente a estratégia definida. Com esta análise, foi possível verificar que os gestores dessa entidade, com vários produtos âncora e procutos complementares, compreenderam a importância deste conceito: no ano seguinte à sua criação foram implementadas estratégias de branding para fazer face aos destinos concorrentes. O Porto e Norte de Portugal possui um conjunto de produtos diversificados sendo que esta entidade regional procurou atribuir características que diferenciasse os seus produtos da concorrência, nomeadamente um destino cosmopolita e glamoroso, com história e tradição (Turismo do Porto e Norte de Portugal, 2015). A estratégia central passou pela criação de uma marca que abrangesse todos os produtos os seus produtos turísticos, dando enfoque em produtos âncora e em produtos complementares de cada sub-região.

\section{O conceito de Marca}

De acordo com a American Marketing Association (2008), "marca é um nome, termo, design, símbolo ou uma combinação, destinada a identificar os produtos ou serviços de um vendedor ou grupo de vendedores e diferenciá-los dos concorrentes". Kotler (1999, p.426) considera que "para os profissionais de marketing, o estabelecimento de uma marca é a arte e a essência do marketing."

Atualmente, o conceito marca é de difícil definição por ser multifacetado, não havendo uma, mas várias definições, dependendo da perspetiva pela qual se perceciona o conceito (Martins, 2017). Por um lado, há abordagens unidimensionais (marca como um instrumento legal, de identificação visual e/ou meio de diferenciação). Por outro lado, há abordagens multidimensionais (funcionais, emocionais, relacionais e estratégicas) que dão um carácter mais holístico (Aaker, 2014; Keller, 2013).

Davies e Chun (2003) recorrem a três metáforas para a exploração do conceito de marca utilizadas na área do marketing: a marca como sinal diferenciador, a marca como uma pessoa e a marca como um ativo.

Vários são os autores que estudaram o termo havendo, por isso, diversas perspetivas. De Chernatony e Riley (1998), procuraram construir uma teoria sobre a marca. Ao analisar mais de 100 revistas académicas e comerciais referentes à década de 1980 e a opinião de vários consultores de marcas, agruparam todas as definições de marca em 12 categorias (figura 1).

De Chernatony e Riley (1998) concluíram que o conceito compreende várias dimensões, devendo ser abordado e interligado de diferentes perspetivas, nomeadamente funcional, emocional, relacional, estratégico, entre outros.

A marca funciona como referência de todos os juízos positivos e negativos que o cliente formou, como quando confrontado com os produtos, com a rede de distribuição, com os colaboradores e com a comunicação da marca (Azoulay e Kapferer, 2003). Ela procura atribuir atributos tangíveis e intangíveis. Para estabelecer uma ligação mais real e significativa com o consumidor, as marcas promovem eventos. São os casos da BMW, a Apple, a Disney ou a Samsung, no sentido de as marcas promoverem a sua identidade (Azoulay e Kapferer, 2003) e/ou consolidá-la (Martins, 2017).

Smilansky (2009) considera que as empresas procuram diferenciar as suas ofertas das ofertas das empresas concorrentes com vista a que haja uma fidelização dos consumidores. Para Smilansky (2009), inicialmente, quando a tomada de decisão dos consumidores era baseada muito de acordo com os preços, as marcas criavam produtos apelativos apostando em preços reduzidos. No entanto, durante o século XX, o foco deixou de ser o produto para passar a ser o consumidor, levando a que as marcas assumissem personalidades únicas, estimulando os consumidores a aspirar um estilo de vida que a 


\section{Figura 1: Categorias da marca}

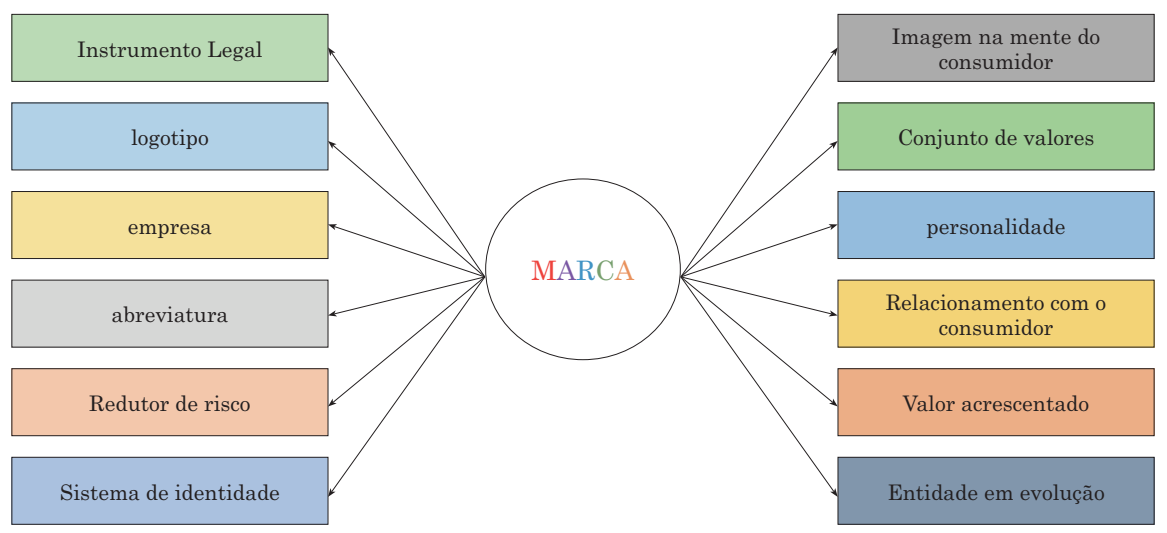

Fonte: De Chernatony e Riley, 1998 (adaptado pelo autor)

marca representa (Martins, 2017). Por conseguinte, a concorrência posicionou-se de forma semelhante, aspeto que tornou a diferenciação difícil para o consumidor. Assim, as empresas passaram a apostar na melhoria da qualidade, a fim de "agregar valor à marca e diferenciar os seus produtos e/ou serviços da concorrência” (Martins, 2017, p.96).

Assim, o recurso à marca tem sido uma prática recorrente por parte de empresas para dar visibilidade aos seus produtos. Nas últimas décadas, essa prática já chegou aos lugares/destinos, assentando numa perspetiva de criação de valor, mediante a adoção de estratégias de diferenciação, num mercado cada vez mais competitivo e globalizado, isto porque a marca é um meio de diferenciação de produtos e serviços (Aaker e Joachimsthaler, 2000). A marca tem sido adotada no setor do turismo, sendo o branding dos destinos turísticos (destination branding) considerado um elemento estratégico de gestão (Martins, 2017).

\section{A marca aplicada ao turismo}

Apesar do conceito "marca" ter sido utilizado na área do marketing desde o final dos anos 80 do século $\mathrm{XX}$, só nas últimas duas décadas é que se tem associado o termo aplicado ao destino (destination branding). à ideia de destino turístico. Essa associação combina serviços e produtos de marketing com um determinado lugar, abarcando várias valências que podem ser de natureza natural, cultural, desportiva, entre outros (Pereira, 2013). A partir dessa altura, vários artigos começaram a abordar a temática (Pike, 2005). Esses estudos, que procuram analisar como os turistas avaliam uma marca relativamente a um destino, concluem que tal é de extrema complexidade (Boo, Busser e Baloglu, 2009), uma vez que abrange "uma multiplicidade de preocupações que necessitam de uma resposta multidisciplinar" (Gnoth, 1998, p.759).

De acordo com Hall (2002), as marcas congregam quatro características: i) uma imagem clara e distinta; ii) um conjunto de associações relacionadas com a qualidade, iii) a habilidade de construir e proporcionar uma vantagem competitiva de médio e longo prazo, e iv) agrega algo mais importante do que um simples conjunto de atributos físicos. Por conseguinte, a marca procura responder, por um lado, às necessidades tangíveis (funcionais e/ou físicas) bem como às intangíveis (emocionais e/ou afetivas) do consumidor. No âmbito do turismo, com as questões da competitividade e da atração de turistas, países, regiões e cidades sentiram a necessidade de adotar o branding com as características evidenciadas por Hall (2002), procurando ser uma estratégia de afirmação do território, com vista a se diferenciarem dos outros. A finalidade dessa diferenciação é a fidelização de uma clientela "fixa", fator essencial no desenvolvimento sustentável de um lugar enquanto destino turístico (Martins, 2017).

De acordo com Pike (2005), o visitante tem neste momento à sua disposição inúmeros destinos turísticos, sendo difícil de os diferenciar. Assim, os lugares devem passar a ser vistos como marca e geridos segundo práticas empresariais, ou seja, a competição que já havia entre as empresas, a mesma competição passou a registar-se no âmbito dos destinos (Martins, 2017). Segundo Kavaratzis e Ashworth (2005, p. 510) "os lugares podem ser facilmente assumidos [como empresas] possuindo as características de identidade, 
diferenciação e personalidade e, portanto, podem ser gerenciados para maximizar a equidade, valor e consciência." Pike (2004) considera que os destinos turísticos têm propriedades similares a produtos e serviços, uma vez que ambos possuem atributos tangíveis e intangíveis. Porém, apesar das semelhanças, o branding é mais complexo no que respeita aos lugares/territórios porque um destino turístico é limitado por atributos incontroláveis, situacionais e que atravessam fronteiras, enquanto que a marca de um produto está dependente da sobrevivência da empresa (Gnoth, 2002). Nesse sentido, para que a marca aplicada ao destino seja bem-sucedida é crucial um envolvimento por parte dos stakeholders (Martins, 2017). Segundo Pike (2005), o nome do local é efetivamente a marca de destino. No entanto, já houve casos em que os nomes dos lugares foram alterados para induzir um maior apelo aos visitantes como, por exemplo, Elston para Surfers Paradise, na década de 1930, a fim de atrair surfistas, ou da ilha Marina Cay, uma das Ilhas Virgens Britânicas no mar das Caraíbas, renomeada para Cuervo Nation, pelos proprietários da marca Tequila. Atualmente e na impossibilidade de alterar o nome, por razões político-administrativas, também é usual fazerem-se associações como forma de promoção como, por exemplo, as Queensland na Austrália, rotuladas com nomes turisticamente atrativos (Sunshine Coast, Coral Coast e Discovery Coast).

Ritchie e Ritchie (1998) consideram que a marca associada a um destino tem, por um lado a uma função de diferenciação e por outro enfatiza a ideia de transmissão de uma experiência memorável e, se possível, exclusivamente disponível no destino em questão. Morgan, Pritchard e Pride (2004) vão mais longe ao considerar que para uma marca de destino ter valor e ser reconhecida como uma marca forte, deve desenvolver uma ligação emocional com os turistas. Por conseguinte, Morrison e Anderson (2002) também consideram que a marca de destino deve possuir uma personalidade única (brand personality), capaz de diferenciar esse destino turístico de outros no âmbito do mesmo segmento de mercado. Segundo Aaker (1997), personalidade é um conjunto de significados que são construídos por um observador para descrever as características interiores de outra pessoa, ou seja, os traços da personalidade são criados através de inferências ou atribuídos com base na observação do comportamento de outra pessoa. Personalidade da Marca é, pois, um conjunto de características humanas associadas a uma marca (Aaker, 1997), algo que está bem patente na literatura do Marketing. Da mesma forma que cada indivíduo se distingue entre os outros pela sua personalidade, as marcas também podem ser distinguidas e diferenciadas umas das outras através da personalidade. Desta forma, é importante que os gestores conheçam quais os fatores que determinam a perceção da Personalidade da Marca e qual a Personalidade da Marca percecionada pelos consumidores de modo a conseguir gerir a mesma. A personificação de marcas atingiu o seu auge quando figuras públicas começaram a representar marcas, estratégia que ajuda as empresas a posicionarem as suas marcas (Azoulay e Kapferer, 2003).

\section{Turismo português no século XXI}

Pode considerar-se que ao longo do século XX, Portugal não tinha uma política estratégica sólida e consistente para o turismo português, tendo havido alguma instabilidade nas formas de organização e gestão da Administração Pública do Turismo (Martins, 2017). Os organismos do turismo, umas vezes eram extintas por um governo, sendo repostas por outro, tendo, por vezes, mudado apenas de nome. É o exemplo do Conselho Nacional do Turismo que foi extinto e substituído pelo Conselho Setorial do Turismo, também extinto passado pouco tempo para dar lugar ao Conselho para a Dinamização do Turismo que por sua vez também foi extinto (Cunha, 2013). No século XXI, tem-se desenvolvido programas de incentivo financeiro, mas a "inconstância e a incoerência das estratégias adotadas não permitem o sucesso desejado" (Cunha, 2013, p. 80). O turismo atualmente transformou-se numa das atividades económicas nacionais de maior relevância com impactos não só económico, mas também a nível social, cultural e do desenvolvimento regional (Cunha, 2013).

Na primeira década do século XXI, introduziram-se algumas alterações na organização institucional, tendo sido criada uma estrutura orgânica, o Turismo de Portugal, I. P., sendo "a Autoridade Turística Nacional responsável pela promoção, valorização e sustentabilidade da atividade turística, agregando numa única entidade todas as competências institucionais relativas à dinamização do turismo, desde a oferta à procura" (Turismo de Portugal, 2017). Este organismo está integrado no Ministério da Economia e tem como missão qualificar e desenvolver as infraestruturas turísticas; desenvolver a formação de recursos humanos; apoiar o investimento no setor; coordenar a promoção interna e externa de Portugal como destino turístico; e regular e fiscalizar os jogos de fortuna e azar (Turismo de Portugal, 2017). Atualmente, Portugal precisa de ultrapassar as lacunas "físicas" e pautar-se por uma política estratégica clara, ambiciosa e exequível com medidas de promoção efetivas do setor junto dos públicos-alvo (Ramos, 
Salazar e Gomes, 2000). Para além disso, deve apostar no desenvolvimento baseado na qualificação e competitividade da oferta, transformando o setor num dos motores de crescimento da economia nacional (Resolução do Conselho de Ministros n ${ }^{\circ}$ 53/2007).

Por conseguinte, a fim de melhorar a resposta à evolução do contexto global e do setor turístico foi aprovado, em 2007, o Plano Estratégico Nacional do Turismo (PENT), através da resolução do conselho de ministros n. ${ }^{\circ} 53 / 2007$, de 4 de abril. Foi desenvolvido para o horizonte temporal 2006-2015, sofrendo revisões em 2011 e 2013, decorrentes da necessidade de (re)adaptação às mudanças estratégicas políticas do programa do XIX Governo, bem como ao período de instabilidade nos mercados financeiros e crescimento económico bastante moderado da economia europeia, principal emissora de turistas para Portugal (Turismo de Portugal, 2013). O PENT foi uma "ação relevante, na medida em que procurou lançar novos destinos turísticos ou reforçar alguns que já vinham a ter algum desenvolvimento como é o caso do Vale do Douro, da Serra da Estrela, do Alqueva, do Oeste Alentejano e da região de Leiria/ Fátima, a fim de se criar um desenvolvimento equilibrado no turismo português, por região, mais descentralizado" (Martins, 2017, p.81).

Em 2008, procedeu-se a uma reorganização das entidades públicas regionais com responsabilidades na área do turismo procurando estabelecer uma melhor articulação e cooperação entre o organismo central do turismo, o Turismo de Portugal, I. P., e as regiões do país visto que uma "articulação, para que seja coerente e consistente, não poderia realizar-se com um número demasiado vasto de interlocutores regionais e locais, sendo que o regime anterior em vigor deu azo a um desenho territorial em grande parte aleatório, por vezes sem racionalidade territorial visível, mesmo sob o simples ponto de vista turístico" (Decreto - Lei n ${ }^{\circ}$ 67/ 2008, de 10 de abril, p. 2171). Entretanto esse decreto-lei foi revogado pela Lei n. ${ }^{\circ} 33 / 2013$, de 16 de maio, que estabelece o regime jurídico das áreas regionais de turismo de Portugal continental, a sua delimitação e características, bem como o regime jurídico da organização e funcionamento das entidades regionais de turismo.

Por conseguinte é redefinida a estrutura organizacional do turismo em Portugal e, para efeitos de planeamento, divide o continente em cinco áreas regionais que coincidem com as unidades territoriais utilizadas para fins estatísticos, as NUTS II (figura 2): Norte; Centro; Lisboa e Vale do Tejo; Alentejo; Algarve (Martins, 2017).

Estas entidades regionais de turismo adotam, atualmente, as seguintes nomenclaturas:

- Turismo do Porto e Norte de Portugal, com sede em Viana do Castelo;

- Turismo Centro de Portugal, com sede em Aveiro;

- Entidade Regional de Turismo da Região de Lisboa, com sede em Lisboa;

- Turismo do Alentejo, com sede em Beja;

- Região de Turismo do Algarve, com sede em Faro (Turismo de Portugal, 2017).

Segundo a Lei n. ${ }^{\circ}$ 33/2013, de 16 de maio, as entidades regionais de turismo têm por missão a valorização e o desenvolvimento das potencialidades turísticas da respetiva área regional de turismo, assim como a gestão integrada dos destinos no quadro do desenvolvimento turístico regional, de acordo com as orientações e diretrizes da política de turismo definida pelo Governo e os planos plurianuais da administração central e dos municípios que as integram.

São atribuições das entidades regionais de turismo: i) colaborar com os órgãos da administração central, com vista à prossecução dos objetivos da política nacional que for definida para o turismo; ii) definir o plano regional de turismo, alinhado com a estratégia nacional de desenvolvimento turístico e promover a sua implementação; iii) assegurar o levantamento da oferta turística regional e sub-regional e a sua permanente atualização e realizar estudos de avaliação do potencial turístico das respetivas áreas territoriais; iv) assegurar a realização da promoção da região no mercado interno alargado, compreendido pelo território nacional e transfronteiriço com Espanha; v) organizar e difundir informação turística, mantendo ou gerindo uma rede de postos de turismo e de portais de informação turística; vi) dinamizar e potenciar os valores e recursos turísticos regionais e sub-regionais; vii) monitorizar a atividade turística regional e sub-regional, contribuindo para um melhor conhecimento integrado do setor (artigo $5^{\circ}$ da Lei n. ${ }^{\circ} 33 / 2013$, de 16 de maio).

Estas entidades institucionais e promotoras das regiões e dos destinos turísticos perceberam a importância e a necessidade de criar uma marca que identifique o território (Martins, 2018). Exemplo claro disso, foi o caso do Turismo do Porto e Norte de Portugal. 
Figura 2: Nomenclatura das Unidades Territoriais para Fins Estatísticos (Portugal)

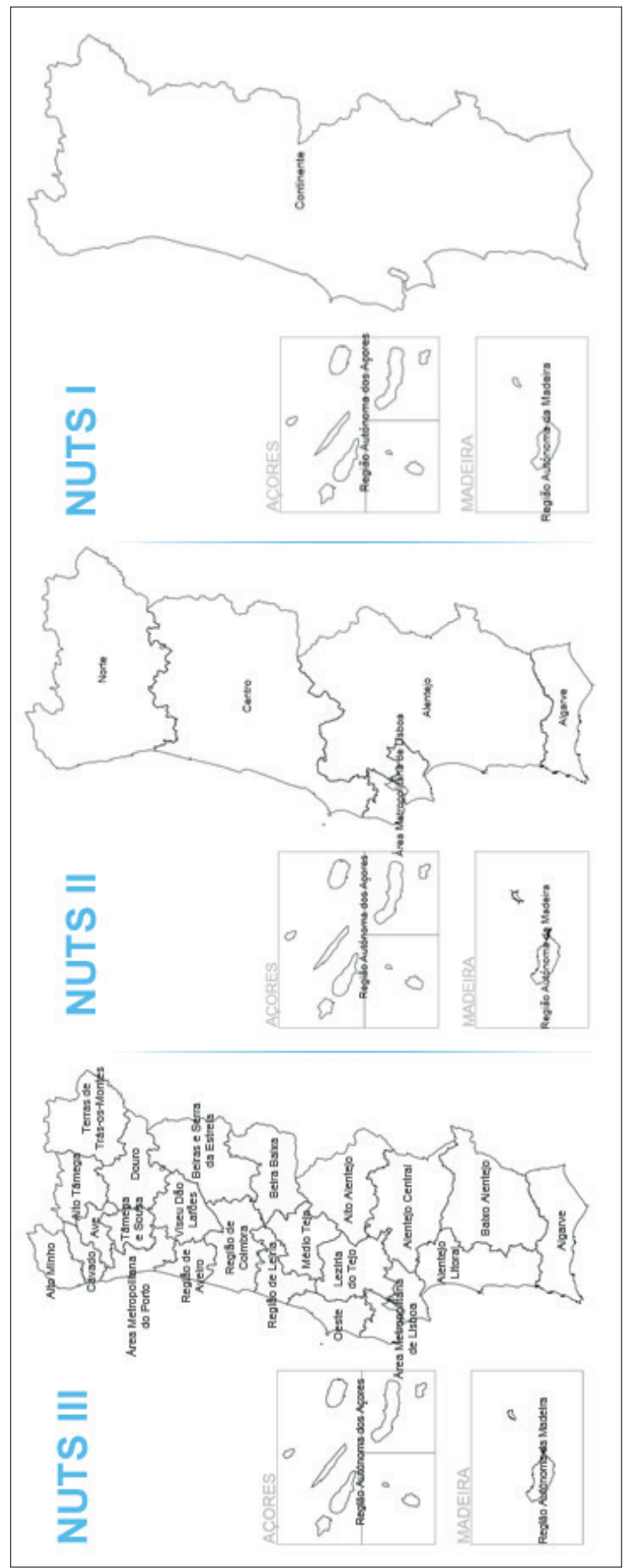

Fonte: Pordata (2013) 


\section{Porto e Norte de Portugal, um exemplo de marca}

O âmbito territorial da entidade regional do Turismo do Porto e Norte de Portugal corresponde à NUT II Norte, agregando os 86 municípios distribuídos pelas oito sub-regiões (NUTS de nível III) - Alto Minho, Cávado, Ave, Área Metropolitana do Porto, Alto Tâmega, Tâmega e Sousa, Douro e Terras de Trás-os-Montes. A Entidade Regional de Turismo do Porto e Norte de Portugal, adotando a denominação de Turismo do Porto e Norte de Portugal, E.R. e a abreviatura de TPNP, E.R., tem a sua sede em Viana do Castelo e é uma pessoa coletiva pública, de natureza associativa, com autonomia administrativa e financeira e com património próprio (Turismo do Porto e Norte de Portugal, 2016). Tem como principais responsabilidades a valorização e o desenvolvimento das potencialidades turísticas da respetiva área regional de turismo, a promoção interna e o mercado alargado dos destinos turísticos regionais, a gestão integrada dos destinos no quadro do desenvolvimento turístico regional.

A entidade regional de Turismo do Porto e Norte de Portugal procurou destacar-se desde cedo, percebendo a importância da marca associada aos destinos. Nesse sentido, em 2009, criou uma marca que fosse agregadora de todos os produtos estratégicos que a zona norte possui, "funcionando como um enorme "chapéu" que engloba várias marcas referentes às sub-regiões" (Martins, 2018, p.91), procurando que fosse uma "imagem e assinatura do Porto e Norte de Portugal que se tornasse a marca turística da região e que pudesse comunicar a região no seu todo, estando unida na diversidade e distinção dos seus produtos para todos os segmentos" (Martins, 2017, p.84).

A atuação da Turismo do Porto e Norte de Portugal, E.R. tem na sua base um diversificado e vasto leque de recursos naturais e patrimoniais, produtos únicos e marcas de grande qualidade, que constituem a oferta turística de um território singular, distribuída pelos seus quatro subdestinos - Porto, Douro, Minho e Trás-os-Montes. De acordo com o quadro 1, é possível verificar a diversidade de produtos distribuída pelas regiões, isto porque ao longo do território, os produtos turísticos ganham um destaque diferenciado, evidenciando diferentes níveis de prioridade na aposta e no desenvolvimento no plano dos subdestinos. Essa diversidade de riqueza dos recursos oferece a cada sub-região ou subdestino um conjunto de produtos âncora e complementares que permite a vivência de experiências diversas, se o visitante considerar na sua estadia apenas um dos subdestinos. Por outro lado, "a complementaridade entre subdestinos permite ao visitante a vivência de experiências específicas e associadas a um único produto turístico, tornando-a mais rica e compreensiva da singularidade do território" (Turismo do Porto e Norte de Portugal, 2015, p. 22).

\section{Quadro 1: Produtos âncora e complementares por subdestino}

\begin{tabular}{|c|c|c|c|c|}
\hline & Porto & Minho & Douro & Trás-os-Montes \\
\hline $\begin{array}{l}\text { Produtos } \\
\text { âncora }\end{array}$ & $\begin{array}{l}\text { - City e Short } \\
\text { Breaks } \\
\text { - Touring Cultural } \\
\text { e Paisagístico } \\
\text { - Turismo Náutico } \\
\text { - Gastronomia e } \\
\text { Vinhos } \\
\text { - Negócios }\end{array}$ & 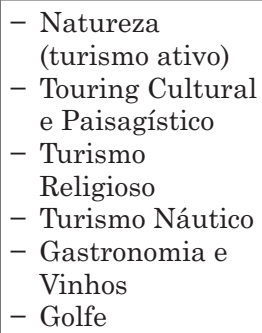 & \begin{tabular}{|l} 
- Turismo Náutico \\
(cruzeiros e \\
passeios no Douro) \\
- Gastronomia e \\
Vinhos (quintas) \\
- Touring Cultural e \\
Paisagístico \\
- Natureza
\end{tabular} & $\begin{array}{l}\text { - Saúde e Bem- } \\
\text { - estar } \\
\text { - Natureza } \\
\text { - Touring Cultural } \\
\text { e Paisagístico } \\
\text { - Gastronomia e } \\
\text { Vinhos }\end{array}$ \\
\hline $\begin{array}{l}\text { Produtos } \\
\text { complementares }\end{array}$ & $\begin{array}{l}\text { - Saúde e Bem- } \\
\text { - estar } \\
\text { - Golfe } \\
\text { - Sol e Mar } \\
\text { - Natureza }\end{array}$ & $\begin{array}{l}\text { - Saúde e Bem- } \\
\text {-estar } \\
\text { - City e Short } \\
\text { breaks } \\
\text { - Sol e Mar }\end{array}$ & $\begin{array}{l}\text { - Turismo Religioso } \\
\text { - Saúde e Bem- } \\
\text {-estar } \\
\text { - Golfe } \\
\text { - Negócios }\end{array}$ & $\begin{array}{l}\text { - Turismo } \\
\text { - Religioso } \\
\text { - Golfe }\end{array}$ \\
\hline
\end{tabular}

Fonte: Turismo do Porto e Norte de Portugal (2015, p.22)

A Estratégia de Marketing Turístico do Porto e Norte de Portugal para o Horizonte 2015-2020 e respetivo Plano de Ação assentam na premissa de que o Porto e Norte de Portugal pode afirmar-se e ser reconhecido como um destino cosmopolita e glamoroso, com história e tradição, com uma diversidade de recursos naturais e patrimoniais de referência mundial, com uma oferta gastronómica e vínica ímpar que se impõe ser experimentado num ambiente de evasão absoluta ou de entretenimento constante 
(Turismo do Porto e Norte de Portugal, 2015). Para tal, a operacionalização da estratégia do Turismo do Porto e Norte de Portugal prevê a implementação de três programas de ação sendo que um deles, a Comunicação e notoriedade do Destino, é um processo de envolvimento dos atores e stakeholders do destino, em prol do desenvolvimento equilibrado e harmonioso do turismo na região.

De acordo com Carvalho (2015, p.91), "o símbolo "TEM" (figura 3), que remete para o conceito de trademark, funciona como o símbolo distintivo da região que identifica a sua oferta como única, sendo assim um elemento de afirmação e diferenciação da sua oferta multiprodutos, direcionada para diferentes segmentos". A estrutura da barra é composta por sete retângulos idênticos, sendo representativos dos sete produtos estratégicos da região (outrora definidos pelo PENT), constituindo a assinatura genérica da marca. De acordo com a sequência, os produtos são: o turismo de negócios, a verde azulado; city e short breaks, a laranja; a gastronomia, a bordô; o turismo de natureza, a verde; o turismo religioso, a púrpura; o touring cultural e paisagístico, a amarelo; e saúde e bem-estar, a azul (figura 3).

Figura 3: Logo da marca Porto e Norte de Portugal e significados

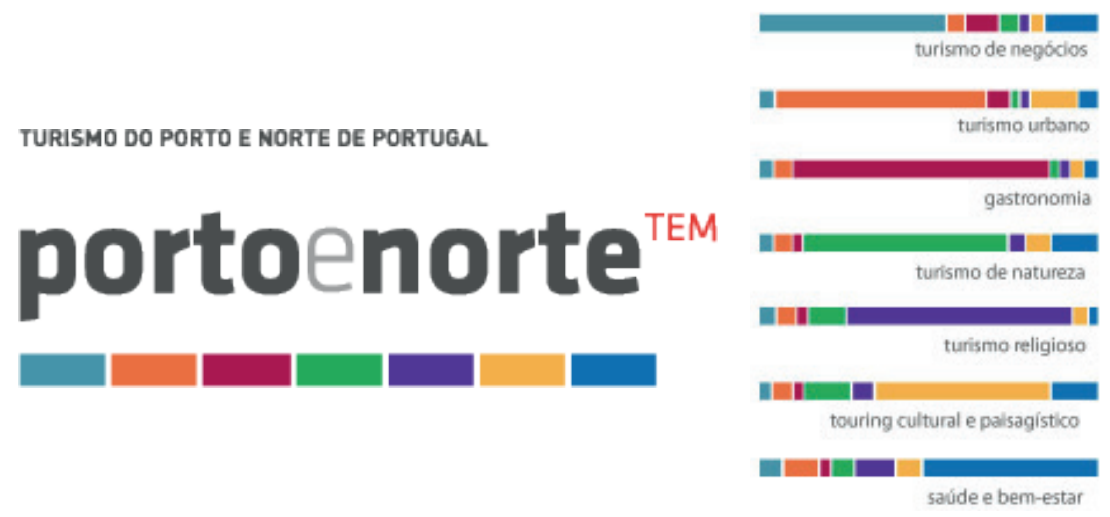

Fonte: Turismo do Porto e Norte de Portugal (2016)

Usualmente, estes elementos são utilizados em conjunto, estando, no entanto, previstas situações que poderão ser usados de forma isolada, em contextos específicos, onde se pretenda destacar um dos produtos (figura 3). Nesses casos, a barra a utilizar deverá ser aquela onde a cor do produto em questão se encontra em evidência, podendo ou não ser acompanhada da designação do referido produto (Turismo do Porto e Norte de Portugal, 2016).

Para além disso, existem as Lojas Interativas de Turismo, com um logo similar (figura 4). O “i”, de informação, funde-se com o símbolo de power e com a sugestão de uma seta reportando para spot interativo onde se disponibilizam conteúdos nas próprias lojas, nas promotoras virtuais, e mesas interativas. Todos os elementos do logo são aplicados na decoração das lojas interativas de turismo, sendo já 85 lojas, para além da loja móvel (autocarro) que funciona como promoção itinerante (Turismo do Porto e Norte de Portugal, 2016).

Figura 4: Logo da marca Porto e Norte de Portugal e significados

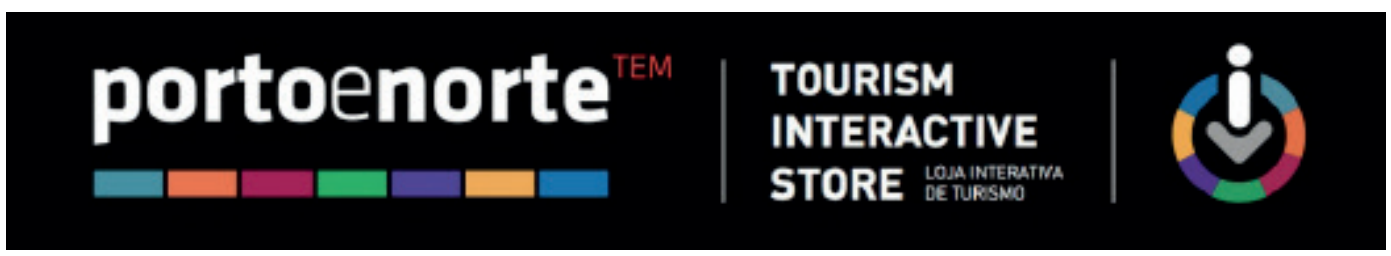

Fonte: Turismo do Porto e Norte de Portugal (2016)

Em suma, em consonância do que se vem fazendo, sensivelmente nas últimas duas décadas, as entidades institucionais das regiões e dos destinos turísticos perceberam o quão importante é a definição de uma marca. Em termos de operacionalização, com vista a aumentar a atratividade do destino e elevar 
os seus níveis de notoriedade, um dos objetivos visa aproveitar os eventos de caráter regional, nacional e internacional com vista à projeção da marca Porto e Norte. Para além disso, em 2018, o Porto e Norte foi considerada Marca de Confiança 2018!, recebendo o Selo da Marca de Confiança na área do turismo.

\section{Conclusão}

No mundo globalizado em que vivemos, cada vez mais competitivo, cada lugar/destino turístico tem de competir com todos os outros lugares. Os destinos turísticos têm propriedades similares a produtos e serviços visto ambos possuírem atributos tangíveis e intangíveis (Pike, 2004). É, pois, necessário a adoção de estratégias de diferenciação para que se destaquem dos outros (Martins, 2017). Essas estratégias deverão passar pela criação e/ou associação de uma marca. No entanto, para que a marca aplicada ao destino seja bem-sucedida é crucial um envolvimento por parte dos stakeholders, procurando o branding dos destinos ser um elemento estratégico de gestão.

No caso da entidade regional do Turismo do Porto e Norte de Portugal, procurou destacar-se desde cedo, ao perceber a importância da marca associada aos destinos turísticos. Por conseguinte, optou pela visão estratégica da criação de uma marca para a NUTII do norte de Portugal. A região contempla vários recursos naturais e patrimoniais distribuídos pelos seus quatro sub-destinos - Porto, Douro, Minho e Trás-os-Montes. Primeiramente, a entidade regional procurou definir os produtos âncora dos produtos complementares de cada sub-região. Seguidamente, criou uma marca que abarcasse todos esses produtos como se fosse um grande "chapéu" que engloba os vários produtos de cada sub-região, mas que transmitisse a imagem como um todo, algo singular, a fim de atrair e fidelizar visitantes. Em termos operacionais, esta entidade apostou na divulgação e promoção dessa marca através da criação de várias lojas interativas transmitindo a ideia de um território singular, cosmopolita, glamoroso, repleto de história e tradições.

Este trabalho tem como principal limitação a análise apenas de uma das entidades de turismo em Portugal. Por conseguinte, seria interessante perceber de que forma as outras entidades de turismo estão a utilizar a marca como ferramenta de marketing.

\section{Bibliografía}

Aaker, D. (2014). Aaker on branding: 20 principles that drive success. New York: Morgan James Publishing.

Aaker, D. e Joachimsthaler, E. (2000). The brand relationship spectrum: The key to the brand architecture challenge. California management review, 42(4), 8-23. Disponível em http://faculty.mu.edu.sa/public/ uploads/1358444333.324brand83.pdf

Aaker, J. (1997). Dimensions of brand personality. Journal of Marketing Research, 34(3), 347-356. Disponível em http://www.haas.berkeley.edu/groups/finance/Papers/Dimensions\%20of\%20BP\%20JMR\%201997.pdf

American Marketing Association (AMA). (2008). The American Marketing Association Releases New Definition for Marketing. Disponível em https://archive.ama.org/archive/AboutAMA/Documents/American\%20 Marketing\%20Association\%20Releases\%20New\%20Definition\%20for\%20Marketing.pdf

Azoulay, A. e Kapferer, J. (2003). Do brand personality scales really measure brand personality? Journal of Brand Management, 11(2), 143-155. Disponível em https://doi.org/10.1057/palgrave.bm.2540162

Boo, S., Busser, J. e Baloglu, S. (2009). A model of customer-based brand equity and its application to multiple destinations. Tourism Management, 30(2), 219-231. Disponível em https://doi.org/10.1016/j. tourman.2008.06.003

Carvalho, P. (2015). Modelo concetual integrativo de Destination Branding - Tourist Mind. Teste empírico no Porto e Norte de Portugal (Tese de Doutoramento) Universidade Fernando Pessoa, Porto. Disponível em http://hdl.handle.net/10284/4895

Cunha, L. (2013). Economia e política do turismo (3. a edição). Lisboa: Lidel - Edicões Técnicas.

Davies, G. e Chun, R. (2003). The use of metaphor in the exploration of the brand concept. Journal of Marketing Management, 19(1-2), 45-71. Disponível em https://www.researchgate.net/publication/233609561_The_ Use_of_Metaphor_in_the_Exploration_of_the_Brand_Concept

De Chernatony, L. e Riley, F. (1998). Defining a "brand": beyond the literature with experts' interpretations. Journal of Marketing Management, 14(5), 417-443. Disponível em https://www.researchgate.net/ publication/247494772_Defining_A_Brand_Beyond_The_Literature_With_Experts\%27_Interpretations

Fischer, M., Völckner, F. e Sattler, H. (2010). How important are brands? A cross-category, cross-country study. Journal of Marketing Research, 47(5), 823-839. Disponível em https://www.researchgate.net/ publication/259839231_How_Important_Are_Brands_A_Cross-Category_Cross-Country_Study 
Gnoth, J. (1998). Branding tourism destinations. Annals of tourism research, 25, 758-759. Disponível em https://www.researchgate.net/publication/248500431_Branding_Tourism_Destinations

Gnoth, J. (2002). Leveraging export brands through a tourism destination brand. The Journal of Brand Management, 9(4), 262-280. Disponível em https://www.researchgate.net/publication/233632603_Leveraging_export_brands_through_a_tourism_destination_brand

Hall, D. (2002). Brand development, tourism and national identity: The re-imaging of former Yugoslavia. Journal of Brand Management, 9(4), 323-334. Disponível em https://doi.org/10.1057/palgrave.bm.2540081

Kavaratzis, M. e Ashworth, G. (2005). City Branding: An Effective Assertion of Identity or a Transitory Marketing Trick?. Tijdschrift voor Economische en Sociale Geografie 96(5), 506-514. Disponível em https://www.researchgate.net/publication/4997029_City_branding_An_effective_assertion_of_identity_or_a_transitory_marketing_trick

Keller, K. (2003). Brand Synthesis: The Multidimensionality of Brand Knowledge. Journal of Consumer Research, 29(4), 595-600. Disponível em https://doi.org/10.1086/346254

Keller, K. (2013). Strategic brand management: Building, measuring, and managing brand equity (4. ${ }^{\mathrm{a}}$ ed.) [PDF]. Disponível em http://www.kvimis.co.in/sites/kvimis.co.in/files/ebook_attachments/Keller\%20 Strategic\%20Brand\%20Management.pdf

Kotler, P. (1999), Administração de marketing: análise, planejamento, implementação e controle. São Paulo: Atlas.

Lei n. ${ }^{\circ}$ 33/2013 de 16 de maio. Disponível em https://dre.pt/application/file/a/261001

Martins, H. (2017). O turismo no Parque Nacional da PenedaGerês: a experiência da marca do destino, o apego ao lugar, a satisfação, os comportamentos próambientais e as intenções comportamentais. (Tese de doutoramento) Universidade de Coimbra, Coimbra.

Martins, H. (2018). A Personalidade da marca do destino e a imagem de marca do destino: um estudo sobre os turistas do PNPG. European Journal of Applied Business and Management, 3(2), 85-108. Disponível em http://nidisag.isag.pt/index.php/IJAM/article/view/277/pdf_24

Morgan, N., Pritchard, A. e Pride, A. (2004). Destination Branding: Creating the Unique Destination Proposition. Oxford: Butterworth-Heinemann.

Morrison, A., e Anderson, D. (2002, junho). Destination branding. Comunicação apresentada no Missouri Association of Convention and Visitor Bureaus Annual Meeting. 10 de junho. Missouri, EUA. Disponível em http://www.macvb.org/intranet/presentation/DestinationBrandingLOzarks6-10-02.ppt

Pereira, C. (2013). Branding de cidades: o caso de Santiago de Compostela (Tese de doutoramento), Universidade de Lisboa, Lisboa. Disponível em http://hdl.handle.net/10400.5/6458

Pike, S. (2004). Destination Marketing Organisations. Oxford: Elsevier.

Pike, S. (2005). Tourism destination branding complexity. Journal of Product \& Brand Management, 14(4), 258-259. Disponível em https://www.researchgate.net/publication/43515204_Tourism_Destination_Branding_Complexity

Pordata. (2013). Base de dados Portugal contemporâneo. Disponível em http://www.pordata.pt/ $\mathrm{O}+$ que+sao+NUTS

Ramos, P., Salazar, A. e Gomes, J. (2000). Trends in Portuguese tourism: a content analysis of association and trade representative perspectives. International Journal of Contemporary Hospitality Management, 12(7), 409-417. Disponível em https://www.researchgate.net/publication/235306136_Trends_in_Portuguese_tourism_A_content_analysis_of_association_and_trade_representative_perspectives

Resolução do Conselho de Ministros n. ${ }^{\circ}$ 53/2007 de 4 de abril. Disponível em https://dre.pt/application/ file/a/520164

Smilansky, S. (2009). Experiential marketing: A practical guide to interactive brand experiences. London: Kogan Page Publishers.

Turismo de Portugal. (2017). Estratégia Turismo 2027 - Liderar o turismo do futuro. Disponível em http:// fortis.pt/files/2017/03/estrat\%C3\%A9gia-turismo-2027.pdf

Turismo do Porto e Norte de Portugal (2015). Estratégia de Marketing Turístico do Porto e Norte de Portugal - Horizonte 2015-2020. Disponível em 2020, maio, 13, de http://www.portoenorte.pt/fotos/gca/plano_estr ategico_10327505915894b4d3a978b.pdf

Turismo do Porto e Norte de Portugal (2016). Plano de ação e orçamento PNP 2017. Disponível em 2017, janeiro, 23, de http://www.portoenorte.pt/client/files/0000000001/3191.pdf

Recibido:

$13 / 06 / 2020$

Reenviado:

$02 / 09 / 2020$

Aceptado:

$23 / 11 / 2020$

Sometido a evaluación por pares anónimos 


\title{
El turismo de golf en Almería y su carácter desestacionalizador
}

\author{
María del Mar Martín García*
}

Universidad de Almería (España)

\begin{abstract}
Resumen: En este artículo se realiza un análisis del turismo de golf que recibe la provincia de Almería. Para ello se ha recogido el número de salidas de cada campo de golf de la provincia desde mayo de 2017 hasta abril de 2019 y su procedencia. El estudio de los datos muestra el crecimiento de este turismo y deja constancia de su carácter desestacionalizador. El turista procedente de Europa cuyo motivo de su viaje es jugar al golf viene en los meses de otoño e invierno, lo que convierte a la provincia de Almería en un destino receptor de turistas durante todo el año. Desde el análisis de las debilidades y fortalezas de Almería como destino de golf, se expresa la necesidad de establecer las claves para un desarrollo sostenible del turismo de golf en la provincia que sitúe a Almería como uno de los principales destinos en Europa para la práctica de este deporte.
\end{abstract}

Palabras Clave: Almería Golf; Destino turístico; Turismo sostenible; Estacionalidad; Golf.

\section{Golf tourism in Almería and its seasonality}

Abstract: This article gives an analysis of golf tourism in Almeria. The research counted number of people playing on each golf course in the Province registering them by their respective countries of residence iover the period between May 2017 and April 2019. Analysis shows how golf tourism has grown and is no longer locked by seasonality, with European tourists travelling in Autumn and Winter with this as their motivation.. This would seem to indicate that Almería could be be an all-year round tourist resort. An analysis of the strengths and weaknesses of Almeria as a golf destination shows that there is a need to promote the Province and put it on the map of golf tourism resorts in Europe.

Keywords: Golf Almeria; Tourist destination; Sustainable tourism; Seasonality; Golf.

\section{Introducción}

En la primera década del presente siglo, se ha producido en España un incremento significativo de la oferta de instalaciones de golf, con una clara vinculación a los espacios litorales, asistiendo al mayor incremento de la oferta en la historia del golf en España. Destaca Andalucía que ocupa la primera posición en número de instalaciones de golf en este país. (Ferreres, 2014).

El desarrollo del turismo de golf es una realidad incuestionable en el ámbito territorial del Mediterráneo y especialmente en las zonas áridas, debido entre otras cosas, a las características climáticas que permiten la práctica deportiva continuada sin interrupción estacional (García Lorca, 2007).

Dentro del conjunto de Andalucía, en la provincia de Almería también se asiste a este incremento de la oferta de golf, contando a día de hoy con un total de ocho campos y dos más en proyecto. Al igual que en el resto de España, este incremento de nuevas instalaciones se ha concentrado entre los años 2005 y 2009 con una clara vinculación al litoral. En Almería desde el año 2000 se han abierto 5 nuevos campos, todos en la zona del levante almeriense, más la escuela pública de golf inaugurada por la Junta de Andalucía en enero del 2017.

Esta oferta de campos de golf en Almería, sitúa a esta provincia como un destino de turismo de golf, receptor de jugadores nacionales e internacionales, cuyo motivo principal de su desplazamiento es jugar al golf. El conjunto de actividades que se generan alrededor de este deporte es lo que se conoce como el turismo de golf, una actividad cuyo valor añadido consiste en romper la estacionalidad

Universidad de Almería (España); E-mail: marmarti@ual.es; https://orcid.org/0000-0003-3842-6114 
característica del sector turístico y renovar su productividad dentro de la economía de una provincia (Centro Euromediterráneo de conocimiento, innovación y formación turística, 2007).

\section{Metodologia}

Para llevar a cabo el estudio del turismo de golf en Almería se ha utilizado un método mixto de investigación combinando la revisión documental y la recogida de datos de campo, tanto cuantitativos como cualitativos.

En cuanto a la investigación documental, se ha revisado literatura escrita relacionada con el turismo de golf, libros, revistas y prensa actual especializada en golf y en turismo, realizando diferentes tipos de búsqueda a través de bases de datos, para obtener un acercamiento a la realidad del sector del turismo de golf en España. Además se han consultados las webs de los destinos de golf cercanos, similares al destino Almería, como Costa del Sol, Costa Blanca y Murcia, junto a los portales de los organismos públicos de turismo de cada uno de esos destinos.

Para completar esta labor y obtener datos concretos sobre este turismo en Andalucía y en la provincia de Almería, se han consultado asociaciones y organismos nacionales e internacionales que realizan estudios sobre el sector o recopilan datos que se han necesitado para la investigación, como la Real Federación Española de Golf (RFEG) ${ }^{1}$ y la Real Federación Andaluza de Golf (RFAG) ${ }^{2}$, la Asociación de Campos de Golf de la Costa Blanca y Comunidad Valenciana (ACGCB), la Asociación de Campos de Golf de Costa Brava, la Asociación Española de Campos de Golf (AECG), el servicio Español Público de Empleo Estatal, la Organización Mundial de Turismo (UNWTO) ${ }^{3}$,The Royal \& Ancient Golf Club de St.Andrews (R\&A) ${ }^{4}$, el Portal de Turismo de España y la web oficial de Turismo de Andalucía. También se ha consultado un organismo internacional llamado KPMG respondiendo a las siglas de sus fundadores, que recopila y publica información golfística, accediendo a través de su página web, www.golfbenchmark.com. KPMG International es una cooperativa suiza y la entidad coordinadora de una red global de empresas independientes que posee una plataforma interactiva que proporciona a las asociaciones de golf, clubes de golf, inversores, desarrolladores y otras partes interesadas de la industria, informes sobre el sector del golf de más de 40 países europeos desde 2015. Para conocer el tráfico aéreo en la provincia se ha accedido a la publicación del informe de tránsito de AENA SME S.A., empresa pública española que gestiona los aeropuertos de interés general en España.

En cuanto a la obtención de datos, tanto cualitativos como cuantitativos, se ha establecido contacto con los responsables de los ocho campos de golf que hay en la provincia, con los responsables de seis de las nueve escuelas de golf y con la Asociación de Campos de Golf de Almería (ACGA). El contacto se ha establecido personalmente en todos los casos, teniendo así la oportunidad de obtener más información en la visita a las instalaciones mediante la observación directa. El proceso de recogida de datos se ha realizado en dos fases.

En la primera fase se llevaron a cabo entrevistas con cada uno de los responsables de las entidades detalladas, recogiendo todas sus opiniones sobre el sector, las necesidades de mejora y las perspectivas de cara al futuro, así como la información relativa al tipo de cliente que reciben, las características, su procedencia y descripción.

En la segunda fase, con el análisis de toda la información recogida, se procedió al diseño de una ficha a cumplimentar por cada campo de golf para la obtención de los datos cuantitativos y cualitativos que completaran el análisis del sector del turismo de golf en Almería. Los datos cuantitativos recogidos son las cifras de salidas al campo de golf por mes referidas a las dos últimas temporadas y su procedencia por tipo de cliente. Los datos cualitativos recogidos responden al detalle de las características del cliente que reciben, con las que hemos completado el perfil del cliente de golf en Almería. Esta ficha se envió por correo electrónico y ha sido cumplimentada por los ocho campos de la provincia.

El trabajo ha concluido con el análisis e interpretación de los resultados obtenidos, estableciendo conclusiones y líneas de trabajo que contribuyan a mejorar el desarrollo del turismo de golf en la provincia de Almería.

\section{Cifras a destacar: número de salidas}

Con el análisis de las cifras de salidas de los campos de golf de la provincia y la información recogida de los responsables de cada uno de ellos, se establece que la demanda de jugadores que reciben se divide en tres tipos de cliente: el cliente local, el cliente visitante y el cliente llamado longstay, anglicismo utilizado para referirnos al cliente cuya estancia en el destino es superior a 21 días. 
En la temporada 2018, como se refleja en la tabla 1, desde mayo de 2017 hasta abril de 2018, el total de salidas de jugadores de los 8 campos de golf de la provincia fue de 313.921 salidas. Si atendemos a la procedencia de las mismas, como vemos en el gráfico 1, el 30,47 \% corresponde al cliente local, el $56,73 \%$ al cliente visitante y el otro $12,80 \%$ al cliente longstay.

Tabla 1: $\mathrm{N}^{\circ}$ Salidas por mes temporada 2017/2018

\begin{tabular}{|c|c|c|c|c|c|c|c|c|c|c|c|c|}
\hline May & Jun & Jul & Ago & Sep & Oct & Nov & Dic & Ene & Feb & Mar & Abr & Total \\
\hline 23.373 & 17.987 & 16.296 & 19.137 & 20.578 & 35.460 & 34.581 & 22.329 & 26.308 & 28.723 & 37.574 & 31.575 & 313.921 \\
\hline
\end{tabular}

Fuente: Elaboración propia

Gráfico 1: Procedencia salidas temporada 2017/2018

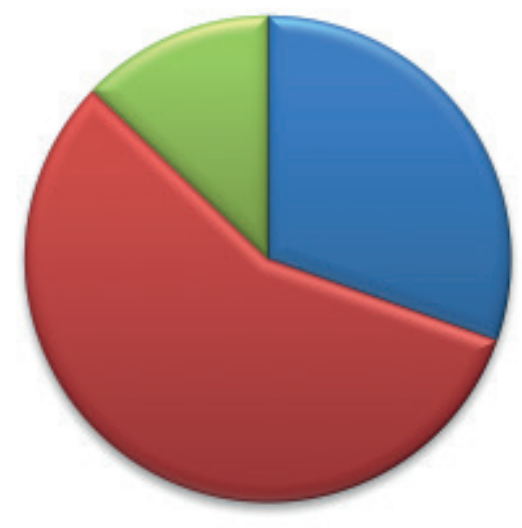

\% local

$\%$ visitante

\% longstay

Fuente: Elaboración propia

Eso traducido en número de jugadores que nos visitan, supone que llegaron a Almería alrededor de 53.756 turistas de golf procedentes de Europa, que visitaron la provincia principalmente en los meses que van desde octubre hasta abril, es decir el otoño y el invierno, tal y como muestra el gráfico 2.

Gráfico 2: Numero de salidas temporada 2017/2018

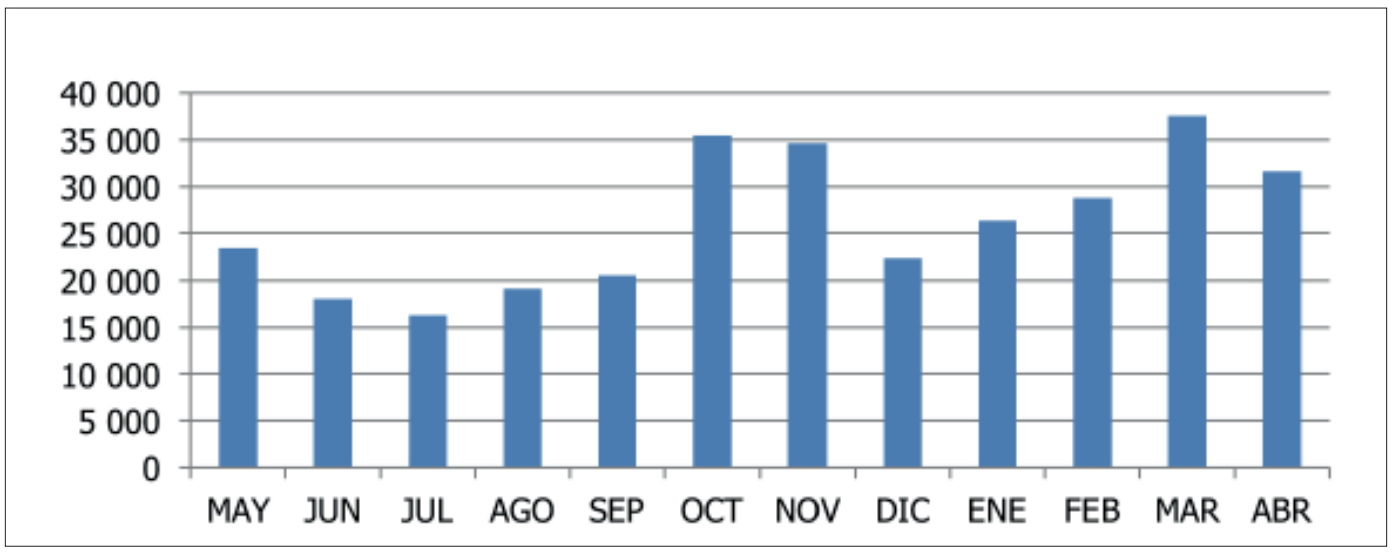

Fuente: Elaboración propia 
En la temporada 2019, con los datos hasta abril, como se muestra en la tabla 2, se ha producido un total de 319.106 salidas, lo que supone un incremento de 5.185 salidas respecto a la temporada anterior. Este incremento de jugadores, se reparte más o menos de manera uniforme entre el cliente local, el cliente visitante y el cliente longstay.

Tal y como se muestra en el gráfico 3, del total de salidas en la temporada 2019, el 30,27 \% corresponde al cliente local, el 56,70\% al cliente visitante y el 13,03\% al cliente longstay. Lo que significa que el número de jugadores aumenta en las tres procedencias, manteniéndose los porcentajes de reparto, con un ligero aumento en el cliente longstay.

Tabla 2: Numero de salidas por mes temporada 2018/2019

\begin{tabular}{|c|c|c|c|c|c|c|c|c|c|c|c|c|}
\hline May & Jun & Jul & Ago & Sep & Oct & Nov & Dic & Ene & Feb & Mar & Abr & Total \\
\hline 25.499 & 17.839 & 16.399 & 19.756 & 19.194 & 35.922 & 36.149 & 22.462 & 26.609 & 28.207 & 39.028 & 32.042 & 319.106 \\
\hline
\end{tabular}

Gráfico 3: Procedencia Salidas Temporada 2018/2019

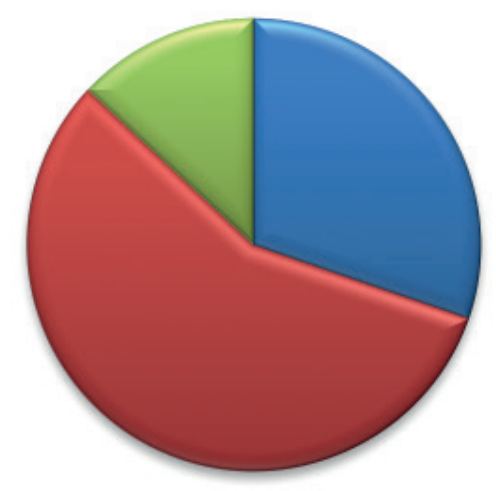

$\%$ local

$\%$ visitante

\% longstay

Fuente: Elaboración propia

Teniendo en cuenta las salidas del cliente visitante y el cliente longstay en la temporada 2019, podemos afirmar que han llegado a Almería aproximadamente 54.728 jugadores de golf que se han repartido por los 8 campos de la provincia, siendo los países de mayor procedencia, Reino Unido, Austria, Alemania, Bélgica y Países Nórdicos.

Gráfico 4: Numero de salidas temporada 2018/2019

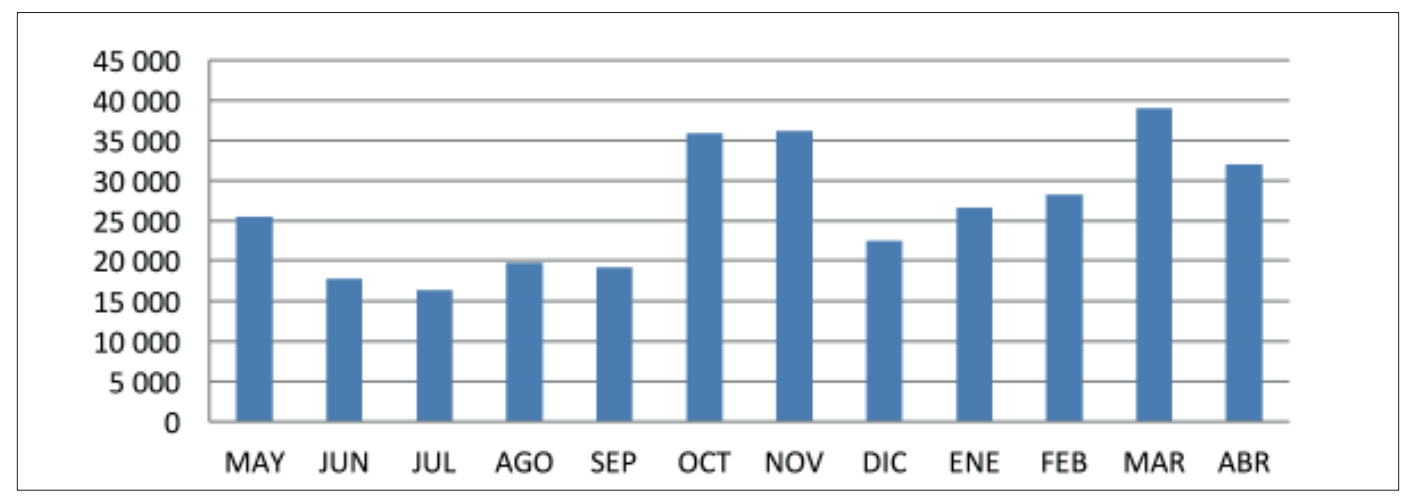

Fuente: Elaboración propia 
Si observamos los datos por meses, gráfico 2 y 4, vemos que la máxima ocupación se produce en los meses de octubre/noviembre y febrero/marzo/abril, coincidiendo con los meses de menor ocupación turística tradicional, lo que convierte al turismo de golf en Almería en una actividad complementaria al turismo de sol y playa, permitiendo que la planta turística permanezca abierta todo el año. Son los ingresos indirectos que genera este turismo en los meses de baja ocupación para la mayoría de la oferta turística, ingresos en el sector del transporte, hostelería, restauración y ocio en general.

La ventaja del turismo de golf es su capacidad desestacionalizadora, ya que el turista de golf viaja en temporada baja para el resto de la industria turística (Ortega, 1992).

Los gestores de las instalaciones señalan que el clima de la provincia de Almería, con temperaturas adecuadas para practicar este deporte en los meses de otoño e invierno, es el valor añadido para el turista de golf procedente de Europa que no puede jugar durante estos meses en su país de origen. Según los datos mostrados, podemos considerar que el turismo de golf es, además de necesario, estratégico para el sector turístico en la provincia de Almería, ya que dinamiza la economía de las zonas litorales de la provincia en los meses de baja ocupación.

\section{Perfil del turista de golf:}

De la información recogida de los responsables de las instalaciones, en contacto continuo con los clientes, se señalan las características de los tres tipos de cliente de golf que recibe la provincia de Almería.

Cliente local: es el cliente que reside en la provincia y juega habitualmente durante todo el año en el mismo campo de golf, elegido en la mayoría de los casos por cercanía a su residencia. Representa alrededor del $30 \%$ de las salidas anuales de todos los campos. Es un cliente asiduo que juega todas las semanas y hace uso con regularidad de todas las instalaciones anexas al campo de golf, como el campo de prácticas, la escuela de golf, la tienda de material de golf y la cafetería-restaurante del campo donde suele jugar. Habitualmente participa en los eventos deportivos como competiciones organizadas en su campo o en los campos cercanos.

Según el artículo que publica la Federación Española de Golf el 9 de enero de 2019 en su web en la sección de noticias, en Almería a 1 de enero de 2019 había 3.036 jugadores federados, siendo la tercera provincia con mayor ratio de jugadores/población de Andalucía y la única junto con Málaga donde se ha producido un aumento del número de jugadores federados con respecto al pasado año (RFEG, 2019).

Cliente visitante: representa casi el $57 \%$ de las salidas de todos los campos de golf de la provincia. El cliente visitante engloba:

- residentes en España

- turista vacacional

- turista de golf

El residente en España, es el jugador procedente de Europa, que reside en Almería o en provincias cercanas, como el litoral de Málaga, Murcia o Alicante. Generalmente forman asociaciones deportivas sin ánimo de lucro, las llamadas Golf Society para obtener mejores condiciones de juego en los campos de golf. Suelen jugar en grupo organizando competiciones a lo largo de todo el año en todos los campos de la provincia. También se incluye aquí el turista de golf nacional que aprovecha los fines de semana o días festivos del otoño e invierno para salir de su lugar de residencia y jugar en campos de golf de la zona sur de España. Almería está entre esas zonas visitadas con el único motivo de jugar al golf.

Turista vacacional: es el turista que viene de vacaciones a las zonas litorales de Almería en los meses de primavera y verano, cuando no trabaja la tour operación de golf. Su motivo del viaje no es jugar al golf. Viaja en familia o con amigos por ocio, recreo o diversión y si es jugador, visita al menos un campo de la provincia durante su estancia.

El número de salidas del turismo vacacional, principalmente las que se producen en el mes de agosto, ha experimentado un incremento progresivo en los últimos años y se estima que seguirá en alza una vez que se mejoren infraestructuras en general y oferta complementaria, que es lo que más valora este tipo de cliente. Este turista viaja atraído por el sol y playa, gastronomía, turismo deportivo, rural o urbano, lo que permite establecer sinergias entre todas las actividades que conforman la oferta turística en Almería, aumentando la capacidad de ofrecer al que visita la provincia un amplio abanico de posibilidades que hagan de su experiencia un motivo para volver a visitar y recomendar el destino Almería. 
Turista de golf: es el cliente visitante internacional cuyo único motivo del viaje es jugar al golf. Dentro de los clientes visitantes es la partida más importante por ser la más numerosa y la que no ha dejado de crecer en los últimos años. Representa el $87 \%$ de las salidas de los clientes visitantes. El turista de golf viene sólo los meses de otoño e invierno, cuando no pueden practicar este deporte en sus países de origen. Procede del norte y centro de Europa, principalmente de Reino Unido, Bélgica, Irlanda, Alemania, Austria y Países Nórdicos. Aunque la motivación para este tipo de turismo es la oferta de golf, también valora la cercanía a la costa, las infraestructuras de acceso, la seguridad del destino y la oferta complementaria, en especial la gastronómica.

Es un cliente que viene a través de la tour operación, la estancia media es de 6 días y suele viajar con amigos o en pareja. Se alojada en los hoteles cercanos a los campos o en los resorts de los que forma parte el campo de golf y la media de edad de este cliente es de 55 años.

Cliente Longstay: es el turista de golf procedente de los Países Nórdicos, cuya estancia en el destino es superior a 21 días. Representa el $13 \%$ de las salidas anuales. Es un cliente fiel al destino, en edad de jubilación, que realiza todos los años un viaje internacional para jugar al golf, recomendando el destino cuando llegan a su país de origen. Entre las características de este cliente se encuentran que viaja en pareja, se aloja en apartamento turístico a pie del campo de golf en el que juega durante toda su estancia, conoce el destino por experiencia propia, y la estancia media de este cliente es de 25 días, jugando una media de 19 veces. Suelen volver con amigos que también viajan en pareja, es decir, es un tipo de cliente con el que funciona el boca-oreja.

Valora principalmente el clima, poder jugar todos los días de su estancia, la oferta gastronómica y la cultural. Los gestores de los campos hacen referencia al aumento que se está produciendo en la duración de la estancia" En los dos últimos años entre un 15-20\% de las parejas están ampliando el periodo de estancia a 6 semanas para la siguiente temporada y la gran mayoría hacen su reserva antes de marcharse a su país de origen."

La información recogida muestra que existe un cliente procedente de Europa que llega a Almería con el único motivo de jugar al golf. Como hemos podido observar, además de las condiciones climatológicas idóneas y las instalaciones de golf, también valora la seguridad del destino España, las conexiones e infraestructuras y la oferta complementaria, especialmente la gastronómica.

\section{Mercado europeo de jugadores}

Según el informe estadístico elaborado en octubre de 2018 por KPMG, en Europa a final de 2017 había un total de 4.142.390 jugadores de golf, estando más del 50\% del mercado europeo de jugadores de golf concentrado en los siguientes cinco países: Inglaterra, Alemania, Suecia, Francia y Países Bajos. El primer lugar en número de jugadores lo ocupa Inglaterra, país de larga tradición golfística, sigue siendo el que más jugadores de golf aporta, el 15,83 \% del total de jugadores europeos, lo que supone 655.839 jugadores. Le sigue muy de cerca Alemania que en los últimos 10 años ha experimentado un rápido crecimiento, aportando al mercado el $15,57 \%$ de jugadores. Suecia es el país que más crecimiento de jugadores ha experimentado con respecto al año anterior y ha aportado el 11,31\% de jugadores europeos al mercado. Completan el 61,97 \% del mercado los países de Francia y Paises Bajos, con el $9,90 \%$ y el $9,36 \%$ de jugadores europeos respectivamente (KPMG, 2018).

Uno de los últimos estudios sobre turismo de golf en España, constata que la mitad de los viajes de golf realizados por ingleses y suecos son de carácter internacional y en Alemania, el 90\% de los destinos elegidos por los jugadores de golf se encuentran en el extranjero. En este escenario España se configura como el principal destino de golf en el extranjero de los turistas británicos, alemanes, y suecos, siendo el segundo destino elegido por los franceses, después de Marruecos (Gabinete de Estudios de la Cámara Oficial de Comercio, Industria, Servicios y Navegación de Alicante, 2016)

Del análisis del mercado europeo de jugadores se desprende que el gran número de jugadores que poseen países como Inglaterra o Alemania unido a la gran popularidad de este deporte en los países de la zona norte y centro de Europa, es el motivo para que estos países se hayan convertido en emisores de jugadores en la temporada de otoño e invierno cuando sus campos de golf están cerrados.

Los países del sur de Europa y de la cuenca mediterránea son los receptores de estos jugadores. La razón principal para elegir los destinos del sur durante el otoño e invierno es la búsqueda de condiciones climatológicas idóneas para poder jugar al golf y de una oferta de campos variada. Entre estos países receptores del turismo de golf, se encuentra España, como uno de los principales países que recibe 
a jugadores procedentes de Europa durante la temporada que va desde octubre hasta abril (Centro Euromediterráneo de conocimiento, innovación y formación turística, 2007)

En este sentido, cuando se visita el portal de Turismo de España, puede verse entre sus publicaciones que España es líder del turismo europeo de golf. La noticia, consultada en mayo de 2019, relata que cada año miles de personas lo eligen para practicar este deporte. (Portal Oficial de Turismo de España, 2019).

El destino principal dentro de este país es Andalucía, que fue elegida como destino europeo de golf del año en los Premios 2017 que concede la Asociación Internacional de Operadores de Golf (IAGTO). ${ }^{5}$ Con más de cien campos de golf, Andalucía es la número uno en instalaciones, en servicios y en la promoción y comercialización del golf (web oficial de turismo de Andalucía, 2018).

Andalucía se ha convertido en la Comunidad Autónoma de España líder en la recepción de este tipo de turistas, con el consiguiente aumento del número de campos de golf (Riquel y Vargas, 2012).

Así, actualmente el segmento del golf es uno de los más competitivos y de mayor impacto para la industria turística andaluza contribuyendo de manera muy significativa a romper la estacionalidad en el litoral andaluz, al mantener el sector hotelero abierto durante todo el año, siendo Andalucía un área receptora del mercado europeo, donde es imposible practicar este deporte durante los meses de otoño e invierno. Destaca en el destino Andalucía la provincia de Málaga, cuyo litoral junto con el gaditano Campo de Gibraltar conforma la famosa Costa del Sol, conocida en Europa como el destino Costa del Golf que cuenta actualmente con más de 70 campos de golf y ha conseguido una especialización turística en este segmento. Si bien, en los últimos años ha crecido el interés por otros destinos como Canarias, Comunidad Valenciana y Cataluña (Reyes Bazán, 2016).

A modo de reflexión, en Almería, al igual que sucede en la Costa del Sol o la Costa del Golf, la marca del destino, el sector del golf puede ser un importante elemento dinamizador del turismo que ofrece la provincia, ya que rompe la estacionalidad tan característica de este sector, cualifica la oferta turística y diversifica la actividad económica.

\section{Almeria un destino de golf}

Hasta hace unos años, el éxito de Almería como destino turístico descansaba fundamentalmente en el segmento tradicional de sol y playa, sin embargo, en los últimos años se asiste a una intensificación de la segmentación del mercado turístico, de forma que están surgiendo nuevos cauces de crecimiento del turismo frente al tradicional de sol y playa, que pueden ser aprovechados en la provincia. Entre estos nuevos segmentos turísticos se encuentra el turismo de golf (Aznar Sánchez, 2003).

Según los expertos en turismo, la capacidad de un área turística para ser un destino de golf depende de tener un mínimo de campos de golf que no estén a mucha distancia entre sí, que compongan una variada oferta con tarifas adecuadas a la tipología del campo, con infraestructuras, conexiones y otros atractivos que complementen la oferta de golf, además de unas condiciones climáticas que aseguren la práctica de este deporte durante todo el año (Centro Euromediterráneo de conocimiento, innovación y formación turística, 2007)

En virtud de todo lo expuesto anteriormente, podemos afirmar que Almería reúne las condiciones para ser un destino de golf. La oferta compuesta por ocho campos de golf, con proximidad y buena conexión por carretera entre ellos, unido a las condiciones climáticas de la provincia, con muchas horas de sol durante todo el año, permite que los jugadores de golf que llegan a Almería puedan disfrutar durante su estancia de diferentes experiencias de juego en diversos entornos, bien con vistas al mar o rodeados por montañas.

Sin embargo, del análisis del sector, se desprende que Almería como destino turístico de golf no es aún un destino consolidado, es un destino débil frente a otros cercanos como Costa del Sol, Costa Blanca o la región de Murcia. En definitiva un destino aún en vías de desarrollo.

Con la información recogida y los datos analizados, hemos profundizado en el análisis de las fortalezas y las debilidades de Almería como destino para la práctica de este deporte frente a otros ya consolidados.

Actualmente las fortalezas son principalmente, el clima y el precio. Almería es un destino más económico que los destinos cercanos como la Costa del Sol (RFAG, 2019) o la Costa Blanca (ACGCB, 2019). En la provincia el precio medio del green fee ${ }^{6}$ para el cliente visitante extranjero es entre un $25 \%$ y un $30 \%$ menos costoso que en los destinos de golf cercanos. En referencia al clima, Almería es una de las provincias de Europa con más horas de sol, lo que garantiza el juego durante prácticamente toda la estancia del cliente. 
El otro punto fuerte es que es un destino en pleno desarrollo, con una alta capacidad de adaptación a la demanda del cliente, frente a otros destinos ya consolidados con estructuras productivas más rígidas y con menos flexibilidad frente al mercado turístico continuamente cambiante.

Con respecto a las debilidades, cabe considerar como la más importante la deficitaria red de infraestructuras en general, que impide el acceso a la provincia en condiciones óptimas. El aeropuerto cuenta con un número muy reducido de vuelos internacionales y una escasa conexión con los países emisores del turismo de golf. En el año 2018 Almería ha sido el único aeropuerto de Andalucía que ha perdido pasajeros, quedándose por debajo del millón, concretamente 992.043 pasajeros lo que supone una caída con respecto al año anterior de 1,5\%. Actualmente, en la temporada de golf, los únicos vuelos directos con Europa existentes son con Bruselas, Dússeldorf y Londres (web oficial aeropuerto de Almería, AENA, 2019)

Los responsables de los campos de golf resaltan que la mayoría del turismo que reciben procedente de Irlanda, Austria o Países Nórdicos, llega a la provincia a través del aeropuerto de Málaga o Alicante, lo que hace que sea más fácil para el cliente elegir el destino Costa Blanca o Costa del Sol que posee un aeropuerto internacional y donde hay más de 70 campos con una amplia oferta complementaria.

Otra cuestión a mejorar es la oferta complementaria cercana a los campos de golf durante los meses de otoño e invierno, ya que la mayoría del sector hotelero y de restauración situados fuera del entorno de la ciudad, cierran sus puertas una vez finalizada la temporada de verano. Cabe destacar que para el jugador de golf es importante la infraestructura en general, demandando mejores conexiones dentro de la provincia y con las provincias limítrofes. Esta mejora se proyecta como un aspecto que facilitaría el desarrollo de actividades complementarias como la restauración, las visitas culturales e históricas, las fiestas tradicionales, los centros comerciales y de ocio, el turismo de aventura o de salud e incluso el traslado a otras provincias cercanas para visitar monumentos, museos o zonas con valor histórico y cultural.

La aproximación a la realidad muestra también la necesidad de cualificación de los recursos humanos que requiere el sector turístico en general y más específicamente el del golf. Es necesario dar respuesta a la incipiente demanda de profesionales provocada con la especialización de la oferta a medida que se produce el desarrollo en el sector.

Los principales implicados en el sector señalan que es necesario mejorar en general la percepción social del golf en la provincia para poder apostar por un turismo sostenible y consolidar Almería como un destino de golf.

"La sociedad en general debe ser consciente que esta actividad aporta valor a la economía de la provincia, rompiendo la estacionalidad del sector turístico. Además es un deporte saludable, accesible a personas de distinto poder adquisitivo y de cualquier edad, siendo una actividad controlada y respetuosa con el medio ambiente".

Por último, los datos analizados indican la falta de apoyo al destino Almería de la administración pública en general. En el sector turístico, por delante de las administraciones, siempre han ido los empresarios del sector, y en el caso de Almería, esta afirmación es aún más cierta (Fernández-Revueltas, 2005). Teniendo en cuenta el apoyo institucional en otros destinos como la Costa del Sol, Canarias o Baleares donde las administraciones públicas se implican y dedican una parte de sus recursos a la promoción exterior, se muestra que la provincia de Almería va con retraso en este aspecto, aunque hemos podido comprobar que en los últimos años esta tendencia está cambiando, y ya existen acciones por parte del Servicio Provincial de Turismo de la Diputación de Almería promocionando el turismo de sol y playa con la marca Costa de Almería. Este turismo de sol y playa conlleva una alta estacionalidad, concentrando las pernoctaciones en los meses de junio a septiembre. Así, Almería ha conseguido una mayor conexión área con Europa en los meses estivales (AENA, 2018), sin embargo, a modo de discusión nos preguntamos qué sucede con el sector turístico el resto del año y qué sucede con el turismo que no es Sol y Playa.

Desde la visión global del turismo de golf en Almería obtenida con este estudio consideramos que hay una gran labor a realizar por parte de todos los agentes públicos por el sector turístico en Almería. 


\section{Asociación de campos de golf de almería}

Los datos analizados justifican el beneficio para la provincia de consolidar el destino, siendo vital unir esfuerzos de todas las empresas involucradas en el sector del golf en Almería. Los responsables de los campos de golf manifiestan que desde hace varios años son conscientes de la necesidad de crear una asociación de campos de golf que ayude a situar el destino Almería como uno de los principales destinos en Europa para la práctica del golf y en uno de los ejes de la industria turística de la provincia. La experiencia en otras zonas con el mismo denominador común es muy positiva, como por ejemplo la asociación de campos de golf de la Costa Blanca.

En efecto, el estudio del sector muestra que la consolidación del destino Almería requiere dar una respuesta conjunta y adecuada a diferentes aspectos, como formar profesionales en el sector, mejorar la cantidad y calidad de la oferta complementaria durante los meses de otoño e invierno, concienciar sobre lo que representa el sector para el desarrollo de la provincia, realizar una comercialización conjunta y conseguir el apoyo institucional para llevar a cabo una acción promocional de la imagen global que se proyecta en los destinos internacionales de la oferta de golf en Almería.

La asociación de campos de golf de Almería (ACGA) nace en 2019, con el objetivo de consolidar Almería como un destino turístico de golf. Entre las acciones a llevar a cabo se encuentran la de promocionar y transmitir las ventajas competitivas que tiene la provincia, desarrollar y potenciar una cultura colaborativa en la oferta de instalaciones para proyectar una imagen unificada y fuerte de Almería como destino de golf en Europa, promover iniciativas de colaboración con el resto del sector turístico para crear una oferta conjunta con restauración, alojamiento, transporte, cultura, ocio, etc. Asimismo, conseguir el apoyo institucional para llevar a cabo un plan de promoción exterior que incluya a toda la industria turística, para mejorar las conexiones e infraestructuras de acceso a la provincia, y en definitiva para facilitar y apoyar la actividad turística en la provincia de Almería.

\section{Conclusiones}

Con el acercamiento a la realidad del turismo de golf en Almería y fruto del estudio de las diferentes consideraciones recogidas de cada uno de los actores involucrados en el sector, extraemos las siguientes conclusiones.

Se ha mostrado que existe un mercado europeo de jugadores, en el que España se ha posicionado como uno de los principales países receptores, destacando Andalucía como principal destino elegido por los países del centro y norte de Europa, para jugar al golf durante el otoño e invierno.

La razón principal para elegir los destinos del sur es la búsqueda de condiciones climatológicas idóneas para practicar este deporte y una oferta de campos variada. Este turismo de golf consigue romper la estacionalidad que satura los destinos turísticos los meses de verano y los deja vacíos durante el otoño e invierno, dinamizando todo el sector turístico, consiguiendo que permanezca activo durante todo el año (Babinger, 2012).

En el conjunto del destino Andalucía se encuentra la provincia de Almería que con una oferta de ocho campos de golf, es un destino de turismo de golf en pleno desarrollo. Las cifras analizadas muestran que en los meses de octubre/noviembre y febrero/marzo/abril se produce el aumento de salidas en los campos de golf de jugadores procedentes principalmente de Reino Unido, Bélgica, Irlanda, Alemania, Austria y Países Nórdicos, dinamizando el sector turístico de la provincia en la tradicional temporada baja, gracias al valor añadido del turismo de golf, su capacidad desestacionalizadora.

Los datos obtenidos manifiestan el crecimiento y por tanto la importancia que este subsector turístico está adquiriendo en Almería, por lo que entendemos que se hace necesario una atención especial y una profundización en el conocimiento de todos aquellos aspectos más relevantes que inciden directamente o indirectamente en su desarrollo.

Entre estos aspectos cabe destacar la necesidad de mejorar las conexiones e infraestructuras, la cantidad y calidad de la oferta complementaria durante los meses de otoño e invierno, la cualificación de los recursos humanos y el cambio en la percepción social negativa del golf, demostrando con datos que puede ser un turismo generador de riqueza en la provincia.

En este proceso de desarrollo del turismo de golf, la recién estrenada ACGA nace con el objetivo de consolidar Almería como destino de golf, impulsando la comercialización conjunta de la oferta, la imagen global que se proyecta en Europa y creando sinergias con el resto del sector turístico para conseguir 
que Almería como provincia sea capaz de crear una oferta turística en conjunto más novedosa y de más calidad, acorde a las necesidades del turista de hoy, atendiendo a un mercado cada vez más exigente.

Hoy es necesario tener en cuenta una demanda informada, exigente y cambiante para la cual temas como calidad, sostenibilidad y competitividad, forman parte de los criterios para elegir destino (Canales Ronda y Hernández Fernández, 2019).

Considerando todo lo expuesto anteriormente se indica que el desarrollo de este turismo debe hacerse desde el punto de vista de la sostenibilidad.

En este sentido, The Royal and Ancient, organismo cuyos estudios y directrices son de utilidad para las federaciones y clubes de golf de todo el mundo, define la sostenibilidad de los campos de golf como "Optimizar la calidad del campo de golf en armonía con la conservación de su entorno natural bajo gestión económicamente acertada y socialmente responsable" (The Royal \& Ancient Golf Club de St.Andrews R\&A, 2017). Y la organización mundial de turismo define el concepto de desarrollo sostenible del turismo como "El turismo que tiene plenamente en cuenta las repercusiones actuales y futuras, económicas, sociales y medioambientales para satisfacer las necesidades de los visitantes, de la industria, del entorno y de las comunidades anfitrionas" (UNWTO, 2019)

En consecuencia y desde el análisis realizado, se expresa la conveniencia de establecer las claves para un desarrollo sostenible del turismo de golf en la provincia que ayude a situar el destino Almería como uno de los principales destinos en Europa para la práctica de este deporte y en uno de los ejes de la industria turística, a través de estrategias a medio y largo plazo de desarrollo sostenible, realizando una correcta planificación (Rodriguez, 2009), apoyándose en la idea de que el turismo de golf es un gran motor de desarrollo, de creación de riqueza, bienestar y empleo y en la necesidad de preservar el entorno medioambiental, paisajístico, cultural y social. En definitiva el desarrollo turístico en clave de sostenibilidad.

La consideración de la dimensión territorial y medioambiental, es determinante para garantizar la competitividad del destino (Espejo Marín, 2004)

Por último, por los datos aquí presentados, se expresa la importancia de prestar mayor atención por parte de los agentes públicos al turismo de golf, valorando la capacidad desestacionalizadora de este sector y por tanto el valor añadido a la industria turística de la provincia. Se considera indispensable un esfuerzo por parte de la Consejería de Turismo y Deportes, la Diputación Provincial, Ayuntamientos y Universidad, implicándose en la labor de concienciación positiva de este turismo, en la mejora de infraestructuras, accesos, señalización y en la promoción del destino entendiéndolo como una inversión que a largo plazo origina beneficios en el sector turístico y el desarrollo de la provincia.

Del análisis del sector constatamos que Almería cuenta con una completa oferta de campos de golf, capaz de hacer sentir al visitante diferentes experiencias, una gran variedad de establecimientos hosteleros, empresas turísticas de diversa índole, una adecuada oferta gastronómica, y un clima para practicar este deporte al aire libre los 365 días del año. En definitiva Almería reúne las condiciones para ser uno de los principales destinos de golf en Europa.

\section{Bibliografía}

Asociación de Campos de Golf de la Costa Blanca y Comunidad Valenciana (ACGCB). (2019). https:// www.golfcostablanca.org/noticias/ (acceso 22/01/2019)

Aznar Sánchez, J.A. (2003). Análisis estructural del sector turístico en Almería. Cuadernos de Turismo,11,16-17.

Babinger, F. (2012). El golf en España: la concentración social y territorial de un fenómeno que trasciende ampliamente lo deportivo. Ería, 88, 185-197.

Canales Ronda P. y Hernández Fernández A. (2019). La actividad comercial en las empresas turísticas. Cuadernos de Turismo, 43, 249-269.

Centro Euromediterráneo de conocimiento, innovación y formación turística. (2007). El producto turístico del golf en los países del mediterráneo.

Espejo Marín, C. (2004). Campos de golf y medio ambiente, una interacción necesaria. Cuadernos de turismo, 14, 67-112

Fernández-Revueltas Pérez, L. (2005). 25 Años de "Costa de Almería” y ¿ahora qué? En J.Molina (Ed.), La Economía de la provincia de Almería (pp.365-412). Almería, España: Caja Rural Intermediterránea Cajamar

Ferreres Bonfil, JB. (2014). Turismo de Golf. En G. Sánchez (Ed.) 20 Años de la actividad turística en España. Barcelona, España: AECIT 
Gabinete de Estudios de la Cámara Oficial de Comercio, Industria, Servicios y Navegación de Alicante. (2016). Impacto económico del sector del golf en la provincia de Alicante.

García Lorca, A.M. (2007). Reflexiones sobre el modelo de turismo de golf en un litoral árido: Almería. Paralelo 37, 19, 209-224

KPMG The European Golf Course Owners Association. (2018). Golf Participation Report for Europe. https://assets.kpmg/content/dam/kpmg/xx/pdf/2018/11/golf-participation-report-for-europe-2018.pdf (Acceso el 10/07/2019)

Organización Mundial de Turismo (UNWTO) (2018). https://www.unwto.org/es/desarrollo-sostenible (acceso 29 de marzo de 2018) Ortega Martínez, E. 1992: La economía del golf: su evolución en el mundo y en España. Estudios turísticos, 144, 19-40

Portal Oficial de Turismo de España. (2019). https://www.spain.info/es/que-quieres/deportes/golf/ (acceso el 16/05/2019)

Real Federación Española de golf (R.F.E.G.) (2019). http://www.rfegolf.es/Noticias/NewsDetails. aspx?NewsId=9623 (acceso 24/05/2019).

The Royal \& Ancient Golf Club de St.Andrews ( R\&A). (2017). http://clubmanagerspain.com/reportajes/ clubes-deportivos-y-medioambiente/151-st-andrews-y-el-golf-sostenible.html (acceso 27/2/2018)

Reyes Bazán. (2016). El campo de golf como instrumento de regeneración y protección

del medio ambiente. En F. Bombillar (Ed.), Diferentes perspectivas del derecho deportivo en Andalucía, libro homenaje al profesor Rafael Barranco Vela (pp 47-59). España: Comares

Riquel Ligero, F.J y Vargas Sánchez, A. (2012). Legitimidad social versus desempeño en

las políticas de responsabilidad social mediambiental de los campos de golf andaluces. Visión de Futuro Año 9,16 (2).

Rodríguez Vaquero, J. (2009). Turismo urbano y sistema territorial Almería, modelo emergente. Nimbus, 23-24, 171-181

Serrano Gómez,V. (2013). Evolución de la práctica del golf, características y dimensión económica. Revista española de educación física y deportes, 403,63-80

Web Oficial Aeropuerto de Almería. (2018). http://aena.mobi/m/es/aeropuerto-almeria/almeria.html (acceso 30/04/2019)

Web Oficial Aeropuerto de Almería. (2019). http://www.aena.es/csee/Satellite?c=Page\&cid=111358247 6711\&pagename=Estadisticas\%2FEstadisticas (acceso 22/09/2019)

Web oficial de turismo de Andalucía. (2018). https://www.andalucia.org/es/andalucia-destino-europeo-de-golf-del-ano (acceso 13/2/2018)

\section{Notas}

1 Real Federación Española de Golf (RFEG), es el organismo máximo responsable a nivel del estado español para la práctica del deporte del golf. Es obligatorio que se federen en este organismo todos los clubes de Golf y los jugadores que practican este deporte.

2 Real Federación Andaluza de Golf (RFAG), es la Federación Autonómica, organismo colaborador de la Real Federación Española de Golf responsable de la práctica del deporte de golf dentro de la Autonomía de Andalucía.

3 La Organización Mundial del Turismo (UNWTO) es el organismo especializado de las Naciones Unidas encargado de la promoción de un turismo responsable, sostenible y accesible para todos.

4 The Royal \& Ancient (R\&A) es el organismo que regula las Reglas del Golf en el mundo junto a la United States Golf Association (USGA). Los estudios y directrices del R\&A, ubicada en St. Andrews, Escocia, son de utilidad para las federaciones y clubes de golf de todo el mundo. Ambos organismos comparten la gobernanza del golf en el mundo. Cada organización tiene su propia jurisdicción, la USGA gobierna en Estados Unidos y México y el R\&A en el resto del mundo. La jurisdicción del R\&A abarca 143 organizaciones de golf amateurs y profesionales, regulando el juego de más de 30 millones de jugadores en más de 126 países.

5 La IAGTO es la Asociación Internacional de Operadores de Golf que cuenta en la actualidad con más de 650 tour operadores especializados en el segmento golf, procedentes de 61 países, que controlan la comercialización de aproximadamente el $87 \%$ de los paquetes vacacionales de golf del mundo.

6 Green fee: es el precio estipulado por los campos de golf para poder jugar en ellos. El mismo puede variar según el día de la semana, hora, nivel, y si el jugador es miembro o no del club (Serrano, 2013)

Recibido:

$30 / 11 / 2019$

Reenviado:

$07 / 06 / 2020$

Aceptado:

$28 / 07 / 2020$

Sometido a evaluación por pares anónimos 


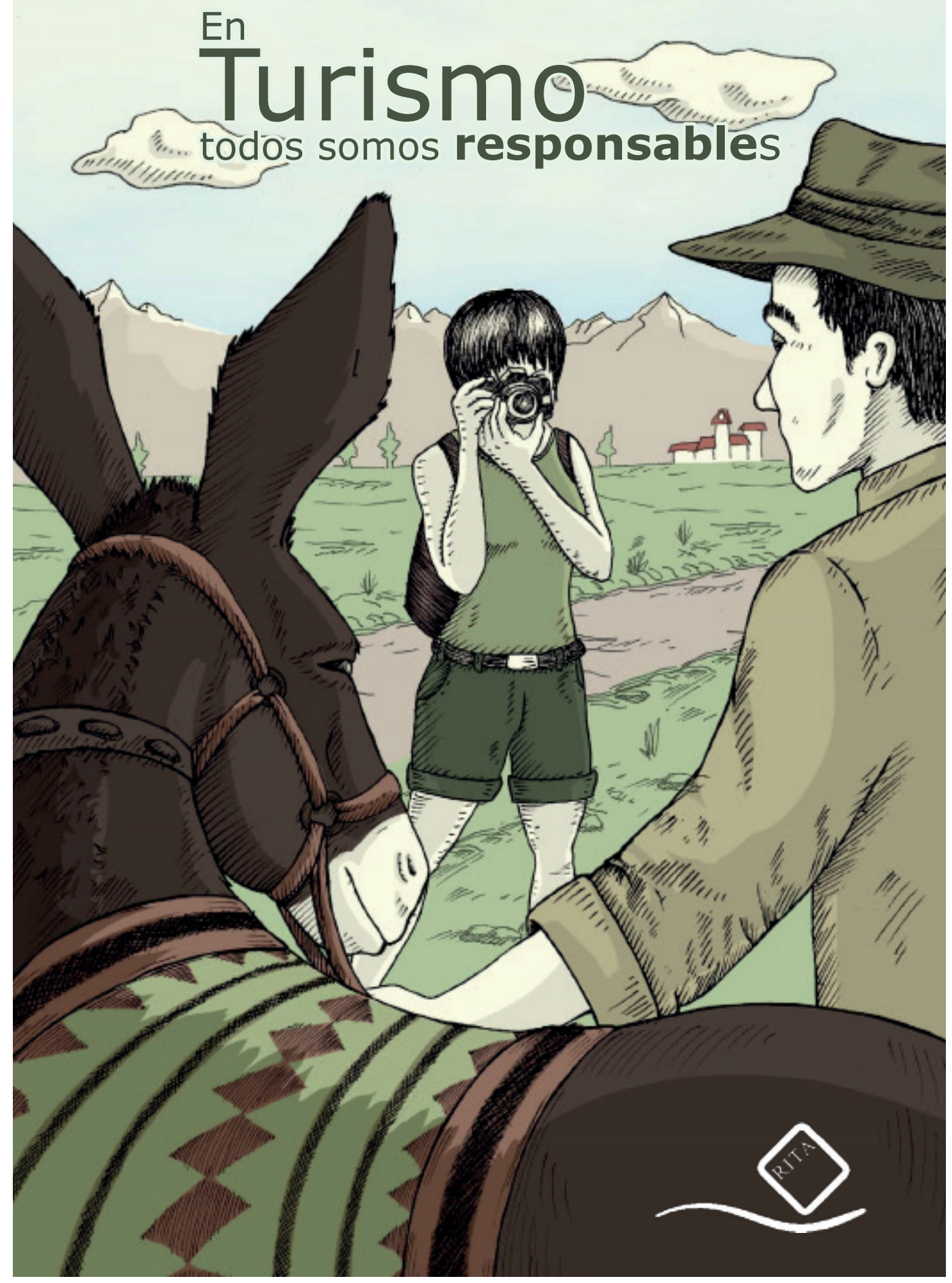




\title{
El parque del Buen Retiro de Madrid: valor patrimonial y uso ciudadano y turístico
}

\author{
María Pilar Palomar Anguas* \\ Universidad Rey Juan Carlos (España)
}

\author{
Daya Morales Jaime**
}

Investigadora independiente

\begin{abstract}
Resumen: Tras la exposición de los objetivos y metodología, se realiza un comentario sobre la preservación del patrimonio en España, en particular de El Retiro, así como de la reciente presentación de la candidatura "Paseo del Prado y el Retiro. Paisaje de las Artes y las Ciencias" a la lista del Patrimonio Mundial de la UNESCO. La evolución de El Retiro ha ido de la mano de su desarrollo como Real Sitio. La descripción de su patrimonio permite conocer detalles de su historia hasta la actualidad, que ha configurado un magnífico entorno de gran exotismo en el corazón de Madrid. El análisis de los recursos y de la actividad turística y cultural que soporta, junto con los resultados de una encuesta realizada a los visitantes, evidencian su gran aceptación por parte de residentes y turistas; también la existencia de problemas en la gestión e información dirigida al público, que respectivamente repercuten en el mantenimiento y aprovechamiento de este espacio singular.
\end{abstract}

Palabras Clave: Parque de El Retiro; Patrimonio Mundial; Jardín Histórico; Bien de Interés Cultural (BIC); Turismo.

\section{The Buen Retiro Park in Madrid: heritage value and citizen and tourist use}

Abstract: After outlining the objectives, methodology and making brief allusion to concepts and laws in relation to the preservation of heritage in Spain, and the recent presentation of the candidacy "Paseo del Prado $y$ el Retiro. Landscape of the Arts and Sciences" to the UNESCO World Heritage list, the article goes on to give a brief historical description of the evolution of the Retiro Park, since its origins, as a highly exotic Royalty Site in the heart of Madrid. An analysis of the park'sresources and the tourist and cultural activity offered in El Retiro is given together with the results of a survey carried out among visitors, showing the great acceptance of the site by residents and tourists alike but also highlighting the existence of certain management and information problems iwhich respectively affect the maintenance and use of this unique space.

Keywords: El Retiro Park; World Heritage; Historical Garden; Cultural Interest Asset (BIC); Tourism.

\section{Introducción. Objetivos, metodología y contexto.}

Este trabajo tiene, entre otros objetivos, ilustrar sobre el patrimonio cultural y la larga historia del Parque del Buen Retiro, para lo cual se detallan los bienes patrimoniales más importantes y se describe algunos de ellos, así como los momentos destacables de su larga historia. Para ello se ha realizado una revisión documental con la que se intenta trascender su valoración como mero parque de ocio de cara a la mayor parte de la ciudadanía y visitantes. Aunque dicha estimación no debe ser desdeñable, si es deseable un mayor conocimiento y disfrute de los bienes patrimoniales, en su momento creados por la corte para su disfrute exclusivo.

Tras la presentación de este patrimonio, el trabajo se dirige hacia otros objetivos como son: el análisis de la gestión y mantenimiento del parque; el nivel de conocimiento y valoración de la ciudadanía y otros

\footnotetext{
Universidad Rey Juan Carlos (España); Membro dos grupos de pesquisa TADAT (URJC) e GIGATU (PUCP); Email: pilar. palomar@urjc.es; https://orcid.org/0000-0003-1615-0858

** Investigadora independiente; E-mail: dayamoralesj@gmail.com; https://orcid.org/0000-0001-8146-7187
} 
visitantes del patrimonio natural y cultural del parque; el conocimiento de los recursos patrimoniales más atractivos para los usuarios y, por último, la delimitación de áreas del parque en función de los flujos de los visitantes para su uso turístico o de ocio ciudadano.

$\mathrm{El}$ análisis de la gestión y mantenimiento del parque se realiza gracias a la información aportada por la segunda de las coautoras, derivada de su propia experiencia de trabajo en el Palacio de Cristal, y de las entrevistas y encuestas realizadas a trabajadores ${ }^{1}$ del parque y a visitantes ${ }^{2}$, respectivamente. A lo anterior se añade la observación de campo de los flujos de visitantes.

Dichas entrevistas y la información documental permiten esbozar los problemas que ha de afrontar el mantenimiento del patrimonio, especialmente el natural. Por otro lado, y gracias a las encuestas a visitantes y al contacto directo con ellos, se ha podido evaluar su nivel de conocimiento del patrimonio y de los recursos turísticos disponibles, así como su valoración y uso real de los mismos.

La valoración del patrimonio por la sociedad y sus instituciones ha crecido a lo largo del siglo anterior, pese a los tremendos desastres sufridos por aquel con las dos guerras mundiales. Afortunadamente y finalizada la segunda de ellas la protección del patrimonio y de la cultura fue un deseo urgente que, en 1945, dio paso a la creación de la Organización de las Naciones Unidas para la Educación, la Ciencia y la Cultura (UNESCO) y, ya en 1972, a la Convención que establecía las pautas para dicha protección.

En España, pese a la tardía ratificación de dicha convención, en 1982, y la inscripción en 1984 de los primeros bienes en la lista del Patrimonio Mundial ${ }^{3}$, el interés por la salvaguardia del patrimonio, expresado en la legislación, se remonta a la primera mitad del siglo diecinueve (Palomar, 2019), como consecuencia de las desamortizaciones de José Bonaparte (1809) y de Mendizabal (1836). Posteriormente nuestro patrimonio ha pasado por numerosas vicisitudes físicas y legales, como fue la alternancia entre los gobiernos republicanos y las restauraciones monárquicas. No obstante, el parque de El Retiro, objetivo de este trabajo, ha permanecido como bien público ${ }^{4}$ desde 1868, gozando de protección desde $1935^{5}$, merced a su declaración como Jardín Histórico o Artístico en dicho año y a su calificación en $1985^{6}$ como Bien de Interés Cultural (BIC) en la categoría de Jardín Histórico.

Un hito importante en esta línea de pensamiento, ha sido la presentación de la Candidatura para formar parte de la lista del Patrimonio Mundial de la UNESCO de la totalidad del parque del Buen Retiro y su entorno museístico y monumental.

\section{La candidatura a la lista del Patrimonio Mundial de la UNESCO: "Paseo del Prado y el Retiro. Paisaje de las Artes y las Ciencias".}

El Parque de El Retiro ha sido promovido a la lista de Patrimonio Mundial de la UNESCO a través del Consejo de Patrimonio Histórico, que el pasado año presentó la candidatura: "Paseo del Prado y El Retiro. Paisaje de las Artes y las Ciencias"'. El proyecto involucra grupos, organizaciones, instituciones y comunidades a todos los niveles, buscando un carácter participativo e innovador. Entre ellas la Real Academia Española, la Bolsa de Comercio, el Palacio de Fomento (hoy Ministerio de Agricultura), el Cuartel General de la Armada y Museo Naval, la Iglesia de los Jerónimos y la Asociación de los Amigos del Buen Retiro. De igual manera, están integradas las tres administraciones ${ }^{8}$ y los partidos políticos con representación municipal.

La candidatura plantea el valor universal y excepcional de este bien patrimonial por la unión en el mismo entre naturaleza, cultura y ciencia. La UNESCO podrá considerar y valorar los extraordinarios elementos paisajísticos y arquitectónicos que han resultado de su evolución, desde su origen como Real Sitio y escenario del Siglo de Oro español, hasta su completa integración en el corazón del Madrid de hoy. Un reconocimiento que significaría una puesta en valor ante la comunidad internacional, una concienciación ciudadana de su importancia histórica, cultural y natural y, también una contribución a su conservación.

Los espacios incluidos en la candidatura (Fig. 1) comprenden el eje del Paseo del Prado y el barrio de los Jerónimos, con más de una veintena de edificios monumentales, algunos de los cuales albergan grandes pinacotecas. También fuentes y rotondas emblemáticas, como la Fuente de la Cibeles y la Puerta de Alcalá, en la Plaza de la Independencia, situándose en ésta la entrada principal de El Retiro, que se extiende hasta las inmediaciones de la estación de Atocha, una férrea y bella estructura también incluida en la candidatura. 
Figura 1: Recinto del espacio incluido en la Candidatura a la UNESCO

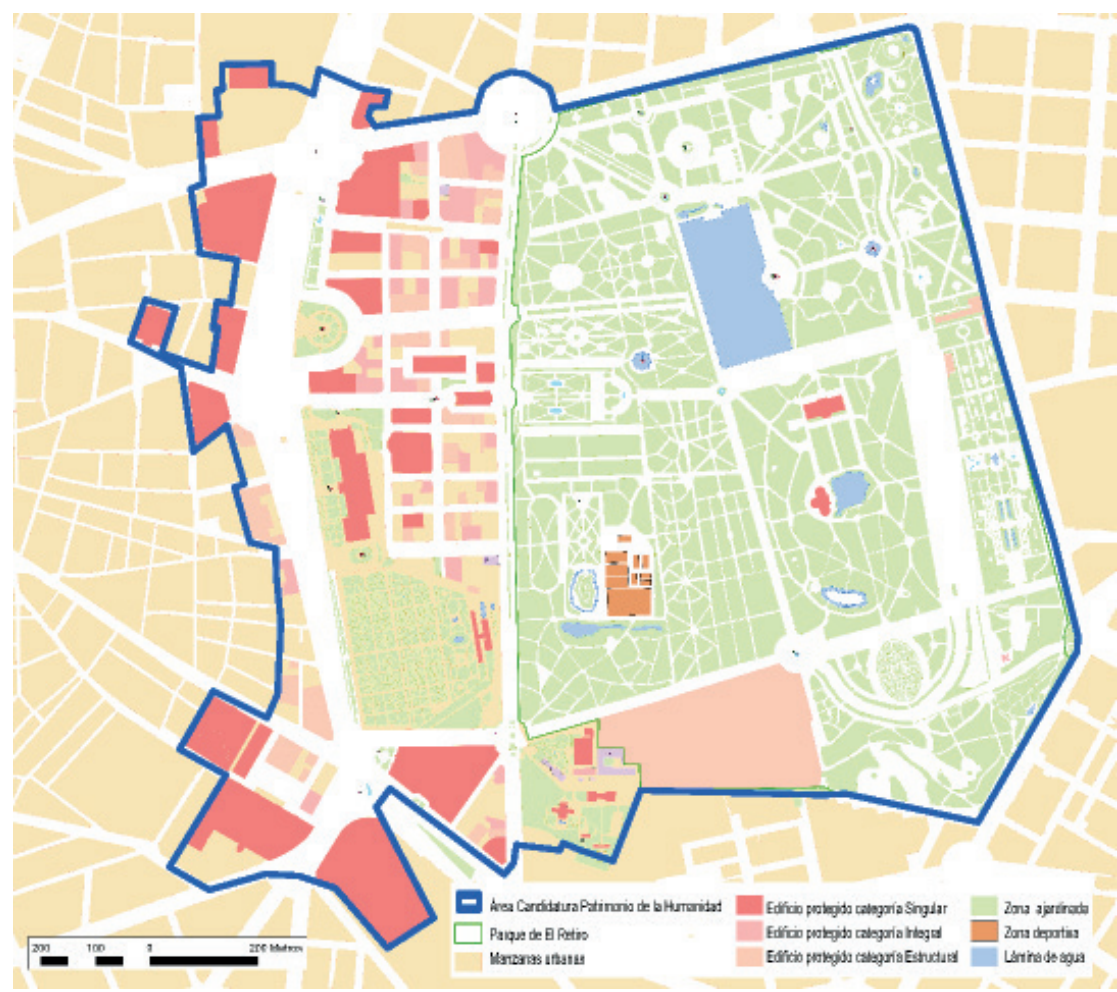

Fuente: Elaboración propia.

\section{El Retiro: Testigo de la historia de Madrid}

En su origen fue un espacio boscoso con recursos hídricos ${ }^{9}$, que propiciaron la reubicación en el mismo del Monasterio e Iglesia de los Jerónimos ${ }^{10}$. Este fue el germen del Real Sitio de El Retiro y de todas las edificaciones monumentales y obras de reforestación o de ajardinamiento - en especial realizadas en los siglos XVII y XVIII - que fueron ocupando la suave ladera situada al este del arroyo de la Castellana, del Prado o del Carcavón (Domínguez, 2019), que venía a ser el límite oriental del Madrid de los Austrias. En definitiva, la ubicación de El Retiro es una consecuencia del traslado de aquel monasterio y su reedificación en los primeros años del siglo XVI.

Junto al Monasterio, Felipe II ordenó la construcción del "cuarto real" o cuarto de San Jerónimo, que comprendía un número reducido de estancias utilizadas por la realeza como lugar de descanso o retiro ocasional, especialmente en Cuaresma; también como lugar de recepción de visitantes notables a la reciente capital que vino a ser Madrid.

En 1629, por iniciativa y con la tenacidad del Conde Duque de Olivares, Felipe IV inició el desarrollo de un vasto proyecto que culminó con la edificación del palacio en solo tres años (Fig. 2). Éste presentaba un cuerpo principal de estilo herreriano, con un gran patio central y torres en sus esquinas, similar al Monasterio de Escorial, pero en este caso con materiales menos duraderos (ladrillo y madera) y una ejecución muy apresurada. La austeridad y escasa vistosidad del edificio contrastaba con su interior, repleto de obras de arte (pintura, escultura, muebles y objetos diversos) creadas en España durante "el siglo de oro español", y también traídas de otros países europeos, merced a las apremiantes gestiones del mismo Conde Duque (Brown y Elliot, 2016).

El recinto palaciego también albergó el Coliseo del Buen Retiro, espacio de representaciones teatrales y operísticas para la corte, asimismo abierto al público, que pudo asistir a las grandes obras teatrales del siglo de oro. No en vano Calderón de la Barca fue nombrado su director (Flórez, 1998). 


\section{Figura 2: Vista del Palacio y Jardines del Buen Retiro (1637). Atribuido a Jusepe Leonardo.}

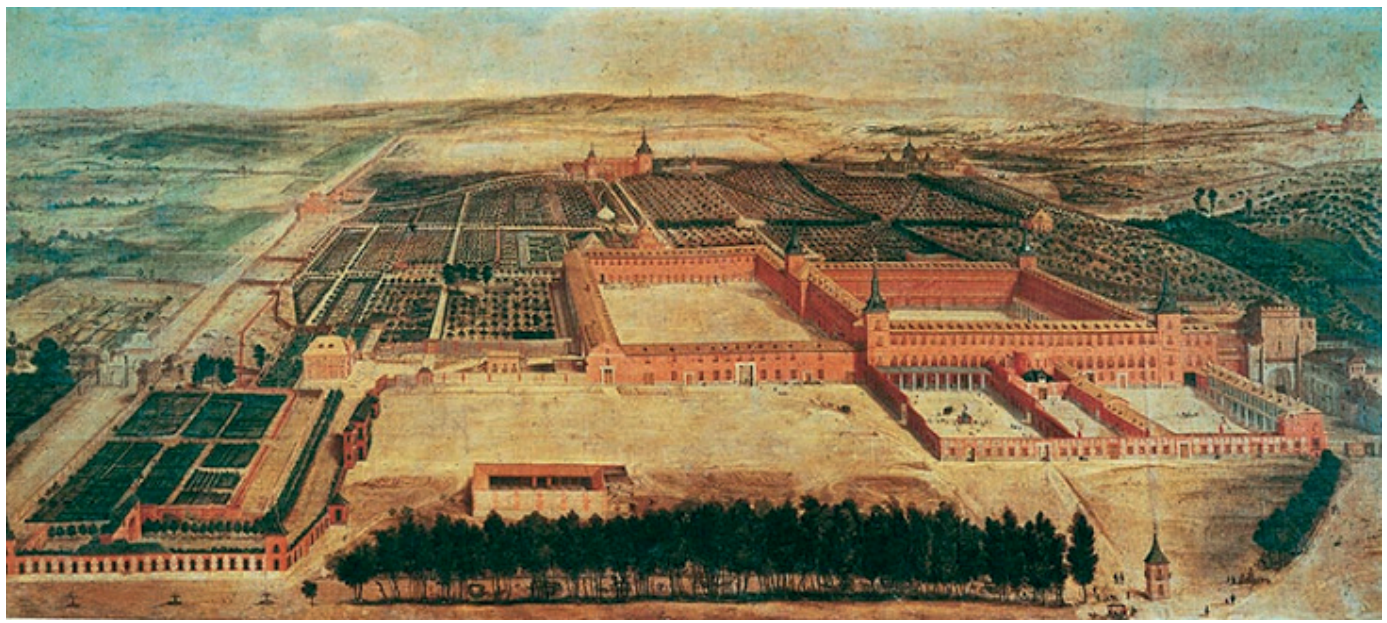

Fuente: Patrimonio Nacional.

Paralelamente, los exteriores del palacio fueron objeto de ajardinamiento, con especial protagonismo del agua en el diseño de estanques, canales y fuentes para el recreo y descanso de la realeza y la corte. Estos espacios verdes fueron escenario de representaciones teatrales, fuegos artificiales, cacerías, corridas de toros, luchas entre fieras y paseos en góndola (Durán, 2002).

El Real Sitio de El Buen Retiro, así creado en el lado oriental de la ciudad, coexistió hasta el siglo XIX con las antiguas propiedades reales situadas en el lado occidental: Palacio Real, jardines anejos y Casa de Campo, a las que, a finales del siglo XVIII, se añadió la Real Posesión de La Florida (fig. 3).

Figura 3: Plano de Madrid de 1762. Escala 1:31.000.

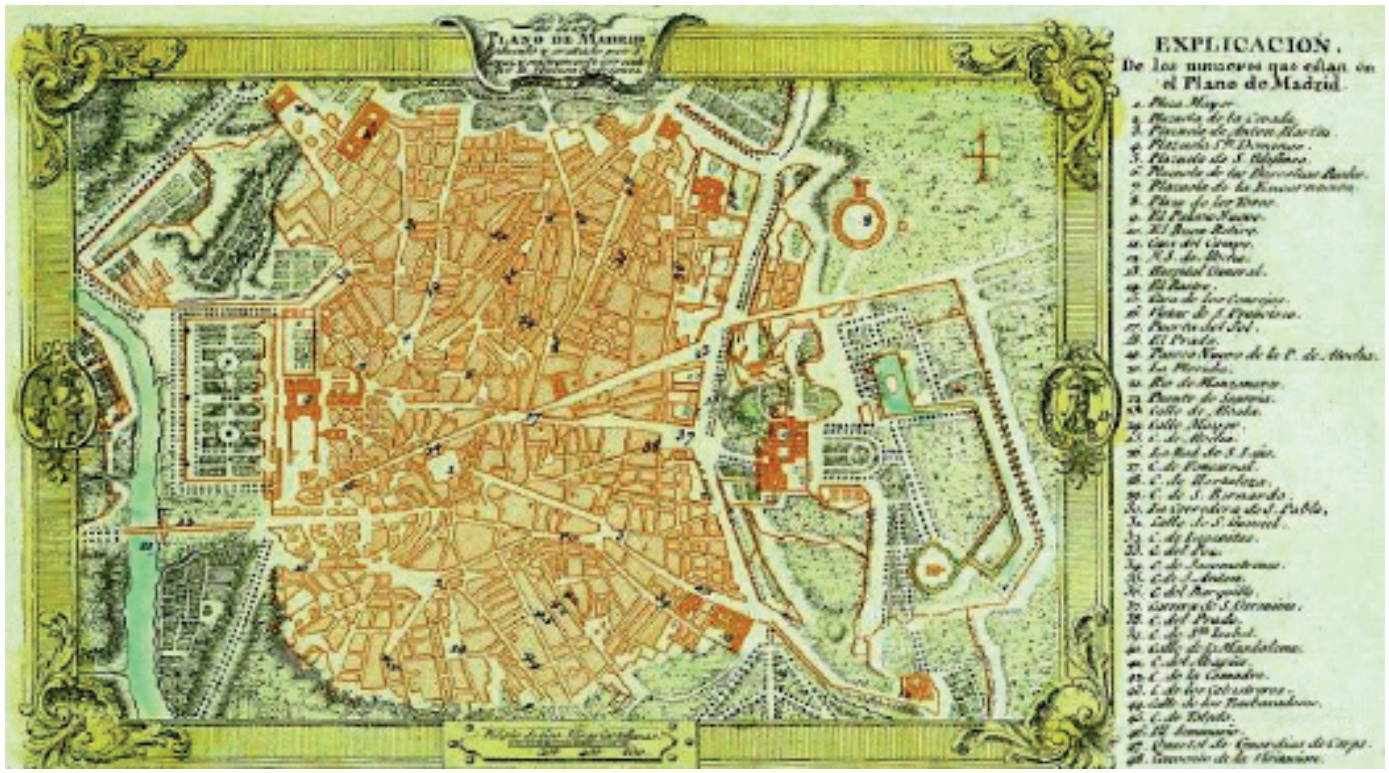

Fuente: Real Academia de la Historia. 
Con la dinastía borbónica (Felipe V, Fernando VI, Carlos III y Carlos IV), hasta la invasión francesa y la consiguiente guerra de la independencia (1808-1814), el espacio actualmente comprendido en la candidatura presentada a la UNESCO, fue adquiriendo nuevos edificios y monumentos propios de la época de la Ilustración, siendo Carlos III el artífice principal de esta etapa. Tales son el Real Estudio de Historia Natural (actual edificio principal del Museo del Prado), el Real Observatorio Astronómico y las emblemáticas fuentes de Cibeles, Neptuno, Apolo y las Fuentecillas, todo ello posterior al Jardín Botánico y a la Real Fábrica de Cerámica (Fig.4).

Figura 4: Fragmento del Plano geométrico de Madrid, 1785, correspondiente al Real Sitio de El Retiro

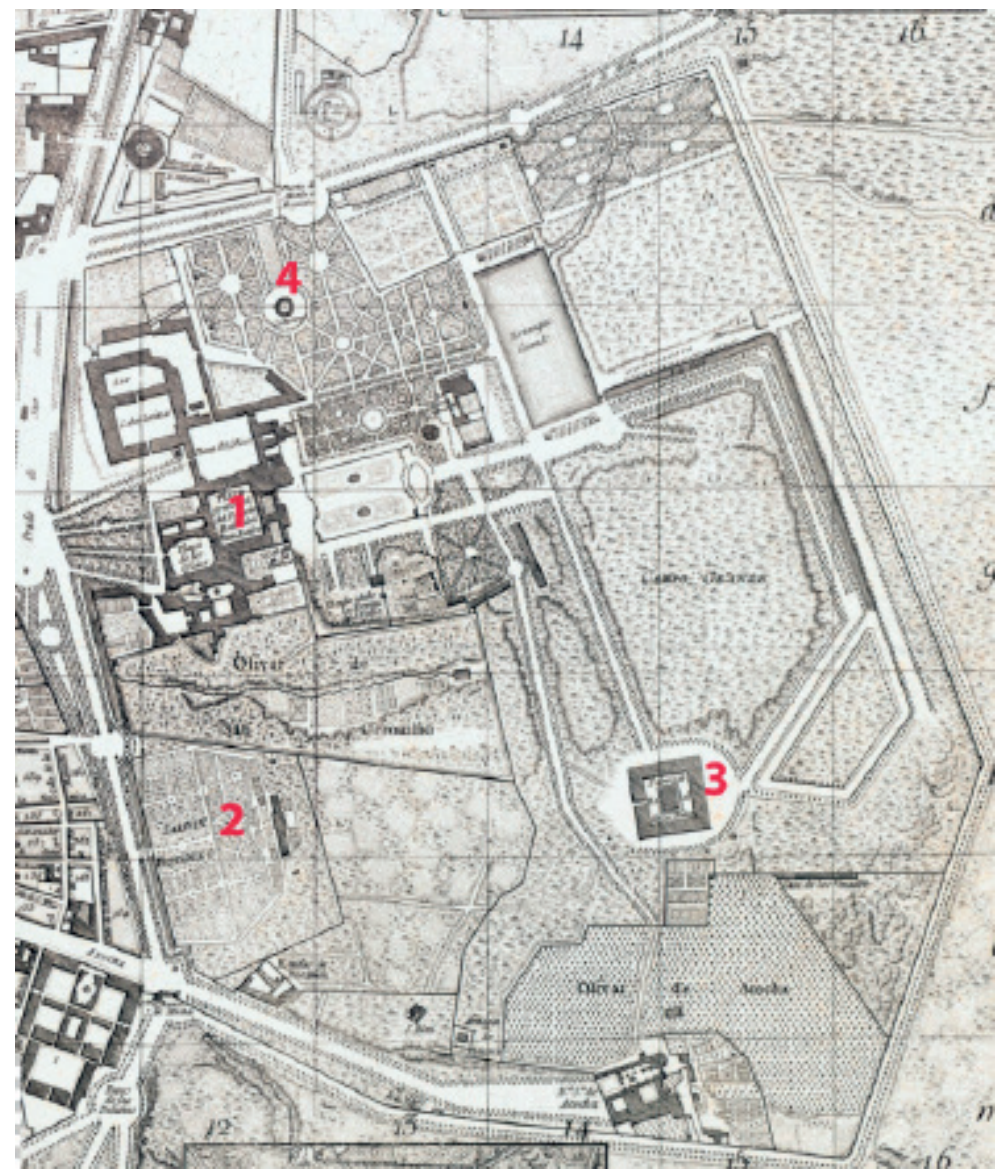

Autor: López de Vargas Machuca. Tomás. 1: Complejo palaciego; 2: Jardín Botánico; 3: Real Fábrica de Cerámicas; 4: La Leonera.

Tras la guerra de independencia y la ocupación de El Retiro como cuartel general por el ejército francés, el palacio de los Austrias quedó prácticamente destruido ${ }^{11}$ y en situación de abandono, en tanto que sus exteriores fueron objeto de importantes restauraciones que cambiaría definitivamente su configuración. Fernando VII realizó "el reservado", con sus extravagantes "caprichos". Lo más conocido de sus incorporaciones al parque fue la Casa de Fieras ${ }^{12}$, en 1830 (Aparisi, 2011a), que fue el "zoo" madrileño hasta su traslado, en 1977, al actual emplazamiento en Batán (Casa de Campo).

Con Isabel II se produjo la intervención más decisiva en el entorno de las ruinas del palacio, con la venta en 1865 y posterior urbanización de todo el espacio situado al norte del jardín botánico hasta la 
calle de Alcalá, hoy barrio de los Jerónimos. Con esta intervención quedó definido el límite occidental de El Retiro a lo largo de la calle Alfonso XII, entre la Puerta de Alcalá y la Estación de Atocha (Fig. 5).

Como se ha visto anteriormente, en 1868 El Retiro se convierte en un espacio de recreo para los madrileños. Pero también fuente de problemas y desencuentros entre la gestión y gestores municipales del mismos y los funcionarios de Patrimonio de la Corona, todavía propietaria de los bienes del parque. Sirve de ejemplo el traslado, por parte de Patrimonio, de los animales alojados en la Casa de Fieras a la Casa de Campo, que posteriormente fueron devueltos. En estas idas y vueltas algunos ejemplares desaparecieron (Cayetano, 2011)

Las modificaciones e incorporaciones posteriores al propio recinto del parque han ido enriqueciendo su patrimonio natural y cultural hasta fechas recientes; un patrimonio, que descrito con brevedad, permite conocer algo más sobre la historia del propio parque hasta la actualidad ${ }^{13}$.

\section{Figura 5: Trabajos del Plano de Madrid. Distrito del Congreso: Parque del Retiro, Jardín Botánico y Paseo del Prado. 1910. Escala 1:4.000}

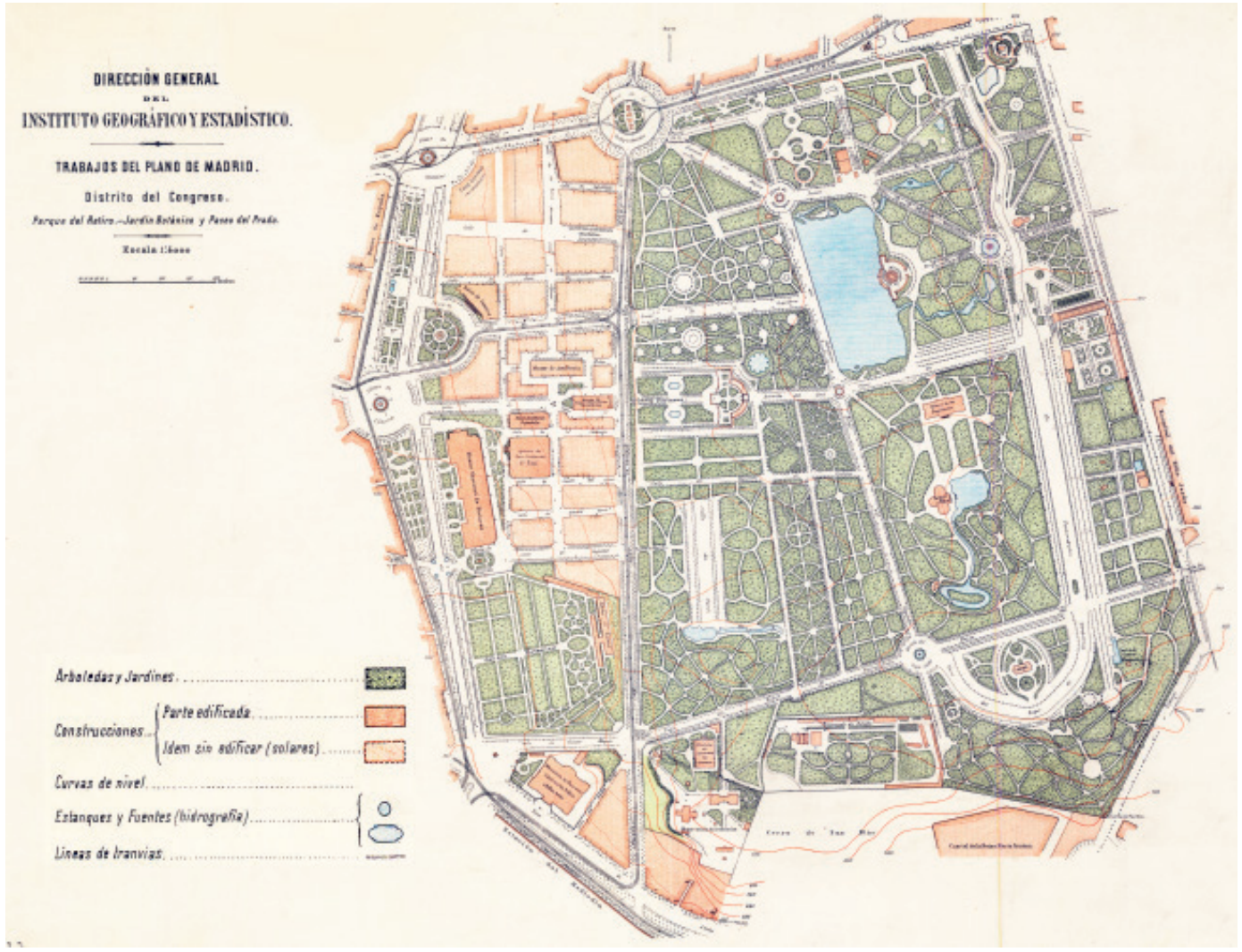

Fuente: Dirección General del Instituto Geográfico y Estadístico.

\section{Recursos Patrimoniales de El Retiro}

El Retiro ha sufrido grandes modificaciones a lo largo del tiempo, y algunos de sus elementos patrimoniales han desaparecido o han sido transformados. Lo que permanece se caracteriza por la imbricación entre elementos naturales, arquitectónicos y de ornato, que han seguido una evolución simultánea e interdependiente, puesto que la ordenación del espacio para su ajardinamiento en muchos casos fue acompañada de edificaciones, esculturas, fuentes, etc. Todo ello de acuerdo con los 
gustos de cada época, en ocasiones superponiéndose unos a otros mediante modificaciones, traslados y nuevas incorporaciones de elementos patrimoniales. Se revisan así los recursos naturales y materiales que perduran; su descripción resumida aporta más detalles de la historia ligada al parque, algunos anecdóticos, otros de mayor calado.

\subsection{Jardines y zonas verdes.}

La masa verde de El Retiro limpia la contaminación ambiental (Gómez-Moreno et al. 2019) y atenúan la temperatura de su interior y en el entorno más próximo de la ciudad (Aram et al. 2019). Constituye un pulmón incrustado en el casco urbano de la ciudad, con $570.000 \mathrm{~m}^{2}$ de zona ajardinada y 17.508 árboles, localizados en su mayoría sobre césped o praderas naturales. De las 163 especies catalogadas, el castaño de Indias (Aesculus hippocastanum) es la más abundante, alcanzando el 34,32\% del número de ejemplares. El plátano de sombra (Platanus x hybrida) y el árbol del amor (Cercis siliquastrum) suponen el 5,3\% y 4,2\% del arbolado respectivamente. Otras especies destacadas por su importante presencia son: la palmera excelsa (Trachycarpus fortunei), el ciprés mediterráneo (Cupressus sempervirens), el almez (Celtis australis), la acacia de tres espinas (Gleditsia triacanthos), el pino piñonero (Pinus pinea), la acacia del Japón (Sophora japónica) y el olmo de Siberia (Ulmus pumila), cuya abundancia oscila entre el 3,5\% la primera y 2,26\% las dos últimas (Ayuntamiento de Madrid, 2019a).

La gran diversidad del arbolado del parque es la lógica consecuencia de su larga historia. Se han identificado 923 árboles con elevado interés histórico o paisajístico, que equivalen al 5\% del total (Ayuntamiento de Madrid, 2016a). Ocho de ellos están catalogados como árboles singulares (Decreto 18/1992, de 26 de marzo; Orden 68/2015, de 20 de enero) (Tabla 1 y Fig. 6).

Tabla 1: Árboles singulares de El Retiro

\begin{tabular}{|c|c|c|c|}
\hline & Nombre común & Nombre cientifico & Localización \\
\hline 1 & Ahuehuete del Parterre & Taxodium mucronatum & Parterre del parque de El Retiro \\
\hline 2 & $\begin{array}{l}\text { Arce Plateado de los Jardines de Cecilio } \\
\text { Rodríguez }\end{array}$ & Acer saccharinum & Jardines de Cecilio Rodríguez \\
\hline 3 & Cedro del Parque de El Retiro & Cedrus libanotica & $\begin{array}{l}\text { Antiguo Reservado, cerca monumento } \\
\text { General Martínez Campos, }\end{array}$ \\
\hline 4 & $\begin{array}{l}\text { Ciprés Calvo del Estanque del Palacio } \\
\text { de Cristal }\end{array}$ & Taxodium distichum & $\begin{array}{l}\text { Campo Grande, en el Estanque del } \\
\text { Palacio de Cristal }\end{array}$ \\
\hline 5 & Palmera de Fortune de El Retiro & Trachycarpus fortunei & $\begin{array}{l}\text { Campo Grande, cerca de la ría de } \\
\text { patinar }\end{array}$ \\
\hline 6 & $\begin{array}{l}\text { Pino Carrasco de la Rosaleda de El } \\
\text { Retiro }\end{array}$ & Pinus halepensis & Rosaleda de El Retiro \\
\hline 7 & Eucalipto azul del Retiro & Eucaliptus globulus & $\begin{array}{l}\text { Antiguo Reservado, entre el } \\
\text { embarcadero y el Paseo de Coches }\end{array}$ \\
\hline 8 & Tejo del Palacio de Velázquez del Retiro & Taxus baccata & $\begin{array}{l}\text { Campo Grande, próximo al Palacio de } \\
\text { Velázquez del Retiro }\end{array}$ \\
\hline
\end{tabular}

Fuente: elaboración propia a partir de Comunidad de Madrid, 2013 y Orden 68/2015, de 20 de enero. 
Figura 6: Ahuehuete. Catalogado como Árbol Singular

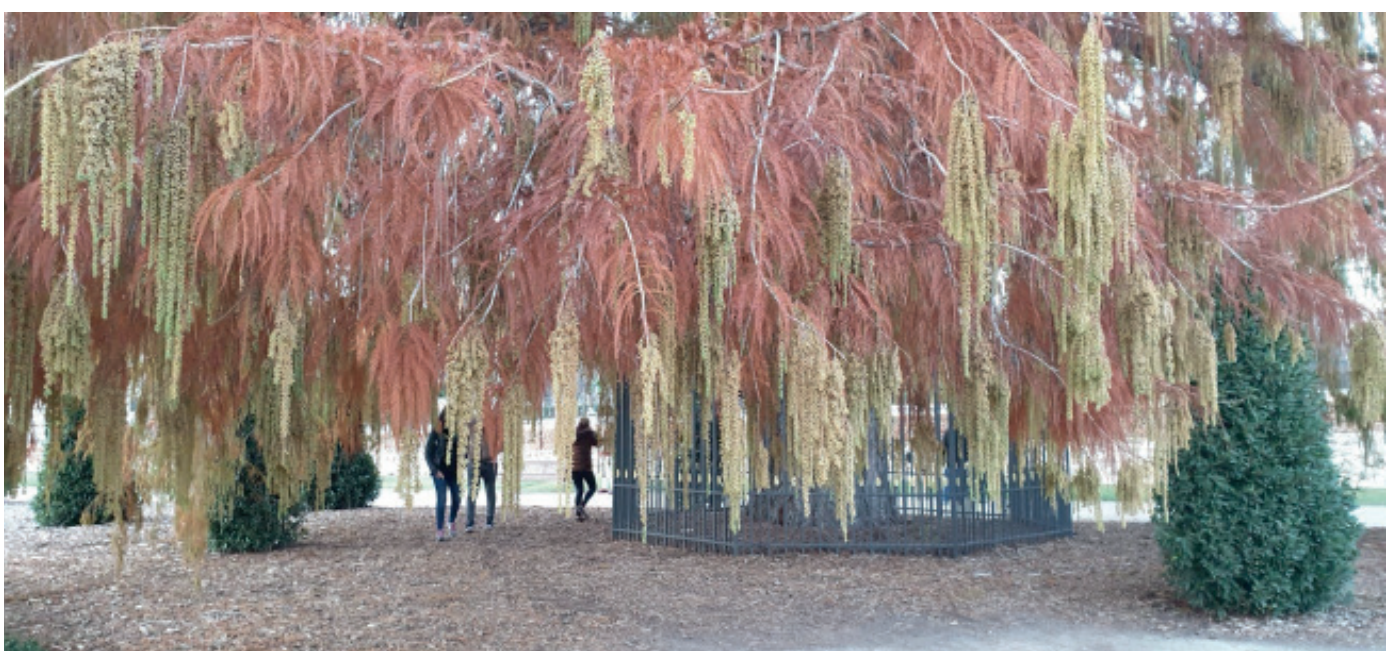

Fuente: Elaboración propia.

El parque de El Retiro carece de un orden en torno a un eje principal y obedece a una yuxtaposición de recuadros de arbolados y jardines contiguos, pero a la vez independientes, con diferentes diseños que se han ido transformando según los gustos de cada época (Fig. 7) (Ayuntamiento de Madrid, 2016a).

Figura 7: Zonas verdes de El Retiro

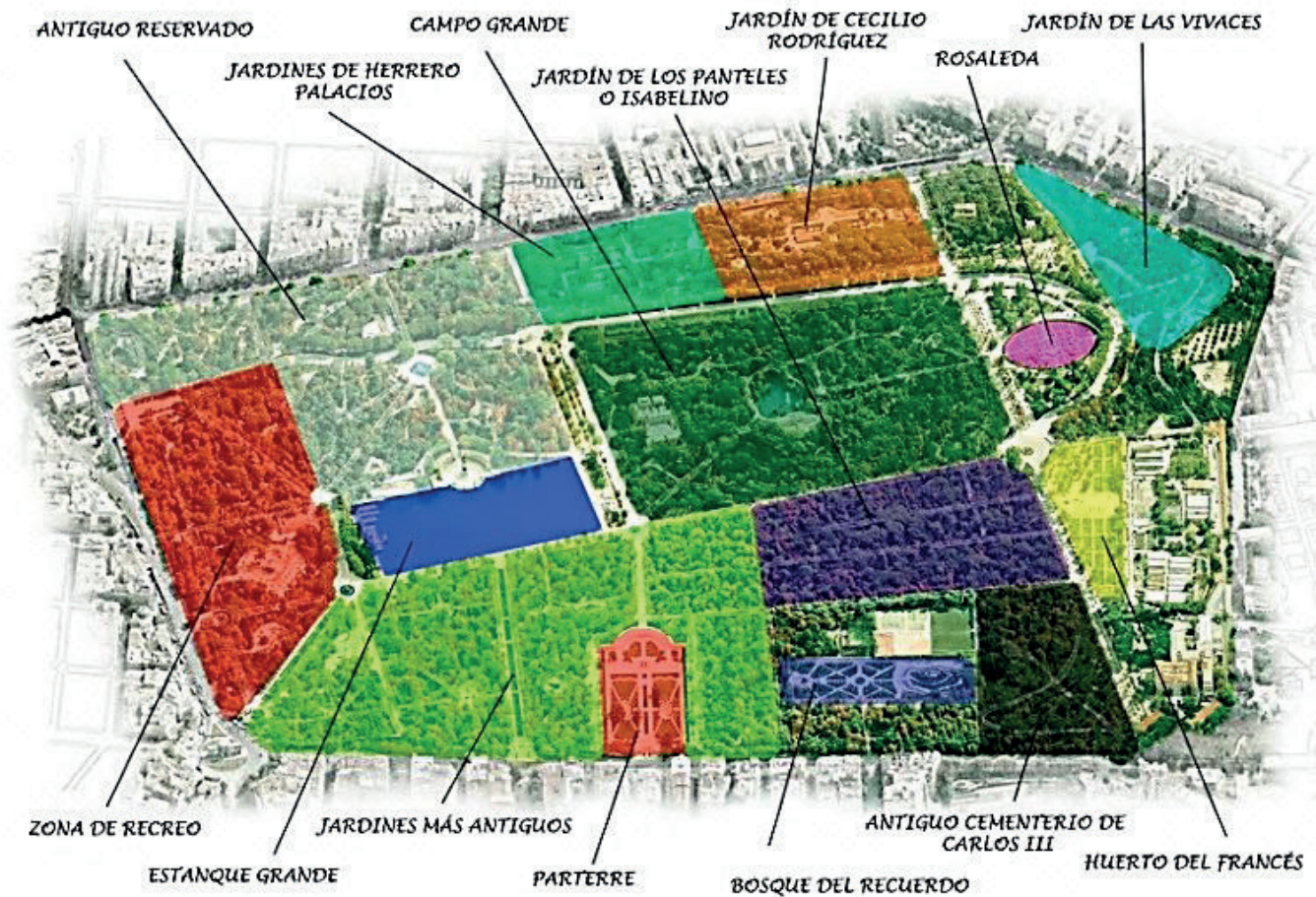

Fuente: Elaboración propia a partir de información del Ayuntamiento de Madrid. 
Los jardines más antiguos se encuentran en la zona oeste, donde destaca el Parterre, jardín de estilo francés diseñado con Felipe V y posteriormente modificado con Isabel II. Ocupa el lugar del antiguo jardín ochavado existente con Felipe IV y Carlos II.

En el lado oriental, el Antiguo Reservado hace referencia al espacio que se reservó Fernando VII, tras los desastres de la Guerra de Independencia, realizando en el mismo los denominados "caprichos", tan de moda en los jardines románticos de la época. Aunque reformados, algunos han pervivido hasta la actualidad, como la Casita del Pescador, la Montaña Artificial, la Casa de Vacas y la Casa del Contrabandista. Las dos últimas están muy modificadas y hoy en día convertidas respectivamente en un centro cultural y en Florida Retiro, un espacio de restauración y espectáculos. Otros caprichos fueron demolidos enteramente, como las Casas del Rico y del Pobre y la Casa Rústica o Persa.

También en el siglo XIX, con Isabel II se crea en 1841 el Jardín de los Planteles o Isabelino, de trazado geométrico con numerosos setos y árboles de sombra. El Campo Grande, lugar para la caza menor hasta mediados del siglo XIX, fue ajardinado en esta misma época, aunque su transformación en jardín paisajista, que ha perdurado hasta la actualidad, se realizó en 1878, cuando ya era propiedad municipal. Posteriormente, en este espacio se levantaron el Palacio de Velázquez (1883) y el Palacio de Cristal (1887).

En 1905 se inauguró la "Zona de Recreos", con paseos arbolados, kioscos de bebidas y de música, y un teatro hoy desaparecido. Otras incorporaciones realizadas en el siglo XX son: la Rosaleda (1915), los Jardines de Cecilio Rodríguez y de Herrero Palacios (década de los 40) y el Jardín de Vivaces (década de los 60). El bosque del Recuerdo, inaugurado en marzo de 2005 y dedicado a las víctimas del atentado del 11 de marzo de 2004, es el último espacio verde creado en El Retiro.

\subsection{El agua en El Retiro: fuentes, estanques y rías}

El agua, muy presente en El Retiro, en su origen sirvió para el disfrute de la monarquía, mediante la navegación en falúas o góndolas por los canales y estanques. De ellos, el Estanque de las Campanillas y el Estanque Grande, con su diseño actual, son los únicos elementos que se conservan desde el siglo XVII. En el segundo de ellos se realizaron representaciones teatrales y naumaquias hasta finales del siglo XIX (Mariblanca, 1991 y 2008)

\section{Figura 8: Una de las dos fuentes simétricas denominadas de la Alcachofa del Parterre (1712) Al fondo el Ahuehuete}

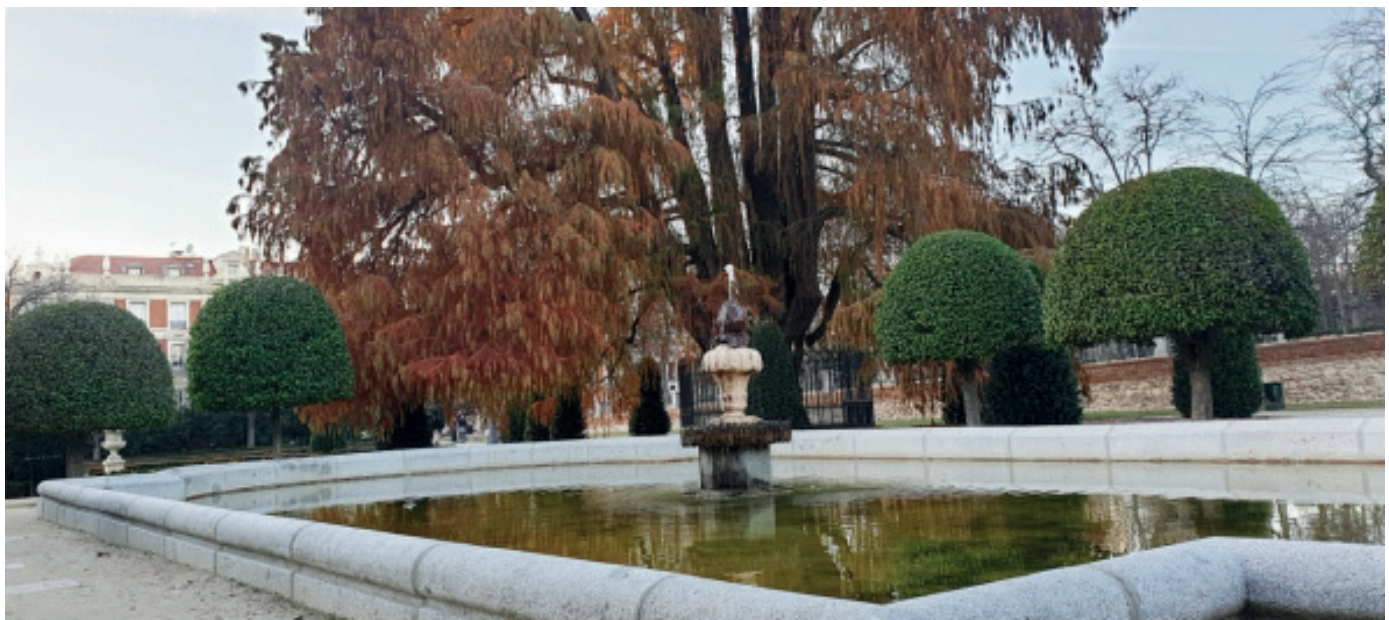

Fuente: Elaboración propia.

Las fuentes monumentales (Tabla 2 y Fig. 8), en su mayoría de estilo barroco, representan pasajes mitológicos, como la fuente de La Alcachofa o de los Tritones (1781-1782). Destaca por su originalidad y exotismo la fuente egipcia (1819-1850), conocida por los madrileños como "la tripona". 
Las rías, acompañadas de puentes, pasarelas y vegetación, son itinerarios sofisticados que han servido tanto para su navegación como pistas de patinaje, durante los rigurosos inviernos de hace pocas décadas.

Tabla 2: Fuentes, Estanques y Rías de El Retiro.

\begin{tabular}{|c|c|c|c|c|c|}
\hline Fuentes & Fecha & Estanques & Fecha & Rias & Fecha \\
\hline Fuente de Cupido de La Rosaleda & 1700 & Estanque de las Campanillas & 1632 & $\begin{array}{l}\text { Ria Norte y estanque de la } \\
\text { Montaña Artificial del Retiro }\end{array}$ & 1817 \\
\hline Fuente del Fauno de La Rosaleda & 1700 & Estanque grande del Retiro & 1634 & Ria del paseo de Colombia & \pm 1900 \\
\hline Fuentes de la Alcachofa del Parterre & 1712 & $\begin{array}{l}\text { Estanque del Palacio de Cristal } \\
\text { Estanques gemelos de la antigua }\end{array}$ & 1887 & $\begin{array}{l}\text { Ria del paseo de Venezuela } \\
\text { Ria Sur y cascada de la }\end{array}$ & \pm 1900 \\
\hline Fuente con escudo de Madrid & 1750 & Casa de Fieras & 1918 & Chopera & \pm 1900 \\
\hline Fuente del pequeño tritón & 1750 & $\begin{array}{l}\text { Estanque pequeño de los jardines de } \\
\text { Cecilio Rodríguez } \\
\text { Estanques en cascada de los jardines }\end{array}$ & 1925 & & \\
\hline Fuente de la Alcachofa & 1781 & de Cecilio Rodríguez & 1925 & & \\
\hline Fuente Egipcia & 1819 & Estanque óvalo del Retiro & 1940 & & \\
\hline Fuente de Isabel II o de los galápagos & 1831 & Estanque Central de La Rosaleda & 1941 & & \\
\hline Fuente de la Concha del Parterre & 1841 & Estanque del jardin de Vivaces & 1965 & & \\
\hline Fuente de los Delfines del Parterre & 1841 & $\begin{array}{l}\text { Estanque del Bosque de los Ausentes } \\
\text { Estanque e isla ovalada del Parque }\end{array}$ & 2005 & & \\
\hline Fuente de las Cuatro náyades o de las Sirenas & 1900 & $\begin{array}{l}\text { del Retiro } \\
\text { Estanque rústico y puente de los }\end{array}$ & \pm 1870 & & \\
\hline Fuente en la plaza del Mármol & 1941 & jardines de Cecilio Rodriguez & \pm 1929 & & \\
\hline Fuente de la Gaviota & 1962 & & & & \\
\hline Fuente de la Sardana & 1964 & & & & \\
\hline Fuente de Sevilla & 1995 & & & & \\
\hline Fuente nueva de los Delfines del Parterre & 2001 & & & & \\
\hline Fuente de la Gruta & \pm 1825 & & & & \\
\hline Fontines del jardin de los Planteles del Retiro & \pm 1865 & & & & \\
\hline
\end{tabular}

Fuente: Elaboración propia a partir de datos del Ayuntamiento de Madrid, 2019b.

\subsection{Otros bienes patrimoniales arquitectónicos y artísticos}

En la vertiente arquitectónica cabe destacar el Palacio de Velázquez y el Palacio de Cristal, ambos sedes de exposiciones temporales del Museo Nacional Centro de Arte Reina Sofía (4. y 5.3.1.). Entre las modestas edificaciones restantes (tabla 3) destaca por su antigüedad la Ermita de San Pelayo y San Isidoro, situada originalmente extramuros de la ciudad de Ávila. Desde 1896 pasó a formar parte del patrimonio de El Retiro (Ayuntamiento de Madrid, 2019c).

Tabla 3: Bienes arquitectónicos de El Retiro.

\begin{tabular}{|lc|}
\hline \multicolumn{2}{|c|}{ Edificación singular } \\
\hline Ruinas de la ermita de San Pelayo y San Isidoro & 1050 \\
Casa del Pescador del Retiro & 1817 \\
Palacio de Velázquez & 1883 \\
Palacio de Cristal & 1887 \\
Embarcadero del Estanque de El Retiro & 1917 \\
Noria de la Fábrica de Porcelana & 2000 \\
\hline
\end{tabular}

Fuente: Fuente: Elaboración propia a partir de datos del Ayuntamiento de Madrid, 2019b.

La Noria de la Fábrica de Porcelana es el único remanente que queda de dicha instalación. Creada por Carlos III, su desaparición no fue debida a las tropas francesas, como ocurrió con otros bienes inmersos en la fortificación en la que convirtieron El Retiro. Las tropas inglesas, entonces aliadas de España, consiguieron reducir a las anteriores y oportunamente arrasaron lo que quedaba de la fábrica de cerámica, eliminando así un competidor en dicha manufactura (Aparisi, 2011a).

El Retiro presenta una notable colección de esculturas (Tabla 4), en su mayoría conmemorativas de personajes de los ámbitos histórico, literario, científico, artístico y mitológico, lo que le confiere un valor artístico y educativo. Su ubicación en lugares destacados del parque contribuye al equilibrio y armonía con el entorno natural. 
Figura 9: Paseo de Argentina, que une la puerta de España con el Estanque Grande, jalonado por esculturas de monarcas españoles, en su origen destinadas al Palacio Real

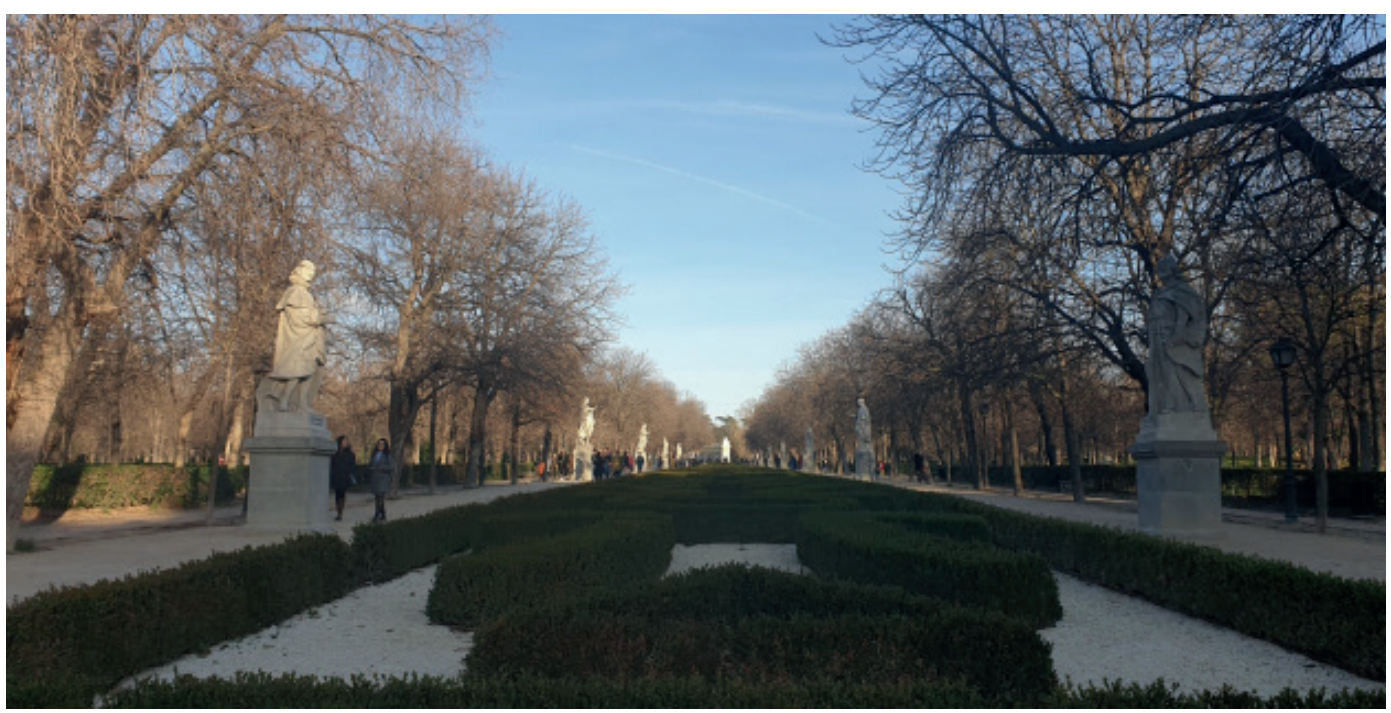

Fuente: Elaboración propia.

Los conjuntos escultóricos focalizan la atracción de los visitantes, en especial el dedicado a Alfonso XII, monumento emblemático de El Retiro, ubicado en el lugar más visible del parque, junto al Estanque Grande (Fig. 10). Diseñado por José Grases Riera y otra veintena de escultores participantes en el proyecto en 1901 (García, 2017), es una estructura de grandes dimensiones con una columnata semicircular, la estatua ecuestre del monarca, que culmina la torre mirador, una escalinata y numerosos elementos escultóricos acompañantes (Peña, 2011).

Figura 10. Estanque Grande con el monumento Alfonso XII al fondo.

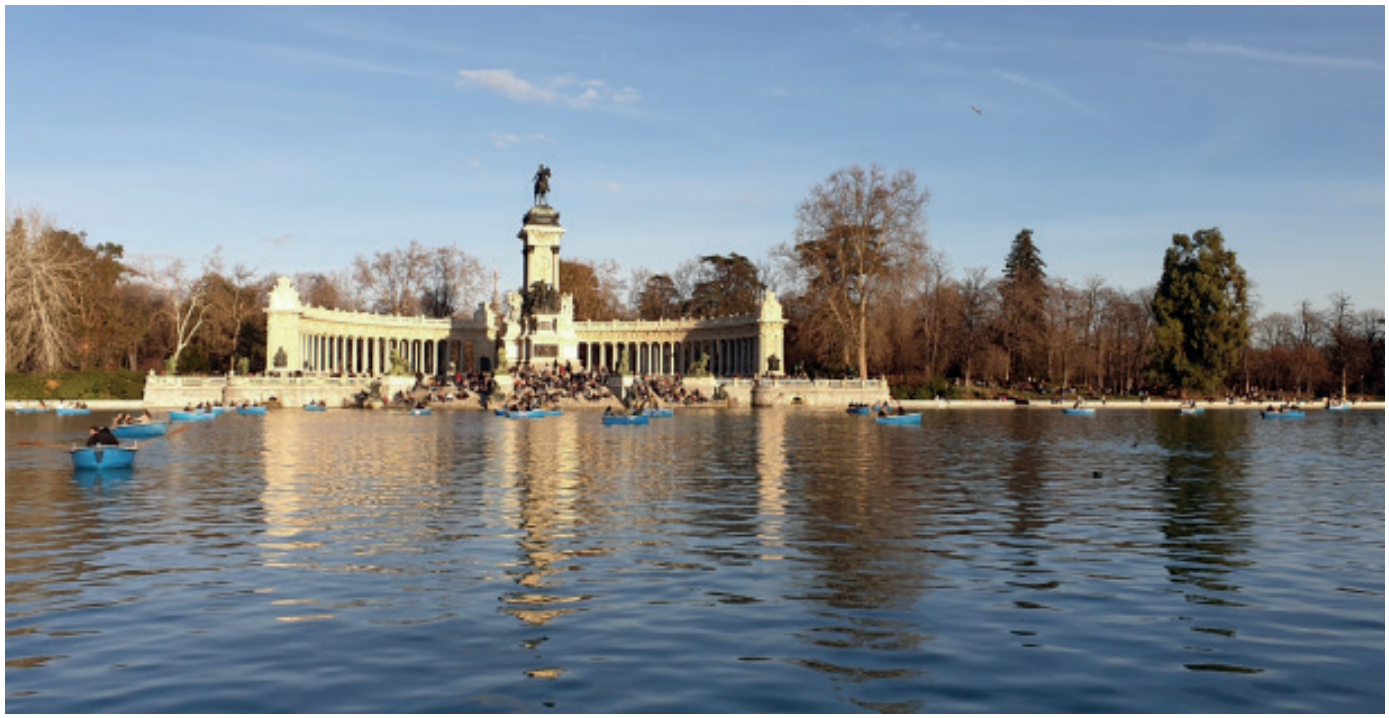

Fuente: Elaboración propia. 
En el ámbito mitológico destaca El Ángel Caído, monumento dedicado a Lucifer realizado en 1887 por Ricardo Bellver Ramón y Francisco Jareño y Alarcón. Fue donada por Alfonso XII al Ayuntamiento de Madrid (Ayuntamiento de Madrid, 2019c).

Tabla 4: Inventario de la colección escultórica de El Retiro.

\begin{tabular}{|c|c|c|c|c|c|c|c|}
\hline $\begin{array}{l}\text { Estatuas } \\
\text { Reyes españoles }\end{array}$ & Fecha & Otras estatuas & Fecha & Grupo Escultórico & Fecha & Esculturas abstractas & Fecha \\
\hline Alonso I El Batallador & 1743 & Diana & 1750 & Hércules y el León de Nemea & 1650 & Dados de Hormigón & 1982 \\
\hline Berenguela & 1743 & Diosa Hera & 1750 & Hércules y la Hidra de Lerna & 1650 & Enrique Tierno Galván & 1986 \\
\hline Carlos I & 1743 & Juan Van-Halen y Sarti & 1846 & Osos sentados de la Casa de Fieras & 1850 & & \\
\hline Carlos II & 1743 & Thalia & 1860 & Alfonso XII & 1901 & & \\
\hline Chintila & 1743 & El Ángel Caido & 1877 & Campoamor & 1912 & & \\
\hline Enrique II & 1743 & Doctor Benavente & 1885 & Ruperto Chapi & 1917 & & \\
\hline Fernando IV & 1743 & General Martínez Campos & 1907 & Santiago Ramón y Cajal & 1923 & & \\
\hline Garcia I Rey de León & 1743 & Chueca & 1909 & Cuba & 1929 & & \\
\hline Gundemaro & 1743 & Benito Pérez Galdós & 1919 & Francisco de Paula Marti Mora & 1961 & & \\
\hline Ramón Berenguer IV & 1743 & Fray Pedro Ponce de León & 1920 & & & & \\
\hline Sancho IV & 1743 & Doctor Cortezo & 1921 & & & & \\
\hline Sancho IV. El Bravo & 1743 & Tolosa Latour & 1925 & & & & \\
\hline \multirow[t]{7}{*}{ Urraca } & 1743 & Ricardo Codorniu & 1926 & & & & \\
\hline & & Miguel Moya & 1927 & & & & \\
\hline & & Mujer sedente & 1943 & & & & \\
\hline & & Jacinto Verdaguer & 1953 & & & & \\
\hline & & $\begin{array}{l}\text { Doctor Ángel Pulido } \\
\text { Fernández }\end{array}$ & 1954 & & & & \\
\hline & & Jacinto Benavente & 1961 & & & & \\
\hline & & Andrés Eloy Blanco & 1975 & & & & \\
\hline
\end{tabular}

Fuente: Elaboración propia a partir de datos del Ayuntamiento de Madrid, 2019b.

El Retiro tiene dieciocho puertas (Tabla 5) que hacen de él un espacio abierto a la ciudadanía. La monumentalidad de doce de ellas, como la Puerta de Felipe IV, construida en 1690 o la Puerta de España, en 1891 (Fig. 11), es otro atractivo del parque, que en su momento contribuyó a la pompa de las comitivas oficiales que accedía al recinto. De la misma manera contribuyó el cerramiento de forja de hierro, que se abordó de forma decidida en 1870. El vistoso cerramiento que presenta El Retiro fue controvertido a lo largo del pasado siglo, con partidarios de su desaparición, al estilo de los grandes parques de otras ciudades europeas. Por otro lado, los que manifestaban su necesaria protección frente al vandalismo, habida cuenta que se trata de un jardín histórico con abundante patrimonio artístico. En el año 2000 queda cerrado a la circulación rodada y, tras una encuesta del ayuntamiento a vecinos y usuarios, en 2001 la Concejalía de Medio Ambiente procede al cierre del parque en horario nocturno (Aguinaga, 2011). 


\section{Figura 11: Puerta de España (1891)}

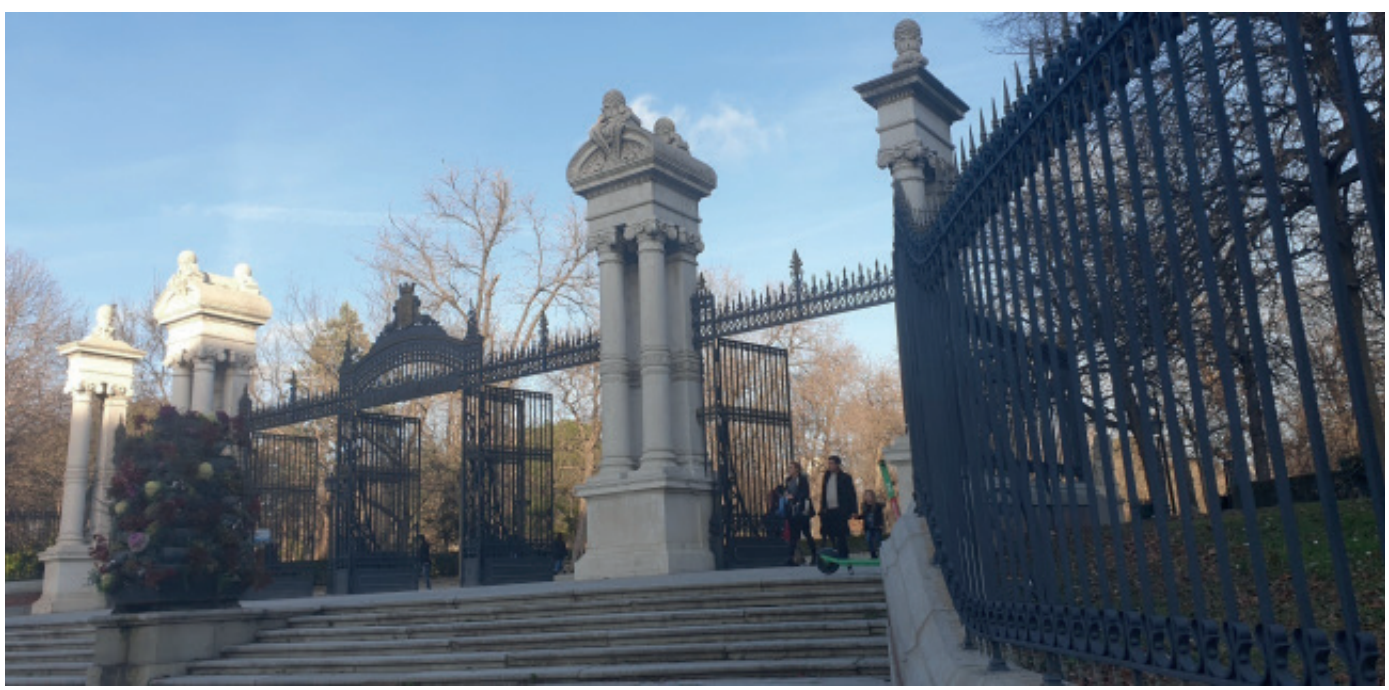

Fuente: Elaboración propia.

Tabla 5: Inventario de puertas, elementos conmemorativos y de ornamentación de El Retiro

\begin{tabular}{|c|c|c|c|c|c|}
\hline Puerta & Fecha & $\begin{array}{l}\text { Elemento conmemorativo, } \\
\text { Lápida }\end{array}$ & Fecha & Elemento de ornamentación & Fecha \\
\hline Puerta de Felipe IV & 1690 & Virgen de los Reyes & 1920 & Jarrones Franceses del Parterre & 1712 \\
\hline Puerta de la Independencia & 1817 & Mariano de Cavia & 1921 & Pedestal del paseo de los Reyes & 1842 \\
\hline Puerta del Olivar de Atocha (J. de C. R.) & 1823 & Luis de Góngora & 1927 & Jarrones de la Rosaleda del Retiro & 1915 \\
\hline Puerta de España & 1891 & Hipólito Yrigoyen & 1928 & Columna-pedestal. J. de C. R. & \pm 1929 \\
\hline Puerta de Murillo & 1893 & Julio Romero de Torres & 1932 & Dos columnas. J. de C. R. & \pm 1929 \\
\hline Puerta de Madrid & 1900 & General Francisco Morazán & 1973 & Ocho columnas. J. de C. R. & \pm 1929 \\
\hline Puerta sur de los Jardines de C. R. & 1929 & Mariscal Francisco Solano López & 1976 & Homenaje a la Mar & 1930 \\
\hline Puerta de la América Española & 1932 & Justo Arosemena & 1978 & Pedestal del paseo Duque de Fernán Núñez & \pm 1950 \\
\hline Puerta de Hernani & 1943 & Laurel y Madroño & 1983 & Cruceiro de la plaza de Galicia & 1980 \\
\hline Puerta de O'Donnell & 1945 & Juantxu Rodriguez & \pm 1990 & Jarrones Franceses nuevos del Parterre & 2001 \\
\hline Puerta de la Reina Mercedes & 1950 & & & & \\
\hline Puerta de Sainz de Baranda & 1950 & & & & \\
\hline Puerta de Dante & 1968 & & & & \\
\hline Puerta de Granada & 2000 & & & & \\
\hline Puerta de Herrero Palacios & 2000 & & & & \\
\hline Puerta del Ángel Caido & 2000 & & & & \\
\hline Puerta del Doce de Octubre & 2000 & & & & \\
\hline Puerta del Niño Jesús & 2000 & & & & \\
\hline
\end{tabular}

Fuente: Elaboración propia a partir de datos del Ayuntamiento de Madrid, 2019b.

\section{Principales manifestaciones culturales}

El Retiro ha sido desde sus origenes lugar de representación de numerosos eventos culturales o de ocio. Si nos remontamos al pasado, podemos mencionar los vuelos en globo aerostático ${ }^{14}$ y las naumaquias realizadas en el Estanque Grande. ${ }^{15}$

Mayor huella dejaron la Exposición de Minería y Bellas Artes (1883) y la Exposición de Filipinas (1887), para las que se construyeron el Palacio de Velazquez y el Palacio de Cristal (Fig. 12 y 13), ambos 
debidos al arquitecto Ricardo Velázquez, a quien el primero debe su nombre. El Palacio de Cristal es un invernadero de grandes dimensiones y mayor belleza, que albergó plantas exóticas durante la mencionada exposición. Como ya se ha mencionado, en la actualidad se utilizan como salas de exposiciones temporales del Museo Nacional Centro de Arte Reina Sofía.

\section{Figura 12: El Palacio de Cristal.}

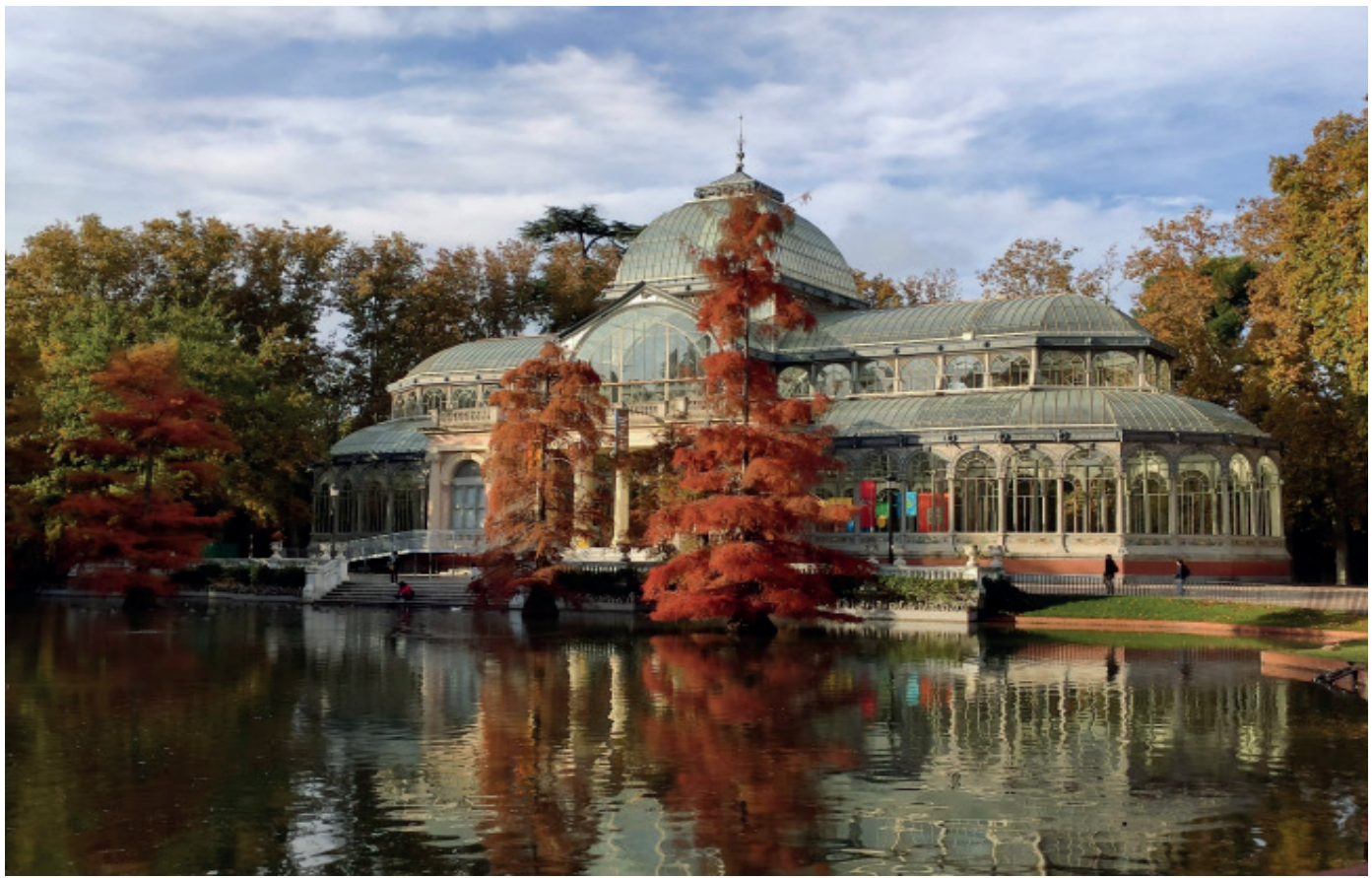

Fuente: Elaboración propia.

Figura 13. Palacio de Velazquez

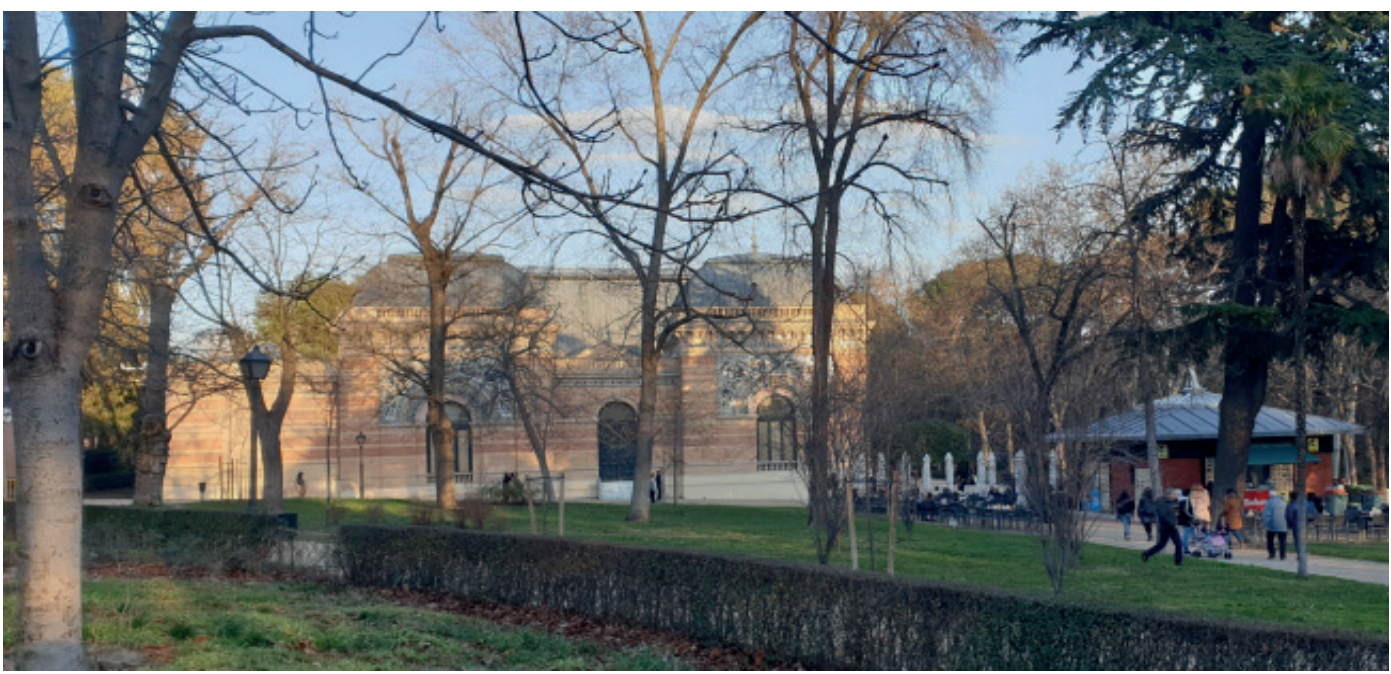

Fuente: Elaboración propia. 
Sin duda, la Casa de Fieras ${ }^{16}$ ha sido el mayor incentivo para el ocio y la visita del Retiro. En mayor o menor medida la fauna exótica siempre ha estado presente en El Retiro, por ser Real Sitio y también ser gusto de la realeza la pertenencia de especies exóticas. En 1634, con Felipe IV, se edificó "La Leonera", cercana a la actual Plaza de la Independencia, (Fig. 4) un recinto ovalado con un foso y jaulas para las fieras que podían ser vistas por la realeza desde una barandilla superior (Aparisi, 2011a). No obstante, la primera colección con mayor importancia, fue un proyecto científico de Carlos III, inaugurado en 1774 como una instalación complementaria al Gabinete de Ciencias Naturales y situada junto al Real Jardín Botánico. Posteriormente Fernando VII ordenó su traslado al edificio de dos plantas conocido como "La Leonera"17, con las jaulas en la planta baja y estancias en la superior (Simón, 1991).

\section{Figura 14: Antigua Casa de Fieras. El edificio "La Leonera" ha sido transformado en la biblioteca municipal Eugenio de Trías.}

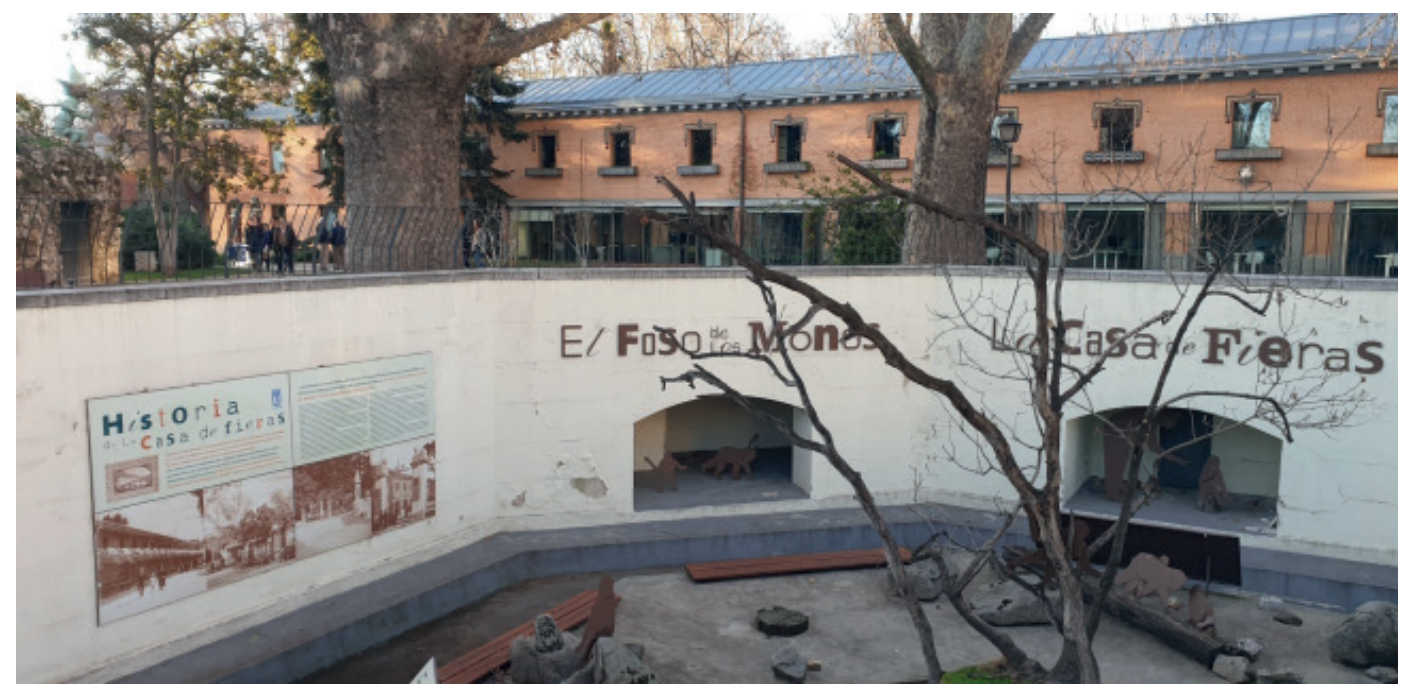

Fuente: Elaboración propia.

En los orígenes de El Retiro la música sirvió para el disfrute de la Corte. Hoy en día el parque es muy frecuentado por artistas callejeros, desde los más clásicos hasta los más alternativos; también por conciertos de la Banda Sinfónica Municipal en el templete de música cercano al Estanque Grande, todos los domingos cuando la meteorología lo permite.

El teatro ha utilizado diferentes espacios a lo largo del tiempo. Primero en las distintas plazas del palacio y en el Coliseo, ya desaparecidos (ver 2.), sin olvidar las naumaquias en el gran estanque. Hoy en día las representaciones teatrales tienen lugar en el Centro Cultural Casa de Vacas y en Florida Retiro; también llegan a los más pequeños con el teatro de títeres al aire libre, que ofrece una amplia programación todos los sábados y domingos a lo largo del año, e incluso un festival internacional anual en los meses de julio y agosto. Se trata de una experiencia de gran tradición y única en Europa (Ayuntamiento de Madrid, 2019d).

La Feria del Libro, ubicada en el paseo de Fernán Núñez, es el evento más conocido y visitado del parque, Desde 1967 reúne durante el mes de junio a libreros, editores, distribuidores, escritores y lectores. Su repercusión es cada vez más grande. Se estima que en 2019 hubo 2,4 millones de visitantes, la gran mayoría de la Comunidad de Madrid (82\%), de otras comunidades autónomas (17\%) y un 1\% procedentes del extranjero (Feria del Libro, 2020).

El Retiro también es lugar de encuentro de diferentes colectivos y asociaciones. Cabe mencionar la asociación amigos de El Retiro "La Cabaña", de carácter vecinal creada en 1981, que tiene su sede en el recinto del parque, donde los asociados practican juegos de mesa y de exterior en un entorno saludable. La Asociación Amigos de los Jardines de El Buen Retiro, desde 2018 viene realizando actividades de divulgación del patrimonio del parque mediante visitas guiadas y conferencias. Por otro parte, el círculo 
del Retiro de Tai Chi Chuan mantiene la práctica del mismo y realiza reuniones anuales desde 2003. También es destacable el activismo reivindicativo con el nombre "puerto seguro", llevado a cabo por Amnistía Internacional en el Estanque Grande (agosto de 2019), en defensa de los migrantes rescatados a la deriva en el mar.

El Aula de ecología La Cabaña del Retiro, gestionada por la Junta Municipal de Distrito de El Retiro, y el Centro de Educación Ambiental de El Retiro realizan actividades para público infantil, juvenil y adulto (itinerarios guiados, talleres, huerto ecológico y arboreto, conferencias, etc.) dirigidas a la población local, así como las actividades deportivas del centro deportivo La Chopera.

\section{Gestión, mantenimiento y uso de El Retiro.}

Se puede afirmar que, gracias a la gestión realizada a lo largo de los siglos, El Retiro presenta un estado de conservación aceptable, si bien son necesarias acciones encaminadas a la mejora de su mantenimiento y solución de problemas existentes. La gestión y mantenimiento del parque presenta la complejidad inherente a su reparto y dispersión entre diferentes organismos de la administración y empresas privadas, lo que en ocasiones dificulta el seguimiento de acciones prioritarias claras, produciéndose ocasionales ausencias de responsabilidades.

\subsection{Los Jardines}

La gran variedad de especies ha provocado una necesaria transformación del suelo autóctono, ya que muchas de ellas son foráneas y necesitan un PH calcáreo específico, que no es precisamente una característica del suelo de Madrid, cuya pobreza en arcilla y nutrientes obliga en muchos casos a su abonado mediante fertilizantes de liberación lenta, con nitrógeno, potasa y fósforo.

También merece especial atención el impacto del arbolado sobre el patrimonio monumental, dado que el desarrollo radicular de aquél llega a afectar a este, haciendo necesaria la creación de pantallas enterradas y un estudio específico de la obra necesaria en cada caso. En suma, puede concluirse que el cuidado de esta masa arbórea en el entorno monumental, no es sencillo.

Tratando de afrontar los diversos y numerosos problemas de mantenimiento, en 2016 se creó el Plan Director del arbolado de los Jardines del Buen Retiro, en parte inducido por las caídas de algunos árboles, sin razón aparente ni enfermedades registradas. Con una vigencia de 50 años, estipula su revisión y actualización cada cinco. Este plan pretende diagnosticar las actuaciones necesarias para lograr un arbolado seguro y de calidad (Ayuntamiento de Madrid, 2016a). Para ello se realiza la gestión por zonas del mismo origen, uso y tipología de arbolado y jardinería, dando prioridad al estudio de riesgos y a su revisión periódica. Algunas de las acciones que se llevan a cabo pretenden hacer frente a diversas amenazas como son: fuertes vientos ocasionales, exceso de nitrógeno en algunas zonas, especies invasoras de avifauna, enfermedades fúngicas u otras, como "la socarrina", referible a las quemaduras de los castaños por el sol.

Sin embargo, la principal amenaza es la elevada afluencia de visitantes y usuarios a los Jardines. "Todos los ciudadanos tienen derecho al uso y disfrute de los Jardines del Buen Retiro, (...) pero también el deber y obligación de respetar cualquier elemento del parque, incluido su arbolado" (Ayuntamiento de Madrid, 2016a).

\subsection{Materiales de información turística y de actividades}

El Centro de Información y Educación Ambiental el Huerto del Retiro, gestionado por el Ayuntamiento de Madrid, es en la actualidad el centro con la información más completa del parque, y a su vez también gestiona el Punto de Información del Bosque del Recuerdo, localizado en una antigua cabaña próxima a la calle de Alfonso XII. (Ayuntamiento de Madrid, 2019e). Paralelamente, la Cabaña de El Retiro y el Centro Cultural Casa de Vacas también proporcionan información parcial.

El parque es visitable mediante rutas guiadas. Las rutas oficiales son ofrecidas por el Centro de Información y Educación Ambiental el Huerto del Retiro y por el aula de ecología: La Cabaña del Retiro. Diversas empresas privadas desarrollan rutas a pie o bien en Segway y bicicletas. Por otro lado, las asociaciones sin ánimo de lucro: Asociación de Amigos de los Jardines del Buen Retiro y Asociación Rutas Alter Matrice, así como el Plan Director del Arbolado de los Jardines del Retiro, organizan conferencias y diversas rutas por el parque.

No hay un portal web que englobe e informe de todas las actividades que tienen lugar en el parque. Dicha información aparece dispersa en el Centro de Información y Educación Ambiental el Huerto 
del Retiro y en La Cabaña del Retiro. Esta última se publicita a través de sus redes sociales y con el sistema de mensajería a los socios registrados, tras haber realizado una actividad. Ambos centros no aparecen coordinados entre sí.

Las empresas privadas publicitan sus actividades en sus páginas web, en tanto que el ayuntamiento ha desarrollado su propia App para la visita (Ayuntamiento de Madrid, 2016b), pero sin referencias a las anteriores. Se hace notar la descoordinación en este aspecto, dado que los informadores de los dos recintos oficiales de información ubicados en el parque no advierten de la existencia de la App del Retiro.

Aunque escasa y de tamaño reducido, la cartelería del parque proporciona información de interés sobre los elementos patrimoniales del parque (Fig.15).

\section{Figura 15: El reducido tamaño de la cartelería} del parque puede no incentivar su lectura.

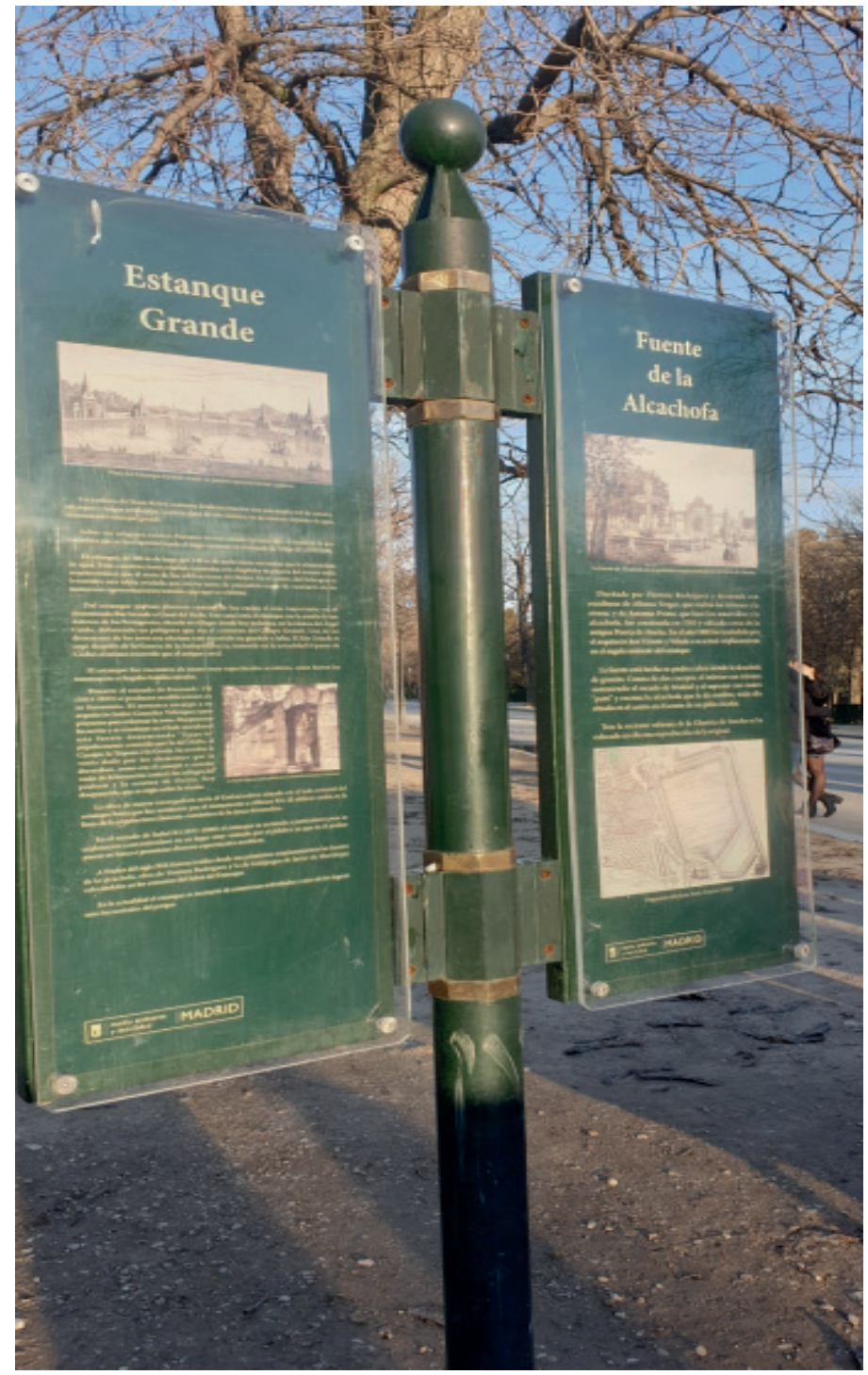

Fuente: Elaboración propia. 


\subsection{Los visitantes}

El Retiro recibe más de 15 millones de visitas cada año, cerca de 2,5 millones durante el mes dedicado a la Feria del Libro (Ayuntamiento de Madrid, 2016a). Es un lugar muy transitado, no solo por los madrileños, también por visitantes foráneos, al ser colindante con el eje del Paseo del Prado y sus distintos museos.

Para aproximarnos al uso que madrileños y turistas hacen de este espacio singular, se ha realizado una encuesta ${ }^{18}$ a 350 individuos, en horarios y días diferentes. En el perfil de los encuestados predomina la población femenina, un 60,3\%, así como los visitantes jóvenes (el 44\% de 20 a 35 años, el 31,7\% de 35 a 55 y el 14,6\% de 55 a 65). En relación con su procedencia (Fig. 16) los visitantes de la capital y de la Comunidad madrileña solo superan levemente el $50 \%$ del total, frente al 46,3\% de foráneos. Un buen indicador del importante uso turístico del parque.

\section{Figura 16: Lugar de origen, frecuencia y forma de visita}

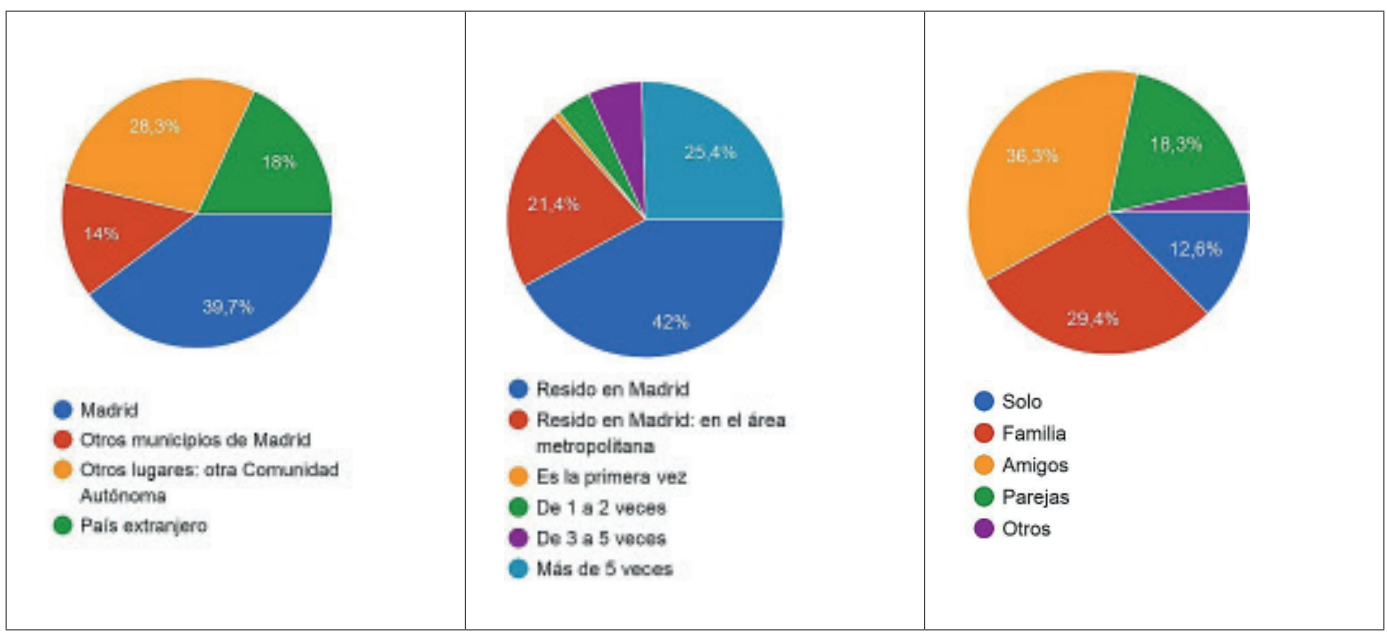

Fuente: Encuesta realizada, elaboración propia.

Entre los visitantes de origen extranjero predominan los franceses, italianos, argentinos y portugueses, seguidos de colombianos, estadounidenses, alemanes, británicos, chinos y japoneses, además de rusos, ucranianos, turcos y búlgaros. En la distribución temporal de las visitas el 76,6\% se realizan el fin de semana y el 23,4 \% entre semana.

El Retiro es objeto de visitas reiteradas, incluso más de 5 en el $25,4 \%$ de los casos, e independientemente de su frecuencia, tienden a ser compartidas en grupos de amigos (36,3\%), en familias (29,4\%), o en parejas $(18,3 \%)$. Años atrás el imaginario social consideraba está últimas como las más asiduas del parque.

\subsubsection{Preferencias y nivel de información.}

Según las mismas encuestas, se evidencia un amplio predominio en la percepción del parque como lugar de paseo, aderezado con visitas a exposiciones, a las barcas del estanque, o algunos de los recursos naturales y culturales, entre los que destacan: la Rosaleda, el Bosque del Recuerdo, los Jardines de Cecilio Rodríguez, árboles singulares y el Parterre en cuanto a las zonas verdes. En los recursos monumentales destacan el Palacio de Cristal, el Estanque Grande y su embarcadero, junto con el monumento a Alfonso XII, fuentes y esculturas. Por el contrario, el Palacio de Velázquez y el Antiguo Reservado de Fernando VII son poco conocidos (Fig. 17).

Entre todos ellos, el Palacio de Cristal destaca como meta principal en la visita al Retiro. La gran afluencia al palacio resulta principalmente de la trasmisión oral de su belleza; también de su promoción en páginas web, oficinas de turismo e incluso estaciones de metro de la ciudad. Su estructura metálica, enteramente acristala y diáfana en su interior, permite admirar el arbolado y estanque circundantes. 
Como todos los lugares singulares, invadidos especialmente en fechas vacacionales, este no es una excepción. El mediano tamaño del edificio y la entrada gratuita al mismo hacen que, en los días festivos, los visitantes del interior se vean impelidos hacia la salida por otros recién llegados.

Por otra parte, las encuestas a los visitantes y sus comentarios espontáneos muestran un desconocimiento bastante general sobre su origen, historia y función actual. Por ser ésta, al igual que el Palacio de Velázquez, sede de exposiciones temporales del Museo Nacional Centro de Arte Reina Sofía, el interior del gran invernadero suele estar ocupado por obras de arte moderno que suelen sorprender a los visitantes. Resulta así que el Museo Reina Sofía es uno de los 20 museos más visitados del mundo, superando al Prado ${ }^{19}$ de forma sorprendente.

En consecuencia, parece necesario establecer un control en la afluencia a dicho recinto, en especial los días de gran concurrencia; evitando el hacinamiento y propiciando un mayor disfrute de la visita, la cual también podría verse enriquecida con un buen diseño de información gráfica sobre el origen e historia del palacio, bien en el interior del mismo o en sus inmediaciones. La información actual se reduce a un pequeño panel situado cerca del edificio.

Contrariamente, el Palacio de Velázquez, aun siendo también sede de exposiciones temporales del mismo museo, solo participa ínfimamente en el cómputo total de visitantes. Su edificio (Fig.13) no posee el exotismo del Palacio de Cristal, su escalinata de acceso y aspecto regio, parecen disuadir a la mayoría de visitantes, que también se ven asaltados por la duda sobre su gratuidad. Es evidente que la información y promoción de este recinto son insuficientes.

En el conocimiento de los recursos históricos por parte de los visitantes destaca la antigua Casa de Fieras, conocida por un $50 \%$ de los entrevistados, en los que predominan los de edad avanzada. Un $36 \%$, jóvenes en su mayoría, desconoce todos los recursos históricos.

En cuanto a las actividades, la Feria del Libro es conocida por el 90,6\% de los encuestados, dada su alta proyección y publicidad. Las actividades programadas, como los conciertos y teatro de títeres, presentan un público con información previa, también con aquel debido al encuentro casual de los paseantes.

Por otro lado, el 92\%, no ha realizado una visita guiada, aunque el 81,4 \% de los mismos la realizaría, lo que evidencia que las rutas ofertadas en el parque están infrautilizadas, por falta de información al respecto. Muchos de los encuestados desconocen su existencia, o la app del Retiro con dicha información. $\mathrm{Al}$ parecer tampoco los informadores hacen referencia a dicho recurso.

Figura 17: Finalidad de la visita, recursos y actividades más visitadas.

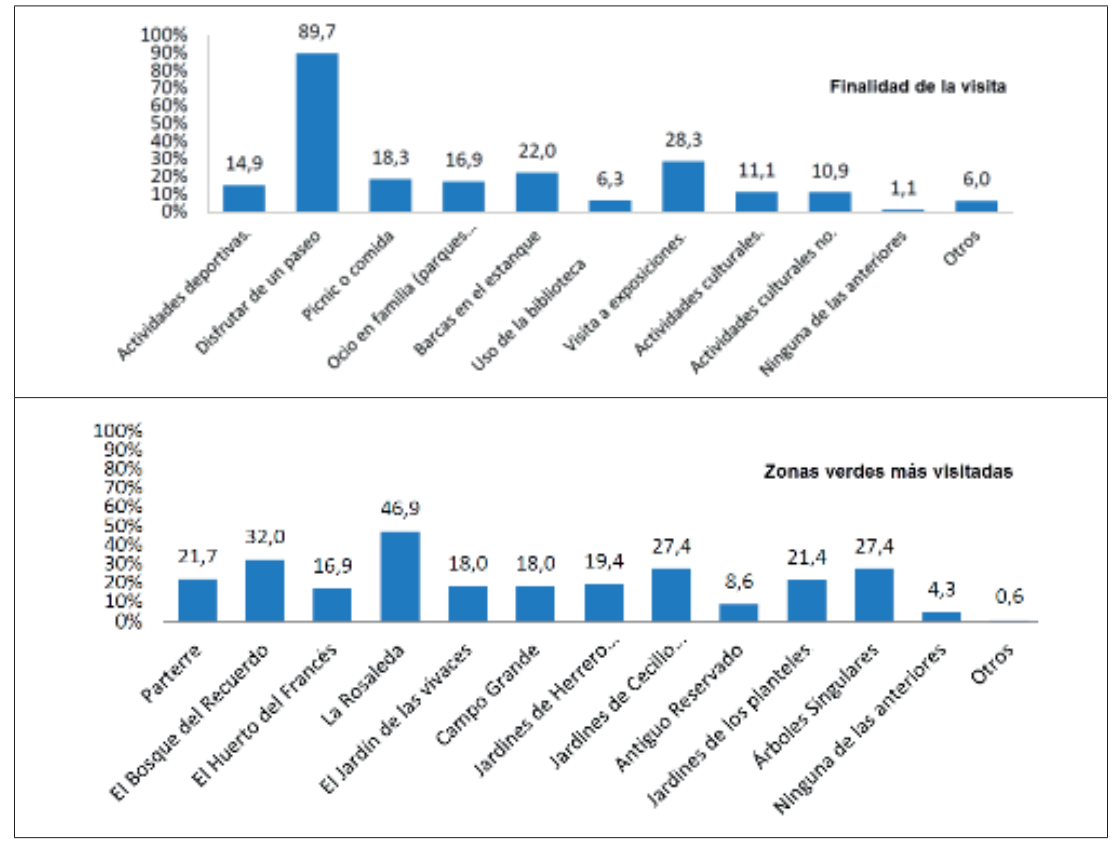


Figura 17: Finalidad de la visita, recursos y actividades más visitadas. (continuación)

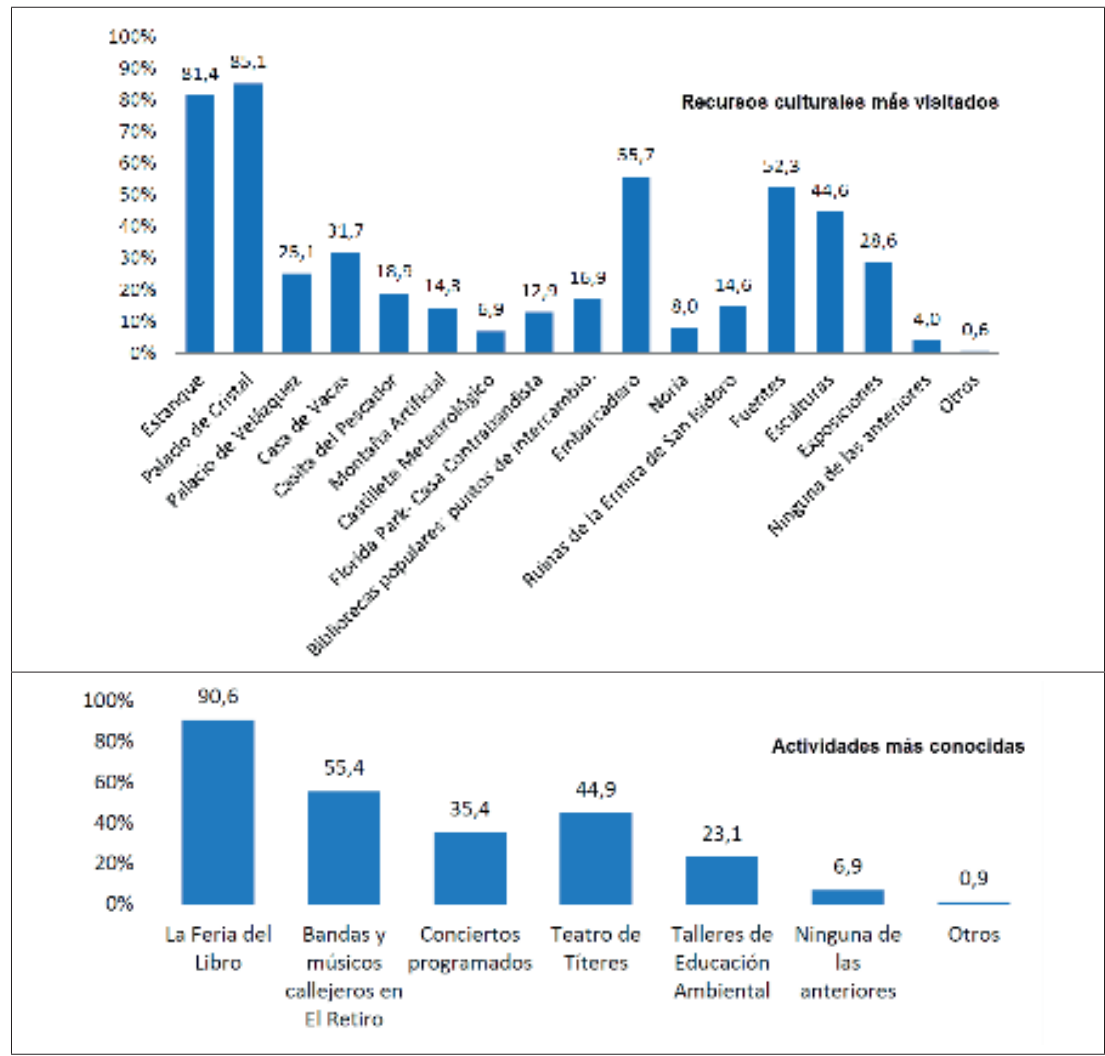

Fuente: Encuesta realizada, elaboración propia.

\subsubsection{Valoración de los componentes del parque, flujos principales y percepción global.}

Los paseos, monumentos y el arbolado alcanzan bastante aceptación. No así los componentes más circunstanciales, como son la información y la señalización (Fig. 18).

\section{Figura 18: La Gestión de El Retiro}

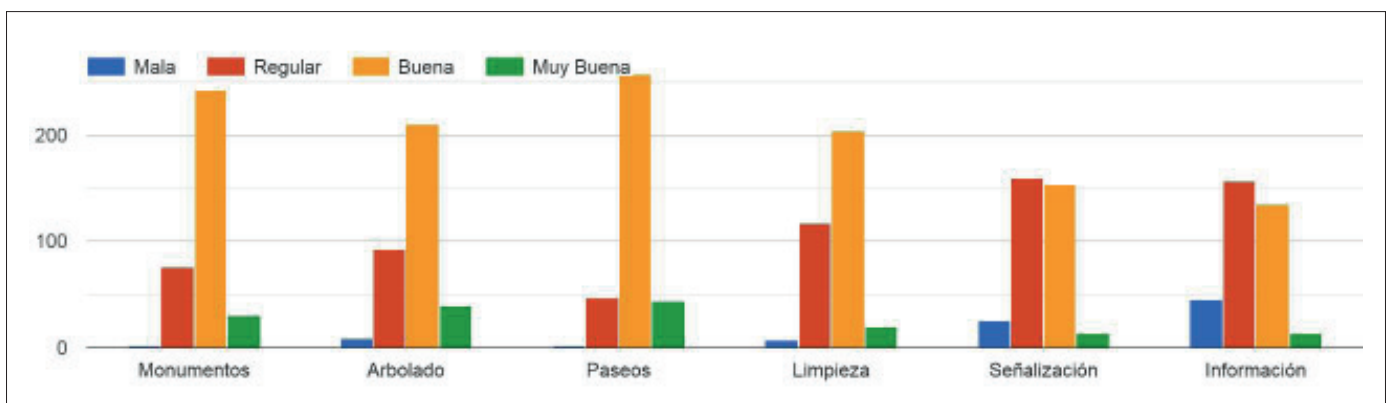

Fuente: Encuesta realizada, elaboración propia.

La Figura 19 muestra las vías del parque más frecuentadas por los visitantes, que vienen a ser aquellas con pavimento y más cómodas de transitar, con una entrada principal en la Puerta de Alcalá (Pza. de la Independencia) y otros tres accesos (Puerta de Felipe IV, Puerta de España y Puerta del 
Ángel Caído) en el lado occidental del parque. El lado oriental es menos frecuentado por el turismo, - exceptuando el periodo correspondiente a la Feria del libro - no así por los locales y el vecindario, donde realizan sus actividades deportivas o recreativas.

\section{Figura 19. Itinerarios más frecuentados por los visitantes.}

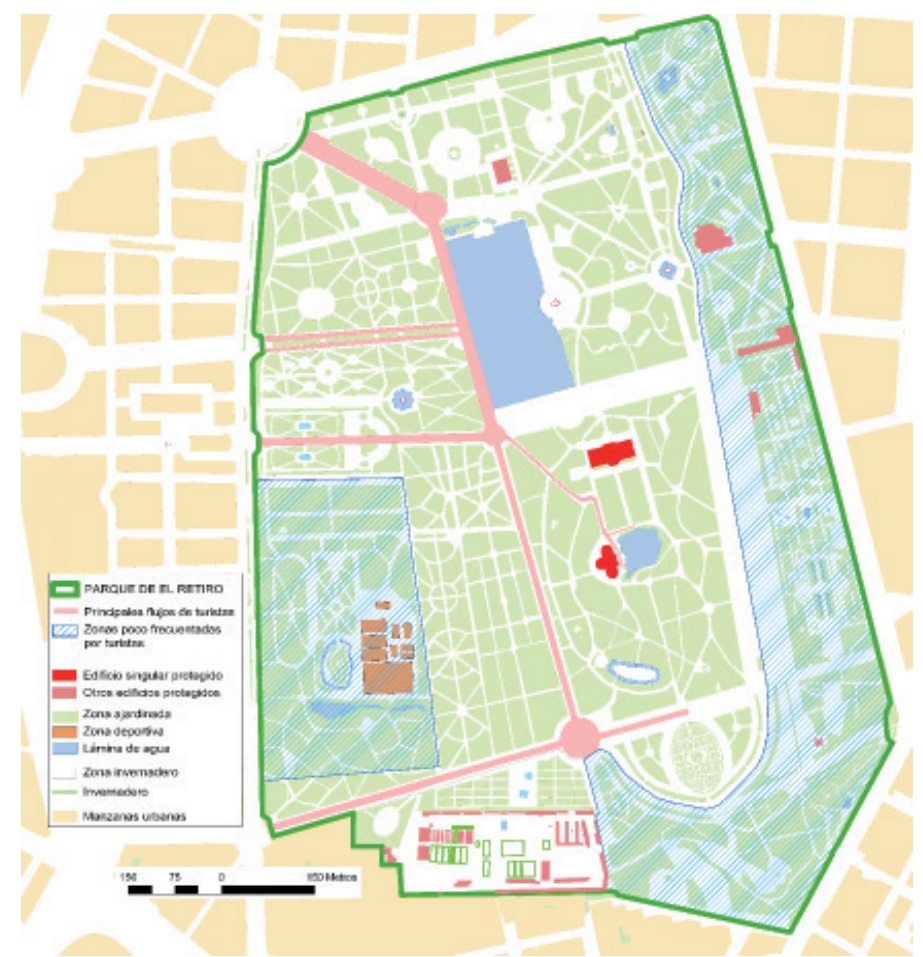

Fuente: Elaboración propia.

Entre los edificios singulares y protegidos, solo el Palacio de Cristal forma parte de estos flujos, en tanto que el Palacio de Velázquez, próximo al anterior, es muy poco visitado, al igual que otros recursos localizados en su mayoría en el sector oriental: Caprichos de Fernando VII, Florida Retiro, la biblioteca Eugenio Trías - ubicada en la antigua Casa de Fieras -, o los jardines de Cecilio Rodríguez.

En la percepción global del parque por los visitantes, el 35,4 \% de los encuestados lo sienten como un lugar de ocio y recreo, el 31,1 \% resaltan su patrimonio natural, el 18, 9 \% el histórico y monumental y el $12 \%$ el cultural. Así resulta que la valoración del patrimonio natural supera a la suma de las correspondientes a monumentos y actividades culturales.

Sorprende gratamente que algunos encuestados lo consideren un espacio que engloba todos los aspectos, idea que ha presidido la realización de este trabajo.

\section{Conclusiones}

La reciente presentación del parque de El Retiro y de su entorno urbano y monumental colindante, como candidatura a la lista del Patrimonio Mundial de la UNESCO, es circunstancia merecedora del análisis y valoración de dicho patrimonio abordados por este trabajo.

El Retiro presenta un patrimonio heterogéneo, característico de un jardín histórico, donde lo natural manejado por la intervención humana, forma parte de la cultura, de igual manera que los monumentos, esculturas y bienes de ornato en general.

$\mathrm{El}$ aspecto más valorado por los visitantes es la belleza del entorno y la integración en el mismo de los conjuntos escultóricos y arquitectónicos; aunque el conocimiento de la historia de estos últimos no alcanza el nivel que merecerían, que además podría proporcionar un mayor disfrute al visitante. 
El Retiro es también un lugar de encuentro de culturas, tal como se desprende de su historia, de la procedencia actual de sus visitantes y de algunas manifestaciones culturales que se realizan en su interior.

El trabajo de campo muestra como el patrimonio y su conservación están estrechamente relacionados con el turismo y el uso ciudadano, donde el visitante que conoce y valora el recurso, lo divulga y hace posible que perdure. En esta interacción patrimonio-visitantes, también se ha podido detectar algunos problemas relacionados con la gestión del parque y con su uso.

En relación con el mantenimiento y gestión del parque, cabe mencionar las dificultades inherentes a la dispersión y reparto de competencias entre diferentes empresas privadas y las administraciones del Estado y municipal, provocando ausencias de iniciativas y tareas necesarias, en ocasiones urgentes, para dicho mantenimiento. Una tarea compleja dada la diversidad de especies vegetales con necesarios cuidados específicos, o las interacciones con el patrimonio monumental producidas por el desarrollo del arbolado, y más aún las derivadas de la gran afluencia de público en algunas áreas; todo lo cual hace necesario un seguimiento constante.

En lo referente a la información, tanto sobre el patrimonio cultural y natural como de las actividades que se realizan en el parque, resulta evidente una falta de centralización de aquella, tanto en centros de información como de forma virtual. Deficiencias que se traducen en la infrautilización de los recursos del parque.

Como es bastante habitual en la geografía hispana, rica en patrimonio, en una visita a El Retiro también se puede sentir la ausencia de una mayor enfatización y realce de lo que se está visitando, (pancartas informativas, agentes o empleados en número suficiente, etc.), a la par que una mayor vigilancia y regulación de la afluencia de público en fechas señaladas; no ya por la salvaguarda del patrimonio, también por el propio visitante y la calidad de su visita o experiencia.

En definitiva, cabe la satisfacción colectiva por la pervivencia y vistosidad que ha mantenido este espacio a lo largo de la historia. También la gratitud hacia todos los que lo han hecho y lo hacen posible. No obstante, tras las épocas anteriores en las que fue de uso exclusivo de la realeza y después de 152 años de uso público, hoy estamos frente a una evidente masificación, especialmente en días señalados. En suma, esta nueva situación solo será sostenible con medios materiales y humanos adecuados y suficientes.

\section{Agradecimientos}

Agradecemos a siguientes personas relacionadas con el parque la realización de las correspondientes entrevistas:

- Técnico en Jardines Históricos de la Comunidad de Madrid (que ha preferido mantener su anonimato)

- Laura Harguindey, coordinadora de La Cabaña de El Retiro, y Educadora Ambiental

- Iván Ramos, encargado de rutas en La Cabaña de El Retiro.

- Ignacio Bazarra Rodríguez, Asociación Amigos de los Jardines del Buen Retiro.

\section{Bibliografía}

Aguinaga López, E. de (2011). Las puertas del Retiro. En Instituto de Estudios Madrileños, El parque del Buen Retiro. (345-360). Madrid: Instituto de Estudios Madrileños, CSIC.

Aparisi Laporta, L.M. (2011a). La Casa de Fieras. En Instituto de Estudios Madrileños, El parque del Buen Retiro. (377-410). Madrid: Instituto de Estudios Madrileños, CSIC.

Aparisi Laporta, L.M. (2011b). Esculturas y otros elementos ornamentales. En Instituto de Estudios Madrileños, El parque del Buen Retiro. (15-50). Madrid: Instituto de Estudios Madrileños, CSIC.

Aram, F.; Solgi, E.; Higueras García, E.; Mosavi, A. \& Várkonyi-Kóczy, A. R. (2019). The Cooling Effect of Large-Scale Urban Parks on Surrounding Area Thermal Comfort. Energies 2019, 12, 3904, 1-21. https:// doi.org/10.3390/en12203904

Ayuntamiento de Madrid (2016a). Plan Director del Arbolado de Los Jardines del Buen Retiro. Resumen Ejecutivo. https://www.madrid.es/UnidadesDescentralizadas/Agua/PlanRetiro/ResumenEjecutivo_PDArboladoRetiro.pdf

Ayuntamiento de Madrid (2016b). Parques Históricos de Madrid: Jardines de El Buen Retiro. [APP] Disponible en appstore o googleplay.

Ayuntamiento de Madrid (2019a). Arbolado parques históricos, singulares y forestales actualizado en 2019. [Base de datos del arbolado en parques y zonas verdes de Madrid]. https://datos.madrid.es/portal/site/ egob/menuitem.c05c1f754a33a9fbe4b2e4b284f1a5a0/?vgnextoid=0101507f09436610VgnVCM2000001f 4a900aRCRD\&vgnextchannel=374512b9ace9f310VgnVCM100000171f5a0aRCRD\&vgnextfmt=default 
Ayuntamiento de Madrid (2019b). Monumentos de la ciudad de Madrid. [Base de datos]. https://datos. madrid.es/portal/site/egob/menuitem.c05c1f754a33a9fbe4b2e4b284f1a5a0/?vgnextoid=eb8e993ae32 2b610VgnVCM1000001d4a900aRCRD\&vgnextchannel=374512b9ace9f310VgnVCM100000171f5a0aR CRD\&vgnextfmt $=$ default

Ayuntamiento de Madrid (2019c). Monumentos y Edificios Singulares [Base de datos]. https://patrimonioypaisaje.madrid.es/portales/monumenta/es/Monumentos-y-Edificios-Singulares/

Ayuntamiento de Madrid (2019d). Teatro de Títeres [Web]. https://teatrotiteresretiro.es/

Brown J. \& Elliot, J. H. (2016). Un palacio para el rey. El Buen Retiro y la corte de Felipe IV, Taurus (Reedición actualizada y ampliada; $1^{a}$ ed. inglesa 1980).

Cabello Carro, P. (2014). Del Patrimonio de la Corona hasta el actual Patrimonio Nacional (1819-1950). Patrimonio Cultural y Derecho, $N^{o} 18$, pp. 249-288.

Carlos Peña, A. de (2011) El monumento de Alfonso XII en El Retiro. En Instituto de Estudios Madrileños, El parque del Buen Retiro. (15-50). Madrid: Instituto de Estudios Madrileños, CSIC.

Cayetano Martín, M.C. (2011). El Retiro “municipal” en el siglo XIX. En Instituto de Estudios Madrileños, El parque del Buen Retiro. (181-207). Madrid: Instituto de Estudios Madrileños, CSIC.

Comunidad de Madrid (2013). Catálogo Regional de Especies Amenazadas de Fauna y Silvestres, y de Árboles Singulares. Guías de la Naturaleza. Consejería de Medio Ambiente, Ordenación del Territorio y Sostenibilidad. http://www.madrid.org/bvirtual/BVCM003442.pdf

Decreto 18/1992, de 26 de marzo, por el que se aprueba el Catálogo Regional de Especies Amenazadas de Fauna y Flora Silvestres y se crea la categoría de árboles singulares. Boletín Oficial de la Comunidad de Madrid, 85, de 09 de abril de 1992, pp 5-11. http://www.madrid.org/rlma_web/html/web/FichaNormativa. icm?ID $=654 \#$

Domínguez Díez, R. (2019). El arroyo de la Castellana: origen del paseo del Prado, Recoletos y Castellana. Madrid Histórico, $\mathrm{N}^{\circ} .82,76-81$.

Durán Cermeño, C. (2002). Jardines del Buen Retiro. Ediciones Doce Calles.

Feria del Libro (2020). Feria del Libro de Madrid. http://www.ferialibromadrid.com/wp-content/uploads/2019/10/ Dossier_de_patrocinio_de_la_feria_libro_madrid.pdf

Flórez Asencio, M. A. (1998). El Coliseo del Buen Retiro en el siglo XVII: teatro público y cortesano. En Anales de historia del arte Vol. 8, 171-196.

García Fernández, J. (2007). "La regulación y la gestión del Patrimonio Histórico-Artístico durante la Segunda República (1931-1939)". e-rph, $\mathrm{n}^{\circ}$ 1, 1-46. Revista electrónica de protección del patrimonio. http://www. revistadepa-trimonio.es/revistas/numero1/legislacion/estudios/articulo.php.

García Gómez, L. (2017). El Retiro paso a paso: guía del parque. Naperma ediciones.

Gómez-Moreno, F.J.; Artíñano, B.; Díaz Ramiro, E.; Barreiro, M.; Núñez, L.; Coz, E.; Dimitroulopoulou, C.; Vardoulakis, S.; Yagüe, C.; Maqueda, G.; Sastre, M.; Román-Cascón, C.; Santamaría, J.M. \& Borge R. (2019). "Urban vegetation and particle air pollution: Experimental campaigns in a traffic hotspot". Environmental Pollution 247, 195-205. DOI: 10.1016/j.envpol.2019.01.016.

Mariblanca Caneyro, R. (1991). El Retiro, sus orígenes y todo lo demás (1460-1988). Ayuntamiento de Madrid, Junta Municipal de Retiro.

Mariblanca Caneyro, R. (2008). Historia del Buen Retiro. Ediciones La Librería.

Museo Nacional Centro de Arte Reina Sofía (2020). El Museo Reina Sofía aumenta un 12\% los visitantes en 2019. https://www.museoreinasofia.es/sites/default/files/notas-de-prensa/nota_visitantes_2019_reina_sofia.pdf

Museo Nacional del Prado (2020). Datos de visitas. https://www.museodelprado.es/museo/datos-visitas

Orden 68/2015, de 20 de enero, de la Consejería de Medio Ambiente y Ordenación del Territorio, por la que se modifica el Catálogo Regional de Especies Amenazadas de Fauna y Flora Silvestres de la Comunidad de Madrid, en su categoría de "Árboles Singulares". Boletín Oficial de la Comunidad de Madrid, 29, 4 de febrero de 2015, pp 53-58. https://www.bocm.es/boletin/CM_Orden_BOCM/2015/02/04/BOCM-20150204-8.PDF

Palomar Anguas, M.P. (2019). La protección del patrimonio: Iniciativas a nivel mundial y el caso de España. En La protección del patrimonio y su uso turístico (pp. 13-48). Dykinson.

Simón Palmer, $\mathrm{M}^{\mathrm{a}}$ C. (1991). El Retiro, parque de Madrid. Ediciones La Librería.

UNESCO (1972). Convención para la protección del patrimonio mundial, cultural y natural, Aprobada en París el 21 de noviembre de 1972. http://whc.unesco.org/archive/convention-es.pdf

\section{Notas}

Entre febrero y noviembre de 2019.

La encuesta se realizó durante una semana en febrero de 2019, tanto de forma presencial - en horas de mañana y tarde, en días laborables y del fin de semana - como online en redes sociales. Para ello, la segunda de las coautoras contó con la colaboración de la asociación cultural AEGEE, de los trabajadores de la Cabaña de El Retiro y los educadores ambientales del CREAS de Pozuelo de Alarcón. Así se obtuvo una muestra con tamaño y representatividad aceptables. 
3 En la actualidad España es el tercer país, tras Italia (54) y China (53), con 48 bienes inscritos.

4 Con el exilio de Isabel II en 1868, el Gobierno Provisional del Sexenio Revolucionario dictó un Decreto creando el Consejo encargado de la "custodia, conservación y administración de los bienes que constituyeron la Corona de España", que entre otros incluía el Real Sitio del Buen Retiro. A los pocos días dicho Consejo entregó este Real Sitio al Ayuntamiento de Madrid, ya como parque de recreo. "El 26 de junio de 1876 una nueva Ley restituyó a la Corona los bienes incautados en 1869 por el original y pactado procedimiento de dar por válidos los bienes que figuraban en la Ley de 1865, con excepción los que han sido enajenados ó dedicados a servicios públicos"(Cabello, 2014).

5 En 1935, por la Orden de 8 de febrero de 1935 publicada en la Gaceta de Madrid, núm. 47, de 16 de febrero de 1935 se declaró Jardín Artístico el del Buen Retiro (García, 2007).

6 Con la Ley 16/1985, de 25 de junio, del Patrimonio Histórico Español.

$7 \quad$ El expediente se presentó ante la Unesco a comienzos de 2019, para su estudio y evaluación por el Comité de Patrimonio Mundial en julio de 2020. Ya en 2015 el Parque de El Retiro había sido incluido en la Lista Indicativa de la UNESCO, con la denominación "Sitio del Retiro y el Pardo en Madrid", requisito previo para poder presentar su candidatura formal.

8 Municipal, autonómica y estatal.

9 Con Felipe II ya se menciona la existencia de un lago y canales naturales, que posteriormente (Felipe IV y Felipe V) fue transformado en el estanque grande de hoy.

10 Durante el reinado de los Reyes Católicos este monasterio se situaba en la ribera del río Manzanares, por ello un lugar menos salubre que el nuevo emplazamiento, donde fue reconstruido según el estilo gótico tardío.

11 Solo permanecen del mismo el Casón del Buen Retiro, que fue salón de baile y representaciones teatrales, y el Salón de Reinos, estancia destinada a recepciones y actos oficiales y posteriormente sede del museo del ejército, hasta el traslado de este al Alcázar de Toledo. Ambos edificios forman parte de la actual ampliación del museo del Prado.

12 La primera colección de animales salvajes se localizó en las inmediaciones del Real Gabinete de Historia Natural, ya con Carlos III; pero el olor poco soportable y su ubicación junto al Paseo del Prado motivó su traslado al extremo más alejado del parque.

13 Una descripción detallada del patrimonio cultural relativo a monumentos, esculturas y ornato general del parque, es la realizada por Aparisi (2011b).

14 En el Archivo Real de Palacio, en los fondos de Administraciones Patrimoniales, Sección Buen Retiro, expediente 11760.5, se pueden encontrar distintos documentos sobre los viajes en globo en el jardín histórico. Así, el 17 de agosto de 1792 Vicente Lunardi pide permiso real para realizar la primera ascensión en globo aerostático en los jardines del Retiro. Voló durante casi una hora hasta Daganzo, cerca de Alcalá de Henares.

15 También en el mismo archivo y sección anteriores, con expediente 10687.58, se puede encontrar el programa de festejos y combates navales durante el reinado de Isabel II, con descripción detallada de los elementos necesarios para ellos.

16 En el siglo XX se llegaron a contabilizar 20.000 visitantes en un solo día. Fue el Zoo de Madrid hasta 1972, cuando se trasladó a las instalaciones de Batán. En la actualidad, sus instalaciones albergan la biblioteca Eugenio de Trías.

17 La instalación realizada por este monarca, fue conocida como la Leonera, al igual que la debida a Felipe IV, situándose en el lado oriental del parque.

18 No existen datos oficiales sobre el perfil y las motivaciones de los usuarios del parque. Sí estimaciones de su número a partir del contaje de visitantes al Palacio de Cristal., que en 2019 se acercó a los dos millones. Para paliar esta falta de información se ha realizado la encuesta, ya mencionada anteriormente en la metodología del trabajo.

19 Durante 2019 el Museo Nacional Centro de Arte Reina Sofía recibió un total de 4.425 .699 visitantes: 1.714 .049 corresponden a la sede principal, 1.994. 979 al Palacio de Cristal, y 716.671 al de Velázquez (Museo Reina Sofía, 2020). Ese mismo año, el Museo del Prado tuvo 3.203.417 visitas (Museo del Prado, 2020). 


\title{
O engajamento on-line do consumidor em mídias sociais de serviços turísticos: uma análise comparativa entre as companhias aéreas brasileiras a partir de suas fanpages
}

\author{
Jacilene Barbosa de Arruda* André Falcão Durão** \\ Alexandre César Batista da Silva*** \\ Carla Borba da Mota Silveira***** \\ Universidade Federal de Pernambuco (Brasil)
}

\begin{abstract}
Resumo: Esta pesquisa teve por objetivo analisar de que forma se dá o engajamento dos consumidores com as companhias aéreas em suas respectivas fanpages. Como suporte teórico, utilizou TICs e mídias sociais, serviços turísticos e o engajamento do consumidor. Trata-se de uma investigação exploratório-descritiva, com abordagem qualitativa e o estudo de casos múltiplos como estratégia de pesquisa. Os resultados mostraram que as fanpages das companhias aéreas precisam de ajustes no que diz respeito à frequência de postagem, postagens de vídeo, redução do tamanho das postagens escritas e resposta ao usuário.
\end{abstract}

Palavras-chave: Companhias aéreas; Mídias sociais; Facebook; Engajamento do consumidor.

On-line consumer engagement on tourism services' socialmedia: a comparative analysis between brazilian air companies' fanpages

Abstract: The overall objective of the research was to analyse how air companies engage with their clients in their respective fan_pages of their regions. The methodology used was critical discourse analysis of air companies fan-pages. This is exploratory-descriptive research, with a qualitative approach and the study of multiple cases as a research strategy. The results show that airline fan pages need greater updating, video posts, longer postings, and greater reponse to their users.

Keywords: Airlines; Social media; Facebook; Consumer engagement.

\section{Introdução}

A Web 2.0 é caracterizada por não ser mais apenas um ambiente estático ou de leitura, como na Web 1.0, pois permite que sejam desenvolvidas respostas mais inteligentes aos usuários, por meio do grande número de compartilhamentos e interações que ocorrem nesse ambiente. Lévy e Lemos (2010) denominaram essa nova onda de computação social, afirmando que nela a criação e organização de conteúdo são feitos pelos próprios utilizadores.

A então chamada Web 2.0, caracterizada por O'Reilly (2007) foi uma nova visão de internet, onde os usuários passaram a ter uma interação maior. mídias sociais como o Facebook, o Instagram e o Twitter são criações deste período.

Nesse contexto de Web 2.0 ou participativa, o Facebook se destaca como ferramenta que agrega os usuários e propicia, constantemente, novas interações por meio de atualizações, o que direciona comportamentos, dadas as regras de utilização, sempre buscando aprimorar a vivência experienciada na rede, tornando-a mais eficiente e de fácil utilização (Oliveira et al., 2017).

\footnotetext{
* Universidade Federal de Pernambuco (Brasil); E-mail: jacilenebarbosa2013.2@gmail.com; https://orcid.org/0000-0002-7190-4598

* Universidade Federal de Pernambuco (Brasil); E-mail: afdurao@gmail.com; https://orcid.org/0000-0001-7505-7173

*** Universidade Federal de Pernambuco (Brasil); E-mail: acbspe@uol.com.br; https://orcid.org/0000-0001-7411-8579

*** Universidade Federal de Pernambuco (Brasil); E-mail: carlaborbasilvera@gmail.com; https://orcid.org/0000-0003-0540-8577
} 
Porém, essa lógica não se restringe apenas à interação entre pessoas, mas também entre empresas e entre empresas e consumidores. Assim, no contexto corporativo, faz-se necessário compreender quem é o cliente que está por trás da linha virtual, qual o seu comportamento diante de ações realizadas dentro e fora da realidade virtual e que tipo de ferramentas são fundamentais para que as empresas consigam atingir e atender aos anseios desses consumidores. E, no caso desta pesquisa, que tem por foco as companhias aéreas, para que estas consigam atingir suas metas de satisfação do cliente por meio de atividades on-line ligadas diretamente às atividades que ocorrem simultaneamente no "mundo real".

Com a internet e suas múltiplas possibilidades de comunicação e interação, empresas de serviços turísticos modificaram fortemente a forma de relacionamento com seus consumidores. As empresas prestadoras de serviços de transporte aéreo, em um contexto da atividade turística, também fazem parte deste conjunto de organizações que tiveram que readequar suas formas de lidar com clientes/ turistas.

Segundo dados do Global Digital Report da agência We Are Social (2019), o número de pessoas com internet no Brasil é de 149 milhões ( $70 \%$ da população). Neste período houve o aumento de 7,2\% dos usuários nas mídias sociais. Os dados também evidenciam que o Brasil está em terceiro no ranking de países que os usuários passam mais tempo na internet, são mais de 9 horas navegando e mais de 3 horas diárias gastas nas mídias sociais.

Ainda segundo dados da Agência We Are Social (2019), os brasileiros passam em média 13min55s na mídia social Facebook, diariamente, sendo uma das mais utilizadas, com destaque para os vídeos que são postados na rede, pois apresentam um percentual de engajamento de $6,83 \%$ dos seguidores das páginas, seguido pelos links de compartilhamento, que representam $6,46 \%$ (contra a média de $5,23 \%$ e $3,90 \%$ dos demais países) e em terceiro lugar estão as fotos, com 5,84\% no percentual de engajamento.

O engajamento, que pode ser entendido como a forma de comprometimento de uma pessoa com alguma coisa por meio da indução, do incitamento e do convencimento, é utilizado para mensurar o desempenho do Facebook e de outras mídias sociais como ferramenta de divulgação (Silva et al., 2013).

De acordo com Fernandes (2019), dos cinco apps (aplicativos) mais baixados no Mundo, quatro são de interação social, são eles: Facebook Messenger, Facebook, WhatsApp e Instagram respectivamente. As possibilidades de uso destas ferramentas por empresas e consumidores são extremamente relevantes, assim como uma pesquisa sobre sua utilização por prestadores de serviços aéreos.

Dados do Balanço de 2017 do Ministério dos Transportes, Portos e Aviação Civil (2018) brasileiro, indicam que:

A movimentação de passageiros (embarque e desembarque) nos aeroportos brasileiros registrou aumento em 10 dos 12 meses do ano de 2017. No comparativo com 2016, o aumento registrado foi de $2,33 \%$. Os 20 principais aeroportos, responsáveis por $90 \%$ da movimentação de passageiros, movimentaram 205,91 milhões de viajantes contra 201,22 milhões no ano anterior(parág. 1).

Ainda de acordo com o ministério dos transportes, portos e aviação civil (2017), a movimentação no mercado doméstico teve um crescimento de $2,12 \%$ no ano. Já as viagens internacionais registraram alta de $4,20 \%$, o que se deve, segundo o ministro da pasta, ao crescimento positivo das expectativas econômicas, que tendem a evoluir e apresentar taxas de crescimento acima de $4 \%$ ao ano, a partir de 2019 (Ministério dos Transportes, Portos e Aviação Civil, 2018).

Tendo em vista a importância desse contexto, as empresas prestadoras de serviços de transportes aéreos não podem ficar alheias a essa evolução tecnológica e devem utilizar suas mídias sociais on-line como ferramentas essenciais de comunicação e venda no mercado, integrando o seu mix de marketing. É importante que essas práticas estejam em consonância com o perfil do consumidor atual, cada vez mais exigente, ávido por informações e por experiências prazerosas no ambiente virtual.

Dado o cenário apresentado, esta pesquisa tem por foco de análise o Facebook das quatro companhias aéreas com maior representatividade no mercado brasileiro: LATAM, GOL, AZUL e AVIANCA (Agência Nacional de Aviação Civil [ANAC], 2018).

A LATAM tem o maior número de seguidores (11.363.540) na sua página do Facebook. Logo em seguida está a Azul Linhas Aéreas, com o total de 4.152.280 seguidores em sua Fanpage. A GOL alcançou 1 milhão de fãs 2 anos depois de sua chegada nesta rede social e atualmente conta com 3.521.685 seguidores em sua página. Já a AVIANCA é a que possui a menor quantidade de seguidores (1.653.661). 
Assim, esta pesquisa estabelece um comparativo entre essas quatro companhias aéreas, destacando a quantidade de seguidores em suas páginas no Facebook e seus respectivos percentuais de engajamento (que serão discutidos no decorrer deste trabalho), além de apresentar uma tipologia de postagens, onde alguns tipos de posts geram mais engajamento que outros.

Tomando por base a premissa de que as companhias aéreas LATAM, GOL, AZUL e AVIANCA, são as empresas aéreas que investem em mídias sociais na atualidade, sendo esta uma das razões que motivou o desenvolvimento desta pesquisa, emerge o questionamento norteador do estudo:de que forma se dá o engajamento dos consumidores das companhias aéreas brasileiras em suas respectivas Fanpages?

Para o desenvolvimento dos resultados da pesquisa, foram utilizados como metodologia, a ferramenta LikeAlyzer e a observação on-line não participante. As empresas aéreas LATAM, GOL e AZUL oscilam no engajamento on-line, enquanto a empresa aérea AVIANCA, segundo resultados da pesquisa, apresenta dificuldades nesta rede social (Facebook). Os resultados, portanto, mostraram que as fanpages das companhias aéreas precisam de ajustes no que diz respeito à frequência de postagem, postagens de vídeo, redução do tamanho das postagens escritas e resposta ao usuário.

\section{Revisão de literatura}

\subsection{Redes Sociais e Serviços Turísticos}

Segundo a OMT (2013), os consumidores estão tendo mais acesso às informações sobre produtos e serviços oferecidos pelas organizações, com mais facilidade e rapidez. Por isso estão se tornando cada vez mais exigentes e atentos às práticas que são utilizadas pelas empresas para convencê-los de que seus produtos e serviços atendem melhor às suas necessidades.

De acordo com pesquisa Global (2018) da PricewaterhouseCoopers sobre o comportamento do consumidor brasileiro e suas compras on-line na internet, cerca de $46 \%$ dos entrevistados citaram que as mídias sociais são a fonte de inspiração mais influente na decisão de consumo.

Dentre as vantagens da internet para as organizações, Ogden e Criscitelli (2007) destaca o baixo custo, a agilidade, as formas múltiplas de mensuração, o marketing personalizado, a possibilidade de obter informações sobre os clientes por meio de tecnologias existentes e, assim, poder direcionar seus serviços e a distribuição irrestrita da informação.

Ainda de acordo com Ogden e Criscitelli (2007), para que as mídias sociais de uma empresa sejam utilizadas como ferramentas eficientes de e-marketing, o planejador, além de ter uma compreensão básica de internet, deve elaborar o plano de marketing digital objetivando fortalecer três pilares que sustentam a base do negócio digital: a comunicação, o relacionamento e as vendas.

Para Reino (2012), as empresas precisam executar práticas que possibilitem o estreitamento das relações com os clientes por meio das mídias sociais, já que são canais amplamente utilizados na atualidade, que propiciam interação e a troca de informações de maneira rápida, prática e eficiente. Além disso, para Lacerda (2018), as mudanças na forma da busca por informação no ambiente virtual impactaram drasticamente o processo de decisão e compra do consumidor, evidenciando-se, assim, a importância de planejar bem as ações corporativas de mídias nas mídias sociais.

As mídias sociais, juntamente com outras práticas on-line como sites, blogs, vlogs, entre outros, fazem parte de um conjunto conhecido como mídias sociais, que integram perfis de usuários e comunidades geradas pelos próprios consumidores ou pelas empresas, de maneira que contribuam com uma aproximação e a sensação de estarem mais íntimos com todos que delas fazem parte. Para Yadav e Pavlou (2014), esta interação é de constante mudança, já que as transformações na comunicação não são estáveis. A cada momento, na atualidade, surge uma nova forma de interagir e gerar comunicação, como novos recursos (aplicativos, novas mídias e programas) e assim proporcionar ainda mais experiências e relacionamentos empresa-cliente.

Com enfoque nas mídias sociais, Baldan, Eras, Fedichina e Gozzi (2011) indicam que "as mídias sociais podem contribuir para o fortalecimento da relação com clientes, o que tem feito com que as organizações tenham iniciado um processo de relacionamento e divulgação por meio das novas mídias” (p. 1).

O processo de comunicação e informacão, por meio da internet e mídias sociais, está se tornando um elemento fundamental na competitividade das entidades e destinos turísticos, bem como nas relações que definem o sistema turístico (Mihajlović, 2012).

O rápido desenvolvimento das tecnologias de informação, particularmente a internet, modificou drasticamente o contexto socioeconômico da atividade turística e são esperadas outras mudanças ao 
longo do tempo. Desde sua introdução, a internet se tornou o principal canal de distribuição de negócios relacionados ao turismo, estabelecendo um elo entre a comunicação e as vendas aos consumidores (Jang, 2004; Menezes \& Cunha, 2013), abrangendo praticamente todos os setores ligados ao trade turístico, onde pode-se destacar o de transporte aéreo.

O setor aéreo possui uma intensa competitividade, por isso as empresas aéreas precisam conhecer as necessidades, expectativas e prioridades dos seus clientes para aumentar a vantagem competitiva (Basfirinci \& Mitra, 2015).

Para Hussain, Nasser e Hussain (2015) em função de um setor aéreo competitivo, a satisfação do cliente não é suficiente, é preciso ultrapassar suas expectativas criando relacionamentos de longo prazo, de fidelidade à marca.

Uma das ferramentas que pode ser utilizada para fomentar relações de longo prazo entre clientes e empresas, promovendo a fidelização, são as mídias sociais e a capacidade das empresas em engajar seus consumidores no ambiente on-line corporativo e, consequentemente, obter resultados positivos duradouros, como evidenciado a seguir.

\subsection{Engajamento do Consumidor on-line}

A web, por meio das mídias sociais, permite que os atores das redes sociais participem, colaborem, promovam, compartilhem, opinem e discutam conteúdo e informação de maneira bilateral (Primo, 2007; Suzart \& Dias Filho, 2009; Terra, 2010), o que inclui interagir com as marcas que agora passam a figurar no ambiente on-line por meio das mídias sociais.

A internet permite que os consumidores virtuais pesquisem, comparem preços e declarem sua opinião sobre o produto, marca ou empresa (Cavallini, 2008). Para Santiago (2009, p. 43), os usuários também querem estar inseridos e conectados na web 2.0, pois buscam a socialização.

A ideia de se engajar com uma comunidade de consumidores foi proposta por Algesheimer, Dholakia e Herrmann (2005), que conceituaram o envolvimento da comunidade como uma "motivação intrínseca dos membros para interagir e cooperar com os membros da comunidade" (p. 21).

O engajamento do consumidor é impactado tanto pelo posicionamento em relação ao que a pessoa vivenciou, como também pelo posicionamento em relação aos fatos vivenciados por outras pessoas envolvidas (Gonçalves, 2009). Além disso, as interações aumentam o investimento e o envolvimento emocional, psicológico e físico que um consumidor tem por uma marca (Foreplay, 2011).

Sinha, Ahuja e Medury (2011) argumentam que, quando o conhecimento do consumidor sobre uma marca aumenta (através da mídia social), também aumenta o apego emocional à marca, independentemente do conteúdo das comunicações sociais da marca ser funcional ou emocional por natureza.

Segundo Rodrigues e Toaldo (2015), “o Relatório Anual de Engajamento Digital do Consumidor define engajamento como interações frequentes que fortalecem as relações emocionais, psicológicas ou físicas entre o consumidor e a marca" (p. 5).

Já o Instituto de Pesquisas Forrester Research (2015), dos Estados Unidos da América (EUA), entende que o engajamento está relacionado com o nível de determinados fatores, como o envolvimento, a interação, a intimidade e a influência que um indivíduo obtém com determinada marca ao longo do tempo.

Damacena e Marra (2012) afirmam que pesquisas sobre engajamento vêm crescendo cada vez mais em diversas áreas. Embora sujeito a várias interpretações, engajamento do consumidor é frequentemente entendido como um construto motivacional, com intensidade variada. Envolve um objeto (ou seja, uma marca) e um assunto (isto é, o consumidor), e tem uma valência (positiva versus negativa) (Brodie et al., 2011a; Hollebeek\& Chen, 2014).

Sheehan e Morrison (2009) apontam para a necessidade de criatividade no desenvolvimento de mensagens de marca que possam ser efetivamente entregues na mídia social e tradicional, ao mesmo tempo em que estimula o engajamento do consumidor a fim de produzir resultados de marca desejados.

As estratégias criativas podem aumentar a motivação, a oportunidade e/ou a capacidade do receptor de processar informações de um anúncio (Macinnis, Moorman\&Jaworski, 1991). Turchi (2012) acredita que "não basta apenas uma sacada criativa para o sucesso de uma campanha: planejamento e inteligência digital são fundamentais". (p. 70)

Pelo exposto, observa-se a relevância que a estratégia desenvolvida pelas empresas nas suas mídias sociais tem, uma vez que essas ferramentas propiciam que ocorra o engajamento do consumidor e, mais que isso, também a interação, para que ele se sinta parte da empresa e tenha uma integração de forma mais efetiva. 


\section{Metodologia}

Esta pesquisa caracterizou-se como exploratória e descritiva, de caráter qualitativo. A pesquisa exploratória se restringe à definição dos objetivos e a busca de maiores informações, neste caso, sobre o uso de mídias sociais por companhias aéreas. De acordo com Cervo et al.(2007) e Flick (2009), estudos de natureza exploratória objetivam a familiarização ou nova percepção de um certo fenômeno, podendo advir novas ideias ou formulações de ideias mais gerais. Na pesquisa descritiva estuda-se a relação entre o assunto abordado, a comunidade ou grupo em questão e a realidade pesquisada, onde é realizada a análise e descrição destes.

A estratégia de pesquisa adotada foi a de estudos de casos múltiplos, utilizando-se da observação on-line não participante que, segundo Ferreira et al. (2012), acontece em um cenário onde o pesquisador não está diretamente envolvido na situação analisada e não interage com o objeto da observação.

A observação on-line não participante foi realizada durante o período de três meses (março, abril e maio de 2018), no qual foram observados os conteúdos postados pelas empresas aéreas LATAM, GOL, AZUL e AVIANCA em suas páginas na rede social Facebook e a influência desses posts como ferramenta para o engajamento do consumidor.

Para análise do conteúdo on-line assumiu-se uma postura interpretativista, que segundo Mabrouki (2014) não se pode ter uma única representação da realidade, sendo esta representada pela observação do pesquisador na rede social Facebook.

Quanto à abordagem do problema norteador do estudo, a pesquisa caracteriza-se como qualitativa que, segundo Santos e Costa (2015) “[...] pode ser configurada em cenários presenciais ou on-line”. (p.59). A pesquisa quando realizada no cenário on-line permite a observação com mais afinco.

A coleta dos dados foi feita com a utilização da ferramenta LikeAlyzer, no período de março/ abril de 2018. Esta ferramenta já foi utilizada em estudos anteriores (Angelis, 2014; Afonso, 2014; Pires, 2017; Medeiros, 2016; França, 2017; Alcantara, 2018). A ferramenta LikeAlyzer, criada pela empresa Meltwater, permite a obtenção de valores das páginas no Facebook e o acesso a dados e a taxa de crescimento/decréscimo de utilizadores e seus níveis de interação. Outra vantagem da utilização desta ferramenta é que os dados obtidos reportam-se sempre a um espaço de 30 dias, o que torna possível ter uma ideia da forma de funcionamento da página e se a estratégia a ser usada apresenta bons resultados, sendo possível também obter recomendações para melhorias na página que está sendoanalisada, permitindo verificar se esta forma de comunicação está, ou não, sendo bem aproveitada.

\section{Resultados e análises}

\subsection{Dados Descritivos Ferramenta LikeAlyzer}

Segundo a ferramenta LikeAlyzer, o visual (foto/vídeo do perfil e capa) das páginas das empresas aéreas LATAM, GOL, AZUL e AVIANCA no Facebook oferecem para o visitante uma ótima primeira impressão, indicando uma percepção inicial positiva dos usuários sobre as páginas das empresas pesquisadas.

Outro aspecto avaliado por meio da ferramenta foi a quantidade de informações que as empresas disponibilizam na fanpage e, de forma complementar, o LikeRank ${ }^{\mathrm{TM}}$ (Pontuação da página no Facebook de $0 \%$ a $100 \%$ ), sendo estes dados representados na tabela 1.

\section{Tabela 1: Informações na Fanpage}

\begin{tabular}{|l|c|c|c|c|}
\hline LikeAlyzer & LATAM & GOL & AZUL & AVIANCA \\
\hline LikeRank $^{\mathbf{T M}}$ & $67 \%$ & $68 \%$ & $66 \%$ & $66 \%$ \\
\hline Sobre as empresas & $56 \%$ & $81 \%$ & $56 \%$ & $100 \%$ \\
\hline
\end{tabular}

Fonte: Elaborado pelos autores (2019)

Foram destacados itens como: marcos históricos, informações de contato e localização. Outro ponto avaliado foi a atividade, ou seja, como estas empresas estão utilizando esta rede social para se comunicar com o público. Sendo estes resultados demonstrados na tabela 2. 
Tabela 2: Atividade no Facebook

\begin{tabular}{|l|c|c|c|c|}
\hline LikeAlyzer & LATAM & GOL & AZUL & AVIANCA \\
\hline Atividade & $57 \%$ & $57 \%$ & $64 \%$ & $86 \%$ \\
\hline Fotos & $17 \%$ & $0 \%$ & $53 \%$ & $75 \%$ \\
\hline Notas & $75 \%$ & $0 \%$ & $6 \%$ & $0 \%$ \\
\hline Vídeos & $8 \%$ & $100 \%$ & $41 \%$ & $25 \%$ \\
\hline Posts por dia & 0.4 & 0.2 & 0.6 & 0.9 \\
\hline Eventos & 0 & 0 & 0 & 0 \\
\hline Vídeos nativos do Facebook & 13 & 25 & 25 & 25 \\
\hline Tamanho médio do post & 120 & 206 & 168 & 147 \\
\hline Páginas curtidas & 1 & 10 & 1 & 44 \\
\hline
\end{tabular}

Fonte: Elaborado pelos autores (2019)

Apenas a companhia aérea AVIANCA consegue manter o nível de atividade na rede social, as demais empresas aéreas, segundo indica a ferramenta LikeAlyzer (2018), deixam seus seguidores desejando mais. A pontuação sobre as fotos no Facebook é de $0 \%$ apenas para a companhia aérea GOL, as demais companhias aéreas apresentam índices baixos e medianos, respectivamente. Quando se avalia o item notas, a pontuação é satisfatória apenas para a LATAM. No que se refere aos vídeos, os postados pela GOL apresentam-se como extremamente satisfatórios.

Com relação à quantidade de posts diários, é evidenciado pela LikeAlyzer (2018) que uma página de Facebook deve otimizar o número de mensagens por dia para aumentar o engajamento do usuário, postar muito pouco ou demais pode prejudicar o engajamento. A AVIANCA possui a maior média de posts/dia e a GOL a menor média. É necessário que esta atividade no Facebook seja bem direcionada e consequentemente aproveitada.

Os vídeos nativos do Facebook representam valores iguais para as companhias aéreas GOL, AZUL e AVIANCA (25 vídeos/companhia aérea), apenas a LATAM possui um quantitativo inferior às demais (13 vídeos), e representam o tipo mais envolvente de conteúdo no Facebook. As páginas que os aproveitam provavelmente melhorarão o seu nível de engajamento total entre seus seguidores (LikeAlyzer, 2018).

O tamanho médio dos posts das empresas LATAM, AVIANCA, AZUL e GOL variam entre 120-206 caracteres. Segundo dados da pesquisa apresentados pela empresa Meltwater, responsável pela ferramenta LikeAlyzer, o tamanho do post é um item muito importante, no qual mensagens cujo tamanho varia entre 40-100 caracteres, em média, são responsáveis por mais engajamento entre os usuários. Caracteriza-se pelo envolvimento que o usuário possui com uma determinada fanpage, onde o envolvimento é a percepção de uma pessoa sobre a relevância do objeto em questão com base em necessidades, valores e interesses inerentes (Zaichkowsky, 1985, p. 342).

Curiosidade e diálogo entre páginas incentivam o interesse de domínio cruzado e melhora o engajamento geral (LikeAlyzer, 2018). Os usuários da rede social Facebook no momento em que decidem seguir determinada página, se sentem ansiosos por interagir com as mesmas, para isso é preciso que as companhias aéreas responsáveis por estas mídias sociais possuam agilidade em dar respostas para estes usuários, é aconselhado reduzir o tempo entre um post do usuário e a resposta da empresa. Uma taxa de resposta rápida indica uma marca que se importa com seus fãs/ seguidores (LikeAlyzer, 2018).

Os níveis de resposta das companhias aéreas LATAM, GOL e AZUL são classificados em 100\%, já na companhia aérea AVIANCA os usuários não podem postar e a capacidade de resposta da Fanpage desta empresa é de $0 \%$, o que prejudica a relação da empresa com os consumidores, pois permitir que os usuários postem em uma página é o primeiro passo para aumentar o engajamento (LikeAlyzer, 2018), já que a ausência de interações frequentes enfraquece as relações emocionais e psicológicas entre o consumidor e marca, algo fundamental para o engajamento (Rodrigues \& Toaldo, 2015).

Com relação ao engajamento em si dos usuários com as páginas das empresas, os resultados estão apresentados na tabela 3 . 


\section{Tabela 3: Engajamento}

\begin{tabular}{|l|l|l|l|l|}
\hline LikeAlyzer & LATAM & GOL & AZUL & AVIANCA \\
\hline Engajamento & $55 \%$ & $45 \%$ & $48 \%$ & $43 \%$ \\
\hline Pessoas falando sobre isso & 10.043 & 23.502 & 23.063 & 14.015 \\
\hline Total de Likes da Página & 11.285 .528 & 3.521 .677 & 4.185 .221 & 1.650 .467 \\
\hline
\end{tabular}

Fonte: Elaborado pelos autores (2019)

Observa-se que o engajamento das empresas com os usuários é bem próximo, tendo a LATAM o melhor resultado, mas não tão distante das outas três empresas e, como pode ser observado, as companhias aéreas podem melhorar nesse quesito. A quantidade de pessoas falando sobre isso é medida por meio da qual observa-se o quantitativo de pessoas que interagiram com a página ou com o conteúdo, de qualquer maneira, nos últimos sete dias. Já no que se refere ao total de Likes na Página, quanto maior melhor, quanto mais seguidores atuais a página adquire mais alcance terá. Segundo Chu e Kim (2011), o número de fãs que essas páginas apresentam é considerado um dos mais fortes indicadores do poder da marca da empresa.

\subsection{Observação on-line não participante}

Como método maior de aprofundamento foi investigado na rede social Facebook publicações que apresentassem um contexto maior de envolvimento dos usuários nas fanpages da LATAM, GOL, AZUL e AVIANCA. As publicações analisadas foram dos meses de março, abril e maio de 2018, somando o total de 28 publicações da companhia aérea LATAM, 21 publicações da companhia aérea GOL, 52 publicações da companhia aérea AZUL e 65 publicações da companhia aérea AVIANCA. Foram analisados itens como: total de reações, comentários e compartilhamentos de cada publicação destes meses citados. Sendo apresentado na tabela 4 o quantitativo de reações de cada publicação, a qual representou um maior nível de envolvimento com os usuários desta rede social.

Souza (2016) descreve as possibilidades de reações que os usuários podem ter às postagens no Facebook e o que elas podem significar. O Like não expressa nenhuma forte reação ou mudança de humor em relação a alguma publicação no perfil de um amigo ou página de marcas. Também é a opção mais "preguiçosa", já que um simples clique no botão conta como curtida no post. O Like também pode ser usado para demonstrar aprovação de um argumento, notícia ou foto no seu feed, embora não tão forte quanto o Amei. A ideia por trás desse botão do Facebook é demonstrar forte aprovação a uma atualização publicada na rede. O Haha é voltado para conteúdos engraçados, substituindo até mesmo os antigos comentários de risos. Há quem o use para ser irônico/sarcástico ou demonstrar um pouco mais de simpatia que o simples Curti. O Uau é o novo botão ideal para quando algo lhe surpreende no Facebook. O Sad também pode ser usado como forma de desaprovação. O Grr é a reação que pode ser usada para demonstrar raiva ou total desaprovação com o conteúdo publicado nesta rede social.

Tabela 4: Total de reações na postagem

\begin{tabular}{|l|l|}
\hline LATAM & 29.190 \\
\hline GOL & 18.714 \\
\hline AZUL & 60.762 \\
\hline AVIANCA & 11.000 \\
\hline
\end{tabular}

Fonte: Elaborado pelos autores (2019)

A postagem da empresa aérea LATAM nesta rede social foi publicada às $10 \mathrm{~h}$, no dia 18 de Abril de 2018 (quarta-feira). Uma divulgação sobre a LATAM Cargo (serviço de transporte de cargas), tendo como mensagem o texto "sua encomenda de norte a sul no mesmo dia" junto a uma imagem que retrata as regiões e a entrega de uma encomenda. O dia e horário também são requisitos para um maior alcance de público, o quantitativo de reações na postagem desta companhia dividiu-se em 29 mil likes, 121 
reações do tipo love, 38 do tipo haha, 17 do tipo wow, 2 do tipo sad e 12 do tipo angry. Para Perinoto (2013), pode-se reafirmar que a imagem é um item de grande relevância para a quantidade de reações, o que pôde ser verificado nessa postagem.

A empresa aérea GOL teve o menor número de publicações entre os meses observados (março, abril e maio). A postagem que gerou o maior quantitativo de reações foi em formato de vídeo, sendo este publicado às 19h28min, no dia 20 de Março de 2018, alcançando o total de 926 mil visualizações, tendo como legenda de publicação: "Para buscar a sexta estrela a gente vai até o céu! Confira a nova pintura da aeronave Canarinho, pronta para decolar rumo ao Hexa! GOL. Transportadora Oficial da Seleção e dos Brasileiros. \#VoaCanarinho \#VoeGOL”. O quantitativo de reações nesta postagem dividiu-se em 17 mil likes, 1 mil love, 62 haha, 617 wow, 5 sad e 30 angry.

A postagem da empresa aérea AZUL no Facebook gerou o maior número de reações em comparativo com as demais fanpages (LATAM, GOL e AVIANCA), a mesma procura interagir com os usuários desta rede social por meio de uma pergunta em complemento à imagem postada, um dos itens essenciais na busca pelo engajamento. Postagens que contêm citações, perguntas, dicas, solicitação de participação do usuário em perguntas convidativas, postagens diferentes na fanpage, memes, temas em alta, imagens, vídeos, "concursos" (do tipo "marque um amigo"), chamadas para ação (do tipo "comente aqui" ou "clique no link para saber mais"), trivias (podendo utilizar-se também das hashtags para maior engajamento do usuário), links, posts compartilhados por outras páginas do Facebook, Storytelling possuem melhor engajamento quando postadas em formato de vídeo). A postagem foi realizada no dia 7 de Maio de 2018, sendo publicada em período noturno do início da semana, onde as reações dividiram-se em 55 mil likes, 4,4 mil love, 46 haha, 1,3 mil wow, 10 sad e 6 angry. Segundo Gastal (2005) quando se relaciona marketing digital e turismo, a imagem é extremamente relevante para este alcance de público.

A AVIANCA, por meio de sua rede social Facebook, fez uma publicação em homenagem ao Dia Internacional da Mulher (08 de março), porém a mesma recebeu diversos comentários de insatisfação para com a publicação e para com a didática da empresa em certos acontecimentos, tendo esta o menor índice de engajamento em comparativo com as demais companhias aéreas (LATAM, GOL e AZUL). O fato de ter feito uma publicação em homenagem ao Dia Internacional da Mulher e neste dia a empresa ter realizado um voo com a tripulação apenas do sexo feminino gerou revolta entre seus usuários. A postagem contém duas fotos, cada uma possui o total de 118 e 182 reações, respectivamente. Já a publicação totaliza 11 mil reações, onde 1,8 mil demonstra sentir-se zangada com a publicação.

Os comentários analisados foram ditos os mais relevantes, que são os comentários de amigos e de pessoas com mais visualizações, reações, respostas e outros que aparecem no topo. O quantitativo de compartilhamentos demonstra o quanto este usuário está envolvido com a postagem. Na tabela 5 está representado o número total de comentários e compartilhamentos das quatro postagens que tiveram o maior nível de engajamento.

\section{Tabela 5: Comentários e Compartilhamentos na publicação}

\begin{tabular}{|l|c|c|}
\hline Empresa & Comentários & Compartilhamentos \\
\hline LATAM & 107 & 141 \\
\hline GOL & 935 & $3,1(\mathrm{mil})$ \\
\hline AZUL & $1,6(\mathrm{mil})$ & $2,405(\mathrm{mil})$ \\
\hline AVIANCA & $1,4(\mathrm{mil})$ & 264 \\
\hline
\end{tabular}

Fonte: Elaborado pelos autores (2019)

Todos os comentários ditos relevantes contêm diversos tipos de reclamações para com a empresa LATAM, sobre vários tipos de serviços prestados pela empresa. O comentário do topo possui o maior número de reações (likes) que os comentários dos demais usuários, o comentário foi feito dois dias após a postagem no período da tarde. A LATAM respondeu a este usuário no mesmo dia do comentário já em período noturno, o feedback foi reportado 13 dias após o último comentário da LATAM, sendo ele, segundo a reclamação, satisfatório.

A empresa aérea GOL teve o maior número de compartilhamentos em comparativo com as demais empresas aéreas (LATAM, AZUL e AVIANCA). Os comentários na postagem desta companhia aérea 
dividiram-se em elogios, algumas reclamações e sugestões. O comentário do topo possui 40 reações, divididas em 33 likes, 2 love e 5 haha. A partir deste comentário surgem 35 respostas, onde a GOL se pronuncia 6 vezes, os usuários criaram um certo "bate-papo" neste comentário do topo, o qual teve fim 36 dias após a postagem da GOL, onde este comentário inicial do tipo relevante fez alusão à legenda de publicação da empresa aérea GOL, fazendo também uma reclamação referente ao serviço de bordo (WI-FI) e o lanche servido nos voos desta empresa aérea, a partir desse momento o usuário também ironiza a publicação da GOL através de seu comentário, enaltecendo o valor/importância do cliente GOL para a Companhia Aérea. As respostas que surgem a seguir se apoiam neste comentário inicial contando também seus relatos, em acordo ou desacordo com este.

A publicação da AZUL teve o maior número de comentários entre as fanpages observadas (LATAM, GOL e AVIANCA). A empresa foi a única que teve como resultado da análise de publicações na fanpage, do item comentários mais relevantes, o comentário do topo com destaque para elogio. O usuário reage com um comentário feliz e recebe 48 tipos de reações, gerando novos comentários/respostas (25 respostas), os usuários formam um tipo de "bate-papo" neste comentário do topo onde discutem sobre suas profissões, questões financeiras e a capacidade/planejamento de viajar para Paris (foto em destaque), a cada nova resposta neste comentário inicial surgem novas reações, demonstrando envolvimento com a publicação. Os demais comentários do tipo relevantes possuem elogios, relatos e algumas reclamações. Apenas um único usuário respondeu uniformemente ao conteúdo/pergunta postado pela AZUL na rede social Facebook, o usuário marcou outros 5 amigos na postagem "dizendo levá-las para Paris em seu aniversário", é importante ressaltar que o usuário ao marcar outros usuários em uma postagem, faz com que o público para essa publicação também aumente, atingindo um maior alcance de postagem, este fato corrobora com os argumentos de Falls (2010).

A publicação da AVIANCA gerou revolta entre seus usuários onde os comentários expõem casos de assédio em voos, entre outros assuntos, que segundo estes usuários foram "vedados" pela empresa aérea. O comentário inicial possui 199 reações (valor maior que as reações nas duas fotos da publicação), deste comentário inicial surgem 22 respostas, a AVIANCA se pronuncia no dia seguinte ao comentário, porém não satisfaz aos anseios de seus usuários, logo as respostas se estendem até o dia 14 de Março. Apenas uma pequena parcela de usuários faz comentários parabenizando a empresa. A resposta da companhia aérea AVIANCA ao comentário inicial obteve 76 reações, onde 49 usuários responderam com tonalidade raivosa, a mensagem dizia: "Oi, Jacky! Na verdade, o que fizemos de diferente neste dia foi apenas acompanhar o voo desta tripulação. Não é incomum que esse tipo de escala exista aqui na Avianca Brasil. :)".

\section{Considerações finais}

O engajamento do consumidor on-line com as empresas aéreas LATAM, GOL, AZUL e AVIANCA revela-se por meio das interações de seus usuários em suas fanpages. Estas interações ocorrem por meio dos comentários deixados no post, pelas reações e ele, pelos compartilhamentos, pelas curtidas na página, pelas opiniões sobre cada empresa aérea e pelos elegios, críticas e sugestões. A audiência do cliente pode ser vista como uma medida da qualidade de uma relação entre o cliente e uma empresa (De Wulf \& Odekerken-Schro“Der, 2001).

A fanpage da companhia aérea LATAM caracteriza-se por não curtir e interagir com as demais páginas do Facebook. As companhias aéreas GOL e AZUL se mostram atenciosas com os seus internautas nesta rede social, a AVIANCA possui conteúdos que chamam a atenção, porém os seguidores não podem postar conteúdo nesta página, o que dificulta o engajamento destes usuários. São pontos semelhantes entre essas empresas: a quantidade de conteúdo postado e a falta de eventos no Facebook, porém estas empresas levam vantagem quando se faz referência ao tamanho do post, pois demonstram prezar pela qualidade do mesmo, resultando no excelente engajamento, corroborando com a argumentação de Sheehan e Morrison (2009).

A análise realizada possibilitou observar que há pontos a serem melhorados, onde beneficiam-se tanto os usuários quanto as respectivas empresas aéreas, ao abordar suas carências enquanto fanpages e sua influência na qualidade e prestação do serviço, apontando suas fraquezas à medida que avalia suas referências de engajamento. Estas empresas têm potencial para melhorarem suas ações e postagens nesta rede social, tendo como resultado a otimização da prestação de serviço ao consumidor favorecendo o engajamento on-line. 
Este estudo sobre as companhias aéreas brasileiras e suas mídias sociais, neste caso (o Facebook) se torna de grande valia para futuras pesquisas sobre engajamento do consumidor on-line e serviços turísticos, em específico, o serviço de transporte aéreo, uma vez que dispõe de grande quantidade de informações sobre estes, sendo recomendado para futuras pesquisas a exploração também de outras mídias sociais, como o Twitter e o Instagram destas empresas.

\section{Bibliografía}

Afonso, C. (2014). A utilização de plataformas de social media pelos museus. Lisboa: ISCTE-IUL, 2014. (Dissertação de mestrado). Recuperado de:http://hdl.handle.net/10071/9446

Alcantara, J. (2018). Distribuição de conteúdo nas redes sociais, desafios a serem vencidos e estratégias para enfrentá-los. Ano XIV, n. 05. maio/2018. NAMID/UFPB - Recuperado de: http://periodicos. ufpb.br/ojs2/index.php/tematica

Algesheimer, R. \& Dholakia, U. M. \& Herrmann, A. (2005). The social influence of brand community: evidence from European car clubs, Journal of Marketing, Vol. 69 No. 3, pp. 19-34.

Angelis, F. (2014). Governança em tempos de redes sociais e as manifestações de junho de 2013 no Brasil. Democracia Digital e Governo Eletrônico, Florianópolis, $n^{\circ} 11, p$. 264-294.

Balanço 2017 (2018). Recuperado de http://transportes.gov.br/ultimas-noticias/6769-setor-a\%C3\%A9reo-registra-crescimento-de- $2 \% 2 \mathrm{C} 33$-na-movimenta $\% \mathrm{C} 3 \% \mathrm{~A} 7 \% \mathrm{C} 3 \% \mathrm{~A} 30$-de-passageiros-e-10\%2C 47 -nas-cargas.html

Baldan, A. K., Eras, A. L., Fedichina, M. A. H. \& Gozzi, S. (2011). A Estratégia de Relacionamento com o Cliente por meio das Redes Sociais. Anais do XIV Seminários em Administração, São Paulo, SP, Brasil.

Basfirinci, C. \& Mitra, A. (2015). A cross cultural investigation of airlines service quality through integration of Servqual and the Kano model. Journal of Air Transport Management, v. 42, p. 239-248.

Brodie, J. R., Hollebeek, L., Juric, B. \& Ilic, A. (2011). Consumer engagement: conceptual domain, fundamental propositions and implications for research, Journal of Service Research, Vol. 14 No. 3, pp. 252-271.

Cavallini, R. (2008). O marketing depois de amanhã: explorando novas tecnologias para revolucionar a comunicação. 2 ed. São Paulo.

Cervo, A. et al. (2007). Metodologia científica. 6. ed. São Paulo: Pearson Prentice Hall.

Chu, S. C. \& Kim, Y. (2011). Determinants of consumer engagement in electronic word-of-mouth (eWOM) in social networking sites. International journal of Advertising, v. 30, n. 1, p. 47-75.

Damacena, C. \& Marra, G. S. (2012). Engajamento do consumidor: revisão teórica do conceito e seus antecedentes. São Paulo. Recuperado de: <http://www.regeusp.com.br/arquivos/2013.2.6.pdf>

De Wulf, K. \& Odekerken-Schro"der, G. (2001). A critical review of theories underlying relationship marketing in the context of explaining consumer relationships, Journal for the Theory of Social Behaviour, Vol. 31 No. 1, pp. 73-102.

Falls, J. (2010). What is engagement and how do we measure it? Social Media Explorer. Recuperado de http://www.socialmediaexplorer.com/2010/01/04/what-isengagement-and-how-to-we-measure-it.

Fernandes, R. (2019). Saiba quais foram os 10 aplicativos mais baixados no mundo. Redes sociais como Facebook, Whatsapp, Instagram e o fenômeno Tik Tok estão na lista. Recuperado de https://www. techtudo.com.br/noticias/2019/01/saiba-quais-foram-os-10-aplicativos-mais-baixados-de-2018-no-mundo.ghtml

Ferreira, L. B., Torrecilha, N. \& Machado, S. H. S. (2012). A técnica de observação em estudos de administração. XXXVI Encontro da ANPAD. Rio de Janeiro/ RJ - 22 a 26 de setembro.

Flick, U. (2009). Uma introdução à pesquisa qualitativa. Porto Alegre: Bookman.

Foreplay. (2011). Relatório mundial de engajamento digital do consumidor 2011: dados, insights e tendências. 2011. Recuperado de http://www.foreplay.com.br/engajamento_digital_2011.pdf.

Forrester (2015). Forrester. Recuperado de https://go.forrester.com/blogs/14-04-29-instagram_is_the_ king_of_social_engagement/.

França, M. N. \& Carvalho, A. M. G. (2017). Monitoramento de mídias sociais: um estudo exploratório em bibliotecas universitárias públicas federais. XVIII Encontro Nacional de Pesquisa em Ciência da Informação - ENANCIB 2017. 23 a 27 de outubro de 2017 - Marília - SP.

Gastal, S. (2005). Turismo, imagens e imaginários. São Paulo: Aleph.

Gonçalves, P. (2009). Modalidade e engajamento em editoriais de imprensa paulistana de bairro. In: Congresso Nacional de Linguística e Filosofia. Anais. Rio de Janeiro: CiFEFIL, 2009. 2115-2127. 
Hollebeek, 1. \& Chen T. (2014). Exploring positively-versus negatively-valenced brand engagement: a conceptual model, Journal of Product \& Brand Management, Vol. 23 No. 1, pp. 62-74.

Hussain, R., Nasser, A. A. \& Hussain, Y. K. (2015). Service quality and customer satisfaction of a UAE-based airline: an empirical investigation. Journal of Air Transport Management, v. 42, p. 167-175.

Jang, S. (2004). The past, present, and future researchof on-line information search. JournalofTravel \& Tourism Marketing, 17(2/3), 41-47.

Lacerda, D.R.A. (2018). Busca por informação no processo decisório dos consumidores: uma interação entre usuários e influenciadores de moda nas midias sociais. Trabalho de Conclusão de Curso, Graduação em Administração, Universidade de Brasília, Brasília, Brasil.

Lemos, A.\& Levy, P. (2010). O Futuro da Internet: Em Direção a uma Ciberdemocracia Planetária . (1st ed.). São Paulo: Paulus Editora.

Likealyzer (2018). Likealyzer. Recuperado de: https://www.meltwater.com/likealyzer-sunset.

Mabrouki, N. (2014). Méthodologie de recherche: regardépistémologique. Recuperado de: <http://economia. $\mathrm{ma} / \mathrm{fr} / \mathrm{bg} /$ nabil-el-mabrouki/methodologie-de-recherche-regard-epistemologique-1>. 2014.

Macinnis, D., Moorman, C. \& Jaworski, B. (1991). Enhancing and measuring consumers'motivation, opportunity and ability to process brand information. Journal of Marketing, 55, 32-53.

Medeiros, D. \& Lucas, E. R. O. (2016). As bibliotecas nacionais latino-americanas e o capital social. Perspect. ciênc. inf., Belo Horizonte, v. 21, n. 4, p. 202-224.

Menezes, V. O. \& Cunha, S. K. (2013). Inovação como instrumento de desenvolvimento da atividade turística. Observatório de Inovação do Turismo Revista Acadêmica.

Mihajlovic, I. (2012). The Impact of Information and Communication Technology (ICT) as a Key Factor of Tourism Development on the Role of Croatian Travel. Agencies International Journal of Business and Social Science. Vol. 3, No. 24

Ogden, J. \& Criscitelli, E. (2007). Comunicação Integrada de Marketing: modelo prático para um plano criativo e inovador. São Paulo: Prentice Hall.

Oliveira, A, Durão, A \& Silveira, C. (2017). Marketing Digital e a Rede Social Facebook nos Serviços Turísticos: uma investigação sobre a interação entre os consumidores finais e a companhia aérea LATAM. Id on Line Multidisciplinary and Psycology Journal, 11(37), 178-195. https://doi.org/10.14295/ idonline.v11i37.820.

Organização Mundial do Turismo (OMT) (2013). E-business para o turismo. Porto Alegre: Bookman, 2013.

O'Reilly, T. (2007). What is Web 2.0: Design Patterns and Business Models for the Next Generation of Software. Communications \& Strategies, 1(First Quarter), 17. https://doi.org/10.2139/ssrn.1008839

Perinotto, A. R. C., 2013. Investigando a comunicação turística de Parnaíba/PIBrasil: Internet e redes sociais, descrição e análise. Turydes: revista de investigación en turismo y desarrollo local, v. 6, n. 15.

Pires, O. (2017). Avaliando a utilização do Facebook como ferramenta de marketing para novos empreendimentos na área de tecnologia da informação. 91 páginas. Trabalho de Conclusão de Curso (graduação) - Universidade Federal do Ceará, Campus de Quixadá, Curso de Redes de Computadores, Quixadá.

PricewaterhouseCoopers. (n.d.). Global Consumer Insights Survey 2018. Recuperado de: https://www. pwc.com.br/pt/setores-atividade/varejo-consumo/gcis2018.html.

Primo, A.(2007). O aspecto relacional das interações na Web 2.0. Recuperado de: <http://www.moodle. ufba.br/file.php/10203/cultura_digital/web2_primo.pdf>.

Reino, L. S. A. (2012). Redes Sociais e Marketing Digital, o Caso do Firula's Café. Recuperado em 30 de setembro de 2019 de http: / /www.bocc.ubi.pt/.

Rodrigues, A. I. \& Toaldo, M. M. (2015). Interação e engajamento entre marcas e consumidores / usuários no Facebook. Recuperado de: <http://portalintercom.org.br/anais/nacional2015/resumos/R10-3205-1.pdf>.

Santiago, A. (2009). O uso corporativo da Web 2.0 e seus efeitos no relacionamento com o consumidor. Recuperado de: http://www.bookess.com/read/3110-o-uso-corporativoda-web-20-e-seus-efeitos-no-relacionamento-com-o-consumidor/.

Santos, V. L. P. \& Costa, C. J. S. A. (2015). A observação on-line como instrumento investigativo: uma experiência utilizando fórum de discussão. Debates em Educação - ISSN 2175-6600. Maceió, Vol. 7 , n. 15, Jul./Dez. 2015.

Sheehan, K. \& Morrison, D. (2009). The creativity challenge: media confluence and its effects on the evolving advertising industry. Journal of Interactive Advertising, 9, 40-43.

Silva, A. P.; Pereira, F. A.; Correia-Neto, J. S. (2013). Engajamento digital: um estudo com páginas de instituições de ensino superior no Facebook. Revista Brasileira de Administração Científica, 4(2), 140-157. http://dx.doi.org/10.6008/ESS2179_684X.2013.002.001므 
Sinha, N., Ahuja, V. \& Medury, Y. (2011). Corporate blogs and internet marketing-using consumer knowledge and emotion as strategic variables to develop consumer engagement. Journal of Database Marketing and Customer Strategy Management, 18, 185-199.

Souza, E. (2016). Entenda os significados dos botões do Facebook Reactions.Techtudo, 2016. Recuperado de: $<$ <ttp://www.techtudo.com.br/dicas-e-tutoriais/noticia/2016/02/grr-uau-haha-entenda-significados-dos-botoes-do-facebook-reactions.html>.

Suzart, J. A. \& Dias Filho, J. M. (2009). A web 2.0 e os programas brasileiros de pós-graduação em Contabilidade. In: Encontro da ANPAD, 33. 2009, São Paulo. Anais eletrônicos. São Paulo: Associação Nacional de Pós-Graduação e Pesquisa em Administração. Recuperado de :<http://www.anpad.org. br/download_pdf.php?cod_edicao_trabalho=10636\&cod_evento_edicao=45>.

Terra, C. (2010). Usuário-mídia: a relação entre a comunicação organizacional e o conteúdo gerado pelo internauta nas mídias sociais. 2010. 217 p. (Tese deDoutorado) - Universidade de São Paulo, São Paulo.

Turchi, S. (2012). Estratégias de marketing digital e-commerce. São Paulo: Atlas, 2012.

We Are Social (2019). Global Digital Report 2019: essential insights into internet, social media,mobile, andecommerce use aroundthe world [Blog]. Recuperado de: https://digitalreport.wearesocial.com/

Yadav, M.S. \& Pavlou, P.A. (2014). Marketing in Computer-Mediated Environments: research synthesis and new directions. Journal of Marketing. Vol. 78, n.1. https://doi.org/10.1509/jm.12.0020

Zaichkowsky, J. (1985). Measuring the involvement construct. Journal of Consumer Research, 12, 341-352. https://doi.org/10.1086/208520

\section{Notas}

1 Realização da análise dos dados com a ferramenta LikeAlyzer no dia 27 de abril de 2018. 


\title{
Instagram: inspiración, reconocimiento social y motivación en la elección del destino turístico
}

\author{
Rosario Lucía Angaramo Corvalán* \\ Investigador independiente
}

\author{
Vanesa Pérez-Torres** \\ Universidad Rey Juan Carlos (España)
}

\begin{abstract}
Resumen: Instagram es una red social basada principalmente en imágenes que contiene gran cantidad de información sobre viajes y turismo. Además, permite explorar destinos a través del contenido publicado por familiares, amigos y conocidos, por empresas turísticas, o por personajes populares como blogueros de viajes o influencers. Este estudio tiene como objetivo analizar las publicaciones de un grupo de influencers en Instagram y su posible relación con la inspiración, el reconocimiento social y la motivación en la elección de destinos turísticos de sus seguidores. Se ha realizado un análisis cualitativo de varias publicaciones realizadas por influencers de viajes a través de la identificación de contenido manifiesto y latente relacionado con el objetivo de la investigación. Los resultados muestran que los seguidores manifiestan su reconocimiento social a los influencers por medio de mensajes de apoyo y "me gusta", se identifican con las actividades que realizan y expresan su motivación por realizar los mismos viajes.
\end{abstract}

Palabras Clave: Instagram; Inspiración; Reconocimiento social; Motivación; Elección de destino.

Instagram: Inspiration, social identification and motivation in the destination choice

Abstract: Instagram is a social media network that uses mainly images that offer information on places and tourism. It allows people to explore destinations through content published by family, friends and acquaintances, tourism companies, or by public figures such as travel bloggers or influencers. The objective of this study is to analyse posts on Instagram of a group of influencers and their possible relationship with inspiration, social identification and motivation in the destination choice of their followers. A qualitative analysis of several Instagram posts uploaded by travel influencers was carried out identifying manifest and latent content of the same relating to the research objective. The findings show that the followers express their social identification with the influencers in comments of support and likes, for the activities the influencers carry out and they express their motivation to travel to the same places.

Keywords: Instagram; Inspiration; Social identification; Motivation; Destination choice.

\section{Introducción}

Las redes sociales se han posicionado como una plataforma importante para la inspiración y motivación en la elección de un destino turístico. Algunas redes sociales pensadas exclusivamente para el turismo, como TripAdvisor, ayudan a los turistas a obtener información sobre distintos lugares así como recomendaciones de las actividades a realizar y otra serie de consejos. También redes sociales como Facebook o Instagram pueden servir como un instrumento a través del cual conocer nuevos destinos, ya que a partir de las publicaciones de los diversos contactos, los usuarios pueden verse inspirados a

* Investigador independiente; E-mail: rosario.ac95@gmail.com; https://orcid.org/0000-0003-2917-1711

* Universidad Rey Juan Carlos (España); E-mail: vanesa.perez@urjc.es; https://orcid.org/0000-0001-6027-2233 
realizar los mismos viajes. Un estudio de Think with Google (2017) señaló que las redes sociales pueden funcionar como una fuente importante de inspiración para los viajes.

Según este estudio, los encuestados se inspiraron en el contenido de viajes publicado por amigos y familiares, por gente anónima y por famosos e influencers.

La red social Instagram se caracteriza por albergar gran cantidad de contenido relacionado con los viajes y el turismo por lo que se trataría de una red social "inspiracional" cuyo contenido más consumido en la plataforma es el de los viajes (47\%), situándose al mismo nivel el contenido "belleza" (The Cocktail Analysis, 2016). Al ser una aplicación basada principalmente en imágenes, consigue crear conciencia de los destinos en los turistas potenciales de manera rápida y sencilla (Özdemir y Çelebi, 2015). Así, proporciona conocimiento sobre los lugares de manera automática, ya que si los turistas potenciales tienen interés en un destino concreto pueden buscarlo por medio de un hashtag o a través de la pestaña de ubicación, mientras que si están buscando inspiración para decidir su próximo viaje, pueden visitar cualquier cuenta de viajes en las que tendrán acceso a gran cantidad de imágenes de distintos sitios turísticos. También puede ocurrir que se vean inspirados por alguna publicación que les llame la atención mientras navegan a través de la red social.

Además, esta plataforma permite explorar el destino a través de diferentes perspectivas, puesto que los usuarios pueden tener acceso al contenido de viajes publicado por sus familiares, amigos y conocidos, por empresas turísticas, o por personajes populares en redes sociales como blogueros de viajes o influencers. Éstos son usuarios muy activos e influyentes en las redes sociales, funcionan como líderes de opinión y desempeñan un papel clave en el entorno en línea (Minazzi, 2015). Los influencers se caracterizan por contar con una cantidad importante de seguidores, por tener un elevado prestigio en su campo de opinión y por generar comportamientos de compra y tendencias concretas (De la Ballina, 2017). Entre los más conocidos influencers de viajes en España se encuentran Viajeros Callejeros, (una pareja joven de Gerona), Enrique Álex (un joven madrileño de 29 años en un viaje continuo sin fecha de fin), Molaviajar (una familia amante de los viajes), Paco Nadal (un periodista especializado en viajes) o Marina Comes (una joven que dejó su trabajo de abogada para viajar).

Las publicaciones realizadas en Instagram por los influencers de viajes suelen estar orientadas a obtener reconocimiento social, aumentar el número de seguidores y fidelizar a los que ya tienen a partir de ofrecerles contenidos atractivos sobre destinos turísticos. Sus seguidores suelen considerarlos personas en las que pueden confiar para tomar decisiones de viaje. La posibilidad de obtener más "me gusta" en sus publicaciones y por tanto más reconocimiento social hace que este tipo de influencers suban gran cantidad de contenidos atractivos sobre sus viajes en Instagram. Sin embargo, su influencia sobre la elección de destinos depende de múltiples factores: por ejemplo, en la investigación de Magno y Cassia (2018), en el que se estudió el impacto de los blogueros de viajes en las intenciones de viaje en sus seguidores, se encontró que la intención de un seguidor de adoptar las sugerencias de viaje proporcionadas por el bloguero dependía tanto de la confianza en el bloguero como de la calidad de la información proporcionada por éste. En otro estudio sobre la utilización del marketing de influencers para el fomento de las áreas rurales en Grecia se sugirió que los influencers podían influir en gran medida en la toma de decisiones de los viajes, sobre todo en la generación de los millennials. Normalmente esta generación tiende a aceptar los mensajes provenientes de los personajes a quienes admiran o consideran como semejantes. También se encontró que la confianza era importante para que los seguidores se vieran influenciados por los influencers, junto a otros factores como la cantidad de seguidores, la personalidad expresada a través de sus publicaciones y la autenticidad de sus actividades realizadas (Chatzigeorgiou, 2017).

Los estudios previos sobre influencers y turismo han estado centrados en su mayoría en redes sociales como Facebook (Leung et al., 2013) y menos en Instagram (Gumpo et al., 2020) por lo que todavía existen pocas investigaciones orientadas a esta red social y a explorar cómo las publicaciones de los influencers pueden estar relacionadas con la inspiración, el reconocimiento social o la motivación para elegir destinos de viajes (Gumpo et al., 2020; Seeler, Lück y Schänzel, 2019). Teniendo en cuenta lo anterior esta investigación pretende ampliar el conocimiento de la utilización de redes sociales para la motivación y la elección de destinos a través del análisis de las publicaciones de los influencers desde una aproximación metodológica cualitativa.

Para lograr este objetivo, se ha llevado a cabo un análisis de contenido de las publicaciones de seis influencers españoles en el ámbito turístico y de los comentarios de sus seguidores en Instagram. El diseño metodológico cualitativo se ha utilizado previamente en investigaciones relacionadas con redes sociales y turismo (Carneiro y Ferreira, 2019; Chatzigeorgiou y Christou, 2020; Martínez-Salas et al., 2019), ya que permite profundizar en los mensajes explícitos (publicaciones de los influencers y comentarios de los seguidores) y en aquellos mensajes implícitos o latentes que se pueden inferir de lo publicado a través de los temas y categorías que surgen del análisis (Andreu, 2000; Chatzigeorgiou 
y Christou, 2020; Piñuel-Raigada, 2002). En los resultados se ha comprobado que los influencers, en general, tienen un impacto en la inspiración, el reconocimiento social y en las elecciones turísticas de sus seguidores. A pesar de ello, no todos tienen el mismo grado de influencia, ya que los influencers de viaje o "travel influencers" son los que más experiencias turísticas comparten, con publicaciones más especializadas, y por tanto más orientadas a las expectativas de viaje de sus seguidores. También se encontró que factores como la similitud en el estilo de vida y la cercanía que muestra el influencer resultan fundamentales para entender la capacidad de influencia que tienen sobre su audiencia.

\section{Revisión de la literatura}

Instagram e inspiración para realizar los viajes: la inspiración es un estado motivacional complejo que puede experimentarse en distintos ámbitos de la vida (Meier y Schäfer, 2018; Thrash et al., 2014). Una revisión de las publicaciones científicas realizadas sobre redes sociales y turismo muestra que éstas tienen influencia en todas las etapas del proceso de viaje, aunque especialmente en las etapas previas de inspiración y planificación (Leung et al., 2013). Los turistas eligen contenido publicado en las redes sociales, motivados principalmente por obtener información de los viajes y poder inspirarse para realizar la planificación de los suyos.

Actualmente los turistas son consumidores de experiencias secundarias de viaje a través de las narrativas digitales de sus amigos, conocidos o influencers en las redes sociales que sirven de fuente de inspiración para sus viajes (Seeler et al., 2019). De acuerdo con Ouwerkerk y Johnson (2016) la inspiración es un motivo importante en la elección de las cuentas a seguir en Instagram. Los resultados de su estudio mostraron que la inspiración se relacionaba significativamente con el tiempo empleado en esta red social, así como con el número de cuentas seguidas. Así, la utilización de Instagram puede proporcionar a los usuarios nuevas ideas e impulsos, lo que podría motivarlos a realizar nuevas actividades y llevar a cabo un nuevo estilo de vida (Meier y Schäfer, 2018).

La inspiración posee tres componentes que pueden ser aplicados al caso de Instagram y los viajes (Thrash et al., 2014). El primero de ellos es la trascendencia y tiene lugar cuando los usuarios toman conciencia de nuevas o mejores posibilidades, como ocurre cuando se conoce un nuevo destino a través de la publicación de un amigo. El segundo es la evocación, dado que se entiende que la inspiración ocurre de manera pasiva y es evocada por el estímulo. Esto significa que la información que se obtiene acerca de ese nuevo destino ocurre por casualidad. El tercer componente es la motivación, pues la inspiración desencadena la motivación, provocando que el individuo realice un viaje a ese mismo destino. Así, Instagram se sitúa como una plataforma que aporta inspiración y que incluso puede activar el deseo de realizar un viaje si el contenido que se encuentra se adapta a la personalidad y gustos del usuario (Meier y Schäfer, 2018).

Instagram, reconocimiento social y motivación en la elección de destinos: Una de las características asociadas a Instagram y su relación con los viajes es la denominada "instagrameabilidad". Ésta hace referencia a las posibilidades de los destinos de ofrecer elementos que puedan obtener más "me gusta" al ser publicados. Lugares con playas populares, monumentos espectaculares, hoteles con vistas excepcionales, piscinas lujosas y comidas exóticas son ejemplos de lo que es "instagrameable". De acuerdo con una encuesta realizada por la compañía de seguros de hogar Schofields Insurance (2017), más del 40\% de los 1.000 británicos encuestados entre 18 y 33 años - por lo tanto, millennials-afirmaron que la "instagrameabilidad" se encontraba entre sus motivos principales en la elección de sus destinos vacacionales. Destaca que la capacidad de los destinos de proporcionar fotografías "instagrameables" fue identificada como la motivación principal, por encima de otros factores presentes en la encuesta como el desarrollo personal, la gastronomía local o las oportunidades de realizar visitas turísticas. También, el informe de Booking (2017) señaló que uno de cada tres viajeros tiene como objetivo tomar fotografías y probar nuevas experiencias para así poder publicarlas en las redes sociales. Del mismo modo, en un estudio de Expedia (2018), los encuestados consideraron las posibilidades de visitar lugares únicos que puedan producir buenas fotografías como un factor importante a la hora de elegir las experiencias y las actividades a realizar en sus viajes. Este tipo de fotografías "instagrameables" sobre viajes y las vacaciones se ha intensificado durante los últimos años. Algunos autores consideran que estas imágenes, como los "selfies" son, en sí mismos, un fenómeno nuevo e importante en la fotografía turística (Balomenou y Garrod, 2019).

Para algunas personas este tipo de fotografías sirven como una herramienta a través de la cual proyectar la imagen deseada de sí mismos. Hay que tener en cuenta que el formato de Instagram y otras redes sociales similares permite a las personas elegir, editar e incluso eliminar con cuidado lo que se publica. Instagram también permite que la audiencia de una persona, en este caso los "seguidores", esté bajo el 
control del usuario, pues éste puede elegir quien forma parte de ella (Moon et al., 2016). Adicionalmente, otros factores también permiten controlar la imagen que se proyecta de uno mismo. Este control puede ser resultado de las posibilidades que ofrecen las cámaras digitales. Los viajeros ahora no tienen que conformarse con aquellas imágenes estéticamente poco atractivas, ya que las que no gustan se pueden borrar, pudiéndose repetir el proceso ilimitadamente. Esto permite a los turistas la experimentación y un mayor control sobre cómo se representan ellos mismos y los lugares que visitan (Urry y Larsen, 2011).

A pesar de que las redes sociales han intensificado el deseo de una vida ideal, autores como Markwell (1997) ya habían notado la existencia de una voluntad de crear una versión de una experiencia que pareciera perfecta para poder ser enseñada al volver a casa. Este autor explicaba que la capacidad de seleccionar qué elementos y paisajes fotografiar brindaba a los turistas un grado de control sobre la evidencia tangible de su experiencia que traían a volver a casa. Por consiguiente, los turistas elegían fotografiar aquello que pudiera reforzar el mito de las vacaciones perfectas.

Esta exaltación del ego también aparece en la propuesta de Dann (1977) como un factor motivador para viajar relacionado con la necesidad de las personas de obtener reconocimiento social. Algunos estudios recientes sugieren que los turistas se centran más en el "yo" que en el destino en sí. En lugar de elogiar lo extraordinario del destino turístico, algunos turistas buscan capturar lo extraordinario de sí mismos. Por tanto, las atracciones turísticas tradicionales adquieren una importancia relativa diferente (Dinhopl y Gretzel, 2016). Ahora el destino ya no es el elemento más importante en las fotografías de un turista, sino el turista y el sitio, siendo este último el escenario del primero (Balomenou y Garrod, 2019).

Otros estudios señalan que el público con el que se comparte el contenido es el que ha ganado mayor importancia en la actividad turística. Dinhopl y Gretzel (2016) sugerían que la audiencia con la que se comparten las fotografías del viaje es fundamental para la experiencia turística. Esta idea también se encuentra en el trabajo de Urry y Larsen (2011), quienes sugerían que la "mirada del turista" también involucraba a amigos, familiares y conocidos, puesto que las miradas individuales están mediadas y afectadas por las miradas de los demás. Esto se debe a que los turistas imaginan cómo se verían en ciertos escenarios turísticos y cómo serían evaluados por sus audiencias (Carneiro y Ferreira, 2019). Dinhopl y Gretzel (2016) también afirmaron que los turistas miran los escenarios con los ojos de su público imaginado.

Para Lo y McKercher (2015), las expectativas de la audiencia desempeñan un papel importante en la formación de la "imagen ideal". Según estos autores, ser consciente de las posibles reacciones de la audiencia con las que se comparten las fotografías del viaje influye significativamente el proceso mediante el cual se capturan y se comparten las fotografías. Esta idea ya había sido expuesta por Markwell (1997) en un estudio sobre las dimensiones sociales de la fotografía. El autor concluyó que la conciencia de la audiencia influía significativamente en el modo por el cual se sacaban y se compartían las fotografías del viaje. Lo y McKercher (2015) también encontraron este fenómeno en las redes sociales, pues los turistas hacen suposiciones sobre cómo reaccionarán sus seguidores a sus publicaciones de las redes sociales. De hecho, sugieren que esas expectativas pueden impulsarlos a publicarlas. Por tanto, se entiende que algunos usuarios de Instagram tienen en cuenta a sus seguidores en el proceso de tomar las fotografías y su posterior publicación en redes, y que además el feedback que pueden recibir los anima a realizar las publicaciones (Carneiro y Ferreira, 2019).

La audiencia juega un papel relevante en el comportamiento de los turistas que publican en Instagram, pues de ellos se espera obtener el reconocimiento social (Lo y McKercher, 2015; Dinhopl y Gretzel, 2016; Urry y Larsen, 2011). Los usuarios activos en las redes sociales, cuando suben contenido propio, buscan el reconocimiento y la aprobación de las personas con las que están conectados y, por tanto, utilizan las redes para construir una imagen de sí mismos que reciba la mirada favorable de los otros (Grace et al., 2012). Este tipo de reconocimiento ha estado presente desde hace décadas en los estudios sobre motivación turística. Por ejemplo, en un estudio de Crompton (1979), varios de los encuestados afirmaban que muchos de sus conocidos viajaban solo para conseguir una buena opinión de los demás. También en los estudios de Riley (1995), donde las actitudes de búsqueda de reconocimiento y prestigio se podían encontrar después de la realización del viaje en la exhibición de recuerdos del lugar visitado. Esta práctica es la que realizan hoy en día todos los viajeros (usuarios e influencers) que exhiben sus experiencias turísticas en Instagram a través de compartir narrativas digitales que buscan reconocimiento social y que pueden influir en la elección de destinos turísticos (Seeler et al., 2019).

\section{Método}

Diseño: Esta investigación tiene un diseño cualitativo basado en el análisis de contenido que permite la interpretación de las publicaciones realizadas en Instagram a partir del contenido manifiesto o explícito (como el título de las publicaciones y los comentarios) y del contenido latente relacionado 
con los destinos turísticos (inspiración, reconocimiento social y motivación), la comparación entre el influencer y los seguidores y el impacto en las decisiones turísticas (Andreu, 2000; Piñuel-Raigada, 2002).

Procedimiento: teniendo en cuenta los objetivos del estudio se ha procedido en primer lugar a la selección de los influencers. Los criterios de selección han sido: 1) influencers españoles con perfil público en Instagram; 2) los perfiles tenían que tener al menos 50 mil seguidores en Instagram, para que sus publicaciones alcanzaran una audiencia de gran tamaño; 3) tenían que tener relación con los viajes y el turismo. Los seis influencers elegidos tenían relación con el ámbito de los viajes y el turismo y se dividieron en tres grupos:

Influencers de viajes: personas que viajan y dan consejos sobre los sitios que visitan, suben vídeos a YouTube y publican artículos en sus blogs. En esta categoría los perfiles que se han escogido han sido los de @Molaviajar (91 mil seguidores) y @Enriquealexgarde (108 mil seguidores). ${ }^{1}$

Fotógrafos de viajes: fotógrafos profesionales que viajan y publican sus fotografías. A diferencia de los influencers de viajes no dan consejos, ni tampoco se exhiben públicamente, tanto en relación a su personalidad como a su físico. A pesar de ello, cuentan con una base de seguidores bastante mayor que la de los influencers de viajes, hasta cuatro o cinco veces más. Los dos perfiles seleccionados para esta categoría han sido@Misswinter (507 mil seguidores) y @Ovunno (417 mil seguidores).

Mega influencers que viajan: son influencers que tienen un carácter más "general", que no se limitan a los viajes y el turismo pero que viajan con asiduidad. La decisión de incluir a este tipo de influencers se tomó por la gran cantidad de seguidores que tenían y la cantidad de viajes que realizan en periodos cortos de tiempo. En esta categoría se han elegido los perfiles de @Dulceida (2,5 millones de seguidores) y @Melomoreno (783 mil seguidores).

En segundo lugar, se procedió a la elección de las publicaciones realizadas por los seis influencers. Esta selección se realizó cada dos semanas durante los meses de julio, agosto y septiembre del año 2018, lo cual resultó muy conveniente, pues durante el periodo estival la publicación de fotografías de viajes aumenta en Instagram en relación con el resto del año. De cada influencer se seleccionó al menos una publicación subida en este intervalo de tiempo. Sin embargo, en algunos casos no se seleccionó ninguna publicación de algunos influencers, pues no todos publicaron algo nuevo durante ese periodo de tiempo.

Se decidió seleccionar aquellas publicaciones que tuvieran relación con los viajes, preferiblemente aquellas en las que en la descripción se hablaba del destino y también aquellas en que las se viera claramente el paisaje o atracción turística relacionada con el destino turístico. Del mismo modo, se seleccionaron aquellas publicaciones que tuvieran un mayor número de comentarios con el objetivo de conseguir un mayor contenido para poder analizar posteriormente. Igualmente, se optó por elegir publicaciones en las que el influencer estuviera en destinos de los que no hubiera publicado anteriormente.

En tercer lugar, se realizó el registro en una ficha de observación donde se añadió la fotografía publicada junto con su pie de foto, la fecha, el destino y el número de "me gusta". También se añadieron los comentarios de los seguidores que fueron seleccionados bajo el criterio del investigador: se prefirió trabajar con aquellos comentarios que resultaban de interés para el objeto de investigación, a la vez que se evitaron comentarios simples y breves con emojis (por ejemplo: “Qué hermosa!", "Preciosa ڤ”). En la ficha de observación se registraron un total de 29 publicaciones, de las que solo 16 cumplían este criterio. Toda la recopilación de los datos se realizó de manera manual.

Análisis de datos: se realizó un análisis de contenido cualitativo de los comentarios realizados por los seguidores de los influencers en las publicaciones registradas en la ficha de observación a través de un proceso de categorización y codificación. Para la realización de la tabla de codificación se ha seguido el proceso denominado "codificación abierta" (perteneciente al análisis cualitativo de datos), en el que el investigador clasifica libremente la información que encuentra para ir descubriendo los temas presentes (Cáceres, 2003). De este modo, se agruparon los comentarios que tuvieran relación entre sí con la finalidad de ir creando códigos. Con la identificación de los códigos fueron surgiendo también las categorías, al encontrar relación entre distintos grupos de códigos. Lo mismo ocurrió con los temas, que iban surgiendo cuando se detectaba alguna relación entre las categorías. De este modo surgieron códigos, categorías y temas.

De acuerdo con el análisis de contenido emergieron tres temas principales:

A) Destinos turísticos: en este tema se agruparon los comentarios en los que la información más relevante se centraba en un lugar de viaje (inspiración, reconocimiento social, motivación). 
B) Comparación entre la vida del influencer y del seguidor: son comentarios que reflejan la similitud o diferencia entre el estilo de vida del influencer y del seguidor.

C) Impacto del influencer en las decisiones turísticas de sus seguidores: son los comentarios que demuestran que la actividad desarrollada por el influencer tiene un impacto en las decisiones de viaje de los seguidores (elección de destino).

Tabla de codificación

\begin{tabular}{|c|c|c|c|}
\hline Temas & Categorías & Códigos & Ejemplo de comentarios \\
\hline \multirow{5}{*}{ A. Destinos turísticos } & \multirow{2}{*}{$\begin{array}{l}\text { El destino que está } \\
\text { visitando el influencer }\end{array}$} & $\begin{array}{l}\text { Dejar comentarios } \\
\text { positivos sobre el } \\
\text { destino }\end{array}$ & $\begin{array}{l}\text { Seguidor de Dulceida: Woow } \\
\text { que increíble lugar }\end{array}$ \\
\hline & & $\begin{array}{l}\text { Recomendar } \\
\text { actividades } \\
\text { relacionadas con el } \\
\text { destino } \\
\end{array}$ & $\begin{array}{l}\text { Seguidor de Enrique: Sube al } \\
\text { Shanghai World Financial center!! }\end{array}$ \\
\hline & \multirow{3}{*}{$\begin{array}{l}\text { El lugar de origen de los } \\
\text { seguidores }\end{array}$} & $\begin{array}{l}\text { Agradecer que el } \\
\text { influencer ha visitado } \\
\text { el lugar de origen de } \\
\text { los seguidores }\end{array}$ & $\begin{array}{l}\text { Seguidor de Oliver: Que lindo } \\
\text { mi pais, espero que les haya } \\
\text { gustado mucho chicos! }\end{array}$ \\
\hline & & $\begin{array}{l}\text { Estar orgulloso de } \\
\text { que el influencer esté } \\
\text { visitando su lugar de } \\
\text { origen }\end{array}$ & $\begin{array}{l}\text { Seguidor de Enrique: He visto } \\
\text { el video y me ha encantado! Mi } \\
\text { México es un país hermoso }\end{array}$ \\
\hline & & $\begin{array}{l}\text { Recomendar al } \\
\text { influencer que viaje } \\
\text { al lugar de origen del } \\
\text { seguidor }\end{array}$ & $\begin{array}{l}\text { Seguidor de Enrique: Ven a } \\
\text { Tabasco al festival del queso } \\
\text { en Tenosique Tabasco, enserio } \\
\text { conoce esta parte de México que es } \\
\text { divina. Queso y mucha montaña y } \\
\text { puenting y asiiiii }\end{array}$ \\
\hline \multirow{4}{*}{$\begin{array}{l}\text { B. Comparación entre } \\
\text { la vida del influencer y } \\
\text { el seguidor }\end{array}$} & $\begin{array}{l}\text { El seguidor tiene un } \\
\text { estilo de vida similar }\end{array}$ & $\begin{array}{l}\text { El seguidor comparte } \\
\text { la misma experiencia } \\
\text { que el influencer }\end{array}$ & $\begin{array}{l}\text { Seguidor de Molaviajar: Es } \\
\text { espectacular. Estuvimos el año } \\
\text { pasado y es totalmente cierto } \\
\text { que es muy difícil describir la } \\
\text { sensación de estar viendo algo tan } \\
\text { maravilloso }\end{array}$ \\
\hline & \multirow{3}{*}{$\begin{array}{l}\text { El seguidor no tiene un } \\
\text { estilo de vida similar }\end{array}$} & $\begin{array}{l}\text { El seguidor manifiesta } \\
\text { las diferencias }\end{array}$ & $\begin{array}{l}\text { Seguidor de Melo Moreno: } Y \\
\text { uno es pobre y no tiene ni para } \\
\text { salir a la tienda de la esquina... }\end{array}$ \\
\hline & & $\begin{array}{l}\text { El influencer provoca } \\
\text { en el seguidor deseo de } \\
\text { realizar el mismo viaje }\end{array}$ & $\begin{array}{l}\text { Seguidor de Melo Moreno: Que } \\
\text { envidia llevameee } \\
\text { Seguidor de Dulceida: que } \\
\text { envidia chaval yo quiero ir ahi } \\
\text { Seguidor de Oliver: Que ganas } \\
\text { me entran de ir alli } \bullet \text { Gracias por } \\
\text { la foto } \\
\text { Seguidor de Elena: La foto es } \\
\text { realmente increíble. Ojalá estar } \\
\text { allí para fotografiarlo }\end{array}$ \\
\hline & & $\begin{array}{l}\text { El seguidor agradece } \\
\text { poder viajar a través } \\
\text { del influencer al no } \\
\text { poder hacerlo él mismo }\end{array}$ & $\begin{array}{l}\text { Seguidor de Elena: Hermoso } \\
\text { paisaje. Propio de la toscana } \\
\text { italiana. Viajo a través de tus } \\
\text { fotos. Y me deleito con los detalles } \\
\text { que muestras. } \\
\text { Seguidor de Dulceida?: Si } \\
\text { en fotos ya es una pasada en } \\
\text { persona estar ahí tiene que ser } \\
\text { impresionante! Deseando ver el } \\
\text { blog, me encanta "viajar" contigo } \\
\text { Estás preciosa y la calidad de } \\
\text { imagen es brutal }\end{array}$ \\
\hline
\end{tabular}




\begin{tabular}{|c|c|c|c|}
\hline Temas & Categorías & Códigos & Ejemplo de comentarios \\
\hline \multirow{7}{*}{$\begin{array}{l}\text { C. Impacto del } \\
\text { influencer en las } \\
\text { decisiones turísticas } \\
\text { de sus seguidores }\end{array}$} & \multirow{4}{*}{$\begin{array}{l}\text { El influencer como } \\
\text { fuente de inspiración } \\
\text { para sus seguidores }\end{array}$} & $\begin{array}{l}\text { Intención de realizar } \\
\text { el mismo viaje a corto } \\
\text { plazo }\end{array}$ & $\begin{array}{l}\text { Seguidor de Molaviajar: } \\
\text { estamos viendo todos los videos } \\
\text { costa oeste!!! Futuro viaje en } \\
\text { puerta!!! Graaacias!!!! }\end{array}$ \\
\hline & & $\begin{array}{l}\text { Apuntar destinos } \\
\text { nuevos }\end{array}$ & $\begin{array}{l}\text { Seguidor de Molaviajar: Estoy } \\
\text { aprovechando el verano para ver } \\
\text { todos los vídeos (desde el primero } \\
\text { literalmente) y apuntar destinos } \\
\text { y consejos. He cumplido } 18 \text { este } \\
\text { año y estoy ahorrando desde hace } \\
\text { varios años para poder hacer } \\
\text { viajes como los vuestros }\end{array}$ \\
\hline & & $\begin{array}{l}\text { Agradecer al influencer } \\
\text { por haberle animado a } \\
\text { realizar algo }\end{array}$ & $\begin{array}{l}\text { Seguidor de Melo Moreno: Me } \\
\text { encantas! A parte de divertida, } \\
\text { eres muuuu sabia! Estoy en } \\
\text { Australia desde hace } 3 \text { años y } \\
\text { una de las razones por las que me } \\
\text { decidi fue ver tus videos de cuando } \\
\text { estuviste aquí. Así que muchas } \\
\text { thanks my friend! No cambies } \\
\text { JAMÁS!!! }\end{array}$ \\
\hline & & $\begin{array}{l}\text { Tener más ganar de } \\
\text { viajar }\end{array}$ & $\begin{array}{l}\text { Seguidor de Molaviajar: Sois } \\
\text { increíbles! Cada video me gusta } \\
\text { más, me inspiráis a que viaje cada } \\
\text { vez más! } \\
\text { Seguidor de Melo Moreno: Oh } \\
\text { por dios te admiro un monton, } \\
\text { eres increible me inspiras a querer } \\
\text { viajar ya sea con poco, te quiero } \\
\text { un chingo (como se dice en méxico } \\
\text { cuando quieres decir monton }\end{array}$ \\
\hline & \multirow{3}{*}{$\begin{array}{l}\text { Los consejos del } \\
\text { influencer son útiles para } \\
\text { sus seguidores }\end{array}$} & $\begin{array}{l}\text { Agradecer consejos } \\
\text { anteriores }\end{array}$ & $\begin{array}{l}\text { Seguidor de Molaviajar: } \\
\text { Muchas gracias sois muy grandes } \\
\text { dándonos consejos a todos los } \\
\text { "molaviajeros" gracias por la guia } \\
\text { de tailandia me sirvio mucho } \\
\text { ahora a ahorrar para la costa } \\
\text { oeste }\end{array}$ \\
\hline & & Pedir nuevos consejos & $\begin{array}{l}\text { Seguidor de Molaviajar: } \\
\text { Hola iii una preguntita, no } \\
\text { hay restricciones para subir al } \\
\text { mirador con bebés? }\end{array}$ \\
\hline & & Filtros de Instagram & $\begin{array}{l}\text { Seguidor de Dulceida: Soy } \\
\text { la última parda pero de qué } \\
\text { aplicación es ese filtro A4?? }\end{array}$ \\
\hline
\end{tabular}

Además, se analizaron los perfiles de los seis influencers a partir de la tabla de codificación y de la ficha de observación para valorar la posible relación entre los tipos de comentarios y las características de cada uno de ellos.

\section{Resultados}

A continuación se presenta el análisis de los tres temas surgidos durante el proceso de codificación de los comentarios de los seguidores (destinos turísticos; comparación entre la vida del influencer y del seguidor; e impacto del influencer en las decisiones turísticas de sus seguidores). Posteriormente se analizan los perfiles de cada uno de los influencers y su efecto en los seguidores, además del contenido publicado.

\section{Análisis de los temas}

A. Destinos turísticos: En este grupo se incluyeron los comentarios en los que la información principal tenía relación con un lugar físico de destino. En este apartado predomina el reconocimiento social 
del influencer por parte de sus seguidores, ya que predominan mensajes de agradecimiento por compartir destinos turísticos. Dentro del grupo de comentarios se puede hacer una distinción entre los que el destino se veía desde un punto de vista "extranjero" y en los que era evidente una relación entre el destino que estaba visitando el influencer y el lugar de origen del seguidor. Cuando el destino que visitaba el influencer coincidía con el país de una parte importante de sus seguidores (en su mayoría países de Hispanoamérica), los comentarios provenientes de estos seguidores predominaban visiblemente sobre el resto. Esto es lo que ocurrió cuando Enrique Álex estuvo recorriendo México y Ecuador y cuando Oliver Vegas viajó a Argentina. En esta categoría se distinguieron tres tipos de mensajes de los seguidores: agradecer al influencer por enseñar el lugar de donde proviene el seguidor (por ejemplo: seguidor de Enrique: Que lindo mi pais, espero que les haya gustado mucho chicos!,) manifestar que está orgulloso de su país y aprovechar la ocasión para recomendar al influencer que visite su ciudad (por ejemplo: seguidor de Enrique: Alex bienvenido y por favor visiten San Cristina de las Casas, es un lugar mágico, les gustará!!!). En cambio, cuando el destino que estaba visitando el influencer no coincidía con el lugar de origen de una parte considerable de sus seguidores, se observó más variedad de comentarios y escritos por seguidores procedentes de distintos lugares. En estos casos se pueden observar comentarios más objetivos, a veces se realizados desde la propia experiencia del seguidor en el lugar. Cuando esto ocurría, los seguidores aprovechaban también para dar consejos al influencer sobre qué hacer en ese destino (por ejemplo: seguidor de Enrique: Recomiendo que vayan a Qibao en Shangai).

B. Comparación entre la vida del influencer y del seguidor: En este tema se han incluido los comentarios en los que es posible advertir si hay similitudes o diferencias entre la vida llevada por el influencer y el seguidor. Estos comentarios se dividieron en dos categorías: en las que existe una similitud y en la que es clara la diferencia. En el primer caso, los seguidores suelen afirmar que ellos han tenido una experiencia parecida a la del influencer y que están de acuerdo con los sentimientos que les ha suscitado algún viaje (identificación). Esto es más observable en los comentarios de los seguidores de Molaviajar, por ejemplo: Es espectacular. Estuvimos el año pasado y es totalmente cierto que es muy difícil describir la sensación de estar viendo algo tan maravilloso. En el segundo caso, los seguidores suelen reaccionar de distintas maneras ante las diferencias en el estilo de vida. A veces el seguidor expone libremente las diferencias, principalmente en relación a los recursos económicos; otras veces los seguidores expresan que tienen envidia y que les gustaría estar realizando el mismo viaje (motivación explícita); y a veces los seguidores agradecen a los influencers poder conocer el mundo a través de ello, ya que ellos no tienen la posibilidad de visitar esos destinos (motivación implícita). Por ejemplo: seguidor de Enrique: Gracias por permitirme conocer el mundo a través de tu cámara @enriquealexgrade. Amo tus vídeos. Los comentarios que reflejan la diferencia entre los estilos de vida son más frecuentes en las publicaciones de Dulceida, pero también ocurre en los de Melo Moreno y en los de Enrique Álex. En el caso de Oliver Vegas y Elena se ha observado algo destacable, ya que algunos de los seguidores afirmaban que le gustaría estar en el mismo destino para poder fotografiarlo (motivación explícita), por ejemplo: seguidor de Elena: La foto es realmente increíble. Ojalá estar allí para fotografiarlo. Así, muchos de sus seguidores tienen un gran interés en la fotografía y no tanto en el turismo. También se ha observado que los seguidores de los seis influencers les agradecían poder viajar a través de sus vídeos y fotografías (motivación implícita).

C. Impacto del influencer en las decisiones turísticas de sus seguidores: Los comentarios de este tema reflejan que el influencer puede tener algún impacto en las decisiones turísticas de sus seguidores a partir de la inspiración, la motivación hacia los viajes y el rol de consejero o experto. Por un lado, pueden servir como inspiración y motivación, tanto para ayudarle a elegir destino turístico o para animarle a viajar más; por otro lado, pueden ayudar a sus seguidores en los viajes que realizan a través de consejos y recomendaciones. Respecto a la inspiración, los influencers pueden generar impacto en sus seguidores en diversos grados: a veces pueden llegar a realizar el mismo viaje que han visto en Instagram o YouTube (por ejemplo: seguidor de Molaviajar: Yo fui!!!!gracias a vosotros y vuestros videos anteriores!!sois geniales!!!!Gracias por los videos y el blog chic@s!!!!); otras veces consideran los destinos de sus influencers como destinos potenciales (por ejemplo: seguidor de Molaviajar: Me encantáis familia, creo que el próximo año va caer este viajazo); y otras veces los animan a viajar más en general. También se ha observado que pueden influir en otras actividades que no sean turísticas pero que impliquen movilidad, como en el caso de una seguidora de Melo Moreno que decidió mudarse a Australia después de haber visto un vídeo suyo sobre este país. 
Los consejos de los influencers también son importantes para los seguidores y esto se observa especialmente en la familia Molaviajar. Se ha observado que a veces los usuarios piden consejos sobre su experiencia en algún destino, puesto que los seguidores también viajan con niños.

\section{Análisis de los influencers}

A partir de los comentarios recibidos en las publicaciones de cada influencer y de la información obtenida a partir de la ficha de observación se analizó el perfil de cada uno para entender la relación con sus seguidores y averiguar si existe algún tipo de conexión con la inspiración, la motivación y la elección de destino.

@Enriquealexgarde/Enrique Álex: Cuando se elaboró la ficha de observación Enrique Álex era el que menos seguidores tenía de los seis influencers; no obstante, ha superado a la familia Molaviajar (datos de febrero de 2019). A pesar de contar con una base de seguidores más reducida, recibía más comentarios y "me gusta" que alguno de ellos (Misswinter, Ovunno y Molaviajar). El ratio feedback/número de seguidores fue el más alto del grupo: en torno al 13\% de los seguidores suelen dar "me gusta" a sus fotos.

Hay diversas razones que explican un feedback tan elevado. Por un lado, Enrique Álex procura contestar a los comentarios y posiblemente sea consciente de la importancia de la interacción con sus "fans". Por otro lado, el influencer también muestra muchos aspectos de su vida: cuenta historias de sus viajes, expresa sus sentimientos, suele aparecer con su pareja, etc. Esto también ocurre con el aspecto físico: en casi todas las fotos sale posando en el destino y rara vez publica una fotografía en la que solo se vea el paisaje. Por estas razones, los seguidores pueden percibirlo como una persona cercana, lo que los anima a dejar comentarios. No obstante, es posible que esto pueda producir que los seguidores se centren solo en estos temas y se olviden del destino de la publicación. Por lo que se observa en los comentarios, se podría sugerir que muchos de los seguidores no pueden permitirse viajar. A pesar de ello, siguen este tipo de perfiles en las redes sociales porque sirve como una manera de descubrir destinos que de otra manera desconocerían. A veces incluso algunos de sus seguidores le agradecen poder conocer el mundo a través de sus fotografías y vídeos. Este influencer muestra una imagen completa de los destinos que visita, lo que permite que sus seguidores los conozcan con bastante detalle, y en algunas ocasiones los puede animar a viajar.

@Misswinter/Elena: El perfil de Elena es totalmente opuesto al de Enrique Álex. A pesar de que esta instagrammer tiene una gran cantidad de seguidores (hasta cinco veces más que Enrique Álex y Molaviajar) recibe muy pocos comentarios. Normalmente en cada publicación consigue entre 5 y 50 comentarios sin contar sus respuestas y aproximadamente solo un $0.6 \%$ de sus seguidores dan "me gusta" a sus fotos. Posiblemente la ausencia de feedback se deba a que Elena no conecta con sus seguidores: nunca muestra su cara en sus fotografías, no cuenta sus experiencias en sus viajes, ni habla de aspectos personales de su vida. Los seguidores conocen muy poco de ella y no perciben que haya vínculo entre ellos. En esta cuenta la fotografía juega un papel importante. Por consiguiente, muchos de sus seguidores están interesados en el mundo de la fotografía y no tanto en el de los viajes. Algunos lo que esperan encontrar en la cuenta son fotografías de buena calidad, bien encuadradas, con buenos planos, etc.

@Ovunno/Oliver Vegas: Oliver tiene un perfil muy parecido al de Elena. Al igual que ella, cuenta con un gran número de seguidores, superior al de Enrique Álex y Molaviajar, pero obtiene muy poco feedback. No obstante, la diferencia entre seguidores y comentarios no es tan significativa como en el caso de Elena, pues Oliver consigue que al menos 2.47\% de sus seguidores le dan "me gusta" a sus publicaciones. También hay que resaltar que Oliver es posiblemente el más internacional, ya que en torno a la mitad de los comentarios que recibe están en inglés. Su cuenta también es de fotografía y no solo de viajes, lo que se refleja en los comentarios, donde los seguidores comentan frecuentemente sobre el modo en que se ha hecho la fotografía y no sobre el contenido. A pesar de ello, este instagrammer también suele recibir comentarios acerca del destino.

$@$ Molaviajar/Adry, Gosi, Daniela y Oliver: A pesar de que la familia Molaviajar no cuenta con un gran público, sí tiene una comunidad que sigue muy de cerca sus viajes. Y aunque no tienen ni un cuarto de los seguidores de Oliver, reciben la misma cantidad o más de comentarios. Esto se debe a que la familia interactúa constantemente con sus seguidores, pues contestan a los comentarios que reciben en Instagram, dan todo tipo de consejos, diseñan mapas de los destinos y resuelven cualquier duda a través de su email. También se explica por el hecho de que sus seguidores se interesan por los viajes y algunos de ellos siempre tienen presente la intención de viajar. Por consiguiente, la cuenta de Molaviajar funciona como herramienta de ayuda para los viajes ya planeados y de inspiración para 
decidir el destino de un viaje. Otra característica interesante de los seguidores es que éstos tienen una edad similar a los padres Adry y Gosi, y a veces éstos también tienen hijos de la misma edad.

@MeloMoreno/Melo Moreno: Melo tiene una comunidad muy importante de seguidores, la cual ha conseguido gracias a su personalidad mostrada en sus vlogs de YouTube. Su audiencia tiene un perfil muy distinto al suyo, ya que es gente más joven, con menos recursos económicos y muchos procedentes de Hispanoamérica. No obstante, esto no impide que reciba una gran cantidad de feedback: después de Enrique Álex, tiene el ratio más alto de feedback/seguidores, en torno al 8\%, lo cual sorprende para la cantidad de seguidores que ha alcanzado. Respecto a los viajes, sería poco probable que sus seguidores se plantearan realizar el mismo viaje que ella emprende. De ahí que muchos de sus seguidores le agradezcan a Melo que enseñe sus viajes, ya que para ellos supone una manera de conocer el mundo.

@Dulceida/Aida Domenech: Dulceida cuenta con un público importante: normalmente recibe en sus publicaciones entre 400 y 800 comentarios, unos 1.000 o 2.000 si sube algo más llamativo y hasta más de 40.000 si hay un sorteo en la publicación. De los seis influencers es la que publica con más frecuencia, subiendo una o más fotos al día. Se ha observado que algunos de sus seguidores dejan un comentario en todas las publicaciones que sube. Sus seguidores están tan acostumbrados a verla viajar que no les llama la atención cuando la ven en un destino nuevo. Por ejemplo, en el mes de septiembre de 2018 ha estado en cuatros destinos distintos: Hawái, Milán, París y Dubái. También destaca el gran contraste entre la vida que llevan sus seguidores y la que lleva Dulceida, donde los desfiles de moda, los hoteles de lujo y los viajes en helicóptero son lo habitual. En el caso de que algunos de los seguidores viajaran al mismo destino, el modo de realizar el viaje sería muy distinto, salvo algunas excepciones. A veces sus viajes forman parte de una colaboración con alguna empresa que tiene interés en mostrar sus productos o servicios. Esto se observó en el viaje a Hawái, donde Dulceida asistió a clases de inglés organizadas por EF España.

\section{Análisis de los contenidos}

La calidad del contenido y la información proporcionada por el influencer son elementos claves si se quiere que un seguidor adopte las sugerencias de viaje proporcionadas por el influencer (Magno y Cassia, 2018). Se han observado algunos elementos dentro de las publicaciones que pueden tener un mayor efecto en las reacciones y motivaciones de los seguidores: el tipo de destinos turísticos y los tipos de imágenes.

- Tipos de destinos turísticos. Respecto al destino, se ha observado que los destinos que implican un viaje de larga distancia resultaban más atractivos a los seguidores. Las publicaciones que implicaban vacaciones por España no han suscitado tanto interés, como sucedió con la publicación de Elena en Benicasim o de Melo Moreno en Baleares. Lo mismo ocurre con los viajes por Europa, pues tampoco recibieron tanta atención por parte de los usuarios. Esto se puede apreciar en las fotos de Dulceida, ya que sus seguidores mostraron un mayor interés en viajes como el de Hawái que otros realizados a destinos europeos. Estos tipos de imágenes pueden producir una mayor motivación por la novedad en los viajes, ya que implica un cambio en los destinos más conocidos, produciendo interés, sorpresa y la búsqueda de algo nuevo y diferente a lo cotidiano en los potenciales viajeros (Mitas y Bastiaansen, 2018). Por consiguiente, a través de los influencers se pueden conocer nuevos destinos menos conocidos y podrían plantearse realizar ese mismo viaje.

- Tipos de imágenes. Las fotografías que muestran lugares extraordinarios son las más populares entre los seguidores de las cuentas de Instagram analizadas. La calidad de las imágenes es muy importante, por eso, los influencers cuidan aspectos como la luz, la composición y la simetría. Igualmente, a los seguidores les gustan las fotografías con planos fascinantes, las que están hechas con drones o bajo el agua ("instagrameables"). Esto se considera un factor importante en la elección de destinos y en la forma cómo la fotografía turística se convierte en un recurso atractivo para posibles viajeros (Expedia, 2018; Balomenou y Garrod, 2019).

\section{Discusión}

A través de las redes sociales los usuarios que viajan tienen el poder de proyectar imágenes distintas a las que proyectan los medios tradicionales sobre los destinos y, por tanto, pueden producir nuevas percepciones en los turistas potenciales. En el caso de Instagram, al ser una plataforma basada principalmente en la imagen, consigue transmitir información acerca de los atributos de los destinos turísticos de una manera muy sencilla (Özdemir y Çelebi, 2015). La forma en que Instagram influye en el proceso de elección del 
destino difiere de otro tipo de plataformas en línea. Principalmente, esta red social funciona como una fuente de inspiración para los viajes (Ouwerkerk y Johnson, 2016). Muchos de sus usuarios encuentran la inspiración para sus próximos viajes en las publicaciones de sus amigos, familiares, influencers o gente anónima. Si anteriormente las fotografías se enseñaban a un número reducido de personas, aquellas con las que se tenía un trato más cercano, y se acompañaban con el relato de las experiencias del viaje, hoy se comparten con todos aquellos que forman parte de las redes sociales. En consecuencia, esta actividad ha pasado de ser una práctica privada a una pública. Al aumentar el público con el que se comparten, las fotografías del viaje adquieren otro significado. Cuando se trataba de una actividad más privada, la fotografía funcionaba como una herramienta personal que permitía al turista recordar las experiencias del viaje. Pero ahora, al ser una práctica pública, aumenta el nivel de exigencia de esas fotografías. De esta forma la obtención de buenas fotografías durante el viaje se vuelve mucho más importante pasando a ser la "instagrameabilidad" un factor decisivo para los millennials, pues muchos de ellos prefieren elegir lugares "instagrameables" que faciliten luego la obtención de "me gusta" en Instagram (Chatzigeorgiou, 2017).

En este estudio se ha observado que la publicación de imágenes relacionadas con los viajes por distintos tipos de influencers (de viajes, fotógrafos de viajes, mega influencers que viajan) puede servir de inspiración y motivación en las decisiones turísticas de sus seguidores (Özdemir y Çelebi, 2015). Así, la similitud o diferencia entre en el estilo de vida del influencer y del seguidor es un factor relevante a tener en cuenta, ya que las personas que se sienten identificadas con las características o el estilo de vida de algún influencer son las que tienen más probabilidades de realizar acciones o conductas similares de viaje o aceptar sugerencias sobre posibles destinos.

Otra característica importante es la cercanía del influencer en relación a sus seguidores. Ésta es más frecuente cuando realizan la exposición de sus vidas en las redes sociales, dando detalles sobre su vida personal, expresando sentimientos y opiniones y en el caso de los viajes y del turismo, contando las experiencias del viaje. En este caso, los influencers le dan mayor importancia al "yo" que al destino turístico que se convierte en un escenario de su historia personal (Balomenou y Garrod, 2019; Dinhopl y Gretzel, 2016).

Por otro lado, aquellos influencers con un ratio importante de feedback/cantidad de seguidores contribuyen a mantenerse cercanos a su audiencia. En el caso de aquellos que no cuentan con una gran cantidad de seguidores pero que cuentan con una comunidad comprometida (lo que se conoce como engagement) pueden tener más impacto, ya que sus seguidores estarán frecuentemente al tanto de las novedades y el contenido que se publica en su perfil. Es posible que los influencers planifiquen de antemano el tipo de fotografía e historia que quieren compartir con sus seguidores en búsqueda de mayor reconocimiento y popularidad. Además, hay que tener en cuenta que el feedback recibido por quienes les siguen permite adaptar el contenido que se publica al tipo de audiencia en esta red social (Carneiro y Ferreira, 2019; Lo y McKercher, 2015).

De los influencers que se analizaron en este estudio, se observó que aquellos especializados en viajes son los que pueden influir más en la inspiración y motivación para viajar de sus seguidores. Aunque otro tipo de influencers viajen con frecuencia, como los más "generales" y los fotógrafos, aquellos que se dedican a informar a sus seguidores y dan consejos sobre el tipo de viaje, los itinerarios, actividades a realizar, etc. son los que podrán tener mayor impacto en su público. Así, en el análisis se ha encontrado que los influencers pueden funcionar como elemento motivador, ya que varios seguidores afirmaron explícitamente que gracias a ellos tenían más ganas de viajar. Esto se relaciona con los aspectos de transcendencia, evocación y motivación propuestos por Meier y Schäfer (2018), ya que los seguidores tienen la oportunidad de conocer nuevos destinos a través de las publicaciones de los influencers, inspirarse por las historias y fotografías que observan e incluso activar su deseo de realizar un viaje similar.

Finalmente, en relación al contenido que se publica, las fotografías de destinos remotos o exóticos y aquellas más "instagrameables" son las que resultan más populares para los seguidores de estas cuentas de viajes. Este tipo de imágenes produce mayor interés, ya que se caracterizan por ser diferentes a lo habitual y se relacionan con la búsqueda de una motivación por la novedad en los viajes (Mitas y Bastiaansen, 2018).

\section{Implicaciones teórico-prácticas y limitaciones}

Este estudio tiene implicaciones en la comprensión de cuestiones como las motivaciones de viaje y la elección del destino. Con las nuevas tendencias que han ido surgiendo con la revolución de tecnología y las comunicaciones, y en concreto con las redes sociales, el comportamiento turístico se ha visto afectado 
notablemente y aspectos como la motivación turística y la elección del destino merecen ser replanteados para adecuarse al nuevo mundo de las redes sociales e Instagram.

Actualmente la inspiración que ofrecen las publicaciones realizadas por personas influyentes socialmente y por los contactos en las redes sociales funciona como un motivo importante para las decisiones turísticas. Así, los influencers que logran conectar con sus seguidores, ofreciendo información útil (rol de consejero) y atractiva pueden tener mayor impacto en las decisiones de elección de destino de potenciales turistas. Además, la posibilidad de elegir destinos de viaje atractivos ("instagrameables") que puedan otorgar prestigio a través del reconocimiento social se convierte en un factor motivacional a tener en cuenta.

Por otro lado, los resultados de este estudio tienen implicaciones prácticas que pueden ser de gran utilidad para las empresas turísticas. Varios estudios recientes sostienen que las campañas con influencers se han convertido en una herramienta esencial dentro de las estrategias de marketing de las empresas para las redes sociales (Gretzel, 2018). Sin embargo, uno de los principales desafíos para las empresas es poder identificar a los influencers correctos. Este problema se está agudizando especialmente en los últimos años, puesto que cada vez hay más influencers y esto dificulta la elección de la persona correcta. Es fundamental dar respuesta a este problema pues, dar con el influencer adecuado para una campaña de marketing es absolutamente crítico para su éxito (Gretzel, 2018).

Es por ello, que este estudio puede dar respuesta a esta cuestión en el sector turístico. Contrariamente a lo que se puede pensar, puede resultar mucho más provechoso colaborar con influencers de viajes con una cantidad de seguidores moderada que con mega influencers. Aunque el contenido de los mega influencers alcance a una audiencia extremadamente grande, una cantidad muy reducida de sus seguidores mostrará interés en aquello que se esté publicitando, mientras que los seguidores de influencers de viajes, estarán más dispuestos a probar los servicios promocionados. Del mismo modo, puede ser más beneficioso colaborar con aquellos influencers que se muestren cercanos, tengan engagement y aquellos que reflejen un estilo de vida similar a sus seguidores. Todos estos factores pueden ayudar a las empresas a la hora de determinar con quién realizar sus campañas promocionales.

En relación a las limitaciones del estudio hay que señalar que se realizó con una muestra limitada, pues solo se analizaron seis perfiles de influencers. Sería interesante estudiar más adelante una mayor cantidad de perfiles para tener una muestra más grande y, por lo tanto, más representativa, y sobre todo profundizar en el estudio de los influencers de viajes. En segundo lugar, el periodo en el que se analizaron las publicaciones fue solo de tres meses. En el caso de influencers como Dulceida un periodo de esta duración fue suficiente para encontrar material de viajes, pero en otros como por ejemplo Melo Moreno no resultó suficiente. Posiblemente el análisis de otras publicaciones de esta influencer podría haber dado más información sobre el impacto de sus viajes en sus seguidores. También habría que haberse tenido en cuenta que algunos viajeros como Enrique Alex se establecen en un destino turístico durante meses, por lo tanto, un periodo de solo tres meses no da lugar a analizar publicaciones en destinos diferentes. De igual forma, habría que ampliar también el análisis a las características de los usuarios, su perfil sociodemográfico, intereses, etc. con el objetivo de poder realizar posibles segmentaciones de mercado de acuerdo a los perfiles que siguen en las redes sociales. Finalmente, en este trabajo se han dado varios argumentos que apoyan la influencia de Instagram como motivador turístico en las elecciones de los destinos. Sin embargo, todavía es necesario que se realicen más estudios acerca de las redes sociales, y sobre todo en Instagram, pero con un mayor enfoque al individuo y a su comportamiento como turista.

\section{Bibliografía}

Andréu, J. (2000). Las técnicas de análisis de contenido: una revisión actualizada. Fundación Centro Estudios Andaluces - Universidad de Granada, 10(2), 1-34.

Balomenou, N. y Garrod, B. (2019). Photographs in tourism research: Prejudice, power, performance and participant-generated images. Tourism Management, 70, 201-217. http://dx.doi.org/10.1016/j. tourman.2018.08.014

Booking (2017). Tu próximo destino lo decidirán las redes sociales. Recuperado de https://news.booking. com/tu-proximo-destino-lo-decidiran-las-redes-sociales/

Booking (2018). Una sociedad cada vez más conectada: El 19\% de los españoles aspiran a convertirse en influencers viajando. Recuperado de https://news.booking.com/una-sociedad-cada-vez-mas-conectada-el-19-de-los-espanoles-aspiran-a-convertirse-en-influencers-viajando/

Cáceres, P. (2003). Análisis cualitativo de contenido: una alternativa metodológica alcanzable. Psicoperspectivas, 2(1), 53-82. http://dx.doi.org/10.5027/psicoperspectivas-vol2-issue1-fulltext-3 
Carneiro F. y Ferreira A. (2019). Em busca de "likes": A influência das mídias sociais no comportamento do consumidor no consumo de viagens. Pasos, Revista de Turismo y Patrimonio Cultural. 17(1), 113-128. http://dx.doi.org/ 10.25145/j.pasos.2019.17.008

Chatzigeorgiou C. y Christou, E. (2020). Adoption of social media as distribution channels in tourism marketing: A qualitative analysis of consumers' experiences. Journal of Tourism, Heritage \& Services Marketing, 6(1), pp. 25-32, http://dx.doi.org/10.5281/zenodo.3603355

Chatzigeorgiou, C. (2017). Modelling the impact of social media influencers on behavioural intentions of millennials: The case of tourism in rural areas in Greece. Journal of Tourism, Heritage \& Services Marketing, 3(2), 25-29. http://dx.doi.org/10.5281/zenodo.1209125

Dann, G. (1977). "Anomie, ego-enhancement and tourism”. Annals of Tourism Research, 4(4): 184-194. http://dx.doi.org/10.1016/0160-7383(77)90037-8

De la Ballina, F. (2017). Marketing turístico aplicado. Madrid: ESIC

Dinhopl, A. y Gretzel, U. (2016). Selfie-taking as touristic looking. Annals of Tourism Research, 57, 126-139. http://dx.doi.org/10.1016/j.annals.2015.12.015

Expedia Group (2018). Multi-national travel trends. A global look at the motivations and behaviors of travelers. Recuperado de https://www.foresightfactory.co/wp-content/uploads/2016/11/Expedia-Millennial-Traveller-Report-Final.pdf

Grace Chou, H. y Edge, N. (2012). "They Are Happier and Having Better Lives than I Am": The Impact of Using Facebook on Perceptions of Others' Lives. Cyberpsychology, Behaviour and Social Newtworking, 15(2), 117-121. http://dx.doi.org/10.1089/cyber.2011.0324

Gretzel, U. (2018). Influencer marketing in travel and tourism. En Sigala, M. y Gretzel, U. (Eds.), Advances in Social Media for Travel, Tourism and Hospitality: New Perspectives, Practice and Cases (pp. 147-156). New York: Routledge.

Gumpo, C., Chuchu, T., Mariziri, E. y Madinga, N. (2020). Examining the usage of Instagram as a source of information for young consumers when determining tourist destinations. SA Journal of Information Management, 22(1), 1-11. http://dx.doi.org/10.4102/sajim.v22i1.1136

Lee, G. y Tussyadiah, I. (2010). Textual and Visual Information in eWOM: A gap between preferences in information search and diffusion. Information Technology \& Tourism, 12(4), 351-361. http://dx.doi. org/ 10.3727/109830511X13049763022014

Leung, D., Law, R., van Hoof, H. y Buhalis, D. (2013). Social Media in Tourism and Hospitality: A literature review. Journal of Travel \& Tourism Marketing, 30(1-2), 3-22. http://dx.doi.org/10.108 0/10548408.2013.750919

Lo, I. y McKercher, B. (2015). Ideal image in process: Online tourist photography and impression management. Annals of Tourism Research, 52, 104-116. http://dx.doi.org/10.1016/j.annals.2015.02.019

Lyu, S. (2016). Travel selfies on social media as objectified self-presentation. Tourism Management, 54, 185-195. http://dx.doi.org/10.1016/j.tourman.2015.11.001

Magno, F. y Cassia, F. (2018). The impact of social media influencers in tourism. Anatolia, 29(2), 288-290. http://dx.doi.org/10.1080/13032917.2018.1476981

Markwell, K. (1997). Dimensions of photography in a nature-based tour. Annals of Tourism Research, 24(1), 131-155. http://dx.doi.org/10.1016/S0160-7383(96)00053-9

Martínez-Salas A., Monserrat-Gauchi, J.; Segarra-Saavedra, J. (2019). The influencer tourist 2.0: from anonymous tourist to opinion leader". Revista Latina de Comunicación Social, 74, 1344- 1365. http:// dx.doi.org/10.4185/RLCS-2019-1388en

Meier, A. y Schäfer, S. (2018). The positive side of social comparison on social network sites: how envy can drive inspiration on Instagram. Cyberpsychology, Behavior, and Social Networking, 21(7), 411-417. http://dx.doi.org/10.1089/cyber.2017.0708

Minazzi, R. (2015). Social Media Marketing in Tourism and Hospitality. Cham: Springer.

Mitas, O. y Bastiaansen, M. (2018). Novelty: A mechanism of tourists' enjoyment. Annals of Tourism Research, 72, 98-108. http://dx.doi.org/10.1016/j.annals.2018.07.002

Moon, J., Lee, E., Lee, J., Choi, T. y Sung, Y. (2016). The role of narcissism in self-promotion on Instagram. Personality and Individual Differences, 101, 22-25. http://dx.doi.org/10.1016/j.paid.2016.05.042

Munar, A. y Jacobsen, J. (2014). Motivations for sharing tourism experiences through social media. Tourism Management, 43, 46-54. http://dx.doi.org/ 10.1016/j.tourman.2014.01.012

Ouwerkerk, J. y Johnson, B. (2016). Motives for online friending and following: the dark side of social network site connections. Social Media + Society, 2(3), 1-13. http://dx.doi.org/10.1177/2056305116664219

Özdemir, G. y Çelebi, D. (2015). Reflections of Destinations on Social Media. En V. Katsoni (Ed.), Cultural Tourism in a Digital Era (pp. 243-249). Cham: Springer. 
Piñuel-Raigada J. (2002). Epistemología, metodología y técnicas del análisis de contenido. Estudios de Sociolingüistica, 3(1), 1-42.

Riley, R. (1995). Prestige-worthy tourism behavior. Annals of Tourism Research, 22(3), 630-649. http:// dx.doi.org/10.1016/0160-7383(95)00009-U

Schmallegger, D., Carson, D. y Jacobsen, D. (2010). The use of photographs on consumer generated content websites: practical implications for destination image analysis. En N. Sharda (Ed.), Tourism Informatics: Visual Travel Recommender Systems, Social Communities, and User Interface Design (pp. 243-260). Hershey: IGI Global.

Schofield Insurance (2017). Two fifths of millennials choose their holiday destination based on how 'Instagrammable' the holiday pics will be. Recuperado de https://www.schofields.ltd.uk/blog/5123/ two-fifths-of-millennials-choose-their-holiday-destination-based-on-how-instagrammable-the-holiday-pics-will-be/

Seeler, S., Lück, M. y Shänzel, H. (2019). Exploring the drivers behind experience accumulation - The role of secondary experiences consumed through the eyes of social media influencers. Journal of Hospitality and Tourism Management, 41, 80-89. http://dx.doi.org/10.1016/j.jhtm.2019.09.009

Shuqair, S. y Cragg, P. (2017). The immediate impact of Instagram posts on changing the viewers "perceptions towards travel destinations. Asia Pacific Journal of Advanced Business and Social Studies, 3(2), 1-12. http://dx.doi.org/10.25275/apjabssv3i2bus1

The Cocktail Analysis (2016). Observatorio de Redes Sociales. VIII Ola. Recuperado de http://tcanalysis. $\mathrm{com} / \mathrm{blog} / \mathrm{posts} / \mathrm{viii}$-observatorio-de-redes-sociales

Think with Google (2017). Desde la inspiración del viaje hasta la experiencia final. Minerva Travel 2017. Recuperado de https://www.thinkwithgoogle.com/_qs/documents/4749/infografia_minerva_travel_v2.pdf

Thrash T., Moldovan E., Oleynick V. y Maruskin, L. (2014.) The psychology of inspiration. Social and Personality Psychology Compass, 8(9), 495-510. http://dx.doi.org/10.1111/spc3.12127

Urry, J. y Larsen, J. (2011). The Tourist Gaze 3.0. Londres: Sage.

\section{Notas}

1 El número de seguidores es a fecha de septiembre de 2018. 


\title{
Turismo cultural: análise bibliométrica e de redes sociais do campo de turismo no Brasil, 1990-2018
}

\author{
Andre Fontan Kohler* Luciano Antonio Digiampietri** \\ Universidade de São Paulo (Brasil)
}

\begin{abstract}
Resumo: Apresenta-se uma análise bibliométrica e de redes sociais do campo de turismo no Brasil, considerando-o como os artigos publicados em 16 periódicos brasileiros de turismo. Por meio das palavras-chave, é descrita e avaliada sua trajetória (1990-2018), com foco no agrupamento de turismo cultural. Acerca dele, abordam-se a autoria (autores, instituições e distribuição geográfica), periódicos (concentração da publicação), impacto e estrutura intelectual. O agrupamento é claramente delimitado, e congrega palavras-chave "esperadas," que orbitam em torno do turismo cultural, cultura e patrimônio. A autoria é relativamente fragmentada; há clara sobre representação da Região Nordeste do Brasil. Nas referências, chama atenção a orientação de ciências sociais; há relativamente poucos autores e textos preocupados com o turismo cultural como segmento de mercado. É nítido o domínio e centralidade de Margarita Barretto na estrutura intelectual. No impacto, o agrupamento tem uma média de citações reais por artigo pouco abaixo da verificada para o campo.
\end{abstract}

Palavras-chave: Turismo cultural; Bibliometria e análise de redes sociais; Autoria; Estrutura intelectual; Impacto.

Cultural tourism: bibliometric and social network analysis of Brazilian tourism field, 1990-2018

Abstract: We present a bibliometric and social network analysis of the Brazilian field of tourism, taken as the articles of 16 Brazilian tourism journals. Utilizing keywords, we describe and evaluate its trajectory (1990-2018), with focus on the cultural tourism cluster. We study the authorship (authors, institutions and geographic distribution), journals (dispersal of publication), impact and intellectual structure of the cluster. It is clearly delimited, and includes "expected" keywords that orbit around cultural tourism, culture and heritage. Authorship is relatively fragmented; there is an overrepresentation of the Northeast Region of Brazil. In the references, there is a distinct social sciences orientation; there are relatively few authors and texts concerned with cultural tourism as a market segment. Margarita Barretto's dominance and centrality in the intellectual structure is clear. Concerning the impact, the cluster has an average of actual citations per article just below that verified for the field.

Keywords: Cultural tourism; Bibliometric and social network analysis; Authorship; Intellectual structure; Impact.

\section{Introdução}

A palavra "turismo" é utilizada no linguajar cotidiano, inclusive em situações que não estão contempladas em suas definições científicas mais utilizadas. É já comum ouvir de pessoas que elas fizeram turismo na própria cidade onde vivem, quando, por exemplo, passaram o dia no núcleo antigo, a visitar um museu ou centro cultural. O neologismo "turistar" tem sido muito utilizado, principalmente por pessoas mais jovens, para o ato de fazer atividades similares às presentes durante a experiência de turismo, mesmo que elas tenham sido feitas na própria cidade onde se vive.

É possível distinguir três dimensões do turismo, para além de sua utilização no linguajar cotidiano. Em primeiro lugar, há o fenômeno do turismo, o qual ocorre durante as viagens das pessoas, pelos mais

* Universidade de São Paulo (Brasil); E-mail: afontan@usp.br; https://orcid.org/0000-0002-8291-1654

** Universidade de São Paulo (Brasil); E-mail: luciano.digiampietri@gmail.com; https://orcid.org/0000-0003-4890-1548 
variados motivos. Ou seja, o turismo é um fenômeno do mundo exterior. Em segundo lugar, há o estudo e a pesquisa do turismo, os quais resultam, entre outras coisas, em um conjunto de publicações. Por fim, há a educação e o treinamento em turismo, os quais englobam desde cursos técnicos, como, por exemplo, os de formação de guias, até os programas de pós-graduação stricto sensu em turismo (Tribe, 1997).

Assim como ocorre na Administração, conforme retratado por Bertero et al. (1999), o campo de conhecimento de turismo não passou também por um período de "gestação," dado que seus pesquisadores e profissionais formados foram sempre chamados a resolver problemas concretos, bem como para desenvolver novos produtos e inovações no mercado. Ou seja, não houve, em seu início, um espaço suficiente de fundamentação teórica e de reflexão, longe e insulado das pressões de mercado.

Nos últimos anos, tem-se verificado expressivo crescimento da epistemologia da pesquisa em turismo, como atestam Benckendorff e Zehrer (2013) e Koseoglu et al. (2016). Dentro desse crescimento, destaca-se o uso da bibliometria e da análise de redes sociais, que, segundo Koseoglu et al. (2016), consistem em técnicas e métodos capazes de medir e avaliar o estado atual e a trajetória de uma determinada ciência, disciplina ou campo de conhecimento, por meio da utilização, dentre outras coisas, de citações, referências bibliográficas e palavras-chave. Em suma, a bibliometria e a análise de redes sociais permitem responder as seguintes perguntas:

[...] (a) Qual é a estrutura intelectual da disciplina, e como ela evolui? (b) Qual é a estrutura social da disciplina? (c) Quais são as estruturas conceituais da disciplina? (d) Qual é a melhor maneira de avaliar a produção resultante de pesquisa? (e) Como devem ser avaliados o impacto de pesquisadores e instituições? (f) Como a disciplina está a progredir em temas abordados, métodos [de pesquisa] empregados e amostras utilizadas? Ao responder essas perguntas, possíveis vieses subjetivos são minimizados, e inferências de especialistas são validadas, levando a escolas de pensamento, e a que conexões inter-relacionadas entre elas sejam delineadas. (Koseoglu et al., 2016: 181, tradução nossa)

O presente artigo apresenta uma análise bibliométrica e de redes sociais do campo de turismo no Brasil, considerando-o como o conjunto de artigos publicados em 16 periódicos brasileiros de turismo. Por meio das palavras-chave de cada artigo, é descrita e avaliada a trajetória do supracitado campo, no período 1990-2018, bem como se aprofunda o agrupamento centrado na palavra-chave "turismo cultural."

Como objeto de estudo, trabalha-se com a totalidade de artigos publicados nas revistas científicas brasileiras de turismo, no período 1990-2018. Segue-se o que é mais comum de encontrar nos estudos bibliométricos de turismo, a saber: consideraram-se, para análise, os artigos completos, unicamente, com a exclusão de editoriais, resenhas, entrevistas e todo o resto (Benckendorff \& Zehrer, 2013; Strandberg et al., 2018; Racherla \& $\mathrm{Hu}, 2010)$.

Jamal et al. (2008) e McKercher (2005) indicam que não se deve restringir o estudo bibliométrico a uma fração muito diminuta do campo de conhecimento, em virtude do risco de os resultados da pesquisa não serem representativos. Contudo, é comum encontrar pesquisas que limitam o estudo aos periódicos avaliados como os mais importantes, casos de Ye et al. (2013), Koc e Boz (2014) e Kirilenko e Stepchenkova (2018). Para evitar esse problema, o presente artigo pesquisa um amplo conjunto de periódicos brasileiros de turismo, os quais cumprem, simultaneamente, quatro requisitos.

O primeiro requisito é o periódico ser brasileiro, e ter o sistema de dupla avaliação cega por pares para a publicação de artigos. O segundo é a revista científica ser, apenas, de turismo. Nesse caso, excluíram-se periódicos como, por exemplo, a Marketing \& Tourism Review e a Revista Reuna, a qual se define como uma revista de administração pública e de empresas, contabilidade e turismo. Isso foi feito para evitar a inclusão de artigos que não trabalham com o turismo.

O terceiro requisito é o periódico estar classificado, em fevereiro de 2019, no Qualis Periódicos, Área Administração Pública e de Empresas, Ciências Contábeis e Turismo, com, pelo menos, B5 nas classificações de periódicos (quadriênio 2013-2016) ${ }^{1}$. Por fim, o periódico precisava estar ativo até, pelo menos, o final do ano de 2016.

Por meio desses quatro requisitos, 16 periódicos brasileiros de turismo qualificaram-se para a pesquisa, a saber: a) Anais Brasileiros de Estudos Turísticos (ABET); b) Applied Tourism (AT); c) Caderno de Estudos e Pesquisas do Turismo (CEPT); d) CULTUR - Revista de Cultura e Turismo (CULTUR); e) Caderno Virtual de Turismo (CVT); f) Revista Acadêmica Observatório de Inovação do Turismo (RAOIT); g) Revista Brasileira de Ecoturismo (RBE); h) Revista Brasileira de Pesquisa em Turismo (RBPT); i) Revista Iberoamericana de Turismo (RITUR); j) Revista Latino-Americana de Turismologia (RLAT); k) Revista Rosa dos Ventos (RRV); 1) Revista de Turismo Contemporâneo (RTC); m) Revista Turismo: 
Estudos e Práticas (RTEP); n) Revista Turismo - Visão e Ação (RTVA); o) Turismo em Análise (TA); e p) Turismo e Sociedade (TS).

O presente artigo tem dois objetivos gerais. Para ambos, foram utilizadas, única e tão somente, as palavras-chave dos artigos para a construção e delimitação dos agrupamentos. O primeiro consiste em descrever e analisar a trajetória do agrupamento de turismo cultural, o que inclui, entre outras coisas, a entrada e saída de palavras-chave dele, o número de artigos e as eventuais ligações com outros agrupamentos. Trabalha-se com três períodos de tempo (1990-1999, 1990-2009 e 1990-2018).

O segundo objetivo geral toma o agrupamento de turismo cultural no período 1990-2018, o qual é composto por "turismo cultural", "cultura," "patrimônio cultural," "patrimônio," "identidade," "memória" e "museus." $\mathrm{Na}$ autoria, verifica-se quais são os autores e instituições mais produtivos, assim como, tomando a sede destas, como a produção se distribui entre as unidades da federação e entre o Brasil e países estrangeiros. Pensando no conjunto de artigos publicados, cumpre ver a distribuição entre os 16 periódicos brasileiros de turismo, comparando-a com a do campo como o todo, e verificar o porquê desses resultados.

No impacto (citações), cumpre ver o desempenho do agrupamento de turismo cultural, em relação aos 3.887 artigos do campo de turismo no Brasil. Além disso, cumpre analisar, individualmente, os artigos do agrupamento pertencentes ao conjunto de artigos com mais alto impacto do campo de turismo no Brasil. Por fim, cumpre verificar a estrutura intelectual do agrupamento, por meio das referências bibliográficas de seus artigos. Isso implica em verificar os autores, as obras e as revistas científicas mais citadas, assim como aquelas citadas frequentemente em conjunto.

Para ambos os objetivos gerais, cumpre destacar e comentar não apenas as presenças e as relações existentes, mas também as lacunas e os silêncios. Cumpre, dessa forma, questionar, sempre que possível, quais resultados eram esperados para o agrupamento de turismo cultural, mas que não apareceram na pesquisa.

$\mathrm{O}$ artigo justifica-se por meio de três pontos. Em primeiro lugar, verifica-se que para o Brasil, assim como para vários países em desenvolvimento e/ou cientificamente periféricos, há parte considerável de sua produção científica que não é contemplada pelas bases de dados internacionais. Isso é resultado, principalmente, de a produção científica estar concentrada em periódicos nacionais e regionais, o que faz com que seja mais difícil sua descrição e análise, por meio de estudos bibliométricos (Leta \& Lewison, 2003). Esse parece ser o caso do campo de turismo no Brasil.

Segundo, como bem argumenta McKercher (2005), os artigos publicados em periódicos, que utilizam o sistema de avaliação cega por pares, são o elemento mais importante para a avaliação da qualidade de uma pesquisa, de um pesquisador e de uma instituição. As revistas científicas constituem-se em um objeto de estudo, cuja análise é capaz de apontar a trajetória e os rumos de um campo de conhecimento, acadêmica e profissionalmente (Xiao \& Smith, 2006).

Por fim, a bibliometria e a análise de redes sociais permitem que os pesquisadores estudem o turismo como um sistema de construção de conhecimento (Kirilenko \& Stepchenkova, 2018).

\section{Revisão de literatura}

A partir da revisão de literatura analítica, Benckendorff e Zehrer (2013) caracterizam o turismo de três formas, a saber: a) turismo como campo de conhecimento fragmentado e interdisciplinar; b) turismo como campo de conhecimento que não conta com uma abordagem teórica unificada, mas sim abordagens teóricas múltiplas, derivadas e advindas do conjunto de disciplinas que trabalham com o fenômeno do turismo; e c) "[...] fase de fertilização pós-disciplinar, e pode ser descrito como um campo fragmentado e coerente [...]" (Benckendorff \& Zehrer, 2013: 123, tradução nossa).

Tribe (2010) aponta que o campo de turismo é formado por uma comunidade heterogênea e, em certos pontos, divergente entre si, o que resulta na contribuição de uma grande variedade de teorias, abordagens e disciplinas contributivas.

Utilizando-se de Biglan (1973), Laws e Scott (2015) descrevem o turismo como um tipo específico de campo de conhecimento. Biglan (1973) constrói sua tipologia por meio das seguintes dimensões: a) até qual ponto existe ou não um paradigma?; b) o objeto de estudo é mais "puro" e teórico ou mais prático e aplicado?; e c) o envolvimento se dá mais com sistemas vivos ou inertes? Segundo Laws e Scott (2015), o turismo é um campo soft (não há nenhum paradigma dominante), aplicado (há forte ligação com o mercado profissional) e inerte, pontos que explicam sua heterogeneidade e falta de teorias e metodologias de pesquisa dominantes.

Como bem sintetizam Mulet-Forteza et al. (2019), a bibliometria é um meio para a análise da trajetória da estrutura social, da estrutura intelectual e dos conceitos e definições-chave de uma 
ciência, disciplina ou campo. A bibliometria tem, como objeto de estudo, os resultados publicados da pesquisa - monografias, dissertações e teses, artigos de periódico, livros etc. -, e seu emprego é baseado em métodos quantitativos.

A análise de redes sociais não se constitui em uma teoria; trata-se de um conjunto de técnicas e métodos para a análise e avaliação de estruturas sociais e intelectuais de uma ciência, disciplina ou campo (Otte \& Rousseau, 2002).

Ao invés de se centrar nas características individuais dos elementos em questão, o foco da análise de redes são as relações estabelecidas entre eles. A análise de redes permite a verificação da estrutura de uma ciência, disciplina ou campo, o surgimento, consolidação e declínio de temas, metodologias e teorias, o padrão de coautorias e outros pontos mais (Benckendorff, 2009; Benckendorff \& Zehrer, 2013).

Por exemplo, Benckendorff (2009) busca identificar agrupamentos de temas, tópicos e objetos de estudo, por meio da análise de redes das palavras-chave dos artigos publicados por pesquisadores australianos e neozelandeses nos Annals of Tourism Research e Tourism Management, no período 1994-2007.

\section{Metodologia de pesquisa}

A metodologia de pesquisa baseia-se em seis etapas, a saber: a) coleta de dados; b) verificação e desambiguação de nomes; c) construção e delimitação dos agrupamentos; d) cálculo de índices e de métricas e montagem de rankings; e) construção de redes sociais (autoria) e de redes de referências bibliográficas (autores, obras e revistas científicas); e f) análise qualitativa dos dados, rankings e grafos criados.

No período 1990-2018, o campo de turismo no Brasil é composto por cinco agrupamentos (turismo cultural, destino turístico, ecoturismo, sustentabilidade e hospitalidade). Dado que todos compartilham procedimentos metodológicos comuns, pois partem do mesmo banco de dados, e usam as mesmas ferramentas computacionais desenvolvidas pelos autores, apresenta-se, nesse artigo, a metodologia de pesquisa de forma resumida. Para os leitores interessados em ler a metodologia de pesquisa completa, recomenda-se Köhler e Digiampietri (2021), os quais abordam o agrupamento de hospitalidade.

\subsection{Coleta de dados}

Por meio dos arquivos (.pdf) descarregados dos sítios eletrônicos de cada um dos 16 periódicos brasileiros de turismo, foram coletados dados referentes à autoria e às referências bibliográficas de 3.887 artigos, publicados no período 1990-2018.

As referências bibliográficas foram classificadas nas seguintes categorias: a) Artigo de periódico (campo de turismo); b) Artigo de periódico (outros); c) Livro; d) Capítulo de livro; e) Monografia (mestrado/ doutorado); f) Comunicação - art. completo anais evento; e g) Outros.

A coleta das citações foi feita no Google Acadêmico, A utilização do Google Acadêmico tem sido defendida por muitos autores atuantes no campo de turismo, em virtude de muitas de suas revistas não fazerem parte de índices de impacto (Jamal et al., 2008; McKercher, 2008; Hall, 2011; Strandberg et al., 2018; Law \& Veen, 2008; Koseoglu et al., 2016). A ferramenta lista todas as citações recebidas pelo trabalho em análise, proporcionando uma análise mais rica do que aquela possível por vários índices de impacto, os quais listam, apenas, as citações feitas por artigos de periódico.

Para toda e qualquer citação, foram aplicados três filtros, a saber: a) autocitação (há, no mínimo, um autor em comum entre o trabalho citado e o que o cita; b) erro (o documento que a ferramenta aponta que cita o artigo não existe, ou ele existe, mas não cita o artigo, diferentemente de o que o Google Acadêmico aponta); e c) redundância (o documento que cita aparece duas ou mais vezes na lista do Google Acadêmico).

Assim como foi feito para as referências bibliográficas, as citações foram classificadas em uma de sete categorias.

\subsection{Verificação e desambiguação de nomes.}

Todo o processo de verificação e desambiguação de nomes foi feito de maneira manual, por meio de sucessivas rodadas de revisão e correção. Isso permitiu dar mais segurança ao conjunto de dados trabalhados e apresentados nesse artigo.

A verificação e a desambiguação de nomes foram feitas para a autoria, as referências bibliográficas e as citações. O caso de alguns livros é digno de nota. Com a finalidade de verificar a importância de alguns livros na estrutura intelectual do campo de turismo no Brasil, foram reunidas as versões em português e em inglês de vários volumes. 


\subsection{Construção e delimitação dos agrupamentos.}

No presente artigo, os agrupamentos de palavras-chave foram construídos a partir de uma adaptação do método de Grauwin e Jensen (2011). O método original foi desenvolvido para agrupar artigos utilizando uma medida de similaridade, chamada de acoplamento bibliográfico (bibliographic coupling) (Kessler, 1963), a qual atribue uma similaridade a cada par de artigos, com base nas referências bibliográficas compartilhadas por eles (Koseoglu et al., 2016).

A adaptação utiliza no presente artigo calcula a similaridade entre trabalhos, com base nas palavras-chave compartilhadas por eles, assumindo que quanto mais alto o número de palavras-chaves compartilhadas, mais alta será a chance de os trabalhos possuírem temática semelhante.

O método de construção de agrupamentos é sensível tanto a palavras-chave muito frequentes, mas com baixo poder descritivo, as quais podem levar à criação de grupos com múltiplas temáticas, quanto a palavras-chave com frequência muito baixa, que podem levar à criação de grupos muito pequenos e artificiais. Assim, as palavras-chave "turismo" e "Brasil" foram desconsideradas, por sua alta frequência e baixo poder descritivo. Para cada período de análise, diferentes limiares foram estabelecidos para a exclusão de palavras-chave com baixa frequência e baixa co ocorrência. Para 1990-1999, foram descartadas as palavras-chave com frequência mais baixa do que três e co ocorrência mais baixa do que dois. Para 1990-2009, foram descartas as palavras-chave com frequência abaixo de cinco e co ocorrência abaixo de três. Já para 1990-2018, os limiares foram iguais a 20 e cinco, respectivamente.

Para a construção dos agrupamentos, foram considerados apenas os artigos que têm a palavra-chave com mais alta frequência, e/ou que contêm duas ou mais palavras-chave quaisquer do agrupamento.

\subsection{Cálculo de índices e de métricas e montagem de rankings.}

Dado que o agrupamento de turismo cultural tem, apenas, 139 artigos (1990-2018), optou-se pelo cálculo de um pequeno conjunto de índices e de métricas. Avaliou-se ser mais proveitoso a análise qualitativa das tabelas e dos grafos construídos, a fim de verificar as particularidades desse agrupamento.

Foi utilizado o método da contagem simples, por meio do qual cada elemento (por exemplo, autor) recebe um ponto por artigo assinado, havendo ou não coautores. As palavras-chave e as referências bibliográficas foram contadas, também, por meio da contagem simples.

Para as citações, foram calculados a média, a mediana e o desvio-padrão, tanto para o agrupamento de turismo cultural quanto para o campo como um todo, assim como a contagem simples. Para todo e qualquer artigo, foram calculadas as citações reais, as quais são iguais às citações nominais subtraídas de autocitações, erros e redundâncias.

\subsection{Construção de redes sociais (autoria) e de redes de referências bibliográficas (autores, obras e revistas científicas).}

Foram construídas as seguintes redes: a) palavras-chave; b) referências bibliográficas - autores; c) referências bibliográficas - obras; e d) referências bibliográficas - revistas científicas. Dado o baixo número de artigos no agrupamento de turismo cultural, as redes construídas para os dados de autoria dos artigos (autores, instituições, unidades da federação e países) não são mostrados, dado que não expõem relações significativas de coautoria.

A literatura não indica pontos de corte à análise de redes sociais, de aplicação universal. Desse modo, foram definidos pontos de corte para o conjunto de redes construídas (autores, obras e revistas científicas), levando-se em conta, simultaneamente, os cinco agrupamentos. Por meio da utilização de diversos parâmetros, foram definidos os seguintes pontos de corte para a inclusão nas redes de autores, obras e revistas científicas (referências bibliográficas): a) frequência mínima de 10\%, com arredondamento para baixo (13 de 139 artigos); e/ou b) aresta com, no mínimo, 5\% dos artigos, com arredondamento para baixo (6 de 139 artigos).

Para a construção das redes - e, consequentemente, dos gráficos -, foram utilizadas ferramentas computacionais desenvolvidas pelos autores do presente artigo.

\subsection{Análise qualitativa dos dados, rankings e grafos criados.}

Para as várias tabelas e grafos criados, foi feita uma análise qualitativa, a fim de compreender as particularidades do agrupamento de turismo cultural. No caso dos autores, acessou-se seu Currículo Lattes, se existente, a fim de avaliar sua produção científica. Já para as obras específicas, havia já o conhecimento prévio de quase todas elas. Para as até então não lidas, foi feita uma leitura transversal. Todas as revistas 
científicas constantes do ranking e/ou do grafo da estrutura intelectual (referências bibliográficas) do agrupamento de turismo cultural eram já de conhecimento dos autores do presente artigo.

Foi realizada, também, a classificação dos artigos dos agrupamentos, por meio de Tribe $(1997,2010)$, em estudos ligados a negócios turísticos (tourism business studies) e em estudos não ligados a negócios turísticos (non-business tourism studies). Contudo, Tribe $(1997,2010)$ não fornece parâmetros para tal classificação; logo, ela foi feita a critério dos autores do presente artigo.

\section{Resultados}

No período 1990-2018, os 16 periódicos brasileiros de turismo publicaram 3.887 artigos, que, em conjunto, apresentam 108.595 referências bibliográficas, das quais 69.022 únicas, e foram citados 10.882 vezes por outros trabalhos. A Tabela 1 traz os dados básicos do objeto de estudo, divididos para os períodos 1990-1999, 1990-2009 e 1990-2018.

Os gráficos 1, 2 e 3 trazem os agrupamentos do campo de turismo no Brasil para os períodos 1990-1999, 1990-2009 e 1990-2018, respectivamente. O tamanho dos nós representa a quantidade de artigos, ao passo que a grossura das arestas indica a quantidade de artigos que têm, conjuntamente, as duas palavras-chave em questão.

Para fins de visualização, para cada agrupamento, manteve-se, sempre que possível, o padrão de cores, ao longo dos períodos. Foram apresentados os rótulos apenas da palavra-chave com mais alta frequência em cada um deles, com exceção do de turismo cultural, objeto do presente artigo. As arestas externas (entre palavras-chave de agrupamentos diferentes) têm cor preta. Por fim, foram colocadas palavras-chave isoladas apenas com alta frequência.

Tabela 1: Campo de turismo no Brasil - dados básicos (1990-1999, 1990-2009 e 1990-2018)

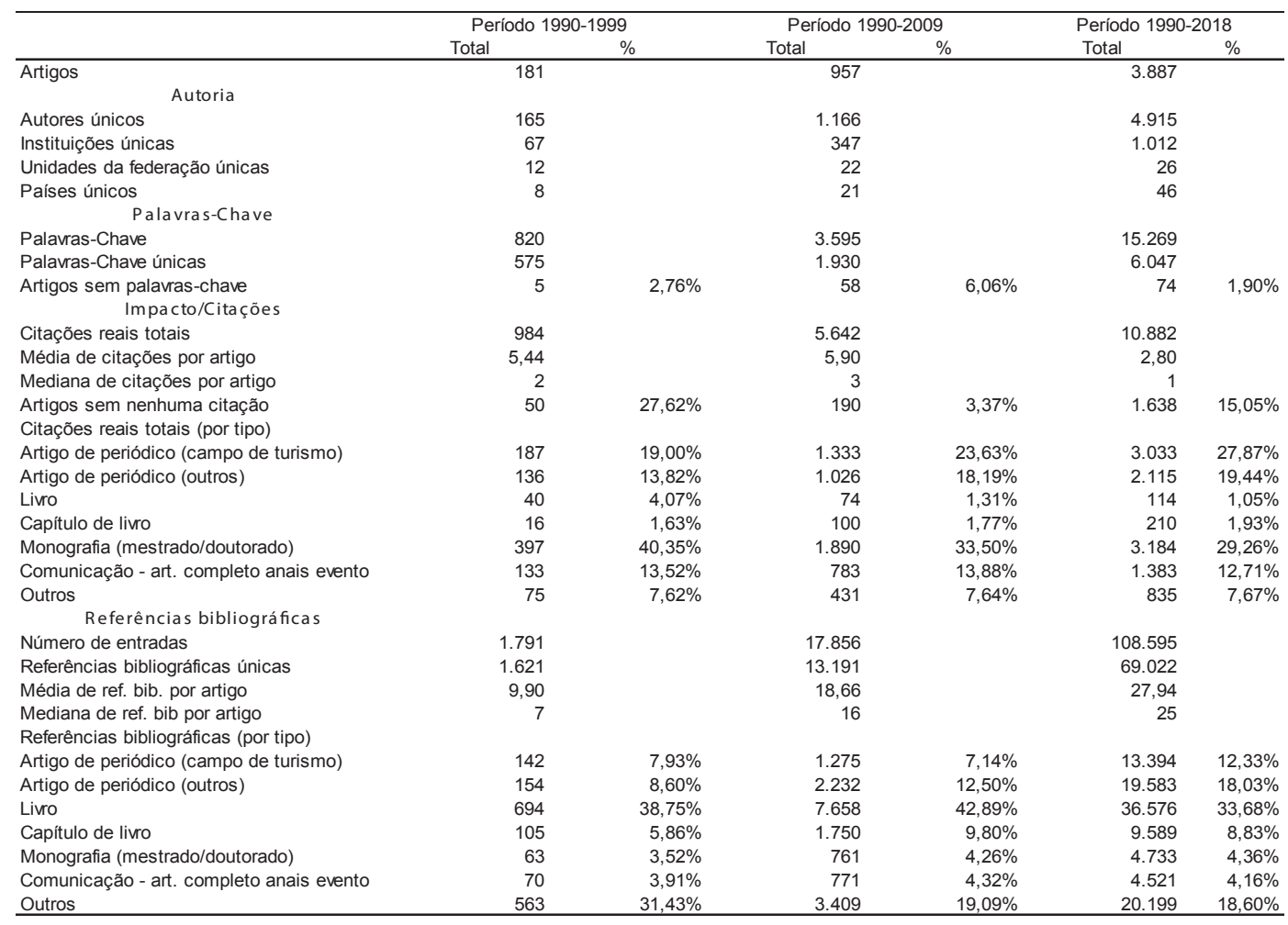

Fonte: Köhler e Digiampietri (2021). 
Gráfico 1: Campo de turismo no Brasil - agrupamentos (1990-1999)

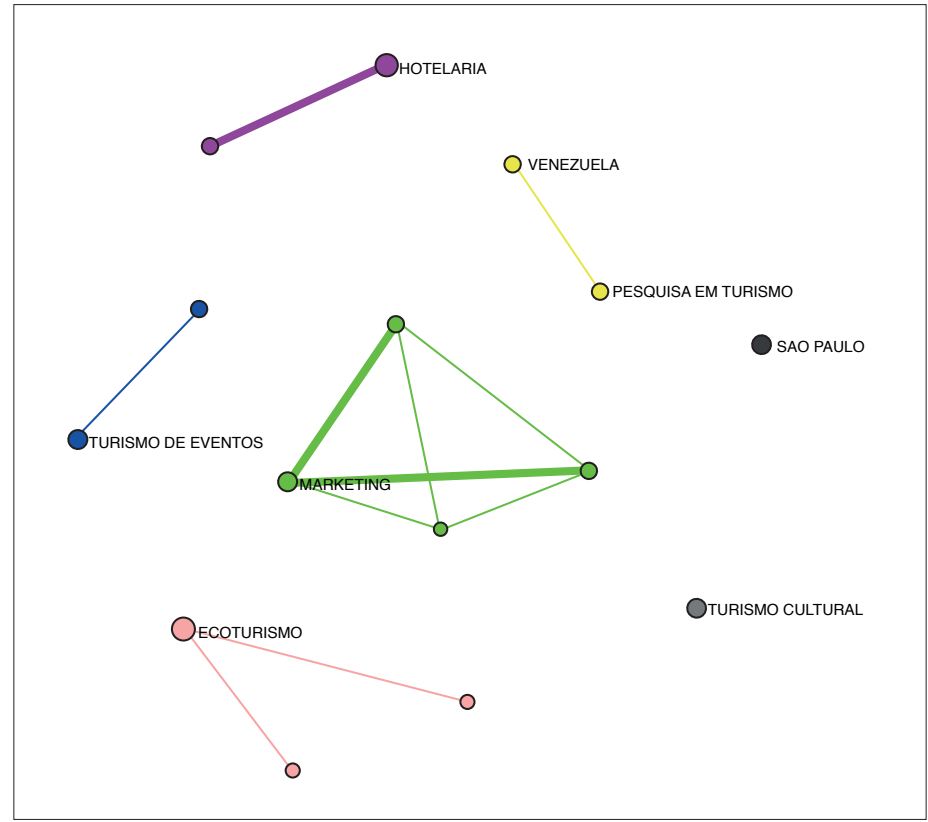

Fonte: Elaboração própria.

Gráfico 2: Campo de turismo no Brasil - agrupamentos (1990-2009)

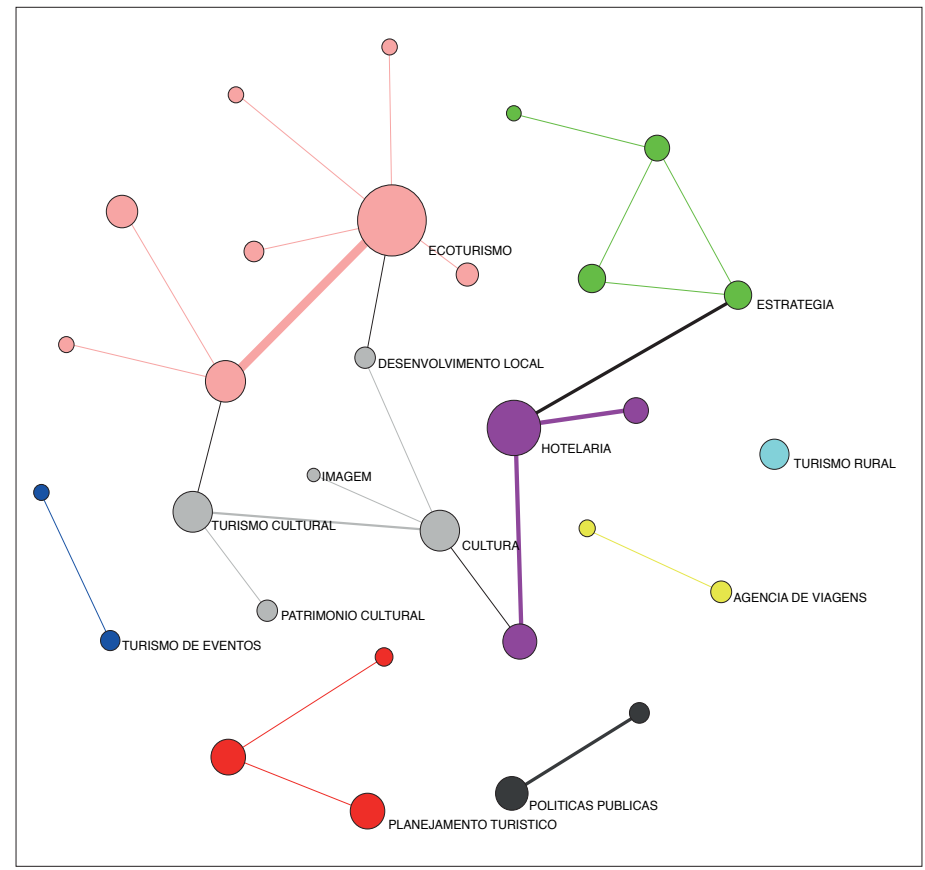

Fonte: Elaboração própria. 
Gráfico 3: Campo de turismo no Brasil - agrupamentos (1990-2018)

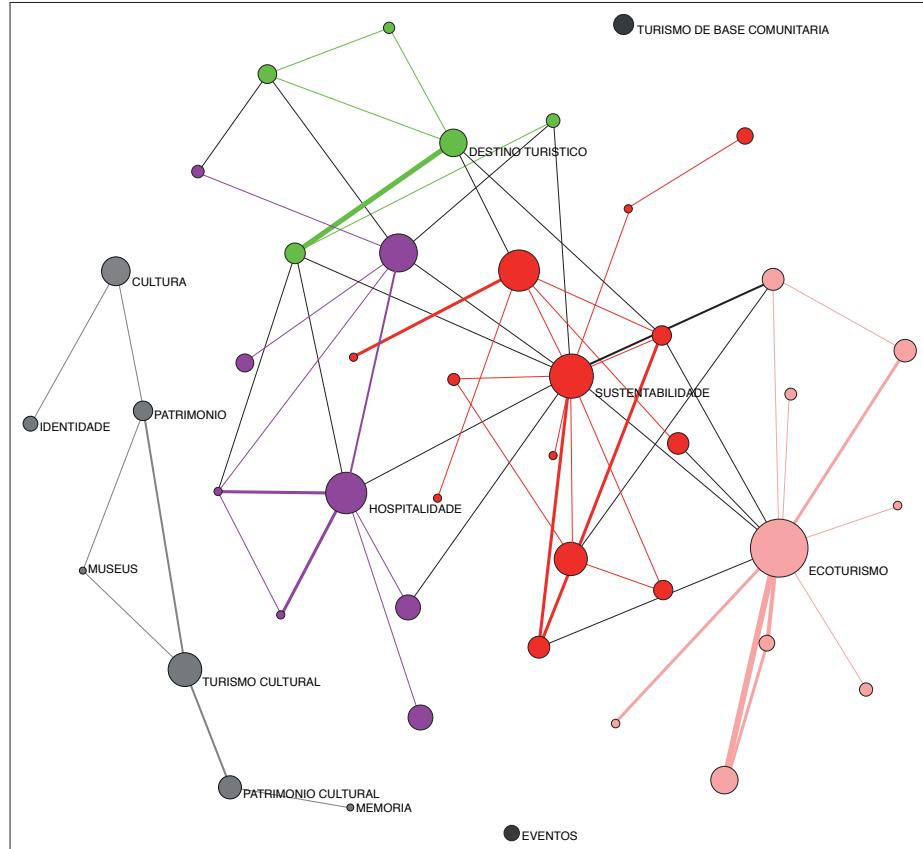

Fonte: Elaboração própria.

A Tabela 2 traz uma série de dados básicos para cada agrupamento (1990-2018); isso permite a análise do agrupamento de turismo cultural, em perspectiva comparada:

Tabela 2: Campo de turismo no Brasil - dados básicos por agrupamento (1990-2018)

\begin{tabular}{|c|c|c|c|c|c|c|c|c|c|c|c|c|}
\hline & \multicolumn{2}{|c|}{ Turismo Cultural } & \multicolumn{2}{|c|}{ Ecoturismo } & \multicolumn{2}{|c|}{ Destino Turistico } & \multicolumn{2}{|c|}{ Hospitalidade } & \multicolumn{2}{|c|}{ Sustentabilidade } & \multicolumn{2}{|c|}{ Universo de artigos } \\
\hline & Total & $\%$ & Total & $\%$ & Total & $\%$ & Total & $\%$ & Total & $\%$ & Total & $\%$ \\
\hline Artigos & 139 & & 208 & & 98 & & 157 & & 213 & & 3.887 & \\
\hline Autores únicos & 219 & & 438 & & 170 & & 240 & & 433 & & 4.915 & \\
\hline Instituições únicas & 98 & & 145 & & 77 & & 91 & & 165 & & 1.012 & \\
\hline Unidades da federaçäo únicas & 24 & & 24 & & 17 & & 21 & & 23 & & 26 & \\
\hline $\begin{array}{l}\text { Paises únicos } \\
\qquad / \mathrm{mpacto} / \text { Citacôes }\end{array}$ & 11 & & 11 & & 9 & & 10 & & 14 & & 46 & \\
\hline Citações reais totais & 366 & & 661 & & 323 & & 395 & & 746 & & 10.882 & \\
\hline Média de citaçöes por artigo & 2,63 & & 3,18 & & 3,30 & & 2,52 & & 3,50 & & 2,80 & \\
\hline Mediana de citações por artigo & 1 & & 2 & & 1 & & 1 & & 1 & & 1 & \\
\hline $\begin{array}{l}\text { Artigos sem nenhuma citação } \\
\text { Citações reais totais (por tipo) }\end{array}$ & 63 & $45,32 \%$ & 65 & $31,25 \%$ & 39 & $39,80 \%$ & 72 & $45,86 \%$ & 95 & $44,60 \%$ & 1.638 & $42,14 \%$ \\
\hline Artigo de periódico (campo de turismo) & 79 & $21,58 \%$ & 185 & $27,99 \%$ & 112 & $34,67 \%$ & 134 & $33,92 \%$ & 216 & $28,95 \%$ & 3.033 & $27,87 \%$ \\
\hline Artigo de periódico (outros) & 67 & $18,31 \%$ & 170 & $25,72 \%$ & 53 & $16,41 \%$ & 74 & $18,73 \%$ & 148 & $19,84 \%$ & 2.115 & $19,44 \%$ \\
\hline Livo & 2 & $0,55 \%$ & 9 & $1,36 \%$ & 3 & $0,93 \%$ & 5 & $1,27 \%$ & 9 & $1,21 \%$ & 114 & $1,05 \%$ \\
\hline Capitulo de livro & 12 & $3,28 \%$ & 10 & $1,51 \%$ & 5 & $1,55 \%$ & 9 & $2,28 \%$ & 11 & $1,47 \%$ & 210 & $1,93 \%$ \\
\hline Monografia (mestrado/doutorado) & 114 & $31,15 \%$ & 164 & $24,81 \%$ & 84 & $26,01 \%$ & 94 & $23,80 \%$ & 210 & $28,15 \%$ & 3.184 & $29,26 \%$ \\
\hline Comunicação - art. completo anais evento & 50 & $13,66 \%$ & 71 & $10,74 \%$ & 30 & $9,29 \%$ & 46 & $11,65 \%$ & 95 & $12,73 \%$ & 1.383 & $12,71 \%$ \\
\hline Outros & 42 & $11,48 \%$ & 52 & $7,87 \%$ & 36 & $11,15 \%$ & 33 & $8,35 \%$ & 57 & $7,64 \%$ & 835 & $7,67 \%$ \\
\hline Referências bibliográficas & & & & & & & & & & & & \\
\hline Número de entradas & 3.389 & & 5.583 & & 3.704 & & 4.516 & & 6.312 & & 108.595 & \\
\hline Referências bibliográficas únicas & 2.782 & & 4.334 & & 2.999 & & 3.547 & & 5.232 & & 69.022 & \\
\hline Média de ref. bib. por artigo & 24,38 & & 26,84 & & 37,80 & & 28,76 & & 29,63 & & 27,94 & \\
\hline $\begin{array}{l}\text { Mediana de ref. bib por artigo } \\
\text { Referências bibliográícas (por tipo) }\end{array}$ & 23 & & 23,5 & & 33 & & 27 & & 26 & & 25 & \\
\hline Artigo de periódico (campo de turismo) & 245 & $7,23 \%$ & 450 & $8,06 \%$ & 893 & $24,11 \%$ & 389 & $8,61 \%$ & 769 & $12,18 \%$ & 13.394 & $12,33 \%$ \\
\hline Artigo de periódico (outros) & 351 & $10,36 \%$ & 853 & $15,28 \%$ & 706 & $19,06 \%$ & 860 & $19,04 \%$ & 1.035 & $16,40 \%$ & 19.583 & $18,03 \%$ \\
\hline Livo & 1.437 & $42,40 \%$ & 1.681 & $30,11 \%$ & 1035 & $27,94 \%$ & 1804 & $39,95 \%$ & 1.979 & $31,35 \%$ & 36.576 & $33,68 \%$ \\
\hline Capitulo de livo & 359 & $10,59 \%$ & 634 & $11,36 \%$ & 208 & $5,62 \%$ & 463 & $10,25 \%$ & 612 & $9,70 \%$ & 9.589 & $8,83 \%$ \\
\hline Monografia (mestrado/doutorado) & 138 & $4,07 \%$ & 338 & $6,05 \%$ & 161 & $4,35 \%$ & 208 & $4,61 \%$ & 276 & $4,37 \%$ & 4.733 & $4,36 \%$ \\
\hline Comunicaçã̃o - art. completo anais evento & 100 & $2,95 \%$ & 252 & $4,51 \%$ & 157 & $4,24 \%$ & 144 & $3,19 \%$ & 287 & $4,55 \%$ & 4.521 & $4,16 \%$ \\
\hline Outros & 759 & $22,40 \%$ & 1.375 & $24,63 \%$ & 544 & $14,69 \%$ & 648 & $14,35 \%$ & 1.354 & $21,45 \%$ & 20.199 & $18,60 \%$ \\
\hline
\end{tabular}

Fonte: Köhler e Digiampietri (2021). 
A Tabela 3 traz a lista com os autores com mais alta produção do agrupamento de turismo cultural, assim como a Tabela 4 apresenta o mesmo tipo de dados para as instituições:

Tabela 3: Agrupamento de turismo cultural - autores com mais alta produção (1990-2018)

\begin{tabular}{|c|c|c|c|c|c|}
\hline \multirow[b]{3}{*}{ Nome do autor } & \multicolumn{5}{|c|}{ Campo de turismo no Brasil - 16} \\
\hline & \multicolumn{2}{|c|}{ Agrupamento de turismo cultural } & \multicolumn{2}{|c|}{ periódicos } & \multirow{2}{*}{$\begin{array}{c}\% \text { do agrupamento } \\
\text { sobre o campo }\end{array}$} \\
\hline & Posição & Artigos & Posição & Artigos & \\
\hline Karoliny Diniz Carvalho & $1^{\circ}$ & 7 & $20^{\circ}$ & 14 & $50,00 \%$ \\
\hline Pedro de Alcântara Bittencourt César & $2^{\circ}$ & 4 & $13^{\circ}$ & 19 & $21,05 \%$ \\
\hline Silvana Pirillo Ramos & $3^{\circ}$ & 3 & $107^{\circ}$ & 7 & $42,86 \%$ \\
\hline Mario Jorge Pires & $3^{\circ}$ & 3 & $133^{\circ}$ & 6 & $50,00 \%$ \\
\hline Janete Ruiz de Macedo & $3^{\circ}$ & 3 & $133^{\circ}$ & 6 & $50,00 \%$ \\
\hline Roselys Izabel Correa dos Santos & $3^{\circ}$ & 3 & $176^{\circ}$ & 5 & $60,00 \%$ \\
\hline Neus Crous-Costa & $3^{\circ}$ & 3 & $176^{\circ}$ & 5 & $60,00 \%$ \\
\hline
\end{tabular}

Fonte: Elaboração própria.

Tabela 4: Agrupamento de turismo cultural - instituições com mais alta produção (1990-2018)

\begin{tabular}{lccccrr}
\hline & \multicolumn{2}{c}{$\begin{array}{c}\text { Agrupamento de turismo } \\
\text { cultural }\end{array}$} & \multicolumn{2}{c}{$\begin{array}{c}\text { Campo de turismo no Brasil - 16 } \\
\text { periódicos }\end{array}$} & $\begin{array}{c}\text { \% do agrupamento } \\
\text { sobre o campo }\end{array}$ \\
Nome da instituição & Posição & Artigos & & Posição & Artigos & 82 \\
\hline Universidade Estadual de Santa Cruz & $1^{\circ}$ & 14 & $9^{\circ}$ & $17,07 \%$ \\
Universidade de São Paulo & $2^{\circ}$ & 9 & $1^{\circ}$ & 251 & $3,59 \%$ \\
Universidade do Vale do Itajaí & $3^{\circ}$ & 6 & $2^{\circ}$ & 219 & $2,74 \%$ \\
Universidade de Caxias do Sul & $4^{\circ}$ & 5 & $5^{\circ}$ & 136 & $3,68 \%$ \\
\hline
\end{tabular}

Fonte: Elaboração própria.

É possível comparar a participação desses autores e instituições no agrupamento de turismo cultural com a no campo de turismo no Brasil, assim como o quanto da produção do autor ou instituição liga-se a aquele. 
A Tabela 5 mostra a distribuição da produção do agrupamento de turismo cultural e do campo de turismo no Brasil, entre as unidades da federação e grandes regiões do Brasil. Já a Tabela 6 traz os principais países responsáveis pela produção do supracitado agrupamento:

Tabela 5: Agrupamento de turismo cultural - unidades da federação e grandes regiões do Brasil com mais alta produção (1990-2018)

\begin{tabular}{|c|c|c|c|c|c|}
\hline \multirow{2}{*}{$\begin{array}{l}\text { Nome da unidade da federação ou } \\
\text { grande região }\end{array}$} & \multicolumn{2}{|c|}{$\begin{array}{c}\text { Agrupamento de turismo } \\
\text { cultural }\end{array}$} & \multicolumn{2}{|c|}{$\begin{array}{c}\text { Campo de turismo no Brasil - } \\
16 \text { periódicos }\end{array}$} & \multirow{2}{*}{$\begin{array}{l}\% \text { do agrupamento } \\
\text { sobre o campo }\end{array}$} \\
\hline & Posição & Artigos & Posição & Artigos & \\
\hline São Paulo & $1^{\circ}$ & 23 & $1^{\circ}$ & 667 & $3,45 \%$ \\
\hline Bahia & $2^{\circ}$ & 16 & $8^{\circ}$ & 157 & $10,19 \%$ \\
\hline Rio Grande do Sul & $3^{\circ}$ & 9 & $4^{\circ}$ & 324 & $2,78 \%$ \\
\hline Minas Gerais & $3^{\circ}$ & 9 & $6^{\circ}$ & 313 & $2,88 \%$ \\
\hline Santa Catarina & $5^{\circ}$ & 6 & $2^{\circ}$ & 379 & $1,58 \%$ \\
\hline Paraná & $5^{\circ}$ & 6 & $3^{\circ}$ & 328 & $1,83 \%$ \\
\hline Rio Grande do Norte & $5^{\circ}$ & 6 & $7^{\circ}$ & 221 & $2,71 \%$ \\
\hline Rio de Janeiro & $8^{\circ}$ & 5 & $5^{\circ}$ & 317 & $1,58 \%$ \\
\hline Maranhão & $9^{\circ}$ & 4 & $17^{\circ}$ & 54 & $7,41 \%$ \\
\hline Mato Grosso do Sul & $10^{\circ}$ & 3 & $13^{\circ}$ & 87 & $3,45 \%$ \\
\hline Piauí & $10^{\circ}$ & 3 & $16^{\circ}$ & 61 & $4,92 \%$ \\
\hline Goiás & $10^{\circ}$ & 3 & $19^{\circ}$ & 32 & $9,38 \%$ \\
\hline Alagoas & $10^{\circ}$ & 3 & $20^{\circ}$ & 31 & $9,68 \%$ \\
\hline Paraíba & $14^{\circ}$ & 2 & $10^{\circ}$ & 101 & $1,98 \%$ \\
\hline Pernambuco & $14^{\circ}$ & 2 & $12^{\circ}$ & 90 & $2,22 \%$ \\
\hline Sergipe & $14^{\circ}$ & 2 & $14^{\circ}$ & 70 & $2,86 \%$ \\
\hline Mato Grosso & $14^{\circ}$ & 2 & $22^{\circ}$ & 24 & $8,33 \%$ \\
\hline Distrito Federal & $18^{\circ}$ & 1 & $9^{\circ}$ & 104 & $0,96 \%$ \\
\hline Ceará & $18^{\circ}$ & 1 & $11^{\circ}$ & 92 & $1,09 \%$ \\
\hline Amazonas & $18^{\circ}$ & 1 & $18^{\circ}$ & 34 & $2,94 \%$ \\
\hline Tocantins & $18^{\circ}$ & 1 & $21^{\circ}$ & 25 & $4,00 \%$ \\
\hline Roraima & $18^{\circ}$ & 1 & $23^{\circ}$ & 21 & $4,76 \%$ \\
\hline Espírito Santo & $18^{\circ}$ & 1 & $24^{\circ}$ & 18 & $5,56 \%$ \\
\hline Rondônia & $18^{\circ}$ & 1 & $25^{\circ}$ & 5 & $20,00 \%$ \\
\hline Pará & $25^{\circ}$ & 0 & $15^{\circ}$ & 69 & $0,00 \%$ \\
\hline Acre & $25^{\circ}$ & 0 & $26^{\circ}$ & 1 & $0,00 \%$ \\
\hline Amapá & $25^{\circ}$ & 0 & $27^{\circ}$ & 0 & Não se aplica \\
\hline Região Nordeste & $1^{\circ}$ & 39 & $3^{\circ}$ & 877 & $4,45 \%$ \\
\hline Região Sudeste & $2^{\circ}$ & 38 & $1^{\circ}$ & 1315 & $2,89 \%$ \\
\hline Região Sul & $3^{\circ}$ & 21 & $2^{\circ}$ & 1031 & $2,04 \%$ \\
\hline Região Centro-Oeste & $4^{\circ}$ & 9 & $4^{\circ}$ & 247 & $3,64 \%$ \\
\hline Região Norte & $5^{\circ}$ & 4 & $5^{\circ}$ & 155 & $2,58 \%$ \\
\hline
\end{tabular}

Fonte: Elaboração própria.

Tabela 6: Agrupamento de turismo cultural - países com mais alta produção (1990-2018)

\begin{tabular}{|c|c|c|c|c|c|}
\hline \multirow[b]{2}{*}{ Nome do país } & \multicolumn{2}{|c|}{$\begin{array}{c}\text { Agrupamento de turismo } \\
\text { cultural }\end{array}$} & \multicolumn{2}{|c|}{$\begin{array}{c}\text { Campo de turismo no Brasil - } \\
16 \text { periódicos }\end{array}$} & \multirow{2}{*}{$\begin{array}{c}\text { \% do } \\
\text { agrupamento } \\
\text { sobre o campo }\end{array}$} \\
\hline & Posição & Artigos & Posição & Artigos & \\
\hline Brasil & $1^{\circ}$ & 104 & $1^{\circ}$ & 3147 & $3,30 \%$ \\
\hline Espanha & $2^{\circ}$ & 11 & $2^{\circ}$ & 156 & $7,05 \%$ \\
\hline Portugal & $3^{\circ}$ & 9 & $3^{\circ}$ & 142 & $6,34 \%$ \\
\hline Mexico & $4^{\circ}$ & 4 & $4^{\circ}$ & 139 & $2,88 \%$ \\
\hline Colombia & $5^{\circ}$ & 3 & $14^{\circ}$ & 10 & $30,00 \%$ \\
\hline Argentina & $6^{\circ}$ & 2 & $5^{\circ}$ & 60 & $3,33 \%$ \\
\hline Equador & $6^{\circ}$ & 2 & $7^{\circ}$ & 23 & $8,70 \%$ \\
\hline Franca & $6^{\circ}$ & 2 & $8^{\circ}$ & 21 & $9,52 \%$ \\
\hline Venezuela & $9^{\circ}$ & 1 & $6^{\circ}$ & 26 & $3,85 \%$ \\
\hline Cuba & $9^{\circ}$ & 1 & $11^{\circ}$ & 14 & $7,14 \%$ \\
\hline Uruguai & $9^{\circ}$ & 1 & $12^{\circ}$ & 13 & $7,69 \%$ \\
\hline
\end{tabular}

Fonte: Elaboração própria. 
Por fim, em termos de produção, a Tabela 7 traz a lista com os 16 periódicos do campo de turismo no Brasil, mostrando, em número de artigos, o quanto cada um deles representa do campo como um todo e do agrupamento de turismo cultural, bem como a sobre representação ou a sub-representação daí resultante - nesse último caso, 100\% significa que não há nenhuma delas:

Tabela 7: Agrupamento de turismo cultural - publicação nos 16 periódicos selecionados (1990-2018)

\begin{tabular}{|c|c|c|c|c|c|}
\hline \multirow[b]{2}{*}{ Nome do periódico } & \multicolumn{2}{|c|}{$\begin{array}{c}\text { Agrupamento de turismo } \\
\text { cultural }\end{array}$} & \multicolumn{2}{|c|}{$\begin{array}{c}\text { Campo de turismo no Brasil - } 16 \\
\text { periódicos }\end{array}$} & \multirow{2}{*}{$\begin{array}{c}\text { Representação } \\
\text { (turismo cultural / } \\
\text { campo) }\end{array}$} \\
\hline & Artigos & Porcentagem & Artigos & Porcentagem & \\
\hline ABET & 3 & $2,16 \%$ & 141 & $3,63 \%$ & $59,50 \%$ \\
\hline AT & 0 & $0,00 \%$ & 80 & $2,06 \%$ & $0,00 \%$ \\
\hline CEPT & 2 & $1,44 \%$ & 88 & $2,26 \%$ & $63,55 \%$ \\
\hline CVT & 16 & $11,51 \%$ & 463 & $11,91 \%$ & $96,64 \%$ \\
\hline CULTUR & 23 & $16,55 \%$ & 251 & $6,46 \%$ & $256,24 \%$ \\
\hline RAOIT & 4 & $2,88 \%$ & 189 & $4,86 \%$ & $59,18 \%$ \\
\hline RBE & 4 & $2,88 \%$ & 357 & $9,18 \%$ & $31,33 \%$ \\
\hline RBPT & 8 & $5,76 \%$ & 266 & $6,84 \%$ & $84,10 \%$ \\
\hline RTC & 6 & $4,32 \%$ & 98 & $2,52 \%$ & $171,21 \%$ \\
\hline RITUR & 20 & $14,39 \%$ & 206 & $5,30 \%$ & $271,50 \%$ \\
\hline RLAT & 0 & $0,00 \%$ & 48 & $1,23 \%$ & $0,00 \%$ \\
\hline RRV & 9 & $6,47 \%$ & 311 & $8,00 \%$ & $80,92 \%$ \\
\hline RTEP & 5 & $3,60 \%$ & 117 & $3,01 \%$ & $119,50 \%$ \\
\hline RTVA & 9 & $6,47 \%$ & 438 & $11,27 \%$ & $57,46 \%$ \\
\hline TS & 11 & $7,91 \%$ & 239 & $6,15 \%$ & $128,70 \%$ \\
\hline TA & 19 & $13,67 \%$ & 595 & $15,31 \%$ & $89,30 \%$ \\
\hline TOTAL & 139 & $100 \%$ & 3887 & $100 \%$ & $100,00 \%$ \\
\hline
\end{tabular}

Fonte: Elaboração própria.

Para discutir a estrutura intelectual, são abordados os autores, as obras e as revistas científicas com mais alta frequência, nas referências bibliográficas, e/ou que aparecem nas redes de cocitação. A Tabela 8 traz o ranking de autores, ao passo que o Gráfico 4 apresenta a rede com todas as cocitações relevantes:

Tabela 8: Agrupamento de turismo cultural - autores mais referenciados (1990-2018)

\begin{tabular}{|c|c|c|c|}
\hline Nome do autor & Citações (ref. bib.) & Nome do autor & Citações (ref. bib.) \\
\hline Brasil & & 155 Françoise Choay & 15 \\
\hline Margarita Barretto & & 51 Greg Richards & 15 \\
\hline Néstor García Canclini & & 36 Pedro Paulo A. Funari & 15 \\
\hline UNESCO & & 35 Milton A. dos Santos & 14 \\
\hline Mario Carlos Beni & & 24 Jacques Le Goff & 13 \\
\hline Organização Mundial do Turismo & & 21 José N. Coelho Meneses & 12 \\
\hline Stuart Hall & & 21 Pierre Nora & 11 \\
\hline Reinaldo Dias & & 20 Ada de Freitas M. Dencker & 10 \\
\hline John Urry & & 16 Flávia Roberta Costa & 9 \\
\hline
\end{tabular}

Fonte: Elaboração própria. 


\section{Gráfico 4: Agrupamento de turismo cultural - rede de cocitação de autores (referências bibliográficas) (1990-2018)}

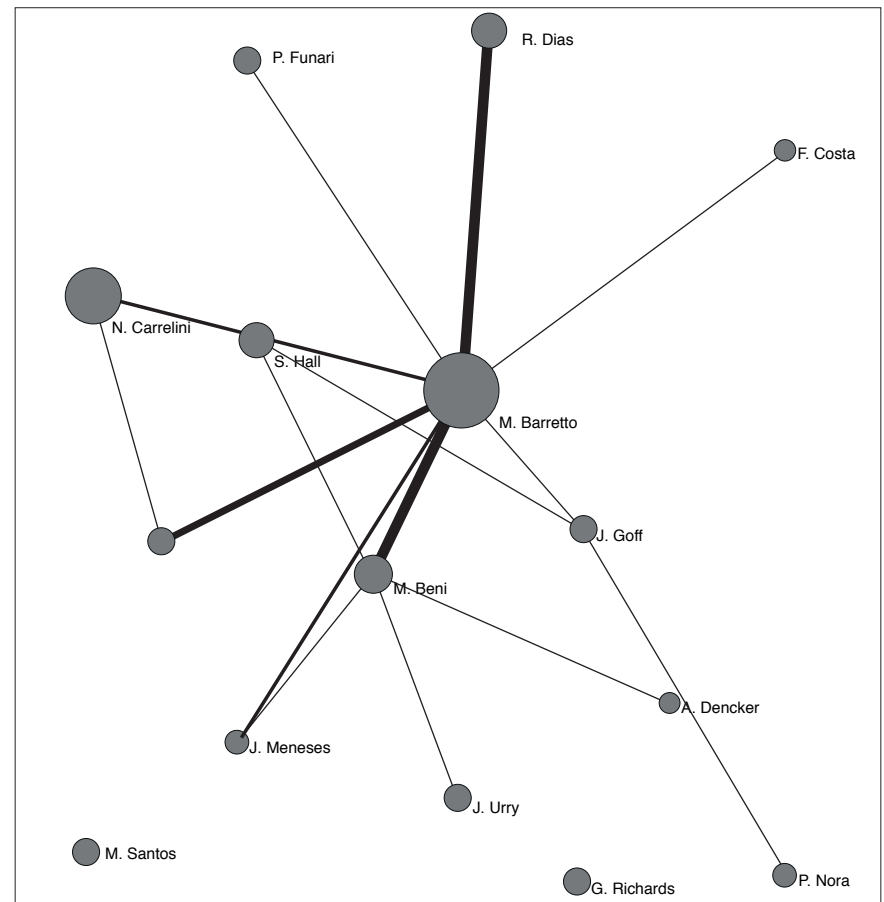

Fonte: Elaboração própria.

Foram retirados, do Gráfico 4, os autores que representam governos e instituições - Brasil, UNESCO e Organização Mundial do Turismo.

A Tabela 9 traz as obras mais citadas, ao passo que o Gráfico 5 ressalta as que são mais citadas conjuntamente. Por fim, a Tabela 10 traz as revistas científicas; apresentam-se, nesse caso, a frequência de vezes nas quais elas aparecem nas referências bibliográficas, bem como o número de artigos do agrupamento de turismo cultural nos quais elas aparecem em, pelo menos, uma referência bibliográfica (doravante denominada de "presença", no presente artigo). Os periódicos que constam em menos de 10\% (arredondamento para baixo) dos artigos, no que concerne a presença, mas que tenham atingido, pelo menos, esse ponto de corte na frequência, aparecem tachados de cinza:

Tabela 9: Agrupamento de turismo cultural - obras mais referenciadas (1990-2018)

\begin{tabular}{lc}
\hline Referência Bibliográfica & Citações (ref. bib.) \\
\hline Barretto (2003) & 24 \\
Beni (1998) & 17 \\
Brasil (2010) & 16 \\
Choay (2006) & 15 \\
Funari e Pinsky (2014) & 15 \\
Urry (2002) & 13 \\
Hall (2004) & 13 \\
Meneses (2013) & 13 \\
Goff (2013) & 11 \\
Dias (2006) & 10 \\
\hline
\end{tabular}

Fonte: Elaboração própria. 
Gráfico 5: Agrupamento de turismo cultural - rede de cocitação de obras (referências bibliográficas) (1990-2018)

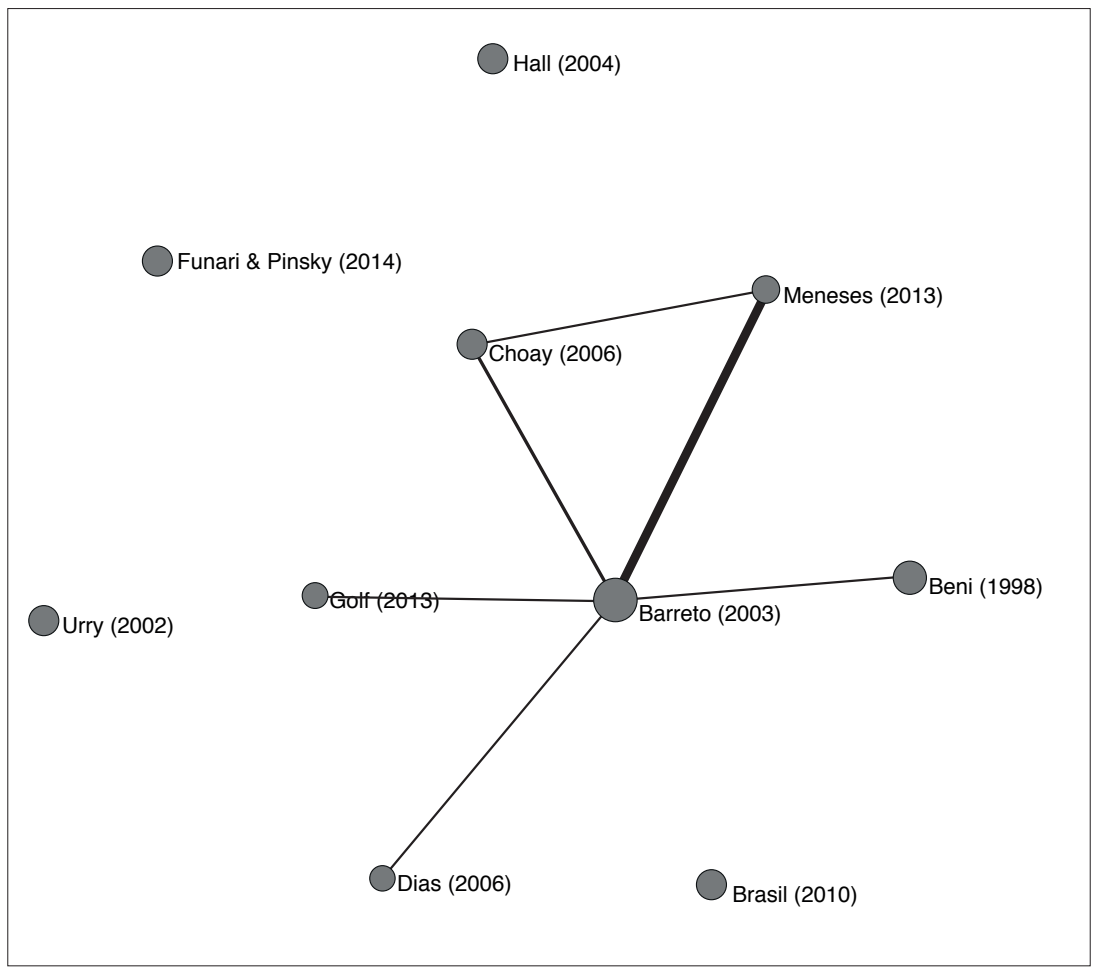

Fonte: Elaboração própria.

Tabela 10: Agrupamento de turismo cultural - revistas científicas mais referenciadas (1990-2018)

\begin{tabular}{lcc}
\hline Nome do periódico & Presença & Frequência \\
\hline Pasos. Revista de Turismo y & 23 & 29 \\
Patrimonio Cultural & 16 & 40 \\
Annals of Tourism Research & 13 & 15 \\
Horizontes Antropológicos & 13 & 17 \\
Revista Turismo - Visão e Ação & & \\
Revista do Patrimônio Histórico e & 10 & 14 \\
Artístico Nacional & 9 & 19 \\
Tourism Management & 9 & 15 \\
Cuadernos de Turismo & 3 & 13 \\
Cahier Espaces & 3 &
\end{tabular}

Fonte: Elaboração própria.

Há poucos periódicos que são citados, conjuntamente, em número relevante. Há apenas dois pares relevantes, a saber: a) Annals of Tourism Research e Tourism Management, com seis artigos; e b) Horizontes Antropológicos e Pasos. Revista de Turismo y Patrimonio Cultural, com também seis artigos. Todas as outras cocitações aparecem em quatro ou menos artigos. 


\section{Discussão de resultados}

A Tabela 1 permite que se vislumbre, em síntese, o significativo crescimento e amadurecimento do campo de turismo no Brasil, notadamente no caso da autoria e das referências bibliográficas. No que concerne estas últimas, a média e a mediana das referências bibliográficas por artigo têm crescimentos de $182,3 \%$ e de $257,1 \%$, respectivamente, do período $1990-1999$ para 1990-2018.

Houve também uma significativa mudança na composição das referências bibliográficas. Em 1990-1999, as referências bibliográficas do tipo "Livro" e "Outros" respondiam por mais de 70\% do total. No caso de "Outros", havia muitos trabalhos de conclusão de curso e documentos institucionais. No período 1990-2018, verifica-se uma diminuição da importância de "Outros", ao passo que os artigos de periódico (de turismo e outros) passaram de 16,53\% (1990-1999) para 30,37\% (1990-2018). Avalia-se como amadurecimento do campo não apenas o crescimento dessas média e mediana, mas também o aumento da importância das revistas científicas nas referências bibliográficas.

A discussão dos resultados está subdividida em cinco subseções, a saber: a) a trajetória do agrupamento de turismo cultural, de 1990-1999 a 1990-2018; b) a produção do agrupamento, por autores, instituições, unidades da federação, grandes regiões e países; c) a estrutura intelectual do agrupamento, por meio das referências bibliográficas de seus artigos; d) a distribuição dos artigos do agrupamento de turismo cultural entre os 16 periódicos do campo de turismo no Brasil; e e) o impacto do agrupamento de turismo cultural.

\subsection{A trajetória do agrupamento de turismo cultural, de 1990-1999 a 1990-2018}

No período 1990-1999, o campo de turismo no Brasil era composto, majoritariamente, pelo periódico TA - a RTVA foi criada apenas em 1998. Há apenas 181 artigos, dos quais cinco não apresentam palavras-chave. Dentro desse quadro, não é de se estranhar, como mostra o Gráfico 1, que haja agrupamentos com poucas palavras-chave, cada um deles, e nenhuma ligação entre si (ausência de arestas externas).

Apesar de "turismo cultural" ser a quinta palavra-chave mais utilizada, com frequência igual a sete, ela não forma nenhum agrupamento, permanecendo isolada. "Cultura" tem frequência igual a três, e está também isolada. De todo modo, os dados do período 1990-1999 precisam ser vistos com cautela, dado que a base de artigos é muito reduzida, e a coleta de dados mostrou que há baixa normalização na utilização de palavras-chave, nesse período.

No período 1990-2009, há a formação de oito agrupamentos, dos quais o centrado na palavra-chave "ecoturismo" é o mais importante. Surgem as primeiras arestas externas, que ligam palavras-chave de agrupamentos diferentes. Dentre os oito existentes, o de turismo cultural é o que mais se liga a outros agrupamentos, o que forma um contraste interessante com o encontrado para o período 1990-2018.

No período 1990-2009, as palavras-chave "turismo cultural" e "cultura" dividem o quarto lugar no ranking das mais citadas, e formam um agrupamento junto com "desenvolvimento local," "patrimônio cultural" e "imagem," esta última com frequência igual a seis, pouco acima do corte mínimo para 1990-2009.

Percebem-se algumas particularidades do agrupamento de turismo cultural, úteis para se analisar sua trajetória. Primeiro, é patente sua baixa capilaridade - há forte polarização exercida por "turismo cultural" e por "cultura." Todas as arestas - internas e com palavras-chave de outros agrupamentos - têm baixo valor; a mais alta liga "turismo cultural" a "patrimônio cultural" (cinco artigos).

É interessante notar também que há uma palavra-chave que não era esperada - "imagem" -, dado que há um agrupamento que traz as palavras-chave "estratégia", "planejamento", "marketing" e "comunicação".

Por mais que ambas as arestas tenham valor igual apenas a três, "cultura" liga-se a "desenvolvimento local" (aresta interna), ao passo que "turismo cultural" liga-se a "desenvolvimento sustentável" (aresta externa). É ilustrativo da trajetória do agrupamento de turismo cultural o fato de as palavras-chave ligadas à temática do desenvolvimento não terem mais nenhuma ligação com ele, no período 1990-2018.

O período 1990-2018 traz o agrupamento de turismo cultural com apenas 139 artigos, muito atrás daqueles centrados em "sustentabilidade" (213) e em "ecoturismo" (208). É possível perceber, por meio da frequência absoluta e da formação dos agrupamentos, que houve a perda de importância relativa do turismo cultural no campo de turismo no Brasil, frente a temáticas ligadas à natureza, ao rural e à sustentabilidade.

As principais palavras-chave continuam a ser "turismo cultural" (108 artigos) e "cultura" (91), em termos de frequência, mas o Gráfico 2 mostra que a última deixou de polarizar o agrupamento com a primeira. Ele centra-se, agora, entre "turismo cultural", de um lado, e "patrimônio" (61) e "patrimônio cultural" (76), do outro. De resto, saíram as palavras-chave "desenvolvimento local" e "imagem", e entraram palavras-chave mais ligadas às ciências sociais - "identidade" (47 artigos), "museus" (22) 
e "memória" (22) -, que são comumente encontradas em estudos acerca do patrimônio cultural, para além do campo de turismo. Dessas três últimas, apenas a primeira tem frequência acima de quatro, no período 1990-2009 - no caso, aparece em nove artigos.

Outro ponto que chama a atenção é o fato de o agrupamento ser o único que não se liga a nenhum dos outros, encontrando-se isolado dentro do campo. Esperava-se que, pelo menos, a palavra-chave "cultura" apresentasse alguma aresta externa, dada sua profundidade conceitual e ampla possibilidade de aplicação. Dado que "turismo cultural" é utilizada, muitas vezes, para delimitar um segmento de mercado, esperava-se também que houvesse alguma aresta externa com os agrupamentos centrados em "destino turístico", "hospitalidade" e/ou "sustentabilidade".

Uma possível explicação para esse isolamento do agrupamento é a predominância de artigos que não se ligam a negócios (non business tourism studies), que representam 89 (64,03\%) dos 139, para utilizar a tipologia proposta por Tribe $(1997,2010)$. Apenas o de ecoturismo tem uma proporção mais alta de artigos que não se ligam a negócios (147 de 208 - 70,67\% do total). Dado que nenhum dos outros quatro têm uma orientação de ciências sociais, e que a maior parte das palavras-chave esteja muito vinculada ao estudo da cultura e do patrimônio cultural, inclusive para além do campo de turismo, é compreensível, ad hoc, que o agrupamento de turismo cultural encontre-se isolado, no período 1990-2018.

\subsection{A produção do agrupamento, por autores, instituições, unidades da federação, grandes regiões e países}

A produção do agrupamento de turismo cultural é relativamente fragmentada, no nível dos autores e instituições. Dos 221 autores únicos, 193 assinam apenas um artigo, sozinhos ou em coautoria. Os dois principais - Karoliny Diniz Carvalho e Pedro de Alcântara Bittencourt César - estão no primeiro centil (1\%) dos autores mais produtivos do campo de turismo no Brasil, ao passo que os demais presentes na Tabela 3 - Silvana Pirillo Ramos, Mario Jorge Pires, Janete Ruiz de Macedo, Roselys Izabel Correa dos Santos e Neus Crous-Costa - produzem relativamente pouco, fora do supracitado agrupamento. Dos sete autores listados na Tabela 3, o que tem a mais baixa porcentagem de seus artigos dentro desse agrupamento é Pedro de Alcântara Bittencourt César, que é também aquele que ocupa a mais alta posição (130) no ranking do campo.

Das 98 instituições, 83 assinam até dois artigos, sozinhas ou em coautoria. Das três primeiras, a Universidade de São Paulo (USP) (nove artigos) e a Universidade do Vale do Itajaí (UNIVALI) (seis) destacam-se como as mais produtivas do campo de turismo no Brasil.

Apesar de ter sido encerrado, a Universidade Estadual de Santa Cruz (UESC) contou já com o Programa de Pós-Graduação em Cultura e Turismo, bem como edita a CULTUR, periódico que mais tem publicado artigos desse agrupamento, como mostra a Tabela 7 . Se a instituição assina apenas $2,11 \%$ dos 3.887 artigos do campo, essa proporção aumenta em torno de cinco vezes para o agrupamento de turismo cultural, sendo quase igual à USP e UNIVALI somadas. Não por acaso, dentre as quatro instituições da Tabela 4, a UESC é a que tem a mais alta porcentagem de seus artigos dentro desse agrupamento, em proporção muito mais alta do que as demais.

Em linhas gerais, a importância da UESC é a principal explicação para o aumento da importância da Região Nordeste no agrupamento, em relação ao campo como um todo. Maranhão e Alagoas mais do que dobram sua participação no agrupamento, em relação ao campo, mas ambos partem de baixas porcentagens. E, como mostra a Tabela 7, o periódico com mais alta sobre representação é editado pela Universidade Federal de Alagoas (UFAL) - a RITUR.

Por fim, no caso dos países, o agrupamento de turismo cultural é aquele no qual o Brasil tem a mais baixa porcentagem. Todos os países que assinam, pelo menos, um artigo têm o português ou o espanhol como idioma oficial, com exceção de França. Dos países estrangeiros, os dois mais importantes guardam estreitas relações culturais com o Brasil. Inclusive, a RITUR é fruto de convênio entre a UFAL e a Universitat de Girona, por meio do apoio da Agencia Española de Cooperación Internacional para el Desarrollo.

É interessante notar que as relativamente altas porcentagens de Espanha e Portugal não se devem a nenhuma instituição em particular, pois sua produção é fragmentada entre várias universidades.

\subsection{A estrutura intelectual do agrupamento, por meio das referências bibliográficas de seus artigos}

Como é facilmente perceptível, por meio da Tabela 2, dentre os cinco agrupamentos, o de turismo cultural é o que apresenta, em suas referências bibliográficas, a mais baixa proporção de artigos de periódico (campo de turismo e outros) e de monografias, assim como a mais alta porcentagem de livros e capítulos de livro. 
Isso é reflexo, provavelmente, de dois pontos, a saber: a) a orientação de ciências sociais, a julgar por suas palavras-chave e isolamento (período 1990-2018): as ciências sociais dependem mais de livros para a construção e transmissão de conhecimento, em relação a outras grandes áreas de conhecimento; e b) a eventual dependência ainda de textos didáticos e introdutórios: a coleta de dados, para o campo de turismo como um todo, revelou que os livros didáticos são ainda muito presentes nas referências bibliográficas, ao contrário, por exemplo, de o que ocorre nos principais periódicos internacionais de turismo (Benckendorff \& Zehrer, 2013; Racherla \& Hu, 2010). Isso demonstra um estágio de ainda amadurecimento do agrupamento, no qual esse fenômeno parece ser mais acentuado.

Que se somem, a esses dois pontos, as mais baixas média e mediana de referências bibliográficas por artigo, dentre os cinco agrupamentos, para se ter algo que não ocorre em nenhum outro, além do de turismo cultural, a saber: praticamente, não há uma rede de periódicos formada - eles não conseguem delimitar uma clara estrutura intelectual.

Como mostram a Tabela 8 e o Gráfico 4, dos 14 autores mais produtivos, três são organizações ou governos, ao passo que dois indivíduos - Mario Carlos Beni e Reinaldo Dias - são autores muito citados no campo como um todo, cuja influência vai muito além desse agrupamento. Dos nove autores restantes, o único que tem uma postura marcadamente orientada ao mercado é Greg Richards; todos os demais transitam entre as várias ciências, disciplinas e campos ligados às ciências sociais.

O Gráfico 4 ressalta o domínio de Margarita Barretto na estrutura intelectual. Não apenas é a autora (indivíduo) mais citada, ela ocupa também papel central no grafo de coautorias - liga-se, por meio de cocitações, com nove outros autores. Apenas Mario Carlos Beni (cinco) e Stuart Hall (quatro) têm quatro ou mais arestas. Chama a atenção o fato de John Urry ligar-se apenas a Mario Carlos Beni, mesmo The tourist gaze (Urry, 2002) tendo se tornado um dos textos centrais na estrutura intelectual dos principais periódicos internacionais de turismo, como mostram Benckendorff e Zehrer (2013).

Dois pontos chamam também a atenção. Primeiro, não há uma aresta que ligue John Urry e Stuart Hall, por mais que ambos sejam muito ligados à discussão da pós-modernidade e turismo. Segundo, por mais que sejam autores relativamente pouco citados, há uma aresta (seis artigos) entre Jacques Le Goff e Pierre Nora, o que indica um subgrupo de artigos que trabalham com história.

A análise das obras mais citadas e cocitadas, por meio da Tabela 9 e do Gráfico 5, permite ir além de o que foi feito com base nos autores. Dos 10 textos, nove são livros - reforça a ainda baixa importância dos artigos de periódico no agrupamento de turismo cultural. Há um texto técnico - Turismo cultural: orientações básicas (Brasil, 2010). Há um contraste curioso, a saber: os cinco livros de autores brasileiros ou radicados no Brasil são didáticos ou introdutórios, ao passo que os quatro volumes de autores internacionais abordam determinado tema ou assunto em profundidade. Há um volume que é o texto mais presente nas referências bibliográficas do campo de turismo no Brasil, e aparece em destaque em todos os agrupamentos - Análise estrutural do turismo (Beni, 1998).

Mais uma vez, reforça-se o domínio de Margarita Barretto no agrupamento. O volume Turismo e legado cultural (Barretto, 2003) ocupa o centro do grafo de cocitações. Há apenas uma aresta que não inclui esse livro.

Reforça-se também a noção, que aparece já nas palavras-chave, do estreito vínculo entre turismo cultural e patrimônio cultural. Por outro lado, é notável a ausência de textos sobre a cultura, por mais que História e memória (Goff, 2013) ligue-se a Turismo e legado cultural (Barretto, 2003).

Há apenas quatro periódicos que são utilizados, nas referências bibliográficas, em, pelo menos, 13 artigos. Temos a segunda revista mais antiga do campo de turismo no Brasil (RTVA) e um dos principais periódicos internacionais de turismo (Annals of Tourism Research). Os dois outros têm afinidade específica ao agrupamento. A Pasos. Revista de Turismo y Patrimonio Cultural tem uma temática muito próxima a do agrupamento, ao passo que a Horizontes Antropológicos é uma das principais revistas brasileiras de antropologia. Dada a lista de principais autores e obras, era esperado que a antropologia fizesse parte importante da estrutura intelectual do agrupamento.

As ausências mais notadas são dois periódicos nacionais, a TA e a CULTUR. A primeira é o periódico pioneiro do campo de turismo no Brasil; a segunda é um periódico que traz, já em seu título, a relação entre turismo e cultura.

\subsection{A distribuição dos artigos do agrupamento de turismo cultural entre os 16 periódicos do campo de turismo no Brasil}

Dos 16 periódicos, apenas dois não publicaram nenhum artigo no agrupamento de turismo cultural. A RLAT é relativamente nova, com apenas 48 artigos publicados. Dos cinco agrupamentos, há artigos 
dessa revista científica apenas no centrado em sustentabilidade. Já a AT tem orientação aplicada, e conta com 80 artigos publicados. Parece ser sintomático o agrupamento de turismo cultural não ter nenhum artigo publicado na única revista científica de orientação marcadamente aplicada do campo de turismo no Brasil.

Os dois periódicos com mais alta sobre representação são ambos da Região Nordeste, cujas instituições responsáveis - UFAL (RITUR) e UESC (CULTUR) - são também sobre representadas no agrupamento. A CULTUR traz a relação entre cultura e turismo em seu próprio nome.

É algo preocupante verificar que, dos cinco agrupamentos, apenas o de turismo cultural é sub representado, simultaneamente, naqueles que são considerados os quatro principais periódicos do campo de turismo no Brasil - CVT, RBPT, RTVA e TA. É difícil afirmar o porquê de isso acontecer. Fazer uma ligação com algumas características da estrutura intelectual do agrupamento, notadamente a baixa representatividade das revistas científicas e a centralidade de textos didáticos e introdutórios, pode ser um caminho promissor. De todo modo, seria necessário ter acesso aos artigos rejeitados pelas supracitadas revistas científicas, preferencialmente com seus pareceres, para elaborar uma análise mais apurada.

\subsection{O impacto do agrupamento de turismo cultural}

De modo geral, os dados relativos ao impacto do agrupamento não diferem muito dos encontrados para o campo de turismo como um todo. Na média de citações reais por artigo, o de turismo cultural fica acima apenas do centrado em hospitalidade, mas apenas um pouco abaixo do verificado para o campo - 2,63 frente a 2,8 .

Dentro do agrupamento de turismo cultural, não há diferença significativa entre os artigos classificados como estudos ligados a negócios turísticos $(2,62)$ e aqueles classificados como estudos não ligados a negócios turísticos $(2,64)$.

No conjunto dos 70 artigos com mais citações ${ }^{2}$, há apenas dois do agrupamento de turismo cultural. Ambos consistem em estudos introdutórios ao tema, com particular preocupação em explicitar conceitos, e indicar e comentar as referências-chave da área. Köhler e Durand (2007) têm uma clara orientação de gestão e marketing, tratando a cultura e o patrimônio cultural como base para a criação de produtos turístico-culturais mercadejáveis. Já Batista (2005) traz uma útil reflexão sobre a importância da memória e identidade para o turismo cultural. Curiosamente, na linha de "santo de casa não faz milagre", ambos são pouco importantes na estrutura intelectual do agrupamento. O primeiro é citado por apenas três artigos, ao passo que o segundo não é por rigorosamente nenhum.

\section{Considerações finais}

Dentre os cinco existentes no período 1990-2018, o agrupamento de turismo cultural é apenas o quarto em número de artigos (139 de 3.887 - 3,28\% do total). Além disso, ele apresentou crescimento, ao longo dos anos 2010, mas em escala não tão alta quanto à verificada nos agrupamentos de "sustentabilidade" e de "ecoturismo." Parece que o turismo cultural está firmemente estabelecido no campo de turismo no Brasil, mas não tem a mesma força que o ecoturismo nem sequer o turismo rural, tampouco as discussões acerca da sustentabilidade, particularmente atreladas à questão do desenvolvimento.

De todo modo, o agrupamento de turismo cultural é claramente delimitado, e congrega um conjunto de palavras-chave "esperadas", que orbitam em torno do turismo cultural, da cultura e do patrimônio.

Chama particular atenção a orientação de ciências sociais presente no agrupamento. Há relativamente poucos artigos preocupados com o turismo cultural como um segmento de mercado, por meio da gestão e/ou do marketing. Isso se reflete, muito claramente, em sua estrutura intelectual. Com exceção de Greg Richards (ranking de autores), as tabelas 8, 9 e 10 e os gráficos 4 e 5 mostram que a estrutura intelectual é marcada, majoritariamente, por autores, obras e periódicos mais ligados às ciências sociais. Por exemplo, não há nenhuma revista científica de marketing nem sequer de administração, que se destaque na estrutura intelectual do agrupamento.

Parece tratar-se também de um agrupamento ainda em estágio de maturação, em relação aos outros quatro e mesmo ao campo de turismo no Brasil. Há mais baixo uso de referências bibliográficas por artigo, na média e na mediana; a porcentagem de artigos de periódico (de turismo e outros) é muito baixa. De todos os agrupamentos, o de turismo cultural é o único que não forma uma rede de cocitações de revistas científicas minimamente estruturada. Trata-se de uma consequência da grande importância dos livros nas referências bibliográficas; no topo do ranking das obras, destacam-se, em número, os livros de caráter didático e introdutório. 
É interessante notar o destaque de Margarita Barretto e seu volume Turismo e legado cultural (Barretto, 2003), tanto nos rankings quanto nas redes de autores e obras. Contudo, por meio da leitura transversal dos 139 artigos, ela parece exercer um papel similar ao de Mario Carlos Beni para o campo como um todo, mas apenas para o agrupamento de turismo cultural. As citações feitas à supracitada autora servem para sustentar afirmações de cunho introdutório ou geral, a exemplo do crescimento do turismo cultural, nos últimos anos.

$\mathrm{Na}$ autoria, destaca-se a sobre representação da Região Nordeste do Brasil no agrupamento, devido, principalmente, à UESC. Há paralelo nessa sobre representação tomando-se os 16 periódicos brasileiros de turismo, com os casos da RITUR e da CULTUR, vistos anteriormente. Ao lado do composto sexo, sol, mar e praia, a cultura e o patrimônio cultural sempre foram usados como atrativos turísticos, no caso da Região Nordeste, inclusive por vários programas federais de grande porte de turismo e patrimônio, a saber: a) Programa de Reconstrução das Cidades Históricas do Nordeste, com sua utilização para fins turísticos; b) Programa MONUMENTA; c) Programas Regionais de Desenvolvimento do Turismo (PRODETUR) - várias edições; e d) Programa de Aceleração do Crescimento - Cidades Históricas. Contudo, é importante fazer a seguinte advertência: a sobre representação deve-se, essencialmente, à UESC. Seu Programa de Pós-Graduação em Cultura e Turismo foi encerrado, há cerca de 10 anos, mas a sobre representação da instituição continuou firme, ao longo dos anos 2010.

Para fechar o presente artigo, cumpre destacar os últimos três pontos. Primeiro, os resultados mostram que o agrupamento tem várias lacunas, em relação ao que é verificado nos periódicos internacionais de turismo. A questão da autenticidade aparece, de forma pronunciada, em poucos artigos. Para nenhum dos três períodos em análise, a palavra-chave "autenticidade" passa pelo ponto de corte. É provável que esse é o motivo principal de Erik Cohen não aparecer entre os principais autores. Com exceção de Greg Richards, há nítida ausência de autores e obras que trabalhem o turismo cultural, sob uma perspectiva de negócios, tanto na esfera privada quanto no setor público.

Segundo, é curioso que a estrutura intelectual do agrupamento não traga, entre seus principais autores, nenhum dos indivíduos listados na Tabela 3, nem sequer os responsáveis pelos dois artigos mais citados - André Fontan Köhler, José Carlos Garcia Durand e Cláudio Magalhães Batista. Outra ausência notada é Mário Jorge Pires, cujo livro Lazer e turismo cultural (Pires, 2001) é muito citado na literatura ${ }^{3}$. O autor é considerado como um dos pioneiros do estudo do turismo cultural no Brasil.

A principal limitação do presente artigo é ter se baseado, para a criação e delimitação dos agrupamentos, nas palavras-chave dos 3.887 artigos do campo de turismo no Brasil. Dado que os próprios autores escolhem suas palavras-chave, por mais que elas possam ser mudadas, conforme sugestões emitidas pelos pareceristas, não há nenhuma garantia de que elas sempre retratem, fidedignamente, o conteúdo do artigo em questão. Além disso, o Tesauro Brasileiro de Turismo é de publicação recente, e sua aplicação obrigatória não atinge todos os periódicos brasileiros de turismo. Outra limitação reside no próprio objeto de estudo; a produção científica em turismo no Brasil vai muito além dos 3.887 artigos publicados nos 16 periódicos selecionados.

Será útil comparar os resultados da presente pesquisa com os agrupamentos criados e delimitados pelo conjunto de referências bibliográficas dos 3.887 artigos - autores, obras e revistas científicas. Trata-se de um caminho promissor para nossas pesquisas futuras.

\section{Bibliografía}

Batista, C. M. (2005). Memória e identidade: aspectos relevantes para o desenvolvimento do turismo cultural. Caderno Virtual de Turismo, 5(3), 27-33.

Barretto, M. (2003). Turismo e legado cultural. Papirus.

Benckendorff, P. (2009). Themes and trends in Australian and New Zealand tourism research: a social network analysis of citations in two leading journals (1994-2007). Journal of Hospitality and Tourism Management, 16(1), 1-15. https://doi.org/10.1375/jhtm.16.1.1

Benckendorff, P. \& Zehrer, A. (2013). A network analysis of tourism research. Annals of Tourism Research, 43, 121-149. https://doi.org/10.1016/j.annals.2013.04.005

Beni, M. C. (1998). Análise estrutural do turismo. Senac.

Bertero, C. O., Caldas, M. P. \& Wood Jr., T. (1999). Produção científica em administração de empresas: provocações, insinuações e contribuições para um debate local. Revista de Administração Contemporânea, 3(1), 147-178. https://doi.org/10.1590/S1415-65551999000100009

Biglan, A. (1973). The characteristics of subject matter in different academic areas. Journal of Applied Psychology, 57(3), 195-203. https://doi.org/10.1037/h0034701 
Brasil. Ministério do Turismo. (2010). Turismo cultural: orientações básicas. http://www.turismo.gov. br/sites/default/turismo/o_ministerio/publicacoes/downloads_publicacoes/Turismo_Cultural_Versxo_Final_IMPRESSxO_.pdf

Choay, F. (2006). A alegoria do patrimônio. 3. ed. Estação Liberdade : UNESP.

Dias, R. (2006). Turismo e patrimônio cultural: recursos que acompanham o crescimento das cidades. Saraiva.

Funari, P. P. \& Pinsky, J. (Orgs.) (2014). Turismo e patrimônio cultural. Contexto.

Goff, J. (2013). História e memória. Editora da UNICAMP.

Grauwin, S. \& Jensen, P. (2011). Mapping scientific institutions. Scientometrics, 89, 943. https://doi. org/10.1007/s11192-011-0482-y

Hall, S. (2004). A identidade cultural na pós-modernidade. Lamparina.

Hall, C. M. (2011). Publish and perish? Bibliometric analysis, journal ranking and the assessment of research quality in tourism. Tourism Management, 32(1), 16-27. https://doi.org/10.1016/j. tourman.2010.07.001

Jamal, T., Smith, B. \& Watson, E. (2008). Ranking, rating and scoring of tourism journals: interdisciplinary challenges and innovations. Tourism Management, 29(1), 66-78. https://doi.org/10.1016/j. tourman.2007.04.001

Kessler, M. M. (1963). Bibliographic coupling between scientific papers. American Documentation, 24, 123-131. https://doi.org/10.1002/asi.5090140103

Kirilenko, A. P. \& Stepchenkova, S. (2018). Tourism research from its inception to present day: subject area, geography, and gender distributions. PLos ONE, 13(11), e0206820. https://doi.org/10.1371/ journal.pone.0206820

Koc, E. \& Boz, H. (2014). Triangulation in tourism research: a bibliometric study of top three tourism journals. Tourism Management Perspectives, 12, 9-14. https://doi.org/10.1016/j.tmp.2014.06.003

Köhler, A.F. \& Durand, J. C. G. (2007). Turismo cultural: conceituação, fontes de crescimento e tendências. Revista Turismo - Visão e Ação, 9(2), 185-198. https://doi.org/10.14210/rtva.v9n2.p185-198

Köhler, A. F. \& Digiampietri, L. A. (2021). Estudos de hospitalidade: análise bibliométrica e de redes sociais do campo de turismo no Brasil, 1990-2018. Revista Hospitalidade, 18(1), 104-135.

Koseoglu, M. A., Rahimi, R., Okumus, F. \& Liu, J. (2016). Bibliometric studies in tourism. Annals of tourism research, 61, 180-198. https://doi.org/10.1016/j.annals.2016.10.006

Law, R. \& Veen, R. (2008). The popularity of prestigious hospitality journals: a Google Scholar approach. International Journal of Contemporary Hospitality Management, 20(2), 113-125. https:// doi.org/10.1108/09596110810852113

Laws, E. \& Scott, N. (2015). Tourism research: building from other disciplines. Tourism Recreation Research, 40(1), 48-58. https://doi.org/10.1080/02508281.2015.1005926

Leta, J. \& Lewison, G. (2003). The contribution of women in Brazilian science: a case study in astronomy, immunology and oceanography. Scientometrics, 57, 339-353. https://doi.org/10.1023/A:1025000600840

McKercher, B. (2005). A case for ranking tourism journals. Tourism Management, 26(5), 649-651. https://doi.org/10.1016/j.tourman.2004.04.003

McKercher, B. (2008). A citation analysis of tourism scholars. Tourism Management, 29(6), 1.226-1.232. https://doi.org/10.1016/j.tourman.2008.03.003

Meneses, J. N. C. (2013). História \& turismo cultural. Autêntica.

Mulet-Forteza, C., Genovart-Balaguer, J., Mauleon-Mendez, E. \& Merigó, J. M. (2019). A bibliometric research in the tourism, leisure and hospitality fields. Journal of Business Research, 101, 819-827. https://doi.org/10.1016/j.jbusres.2018.12.002

Otte, E. \& Rousseau, R. (2002). Social network analysis: a powerful strategy, also for the information sciences. Journal of Information Science, 28(6), 441-453. https://doi.org/10.1177/016555150202800601

Pires. M. J. (2001). Lazer e turismo cultural. Manole.

Racherla, P. \& Hu, C. (2010). A social network perspective of tourism research collaborations. Annals of Tourism Research, 37(4), 1.012-1.034. https://doi.org/10.1016/j.annals.2010.03.008

Tribe, J. (1997). The indiscipline of tourism. Annals of Tourism Research, 24(3), 638-657. https://doi. org/10.1016/S0160-7383(97)00020-0

Tribe, J. (2010). Tribes, territories and networks in the tourism academy. Annals of Tourism Research, 37(1), 7-33. https://doi.org/10.1016/j.annals.2009.05.001

Strandberg, C., Nath, A., Hemmatdar, H. \& Jahwash, M. (2018). Tourism research in the new millennium: a bibliometric review of literature in Tourism and Hospitality Research. Tourism and Hospitality Research, 18(3), 269-285. https://doi.org/10.1177/1467358416642010 
Urry, J. (2002). The tourist gaze. Second edition. Sage.

Ye, Q., Li, T. \& Law, R. (2013). A coauthorship network analysis of tourism and hospitality research collaboration. Journal of Hospitality \& Tourism Research, 37(1), 51-76. https://doi. org/10.1177/1096348011425500

Xiao, H. \& Smith, S. L. J. (2006). The making of tourism research: Insights from a Social Sciences Journal. Annals of Tourism Research, 33(2), 490-507. https://doi.org/10.1016/j.annals.2006.01.004

\section{Notas}

1 O Qualis Periódicos é o sistema brasileiro de avaliação de periódicos, mantido pela Coordenação de Aperfeiçoamento de Pessoal de Nível Superior. Os periódicos são classificados pelas áreas de avaliação, nos quais pesquisadores vinculados aos programas de pós-graduação stricto sensu brasileiros publicaram seus trabalhos. Atualmente, há 49 áreas de avaliação. Cada uma classifica os periódicos considerados relevantes para a área em sete categorias (A1, A2, B1, B2, B3, B4 e B5), sendo A1 a classificação mais importante e B5 a menos.

2 Para a delimitação desse conjunto, foi selecionado o primeiro centil (1\%) dos artigos com mais impacto, para todas as citações reais e para as citações reais, de acordo com cada tipo de quem cita (artigo de periódico, livro, monografia [dissertação de mestrado e tese de doutorado] etc.). Batista (2005) está no primeiro centil das citações reais totais, ao passo que Köhler e Durand (2007) entram na lista, por meio das citações reais feitas por artigos de periódico.

3 Em 08 de agosto de 2020, Pires (2001) tinha 184 citações nominais no Google Acadêmico. Para efeito de comparação, Barretto (2003) apresentava 405 citações nominais, por meio também do Google Acadêmico e na mesma data. 


\title{
Opiniones y Ensayos
}

\section{Nuevas relaciones entre cultura, turismo y territorio en el contexto de la posmodernidad}

\author{
Florencia Viviana Moscoso* \\ Universidad Nacional de La Plata (Argentina)
}

\begin{abstract}
Resumen: Frente a nuevas dinámicas y nuevas miradas del contexto sociocultural, el presente ensayo busca realizar un breve análisis y reflexión sobre la relación entre identidades culturales y las visiones posmodernas de los territorios turísticos, con el objetivo de profundizar sobre la práctica social del turismo en articulación a sus actores, espacios, apropiaciones y proceso sociales mayores. Para alcanzar el propósito del presente trabajo se recurre a la revisión, lectura y análisis crítico de bibliografía pertinente en la temática, poniendo en diálogo distintas miradas y enfoques. Asimismo, se intenta poner en cuestión aquellas concepciones esencialistas en torno al concepto de identidades culturales y su relación con el territorio turístico. En tanto, dentro del campo de investigación en turismo se continuan replicando modelos donde el fenómeno turístico es catalogado como depredador y banalizador de la cultura local. De este modo, se aboga por introducir un eje de investigación incipiente entre la disciplina turística y la denominada geografía cultural, contemplando nuevas conceptualizaciones y complejidades dentro de la tríada turismo, cultura y territorio.
\end{abstract}

Palabras Clave: Geografía cultural; Geografía turística; Territorialización; Identidad cultural; Imaginario turístico.

New relationships between culture, tourism and territory in the context of postmodernit

Abstract: Faced with new dynamics and new views of the socio-cultural context of tourism, this essay seeks to carry out a brief reflection and analysis on the relationship between cultural identities and postmodern visions of tourist territories. The aim is to study the social practice of tourism in articulation with its actors, spaces, appropriations and larger social processes. In order to achieve the purpose of this essay, revision and critical analysis of pertinent bibliography on the subject was used, confronting different perspectives and views. Basic constructs built around the concept of cultural identities and their relationship with place and tourism are likewise questioned. Meanwhile, within the field of tourism research, models continue to be replicated where tourism is classified as a predator and banaliser of the local culture. Research along the axis of tourism and cultural geography is advocated to contemplate the new complex concptualisations within the triad of tourism, culture and territory.

Keywords: Cultural geography; Tourist geography; Territorialisation; Cultural identity; Tourist imaginary.

\section{Introducción}

La geografía ha constituido una de las primeras disciplinas en abordar el estudio del fenómeno turístico como manifestación social, cultural y económica. Durante los primeros años, se puede observar la primacía de un enfoque materialista, funcionalista y utilitaria en las investigaciones que se extiende hasta poco más de la mitad del siglo XX. Dicha visión catalogada como tradicionalista, se centra en explicar y describir el territorio como espacio físico integrado por flujos, atributos y cualidades, un estudio meramente estadístico y analítico (Bertoncello, 2002; Pinassi y Ercolani, 2015). Así, el recorte

Universidad Nacional de La Plata (Argentina); E-mail: florencia.moscoso@econo.unlp.edu.ar; https://orcid.org/0000-0002-4851-4479 
positivista y espacialmente determinista de las primeras investigaciones geográficas del turismo se vincula al desarrollo de una sociedad moderna, caracterizada por la representación cartográfica de territorios coloniales socioculturalmente delimitados, definidos y diferenciados por rasgos específicos (Cohen, 2005; Aitchison, Macleod y Shaw, 2014).

A partir del advenimiento del giro posmoderno y el giro cultural, el campo de la geografía acompaña un movimiento que atraviesa a todas las ciencias sociales. Se destacan estudios sobre movilidad, teorías poscoloniales, investigaciones sobre la geografía de la vida cotidiana, entre otros, que buscan dar respuesta a tendencias emergentes dentro de los estudios sociales (Franklin y Crang, 2001; Cohen, 2005). Bajo esta nueva orientación, el fenómeno turístico es considerado como una importante dimensión para repensar la teoría social (Minca y Oakes, 2014).

Siguiendo los lineamientos de una geografía pos-positivista, aparecen nuevas corrientes que ponen el acento en el territorio como resultado de una construcción social así como en el análisis de representaciones sociales, discursos, prácticas y significados dentro un espacio simbólico mediado por relaciones de poder. El abordaje de lo sociocultural desde referencias territoriales da inicio a nuevas vertientes dentro pensamiento geográfico, entre las cuales se destaca la geografía cultural.

De esta manera el conocimiento geográfico del turismo atravesó, a lo largo del tiempo, un complejo y casi permanente proceso de redefinición en cuanto a su objeto de estudio dando lugar a investigaciones más críticas y reflexivas. Sin embargo, hoy en día algunas investigaciones sobre el turismo siguen reproduciendo análisis tradicionales y ponen el foco en miradas un tanto esencialistas y sustancialistas respecto de la cultura en un espacio físico concreto.

Frente a nuevas dinámicas y nuevas miradas del contexto sociocultural, el presente ensayo busca realizar una breve análisis y reflexión sobre la relación entre identidad cultural y las visiones posmodernas de los territorios turísticos, con el objetivo de profundizar sobre la práctica social del turismo en articulación a sus actores, espacios, apropiaciones y procesos sociales mayores. Para alcanzar el propósito del presente trabajo se recurre a la revisión, lectura y análisis crítico de bibliografía pertinente en la temática, poniendo en diálogo distintas miradas y enfoques. De este modo, se aboga por introducir un eje de investigación incipiente entre la disciplina turística y la denominada geografía Cultural, contemplando nuevas conceptualizaciones y complejidades dentro de la tríada turismo, cultura y territorio.

\section{Territorio como espacio material y simbólico}

Las primeras interpretaciones sobre los procesos de relación entre medio y sujeto, que tuvieron lugar entre los años 1930-1960, sostenían sus argumentos bajo una perspectiva utilitarista y materialista del territorio (Pinassi y Ercolani, 2015). Congruentemente, la reproducción de la sociedad se ajustaba exclusivamente a la disponibilidad de recursos económicos así como al dominio y soberanía de un espacio en términos políticos y jurídicos. Si bien hubo un fuerte predomino de esta mirada sobre la reproducción del territorio, algunos autores, tales como Bertoncello (2002) y Almirón (2004), la han catalogado de reduccionista puesto que deja en segundo plano la importancia de la acción social en los procesos de territorialización.

La sociedad cumple un rol central en la configuración del territorio, ya que a partir de accionar lo define y lo recrea. Así, es posible comprender el espacio físico en correspondencia y como soporte de una estructura social coherente. Bajo esta concepción, el territorio denota un fuerte componente social a través de la apropiación y sentido que le otorga una sociedad. Representa, de este modo, un espacio físico concreto construido a partir de la apropiación e intencionalidad de distintos grupos de actores en un contexto social, político e histórico particular. Cabe destacar, que dicha intencionalidad actúa bajo la forma de un doble sentido, uno predominantemente material y de dominio político-económico mencionado al inicio, y un sentido inmaterial vinculado a la valorización y apropiación simbólica del espacio (Haesbaert, 2013; Meethan, 2001; Paes, 2009). El carácter simbólico del territorio adquiere relevancia como espacio portador de representaciones, prácticas, imaginarios, discursos y narrativas. Un territorio que construye identidad y pertenencia, producto de la materialización de sentidos conferidos por sujetos sociales e individuos históricamente localizados. Como exponen los autores, De Anda et al "el territorio ha guardado una inminente relación espiritual con el hombre desde tiempo inmemorables; espacios cargados de significado gracias a símbolos y códigos que distinguen una cultura de otra" (2019, p. 893).

Las transformaciones que trae consigo la posmodernidad y, por lo tanto, la globalización conducen a replantear la noción de territorio desde una perspectiva integradora y relacional. Haesbaert hace alusión al territorio "como experiencia integrada (...) a través de múltiples escalas que se extienden de 
lo local a lo global" (2013, p.67) y como referencia a múltiples relaciones socio-históricas de poder. Por ser relacional el territorio es movimiento, fluidez e interconexión. Por ser integral es multidimensional y se (re) produce a partir de la relación entre un medio material y un sujeto social. Por tanto, el territorio es producto de prácticas sociales y espaciales que se reflejan y materializan en territorialidad.

La territorialización consiste en crear mediaciones espaciales, prácticas sociales proyectadas por el mercado, por el discurso político, por otros sujetos que ejercen un efectivo poder sobre la reproducción de la sociedad. Poder que es "siempre multiescalar y multidimensional, material e inmaterial, de dominación y apropiación al mismo tiempo" (Haesbaert, 2013, p.82-83) (Paes, 2009).

Algunos autores, tales como Haesbaert (2013) y Restrepo (2006) asocian la territorialidad tanto con la dimensión material como la simbólica. La identidad cultural dispone de un rol importante en la reproducción social del territorio, ya que en relación a un espacio físico las identidades son construcciones de pertenencia históricamente situadas en relación a un Otro, a una exterioridad. Formaciones discursivas que poseen efectos materiales sobre espacios, objetos y sujetos, es decir, se materializan en un territorio en forma de disputa o representación; y una vez territorializadas, continúan transformándose en relación al contexto geográfico, social y político de inserción (Restrepo, 2006).

\section{Identidades territoriales, patrimonio e imaginario turístico}

Las identidades culturales del territorio descansan bajo la reconocida idea de patrimonio cultural. El patrimonio conforma la herencia social, material y simbólica de una sociedad. La expresión espacial del patrimonio tiene raíz en la territorialización de la memoria colectiva, de los imaginarios, signos y significados, materialización que es producto de diferentes intereses y definiciones de lo que se considera que forma parte del acervo identitario de una sociedad.

Paes (2009) ofrece una reflexión acerca del proceso de patrimonialización de las identidades territoriales desde un abordaje geográfico. Para la autora, la patrimonialización involucra un conjunto de prácticas sociales de producción cultural, saberes simbólicos y técnicos legitimados e institucionalizados por diferentes sujetos. Rescata el concepto de lugar de memoria y plantea la re-semantización del espacio geográfico a partir de la reorganización, valorización, selección y disputa por la materialización de la memoria y de las identidades. Como resultado el espacio geográfico es intercedido a partir de múltiples imaginarios, narrativas y discursos que entran en tensión o pueden ser aceptados como representativos de una sociedad.

Ahora bien, las identidades territoriales no solo recaen en la valorización por parte de una sociedad que siente pertenencia con ese acervo cultural, sino que también son susceptibles de convertirse en "objetos de consumo valorizados en la mercantilización turística del paisaje" (traducción propia, Paes, 2009, p.167). De esta forma, la práctica turística interviene como mediadora y consumidora de un espacio simbólico territorializado.

El turismo se emplaza dentro de un espacio con connotaciones culturales, materiales y simbólicas, previamente definidas por una comunidad residente. Como práctica social involucra no solo consumo, sino también la reproducción de un espacio simbólico, en la medida que le confiere a las expresiones culturales -patrimonio, referentes, costumbres- de una sociedad de un valor de cambio y de uso. Así, el turismo constituye un proceso inscripción de significados sociales y de producción de experiencias culturales que suponen el "contacto entre otros culturales que (...) pueden incidir en las dinámicas de identificación colectiva, así como en los procesos de des y re territorialización” (Comparato, 2018, p. 270). En otras palabras, procesos de construcción de nuevas territorialidades, nuevas apropiaciones simbólicas y materiales del territorio. Por esta razón el turismo incide en la configuración del lugar de destino, como proceso de construcción social dinámico, a partir del cual la práctica turística y el territorio se transforman y recrean continuamente el uno al otro.

Asumir la resignificación de las expresiones culturales, por parte del fenómeno turístico, implica pensar una dialéctica entre un territorio presente y un territorio pasado y entre un territorio real y un territorio imaginario. Dentro de esta dialéctica la revalorización no siempre es resultado de una puesta en valor colectivo y por parte de la comunidad residente, sino que se encuentra vinculada a procesos y decisiones sociales, económicas y políticas de un pequeño grupo de actores, en muchos casos, externos a la comunidad. Esto puede conllevar a un desarrollo dicotómico entre la imagen que la sociedad anfitriona tiene de sí misma y la mirada turística.

La activación y valorización turística conducen, por lo tanto, a una reducción del discurso patrimonial, privilegiando expresiones culturales y memorias atractivas para la mirada turística, por sobre otras 
identidades que conviven en un lugar. En particular, este proceso ha marcado una fuerte tendencia hacia la segregación, exclusión, desplazamiento y despojo territorial de los valores simbólicos y de la sociedad misma. De igual manera, la refuncionalización turística del patrimonio incorpora nuevas territorialidades que compiten por el espacio, entre ellas, la mercantilización cultural, el uso privado y público, los intereses sociales, entre otras (Paes, 2009).

El reconocimiento turístico del patrimonio se produce a partir de la construcción del imaginario turístico. Hiernaux (2002), Meethan (2001) y Salazar (2012) definen al imaginario turístico como el conjunto o suma total de creencias, imágenes preconcebidas, discursos, prácticas, valorizaciones en torno a lugares y sociedades. El desarrollo del imaginario toma como antecedentes otras impresiones y experiencias, sistemas de valores que forman parte de la vida cotidiana, un ethos cultural en palabras de Salazar (2012), que orienta la acción de la sociedad a través de la praxis.

El turismo opera como discurso ambivalente (Comparato, 2019) en la construcción de imaginarios, a partir de la recreación, reinvención y reproducción de múltiples relatos sobre las identidades culturales de un territorio. Con un claro objetivo lucrativo extiende y sostiene esquemas de representación que circulan en las sociedades de origen y crean, negocian y transforman los sentidos y significados de las identidades territoriales de una sociedad local (Meethan, 2014; Salazar, 2012).

Para Hiernaux (2002) y Salazar (2012) el imaginario se diferencia de la ideología en el sentido que este último consiste en una lectura normativa, mientras que el imaginario es un tejido de representaciones sociales cambiantes. Si bien los imaginarios pueden no constituir dispositivos ideológicos, es posible encontrar en ellos una cierta legitimación hegemónica que se traducen en imaginarios dominantes. A modo de ejemplo, los imaginarios de la modernidad, de la etapa de expansión del capitalismo y del colonialismo en el resto del mundo, dan forma a un tipo particular de visión predominantemente etnocéntrica y eurocéntrica. Representación exótica y seductora del "mundo salvaje" y de las "culturas primitivas", a partir de la distinción de sus expresiones culturales como esenciales y sustanciales.

Si bien este imaginario fue transformándose, aun hoy continúan reproduciendo una mirada y un relato etnocéntrico que se tornan legítimos acerca de la cultura de un destino. Entender a la cultura de un lugar como confinada, pura y por lo tanto no influenciada por otros ámbitos de la vida social, es suponer equivocadamente que las expresiones simbólicas de una sociedad, desde su origen, son prístinas, intocables e inmutables, rasgos fijos y esenciales (Comparato, 2019). Los promotores de turismo, toman como punto de referencia estas imágenes para el desarrollo de una mirada romántica sobre el destino y su cultura, considerándola homogénea y sin conflicto alguno. Particularmente, muchos turistas llegan a considerar que si no encuentran en el destino aquello que les fue presentado como imaginario a través de la promoción turística, es porque el destino perdió autenticidad. En relación a este punto Reisinger y Steiner plantean el siguiente ejemplo, "si los turistas no esperan que un adolescente en una remoto pueblo de Indonesia use un Walkman, el encuentro con dicho adolescente, puedo llevarlos a lamentar haber perdido una experiencia auténtica" (traducción propia, 2006, p. 74). Para estos autores, la mirada de los turistas hacia la cultura de un destino es un tanto teórica e idealista, ya que confían que su experiencia será acorde con su idea pautada de cómo es o era la vida en Indonesia.

En tal sentido, el proceso de valorización turística, como proceso de valorización de recursos culturales y/o naturales replica los mismos criterios que la patrimonialización, se opta por imágenes y discursos que pueden coincidir o no con el imaginario de la sociedad que habita ese destino. De acuerdo a esto, Meethan (2001) rescata el argumento de Urry (1990), que sugiere que la mirada del turista está determinada, en parte, por la existencia de narrativas que dan marco y definen qué puede y qué no puede ser mirado. Si bien hay coincidencia con Urry (1990) en esta idea, el autor rechaza su manera de comprender la mirada como universal, ya que supone una categoría ideal de turista que responde de la misma manera a los significados prescritos en imágenes.

Aun cuando el imaginario pueda inducir a un entendimiento esencialista de las identidades culturales, predicando por una única representación y relato, existen tantos imaginarios como contextos sociales. No existe un imaginario turístico ideal que refleje el modo de ver el mundo entero, como tampoco hay razón alguna, según Meethan (2001), para suponer que la mirada hacia otras culturas sean intrínsecamente la misma en todos los turistas. Cada sociedad construye sus imaginarios a partir de su historia, su experiencia social y colectiva, a partir de su vínculo con otras sociedades y con el mundo, así como con sus transformaciones internas. Diferentes miradas, situadas en diferentes culturas.

El turismo produce un encuentro y relación entre dos sociedades que se contemplan diferentes. La sociedad del destino turístico se ve influenciada por condiciones externas ajenas a ella, imaginarios de otros lugares que forman representaciones y re-interpretaciones de su identidad cultural. De esta manera, se puede observar encuentros e interacciones sostenidas entre un adentro y un afuera, entre lo interno 
y lo externo, entre lo local y lo global; dicotomías que precisan ser trascendidas para profundizar el conocimiento sobre la complejidad de los espacios culturales actuales en función de continuas y múltiples movilidades, sentidos e imaginarios, es decir, teniendo en cuenta un abanico de territorialidades en diferentes escalas que confluyen y coexisten. En efecto, la identidades territoriales se resignifican a partir de la circulación de imaginarios, de la liminalidad que transforma dichas expresiones en híbridas, dinámicas y sin referentes estables.

En virtud de estas reflexiones cabe preguntar ¿quién determina donde una sociedad traza la línea entre lo local y el afuera? ¿Cómo circulan, interactúan y qué impactos tienen las complejas conjunciones culturales en un territorio atravesado por múltiples dimensiones, movilidades y escalas?.

\section{Identidades territoriales posmodernas}

Para Meethan (2003) un abordaje interpretativo de la cultura desde una perspectiva espacial y geográfica es de importancia, no solo porque el turismo dota a un lugar de un valor de uso y un valor de cambio; sino también porque muchos de los análisis del turismo y la cultura han descansado en el éxito o no que han tenido las culturas para mantenerse y reproducirse a sí mismas, como si fueran contenedores aislados por medio de los cuales la cultura se manifiesta como específica, esencial y auténtica.

Esta concepción sobre las sociedades como terruños aislados y puros entra en tensión frente a la introducción de la globalización y de procesos posmodernos. Muñoz Arroyave (2018) y Terkenli (2002) definen a la globalización como un proceso multidimensional, en tanto involucra aspectos sociales, culturales, históricos, económicos y políticos, que inciden y renegocian permanentemente el territorio y las relaciones sociales. Como resultado se da lugar a la territorialización de fuerzas globales. Territorialización que no es uniforme y que se materializa en una doble vertiente. Por un lado, algunas investigaciones hacen hincapié en una tendencia a la homogeneización de los territorios, procesos que inciden en la eliminación de barreras geográficas y culturales, en la desdiferenciación entre la esfera del trabajo y del ocio, la comprensión del espacio por el tiempo y la propagación de patrones estandarizados de consumo que tienen consecuencia directa, para algunos autores (Terkenli, 2002), en la destrucción, antropofagia cultural y en la preeminencia de una única cultura hegemónica. Bajo esta visión, lo particular y lo microsocial se diluye, se pierden los lazos territoriales e impera la falta de sentido de lugar. Por el otro, investigadores como Muñoz Arroyave (2018) y Meethan (2014) plantean que la globalización actúa como mediadora en la reivindicación, la resignificación, la reafirmación y revalorización de aspectos simbólicos, culturales e identitarios locales. En este sentido, para estos autores, la globalización entiende la coexistencia de procesos de universalización de lo particular (homogeneizadores) como de procesos de particularización de lo universal (heterogéneos).

La movilidad constituye uno de los primeros rasgos distintivos de la posmodernidad y de la globalización, en palabras de Haesbaert la vida contemporánea "está inmersa en una constante movilidad concreta y simbólica" (2013, p.18). Cresswell (2010) conceptualiza la movilidad como una constelación de movimientos, narrativas, objetos, capitales, relaciones sociales. Movilidades que se encarnan en movimientos físicos, representaciones y prácticas que circulan, confluyen y se yuxtaponen en un territorio. De ahí que se entiende a las movilidades como complejos sistemas de flujos que atraviesan los límites del territorio y dan lugar a múltiples interacciones, nuevas redes sociales, nuevos lazos con el espacio, muchas veces resistidas por la sociedad local (Meethan, 2003; Franlink y Crang, 2001; Doering y Duncan, 2016; Knafou, 1996).

La movilidad, para Hiernaux (2002), posibilitó el conocimiento del Otro. El turismo como movilidad hace referencia a aquellos sujetos que, con los recursos económicos necesarios, son capaces de desligarse del espacio concreto e insertarse, al mismo tiempo, en la dinámica de la circulación global. El turismo atraviesa los destinos a través de movilidades y fuerzas externas a ellos, reproduce lo local a través de esquemas de consumo e imaginarios que interesan a los turistas (De Anda et al, 2019). De igual manera, se plantea la noción de movilidad turística como una dimensión transitoria, sin vínculos con el territorio y por lo tanto inauténtica. Es decir que a mayor inmovilidad en las sociedades, mayor la autenticidad de las mismas. Sin embargo, Salazar (2010) se opone a la existencia de la antinomia entre los turistas como sujetos móviles y los locales como sujetos enraizados, inmóviles, puros, no contaminados.

Se ha intentado explicar y comprender al territorio local desde una visión esencialista, circunscribiéndola a una sociedad estática, autocontenida, con prácticas socioculturales claras y fronteras delimitadas. Aún hoy, la mayor parte de las investigaciones abordan el turismo bajo un enfoque donde la movilidad es observada como transgresión e intromisión sobre un territorio impoluto. Un pensamiento un tanto 
reduccionista en su reflexión y comprensión del fenómeno turístico, en tanto piensa a la sociedad de destino como una víctima sin capacidad de reacción y acción, como un mero sujeto pasivo.

Una segunda característica del fenómeno de la globalización y asociada al concepto de movilidad, consiste en la desterritorialización. Este concepto entraña la idea de pérdida y disolución de vínculos territoriales, que algunos suelen llamar el fin del territorio. Haesbaert (2013), menciona que Ortiz (1994) y Santos (1996) asocian la desterritorialización con la aculturación, el desplazamiento de relaciones sociales, el desanclaje de identidades, ideas y personas. En este sentido, y como fue dicho anteriormente, las movilidades globales como fuerzas externas a una sociedad han sido consideradas como amenaza al sentido de lugar y a los lazos culturales con el territorio, llevando al desarraigo y, por ende, a la desterritorialización de lo tradicional, de lo genuino de un lugar.

Bajo este punto de vista, el lugar y la cultura recaen en una idea convencional y tradicional. Sociedades arraigadas a un territorio, autocontenidas y cerradas, repositorios de una cultura inherente, esencial y auténtica. Sobre estos lugares el turismo se introduce como movilidad y fuerza desterritorializante, los turistas son considerados intrusos y despojadores vulgares de la autenticidad de un destino. Si bien hay consenso que el turismo constituye una influencia externa con un gran impacto en la sociedad, la crítica a este enfoque radica en la continua reproducción de una concepción de la sociedad de destino como inocente, pura, auténtica, débil y víctima sin capacidad de acción y decisión (Meethan, 2003; Cohen, 2005).

Se contempla a la posmodernidad como falta de autenticidad en las relaciones sociales, una sociedad alienada de sus vínculos. En relación a los estudios sociológicos del turismo, MacCannell $(1973,1976)$ es el primero en introducir el concepto de autenticidad. Siendo abordado por corrientes objetivistas, constructivistas y posmodernistas, la autenticidad se vuelve un concepto ambiguo y limitado en su definición (Wang, 1999; Reisinger y Steiner, 2006). Dentro de sus argumentos, MacCannell $(1973,1976)$ expone que los turistas persiguen la búsqueda de autenticidad en sus viajes, buscando acceder a los atributos esenciales de la cultura de un destino. No obstante, en un contexto posmoderno, la idea de que la autenticidad está ahí para ser descubierta carece de sentido y se torna cuestionable en un mundo cada vez más rizomático y de transformación constante.

En este sentido, Meethan (2003) y Franklin y Crang (2001) sostienen que es necesario alejarse de la noción dicotómica de lo primitivo e inmóvil como auténtico y lo posmoderno y móvil como inauténtico. En la misma línea, Haesbaert (2013) se opone a la idea de que la movilidad y la globalización sean planteadas como sinónimos de desterritorialización, ya que entiende la destrucción de territorios como una reconstrucción sobre nuevas bases.

En función de este marco, es preciso redefinir la manera de abordar los territorios turísticos y las identidades territoriales a partir definir la idea de lugar como relacional y contextual. Una reproducción social a través de complejas, contradictorias y deliberadas prácticas de representación y acción (Appadurai, 1995). De este modo, en un continuo estado de transición y redefinición, lo local y global se constituyen mutuamente llevando a la configuración de lugares que no son meramente locales ni globales, sino multiterritoriales (Aitchison, MacLeod y Shaw, 2014; Salazar, 2010).

Por otro lado, se busca romper con el modelo contenedor de cultura y una visión romántica de la misma, reemplazando los territorios estáticos e inmóviles por zonas fronterizas híbridas, fluidas, donde las identidades son forjadas a través de la movilidad y la localidad, de las interacciones y la yuxtaposición de múltiples escalas y relaciones (Minca y Oakes, 2006; Doering y Duncan, 2016). Un entretejido donde conviven al mismo tiempo lo individual-colectivo, lo local-global, lo fijo-móvil; un espacio simbólico que se transforma y redefine a partir del conflicto y dinamismo continuo de estos tiempos (Massey, 2004).

El concepto de identidad cultural se replantea, se habla de identidades en plural, de identidades, como dice Restrepo (2006), polifónicas y multiacentuales. Ninguna identidad posee un sentido cerrado y compartido por una sociedad de forma homogénea, sino que es necesario comprenderlas en sus articulaciones, contradicciones, tensiones y antagonismos. Son consideradas sitios de resistencia y empoderamiento más que dominación y sometimiento (Comparato, 2019).

Dentro de la posmodernidad, las identidades se circunscriben dentro de espacios configurados por movilidad y estasis. Catalogadas como híbridas, las identidades culturales son indeterminadas y presentan múltiples conexiones entre un afuera y un adentro (Meethan, 2003; Minca y Oakes, 2006). Así, predomina una identidad cultural, social y territorial construida en el movimiento y por el movimiento. Tal como se señala "la desterritorialización no significa el fin de la localidad, sino su transformación en un espacio cultural más complejo" (Tomlinson, 1999, citado por Haesbaert, 2013, p.192).

Conforme a esto, es preciso dar cuenta que la relación entre cultura y sociedad no se encuentra únicamente restringida a un territorio, sino que implica tanto movilidad global como especificidad cultural y local. Se entiende así que cualquier forma cultural que emerge del encuentro turístico puede 
ser percibida como hibrida y liminal. Consiguientemente esta postura, deja a un lado y rompe con el excesivo localismo cultural, sociedades enraizadas e inmóviles, así como también pone en cuestionamiento la noción de una desmesurada de influencia global (Clifford, 2008).

Es preciso insistir en la idea que la posmodernidad no admite sociedades "impermeables, resistentes a la movilidad, al intercambio y a la negociación de significados" (Ayora Díaz, 2017, p.99). De esta manera, cultura, identidad y territorio se encuentran atravesados por procesos dinámicos y relaciones que se dan en múltiples espacios y escalas (locales, nacionales, regionales, globales); dejando de existir un único verdadero sentido de lugar, naturalizante, consensuado y estático para pasar a un valorización incierta, heterogénea, negociada y de cambio continuo. En este sentido, el mundo contemporáneo nos impone comprender la localidad desde la movilidad, el intercambio, la negociación de sentidos y la circulación de imaginarios, personas, ideas y significados desde una perspectiva multiescalar y rizomática.

\section{Conclusión}

A modo de conclusión, el presente ensayo intentó reflexionar y constituir un espacio de apertura a nuevos interrogantes acerca de la importancia y necesidad de repensar la tríada turismo, territorio, identidades culturales en el marco de la posmodernidad. A partir de la revisión, lectura y análisis bibliográfico, se identificaron distintos abordajes sobre esta tríada. Desde aquellas posturas esencialistas, que fijan las culturas a un territorio delimitado geográficamente las cuales son consumidas por el turismo a partir de discursos e imaginarios estereotipados; hasta miradas más contemporáneas que involucran comprender las identidades culturales a partir de la movilidad, de la dislocación territorial y de complejos procesos de hibridación.

La importancia del turismo como fenómeno sociocultural radica en su rol como vector de las transformaciones territoriales en el marco de la posmodernidad, en tanto involucra flujos y movilidad de sentidos, significados e imaginarios. El mundo actual, no admite una sola versión cultural e identitaria, sino múltiples narrativas y discursos mediados por imaginarios sociales y turísticos. Considerar las identidades culturales como estáticas, inmutables y delimitadas geográficamente es reconocer la imposibilidad de reproducción y transformación social.

Las identidades culturales se construyen sobre la base de relaciones dialógicas entre sujetos individuales, colectivos sociales, diferentes escalas territoriales y mediaciones o dispositivos. Por esta razón, en un mundo globalizado e interconectado, donde son constantes los intercambios de personas e ideas entre distintos territorios, los fronteras geográficas y simbólicas se han desdibujado dando lugar a identidades culturales híbridas y en continuo movimiento. De esta manera, se plantea la necesidad de abordar un nuevo análisis del concepto de identidad cultural que interpele la complejidad que enfrentan los territorios turísticos en un contexto global signado por la movilidad y la liminalidad.

Como destacan los autores De Anda et al (2019), la producción científica en torno al tema de identidad, cultura y turismo refleja un vacío es términos teóricos, conceptuales como metodológicos. De esta manera, el propósito de este ensayo ha sido esbozar un marco de discusión conceptual y teórica sobre esta relación desde una perspectiva geográfica y territorial. En virtud de lo expuesto, se invita a los lectores e investigadores a seguir construyendo y desconstruyendo este análisis a partir de la profundización sobre dicho corpus de conocimiento.

\section{Bibliografía}

Aitchison, C., MacLeod, N. E., Macleod, N. E. \& Shaw, S. J. (2014). Leisure and Tourism Landscapes. Taylor \& Francis.

Almirón, A. (2004) "Turismo y espacio. Aportes para otra Geografía del turismo", GEOUSP, Espaço e Tempo, vol. 16. Departamento de Geografía, Facultad de Filosofía, Letras y Ciencias Humanas, Universidad de San Pablo, pp. 167- 180.

Appadurai, A. (1995). The production of locality. En Richard Pardon, Counterworks: Managing the diversity of knowledge, Londres: Routledge, 204-225.

Ayora Díaz, S. I. (2017). Translocalidad, globalización y regionalismo: cómo entender la gastronomía regional yucateca. Anales de Antropología, 51(2), 96-105. https://doi.org/10.1016/j.antro.2017.03.004

Bertoncello, R. (2002). Turismo y territorio. Otras prácticas, otras miradas. Aportes y transferencias, 6(2), 29-50.

Cohen, E. (2005). Principales tendencias en el turismo contemporáneo. Política y sociedad, 42(1), 11-24. 
Comparato, G. (2018). (De)construyendo los estudios del turismo y la geografía(s). Una aproximación a las mutaciones en América Latina a partir de la segunda posguerra. GeoGraphos. Revista Digital para Estudiantes de Geografía y Ciencias Sociales, 9, 266-290. https://doi.org/10.14198/geogra2018.9.111

Comparato, G. (2019). Entre antropología, estudios culturales y turismo: una propuesta de reflexividad disciplinar diacrónica. PASOS Revista de Turismo y Patrimonio Cultural, 17(2), 313-325.

Clifford, J. (2008). Traveling cultures. En Oakes, T. \& Prince P. L. The Cultural Geography Reader (pp. 328-336). Taylor \& Francis.

Cresswell, T. (2010). Towards a Politics of Mobility. Environment and Planning D: Society and Space, 28(1), 17-31. https://doi.org/10.1068/d11407

De Anda, L. A. S., Jiménez, G. C. \& Martínez, E. E. V. (2019). Fundamentos teórico-metodológicos de la identidad: Una introspección categorial para los estudios turísticos. PASOS Revista de Turismo y Patrimonio Cultural, 17(5), 889-899.

Doering, A. \& Duncan, T. (2016). Mobilities for Tourism Studies and «beyond»: A Polemic. Tourism Analysis, 21(1), 47-59. https://doi.org/10.3727/108354216x14537459508856

Franklin, A. \& Crang, M. (2001). The trouble with tourism and travel theory? Tourist Studies, 1(1), 5-22. https://doi.org/10.1177/146879760100100101

Haesbaert, R. (2013). Del mito de la desterritorialización a la multiterritorialidad. Cultura y representaciones sociales, 8(15), 9-42.

Hiernaux, D. (2002). Turismo e imaginarios. Cuaderno de Ciencias Sociales, 123, 7-32.

Knafou, R. (1996). Turismo e território: por uma abordagem científica do turismo. Turismo e Geografia. Reflexões teóricas e enfoques regionais. São Paulo: HUCITEC, 62-74.

Meethan, K. (2001) Tourism in global society: place, culture, consumption. New York: Palgrave.

Meethan, K. (2003). Mobile Cultures? Hybridity, Tourism and Cultural Change. Journal of Tourism and Cultural Change, 1(1), 11-28. https://doi.org/10.1080/14766820308668157

Meethan, K. (2014). Mobilities, Ethnicity, and Tourism. The Wiley Blackwell Companion to Tourism, 240-250.

Massey, D. (2004). Lugar, identidad y geografías de la responsabilidad en un mundo en proceso de globalización. Treballs de la Societat Catalana de Geografia, 77-84.

Minca, C. y Oakes, T.(2006). Introduction: Traveling Paradoxes. En Travels in paradox: Remapping tourism. Rowman \& Littlefield Publishers.

Minca, C. y Oakes, T. (2014). Tourism after the postmodern turn. The wiley blackwell companion to tourism, 294-303.

Muñoz Arroyave, E. A. (2018). Procesos de territorialización de la globalización a través del turismo. Análisis de las relaciones global-local que promueve este fenómeno. Agora U.S.B., 18(2), 557-572. https://doi.org/10.21500/16578031.3835

Paes, M. T. D. (2009). Patrimônio cultural, turismo e identidades territoriais: um olhar geográfico. Turismo de base comunitária-diversidade de olhares e experiências brasileiras. Rio de Janeiro: Ed. Letra e Imagem, 162-176.

Pinassi, A. y Ercolani, P. (2015). Geografía del turismo: análisis de las publicaciones científicas en revistas turísticas. El caso de Argentina. Cuadernos de geografía: revista colombiana de geografía, 24(1), 214-230.

Reisinger, Y. \& Steiner, C. J. (2006). Reconceptualizing object authenticity. Annals of Tourism Research, 33(1), 65-86. https://doi.org/10.1016/j.annals.2005.04.003

Restepo, E. (2006). Identidades: planteamientos teóricos y sugerencias metodológicas para su estudio. Jangwa pana, 5(1), 24-35.

Terkenli, T. S. (2002). Landscapes of tourism: Towards a global cultural economy of space? Tourism Geographies, 4(3), 227-254. https://doi.org/10.1080/14616680210147409

Wang, N. (1999). Rethinking authenticity in tourism experience. Annals of Tourism Research, 26(2), 349-370. https://doi.org/10.1016/s0160-7383(98)00103-0

Salazar, N. B. (2010). Studying local-to-global tourism dynamics through glocal ethnography.

Salazar, N. B. (2012). Tourism Imaginaries: A Conceptual Approach. Annals of Tourism Research, 39(2), 863-882. https://doi.org/10.1016/j.annals.2011.10.004

Recibido:

$26 / 08 / 2020$

Reenviado:

$16 / 12 / 2020$

Aceptado:

$17 / 12 / 2020$

Sometido a evaluación por pares anónimos 
www.pasosonline.org

\title{
Reseña de Publicaciones
}

\author{
Hiernaux-Nicolas, D., Osorio García, M., Vázquez Gómez, \\ R. (2020) Los imaginarios sociales y el turismo. Conceptos \\ y aplicaciones. México: Universidad Panamericana \\ ISBN IMPRESO: 978-607-7905-78-3 ISBN ELECTRÓNICO: 978-607-7905-79-0
}

\author{
Paula Vera* \\ Universidad Nacional de Rosario. CONICET (Argentina)
}

\begin{abstract}
¿Cómo abordar un fenómeno tan complejo como el turismo? ¿Qué pueden ofrecernos las teorías de los imaginarios y representaciones sociales para ello? ¿Se está gestando un nuevo imaginario turístico? ¿Cuáles son los sentidos que se ponen en relación, se disputan, emergen o se consolidan y que definen los rumbos que va tomando el turismo a nivel global? ¿Cómo impactan los imaginarios sociales del turismo en las concepciones y experiencias del tiempo libre y del ocio? ¿Cómo se espacializan estos imaginarios y cómo inciden en la vida de las comunidades "receptoras"? ...la lista de interrogantes podría seguir extendiéndose y expandiéndose hasta lograr dar cuenta de la gran cantidad de objetos, actores sociales, instituciones, prácticas, imágenes, costumbres, intereses, valores, creencias y deseos que intervienen en la configuración del turismo como fenómeno sociocultural contemporáneo. Y es allí, en esa trama densa y dinámica donde las teorías de los imaginarios y representaciones sociales pueden contribuir a iluminar las modulaciones de las relaciones que se establecen entre distintos elementos porque favorecen el estudio de una tensión nodal. Se hace referencia a la tensión entre lo material y lo simbólico como componentes indisociables de las manifestaciones sociales como es, por ejemplo, el turismo.
\end{abstract}

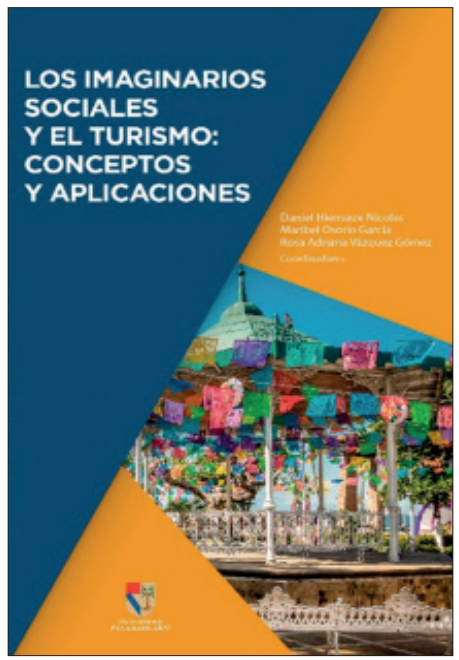

En este sentido, el libro Los imaginarios sociales y el turismo. Conceptos y aplicaciones publicado en 2020 bajo la coordinación de Daniel Hiernaux-Nicolas, Maribel Osorio García y Rosa Adriana Vázquez Gómez reúne contribuciones de gran valor y actualidad ofreciendo pistas para respuestas urgentes y necesarias ${ }^{1}$.

Su estructura se compone de dos partes de cuatro capítulos cada una. En la primera sección se encontrará un cuerpo de textos abocados a reflexiones teóricas y conceptuales. El capítulo uno, "Imaginarios y representaciones sociales. Reflexiones conceptuales y una breve mención al estado del arte en México", fue elaborado con precisión, sencillez y profundidad teórica por las profesoras Lidia Girola y Martha de Alba. En él se reponen conceptualmente los principales rasgos de las teorías sobre los imaginarios y las representaciones sociales como componentes del entramado socio-semántico en el que vive la sociedad. Esto permitiría considerarlos como conceptos complementarios siendo las Representaciones Sociales (RS) una de las formas en que los Imaginarios Sociales (IS) se concretan o materializan. En tal sentido su principal diferencia radicaría en su nivel de abstracción siendo, los IS, construcciones sociales, plurales,

E-mail: paulavera.arg@gmail.com; https://orcid.org/0000-0002-1557-4168 
no conscientes, múltiples, diversos, antagónicos y subyacentes que estructuran la interpretación del mundo. Para complementar su exposición repasan el estado del arte de las investigaciones en estas áreas en México, trabajo ampliamente desarrollado por las autoras en $2018^{2}$.

El capítulo "Notas sobre el estudio de los imaginarios: reflexiones desde la representación y la mitología" a cargo de Milton Aragón Palacios, también hace hincapié en la distinción entre IS y RS y sostiene que los IS antes que un objeto de estudio son un fenómeno desde donde puede abordarse el objeto de investigación. La principal tensión en torno a la que estructurará su argumentación se asienta en lo latente y lo manifiesto como claves de distinción entre los imaginarios y las representaciones. Para profundizar estas disquisiciones recupera autores de la tradición filosófica como Heidegger, Wittgestein, Benjamin, entre otros. A través de una serie de críticas agudas sobre los modos de investigar los IS actualmente, presenta una serie de advertencias, riesgos y posibilidades donde entran a jugar un rol destacado los mitos y las RS.

Por su parte, Daniel Hiernaux-Nicolas en el capítulo "Turismo y tiempo libre: ¿hacia una renovación de los imaginarios?" estructura un texto muy claro y estimulante para reflexionar en torno a los posibles impactos de la pandemia covid-19 en los imaginarios del turismo y el tiempo libre. La hipótesis que sostiene es que los imaginarios del tiempo libre están en un proceso de cambio. En tal dirección su objetivo es presentar algunas pistas para construir un nuevo concepto de "tiempo libre" en tiempos de crisis. Para ello repone la construcción teórica de tiempo libre en las Ciencias Sociales ligado a la sociología del trabajo. Luego plantea cómo el turismo de masas modificó la forma de concebir y practicar el tiempo libre. Por último, a partir de la crisis generada por la pandemia se interroga ¿cómo instaurar un nuevo modelo de tiempo libre que sea verdaderamente un espacio temporal de libertad? Libertad en sentido de tiempo creativo y no meramente de consumo, lo que implicaría una nueva visión de mundo. Este artículo culmina con optimismo y esperanza, y resuena como una invitación a construir ese camino en donde, parafraseando al autor, el tiempo libre, el turismo y el modo de ver -ser- de la sociedad puedan ser diferentes, positivos, respetuosos y constructores de un mundo mejor.

Para cerrar esta primera parte, el capítulo 4 "La imagen y la representación en el turismo de la posmodernidad" de Ilia Alvarado-Sizzo, Álvaro López López, y Fernando Zamora Águila van a exponer que en la posmodernidad, la preeminencia de las imágenes y representaciones espaciales inciden en la experiencia turística. Esto se traduce, por ejemplo, en que las representaciones de las cosas cobran mayor relevancia que la cosa en sí. Es decir que para el turista es más importante registrar y generar imágenes que vivir la experiencia directa. Este fenómeno se evidencia también en la reproducción de imágenes ya establecidas como representaciones del imaginario espacial dominante de los lugares. En tal sentido, los autores sostienen que el estudio de las representaciones espaciales ofrece insumos para comprender la dinámica social contemporánea.

En la segunda parte del libro se exponen resultados de investigaciones empíricas y estudios de caso. Las profesoras Rosa Adriana Vázquez Gómez y Maribel Osorio García en "Imaginarios turísticos de las jóvenes universitarias. Un estudio de caso" comparten los resultados de una investigación realizada en 2019. Parten de destacar la creciente importancia que la población joven tiene en el mercado del turismo, llegando a representar la quinta parte de las llegadas internacionales en 2017. En esa dirección, identificar los imaginarios turísticos de la población joven, específicamente universitarias millenials en la Ciudad de México contribuiría a comprender tanto sus comportamientos y actividades turísticas como los modos en que los viajes constituyen su subjetividad y relaciones sociales. Para ello desarrollaron una investigación cualitativa con entrevistas semiestructuradas y grupos de enfoque. El resultado de este trabajo arroja que existirían cuatro imaginarios turísticos en la población estudiada. La unión familiar y placer de la libertad como significaciones centrales en las subjetividades de las jóvenes que, al cruzar los análisis con la dimensión espacial (destinos de viaje) las autoras identifican un rasgo muy interesante. Quienes escogen destinos rurales y de playa están más afectadas por el imaginario familiar, en tanto que quienes manifiestan un vínculo mayor con el imaginario de la libertad prefieren destinos urbanos. Los otros dos imaginarios periféricos serían la visión de mundo ofrecido por el conocimiento de otras culturas, y a través de quienes poseen una experiencia de viajes desde la infancia las investigadoras identificaron como imaginario emergente el de nuevas experiencias.

A continuación, en el capítulo seis "Miradas sobre Puerto Vallarta desde los imaginarios turísticos", Carlos Virgen Aguilar y Alfonso Zepeda Arce exponen elementos del imaginario sobre Puerto Vallarta como destino turístico a partir del análisis de dos elementos: la marca turística y material hemerográfico de las últimas seis décadas en dos periódicos. Los autores identifican distintos intereses que se conjugan en los imaginarios de los prestadores de servicios, los visitantes, los pobladores, el gobierno y los grandes empresarios que, no obstante, confluyen en la representación preponderante de Puerto Vallarta como 
pueblo típico mexicano. Este es un punto relevante en el trabajo ya que, como destacan los propios autores, los grandes cambios urbanísticos han destruido partes fundamentales que materializaban de algún modo esa tradición y en su lugar sólo quedaron pequeños espacios a modo de muestra. Esta circunstancia nos recuerda al planteo de Armando Silva $(2015)^{3}$ quien en su modelo triádico de la teoría de los imaginarios urbanos postula como una de las situaciones de "percepción de la realidad" aquella donde lo Imaginado es dominante y Real lo potencia.

Mario Alberto Velázquez García y Helene Balslev Clausen presentan el capítulo "La construcción estatal de los imaginarios del Pulque en México". A través de sus páginas, van reponiendo los imaginarios estatales de esta bebida mexicana desde épocas prehispánicas. Si bien los autores aclaran que no se trata de un trabajo historiográfico, hacen uso de esta perspectiva para analizar cómo los distintos imaginarios estatales construidos a lo largo del tiempo han influenciado los espacios de consumo, producción y las prácticas sociales en torno a esta bebida. Para ello componen el binomio relajación/ control que les permite ir tramando diversas aristas económicas, culturales y políticas que fueron marcando continuidades, cambios, contradicciones en el proceso de configuración de este imaginario. Van a identificar cinco IS estatales mexicanos sobre el pulque: sagrado, barbarie, mercantil, riesgo e identidad. En este trabajo se logra demostrar la necesidad del análisis histórico que brinda elementos estructurales para comprender los imaginarios sociales. Si bien no se alude de manera directa al turismo, el pulque es un elemento que hoy aparece promocionado en numerosas páginas oficiales de turismo mexicano, con lo que este capítulo ofrece un estudio muy interesante y de plena vigencia para el fenómeno de los imaginarios turísticos del país.

Por último, como cierre de este magnífico libro, se encuentra "El paisaje de pueblo en la novela Esa Sangre, de Mariano Azuela". En este capítulo, Eloy Méndez Sainz trabaja la obra literaria citada como corpus de representaciones que permitiría para comprender ciertos rasgos de la configuración del paisaje de pueblo. Esta construcción imaginaria que el autor rastrea en la literatura de Azuela, ha participado y sigue teniendo cierto anclaje en los "pueblos mágicos", uno de los destinos turísticos promocionados en el país. El capítulo refuerza la hipótesis de que el paisaje de pueblo es un segmento de realidad vista desde, en y hacia un poblado. Méndez Sainz estructura el análisis de la narrativa según cuatro criterios: los rasgos morfológicos del entorno, el anclaje de la trama en determinados lugares, la construcción de personajes, y la ubicación de una frase que lo articula de algún modo con la representación del entorno.

Luego de haber transitado por los ocho capítulos que nos ofrece este grandioso trabajo, consideramos que este libro es una excelente oportunidad para sumergirse en los estudios de los imaginarios sociales del turismo en la medida en que presenta un abordaje teórico completo y accesible para quienes no son expertos en la materia y, al mismo tiempo, un anclaje en estudios de caso que permite apreciar de manera contundente la potencia de esta perspectiva de análisis para la comprensión de los fenómenos sociales contemporáneos.

\section{Notas}

1 Además de su versión papel, se puede descargar libremente en: https://www.academia.edu/44275634/Daniel_Hiernaux_ Adriana_V\%C3\%A1zquez_Maribel_Osorio_coord_2020_Los_Imaginarios_sociales_y_el_turismo_conceptos_y_ aplicaciones_M\%C3\%A9xico_Universidad_Panamericana

2 La investigación más amplia se encuentra en el libro de la Red Iberoamericana de Investigación en Imaginarios y Representaciones: Aliaga, F., Maric, M.L. y Uribe, C. (2018) "Imaginarios y representaciones sociales. Estado de la investigación en América Latina”. Bogotá: Ediciones USTA

3 Silva, A. (2015) Imaginarios. El asombro social. Bogotá: Ed.U. Externado de Colombia

Recibido:

$02 / 03 / 2021$

Aceptado:

$11 / 03 / 2021$

Sometido a evaluación por pares anónimos 


\section{Carta de Boas Práticas}

DOURO EM MOVIMENTO ALDEIAS COM VIDA

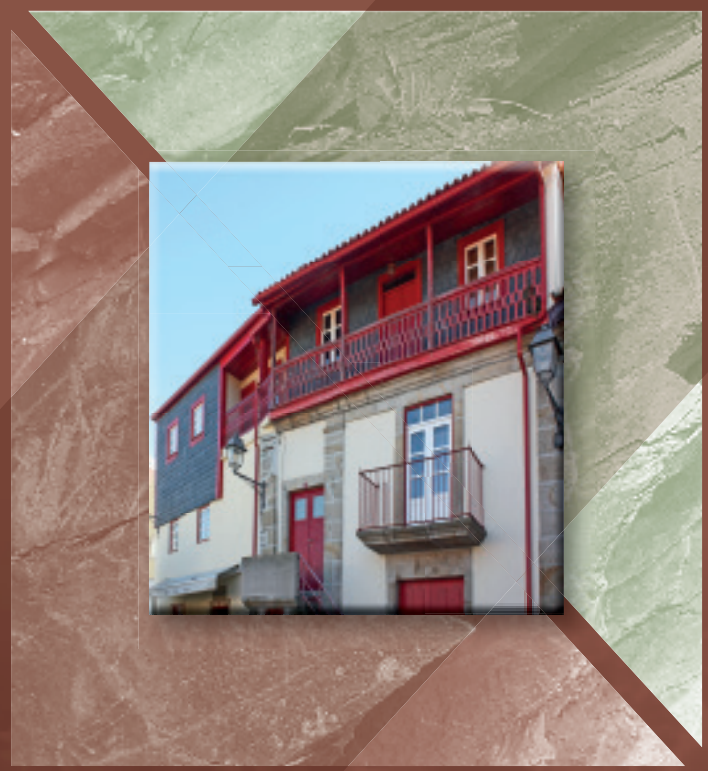

Turismo

Património

Desenvolvimento 


\section{Página Web:}

www.pasosonline.org

\section{Correo electrónico:}

info@pasosonline.org

\section{Correo postal \\ P.O. Box 33}

38360 El Sauzal (Tenerife) España 
